\title{
Electrochemical C-H Activations \\ with 3d and 4d Transition Metal Catalysts
}

\author{
Dissertation \\ for the award of the degree \\ "Doctor rerum naturalium" \\ of the Georg-August-Universität Göttingen
}

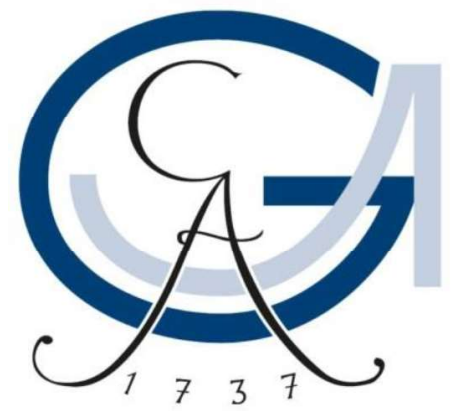

within the doctoral program of chemistry of the Georg-August-Universität School of Science (GAUSS)

\author{
Submitted by \\ Leonardo Massignan \\ From Desio (Italy)
}

Göttingen, 2021 



\section{Thesis Committee}

Prof. Dr. Lutz Ackermann

Institute of Organic and Biomolecular Chemistry

Georg-August-Universität Göttingen

Prof. Dr. Alexander Breder

Institute for Organic Chemistry

Universität Regensburg

\section{Members of the Examination Board}

$1^{\text {st }}$ Reviewer: Prof. Dr. Lutz Ackermann

Institute of Organic and Biomolecular Chemistry

Georg-August-Universität Göttingen

$2^{\text {nd }}$ Reviewer: Prof. Dr. Alexander Breder

Institute for Organic Chemistry

Universität Regensburg

\section{Further members of the Examination Board}

Prof. Dr. Dr. h.c. mult. Lutz F. Tietze

Institute of Organic and Biomolecular Chemistry, Göttingen

Prof. Dr. Manuel Alcarazo

Institute of Organic and Biomolecular Chemistry, Göttingen

Dr. Michael John

Institute of Organic and Biomolecular Chemistry, Göttingen

Dr. Daniel Janßen-Müller

Institute of Organic and Biomolecular Chemistry, Göttingen

Date of the oral examination: 02.12 .2021 



\section{Acknowledgements}

First, I would like to express my sincere gratitude to Prof. Dr. Lutz Ackermann for giving me the opportunity of working in his excellent laboratory and for supervising me during my $\mathrm{PhD}$. Your constant encouragement and insightful suggestions guided me in my studies and have shaped my scientific approach. Your devotion and strong work ethics would surely have a lasting impression on my career.

I am grateful to Prof. Alexander Breder for being my second supervisor, thank you for your valuable input in our meetings and the kind suggestions you provided. I would also like to thank Prof. Dr. Dr. h.c.mult. Lutz F. Tietze, Prof. Dr. Manuel Alcarazo, Dr. Daniel Janßen-Müller, and Dr. Michael John for agreeing to take part in my doctoral defense.

I am thankful to the Institut für Organische und Biomolekulare Chemie, GeorgAugust-Universität Göttingen for the workspace and the instrumental facilities, as well as the analytical departments for the punctual and precise analyses and the kind support.

I gratefully acknowledge Frau Gabriele Keil-Knepel and Frau Bianca Spitalieri for the kind assistance for the administrative works. I sincerely thank Mr. Stefan Beußhausen for taking care of all the instruments in our research group and Mr. Karsten Rauch for the kind support, help, and guidance in the use of all the glassware and in maintaining safety in the lab.

I also would like to thank the colleagues with whom I had the opportunity to collaborate: Dr. Xuefeng Tan, Dr. Cuiju Zhu, Dr. Tjark H. Meyer, Dr. Cong Tian, Dr. Rositha Kuniyil, Dr. João C. A. Oliveira, Dr. Torben Rogge, Dr Youai Qiu, Dr. Antonis M. Messinis, Maximilian Stangier, Xiaoyan Hou, Dr. Johanna Frey, and Aude Salamé. I would like to thank all the people who have proofread and helped me correcting this thesis: Alexej Scheremetjew, Nate Ang, Isaac Choi, Dr. Ramesh C. Samanta, Dr. Johanna Frey, Dr. Bartlomiej Sadowski. 
I want to thank all the other members of the Ackermann group for the constant support and scientific exchange. In particular, Fabio and Antonio for the huge help in the lab, the nice chemical discussions, and the amazing times outside the lab. Moreover, I would like to thank several friends in the group for the nice time in Göttingen: Agnese, Alexej, João, Jongwoo, Max, Mélanie, Nate, Partha, Renato, Santhi, Satheesh, Tjark.

I'd like to take the chance to express my gratitude to my former supervisor Prof. Dr. Elisabetta Rossi, as well as to Dr. Valentina Pirovano.

I would like to thank all the people that enjoyed with me these last four years of my life. Grazie mille to Daniele and Giuseppe, the times all together were unforgettable. Thanks to Justin and Tomoko for the funny dinners and extraordinary cakes. Thank you, Gabriele and Nicole, for being awesome neighbors. Thanks also to Martina for the nice time together.

Most importantly I would like to thank my family. A huge thank to my parents whose support was omnipresent in the smallest and biggest challenges I had to face. Thanks Virginia, Silvio, Massimo, Emma and Adam, for being so cool and lovely. A thank also to Andrea, Mirella, Paola, and Valeria, for always creating a cozy and familiar atmosphere when together.

My utmost gratitude goes to Silvia, unique and lovely partner in my life. Your wise suggestions and tireless efforts were essential. I love to make this travel with you. A special thank goes to Edoardo that made this last year full of love and cuteness. 




\section{TABLE OF CONTENTS}

\section{Introduction ........................................................................................ 1}

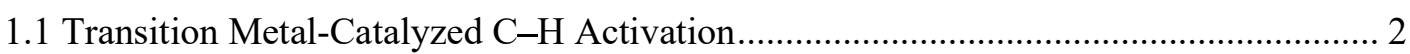

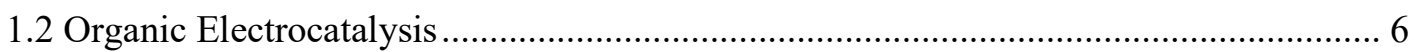

1.2.1 C-H Activation and Electrosynthesis.................................................................. 7

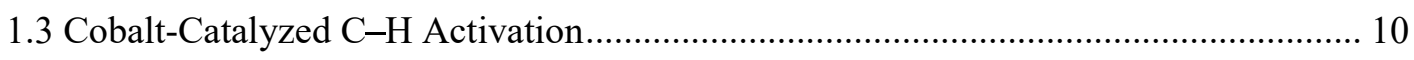

1.3.1 Cobalt-Catalyzed C-H Activation with Chemical Oxidants ................................... 12

1.3.2 Electrochemical Cobalt-Catalyzed C-H Activation............................................... 17

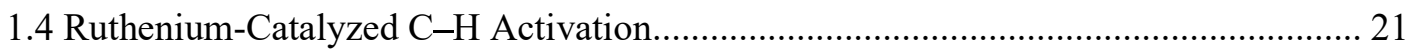

1.4.1 Ruthenium-Catalyzed Oxidative C-H Activation with Chemical Oxidants ............. 23

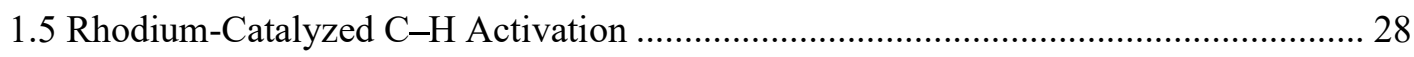

1.5.1 Rhodium-Catalyzed Oxidative C-H Activation with Chemical Oxidant.................. 29

1.5.2 Electrochemical Rhodium-Catalyzed C-H Activation ........................................... 32

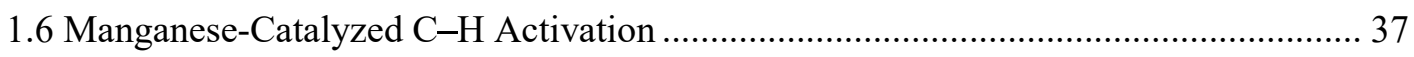

1.6.1 Manganese-Catalyzed C-H Activation with Chemical Oxidants .............................. 39

1.6.2 Electrochemical Manganese-Catalyzed C-H Activation ........................................ 43

\section{Objectives ...................................................................................... 44}

3. Results and Discussion ................................................................ 48

3.1 Electrochemical C-H/N-H Activation by Water-Tolerant Cobalt-Catalysis at Room

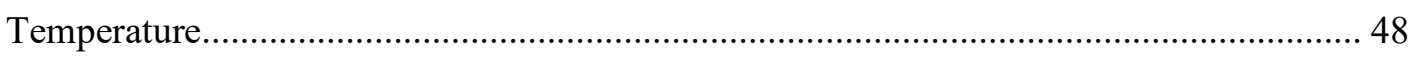

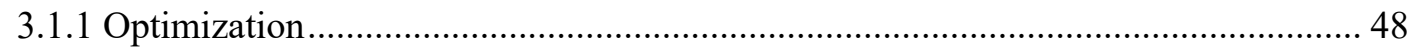

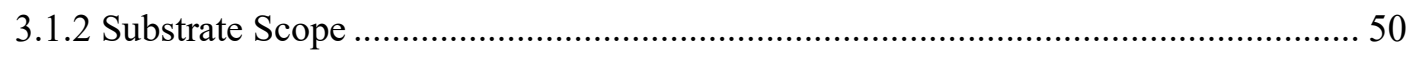

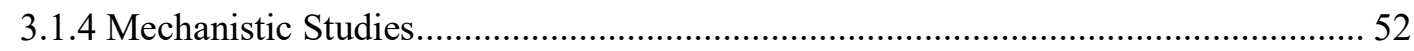

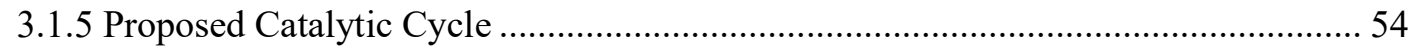


3.2 Electrooxidative Ruthenium-Catalyzed $\mathrm{C}-\mathrm{H} / \mathrm{O}-\mathrm{H}$ Annulation by Weak $O$-Coordination 56

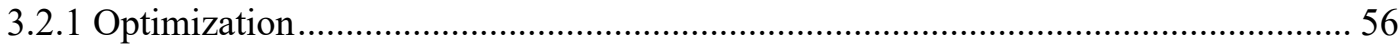

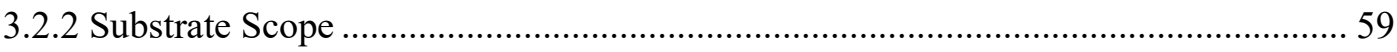

3.2.3 Mechanistic Studies and Proposed Catalytic Cycle .................................................... 62

3.3 C-H Oxygenation Reactions Enabled by Dual Catalysis with Electrogenerated Hypervalent Iodine Species and Ruthenium Complexes .................................................. 64

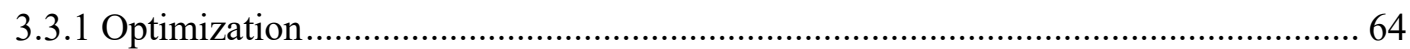

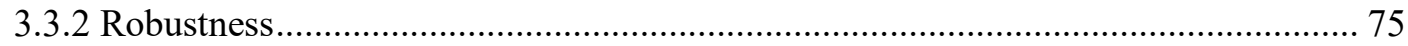

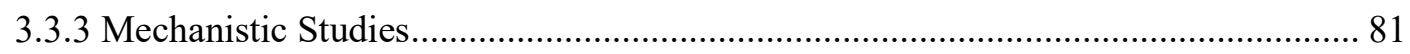

3.4 Rhoda-Electrocatalyzed Bimetallic C-H Oxygenation by Weak $O$-Coordination ....... 88

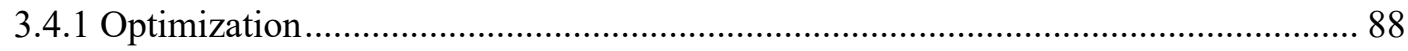

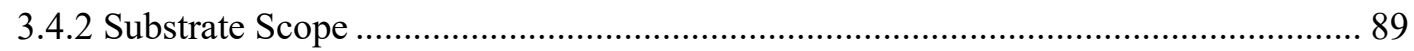

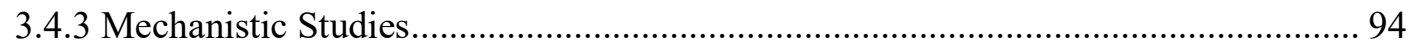

3.5 Manganaelectro-Catalyzed Azine C-H Arylations and C-H Alkylations by Assistance

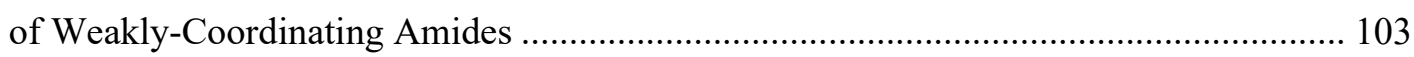

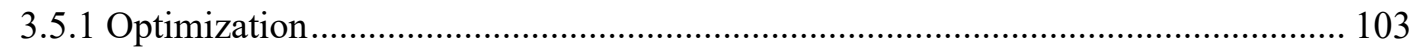

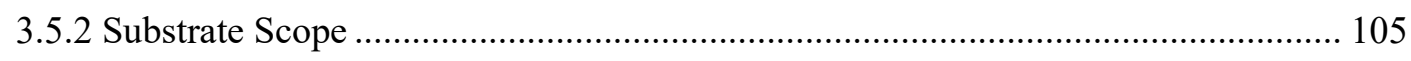

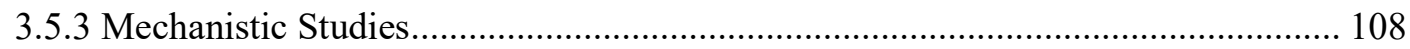

4 Summary and Outlook.......................................................... 114

5. Experimental Data ............................................................... 119

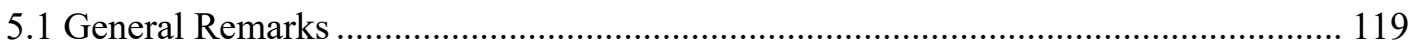

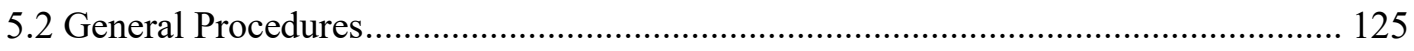

5.2.1 General Procedure A: Electrochemical Cobalt-Catalyzed C-H/N-H Annulation .. 125

5.2.2 General Procedure B: Electrochemical Cobalt-Catalyzed C-H/N-H Annulation .. 125

5.2.3 General Procedure C: Electrochemical Ruthenium-Catalyzed C-H/Het-H

Annulation

5.2.4 General Procedure D: Electrochemical Ruthenium-Catalyzed C-H Oxygenation of Amides 
5.2.5 General Procedure E: Electrochemical Ruthenium-Catalyzed C-H Oxygenation of Ketones.

5.2.6 General Procedure F: Electrochemical Ruthenium-Catalyzed C-H Oxygenation in para-Position.

5.2.7 General Procedure G: Electrochemical Rhodium-Catalyzed C-H Oxygenation of Amides

5.2.7 General Procedure H: Electrochemical Rhodium-Catalyzed C-H Oxygenation of Ketones.

5.2.8 General Procedure I: Electrochemical Manganese(II/III/I)-Catalyzed C-H Arylation

5.3 Electrochemical C-H/N-H Activation by Water-Tolerant Cobalt-Catalysis at Room

Temperature.

5.3.1 Characterization Data

5.4 Electrooxidative Ruthenium-Catalyzed $\mathrm{C}-\mathrm{H} / \mathrm{O}-\mathrm{H}$ Annulation by Weak $O$-Coordination

5.4.1 Characterization Data

5.5 C-H Oxygenation Reactions Enabled by Dual Catalysis with Electrogenerated

Hypervalent Iodine Species and Ruthenium Complexes ................................................. 146

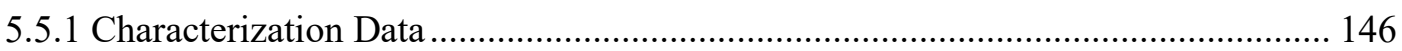

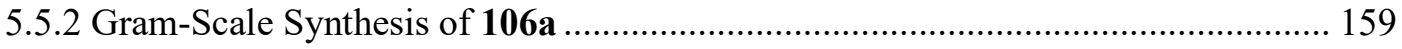

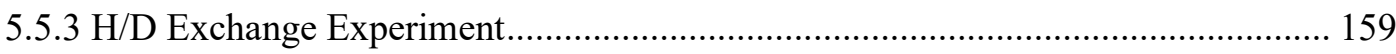

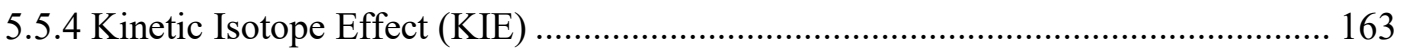

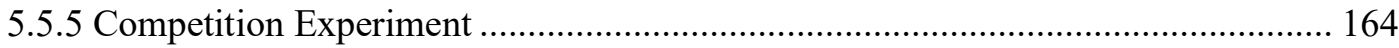

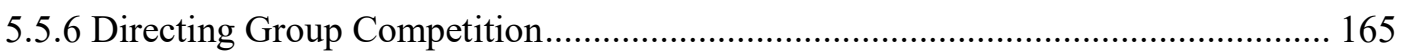

5.5.7 Gas-Chromatographical Analysis of Headspace ................................................... 165

5.6 Rhoda-Electrocatalyzed Bimetallic C-H Oxygenation by Weak $O$-Coordination ..... 167

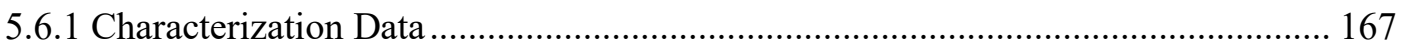

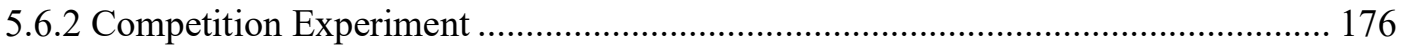

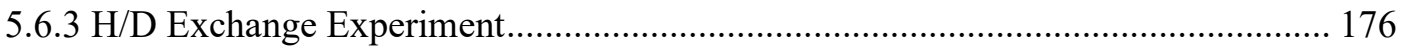

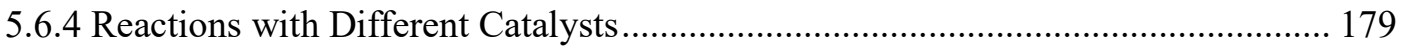

5.6.5 Initial Rate Comparison between $\left[\mathrm{Rh}(\mathrm{OAc})_{2}\right]_{2}$ and $\left[\mathrm{Rh}(\mathrm{OPiv})_{2}\right]_{2} \ldots \ldots \ldots \ldots \ldots \ldots \ldots \ldots . . . . . . . . . .180$ 
5.7 Manganaelectro-Catalyzed Azine $\mathrm{C}-\mathrm{H}$ Arylations and $\mathrm{C}-\mathrm{H}$ Alkylations by Assistance of Weakly Coordinating Amides

5.7.1 Characterization Data

5.7.2 Competition Experiment

5.7.3 Well-defined Manganese Complex 215 as Catalyst.

5.7.4 Dependence on the Current

5.7.5 Cyclic Voltammetry Studies

6. References.

\section{Appendix: NMR Spectra}

7.1 Electrochemical C-H/N-H Activation by Water-Tolerant Cobalt-Catalysis at Room

Temperature

7.2 Electrooxidative Ruthenium-Catalyzed C-H/O-H Annulation by Weak $O$-Coordination

7.3 C-H Oxygenation Reactions Enabled by Dual Catalysis with Electrogenerated

Hypervalent Iodine Species and Ruthenium Complexes

7.4 Rhoda-Electrocatalyzed Bimetallic C-H Oxygenation by Weak $O$-Coordination ...... 255

7.5 Manganaelectro-Catalyzed Azine $\mathrm{C}-\mathrm{H}$ Arylations and $\mathrm{C}-\mathrm{H}$ Alkylations by Assistance of Weakly-Coordinating Amides 271 


\section{List of Abbreviations}

\begin{tabular}{|c|c|}
\hline A & Ampere \\
\hline$A$ & Area \\
\hline$\AA$ & Ångström (s) \\
\hline Ac & acetyl \\
\hline acac & acetyl acetonate \\
\hline Alk & alkyl \\
\hline AMLA & ambiphilic metal-ligand activation \\
\hline aq. & aqueous \\
\hline $\mathrm{Ar}$ & aryl \\
\hline atm & standard atmosphere \\
\hline ATR & attenuated total reflectance \\
\hline BDE & bond dissociation energy \\
\hline BIES & base-assisted internal electrophilic substitution \\
\hline $\mathrm{Bn}$ & benzyl \\
\hline BQ & 1,4-benzoquinone \\
\hline br & broad \\
\hline $\mathrm{Bu}$ & butyl \\
\hline $\mathrm{Bz}$ & benzoyl \\
\hline $\mathrm{C}$ & Celsius \\
\hline$c$ & concentration \\
\hline calc. & calculated \\
\hline cat. & catalytic \\
\hline $\mathrm{CCE}$ & constant current electrolysis \\
\hline $\mathrm{CE}$ & counter electrode or current efficiency \\
\hline CMD & concerted-metalation-deprotonation \\
\hline conc. & concentrated \\
\hline conv. & conversion \\
\hline $\mathrm{Cp}^{*}$ & 1,2,3,4,5-Pentamethylcyclopentadiene \\
\hline $\mathrm{CPE}$ & constant potential electrolysis \\
\hline $\mathrm{CV}$ & cyclic voltammetry \\
\hline
\end{tabular}




\begin{tabular}{|c|c|}
\hline $\mathrm{Cy}$ & cyclohexyl \\
\hline$\delta$ & chemical shift \\
\hline $\mathrm{d}$ & diameter or doublet \\
\hline DCB & 2,3-dichlorobutane \\
\hline DCE & 1,2-dichloroethane \\
\hline DCIB & 1,2-dichloroisobutane \\
\hline $\mathrm{DCM}$ & dichloromethane \\
\hline $\mathrm{dd}$ & doublet of doublet \\
\hline DFT & density functional theory \\
\hline DG & directing group \\
\hline DME & dimethoxyethane \\
\hline DMF & $N, N$-dimethylformamide \\
\hline DMSO & dimethyl sulfoxide \\
\hline DMPU & 1,3-dimethyl-3,4,5,6-tetrahydro-2 $(1 H)$-pyrimidinone \\
\hline dppe & 1,2-bis(diphenylphosphino)ethane \\
\hline $\mathrm{dt}$ & doublet of triplet \\
\hline $\mathrm{e}^{-}$ & electron \\
\hline E & potential \\
\hline$E_{p}$ & peak potential \\
\hline$E_{1 / 2}$ & half-peak potential \\
\hline e.g. & exempli gratia \\
\hline EI & electron ionization \\
\hline equiv & equivalent \\
\hline ESI & electrospray ionization \\
\hline $\mathrm{Et}$ & ethyl \\
\hline EWG & electron-withdrawing group \\
\hline$F$ & Faraday-constant \\
\hline $\mathrm{Fc}$ & ferrocene \\
\hline FE & faradaic efficiency \\
\hline FG & functional group \\
\hline FID & flame ionization detector \\
\hline$G$ & Gibbs free energy \\
\hline GC & gas chromatography or glassy carbon \\
\hline
\end{tabular}




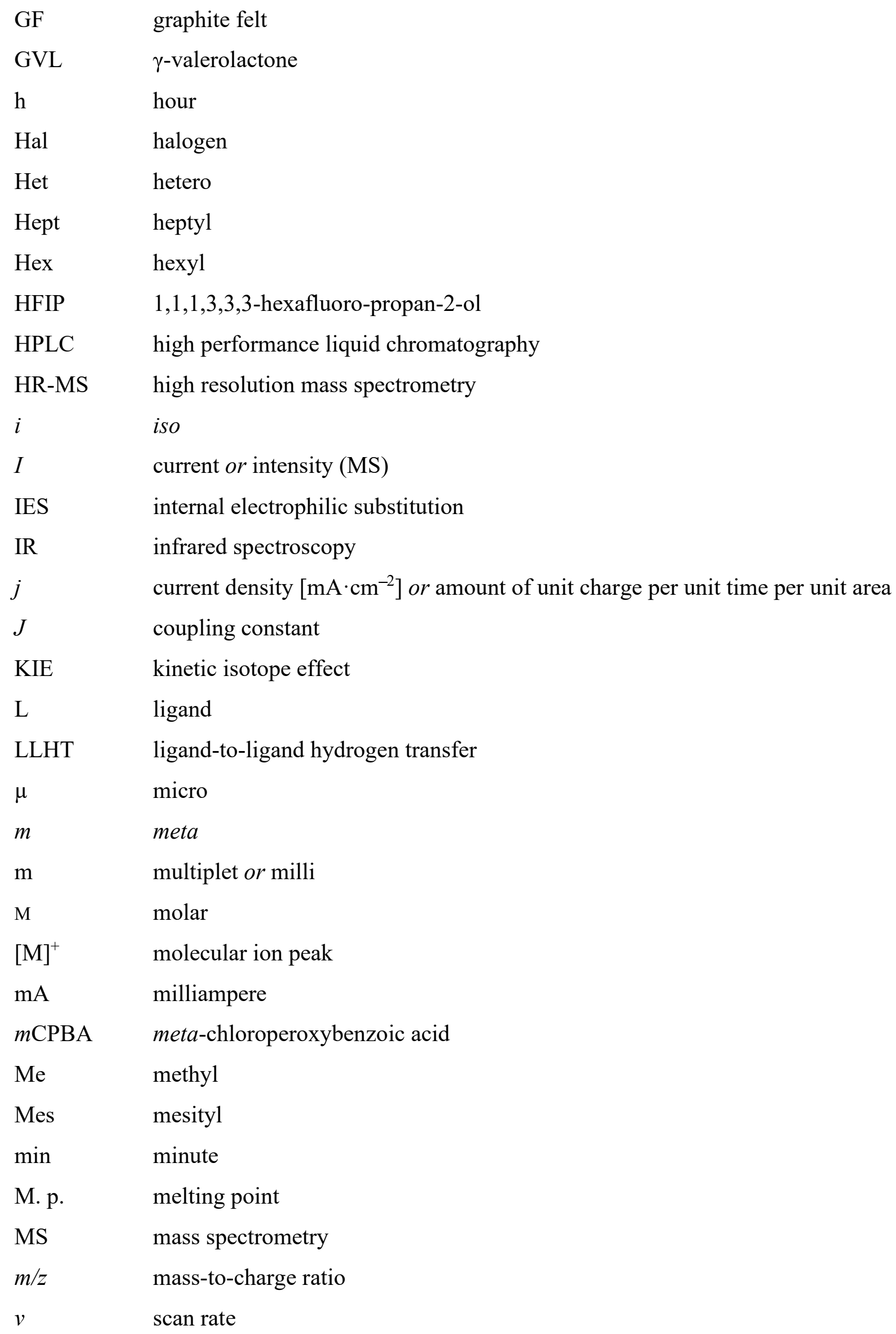


number of transferred electrons or amount of substance in mole

nd not detected

NHE Normal Hydrogen Electrode

NMP N-methyl-2-pyrrolidone

NMR nuclear magnetic resonance

$o$

ortho

OA oxidative addition

OPV oil pump vacuum

p para

$\mathrm{p} \quad$ pentet

PAH(s) polycyclic aromatic hydrocarbons

$\mathrm{Ph} \quad$ phenyl

PIDA (diacetoxyiodo)benzene

PIFA (bis(trifluoroacetoxy)iodo)benzene

Piv pivaloyl

ppm parts per million

$\operatorname{Pr} \quad$ propyl

PTS Polyoxyethanyl- $\alpha$-tocopheryl sebacate

py 2-pyridyl

pym 2-pyrimidinyl

PyO 2-pyridine- $N$-oxide

q quartet

Q 8-aminoquinoline

$\mathrm{R} \quad$ rest

RDE rotating disc electrode

RE reference electrode

ref. reference

r.t. room/ambient temperature

RVC reticulated vitreous carbon

s singlet or second

sat. $\quad$ saturated

SCE saturated calomel electrode

SEM-EDS scanning electron microscopy energy-dispersive X-ray spectroscopy 


$\begin{array}{ll}\text { SET } & \text { single electron transfer } \\ \text { SPS } & \text { solvent purification system } \\ t & \text { tert } \\ \mathrm{t} & \text { triplet } \\ \text { TAM } & \text { triazolyldimethylmethyl } \\ t \text { AmOH } & \text { tert-Amyl alcohol } \\ \text { TFA } & \text { Trifluoroacetic acid } \\ \text { TFAA } & \text { Trifluoroacetic anhydride } \\ \text { TFE } & 2,2,2 \text {-Trifluoroethanol } \\ \text { THF } & \text { tetrahydrofuran } \\ \text { TLC } & \text { thin layer chromatography } \\ \text { TM } & \text { transition metal } \\ \text { TMEDA } & N, N, N \text { ', } N \text { '-Tetramethylethylenediamine } \\ \text { TOF } & \text { time-of-flight } \\ \text { TS } & \text { transition state } \\ \text { V } & \text { volt } \\ v s . & v e r s u s \\ \text { WE } & \text { working electrode } \\ w t \% & \text { percentage by weight } \\ \end{array}$




\section{Introduction}

Organic synthesis went through enormous advances during the past century, opening the way to a vast number of compounds and diverse synthetic routes. These progresses allowed to ameliorate the quality of life, bringing on the prosper development of pharmaceuticals, as well as advances in other fields, such as agrochemical and material science. Even though the benefit for development and wealthiness is undoubted, chemical synthesis is still an inefficient process that requires huge amounts of resources and energy, therefore generating major amounts of undesired by-products and waste. The environmental awareness calls us to develop a more sustainable chemistry. Theoretical principles $^{[1]}$ and green metrics ${ }^{[2]}$ want to furnish guidelines and tools for a thriving chemical sustainability. In 1998, the "12 Principles of Green Chemistry"[3] by Anastas and Warner recognized catalysis as one of the main techniques for a more environmentally benign synthesis (Scheme 1.1). The employment in catalytic amounts, the possible absence of pre-functionalizations, the robustness of syntheses, and the presence of only minor side products, outline catalysis as a very attractive strategy.

In this context, electrochemistry for transition metal-catalyzed redox reactions has recently affirmed itself as a powerful approach towards a more environmental-friendly catalysis. Indeed, with this methodology, stoichiometric redox agents are replaced by current with the use of stable and lasting electrodes. $^{[4]}$

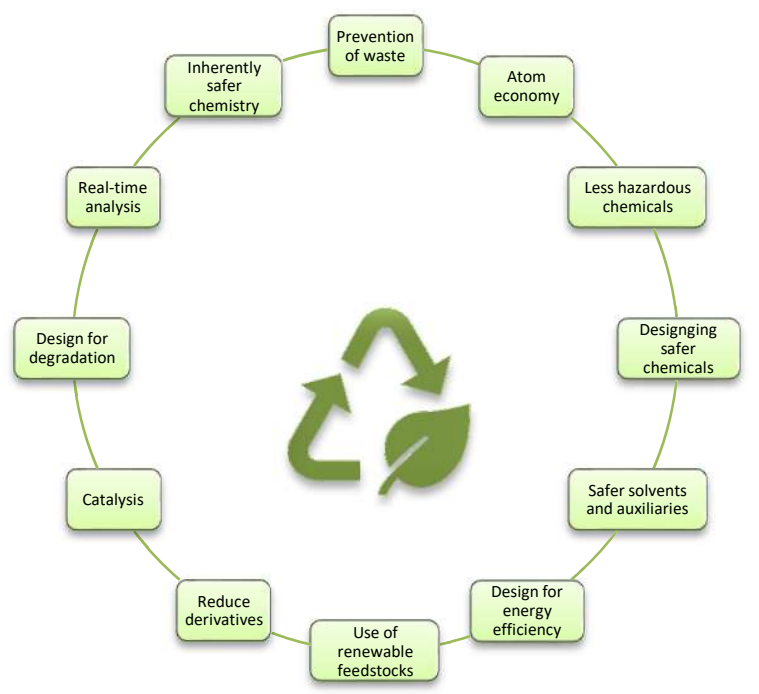

Scheme 1.1 12 Principles of Green Chemistry by Anastas and Warner. 


\subsection{Transition Metal-Catalyzed C-H Activation}

The formation of $\mathrm{C}-\mathrm{C}$ and $\mathrm{C}-\mathrm{Het}$ bonds is of utmost interest in chemistry, since it opens the way for efficient and versatile syntheses. Early examples of transition metal-catalyzed cross-coupling chemistry consisted in the copper-catalyzed reactions by Glaser and Ullmann. ${ }^{[5]}$ During $1970-80$ s, these cross-coupling approaches found large employment after the discovery of palladium-catalyzed cross-coupling chemistry, which led to the development of many named reactions, such as the Suzuki-Miyaura, ${ }^{[6]}$ Negishi, ${ }^{[7]}$ Mizoroki-Heck,,${ }^{[8]}$ Kumada-Corriu, ${ }^{[9]}$ Hiyama, ${ }^{[10]}$ Stille, ${ }^{[11]}$ and Sonogashira-Hagihara ${ }^{[12]}$ reactions. Other landmarks for palladium-catalysis are the Tsuji-Trost reaction $^{[13]}$ and the Buchwald-Hartwig amination. ${ }^{[14]}$ This golden age of palladium-catalysis has been recognized with the award of the Nobel Prize in Chemistry to Heck, Negishi, and Suzuki in $2010 .^{[15]}$

Despite the tremendous influence of cross-coupling reactions in organic synthesis, the aim of a sustainable chemistry is still not fully met (Scheme 1.1.1,a). In fact, this approach requires prefunctionalization of the starting materials, undermining the atom-economy of the overall process. ${ }^{[16]}$ For this reason, direct $\mathrm{C}-\mathrm{H}$ functionalization has emerged as a powerful tool to ameliorate the stepand atom-economy (Scheme 1.1.1,b). ${ }^{[17]}$ Although this approach avoids the functionalization of one substrate, it is still necessary to manipulate the coupling partner, to obtain for example an organic halide. From a step-economical viewpoint, oxidative $\mathrm{C}-\mathrm{H} / \mathrm{C}-\mathrm{H}$ functionalizations, namely crossdehydrogenative couplings, are most desirable (Scheme 1.1.1,c). ${ }^{[4 b, 18]}$ Pre-functionalizations are thus avoided and the waste formation is decreased, formally generating only $\mathrm{H}_{2}$ as by-product, but a stoichiometric oxidant is still inconveniently required. Remarkably, the recent merger of electrochemistry and transition metal catalysis allowed for the use of electricity as cost-effective and environmental-friendly oxidant, avoiding toxic and sacrificial chemicals, thus lowering the waste production. ${ }^{[4]}$ 
(a) Traditional cross-coupling

(b) $\mathrm{C}-\mathrm{H}$ functionalization
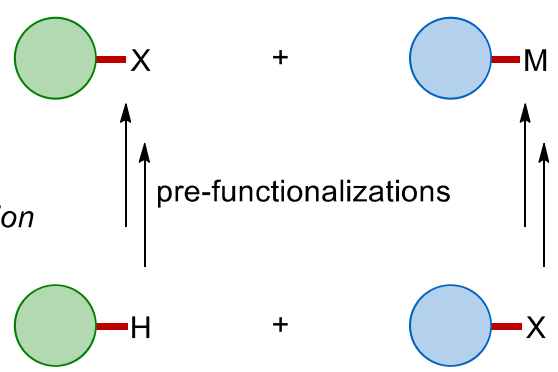

(c) Oxidative $\mathrm{C}-\mathrm{H} / \mathrm{C}-\mathrm{H}$ functionalization
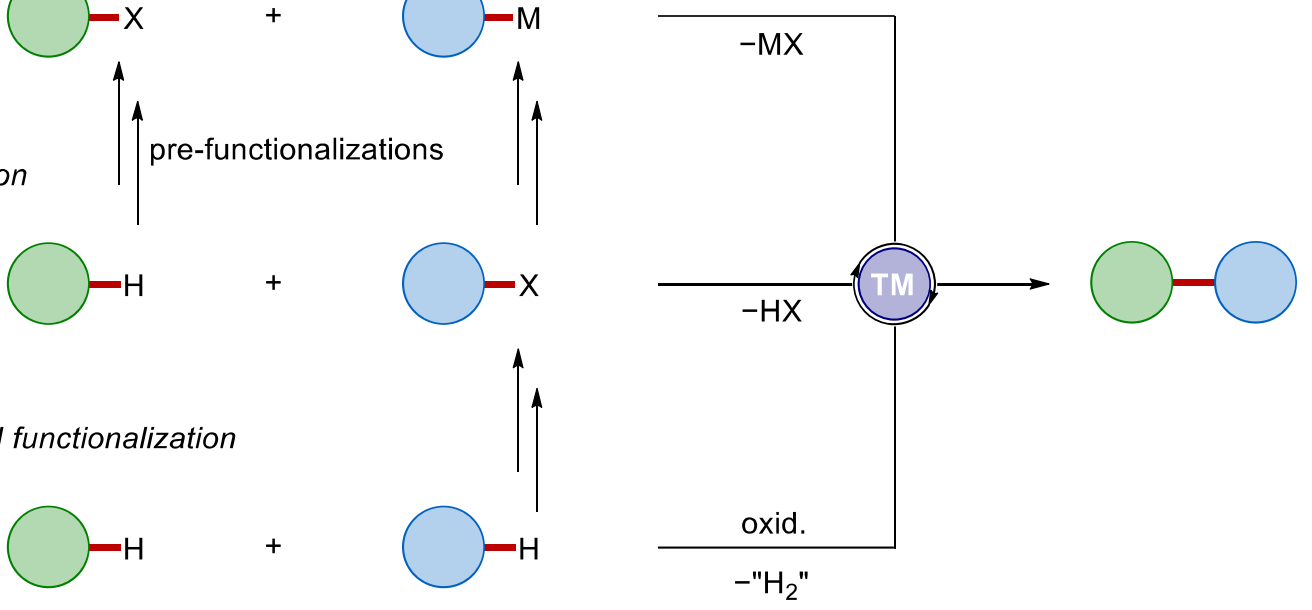

Scheme 1.1.1 Three different modes of $\mathrm{C}-\mathrm{H}$ bond functionalization.

Synthetically meaningful $\mathrm{C}-\mathrm{H}$ activations must face several challenges. Indeed, the bond dissociation energy (BDE) of carbon-hydrogen bonds is usually higher than the one of $\mathrm{C}-\mathrm{X}$ bonds that are typically employed in the cross-coupling approach (e.g., $\mathrm{BDE}(\mathrm{Ph}-\mathrm{H}) \approx 113 \mathrm{kcal} \mathrm{mol}^{-1} v s$. $\left.\mathrm{BDE}(\mathrm{Ph}-\mathrm{Cl}) \approx 97 \mathrm{kcal} \mathrm{mol}^{-1}\right) .{ }^{[19]}$ Moreover, the presence of numerous $\mathrm{C}-\mathrm{H}$ bonds in a molecule of interest, and their similar BDEs increase the challenge for a site-selective activation. ${ }^{[20]}$ Three approaches are thus used by chemists to overcome the problem and reach selectivity, as shown in Scheme 1.1.2. First, in electronically activated substrates, such as activated arenes or heterocycles, the kinetic acidity of one $\mathrm{C}-\mathrm{H}$ bond is higher than the others, making it easier to selectively functionalize. ${ }^{[21]}$ Second, the use of sterically demanding groups helps to shield $\mathrm{C}-\mathrm{H}$ bonds and leads to the activation of the most accessible one. ${ }^{[22]}$ The third approach regards the use of a directinggroup (DG) to coordinate the transition metal catalyst, which can thus activate the bond in its close proximity. ${ }^{[23]}$ On the one hand, the first two approaches are severely limited to the substrate's inherent features and hence the substrate scope is usually rather limited. On the other hand, directing groups (DG), despite being a very efficient mean, have the drawback of needing the incorporation of the DG itself. For this reason, the use of weakly-coordinating, ${ }^{[24]} \operatorname{transient}^{[25]}{ }^{[2 e m o v a b l e}{ }^{[26]}$ or inherent directing groups is preferential. 


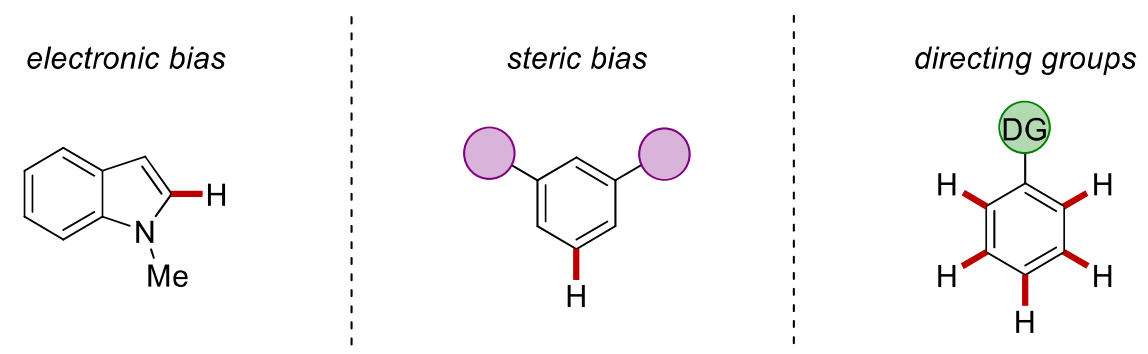

Scheme 1.1.2 Positional selectivity in $\mathrm{C}-\mathrm{H}$ activation.

The crucial $\mathrm{C}-\mathrm{H}$ activation step has been extensively studied, making it possible to identify five different ways to cleave the bond, which depend on the nature of the metal employed, its oxidation state, and the ligands. With the exclusion of radical-type outer-sphere mechanisms, ${ }^{[27]}$ these consist in oxidative addition, electrophilic substitution, $\sigma$-bond metathesis, 1,2-addition, and base-assisted metalation (Scheme 1.1.3). ${ }^{[28]}$ The oxidative additions usually take place with late and electron-rich transition metals in low oxidation states, such as palladium( 0$)$ and ruthenium(0), or iridium(I) and rhodium(I). When late transition metals are in higher oxidation states, they favor an electrophilic substitution. In contrast, early transition metals are reported to preferentially react via $\sigma$-bond metathesis. The 1,2-addition pathway was proposed for early transition metals with an unsaturated $\mathrm{M}=\mathrm{X}$ bond. More recently, base-assisted $\mathrm{C}-\mathrm{H}$ metalation, where a base facilitates the abstraction of a proton through a five- or six-membered transition state, has gained major prominence. 
(a) Oxidative addition

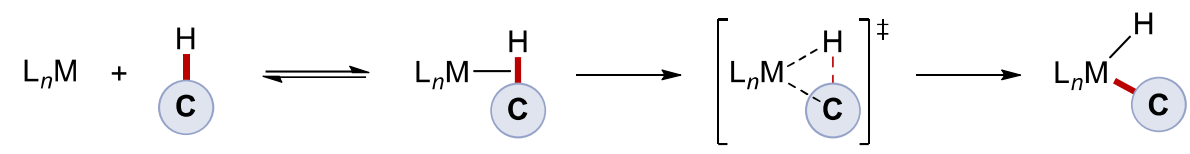

(b) Electrophilic substitution

$$
\mathrm{L}_{n} \stackrel{\oplus}{\mathrm{M}}-\mathrm{X}+\underset{\mathrm{C}}{\mathrm{H}} \longrightarrow \mathrm{L}_{n} \mathrm{M}^{\prime} \stackrel{\oplus}{\mathrm{C}}{ }^{\mathrm{X}} \mathrm{H} \longrightarrow \mathrm{L}_{n} \mathrm{M}^{\oplus} \mathrm{C}+\mathrm{HX}
$$

(c) $\sigma$-Bond metathesis

$$
\mathrm{L}_{n} \mathrm{M}-\mathrm{R}+\underset{\mathrm{C}}{\mathrm{H}} \longrightarrow\left[\begin{array}{cc}
\mathrm{R}-\mathrm{H}^{\mathrm{H}} \\
\vdots & \vdots \\
\mathrm{L}_{n} \mathrm{M}-\cdots & \mathrm{C}
\end{array}\right]^{\ddagger} \longrightarrow \mathrm{L}_{n} \mathrm{M}-\mathrm{C}+\mathrm{RH}
$$

(d) 1,2-Addition

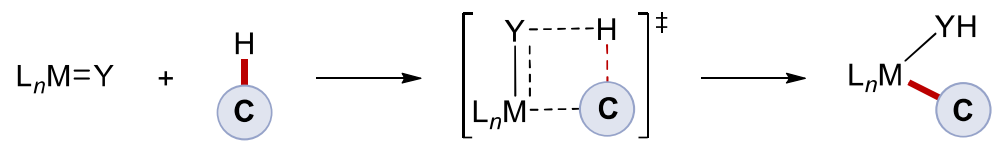

(e) Base-assisted metalation

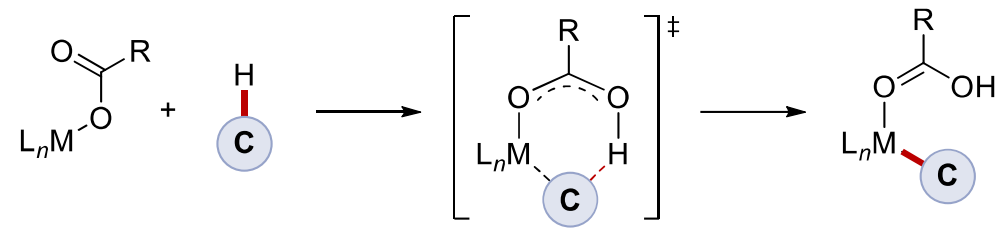

Scheme 1.1.3 Mechanistic pathways for the $\mathrm{C}-\mathrm{H}$ activations.

Transition metal-catalyzed $\mathrm{C}-\mathrm{H}$ activation reactions have primarily been proposed to occur generally via the base-assisted pathway. Extensive studies led to the proposal of different mechanisms (Scheme 1.1.4). ${ }^{[29]}$ Concerted metalation-deprotonation (CMD) and ambiphilic metal-ligand activation (AMLA) have been independently proposed by Fagnou/Gorelsky ${ }^{[30]}$ and MacGregor/Davies, ${ }^{[31]}$ respectively, and are controlled by kinetic $\mathrm{C}-\mathrm{H}$ acidity. Moreover, Ackermann introduced the baseassisted internal electrophilic-type substitution (BIES) as $\mathrm{C}-\mathrm{H}$ activation pathway occurring with carboxylate support. ${ }^{[29,32]}$ 


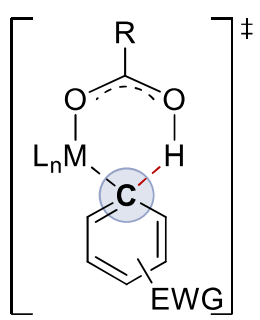

CMD/AMLA

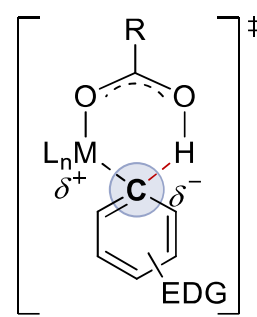

BIES

Scheme 1.1.4 Mechanistic paths for the base-assisted C-H metalation.

\subsection{Organic Electrocatalysis}

Since forms of energy, their consumption, and waste production are nowadays issues of high interest, chemistry is improving its way of producing molecules. An efficient synthesis should envisage a small number of steps to reach the target molecule under mild reaction conditions, together with a good selectivity and high resource-economy. This approach avoids the use of toxic reagents, reducing waste production, and adequate employment of energy. In this context, the use of electrochemistry for molecular syntheses can play a pivotal role (Scheme 1.2.1). Indeed, the replacement of chemical oxidants and reductants with electricity carries different advantages. ${ }^{[33]}$ Firstly, the atom-economy and waste prevention are increased due to the absence of stoichiometric redox reagents in the reaction. It also enhances the safety, as toxic and hazardous reagents are replaced or are generated in-situ and possibly only in small quantities. Moreover, the tunability of the applied redox potential gives a more precise control over the desired redox event, thus allowing for milder reaction conditions and improved selectivities. Lastly, electrosynthesis is usually cost efficient, since the electrodes employed are generally inert and long-lasting.

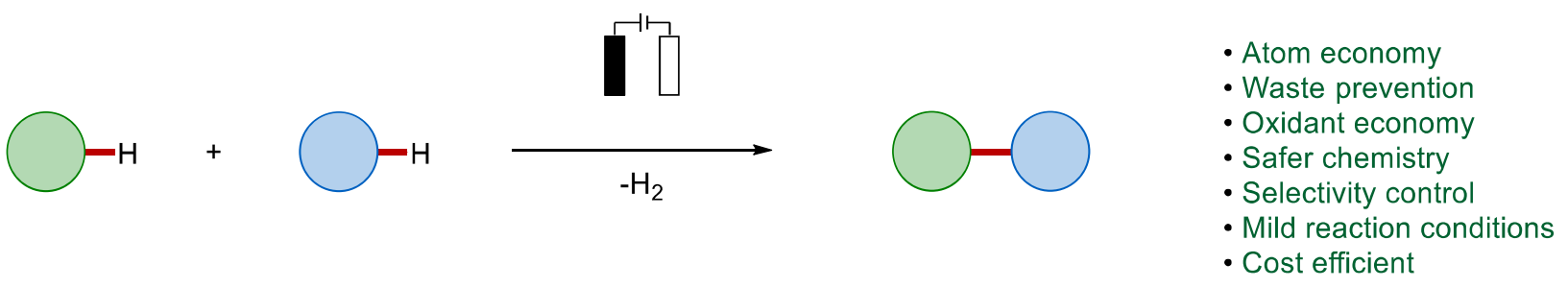

Scheme 1.2.1 Electrochemical approach for cross-dehydrogenative coupling and advantages. 
The origin of electrosynthesis can be traced back to Kolbe electrolysis (Scheme 1.2.2). This first electro-organic reaction, inspired from the work of Faraday in $1834,{ }^{[34]}$ was performed by Hermann Kolbe, from Göttingen, in 1848. ${ }^{[35]}$ The reaction consists of the electrochemical conversion of carboxylic acids to give $\mathrm{CO}_{2}$ and alkanes. From this starting point, electrosynthesis made great steps with the affirmation of foreground reactions, such as the Shono oxidation, ${ }^{[36]}$ as well as industrial applications, like the Simons fluorination ${ }^{[37]}$ and the Monsanto process. ${ }^{[38]}$

2

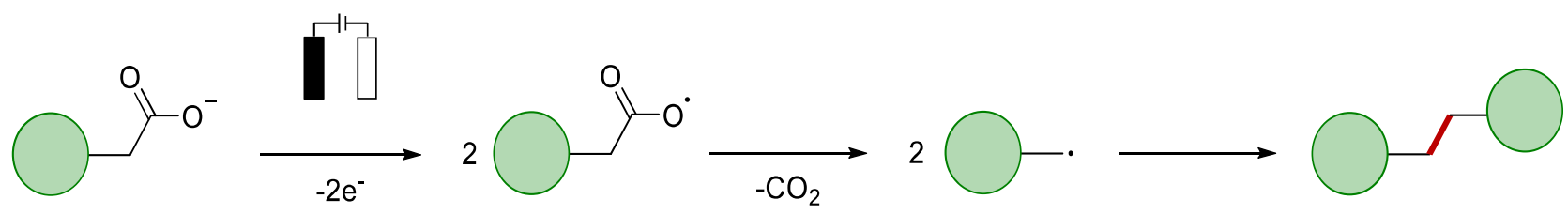

Scheme 1.2.2 The Kolbe reaction.

\subsubsection{C-H Activation and Electrosynthesis}

An early example of merging palladium-catalyzed $\mathrm{C}-\mathrm{H}$ activation and electrosynthesis was reported by Amatore and Jutand (Scheme 1.2.3). ${ }^{[39]}$ The reaction consisted of a Fujiwara-Moritani type alkenylation, where catalytic amounts of benzoquinone $\mathbf{3}$ served as indirect oxidant for the oxidation of palladium(0) species $\mathbf{6}$ formed after the reductive elimination from palladium(II) complex (Scheme 1.2.3). The benzoquinone was thus continuously re-oxidized at the carbon cloth anode. The drawbacks consisted in the need of performing the reaction in a divided cell setup to avoid the electrodeposition of palladium, and in the use of a mediator that decrease the atom-economy of the reaction, even though it is present only in catalytic amounts. 


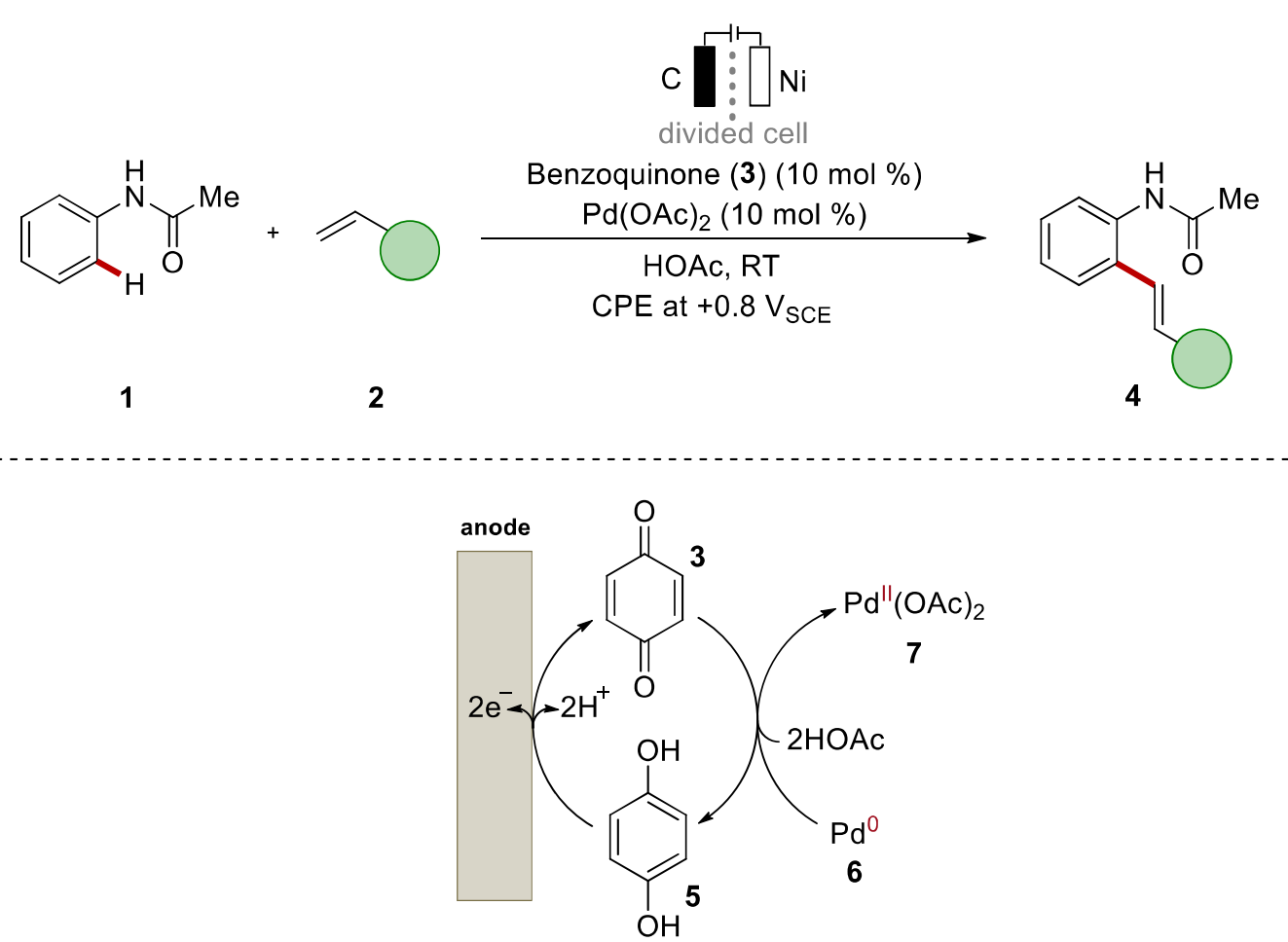

Scheme 1.2.3 Electrochemical palladium-catalyzed alkenylation by Amatore and Jutand.

In 2009, Kakiuchi disclosed electrochemical palladium-catalyzed chlorinations and brominations of 2-phenyl-pyridines (Scheme 1.2.4). ${ }^{[40]}$ In this report, electricity was used to generate the halonium ion from mineral acids, thus avoiding expensive halogenation reagents. The cation was then attacked by the palladacycle, furnishing the desired product 9. The same group extended the approach to iodinations with elemental iodine or potassium iodide. ${ }^{[1]}$ More recently, Mei showed that the use of less corrosive ammonium bromides is also suitable for palladium-catalyzed electrochemical bromination. ${ }^{[42]}$ These approaches were nevertheless limited to strongly coordinating pyridine directing groups.

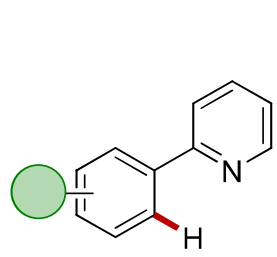

8

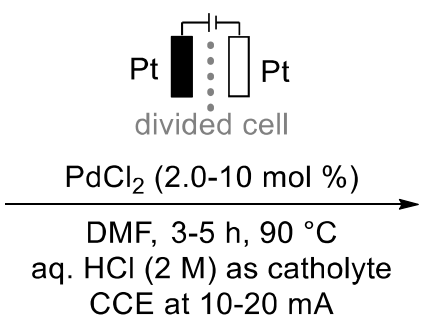

CCE at $10-20 \mathrm{~mA}$

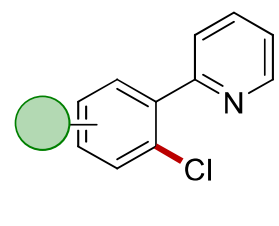

9

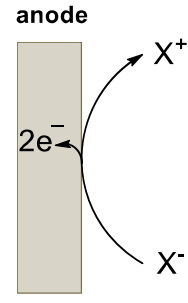

Scheme 1.2.4 Electrochemical palladium-catalyzed halogenation by Kakiuchi. 
Thus far, electrochemistry was used for the regeneration of the mediator or for the formation of halonium cations, but not employed in the direct oxidation of the metal. Budnikova reported the direct oxidation of a palladacycle for the $\mathrm{C}-\mathrm{H}$ perfluorocarboxylation of phenyl pyridines. ${ }^{[43]}$ In 2017 , Mei published the electrochemical palladium-catalyzed $\mathrm{C}\left(\mathrm{sp}^{3}\right)-\mathrm{H}$ oxygenation of oximes (Scheme 1.2.5). ${ }^{[4]}$ The proposed catalytic cycle commences with the coordination of the oxime $\mathbf{1 0}$ to the palladium(II) acetate catalyst 7. Subsequent base-assisted $\mathrm{C}-\mathrm{H}$ activation delivers species $\mathbf{1 3}$ that is then oxidized at the anode to give a high-valent palladium(III) or palladium(IV) complex 14. Finally, reductive elimination yields the desired product $\mathbf{1 1}$ and regenerates the active catalyst 7 . As supported by cyclic voltammetry studies, the palladacycle could be oxidized directly and efficiently on the platinum anode, but the reaction still required a divided cell setup to avoid electrodeposition at the cathode.

The same group performed arene $\mathrm{C}\left(\mathrm{sp}^{2}\right)-\mathrm{H}$ activation likewise. ${ }^{[45]}$ In the following year, the group of Sanford published a similar acetoxylation of $\mathrm{C}\left(\mathrm{sp}^{2}\right)-\mathrm{H}$ and $\mathrm{C}\left(\mathrm{sp}^{3}\right)-\mathrm{H}$ bonds. ${ }^{[46]}$ The electrochemical palladium catalysis was not limited to oxygenation reactions, but Mei and co-workers proved it feasible also for methylation and acylation reactions. ${ }^{[47]}$

This progress represented the state of the art at the outset of my doctoral work. Electrochemical C-H activation was limited to expensive palladium catalysis in a divided cell setup. During the past four years, the field underwent a fast growth with excellent examples from Ackermann, ${ }^{[4 a, 48]}$ Lei, ${ }^{[49]}$ Mei, ${ }^{[50]}$ and $\mathrm{Xu},{ }^{[51]}$ among others. ${ }^{[52]}$ 


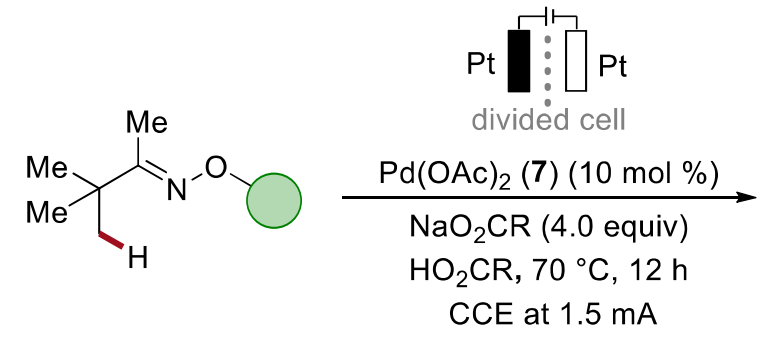

10

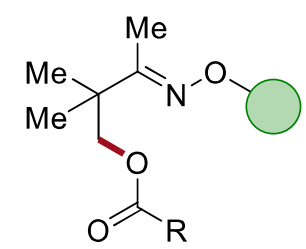

11

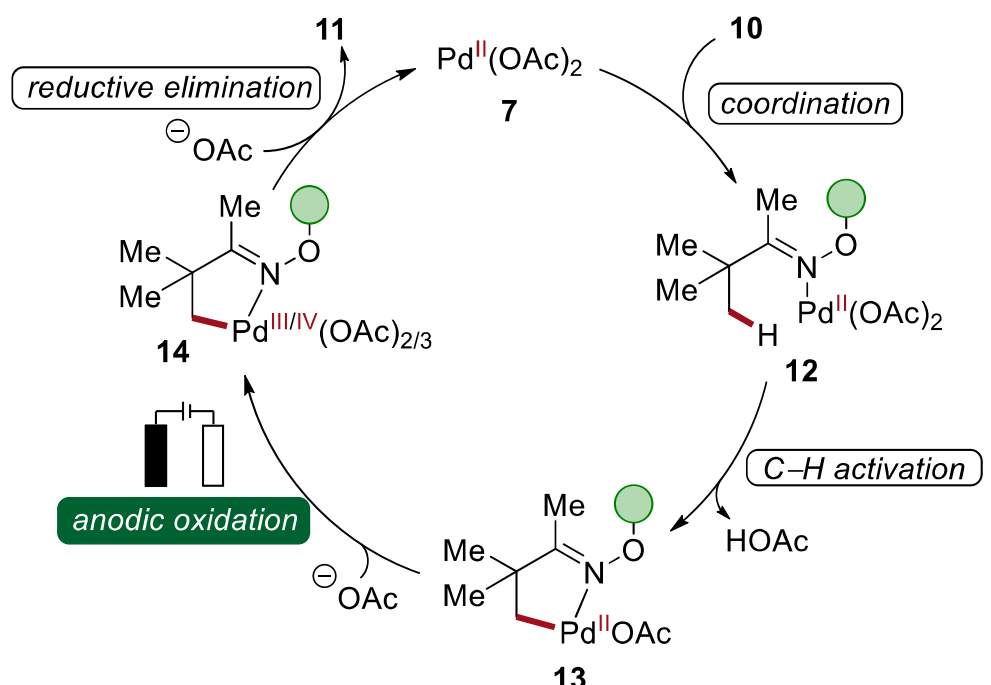

Scheme 1.2.5 Electrochemical palladium-catalyzed $\mathrm{C}\left(\mathrm{sp}^{3}\right)-\mathrm{H}$ oxygenation and proposed catalytic cycle.

\subsection{Cobalt-Catalyzed C-H Activation}

In the last twenty years, cobalt has gained particular attention among the $3 \mathrm{~d}$ metals due to its numerous applications for $\mathrm{C}-\mathrm{H}$ functionalizations. Its reduced cost in comparison to more precious transition metals of the $4 \mathrm{~d}$ and $5 \mathrm{~d}$ series makes its use highly desiderable. There are two reactivities that mainly describe cobalt-catalyzed $\mathrm{C}-\mathrm{H}$ functionalizations, namely the low-valent and high-valent cobalt catalyses. $^{[17]}$

Already in 1941, the catalytic activity of cobalt for the homocoupling of Grignard reagents was revealed by Karash and Fields. ${ }^{[53]}$ Cobalt catalysis for $\mathrm{C}-\mathrm{H}$ activation dates back to 1955 , when a study by Murahashi showed the carbonylative cyclization of imines $\mathbf{1 5}$ with carbon monoxide using dicobalt octacarbonyl as catalyst (Scheme 1.3.1). ${ }^{[54]}$ Even though the conditions were extremely 
harsh, this pioneering work was also presenting the directing group strategy for $\mathrm{C}-\mathrm{H}$ activation. In the following year, they expanded the applicability of the reaction to azobenzenes. ${ }^{[55]}$

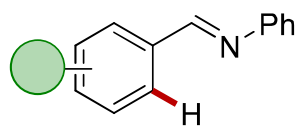

15

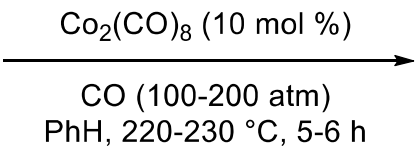

$\mathrm{PhH}, 220-230^{\circ} \mathrm{C}, 5-6 \mathrm{~h}$

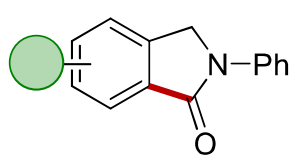

16: $70-80 \%$

Scheme 1.3.1 Cobalt-catalyzed carbonylative cyclization by Murahashi.

After 40 years, Klein proved the ability of cobalt in performing $\mathrm{C}-\mathrm{H}$ cleavage, synthesizing different cyclocobaltated complexes (Scheme 1.3.2). ${ }^{[56]}$ In these studies, the employment of stoichiometric amounts of the cobalt complex $\left[\mathrm{Co}\left(\mathrm{CH}_{3}\right)\left(\mathrm{PMe}_{3}\right)_{4}\right]$ allowed to successfully synthesize 5-, ${ }^{[56 \mathrm{a}-\mathrm{d}, 56 \mathrm{f}]} 6$ ${ }^{[56 \mathrm{~d}]}$ and even the more strained 4-membered ${ }^{[56 \mathrm{e}]}$ cycles, all with different Lewis-basic directing groups, including ketones, phosphines, and pyridines.

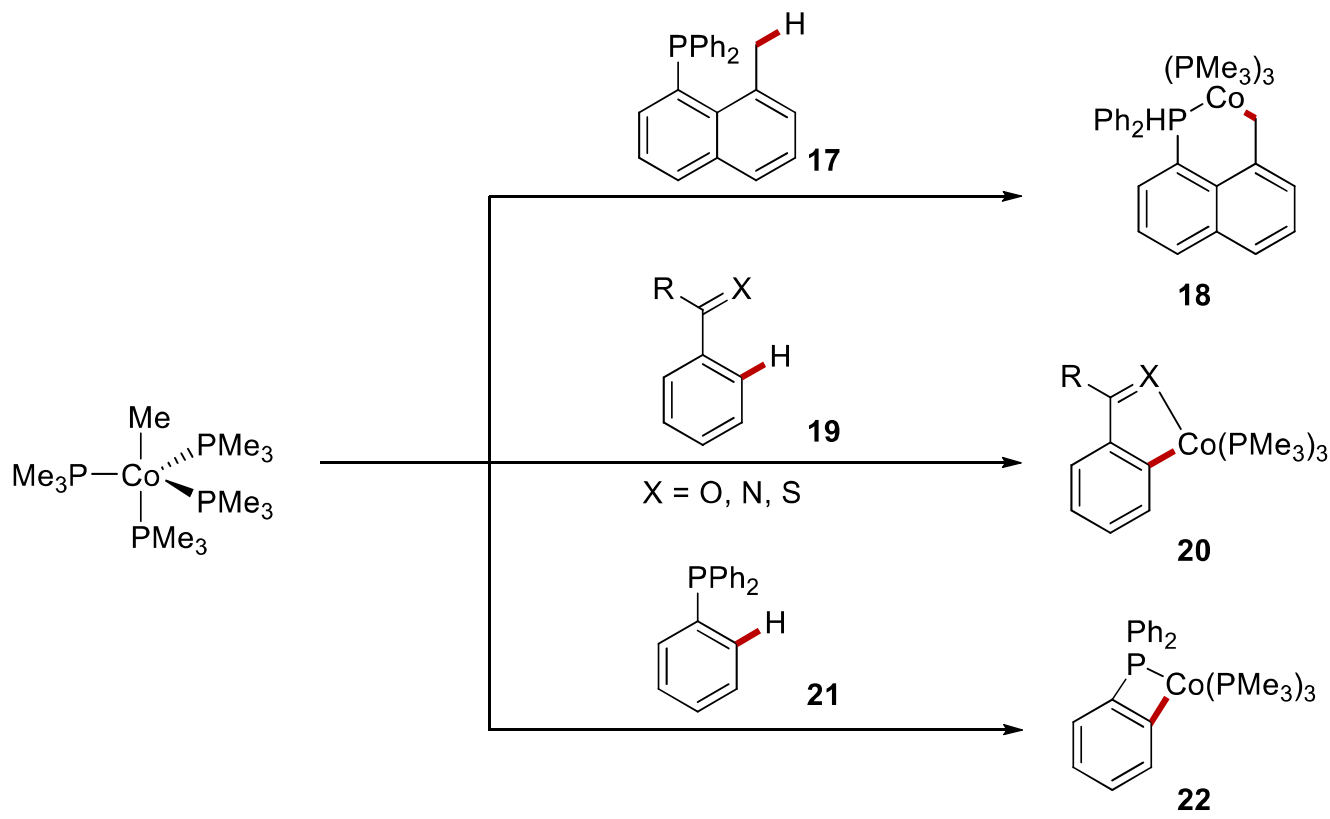

Scheme 1.3.2 Stoichiometric syntheses of cobaltacycles by Klein. 
Another important milestone was the cobalt-catalyzed hydroarylation reported by Kisch and coworkers in 1994 (Scheme 1.3.3). ${ }^{[57]}$ The authors employed a cobalt(I) species and azobenzenes 23 for a successful di-functionalization.

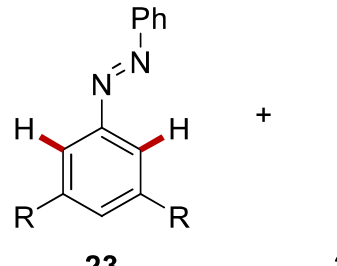

23

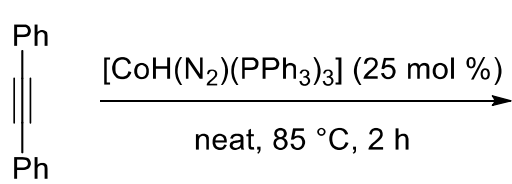

$24 a$

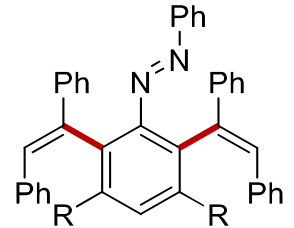

25: $70-80 \%$

Scheme 1.3.3 Cobalt-catalyzed hydroarylation by Kisch.

\subsubsection{Cobalt-Catalyzed C-H Activation with Chemical Oxidants}

In 2014, Daugulis reported on the oxidative $\mathrm{C}-\mathrm{H} / \mathrm{N}-\mathrm{H}$ annulation of benzamides $\mathbf{2 6}$ with alkynes $\mathbf{2 4}$ (Scheme 1.3.4,a). ${ }^{[58]}$ 8-Aminoquinoline was employed to take advantage of a bidentate directing groups for chelation. ${ }^{[59]}$ The formation of a catalytically competent high-valent cobalt(III) cycle was proven by NMR spectroscopy. Manganese(II) acetate was present in stoichiometric amounts as cooxidant together with aerial oxygen. 2,2,2-Trifluoroethanol (TFE) was the best solvent, while carboxylates proved to be essential additives. In the same year they also expanded the reaction to alkenes 31 for $\mathrm{C}-\mathrm{H} / \mathrm{N}-\mathrm{H}$ annulations (Scheme 1.3.4,b). ${ }^{[60]}$ These reports delineated the oxidative cobalt catalysis for heterocycles synthesis as an attractive, versatile, and step-economical approach. ${ }^{[61]}$ 
(a) $\mathrm{C}-\mathrm{H} / \mathrm{N}-\mathrm{H}$ alkyne annulation by Daugulis<smiles>O=C(NO)c1ccccc1</smiles>

26 $+\quad \|_{\mathrm{R}^{2}}^{\mathrm{R}^{1}}$

24
$\underset{\mathrm{Co}(\mathrm{OAc})_{2} \cdot 4 \mathrm{H}_{2} \mathrm{O}(10 \mathrm{~mol} \%)}{\mathrm{Mn}(\mathrm{OAc})_{2}(1.0 \text { equiv })}$
$\mathrm{NaOPiv}$

TFE, $80^{\circ} \mathrm{C}, 6 \mathrm{~h}$<smiles>[R]c1c([R])n(O)c(=O)c2ccccc12</smiles>

27

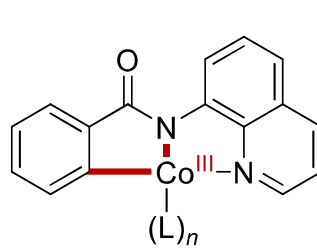

28

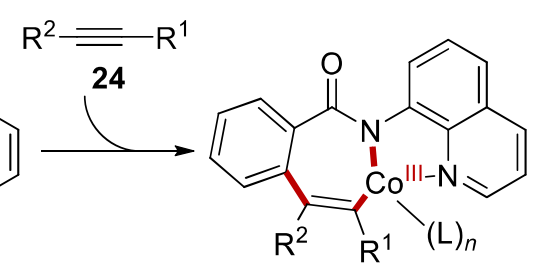

29<smiles>[R]c1c([R])n(-c2cccc3cccnc23)c(=O)c2ccccc12</smiles>

30

27

(b) $\mathrm{C}-\mathrm{H} / \mathrm{N}-\mathrm{H}$ alkene annulation by Daugulis<smiles>O=C(NO)c1ccccc1</smiles>

26<smiles>[R]C=C[R]</smiles>

31

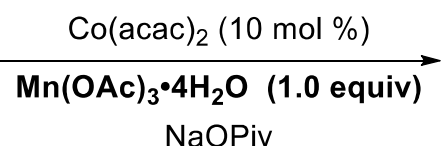

TFE, $80^{\circ} \mathrm{C}, 6 \mathrm{~h}$<smiles>[R]C1C2=CC3CCCC3C=C2C(=O)N1O</smiles>

32

Scheme 1.3.4 Cobalt-catalyzed oxidative $\mathrm{C}-\mathrm{H} / \mathrm{N}-\mathrm{H}$ annulations and their mechanism.

In 2016, Ackermann achieved the synthesis of isoquinolones 34 employing cobalt(II) acetate and a pyridine- $N$-oxide directing group, using for the first time molecular oxygen as the sole terminal oxidant (Scheme 1.3.5,a). ${ }^{[62]}$

Other examples of oxidative annulations using cobalt catalysts were reported with alkenes by the groups of Volla ${ }^{[63]}$ and Ackermann, ${ }^{[64]}$ as well as with allenes by of Volla/Maiti ${ }^{[65]}$ and Cheng ${ }^{[66]}$ (Scheme 1.3.5,b-e). These reports were relying on bidentate 8-aminoquinoline as directing group and manganese acetate as oxidant, besides the report by Cheng that required the presence of a silver(I) salt. 
(a) $\mathrm{C}-\mathrm{H} / \mathrm{N}-\mathrm{H}$ alkyne annulation with $\mathrm{O}_{2}$ as the sole oxidant by Ackermann<smiles></smiles>

33
24

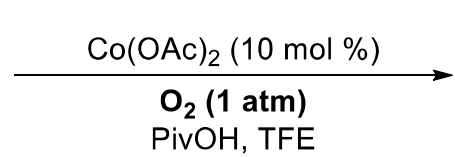

$60{ }^{\circ} \mathrm{C} 16 \mathrm{~h}$<smiles>[R]c1c([R])n([R9])c(=O)c2ccccc12</smiles>

34

(b) $\mathrm{C}-\mathrm{H} / \mathrm{N}-\mathrm{H}$ alkene annulation by Volla<smiles>O=C(NO)c1ccccc1</smiles>

26

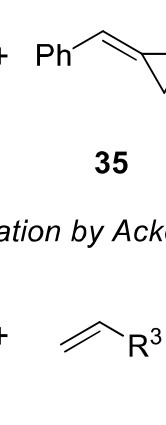

37

$$
\begin{gathered}
\mathrm{Co(acac})_{2}(20 \mathrm{~mol} \%) \\
\mathrm{Mn(OAc)})_{3} \cdot 2 \mathrm{H}_{2} \mathrm{O}(2.0 \text { equiv }) \\
\mathrm{NaOPiv}, \mathrm{TFE} \\
\mathrm{RT}, 48 \mathrm{~h}
\end{gathered}
$$

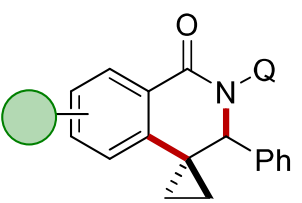

36<smiles>[R3]CC1c2ccccc2C(=O)N1O</smiles>

38

(d) $\mathrm{C}-\mathrm{H} / \mathrm{N}-\mathrm{H}$ allene annulation by Volla/Maiti<smiles>O=C(N[OH2+])c1ccccc1C=CC1CCCCC1</smiles>

26<smiles>[R]C([R])=C=C</smiles>

39

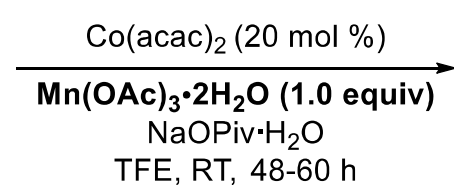
TFE, RT, 48-60 h<smiles>[R7]C1([R7])C(=C)c2ccccc2C(=O)N1O</smiles>

40

(e) $\mathrm{C}-\mathrm{H} / \mathrm{N}-\mathrm{H}$ allene annulation by Cheng<smiles>O=C(N[OH2+])c1ccccc1</smiles>

26<smiles>[R]C=C=C[R]</smiles>

41

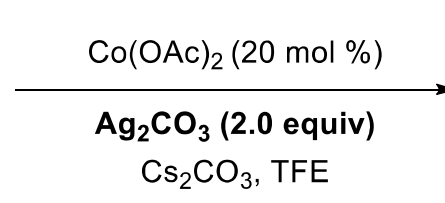

$80{ }^{\circ} \mathrm{C}, 24 \mathrm{~h}$<smiles>[R]Cc1c([R6])c2ccccc2c(=O)n1O</smiles>

42

Scheme 1.3.5 Cobalt-catalyzed oxidative $\mathrm{C}-\mathrm{H} / \mathrm{N}-\mathrm{H}$ annulations.

Besides annulation reactions, different $\mathrm{C}-\mathrm{C}$ and $\mathrm{C}-\mathrm{Het}$ bond formations have furthermore been studied and achieved with oxidative cobalt-catalyzed $\mathrm{C}-\mathrm{H}$ activations.

First, the allylation of quinolinamides $\mathbf{2 6}$ was achieved with alkenes under different reaction conditions (Scheme 1.3.6). ${ }^{[67]}$ The reactions benefited from DCE or chlorobenzene as the solvents, the use of silver(I) salts as chemical oxidants and cobalt acetate as the catalyst. For all the three studies the reaction showed the same selectivity, yielding the desired product $\mathbf{4 4}$ exclusively with allylic selectivity over the styrenyl selectivity of the conventional olefination reactions. 
(a) Maiti

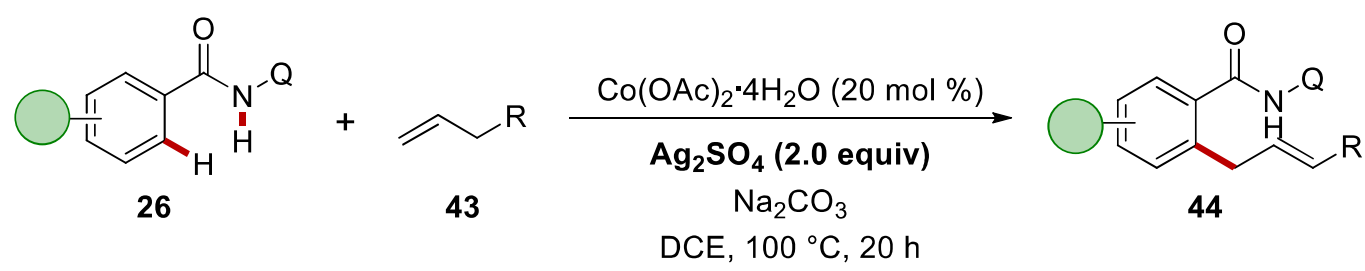

(b) Chatani

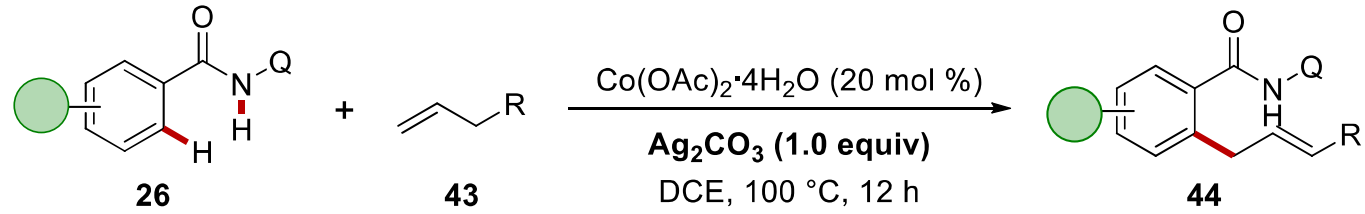

(c) Jeganmohan<smiles>C=CCF</smiles>

26

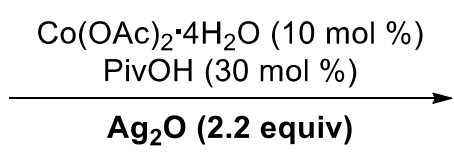

$\mathrm{PhCl}, 100^{\circ} \mathrm{C}, 24 \mathrm{~h}$

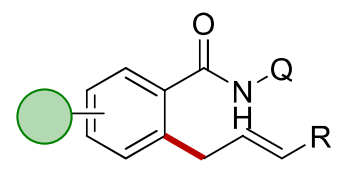

44

Scheme 1.3.6 Cobalt-catalyzed oxidative C-H allylations.

Moreover, Balaraman published the alkynylation in the presence of 8-aminoquinoline directing group via oxidative cobalt-catalyzed $\mathrm{C}-\mathrm{H}$ activation (Scheme 1.3 .7$).{ }^{[68]}$ Cobalt(III) acetylacetonate was employed with large excess of silver carbonate as oxidant at $150{ }^{\circ} \mathrm{C}$. The reaction mainly yielded the bis-alkynylated products 46, unless having substituents in the ortho-position, bulky electron-withdrawing meta-substituents, or when heteroarenes were employed.

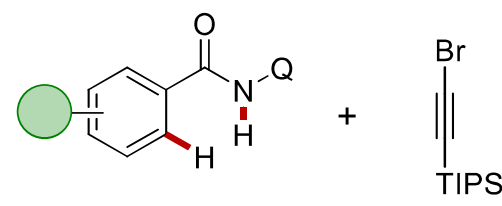

26

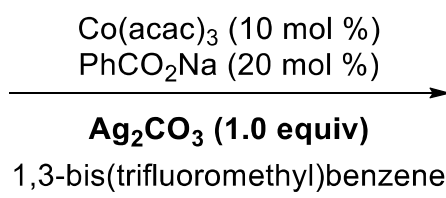

$150{ }^{\circ} \mathrm{C}, 18 \mathrm{~h}$

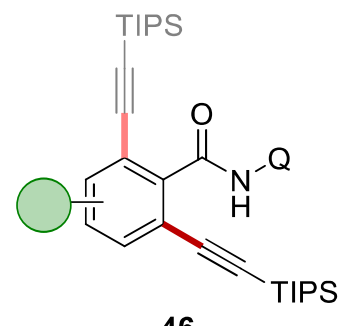

46

Scheme 1.3.7 Cobalt-catalyzed C-H alkynylation.

Regarding C-Het bond formations, in 2015 the oxidative cobalt-catalyzed oxygenation was reported by Niu and Song (Scheme 1.3.8,a). ${ }^{[69]}$ Here, pyridine- $N$-oxide was again employed, while 1.0 
equivalent of silver oxide was used as the oxidant. The access to cobalt-catalyzed $\mathrm{C}-\mathrm{H}$ acyloxylation was disclosed by Zeng, who performed the reaction on arenes 49 with picolinamide as directing group (Scheme 1.3.8,b). ${ }^{[70]}$ Here, carboxylic acids $\mathbf{5 0}$ were used as coupling partners and the reaction required $120{ }^{\circ} \mathrm{C}$ and 2.0 equivalents of silver carbonate to succeed.

(a) Oxygenation by Niu and Song

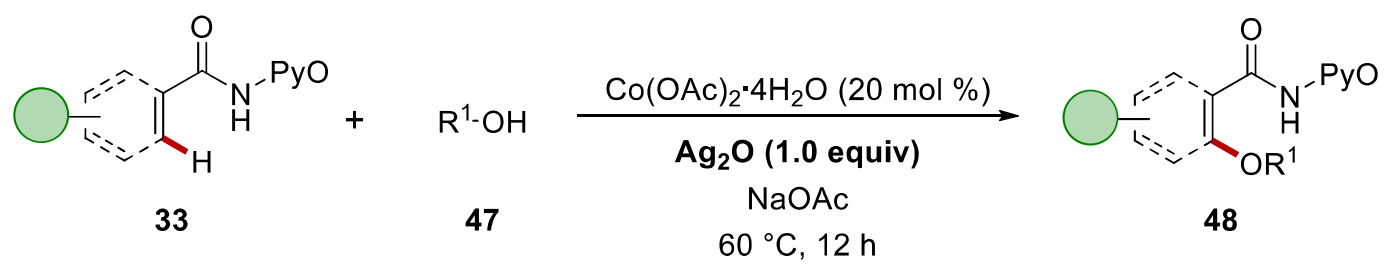

(b) Acyloxylation by Zeng

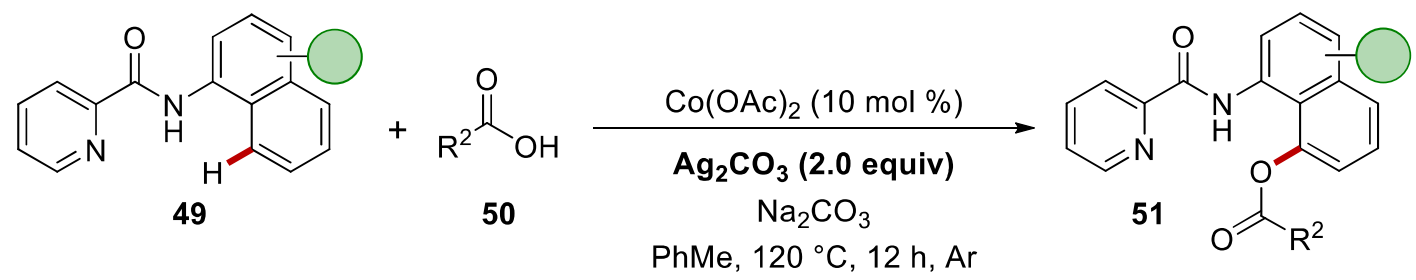

Scheme 1.3.8 Cobalt-catalyzed C-H (a) oxygenation and (b) acyloxylation.

$\mathrm{C}-\mathrm{H}$ amination was likewise found to be a suitable transformation with oxidative cobalt-catalysis. Ge reported the intra- and inter-molecular amination of unactivated $\mathrm{sp}^{3} \mathrm{C}-\mathrm{H}$ bond (Scheme 1.3.9,a). ${ }^{[71]}$ The conditions were very harsh, performing the reaction at $150{ }^{\circ} \mathrm{C}$ with 2.5 equivalents of silver carbonate. Milder conditions were sufficient for the amination of $\mathrm{C}\left(\mathrm{sp}^{2}\right)-\mathrm{H}$ bonds which was reported in the following year by Niu and Song (Scheme 1.3.9,b). ${ }^{[72]}$ 
(a) Intramolecular dehydrogenative amination

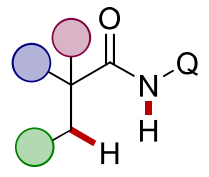

52

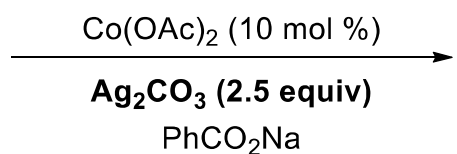

$\mathrm{PhCl}, 150^{\circ} \mathrm{C}, 24-48 \mathrm{~h}$

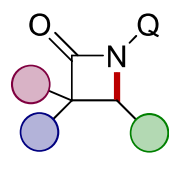

53

(b) Amination of $\mathrm{C}\left(s p^{2}\right)-H$ bonds<smiles>O=CNC(=O)c1ccccc1</smiles>

33
$\mathrm{R}_{\substack{\mathrm{N} \\ \mathrm{H}}}^{1}-\mathrm{R}^{2}$

54
$\underset{\mathrm{AgNO}_{3}(2.5 \text { equiv })}{\mathrm{Co}(\mathrm{OAc})_{2} \cdot 4 \mathrm{H}_{2} \mathrm{O}(10 \mathrm{~mol} \%)}$

$\mathrm{NaOAc}, \mathrm{KNO}_{3}$

$\mathrm{MeCN}, 85^{\circ} \mathrm{C}, 12 \mathrm{~h}$<smiles>[Y6]NC(=O)c1ccccc1N[R12]</smiles>

55

Scheme 1.3.9 Cobalt-catalyzed $\mathrm{C}-\mathrm{H}$ aminations.

\subsubsection{Electrochemical Cobalt-Catalyzed C-H Activation}

Recently, electrochemistry has been employed as green oxidant for C-H activation. In 2017, the first example of merger electrochemistry with $3 \mathrm{~d}$ transition metal-catalyzed $\mathrm{C}-\mathrm{H}$ activation was reported by Ackermann and co-workers using cobalt-catalysis (Scheme 1.3.10). ${ }^{[73]}$ Here, the use of simple cobalt acetate as catalyst and sodium pivalate as base allowed for the oxygenation of benzamides $\mathbf{3 3}$ with pyridine- $N$-oxide as bidentate chelating group. Different aliphatic alcohols 47 underwent the reaction in a divided cell set up with very mild reaction conditions.

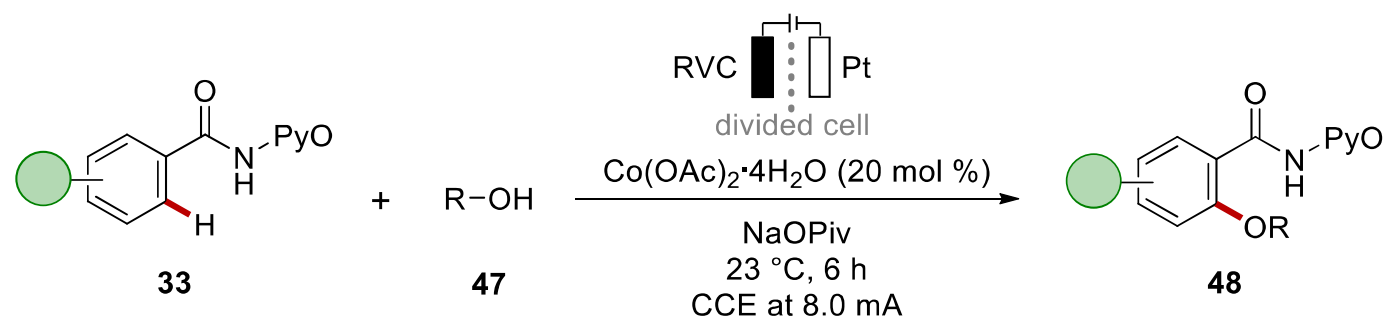

Scheme 1.3.10 Electrochemical cobalt-catalyzed C-H oxygenation.

The above-mentioned cobalt-catalyzed oxygenation from Ackermann was the only research article published prior to the publication of the project in Section 3.1 on Angewandte Chemie. 
After the publication of the influential electrochemical cobalt-catalyzed $\mathrm{C}-\mathrm{H} / \mathrm{N}-\mathrm{H}$ annulations of benzamides with terminal alkynes, discussed in Section 3.1, the group of Lei reported on the electrooxidative annulation with ethylene or ethyne (Scheme $1.3 .11, a),{ }^{[74]}$ while the group of Ackermann further extended the applicability of the cobalt-catalyzed manifold to internal alkynes $\mathbf{2 4}$ on benzhydrazide $\mathbf{5 8}$ with an electroreductively removable directing group (Scheme 1.3.11,b). ${ }^{[75]}$ Following these studies, allenes ${ }^{[76]} 39$, as well as 1,3 -diynes, ${ }^{[77]}$ were also employed for the $\mathrm{C}-\mathrm{H} / \mathrm{N}-$ $\mathrm{H}$ cobalt-catalyzed annulation reaction by the group of Ackermann (Scheme 1.3.11,c). The group of Lei reported a similar reaction, employing sulfonamides as directing group. ${ }^{[78]}$ In 2020 , Ackermann published a remarkable study on the mechanism of electrochemical cobalt catalysis. ${ }^{[79]}$ Herein, the authors could prove a pathway involving Co(III/IV/II) manifold for the $\mathrm{C}-\mathrm{H}$ oxygenation reaction, thus through an oxidatively-induced reductive elimination. They moreover confirmed a $\operatorname{Co}(\mathrm{III} / \mathrm{I})$ cycle for annulation reactions. Indeed, the product $\mathbf{6 0}$ was formed from the reaction between the isolated Co(III) intermediate and the alkyne in absence of electricity.

(a) $\mathrm{C}-\mathrm{H} / \mathrm{N}-\mathrm{H}$ annulation with ethylene or ethyne

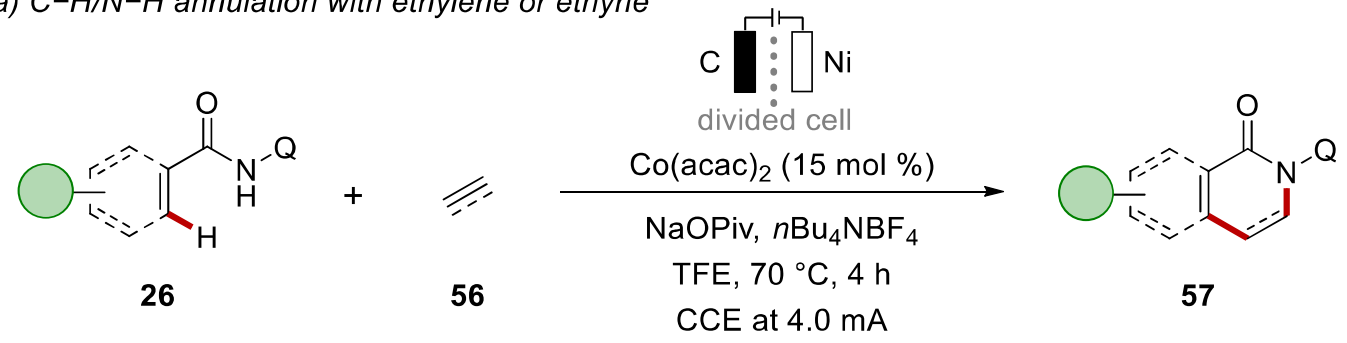

(b) $\mathrm{C}-\mathrm{H} / \mathrm{N}-\mathrm{H}$ annulation with terminal alkynes and removable $D G$

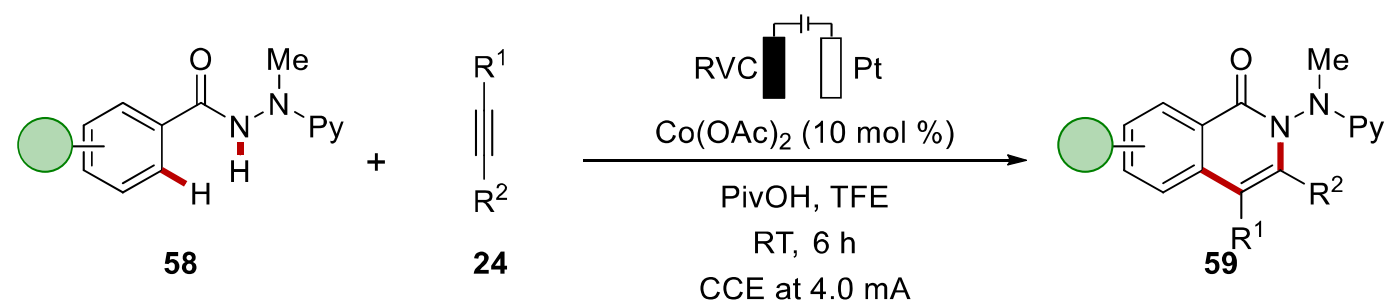

(c) $\mathrm{C}-\mathrm{H} / \mathrm{N}-\mathrm{H}$ annulation with allenes<smiles></smiles>

33

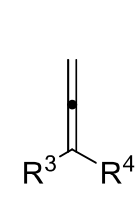

39

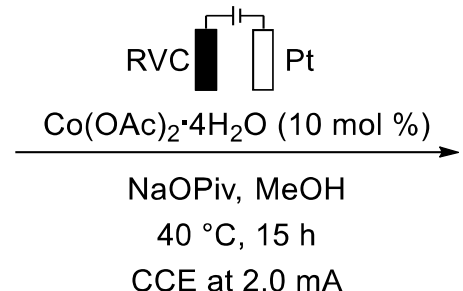

CCE at $2.0 \mathrm{~mA}$<smiles>[R]C([R])c1cc2ccccc2c(=O)n1[Pb]</smiles>

60 
Scheme 1.3.11 Electrochemical cobalt-catalyzed C-H/N-H annulations.

In 2018, Lei reported the electrochemical cobalt-catalyzed $\mathrm{C}-\mathrm{H} / \mathrm{N}-\mathrm{H}$ carbonylation with carbon monoxide in divided cell set up. The approach occurred in an intermolecular, as well as intramolecular fashion, to deliver amides $\mathbf{6 1}$ and phthalimides 62 as annulation product, respectively (Scheme 1.3.12,a). ${ }^{[80]}$ Simultaneously, Ackermann published the annulation with carbon monoxide but in a user-friendly undivided cell set up (Scheme 1.3.12,b) ${ }^{[81]}$ The procedure allowed for the C$\mathrm{H} / \mathrm{N}-\mathrm{H}$ annulation also with isocyanides 64.

(a) $\mathrm{C}-\mathrm{H} / \mathrm{N}-\mathrm{H}$ carbonylation with carbon monoxide by Lei

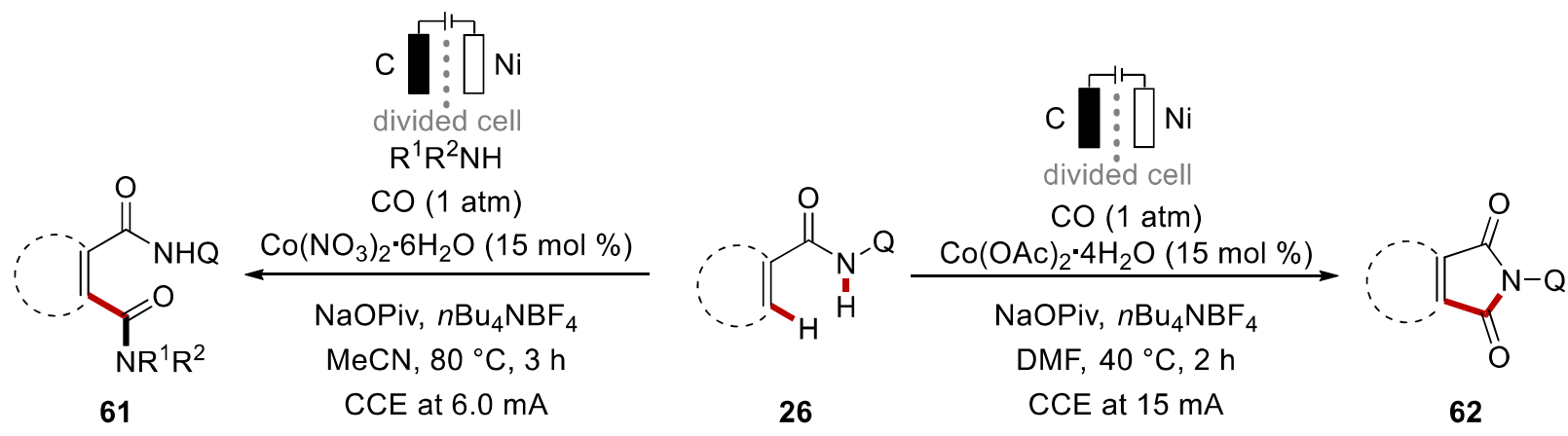

(b) $\mathrm{C}-\mathrm{H} / \mathrm{N}-\mathrm{H}$ annulation with carbon monoxide or isocyanides by Ackermann

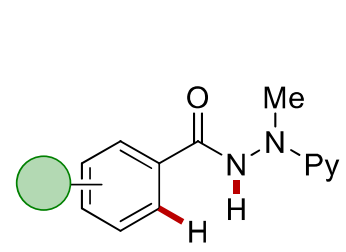

58

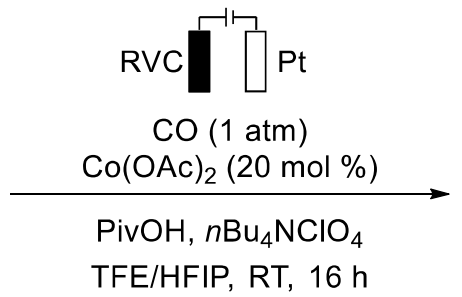

CCE at $3.0 \mathrm{~mA}$<smiles>CN(P)N1C(=O)c2ccccc2C1=O</smiles>

63<smiles>CN1C(=O)c2cc3c(cc2/C1=N/C(C)(C)C)N(C)C3</smiles>

65

Scheme 1.3.12 Electrochemical cobalt-catalyzed $\mathrm{C}-\mathrm{H} / \mathrm{N}-\mathrm{H}$ annulations with carbon monoxide and isocyanides 64 . 
In 2020, the group of Ackermann developed the first electrochemical cobalt-catalyzed allylation reaction on benzamides 26 bearing 8-aminoquinoline as directing group (Scheme 1.3.13). ${ }^{[82]}$ Here, non-electronically activated alkenes $\mathbf{4 3}$ could be used, with the exclusive formation of the allylated products 44 with a high chemo- and regio-selectivities.

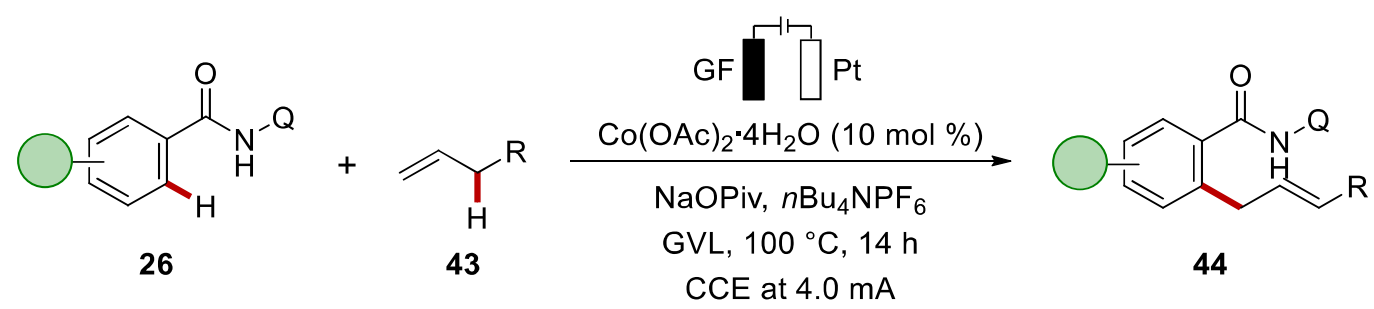

Scheme 1.3.13 Electrochemical cobalt-catalyzed $\mathrm{C}-\mathrm{H} / \mathrm{N}-\mathrm{H}$ allylation.

Besides annulation reactions, diverse $\mathrm{C}-\mathrm{Het}$ bond formation reactions were developed using cobaltaelectro-catalysis. In 2018, an amination reaction was presented by the group of Ackermann (Scheme 1.3.14,a). ${ }^{[83]}$ The reaction employed electricity as oxidant in the renewable solvent $\gamma$ valerolactone $(\mathrm{GVL})$ and in an undivided cell set up at $40{ }^{\circ} \mathrm{C}$. At the same time, also Lei published an electrochemical cobalt-catalyzed $\mathrm{C}-\mathrm{H}$ amination, but this approach required a divided cell and a higher temperature (Scheme 1.3.14,b). ${ }^{[84]}$

After the groundbreaking work on alkoxylation showed at the beginning of this section, another $\mathrm{C}-\mathrm{O}$ bond formation was published by the Ackermann group, featuring $\mathrm{C}-\mathrm{H}$ acyloxylation (Scheme $1.3 .14, c) .{ }^{[85]}$ 
(a) C-H amination by Ackermann

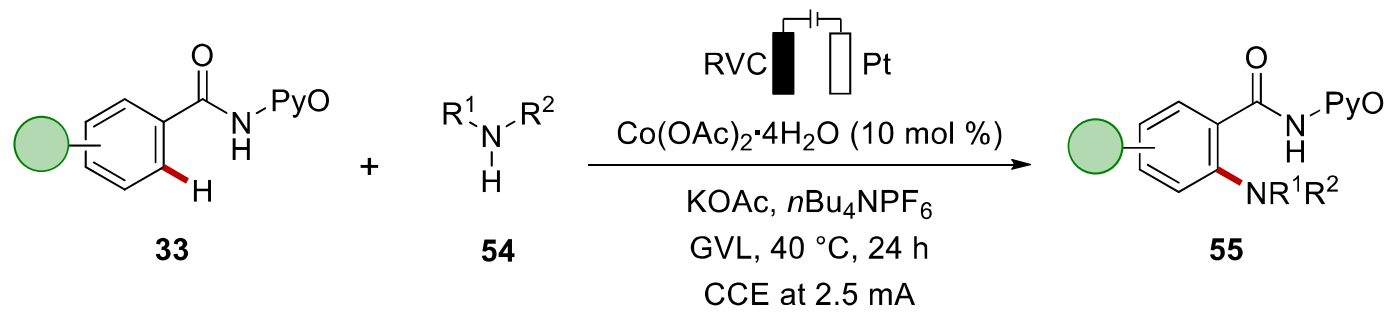

(b) $\mathrm{C}-\mathrm{H}$ amination by Lei<smiles>O=C(NO)c1ccccc1</smiles>

26

$$
\begin{aligned}
& \text { c } \\
& \mathrm{R}_{-1}^{1} \mathrm{~N}_{\mathrm{I}}^{-\mathrm{R}^{2}} \\
& \underset{\mathrm{NaOPiv}, n \mathrm{Bu}_{4} \mathrm{NBF}_{4}}{\mathrm{Co}(\mathrm{OAc})_{2} \cdot 4 \mathrm{H}_{2} \mathrm{O}(20 \mathrm{~mol} \%)} \\
& \mathrm{MeCN}, 65^{\circ} \mathrm{C}, 3.5 \mathrm{~h} \\
& \text { CCE at } 10 \mathrm{~mA}
\end{aligned}
$$<smiles>[R2]NC1=C(C(=O)NO)C=CC2=CCCCC21</smiles>

66

(c) C-H acyloxylation by Ackermann<smiles></smiles>

33

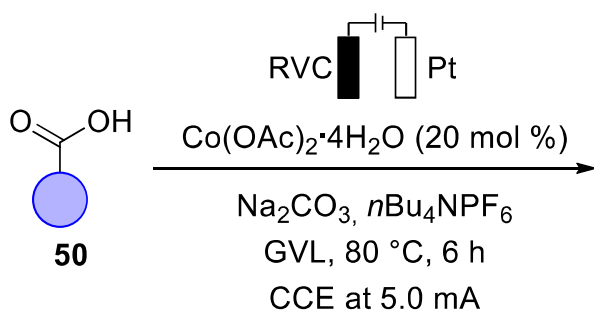

CCE at $5.0 \mathrm{~mA}$<smiles>O=C(NC(=O)c1ccccc1)c1ccccc1</smiles>

Scheme 1.3.14 Electrochemical cobalt-catalyzed C-Het formation.

\subsection{Ruthenium-Catalyzed C-H Activation}

While the initial developments in transition metal-catalyzed $\mathrm{C}-\mathrm{H}$ functionalization have been obtained mainly with palladium and rhodium as catalysts, ruthenium has more recently gained attention due its lower price and versatility. ${ }^{[86]}$ Ruthenium-catalyzed $\mathrm{C}-\mathrm{H}$ activation has been mainly performed with two approaches, one via oxidative addition, usually with low-valent complexes, the other via deprotonation pathway, that requires ruthenium(II) complexes, a base and an oxidant to reoxidize the ruthenium $(0)$ species at the end of the catalytic cycle. ${ }^{[87]}$

The first report on ruthenium $\mathrm{C}-\mathrm{H}$ activation dates back to 1965 when Chatt and Davidson could obtain the stoichiometric $\mathrm{C}-\mathrm{H}$ activation of sodium naphthalene salts forming the ruthenium $(0)$ complex 68 via oxidative addition (Scheme 1.4.1). ${ }^{[88]}$ 


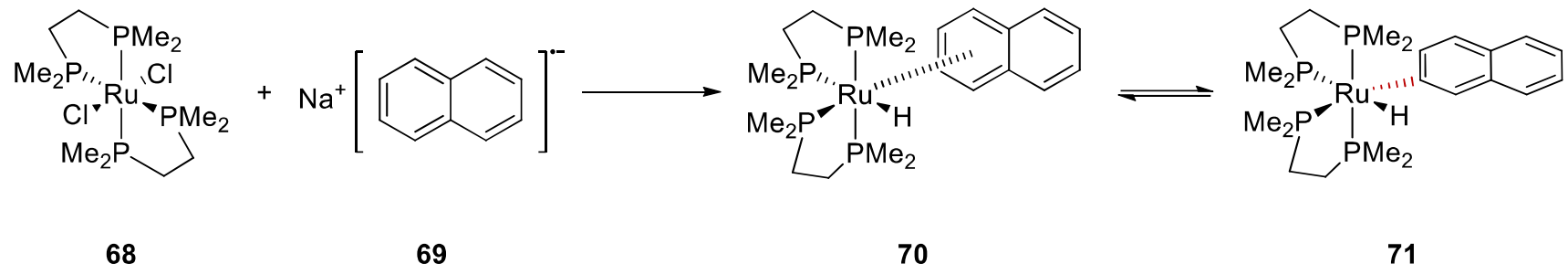

Scheme 1.4.1 First example of ruthenium-mediated $\mathrm{C}-\mathrm{H}$ activation.

Only 21 years later the first catalytic ruthenium $\mathrm{C}-\mathrm{H}$ activation reaction was reported, when Lewis and Smith published a study on the ortho-functionalization of phenols $\mathbf{7 2}$ with ethylene $\mathbf{7 3}$, obtaining mainly the di-alkylated product 75 together with the mono-alkylated one 76 (Scheme 1.4.2). ${ }^{\left[{ }^{[8]}\right.}$ The reaction required harsh conditions and benefited from the use of a transient directing group.

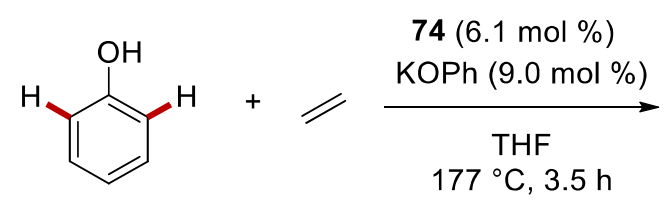

72 73<smiles>CCc1cccc(CC)c1O</smiles>

75<smiles>CCc1ccccc1O</smiles>

76

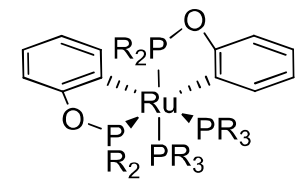

$74(\mathrm{R}=\mathrm{OPh})$

Scheme 1.4.2 First ruthenium-catalyzed $\mathrm{C}-\mathrm{H}$ activation.

Another early example was reported by the group of Moore with the ruthenium(0)-catalyzed acylation using carbon monoxide and olefins. ${ }^{[90]}$ An advance in ruthenium catalysis was achieved in 1993, when Murai published the ortho $\mathrm{C}-\mathrm{H}$ alkylation by weak $O$-coordination ${ }^{[24]}$ with the ruthenium(0) catalyst $\left[\mathrm{RuH}_{2}(\mathrm{CO})\left(\mathrm{PPh}_{3}\right)_{3}\right](\mathrm{Scheme} 1.4 .3) .{ }^{[91]}$ The authors suggested that a fivemembered ruthenacycle $\mathbf{7 9}$ was obtained via chelation-assisted oxidative addition. This methodology had an ample scope, showing for the first time the wide applicability of ruthenium catalyzed $\mathrm{C}-\mathrm{H}$ activation. 
$\overbrace{R^{1}}^{O}+\sim_{R^{2}}^{O}$

77

37
$\left[\mathrm{RuH}_{2}(\mathrm{CO})\left(\mathrm{PPh}_{3}\right)_{3}\right](2.0-6.0 \mathrm{~mol} \%)$

$\mathrm{PhMe}$

$135^{\circ} \mathrm{C}, 0.2-90 \mathrm{~h}$

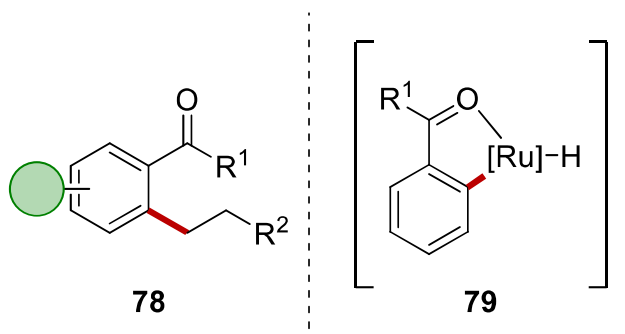

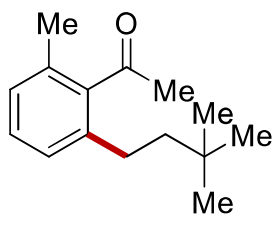

$99 \%(80)$

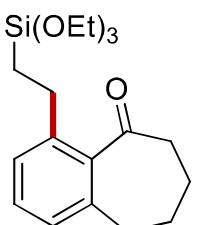

$88 \%(81)$<smiles>CCCCCc1c(C(C)=O)ccc2ccccc12</smiles>

$99 \%(82)$

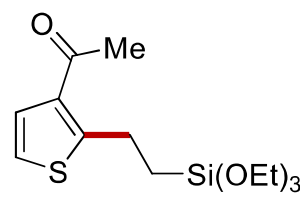

$90 \%(83)$

Scheme 1.4.3 Seminal report of ruthenium-catalyzed direct $\mathrm{C}-\mathrm{H}$ activation.

\subsubsection{Ruthenium-Catalyzed Oxidative $\mathrm{C}-\mathrm{H}$ Activation with Chemical Oxidants}

In 2001, the pioneering work from Milstein showed the Fujiwara-Moritani-type ${ }^{[92]}$ undirected ruthenium $\mathrm{C}-\mathrm{H}$ alkenylation of arenes 84 under high pressure of oxygen as terminal oxidant (Scheme 1.4.4). ${ }^{[93]}$ The reaction proved feasible with different ruthenium(II) and ruthenium(III) sources.

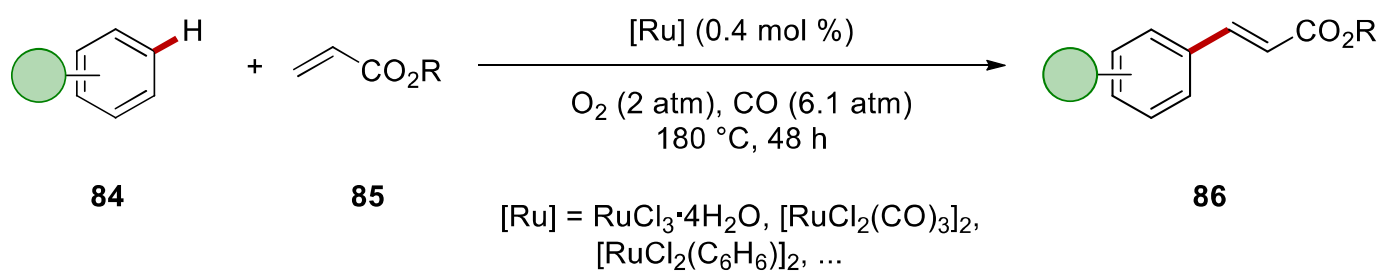

Scheme 1.4.4 First oxidative ruthenium-catalyzed C-H alkenylation.

In 2011, Ackermann achieved the synthesis of isoquinolones $\mathbf{8 8}$ by oxidative ruthenium catalyzed C$\mathrm{H} / \mathrm{N}-\mathrm{H}$ annulation on benzamides 87 and alkynes 24 (Scheme 1.4.5). ${ }^{[94]}$ Copper acetate was employed as oxidant and tert-amyl alcohol as the solvent. 


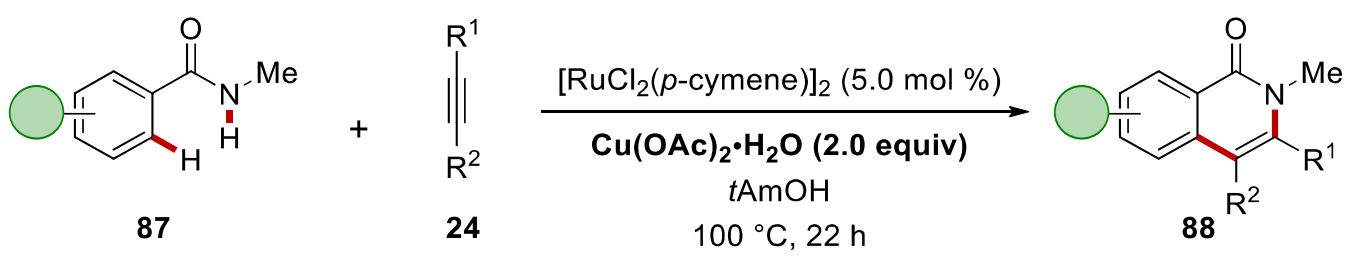

Scheme 1.4.5 Oxidative ruthenium-catalyzed $\mathrm{C}-\mathrm{H} / \mathrm{N}-\mathrm{H}$ annulation.

In 2012, two independent reports by the groups of Ackermann ${ }^{[95]}$ and Jeganmohan ${ }^{[96]}$ were published regarding the oxidative ruthenium-catalyzed annulation on benzoic acids 89 to yield isocumarines 90. The first approach used simple benzoic acids $\mathbf{8 9}$ and internal alkynes $\mathbf{2 4}$ together with copper acetate as the oxidant. Dichloro(p-cymene)ruthenium(II) dimer was the pre-catalyst that in-situ formed a cationic species 91 with the help of potassium hexafluorophosphate and copper acetate (Scheme 1.4.6). This step started the catalytic cycle proposed by the authors, followed by the carboxylateassisted $\mathrm{C}-\mathrm{H}$ ruthenation of the benzoic acid $\mathbf{8 9}$ to give $\mathbf{9 2}$. After migratory insertion, the generated seven-membered ruthenacycle $\mathbf{9 3}$ underwent reductive elimination to yield the product $\mathbf{9 0}$ and a ruthenium(0) species that was re-oxidized by the copper.

Later, Ackermann ameliorated the procedure allowing the reaction to proceed under oxygen or air atmosphere. ${ }^{[97]}$ Thus, even if convenient molecular oxygen was acting as the oxidant, the approach is of difficult scalability due to the hazard of mixing oxygen and flammable solvents. In this report, they were also able to isolate a set of the ruthenium(0) complexes and to study their behavior in the reaction conditions. 


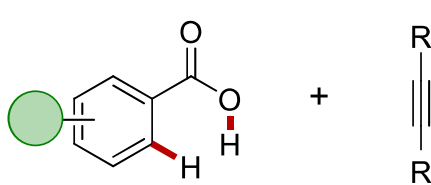

89
$\left.\right|_{\mathrm{R}^{2}} ^{\mathrm{R}^{1}}$

26

$\left[\mathrm{RuCl}_{2}(p \text {-cymene })\right]_{2}(2.5 \mathrm{~mol} \%)$

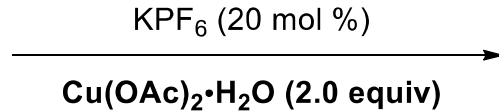

$\mathrm{Cu}(\mathrm{OAc})_{2} \cdot \mathrm{H}_{2} \mathrm{O}(2.0$ equiv $)$ $t \mathrm{AmOH}, 120^{\circ} \mathrm{C}, 16 \mathrm{~h}$

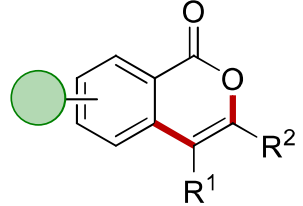

90

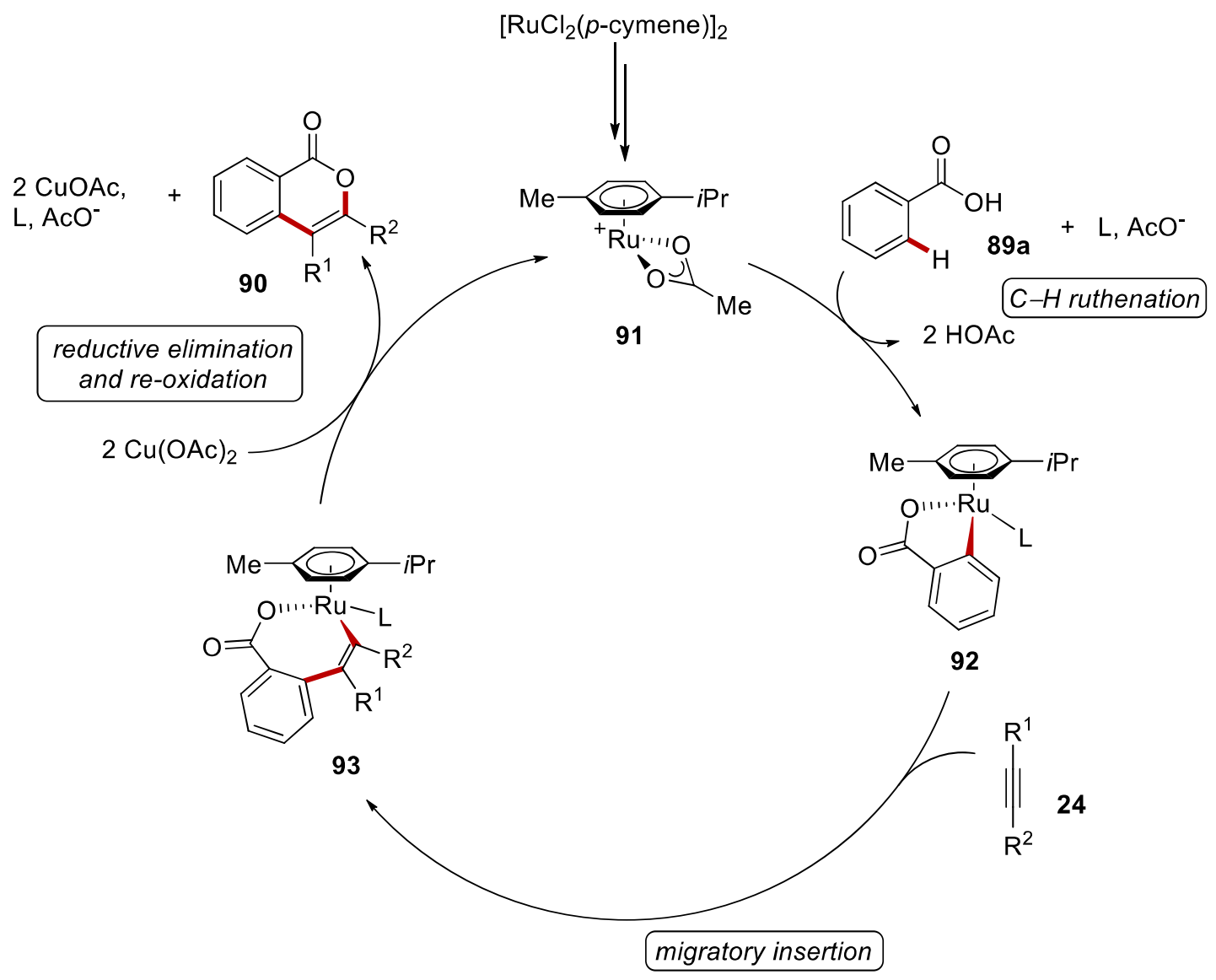

Scheme 1.4.6 Oxidative ruthenium-catalyzed $\mathrm{C}-\mathrm{H} / \mathrm{N}-\mathrm{H}$ annulation and proposed catalytic cycle.

Another approach for the annulation reaction to give isocumarines was reported by Wang and colleagues via $\mathrm{C}-\mathrm{H}$ alkenylation and decarboxylation of $\alpha$-keto carboxylic acids 94 in presence of ruthenium(II) catalyst and copper acetate as oxidant (Scheme 1.4.7). ${ }^{[98]}$

Based on these reports, many other heterocycles have been synthesized by means of oxidative ruthenium-catalyzed $\mathrm{C}-\mathrm{H}$ activation. ${ }^{[99]}$ 


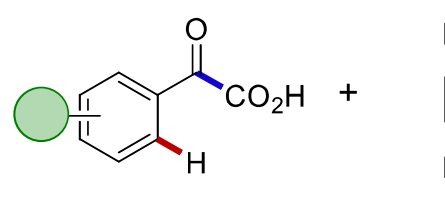

94

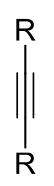

24

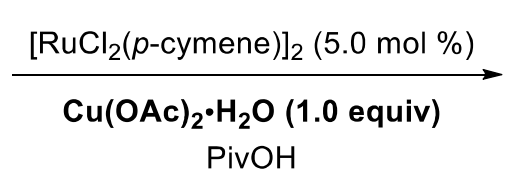

DMF, $120^{\circ} \mathrm{C}, 12 \mathrm{~h}$, air

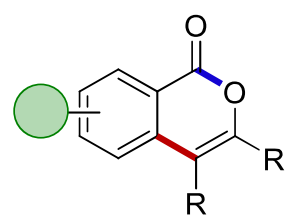

90

Scheme 1.4.7 Oxidative ruthenium-catalyzed $\mathrm{C}-\mathrm{H} / \mathrm{N}-\mathrm{H}$ annulation through decarboxylation.

In 2011, Ackermann reported the synthesis of phtalides by alkenylation of benzoic acids 89 and activated alkenes 37, followed by an oxa-Michael addition (Scheme 1.4.8). ${ }^{[100]}$ Interestingly, the reaction could proceed in water at $80{ }^{\circ} \mathrm{C}$. Later, the same group was able to implement $\mathrm{O}_{2}$ as the oxidant in GVL as green solvent. ${ }^{[101]}$<smiles>CC(C)=C[CH+]Cc1ccccc1</smiles>

89

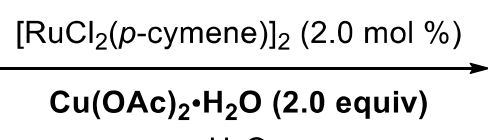

$\mathrm{H}_{2} \mathrm{O}$

$80{ }^{\circ} \mathrm{C}, 16-24 \mathrm{~h}$

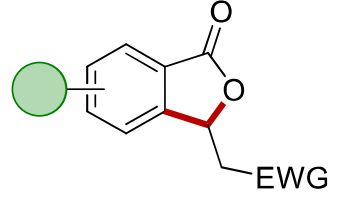

95

Scheme 1.4.8 Oxidative ruthenium-catalyzed C-H/O-H alkylation.

Ruthenium-catalyzed $\mathrm{C}-\mathrm{H}$ activation can also proceed through 6-membered ring intermediates, as shown for the first time by the group of Ackermann in 2012 (Scheme 1.4.9). ${ }^{[102]}$ The reports achieved $\mathrm{C}-\mathrm{H}$ alkenylations with weakly-coordinating directing groups, such as anilides $\mathbf{1}$ and carbamates 97. The following year, reports from $\mathrm{Li}$ and Wang ${ }^{[103]}$ and from Jeganmohan ${ }^{[104]}$ similarly expanded the scope regarding carbamates for this kind of approach. Another interesting ruthenium-catalyzed $\mathrm{C}-\mathrm{H}$ activation occurring via challenging 6-membered ruthenacycle was the $\mathrm{C} 7$ functionalization of indoles reported by Ackermann in 2020. ${ }^{[105]}$ 


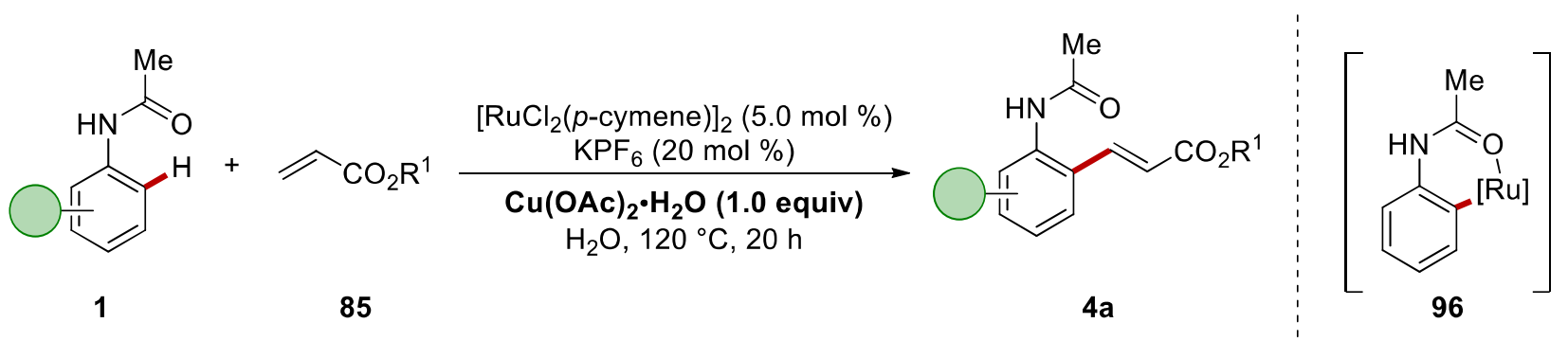

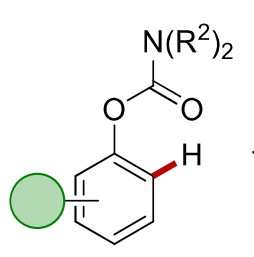

97

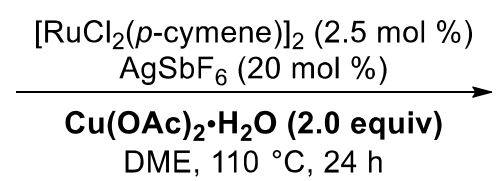

85

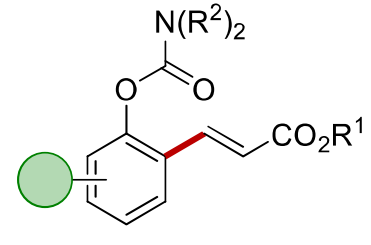

98

Scheme 1.4.9 Ruthenium-catalyzed C-H activation via 6-membered cyclometalated intermediates.

Ruthenium catalysis proved to be versatile also for $\mathrm{C}-\mathrm{Het}$ bond formation. Alongside several examples of $\mathrm{C}\left(\mathrm{sp}^{3}\right)-\mathrm{H}$ and $\mathrm{C}\left(\mathrm{sp}^{2}\right)-\mathrm{H}$ amination, ${ }^{[106]}$ oxygenation reactions with ruthenium catalyst had been extensively studied. Bakke and co-workers studied the $\mathrm{RuO}_{4}$-mediated hydroxylation of $\mathrm{sp}^{3}$ carbons. ${ }^{[107]}$ More recently, Du Bois presented a more versatile methodology for $\mathrm{C}\left(\mathrm{sp}^{3}\right)-\mathrm{H}$ oxygenation, employing catalytic amounts of ruthenium(III) trichloride with a stoichiometric oxidant, allowing for a broader scope (Scheme 1.4.10). ${ }^{[108]}$

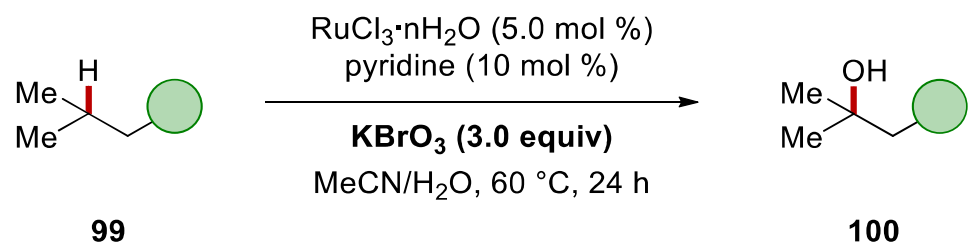

Scheme 1.4.10 Ruthenium-catalyzed $\mathrm{C}\left(\mathrm{sp}^{3}\right)-\mathrm{H}$ oxygenation.

The oxygenation of $\mathrm{sp}^{2}$ carbons is more explored, with two concurrent reports from $\mathrm{Rao}^{[109]}$ and Ackermann, ${ }^{[110]}$ that envisaged the use of an arene-ligand-containing ruthenium(II) catalyst, TFA/TFAA as solvent mixture and a stoichiometric oxidant (Scheme 1.4.11). The approach of Rao worked on esters 101 with potassium persulfate or iodic acid as oxidant, while the one of Ackermann employed tertiary amides $\mathbf{1 0 3}$ and (diacetoxyiodo)benzene. In following reports, the scope was 
shown to include ketones 105, ${ }^{[111]}$ Weinreb amides 106, ${ }^{[12]}$ carbamates $\mathbf{1 0 7},{ }^{[113]}$ anilides $\mathbf{1 0 8},{ }^{[114]}$ and very challenging aldehydes $\mathbf{1 0 9},{ }^{[115]}$ as well as to the para-functionalization of anisoles $\mathbf{1 1 0}$ (Scheme 1.4.11,c). ${ }^{[113]}$ The mechanistic rationale involves the formation of a ruthena(II)cycle with subsequent oxidation to ruthenium(III) or ruthenium(IV) that can thus yield the product and reform the active catalyst.

(a) $\mathrm{C}-\mathrm{H}$ oxygenation on benzoates by Rao<smiles>[R]OC(=O)c1ccc2c(c1)CCCC2</smiles>

101

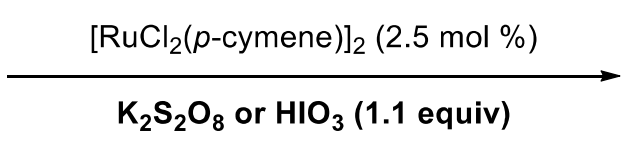

TFA/TFAA

$80^{\circ} \mathrm{C}, 7-11 \mathrm{~h}$<smiles>[R]OC(=O)c1cc2c(cc1O)CCCC2</smiles>

102

(b) C-H oxygenation on benzamides by Ackermann<smiles></smiles>

103 $\left[\mathrm{Ru}\left(\mathrm{O}_{2} \mathrm{CMes}\right)_{2}(p \text {-cymene })\right]_{2}(1.0 \mathrm{~mol} \%)$

Phl(OAc) $)_{2}$ (1.2 equiv)

TFA/TFAA<smiles>[R2]NC(=O)c1cc2c(cc1O)CCCC2</smiles>

104

(c) Reported C-H oxygenation products<smiles>[R]C(=O)c1ccccc1O</smiles>

105<smiles></smiles>

108<smiles>CON(C)C(=O)c1cc2c(cc1O)CCCC2</smiles>

106<smiles>O=Cc1cc2c(cc1O)CCCC2</smiles>

109<smiles>[R16]NC(=O)Oc1cc2[nH]ccc2cc1O</smiles>

107

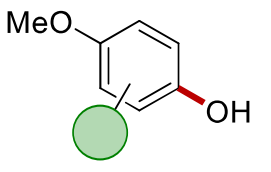

110

Scheme 1.4.11 Oxidative ruthenium-catalyzed C-H oxygenations.

\subsection{Rhodium-Catalyzed C-H Activation}

Similarly to palladium(II)/(0) processes, also rhodium(III)/(I) processes $^{[116]}$ have been studied for organic oxidation reactions. Indeed, analogous to the palladium-catalyzed Wacker process, the 
rhodium-catalyzed Monsanto acetic acid process has been extensively investigated. ${ }^{[38]}$ However, rhodium-catalysis has been underdeveloped compared to the thriving palladium catalysis.

The general mechanism for oxidative rhodium-catalyzed transformations employs a rhodium(III) active species $\mathbf{1 1 1}$ that performs $\mathrm{C}-\mathrm{H}$ activation on a substrate and subsequent functionalization with a coupling partner such as alkynes $\mathbf{2 4}$ or alkenes $\mathbf{3 7}$. Reductive elimination or $\beta$-hydride elimination led to the formation of the product 114 or 115 and a rhodium(I) species 113 that needs to be reoxidized (Scheme 1.5.1).

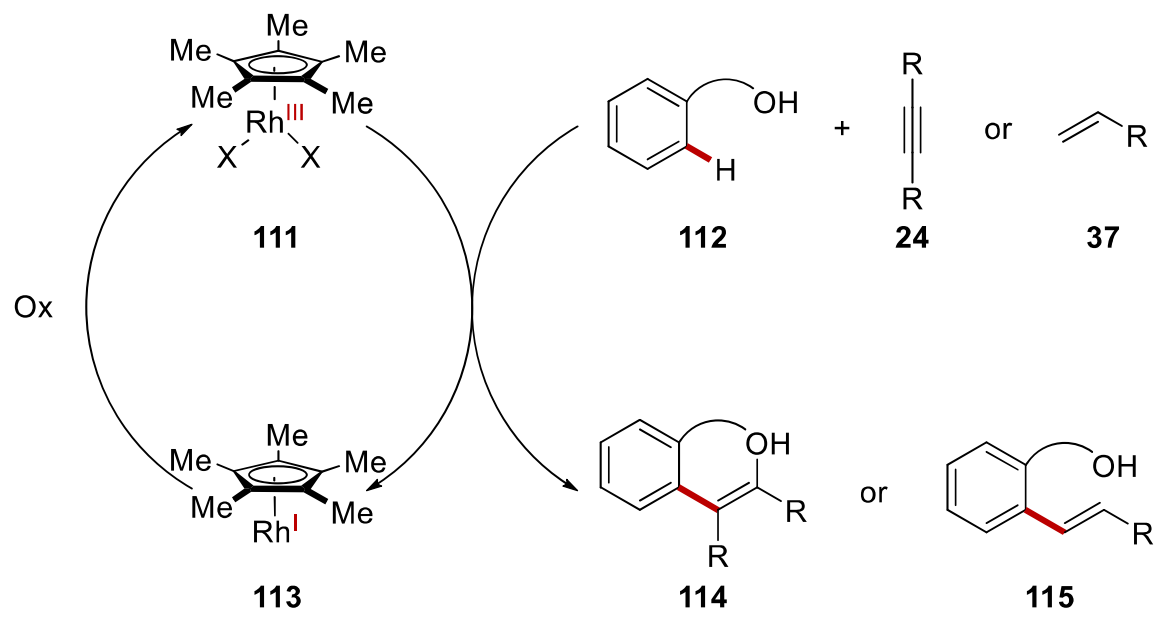

Scheme 1.5.1 Oxidative rhodium-catalyzed $\mathrm{C}-\mathrm{H} / \mathrm{O}-\mathrm{H}$ activation.

In 1987, Maitlis and coworkers proved the ability of rhodium of forming cyclometalated complexes with benzoic acids in stoichiometric amounts, ${ }^{[117]}$ opening the way to studies on rhodium catalysis.

\subsubsection{Rhodium-Catalyzed Oxidative C-H Activation with Chemical Oxidant}

In 2000, Matsumodo and Yoshida presented a rhodium-catalyzed oxidative coupling of benzene with ethylene in the presence of copper(II) acetate as the oxidant. ${ }^{[118]}$ Inspired by the work of Maitlis, in 2007, Satoh and Miura published the annulation reaction between benzoic acids $\mathbf{8 9}$ and alkynes $\mathbf{2 4}$ or alkenes (Scheme 1.5.2). ${ }^{[119]}$ In this procedure, the copper(II) acts as oxidant but it is required only in catalytic amounts since it is re-oxidized by air. This reaction was then further expanded to heteroarenes ${ }^{[120]}$ and to acrylic acids ${ }^{[121]}$ by the same group but with the need for stoichiometric oxidant. 


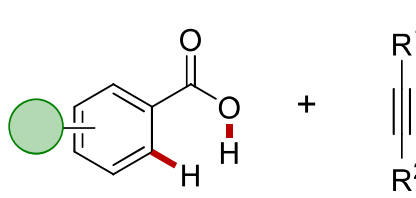

89

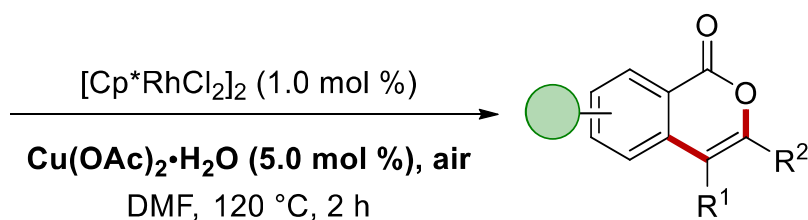

90

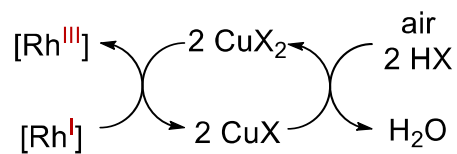

Scheme 1.5.2 Oxidative rhodium-catalyzed C-H/O-H annulation.

Moreover, salicylaldehydes $\mathbf{1 0 9}$ were found to be suitable substrates for the rhodium-catalyzed synthesis of 2,3-diarylchromones 116. The first report was presented by Satoh and Miura in 2008, employing alkynes 24 as coupling partners (Scheme 1.5.3,a). ${ }^{[122]}$ Interestingly, Li could make use of the same substrate 109 with Wilkinson's catalyst, phenylacetylene 117 as coupling partner, and 4picoline- $N$-oxide as oxidant, to access a different pathway and furnish coumarins 118 (Scheme $1 \cdot 5 \cdot 3, \mathrm{~b}) \cdot{ }^{[123]}$

(a) Rhodium-catalyzed synthesis of 2,3-diarylchromones by Satoh and Miura

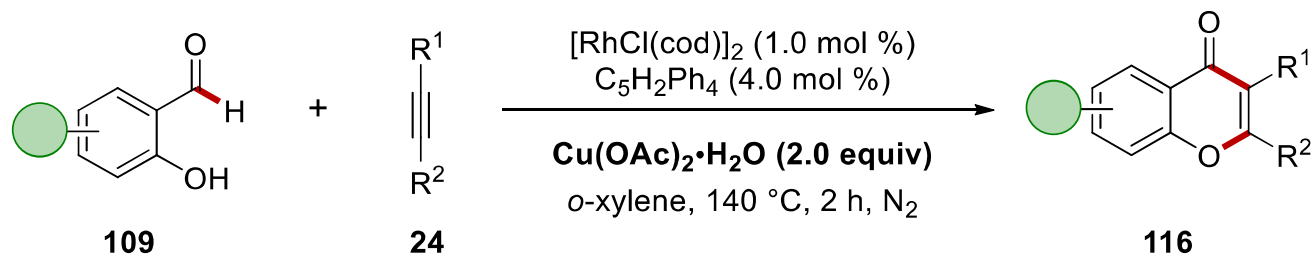

(b) Rhodium-catalyzed synthesis of Cumarines by $\mathrm{Li}$<smiles>O=Cc1cc2c(cc1O)CCCC2</smiles>

109

$$
\stackrel{H}{H}
$$

117
$\left[\mathrm{Rh}\left(\mathrm{PPh}_{3}\right)_{3} \mathrm{Cl}\right](5.0 \mathrm{~mol} \%)$ 4-picoline- $N$-oxide ( 1.3 equiv)

$\mathrm{MeCN}, 120^{\circ} \mathrm{C}, 5 \mathrm{~h}, \mathrm{Ar}$<smiles>O=c1oc2cc3c(cc2cc1Br)CCCC3</smiles>

118

Scheme 1.5.3 Oxidative rhodium-catalyzed C-H/O-H annulation.

These examples were followed by several other rhodium-catalyzed $\mathrm{C}-\mathrm{H} / \mathrm{N}-\mathrm{H}$ annulations, ${ }^{[124]}$ including examples with amides ${ }^{[125]}$ and imines. ${ }^{[126]}$ 
Another oxidative transformation by rhodium-catalyzed $\mathrm{C}-\mathrm{H}$ activation was the hydroxylation of arenes, achieved at first in 2013 by Rao and colleagues (Scheme 1.5.4). ${ }^{[14 a]}$ The authors used simple $\left[\mathrm{Rh}(\mathrm{OAc})_{2}\right]_{2}$ in presence of an excess of oxidant, such as potassium persulfate or (diacetoxyiodo)benzene, to yield 2-acylphenol 102. The synthesis of phenols was also working efficiently on weakly coordinating ketones. This report demonstrated that the reaction could be performed both with ruthenium and rhodium catalysis, with the two metals being similar for selectivity and substrate scope. This is one of the rare examples of rhodium catalysis promoting oxygenation of $\mathrm{C}-\mathrm{H}$ bonds.

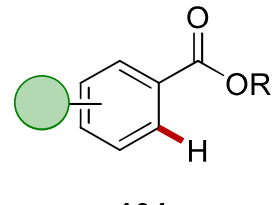

101

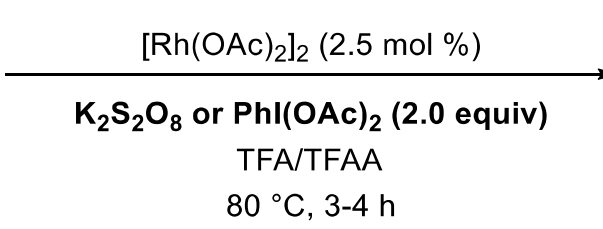

$80^{\circ} \mathrm{C}, 3-4 \mathrm{~h}$

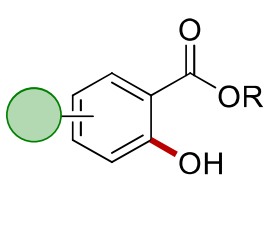

102

Scheme 1.5.4 Oxidative rhodium-catalyzed $\mathrm{C}-\mathrm{H}$ oxygenation.

Other three reports on rhodium $\mathrm{C}-\mathrm{H}$ hydroxylation were published more recently. All of them used a well-defined $\left[\mathrm{RhCp}^{*} \mathrm{Cl}_{2}\right]_{2}$ catalyst in higher loadings compared to the example by Rao. Indeed in 2017, both the groups of $\mathrm{Kim}^{[127]}$ and Zhou ${ }^{[128]}$ independently reported this transformation on 2-aryl pyridines 8 (Scheme 1.5.5,a-b). In the latter report, the authors were also able to obtain the acetoxylation reaction in absence of water. The following year, Wang published the C7hydroxylation and acetoxylation of indolines 121 under mild reaction conditions (Scheme $1.5 .5, \mathrm{c}){ }^{[129]}$ 
(a) Hydroxylation by Kim

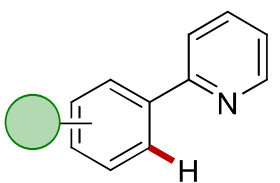

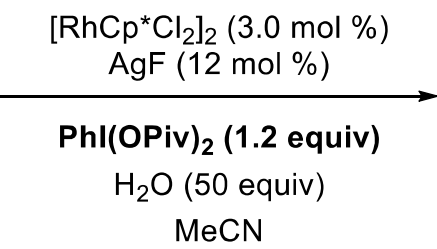

$60-120{ }^{\circ} \mathrm{C}, 15 \mathrm{~h}$

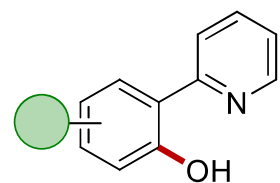

119

(b) Hydroxylation and Acetyloxylation by Zhou
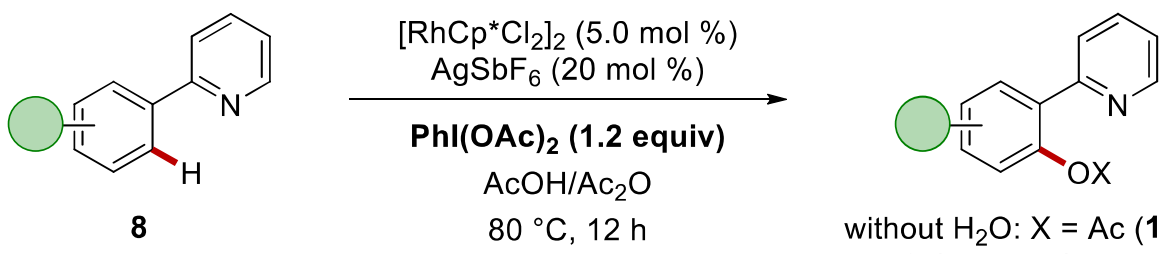

without $\mathrm{H}_{2} \mathrm{O}: \mathrm{X}=\mathrm{Ac}(\mathbf{1 2 0})$

with $\mathrm{H}_{2} \mathrm{O}$ (10 equiv): $X=\mathrm{H}$ (119)

(b) C7-Hydroxylation and Acetyloxylation by Wang<smiles>[R]C1c2ccccc2N(c2ncccn2)C1[R]</smiles>

121

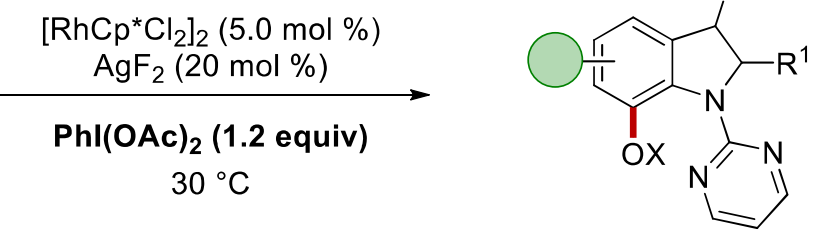

$\mathrm{Ac}_{2} \mathrm{O}, 6 \mathrm{~h}$, air: $\mathrm{X}=\mathrm{Ac}(122)$

$\mathrm{H}_{2} \mathrm{O}$ (10 equiv), DMF, $2 \mathrm{~h}, \mathrm{Ar}: \mathrm{X}=\mathrm{H}$ (123)

Scheme 1.5.5 Oxidative rhodium-catalyzed $\mathrm{C}-\mathrm{H}$ oxygenations.

\subsubsection{Electrochemical Rhodium-Catalyzed C-H Activation}

Due to this expanded use of rhodium catalysis in oxidative $\mathrm{C}-\mathrm{H}$ activation, it was not long before this chemistry was coupled with electricity. In Section 3.2, the first example of electrochemical rhodium $\mathrm{C}-\mathrm{H}$ activation, found during the optimization of the electrochemical ruthenium annulation, is described. ${ }^{[130]}$ In 2018, Ackermann reported the cross-dehydrogenative alkene annulation on weakly $O$-coordinating benzoic acids 89 in presence of $\left[\mathrm{RhCp}^{*} \mathrm{Cl}_{2}\right]_{2}$ as catalyst, potassium acetate as base, and tert-amyl alcohol/water as solvents in an undivided cell at $4.0 \mathrm{~mA}$ constant current electrolysis (Scheme 1.5.6) ${ }^{[131]}$ The mechanistic rationale is very similar to the ruthenium, but here the re-oxidation at the anode takes place on a rhodium(I) to rhodium(III) species. The rhodium catalysis was not limited to $\alpha, \beta$-unsaturated carbonyl substrates, indeed the same group also extended the reactivity to the olefination of electro-poor benzamides in a following report. ${ }^{[132]}$ Electrochemical 
rhodium-catalyzed $\mathrm{C}-\mathrm{H}$ activation also employed alkylidenecyclopropanes (ACPs) to selectively furnish either cyclopropanes or dienes. ${ }^{[133]}$

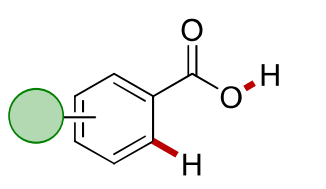

89<smiles>O=C(F)/C=C/[PH3+]</smiles>

85
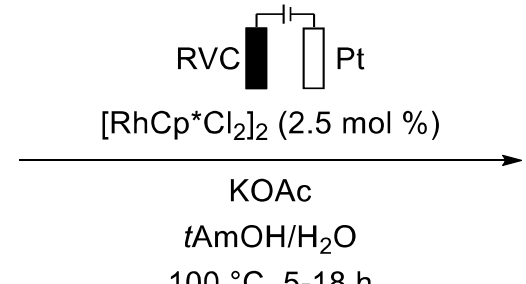

$\mathrm{CCE}$ at $4.0 \mathrm{~mA}$

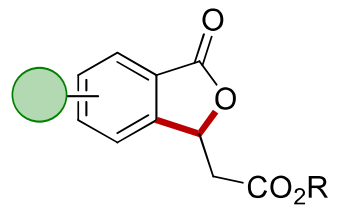

95a

Scheme 1.5.6 Electrochemical rhodium-catalyzed C-H alkene annulation.

Moreover, the first rhodium-catalyzed electrochemical $\mathrm{C}-\mathrm{C}$ activation was achieved by Ackermann in 2019 with outstanding levels of chemo- and position-selectivity (Scheme 1.5.7,a). ${ }^{[134]}$ Interestingly, a competition experiment between the $\mathrm{C}-\mathrm{H}$ and $\mathrm{C}-\mathrm{C}$ showed the preferential activation of the latter bond, providing a way for the synthesis of 1,2,3-trisubstituted arenes (127), that are usually not accessible by $\mathrm{C}-\mathrm{H}$ activation (Scheme 1.5.7,b).

(a) Rhodium-catalyzed C-C activation

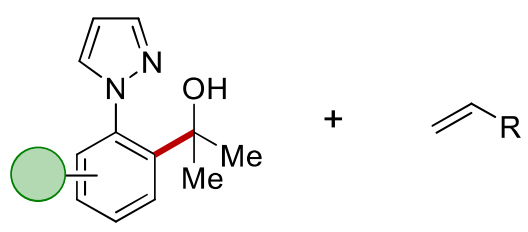

124
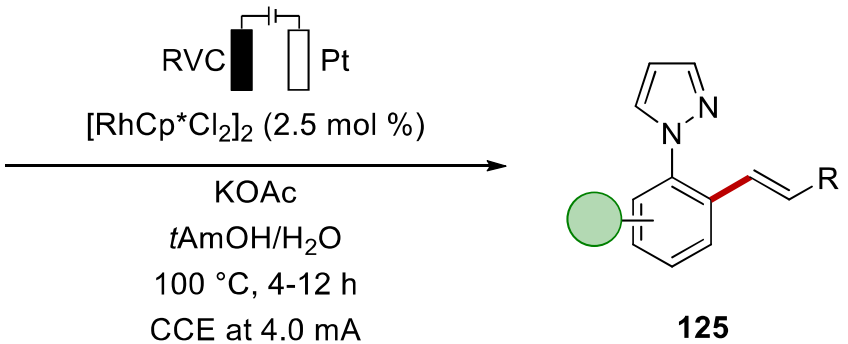

(b) Competition experiment between $\mathrm{C}-\mathrm{H}$ and $\mathrm{C}-\mathrm{C}$ activation<smiles>C=CP</smiles>
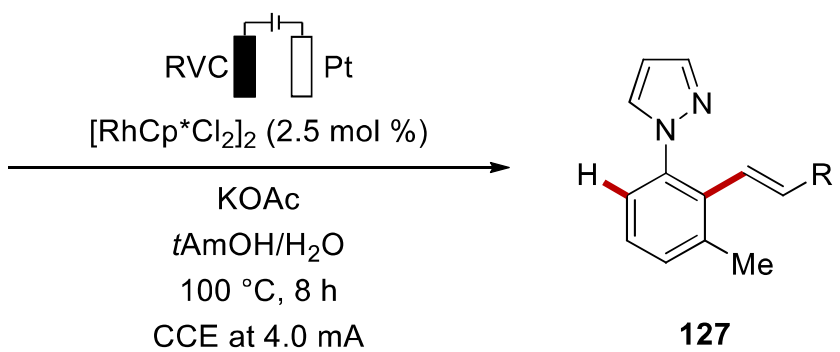

Scheme 1.5.7 (a) Electrochemical rhodium-catalyzed C-C activation and (b) competition experiment. 
Besides alkenes $\mathbf{3 7}$ as coupling partners, alkynes $\mathbf{2 4}$ have also been employed in electrochemical rhodium-catalyzed $\mathrm{C}-\mathrm{H}$ activation for diverse product syntheses. The first report has been published in 2019 by Ackermann and envisaged not only the [2+2+2] cycloaddition, but also the subsequent DDQ-catalyzed electrochemical cyclodehydrogenation to furnish polycyclic aromatic hydrocarbons 130 (PAHs) (Scheme 1.5.8). ${ }^{[135]}$ Furthermore, the approach showed a clear advantage in comparison to classical chemical oxidants, such as $\mathrm{AgOAc}$, or $\mathrm{Cu}(\mathrm{OAc})_{2} \cdot \mathrm{H}_{2} \mathrm{O}$, in the successful transformation of the sensitive iodo-substituted boronic acid 128a. Similarly, the same group could also synthesize nitrogen-doped PAHs (aza-PAHs) in a following report. ${ }^{[136]}$

(a) Rhodium-catalyzed PAH assembly

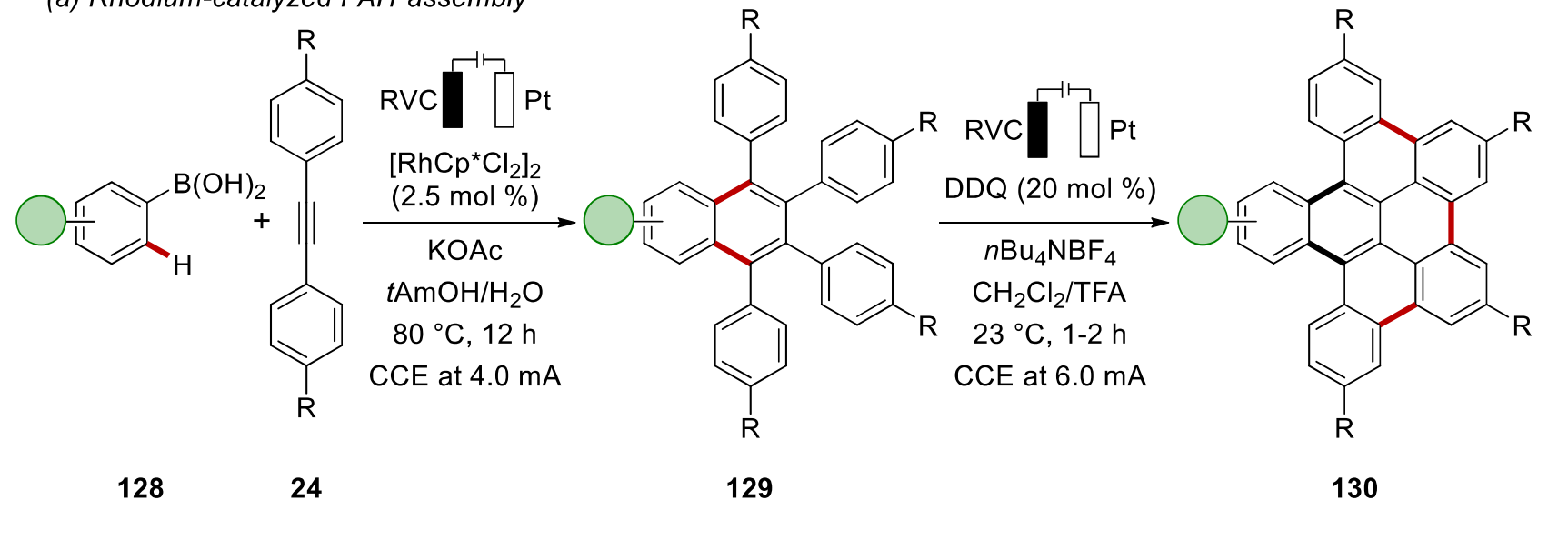

(b) Oxidants comparison

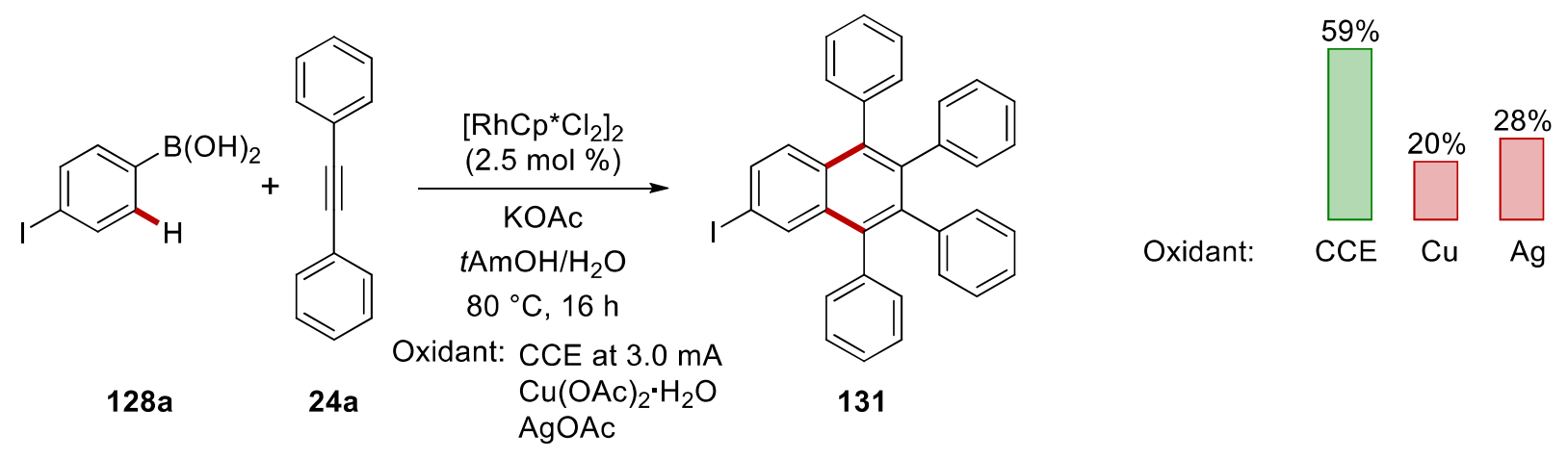

Scheme 1.5.8 (a) Electrochemical rhodium-catalyzed $\mathrm{C}-\mathrm{H}$ activation and (b) comparison of the reaction with different oxidant.

Ackermann also reported the first flow-electrochemical C-H activation in 2019 (Scheme 1.5.9). ${ }^{[137]}$ The studied inter- and intra-molecular alkyne annulations benefited from an efficient electron and 
mass transfer. Thanks to detailed mechanistic studies and the isolation of the rhodium(III)- and rhodium(IV)-complexes, the authors were able to prove the oxidatively-induced reductive elimination, ${ }^{[138]}$ with a catalytic cycle going through a rhodium(III)/(IV)/(II) regime. The rhodium(II) at the end of the catalytic cycle was re-oxidizable both electrochemically or via aerobic oxidation.
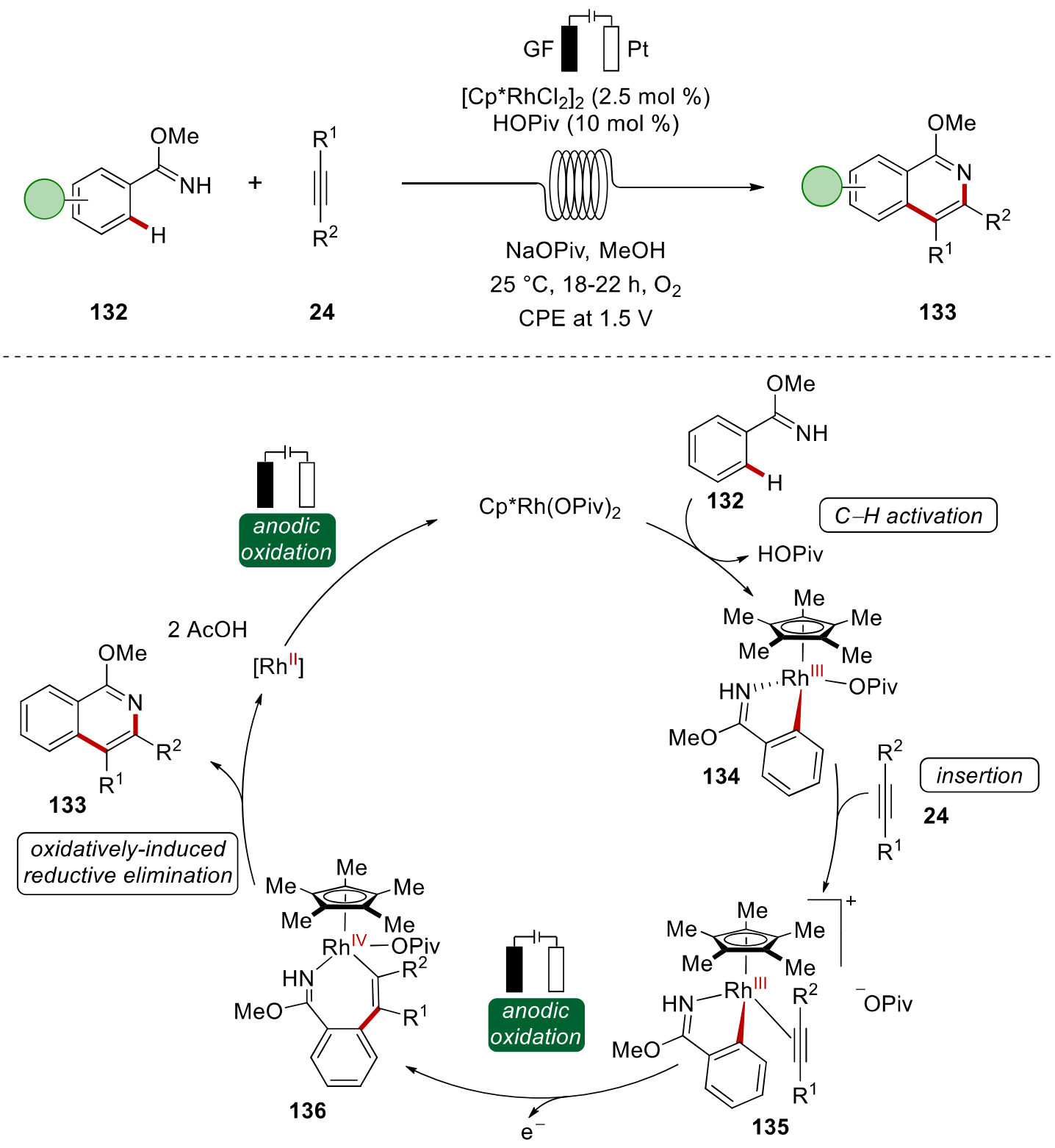

Scheme 1.5.9 Electrochemical rhodium-catalyzed $\mathrm{C}-\mathrm{H} / \mathrm{N}-\mathrm{H}$ annulations in flow conditions.

In the context of alkyne annulations, other three reports of 2021 are worth to be cited. Ackermann reported the [5+2] rhodium-catalyzed annulation via $\mathrm{C}-\mathrm{H} / \mathrm{O}-\mathrm{H}$ activations, opening the way for the electrochemical synthesis of seven-membered benzoxepines 138 (Scheme 1.5.10,a). ${ }^{[139]}$ Mei 
published the divergent vinylic rhodium-catalyzed $\mathrm{C}-\mathrm{H}$ annulation of acrylamides $\mathbf{1 3 9}$, allowing the synthesis of and cyclic imidates 140 and $\alpha$-pyridones 141 depending on the substituent on the amides 139 (Scheme 1.5.10,b). ${ }^{[140]}$ Remarkably, Ackermann developed an electrochemical rhodiumcatalyzed annulation on benzaldehydes 109 to synthesize chromones 116 (Scheme 1.5.10,c). ${ }^{[141]}$ The strategy also allowed the labelling of amino acids and peptides.

(a) [5+2] cycloaddition by Ackermann

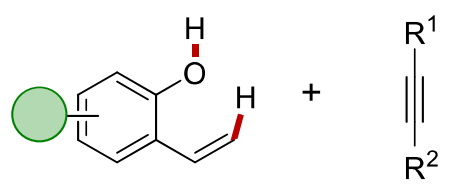

137
24

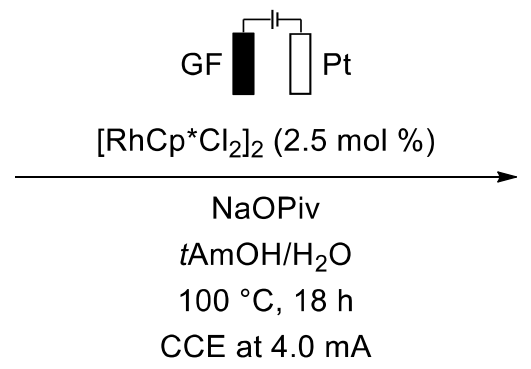<smiles>[R]C1=C([R])Oc2ccccc2C=C1</smiles>

138

(b) Divergent annulation by Mei<smiles>[R]C#C[N+]</smiles>

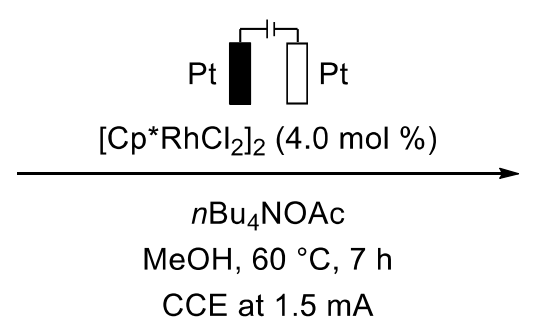<smiles>[R7]c1cc([R])c(=[18O])oc1[18F]</smiles>

$R=-T s(140)$

$\mathrm{R}=-\mathrm{Ph}(141)$

(c) Annulation on benzaldehydes by Ackermann

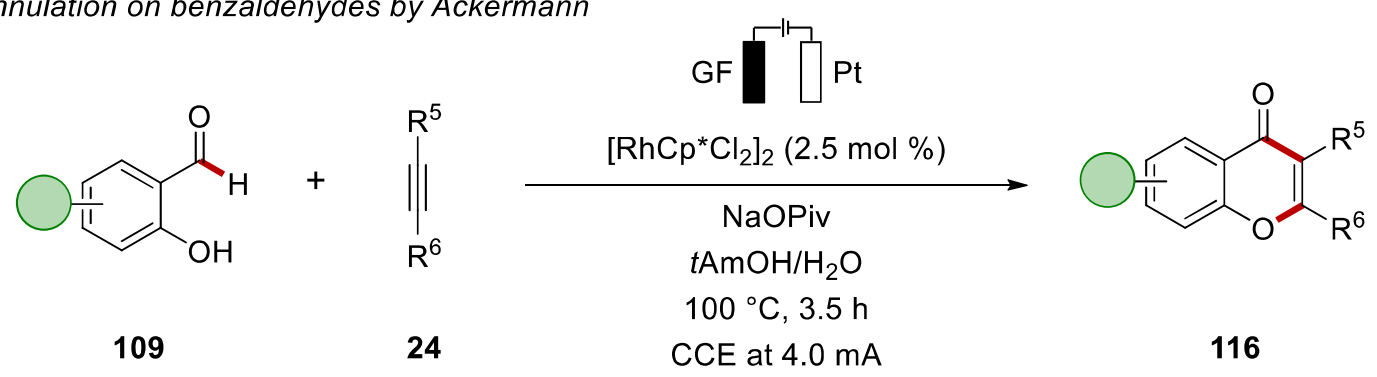

Scheme 1.5.10 Electrochemical rhodium-catalyzed $\mathrm{C}-\mathrm{H} / \mathrm{N}-\mathrm{H}$ annulations.

Besides, $\mathrm{C}-\mathrm{C}, \mathrm{C}-\mathrm{N}$, and $\mathrm{C}-\mathrm{O}$ bonds formation, in $2019 \mathrm{Xu}$ and colleagues reported on the $\mathrm{C}-\mathrm{P}$ bond formation by mean of electrochemical rhodium catalysis (Scheme 1.5.11). ${ }^{[51 \mathrm{a}]}$ The robustness of the reaction was reflected by successfully performing a decagram scale that yielded $62 \%$ and $87.7 \mathrm{~g}$ of the product 144, employing $1.0 \mathrm{~mol} \%$ of the rhodium catalyst. The preparation of the rhodium(III) complex and its study suggested an oxidatively-induced reductive elimination. 


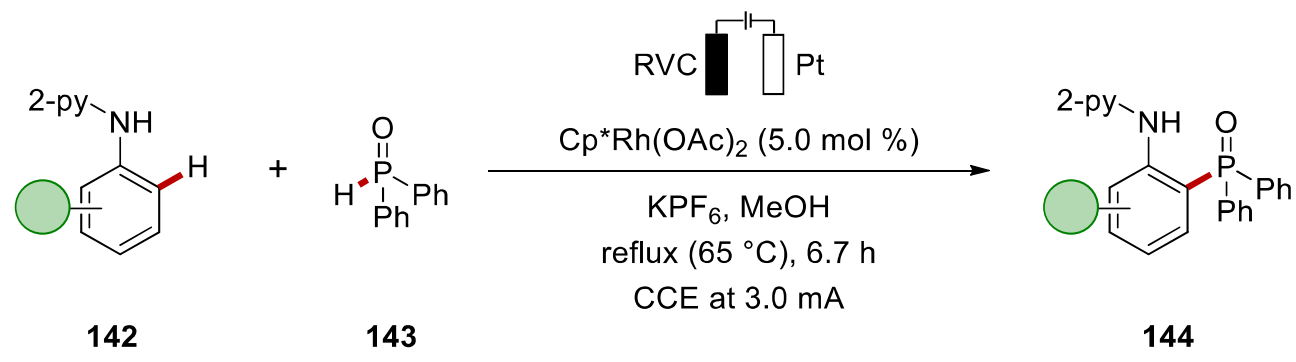

Scheme 1.5.11 Electrochemical rhodium-catalyzed C-H phosphorylation.

\subsection{Manganese-Catalyzed C-H Activation}

Manganese is the third most abundant transition metal and the twelfth most abundant element in the earth's crust. Because of its abundancy and thus its cost-effectiveness, manganese chemistry has become attractive in the past decade. Additionally, the range of oxidation states $(-3$ to +7$)$ makes it an interesting metal for diverse catalytic systems. ${ }^{[17,142]}$ The different high- and low-spin electronic states allow for different possible coordination geometries. Moreover, its low toxicity makes it a good choice for a more environmental benign synthesis. ${ }^{[143]}$

The first example of stoichiometric C-H activation with manganese was reported in 1970 by Stone and Bruce, with the use of the manganese(I) catalyst $\left[\mathrm{MnMe}(\mathrm{CO})_{5}\right] \mathbf{1 4 5}$ to yield complex 146 (Scheme 1.6.1). ${ }^{[144]}$<smiles>c1ccc(/N=N/c2ccccc2)cc1</smiles>

23<smiles>COC(C)=O</smiles>

145

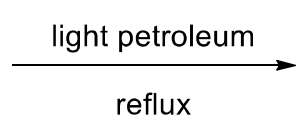

reflux<smiles>O=[N+]([O-])c1ccccc1-n1nc2ccccc2[n+]1[O-]</smiles>

146

Scheme 1.6.1 First example of stoichiometric manganese(I) $\mathrm{C}-\mathrm{H}$ activation.

After this report, several others well-defined manganacycles were synthesized by the groups of Nicholson/Main, ${ }^{[145]}$ Woodgate, ${ }^{[146]}$ and Liebeskind, ${ }^{[147]}$ among others (Scheme 1.6.2). ${ }^{[148]}$ These approaches utilized a $\left[\mathrm{MnX}(\mathrm{CO})_{5}\right]$ catalyst and diverse directing groups, including weakly coordinating ones. 
<smiles></smiles>

147<smiles></smiles>

151<smiles>CC(=O)c1c2ccccc2c2ccccn12</smiles>

148<smiles></smiles>

152<smiles>Cn1c(-c2ccccc2)cn2c3ccccc3c(=O)n12</smiles>

149<smiles>CN1Cc2ccccc2N1C(=O)[O-]</smiles>

153<smiles>O=C([O-])[N+]1c2ccccc2OP1Oc1ccccc1</smiles>

150<smiles>CC(=O)Nc1ccccc1[PH](OC(C)=O)(c1ccccc1)c1ccccc1</smiles>

154

Scheme 1.6.2 Selected examples of well-defined manganacycles.

In 2007, 37 years after the report of Stone and Bruce, the first manganese-catalyzed $\mathrm{C}-\mathrm{H}$ activation was reported by Kuninobu and Takai (Scheme 1.6.3). ${ }^{[149]}$ They initially studied the addition of an aldehyde onto a $\mathrm{C}-\mathrm{H}$ bond in the presence of stoichiometric manganese(I) salt 156. The reaction proved to be feasible only with stoichiometric amounts of manganese, while only traces of the desired product $\mathbf{1 5 7}$ were obtained when the metal was employed in a catalytic fashion (Scheme 1.6.3,a). The addition of triethylsilane to afford the silyl ether product $\mathbf{1 5 9}$ was found to be the key to guarantee turnover, and, thus, afforded the transformation utilizing the manganese in catalytic amounts (Scheme 1.6.3,b). The authors proposed a mechanism that commences with the $\mathrm{C}-\mathrm{H}$ activation via oxidative addition of the aromatic compound to the manganese(I), giving a Mn(III)hydride species 160 (Scheme 1.6.3,c). Afterwards, migratory insertion occurs, and a reductive elimination takes place with the help of triethylsilane that forms the silyl-protected product 159. This step regenerates the active catalyst 156 and gives molecular hydrogen as by-product. In 2015, the group of Wang reported the manganese-catalyzed $\mathrm{C}-\mathrm{H}$ activation of aromatic rings with aldehydes and also nitriles in the absence of the silane, but stoichiometric zinc salts were required ${ }^{[150]}$ From the report of Kuninobu onwards, manganese catalysis thrived with several reports on $\mathrm{C}-\mathrm{H}$ activation reactions, such as annulations, allylations, and alkylations. ${ }^{[17]}$ 
(a) Stoichiometric Manganese(I)-catalyzed $\mathrm{C}-\mathrm{H}$ addition<smiles>Cn1ccnc1-c1ccccc1</smiles>

155

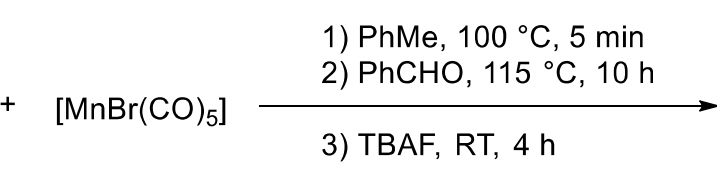

156<smiles>Cn1ccnc1-c1ccccc1C(O)c1ccccc1</smiles>

157

(b) Manganese(I)-catalyzed $\mathrm{C}-\mathrm{H}$ activation<smiles>Cn1ccnc1-c1ccccc1</smiles>

155<smiles>[R]C=O</smiles>

158

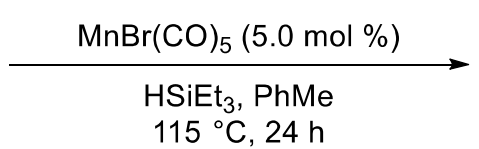

$115^{\circ} \mathrm{C}, 24 \mathrm{~h}$<smiles>[R]C(OCC)c1ccccc1-c1nccn1C</smiles>

159

(c) Proposed catalytic cycle

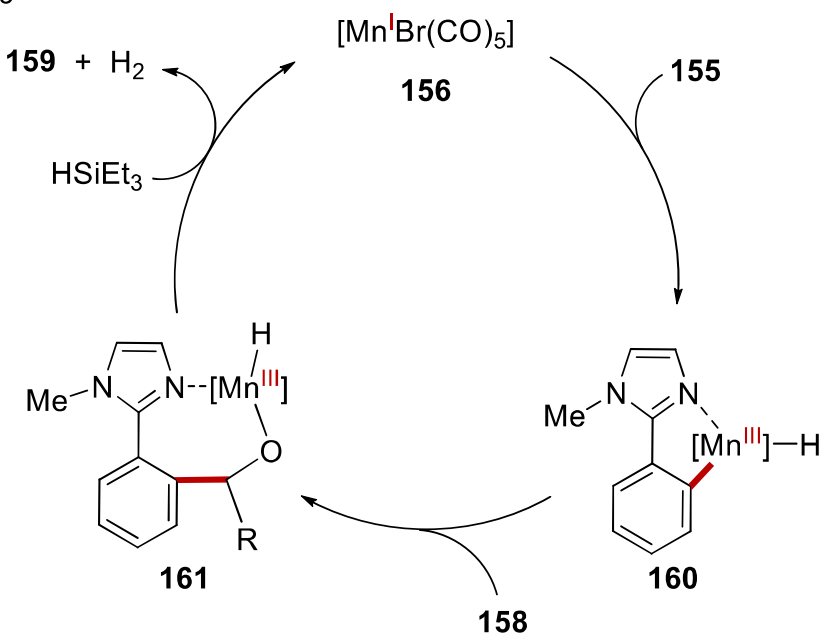

Scheme 1.6.3 Manganese-catalyzed hydroarylation of aldehydes 155: (a) stoichiometric study, (b) catalytic reaction, and (c) proposed catalytic cycle.

\subsubsection{Manganese-Catalyzed C-H Activation with Chemical Oxidants}

Manganese(I) catalysis was generally limited to isohypsic addition reactions with the need of substrates containing multiple bonds. ${ }^{[17]}$ To overcome this major challenge, Ackermann reported in 2017 the first low-valent manganese-catalyzed C-H alkylation with alkyl halides $\mathbf{1 6 3}$ using simple $\mathrm{MnCl}_{2}$ (Scheme 1.6.4,a). ${ }^{[151]}$ Interestingly, the reaction did not require any zinc salts or expensive phosphine ligand. The reaction offered a versatile approach to obtain alkylated benzamide 164 by the assistance of a removable triazolyldimethylmethyl (TAM) directing group. The authors also presented the methylation reaction, and they proposed a catalytic cycle based on their mechanistic 
studies and DFT calculations (Scheme 1.6.4,b). The mechanism starts with a ligand-to-ligand hydrogen transfer (LLHT) type $\mathrm{C}-\mathrm{H}$ activation to furnish complex $\mathbf{1 6 8}$. This is then oxidized by $2,3-$ dichlorobutane (DCB) to give a manganese(III) intermediate 169 that undergoes the transmetalation with the alkyl reagent. After reductive elimination, the product $\mathbf{1 6 6}$ is obtained, and the catalyst is oxidized by DCB to furnish the catalytically active species. 
(a) Low-valent manganese-catalyzed $\mathrm{C}-\mathrm{H}$ alkylations

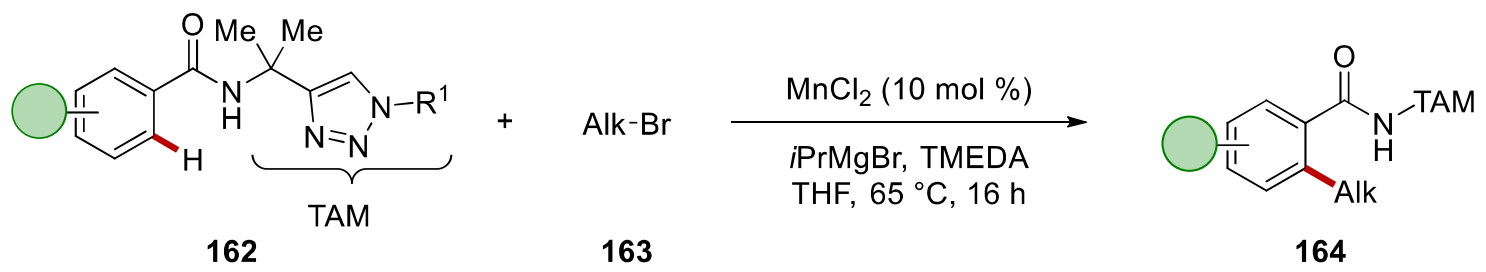

(b) Low-valent manganese-catalyzed $\mathrm{C}-\mathrm{H}$ methylations<smiles>[Y10][AlH2]NC(=O)c1ccc2c(c1)CCCC2</smiles>

162

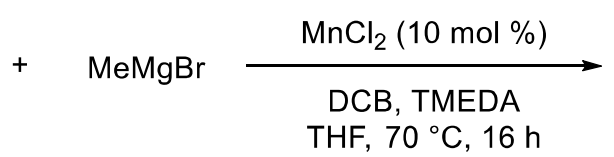

$165 a$

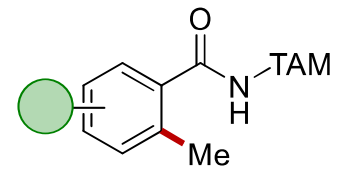

166

(c) Proposed catalytic cycle

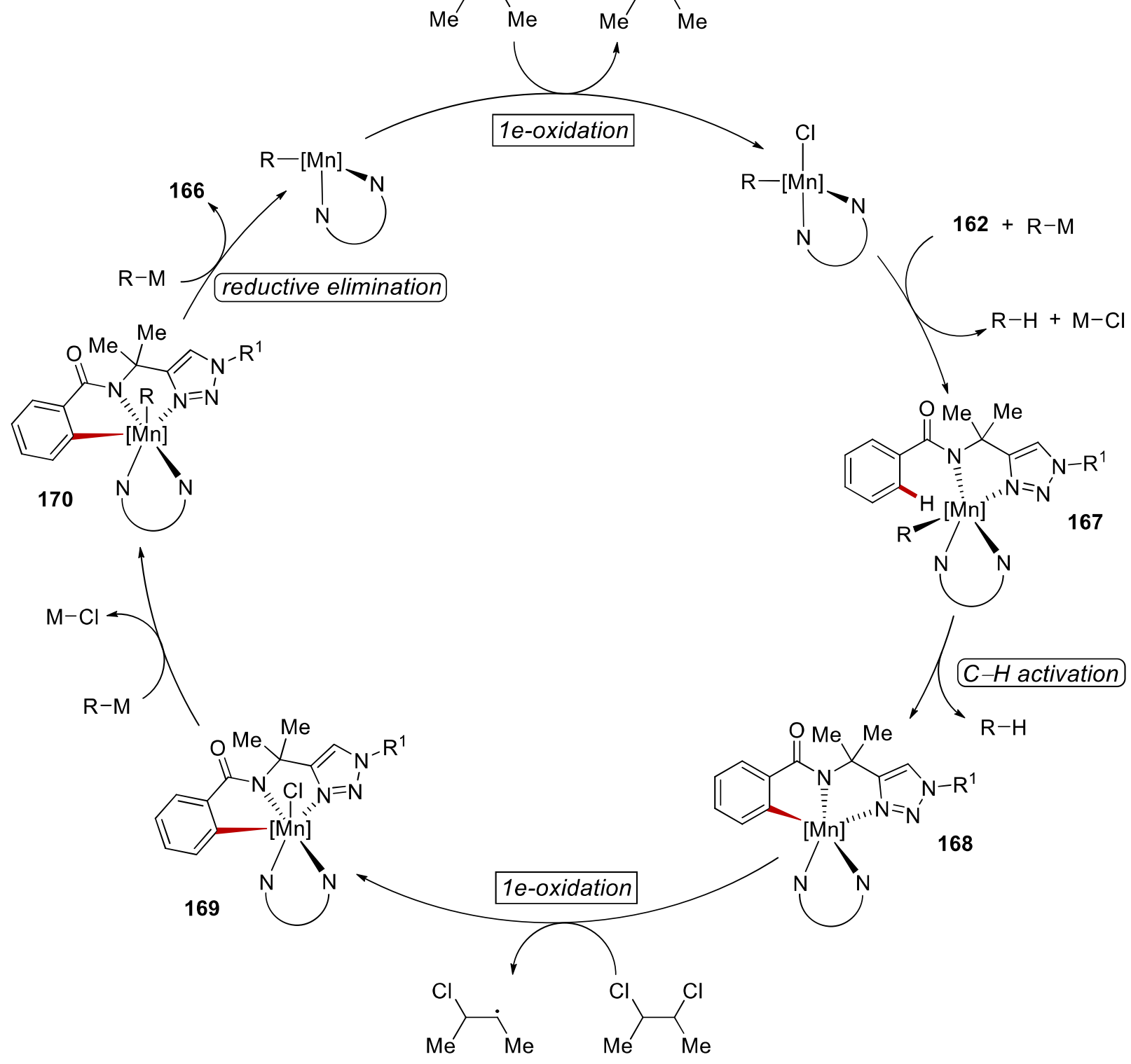

Scheme 1.6.4 First example of low-valent manganese-catalyzed C-H activation. 
Inspired by this work, Nakamura and co-workers published the methylation of secondary amides $\mathbf{8 7}$ (Scheme 1.6.5,a), with 1-bromo-2-chloroethane acting as the oxidant. ${ }^{[152]}$ In contrast, Ackermann reported the manganese-catalyzed alkylation of azines $\mathbf{1 7 2}$ with both primary as well as the more demanding secondary alkyl halides 173 (Scheme 1.6.5,b). ${ }^{[153]}$ Here, examples of oxidative alkylation in the presence of Grignard as coupling partner and 1,2-dichloroisobutane (DCIB) as oxidant were also included.

(a) $\mathrm{MnCl}_{2}$-catalyzed $\mathrm{C}-\mathrm{H}$ methylation by Nakamura<smiles>CNC(=O)c1ccccc1</smiles>

87
$\mathrm{MeMgBr}$

$165 a$

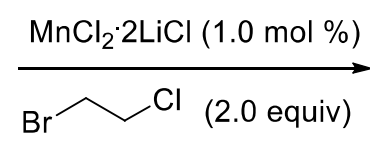

$\mathrm{THF}, 25^{\circ} \mathrm{C}, 24 \mathrm{~h}$<smiles></smiles>

171

(b) $\mathrm{MnCl}_{2}$-catalyzed $\mathrm{C}-\mathrm{H}$ alkylation by Ackermann<smiles></smiles>

172<smiles>[R]CC([X])[R]=[V]</smiles>

173

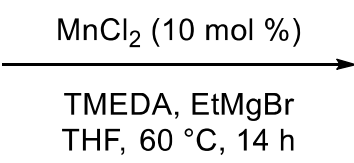

TMEDA, $\mathrm{THF}, 60^{\circ} \mathrm{C}, 14 \mathrm{~h}$

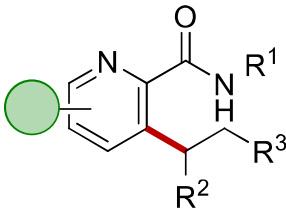

174

Scheme 1.6.5 Low-valent manganese $\mathrm{C}-\mathrm{H}$ (a) methylation and (b) alkylations.

Lastly, in 2018 Ackermann achieved the low-valent manganese-catalyzed arylation reaction on azines 172 under flow conditions, that includes manganese(II) chloride as the catalyst and neocuproine as the ligand for a cost-efficient and environmentally benign transformation (Scheme 1.6.6). ${ }^{[154]}$ The need for toxic and expensive DCIB as oxidant represented a major limitation of the approach. Recently, the same group published an approach that takes advantage of a heterogeneous manganese catalyst for this reaction. ${ }^{[155]}$ 


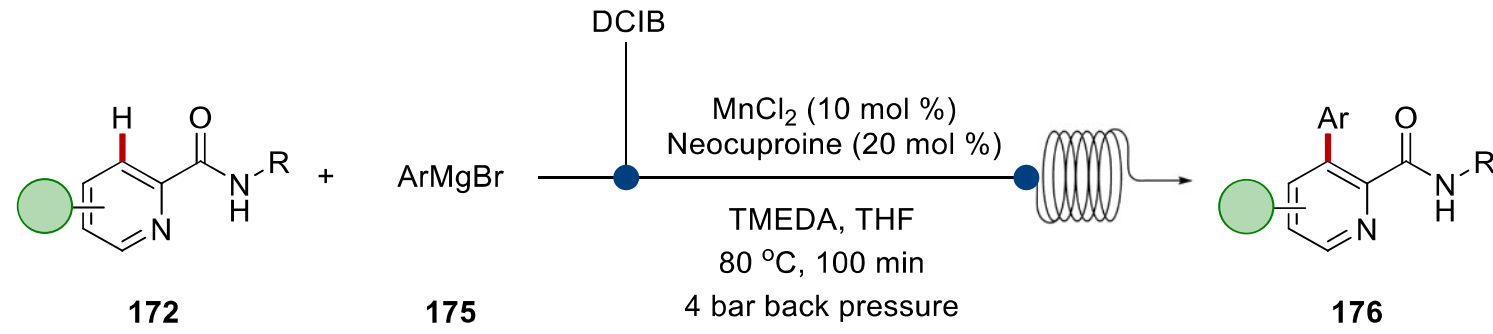

Scheme 1.6.6 Manganese-catalyzed C-H arylations using flow technique.

\subsubsection{Electrochemical Manganese-Catalyzed C-H Activation}

Electrochemical manganese-catalyzed $\mathrm{C}-\mathrm{H}$ activation has proven elusive, in contrast to the numerous examples of its employment in electrochemical olefin difunctionalization developed by the group of Lin, ${ }^{[156]}$ and in the pioneering work of Schäfer. ${ }^{[157]}$ Two independent reports by Lei ${ }^{[158]}$ and Ackermann $^{[159]}$ have highlighted the potential of manganese-catalyzed electrochemical $\mathrm{C}-\mathrm{H}$ activation towards the synthesis of value added chemicals. Both the methods presented an ample scope and good selectivities for the desired azidation. These studies were based on the early reports by Hill ${ }^{[160]}$ and Groves, ${ }^{[161]}$ where they employed a manganese porphyrin or a Schiff-base complex and iodosylbenzene as oxidant to generate the high-valent manganese(V)-oxo intermediate. In the report of Lei, a photo-electrochemical approach was used, while Ackermann could devise a strategy with the sole electrochemistry (Scheme 1.6.7).
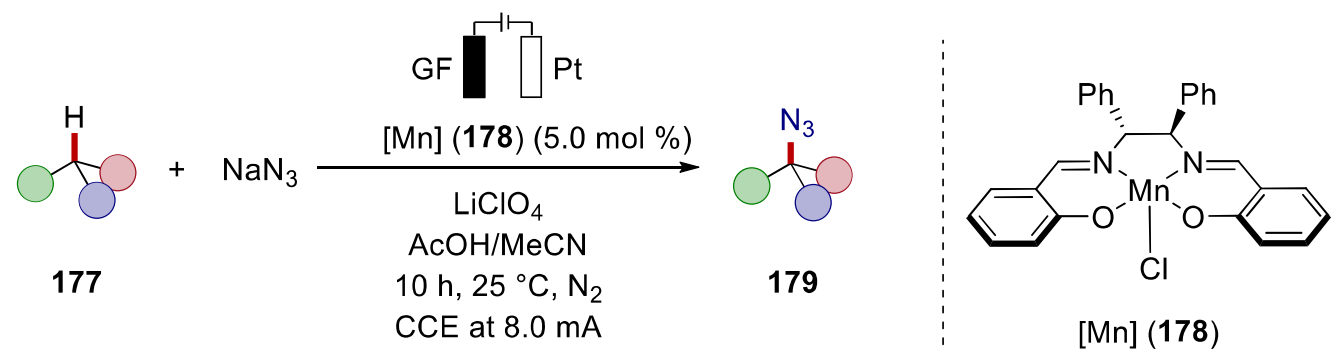

Scheme 1.6.7 Manganese-catalyzed C-H azidations enabled by electricity. 


\section{Objectives}

The development of new approaches for selective $\mathrm{C}-\mathrm{C}$ and $\mathrm{C}-\mathrm{Het}$ bond formations to easily access complex molecules is highly demanded to provide chemists with diverse and efficient synthetic routes. In the last decades, enormous progresses were made in this field, first with the rise of crosscoupling chemistry, and later with step- and atom-economical C-H activation methodologies. ${ }^{[162]}$ These approaches allowed for great advances in organic synthesis, but the green chemistry criteria are still far to be met. Indeed, many procedures relied on harsh conditions, hazardous or toxic chemicals, and on the use of precious metal catalysts. In this scenario, this thesis aims to address the study and development of novel and greener concepts for metal-catalyzed $\mathrm{C}-\mathrm{H}$ activation, in particular focusing on the merger of transition metal catalysis and electrosynthesis as environmentally benign oxidant. ${ }^{[163]}$ This approach could greatly increase the sustainable nature of oxidative transformations.

In the last two decades, cobalt catalysis thrived as a powerful and cost-effective approach for oxidative $\mathrm{C}-\mathrm{H}$ activation, with elegant examples for annulation reactions. ${ }^{[58,60,}$, 164$]$ These methodologies were nevertheless undermined by the need for stoichiometric amounts of toxic metalbased oxidants. Therefore, the investigation of an electrochemical procedure for cobalt-catalyzed C$\mathrm{H} / \mathrm{N}-\mathrm{H}$ annulation reaction had been studied. We aimed to replace the chemical oxidant by anodic oxidation for the regeneration of the active catalyst, thus reducing the waste production (Scheme 2.1).

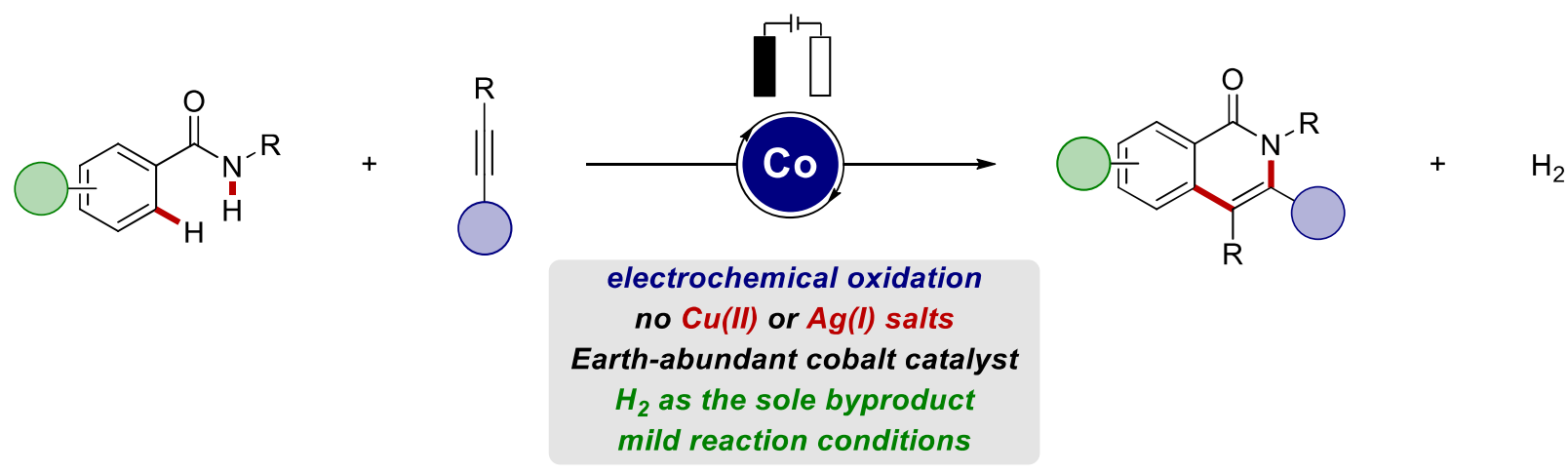

Scheme 2.1 Electrochemical cobalt-catalyzed $\mathrm{C}-\mathrm{H} / \mathrm{N}-\mathrm{H}$ alkyne annulations. 
Ruthenium-catalyzed oxidative $\mathrm{C}-\mathrm{H}$ activation is a powerful tool for the synthesis of heteroarenes with weakly coordinating directing groups. ${ }^{[2]}$ The use of electricity as oxidant for this approach was not reported yet at the onset of the study. We thus became interested in exploring the combination of ruthenium catalysis and electrochemistry, studying its versatility and regioselectivity in the annulation reaction between benzoic acids and unsymmetrical alkynes (Scheme 2.2). This approach would allow us to expand the precedent study on cobalt-catalyzed annulations to internal alkynes by means of ruthenium catalysis.
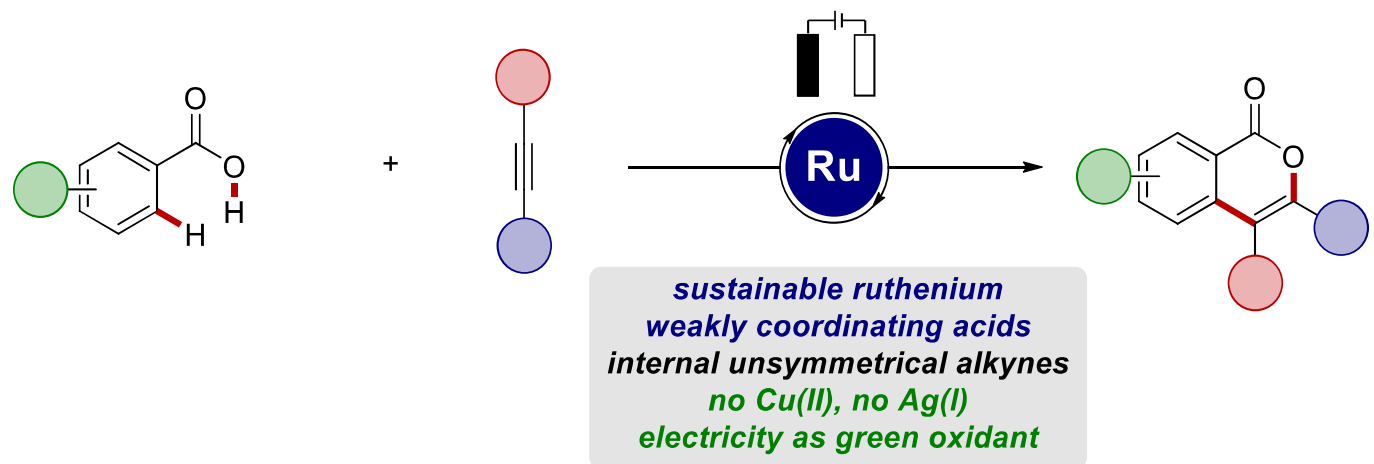

Scheme 2.2 Electrochemical ruthenium-catalyzed C-H/O-H alkyne annulations.

To harness the full potential of electrochemistry, the in-situ synthesis of hazardous chemicals from catalytic amounts of precursor was explored in depth. The hypervalent iodine compounds are a wide class of versatile oxidants which were reported to be electrochemically synthesizable. ${ }^{[165]}$ These compounds are also viable oxidants used in stoichiometric amounts for the ruthenium-catalyzed $\mathrm{C}-\mathrm{H}$ oxygenation reactions. ${ }^{[110-113,115]}$ The aim was therefore to tackle the safety and the costs of these transformations by the in-situ electrochemical formation of hypervalent iodine species from catalytic amounts of iodobenzene. This reactant would act as a mediator for the effective oxidation of the ruthenium catalyst, allowing the $\mathrm{C}-\mathrm{H}$ oxygenation reaction to happen (Scheme 2.3). A detailed optimization study for the formation of the hypervalent iodine and the combination of this in a one-step procedure with the ruthenium-catalyzed reaction were therefore of interest. A successful application of the strategy should prove viable on an ample range of compounds. Since the ability of ruthenium catalyst of performing 
remote functionalizations of substrates is well-known, this approach would also been of utmost interest for the electrochemical oxygenation reaction.

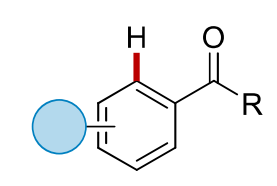

$\mathrm{R}=-\mathrm{NR}_{2},-$-alkyl, - aryl

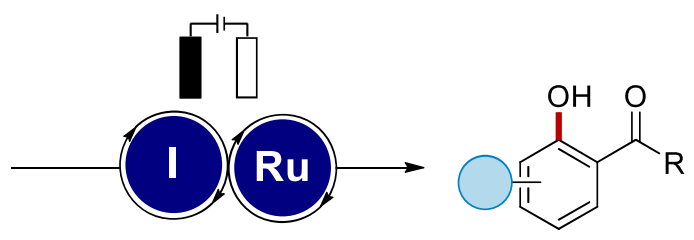

sustainable ruthenium(II) mild reaction conditions iodobenzene as mediator electrochemical formation of PIFA

weakly coordinating ketones

remote functionalization

Scheme 2.3 Electrochemical hypervalent iodine formation for the ruthenium-catalyzed C-H oxygenation reaction.

The effective direct oxidation of a transition metal at the anode would avoid the use of any mediator. Thus, an even more atom-economical approach could be designed. To reach such conditions, rhodium-catalyzed $\mathrm{C}-\mathrm{H}$ oxygenation was considered (Scheme 2.4). The aim was to compare the reactivity and selectivity with the ruthenium manifold, exploring possible new routes in product synthesis. Herein, a detailed study of the mechanism via detailed mechanistic studies, DFT calculations, and cyclic voltammetry would be highly desirable to clarify the pathway for this rhodium-catalyzed transformation, which was underreported for reactions using chemical oxidants and so far, not presented with an electrochemical approach.

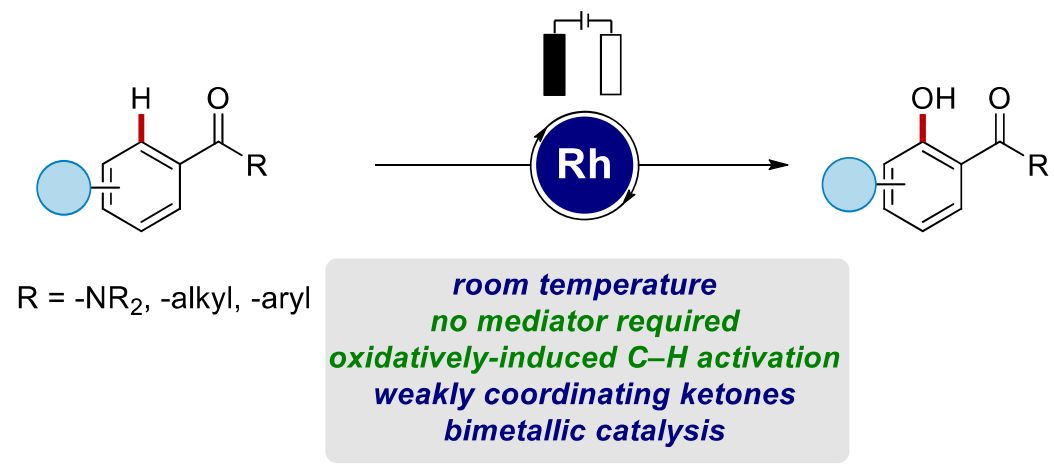

Scheme 2.4 Electrochemical rhodium-catalyzed C-H oxygenation. 
$\mathrm{C}-\mathrm{H}$ arylation reactions are of major interest due to the plethora of biaryl motifs in natural products. ${ }^{[166]}$ After the remarkable development of electrochemical iron-catalyzed C-H arylation, ${ }^{[48 f]}$ the intention was to enable mono-dentate and weakly coordinating amides, while maintaining mild conditions and a broad substrate scope. Thus, the focus was directed towards manganese catalysis (Scheme 2.5). Given the unprecedented electrochemical low-valent 3d metal-catalyzed approaches, a clarification of the overall reaction path and insights in the redox events are of high interest

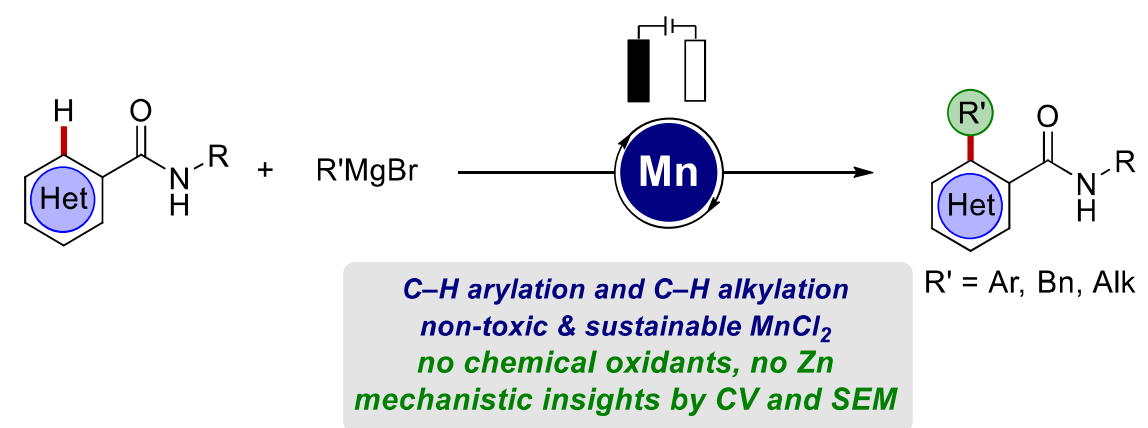

Scheme 2.5 Electrochemical manganese-catalyzed C-H arylations. 


\section{Results and Discussion}

\subsection{Electrochemical $\mathrm{C}-\mathrm{H} / \mathrm{N}-\mathrm{H}$ Activation by Water-Tolerant Cobalt-Catalysis at Room Temperature}

$\mathrm{C}-\mathrm{H} / \mathrm{N}-\mathrm{H}$ alkyne annulations are a valuable tool for the step-economical synthesis of heterocycles. Here, cobalt catalysis has been playing an important role, but it has been strongly limited to the use of stoichiometric chemical oxidants or high reaction temperatures. ${ }^{[58,60,164]}$ Following the groundbreaking work from Ackermann, ${ }^{[73]}$ we intended to employ electricity as oxidant to enable C$\mathrm{H} / \mathrm{N}-\mathrm{H}$ annulation reactions.

\subsubsection{Optimization}

The optimized reaction conditions were elaborated at first by Dr. Cong Tian (Scheme 3.1.1). The reactions were performed in an undivided cell set-up with a reticulated vitreous carbon (RVC) electrode as anode and a platinum (Pt) plate electrode as cathode, with a constant current electrolysis of $4.0 \mathrm{~mA}$ at room temperature. Initial results showed that $\mathrm{H}_{2} \mathrm{O}$ or $\mathrm{MeOH}$ were better solvents than DMSO, with a 1:1 mixture of $\mathrm{H}_{2} \mathrm{O} / \mathrm{MeOH}$ giving the best performance. Moreover, sodium pivalate was found to be a better base in comparison to sodium acetate or to the absence of a base. The control experiment in the absence of electricity gave no product. Notably, the reaction was selective for the annulation product 34aa, and no oxygenation adducts were found, even though a large excess of free alcohol was present as the co-solvent.

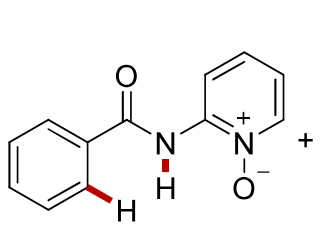

$33 a$

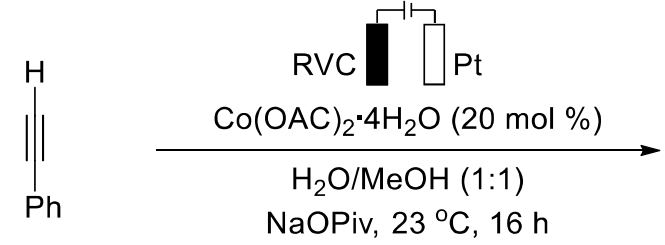

$117 a$<smiles>O=c1c2ccccc2cc(-c2ccccc2)n1P(O)c1ccccc1</smiles>

$34 a a$

CCE at $4.0 \mathrm{~mA}: 76 \%$ without current: --

Scheme 3.1.1 Initial optimized conditions for the $\mathrm{C}-\mathrm{H} / \mathrm{N}-\mathrm{H}$ alkyne annulations by Dr. C. Tian. 
Further optimization studies were performed at the very beginning of my doctoral studies (Table 3.1.1). First, the reaction was tested at $60{ }^{\circ} \mathrm{C}$, which however led to no improvement in the yield (entry 1). Performing the same reaction within a shorter time gave the same result, indicating that heating was probably increasing the rate of the reaction (entry 2). Furthermore, the influence of catalyst loading was studied (entries 3-4). Interestingly, a catalyst loading of $10 \mathrm{~mol} \%$ gave the same result as with $20 \mathrm{~mol} \%$ loading, while a decrease in the amount of cobalt to $1.0 \mathrm{~mol} \%$ yielded only $8 \%$ of the annulated product 34aa. Subsequently, the solvent system was further studied. Changing the ratio of the solvent mixture, with a $3: 1 \mathrm{H}_{2} \mathrm{O} / \mathrm{MeOH}$ ratio, no beneficial effect was observed (entry 5). This was probably due to the lower solubility of the reaction components. Therefore, we investigate the substitution of methanol with a surfactant. ${ }^{[167]}$ Polyoxyethanyl- $\alpha$ tocopheryl sebacate (PTS, $15 \mathrm{wt} \%$ in $\mathrm{H}_{2} \mathrm{O}$ ) was tested, resulting in $31 \%$ isolated product (entry 6). Lastly, HFIP was tested as solvent due to its facilitating effect on $\mathrm{C}-\mathrm{H}$ activation and electrosynthesis, ${ }^{[168]}$ but yielded only $19 \%$ of the desired product (entry 7). Additionally, the use of $\mathrm{Co}(\mathrm{acac})_{3}$ instead of $\mathrm{Co}(\mathrm{OAc})_{2}$ as catalyst was detrimental for the performance (entry 8$)$. Several transition-metal catalysts were tried under the same reaction conditions. Iron, copper, palladium, iridium, ruthenium, and rhodium were found to be ineffective, underlining the unique effectiveness of the cobalt catalyst (entries 9-16).

Table 3.1.1 Further optimization of the electrochemical cobalt-catalyzed alkyne annulation. ${ }^{[a]}$

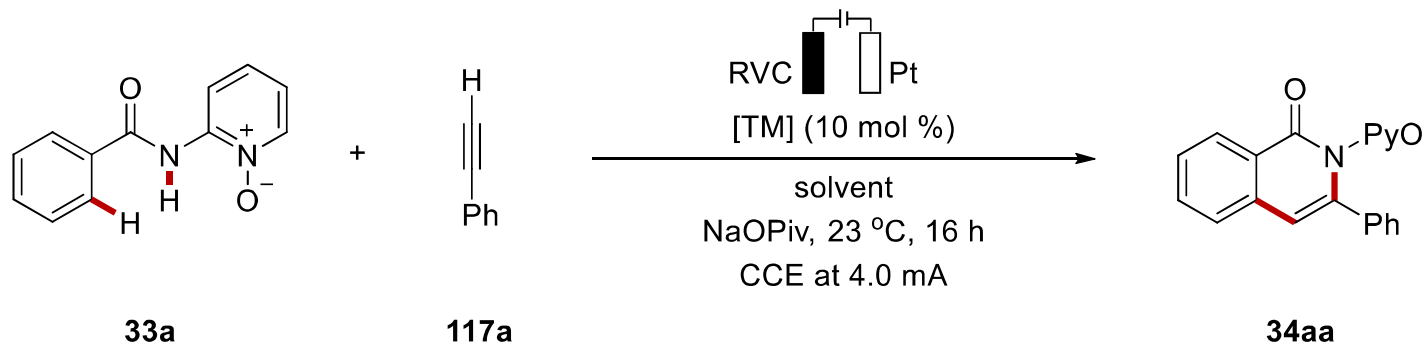

\begin{tabular}{cccc}
\hline Entry & {$[\mathbf{T M}]$} & Solvent & Yield (\%) \\
\hline 1 & $\mathrm{Co}(\mathrm{OAc})_{2} \cdot 4 \mathrm{H}_{2} \mathrm{O}$ & $\mathrm{H}_{2} \mathrm{O} / \mathrm{MeOH}(1: 1)$ & $66^{[\mathrm{b}, \mathrm{d}]}$ \\
2 & $\mathrm{Co}(\mathrm{OAc})_{2} \cdot 4 \mathrm{H}_{2} \mathrm{O}$ & $\mathrm{H}_{2} \mathrm{O} / \mathrm{MeOH}(1: 1)$ & $66^{[\mathrm{b}, \mathrm{c}, \mathrm{d}]}$ \\
$\mathbf{3}$ & $\mathbf{C o}(\mathrm{OAc})_{2} \cdot 4 \mathrm{H}_{2} \mathrm{O}$ & $\mathbf{H}_{2} \mathrm{O} / \mathbf{M e O H}(\mathbf{1 : 1})$ & $\mathbf{7 6}$ \\
4 & $\mathrm{Co}(\mathrm{OAc})_{2} \cdot 4 \mathrm{H}_{2} \mathrm{O}$ & $\mathrm{H}_{2} \mathrm{O} / \mathrm{MeOH}(1: 1)$ & $8^{[\mathrm{e}]}$
\end{tabular}




\begin{tabular}{|c|c|c|c|}
\hline 5 & $\mathrm{Co}(\mathrm{OAc})_{2} \cdot 4 \mathrm{H}_{2} \mathrm{O}$ & $\mathrm{H}_{2} \mathrm{O} / \mathrm{MeOH}(3: 1)$ & 40 \\
\hline 6 & $\mathrm{Co}(\mathrm{OAc})_{2} \cdot 4 \mathrm{H}_{2} \mathrm{O}$ & $\mathrm{PTS} / \mathrm{H}_{2} \mathrm{O}$ & $31^{[b]}$ \\
\hline 7 & $\mathrm{Co}(\mathrm{OAc})_{2} \cdot 4 \mathrm{H}_{2} \mathrm{O}$ & HFIP & $19^{[\mathrm{b}]}$ \\
\hline 8 & $\mathrm{Co}(\mathrm{acac})_{3}$ & $\mathrm{H}_{2} \mathrm{O} / \mathrm{MeOH}(1: 1)$ & - \\
\hline 9 & $\mathrm{Fe}(\mathrm{OAc})_{2}$ & $\mathrm{H}_{2} \mathrm{O} / \mathrm{MeOH}(1: 1)$ & - \\
\hline 10 & $\mathrm{Fe}(\mathrm{acac})_{3}$ & $\mathrm{H}_{2} \mathrm{O} / \mathrm{MeOH}(1: 1)$ & - \\
\hline 11 & $\mathrm{Cu}(\mathrm{OAc})_{2}$ & $\mathrm{H}_{2} \mathrm{O} / \mathrm{MeOH}(1: 1)$ & - \\
\hline 12 & $\mathrm{Pd}(\mathrm{OAc})_{2}$ & $\mathrm{H}_{2} \mathrm{O} / \mathrm{MeOH}(1: 1)$ & - \\
\hline 13 & {$\left[\mathrm{Cp}^{*} \mathrm{IrCl}_{2}\right]_{2}$} & $\mathrm{H}_{2} \mathrm{O} / \mathrm{MeOH}(1: 1)$ & - \\
\hline 14 & $\mathrm{RuCl}_{3}$ & $\mathrm{H}_{2} \mathrm{O} / \mathrm{MeOH}(1: 1)$ & - \\
\hline 15 & $\mathrm{Ru}(p$-cymene $)\left(\mathrm{O}_{2} \mathrm{CMes}\right)_{2}$ & $\mathrm{H}_{2} \mathrm{O} / \mathrm{MeOH}(1: 1)$ & - \\
\hline 16 & {$\left[\mathrm{Cp} * \mathrm{RhCl}_{2}\right]_{2}$} & $\mathrm{H}_{2} \mathrm{O} / \mathrm{MeOH}(1: 1)$ & - \\
\hline \multicolumn{4}{|c|}{$\begin{array}{l}\text { [a] Reaction conditions: Undivided cell, 33a }(0.50 \mathrm{mmol}), 117 \mathrm{a}(1.00 \mathrm{mmol}),[\mathrm{TM}](10 \mathrm{~mol} \%) \text {, } \\
\text { NaOPiv }(2.00 \text { equiv }) \text {, solvent }(10.0 \mathrm{~mL}), 23{ }^{\circ} \mathrm{C}, \mathrm{CCE} \text { at } 4.0 \mathrm{~mA}, 16 \mathrm{~h}, \mathrm{RVC} \text { anode }(10 \mathrm{~mm} \times 15 \mathrm{~mm} \\
\times 6 \mathrm{~mm}) \text {, Pt-plate cathode }(10 \mathrm{~mm} \times 15 \mathrm{~mm} \times 0.125 \mathrm{~mm}) \text {, isolated yield. }{ }^{[\mathrm{b}]}[\mathrm{TM}](20 \mathrm{~mol} \%) .{ }^{[\mathrm{c}]} 8 \\
\text { h. }^{[\mathrm{d}]} 60^{\circ} \mathrm{C} .{ }^{[\mathrm{e}]}[\mathrm{TM}](1.0 \mathrm{~mol} \%) .\end{array}$} \\
\hline
\end{tabular}

\subsubsection{Substrate Scope}

With the further optimized reaction conditions in hand, the scope of the electrochemical $\mathrm{C}-\mathrm{H} / \mathrm{N}-\mathrm{H}$ annulation was explored by employing various amides 33 and phenylacetylene 117a (Scheme 3.1.2). The scope was ample. The more electron-poorer or challenging substrates needed a higher catalyst loading. Differently para-substituted amides 33b-d were well tolerated, either with an electrondonating (34ba) or an electro-withdrawing substituent (34ca). The valuable functional group bromo underwent the annulation without side coupling reaction (34da). Also, the 3,5-dimethoxy substituted amide 33e was successfully converted, yielding the desired product $\mathbf{3 4 \mathbf { e a }}$. To our delight, the reaction was not limited to arene substrates, but was working likewise on the heteroarene thiophene $33 f$. 


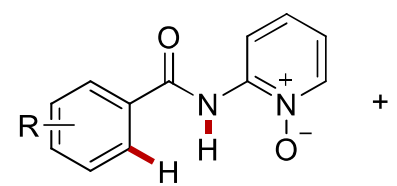

33

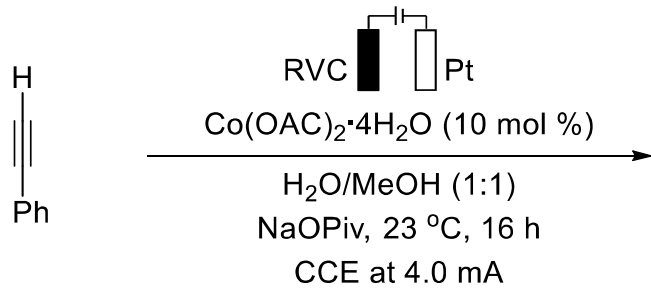

$117 a$

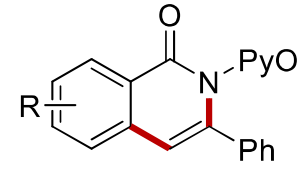

34<smiles>Cc1ccc2c(=O)n([Pb](=O)[O-])c(-c3ccccc3)cc2c1</smiles>

34ba: $73 \%$<smiles></smiles>

34ca: $51 \%^{[a]}$<smiles>O=c1c2ccc(Br)cc2cc(-c2ccccc2)n1[P+](=O)[O-]</smiles>

34da: $65 \%^{[a]}$<smiles></smiles>

34ea: $80 \%$<smiles>O=c1c2ccsc2cc(-c2ccccc2)n1P(O)c1ccccc1</smiles>

34fa: $54 \%{ }^{[a]}$

Scheme 3.1.2 Scope of the electrochemical cobalt-catalyzed $\mathrm{C}-\mathrm{H} / \mathrm{N}-\mathrm{H}$ alkyne annulation of amides 33. ${ }^{[\mathrm{a}]} \mathrm{Co}(\mathrm{OAc})_{2} \cdot 4 \mathrm{H}_{2} \mathrm{O}(20 \mathrm{~mol} \%)$.

The robustness of the electrochemical cobalt-catalyzed $\mathrm{C}-\mathrm{H} / \mathrm{N}-\mathrm{H}$ activation at ambient temperature was further reflected by the annulation of different alkynes $\mathbf{1 1 7}$ with the standard substrate $\mathbf{3 3 a}$ (Scheme 3.1.3). Hence, substituents in the para-position of the phenylacetylenes 117 were well tolerated, especially for electron-rich groups, such as methoxy (34ab) and tert-butyl (34ac). Moreover, alkyl alkynes were also found to be suitable substrates for the desired reaction. Indeed, 1heptyne (117d) underwent the reaction furnishing $55 \%$ of the desired product $34 \mathbf{a d}$. 


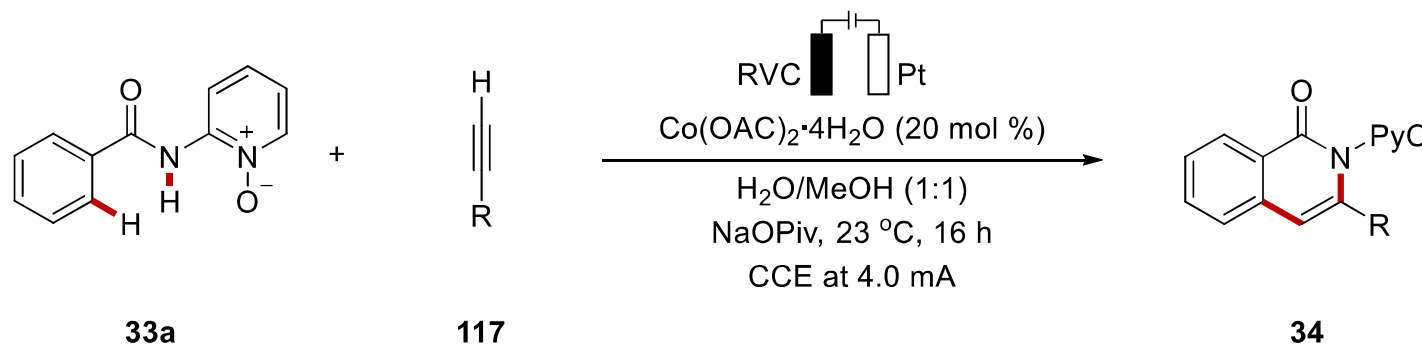<smiles>COc1ccc(-c2cc3ccccc3c(=O)n2[Po](=O)[O-])cc1</smiles>

34ab: $82 \%$<smiles>CC(C)(C)c1ccc(-c2cc3ccccc3c(=O)n2P([O-])O)cc1</smiles>

34ac: $64 \%$<smiles>CCCCCc1cc2ccccc2c(=O)n1[Po](=O)[O-]</smiles>

34ad: $55 \%$

Scheme 3.1.3 Scope of the electrochemical cobalt-catalyzed annulation of alkynes $\mathbf{1 1 7}$.

\subsubsection{Mechanistic Studies}

Given the new electrochemical approach for cobalt-catalyzed $\mathrm{C}-\mathrm{H} / \mathrm{N}-\mathrm{H}$ alkyne annulation, we desired to further understand its mode of action. To this end, Dr. Cong Tian performed intermolecular competition experiments, H/D exchange evaluation in reaction conditions, and KIE studies. The higher reactivity of electron-rich substrates indicated a base-assisted internal electrophilic substitution (BIES) manifold. ${ }^{[29,32]}$ The absence of a significant deuterium incorporation suggested an irreversible, yet facile, $\mathrm{C}-\mathrm{H}$ cleavage as proven by a KIE of $k_{\mathrm{H}} / k_{\mathrm{D}} \approx 1.1$.

Moreover, the ortho-alkynylated substrate 184 was independently prepared by a Sonogashira coupling of the methyl 2-iodobenzoate $\mathbf{1 8 0}$, followed by the insertion of 2-aminopyridine- $N$-oxide 183 as the optimal directing group (Scheme 3.1.4,a). The synthesized substrate 184 was then submitted to the optimized reaction conditions and the product was not obtained (Scheme 3.1.4,b). This result suggested an organometallic alkyne annulation pathway. 
(a) Substrate synthesis

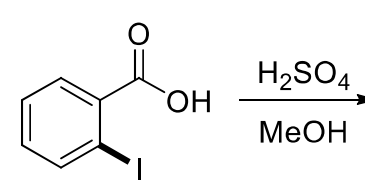

179<smiles>COC(=O)c1ccccc1I</smiles>

180 , quant.

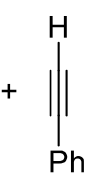

117

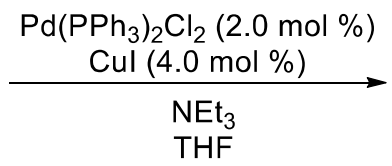
$\mathrm{NHF}$
$\mathrm{THF}$<smiles>COC(=O)c1ccccc1C#CC(C)(C)c1ccccc1</smiles>

$181,82 \%$<smiles>[H][R6](C)(CC#Cc1ccccc1C(=O)Nc1cccc[n+]1[O-])C(C)(C)C</smiles>

(b) Cyclization attempt<smiles>O=C(Nc1cccc[n+]1[O-])c1ccccc1C#Cc1ccccc1</smiles>

184

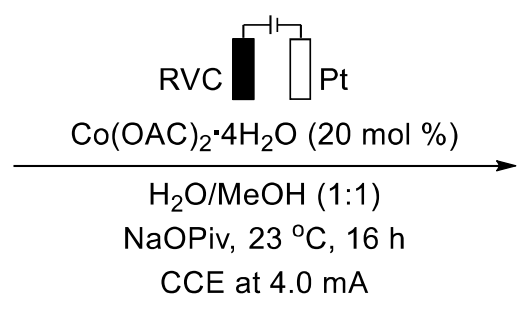

no reaction $\mathrm{MeOH}$

Scheme 3.1.4 Substrate 184 synthesis and attempted cyclization experiment.

To gain insights in the electrochemical event, detailed cyclic voltammetry studies were performed by Dr. T. H. Meyer (Figure 3.1.1). The amide 33a had an oxidation potential of $1.51 \mathrm{~V} v s$. SCE, compared to a catalyst redox event at $1.19 \mathrm{~V} v$ s. SCE. Therefore, the oxidation of the cobalt was 320 $\mathrm{mV}$ lower than the substrate, thus supporting a single-electron oxidation at cobalt. Phenylacetylene 117a did not exhibit a clear oxidation event, a result that, in line with the cyclization attempt, suggested an organometallic annulation. 


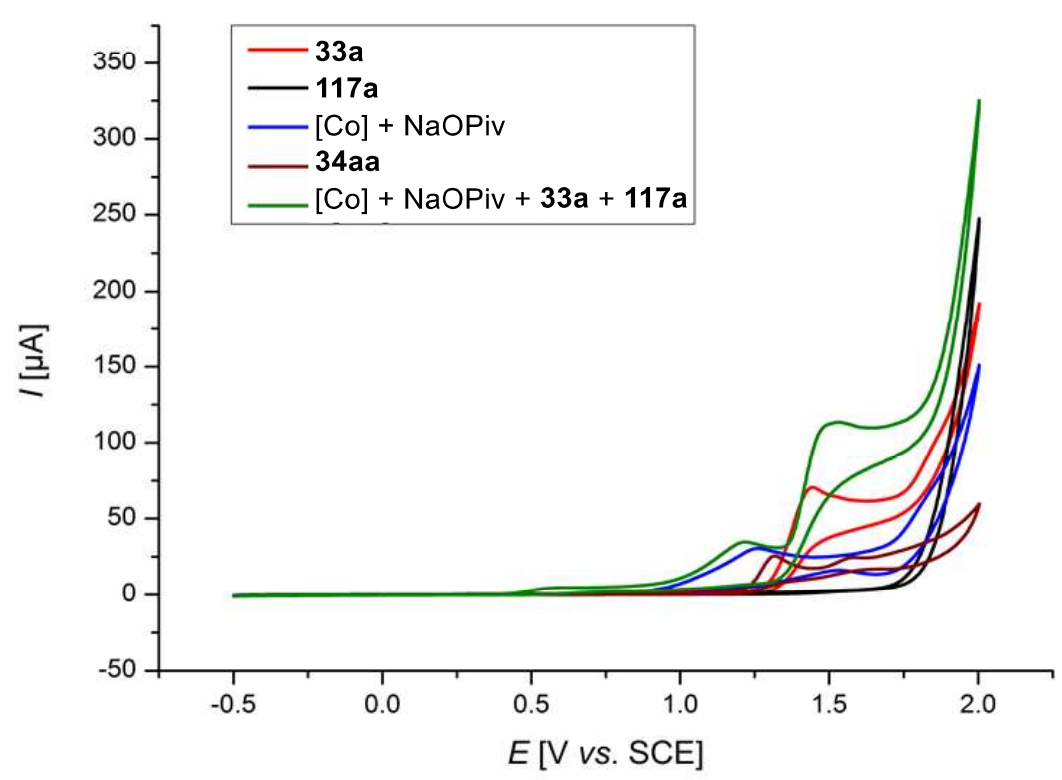

Figure 3.1.1 Cyclic voltammograms at $20 \mathrm{mVs}^{-1}: n \mathrm{Bu}_{4} \mathrm{NPF}_{6}(0.1 \mathrm{M}$ in $\mathrm{MeOH})$, concentration of substrates $1.0 \mathrm{mM}$ (NaOPiv $4.0 \mathrm{mM}$ ). Performed by Dr. T. H. Meyer.

\subsubsection{Proposed Catalytic Cycle}

A catalytic cycle for the $\mathrm{C}-\mathrm{H} / \mathrm{N}-\mathrm{H}$ electrochemical annulation was proposed, and it is based on the mechanistic studies presented above (Scheme 3.1.5). First, the cobalt(II) acetate catalyst undergoes oxidation to the active cobalt(III) carboxylate 185. Second, the amide 33 gives the intermediate 186 through a facile BIES $\mathrm{C}-\mathrm{H}$ cleavage. Alkyne insertion affords the cobalt complex 187 and a subsequent reductive elimination yields the desired product $\mathbf{3 4}$ and cobalt(I) catalyst 30a. This is oxidized at the anode to give the active cobalt(III) catalyst $\mathbf{1 8 5}$. While the cobalt is oxidized at the anode, the formation of $\mathrm{H}_{2}$ takes place at the cathode. 


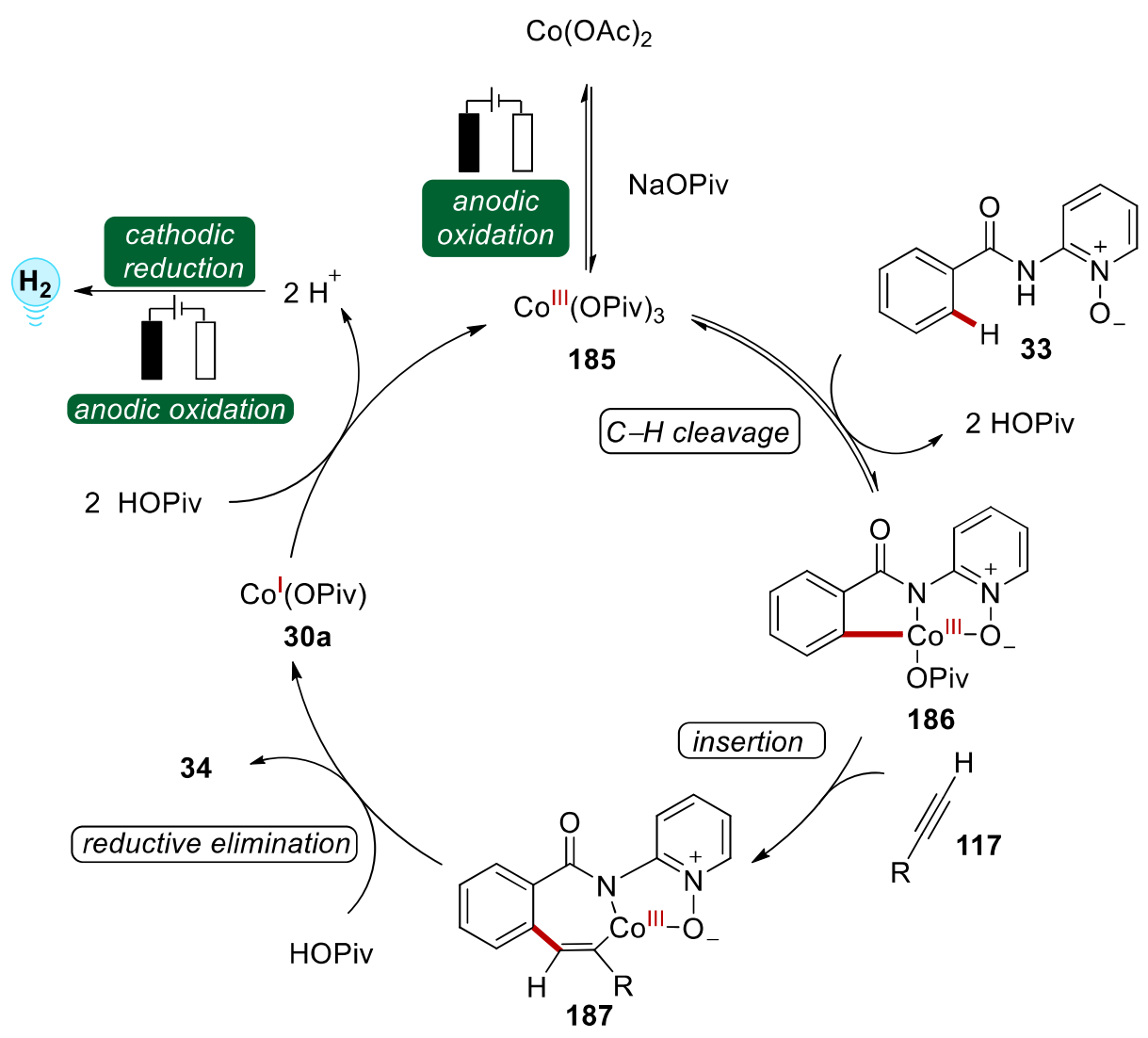

Scheme 3.1.5 Proposed catalytic cycle for the electrochemical cobalt-catalyzed $\mathrm{C}-\mathrm{H} / \mathrm{N}-\mathrm{H}$ annulation. 


\subsection{Electrooxidative Ruthenium-Catalyzed $\mathrm{C}-\mathrm{H} / \mathrm{O}-\mathrm{H}$ Annulation by Weak $O$ - Coordination}

Numerous oxidative reactions have been reported with ruthenium, ${ }^{[87]}$ but its merger with electricity as green oxidant appeared as an important challenge. After the success of coblataelectro-catalyzed reactions, our group focused on opening the way to electrochemical ruthenium catalysis. Simultaneously, Xu reported the synthesis of indoles via the ruthenium-catalyzed electrochemical dehydrogenative annulation of aniline derivatives and alkynes. ${ }^{[51 b]}$ While Xu's report was limited to a strongly coordinating directing group, we focused on weak coordination, which led to the development of the first electrochemical ruthenium-catalyzed $O$-directed $\mathrm{C}-\mathrm{H}$ activation presented in this section.

\subsubsection{Optimization}

At the outset of the study, we investigated the reaction between 4-methoxybenzoic acid $\mathbf{8 9 b}$ and diphenylacetylene 24a, with a ruthenium catalyst and potassium hexafluorophosphate in a mixture of tert-amyl alcohol and water, at $100{ }^{\circ} \mathrm{C}$ and a constant current electrolysis of $4.0 \mathrm{~mA}$ (Scheme 3.2.1). $\left[\operatorname{RuCl}_{2}(p \text {-cymene })\right]_{2}$ and sodium pivalate as additive under a nitrogen atmosphere were employed at first and resulted in a $35 \%$ isolated yield of the desired annulated product (entry 1). By changing the catalyst to $\left[\mathrm{Ru}(\mathrm{OAc})_{2}(p\right.$-cymene $\left.)\right]$ 188a, the product formation increased, but when the reaction was performed under air atmosphere the yield was slightly diminished (entries 2-3). The test reaction in the absence of the catalyst revealed the essential role of the ruthenium catalyst (entry 4). Analogously, the test without any applied current, but with the electrodes in the cell, showed the importance of electricity, as only $11 \%$ of the desired product was obtained (entry 5). Different solvent systems were tried. First, water was employed as the only solvent, but only $5 \%$ of product $90 \mathrm{ba}$ was detected (entry 6). Then the effect of the addition of two surfactants, namely $\alpha$-tocopherol (2 wt. \% in $\mathrm{H}_{2} \mathrm{O}$ ) and polyoxyethanyl- $\alpha$-tocopheryl sebacate (PTS, 4 wt. \% in $\mathrm{H}_{2} \mathrm{O}$ ), was examined giving only very low conversions (entries 7-8). Other organic solvents were also tested, but for these attempts there was the need of adding a supporting electrolyte to increase the conductivity of the media. $\gamma$ - 
Valerolactone, and $o$-xylene were tested without success, while tert-amyl alcohol alone gave $12 \%$ of the desired product 90ba (entries 9-11).

Table 3.2.1 Initial optimization of the electrochemical ruthenium-catalyzed $\mathrm{C}-\mathrm{H} / \mathrm{C}-\mathrm{O}$ annulation. ${ }^{\text {a] }}$

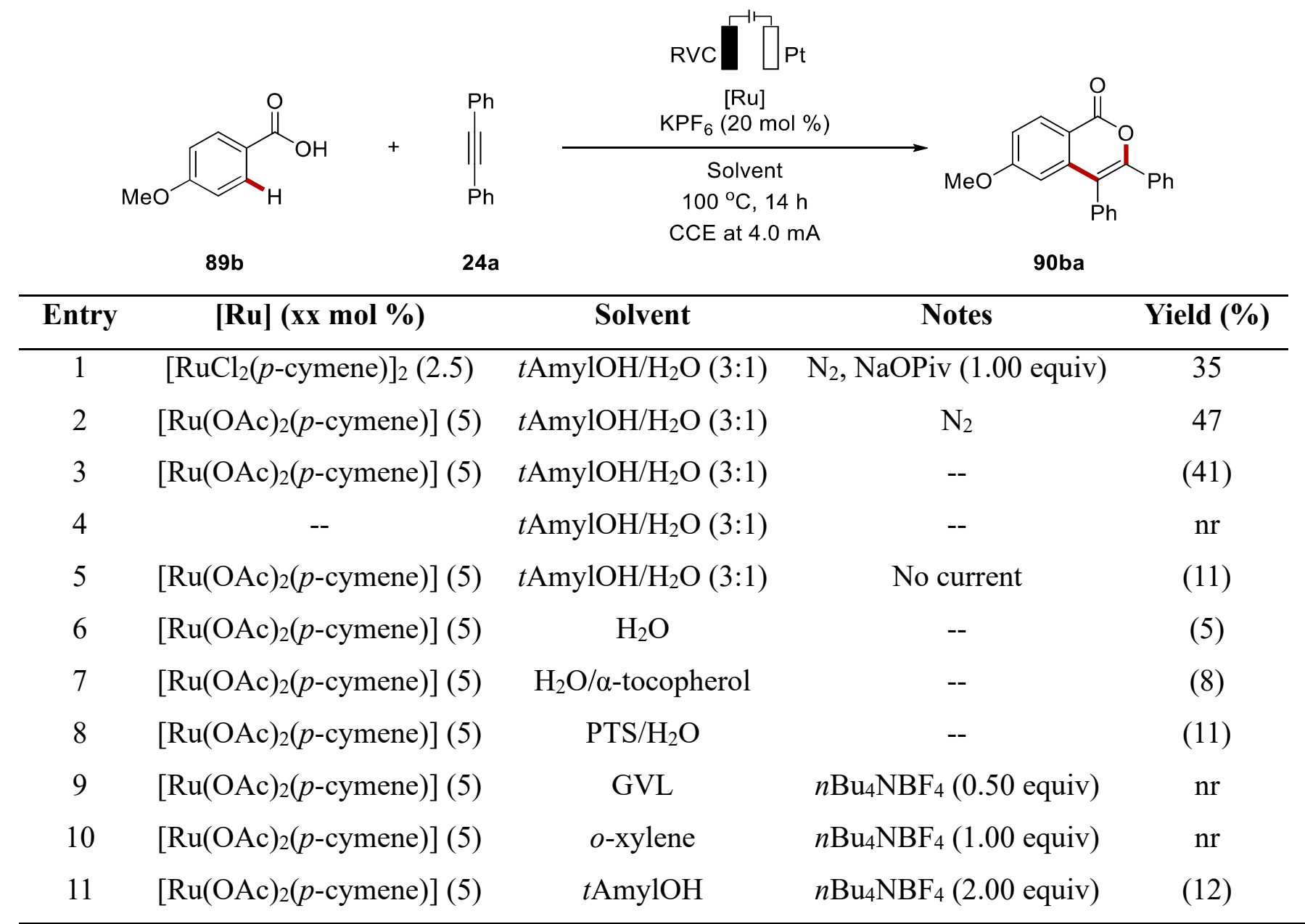

${ }^{[a]}$ Reaction conditions: Undivided cell, 89b (1.00 mmol), 24a $(0.50 \mathrm{mmol}),[\mathrm{Ru}]$ (as specified), $\mathrm{KPF}_{6}(20 \mathrm{~mol} \%)$, solvent $(10.0 \mathrm{~mL}), 100{ }^{\circ} \mathrm{C}, \mathrm{CCE}$ at $4.0 \mathrm{~mA}, 14 \mathrm{~h}, \mathrm{RVC}$ anode $(10 \mathrm{~mm} \times 15 \mathrm{~mm}$ $\times 6 \mathrm{~mm})$, Pt-plate cathode $(10 \mathrm{~mm} \times 15 \mathrm{~mm} \times 0.125 \mathrm{~mm})$, isolated yield, yields in parentheses are determined by ${ }^{1} \mathrm{H}-\mathrm{NMR}$ analysis with 1,3,5-trimethoxybenzene as internal standard.

Since Dr. Youai Qiu was also studying the same type of reaction, forces were joined, and the optimization was then carried on with $o$-toluic acid 89c as the standard substrate (Table 3.2.2). The reaction with $5.0 \mathrm{~mol} \%$ of $\left[\mathrm{RuCl}_{2}(p \text {-cymene })\right]_{2}$ and tert-amyl alcohol/water mixture yielded the desired product 90ca in $85 \%$ isolated yield (entry 1). Changing the base to sodium acetate was found to be detrimental for the catalytic reactivity (entry 2). The solvents had not comparable performance 
to the solvent system in use. Indeed, the reactions in pure tert-amyl alcohol, water, 2,2,2trifluoroethanol (TFE), or acetonitrile, were all found to deliver the products only in low to decent yields (entries 3-6). Decreasing the catalyst loading to $1.0 \mathrm{~mol} \%$ delivered the desired product 90ca in $31 \%$ yield, while lowering the temperature to $80^{\circ} \mathrm{C}$ was found to be beneficial to the reaction, increasing the obtained isolated product to $90 \%$ (entries 7-8). Other transition metal (TM) catalysts were tested at $100{ }^{\circ} \mathrm{C}$ under the optimized conditions (entries 9-11). Interestingly, iridium and cobalt catalysts were found to be completely ineffective for the envisioned reaction, while the pentamethylcyclopentadienyl rhodium dichloride dimer yielded $82 \%$ of the annulated product 90ca. Remarkably, this result represented the first electrochemical rhodium-catalyzed $\mathrm{C}-\mathrm{H}$ activation.

Table 3.2.2 Optimization of the electrochemical ruthenium-catalyzed $\mathrm{C}-\mathrm{H} / \mathrm{C}-\mathrm{O}$ annulation. ${ }^{[\mathrm{a}]}$

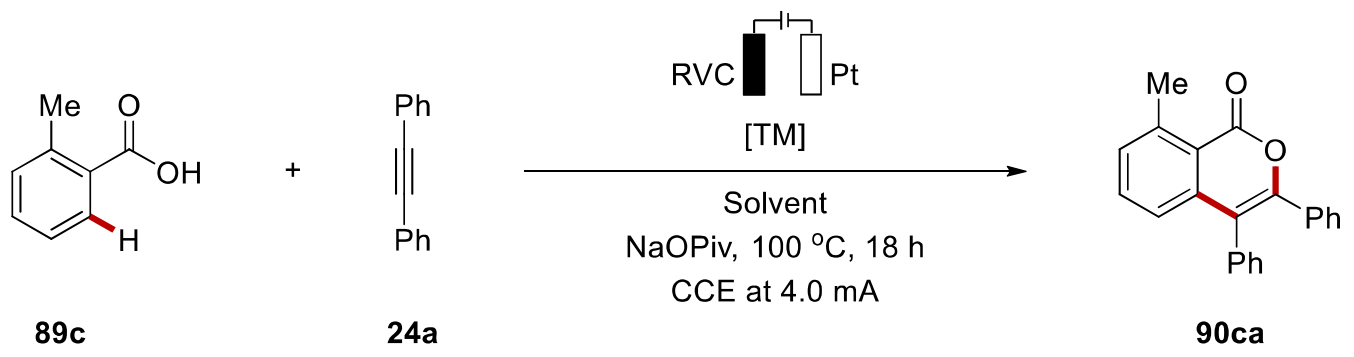

\begin{tabular}{|c|c|c|c|}
\hline Entry & [TM] & Solvent & Yield (\%) \\
\hline 1 & {$\left[\mathrm{RuCl}_{2}(p \text {-cymene })\right]_{2}(5)$} & $t \mathrm{AmylOH} / \mathrm{H}_{2} \mathrm{O}(3: 1)$ & $85^{[\mathrm{b}]}$ \\
\hline 2 & {$\left[\mathrm{RuCl}_{2}(p \text {-cymene })\right]_{2}(5)$} & $t \mathrm{AmylOH} / \mathrm{H}_{2} \mathrm{O}(3: 1)$ & $27^{[\mathrm{c}]}$ \\
\hline 3 & {$\left[\mathrm{RuCl}_{2}(p \text {-cymene })\right]_{2}(5)$} & $t$ AmylOH & 10 \\
\hline 4 & {$\left[\mathrm{RuCl}_{2}(p \text {-cymene })\right]_{2}(5)$} & $\mathrm{H}_{2} \mathrm{O}$ & 44 \\
\hline 5 & {$\left[\mathrm{RuCl}_{2}(p \text {-cymene })\right]_{2}(5)$} & TFE & $35^{[\mathrm{d}]}$ \\
\hline 6 & {$\left[\mathrm{RuCl}_{2}(p \text {-cymene })\right]_{2}(5)$} & $\mathrm{MeCN}$ & 17 \\
\hline 7 & {$\left[\mathrm{RuCl}_{2}(p \text {-cymene })\right]_{2}(1)$} & $t \mathrm{AmylOH} / \mathrm{H}_{2} \mathrm{O}(3: 1)$ & 31 \\
\hline 8 & {$\left[\mathrm{RuCl}_{2}(p \text {-cymene })\right]_{2}(5)$} & $t$ AmylOH/H2O (3:1) & $90^{[\mathrm{b}, \mathrm{e}]}$ \\
\hline 9 & {$\left[\mathrm{Cp}^{*} \mathrm{RhCl}_{2}\right]_{2}(5)$} & $t$ AmylOH $/ \mathrm{H}_{2} \mathrm{O}(3: 1)$ & 82 \\
\hline 10 & {$\left[\mathrm{Cp}^{*} \mathrm{IrCl}_{2}\right]_{2}(5)$} & $t \mathrm{AmylOH} / \mathrm{H}_{2} \mathrm{O}(3: 1)$ & - \\
\hline 11 & {$\left[\mathrm{Cp} * \mathrm{Co}(\mathrm{MeCN})_{3}\left(\mathrm{SbF}_{6}\right)_{2}\right](10)$} & $t \mathrm{AmylOH} / \mathrm{H}_{2} \mathrm{O}(3: 1)$ & - \\
\hline
\end{tabular}

${ }^{[a]}$ Reaction conditions: Undivided cell, 89c $(0.50 \mathrm{mmol}), 24 \mathbf{a}(1.00 \mathrm{mmol})$, [TM] (as specified), NaOPiv (1.00 equiv), solvent $(4.0 \mathrm{~mL}), 100{ }^{\circ} \mathrm{C}, \mathrm{CCE}$ at $4.0 \mathrm{~mA}, 18 \mathrm{~h}, \mathrm{RVC}$ anode $(10 \mathrm{~mm} \times 15 \mathrm{~mm}$ 
$\times 6 \mathrm{~mm})$, Pt-plate cathode $(10 \mathrm{~mm} \times 15 \mathrm{~mm} \times 0.125 \mathrm{~mm})$, isolated yield. ${ }^{[b]}$ Performed by Dr. Youai Qiu. ${ }^{[\mathrm{c}]} \mathrm{NaOAc}$ as additive. ${ }^{[\mathrm{d}]} 70^{\circ} \mathrm{C} .{ }^{[\mathrm{e}]} 80^{\circ} \mathrm{C}$.

\subsubsection{Substrate Scope}

We then moved on to assess the versatility of the electrochemical ruthenium-catalyzed $\mathrm{C}-\mathrm{H} / \mathrm{C}-\mathrm{O}$ annulation. As shown in Scheme 3.2.1, para-methoxy benzoic acid (89b) was converted to the desired product $90 \mathrm{ba}$ in $60 \%$ yield under the optimized conditions. The remaining substrate scope for differently decorated benzoic acids 89 was mainly performed by Dr. Youai Qiu. Interestingly, $m e t a$-substituted benzoic acids were selectively converted to a single regioisomer, with the functionalization occurring on the less sterically hindered position, as shown for product 90da. Moreover, relevant electrophilic functional groups, such as bromo (89e) and cyano (89f), were well tolerated. Furthermore, heterocyclic substrates also underwent the annulation reaction in good yields. Indeed, both thiophene-3-carboxylic acid 89g and 3-furoic acid $89 \mathrm{~h}$ were converted in 79\% and 65\% isolated yield, respectively.

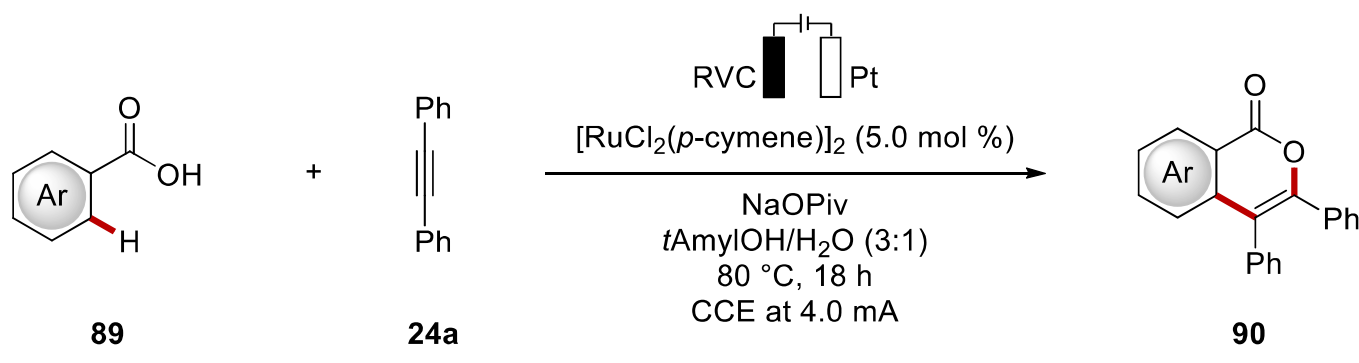<smiles>COc1ccc2c(=O)oc(-c3ccccc3)c(-c3ccccc3)c2c1</smiles>

90ba: $60 \%$<smiles>Cc1ccc2c(-c3ccccc3)c(-c3ccccc3)oc(=O)c2c1</smiles>

90da: $72 \%[a]$<smiles>[R]c1ccc2c(=O)oc(-c3ccccc3)c(-c3ccccc3)c2c1</smiles>

$\mathrm{R}=-\mathrm{Br}(\mathbf{9 0 e a}): 41 \%{ }^{[a]}$

$\mathrm{R}=-\mathrm{CN}(\mathbf{9 0 f a}): 51 \%[\mathrm{a}]$<smiles></smiles>

$Y=S\left(90\right.$ ga): $79 \%{ }^{[a]}$ $Y=O(90 h a): 56 \%[a]$

Scheme 3.2.1 Scope of the electrochemical ruthenium-catalyzed C-H/O-H alkyne annulation by weakly coordinating benzoic acids 89. [a] Performed by Dr. Youai Qiu. 
The robustness of the reaction was also tested with different alkynes $\mathbf{2 4}$, with Dr. Cong Tian mainly focusing on symmetrical alkynes, which were well tolerated by the reaction.

Regarding the substrate scope that I conducted, 3-hexyne 24b was smoothly converted into the desired product $\mathbf{9 0 c b}$ (Scheme 3.2.2). Moreover, asymmetrical alkynes were thus tested. 1-pheny-1butyne (24c) yielded $93 \%$ of product $90 \mathbf{c c}$, together with 5\% of the other regioisomer 90cc'. All the regioisomers were easily separated by column chromatography and characterized. The reaction with substrate $\mathbf{2 4 d}$ gave $81 \%$ of $\mathbf{9 0 c d}$ together with $6 \%$ of $\mathbf{9 0 c d}$. Likewise, $24 \mathbf{f}$ gave $65 \%$ of the major product 90 cf and $7 \%$ of the minor one $\mathbf{9 0 c f}$ ', while substrate $\mathbf{2 4 g}$ gave $88 \%$ and $7 \%$, respectively. In the case of 1-chloro-4-(hex-1-yn-1-yl)benzene $24 \mathrm{e}$ a satisfactory $78 \%$ yield was obtained. The generally accepted rationale behind this kind of selectivity is correlated to the fact that in oxidative type reactions the regio-determining step is usually the alkyne insertion into the $\mathrm{Ru}-\mathrm{C}$ bond that furnishes the seven-membered ruthenacycle, showing the same selectivity in several reports. ${ }^{[95,169]}$ 


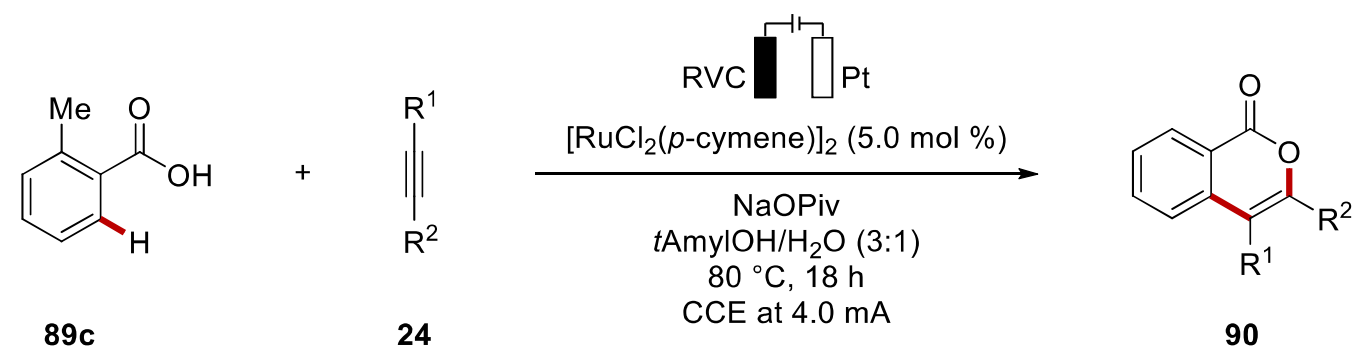<smiles>CCc1oc(=O)c2c(C)cccc2c1CC</smiles>

90cb: $60 \%$<smiles>CCc1c(-c2ccccc2)oc(=O)c2c(C)cccc12</smiles>

90cc: $93 \%$<smiles>CCc1oc(=O)c2c([N+](=O)[O-])cccc2c1-c1ccccc1</smiles>

90cc': $5 \%$<smiles>CCCCCCSc1c(-c2ccc(C)cc2)oc(=O)c2c(C)cccc12</smiles>

90cd: $81 \%$

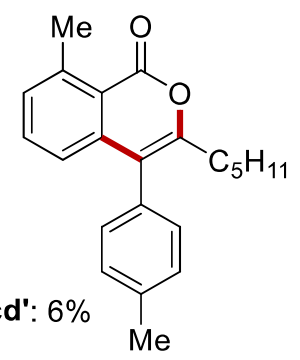<smiles>CCCCc1oc(=O)c2c([N+](=O)[O-])cccc2c1-c1ccc(OC)cc1</smiles><smiles>CCCCc1c(-c2ccc(C(=O)OCC)cc2)oc(=O)c2c(O)cccc12</smiles>

90cg: $88 \%$<smiles>CCCc1c(-c2ccc(Cl)cc2)oc(=O)c2c([N+](=O)[O-])cccc12</smiles>

90ce: $78 \%$<smiles>CCCCc1c(-c2ccc(OC)cc2)oc(=O)c2c(C)cccc12</smiles>

90cf: $65 \%$ $+$ 90cf': $7 \%$ OMe

Scheme 3.2.2 Scope of the electrochemical ruthenium-catalyzed C-H/O-H annulation with alkynes 24.

The envisioned $\mathrm{C}-\mathrm{H} / \mathrm{O}-\mathrm{H}$ alkyne annulation was not limited to benzoic acids $\mathbf{8 9}$ but proved amenable to benzamides 87 likewise (Scheme 3.2.3). Thus, the reaction allowed the synthesis of isoquinolones $\mathbf{8 8}$ in good yields. The reaction between $N$-methylbenzamide 87a and ethyl 4-(hex-1yn-1-yl)benzoate $\mathbf{2 4 g}$ provided $42 \%$ of product $\mathbf{8 8 a g}$, while the other regioisomer was not detected. 


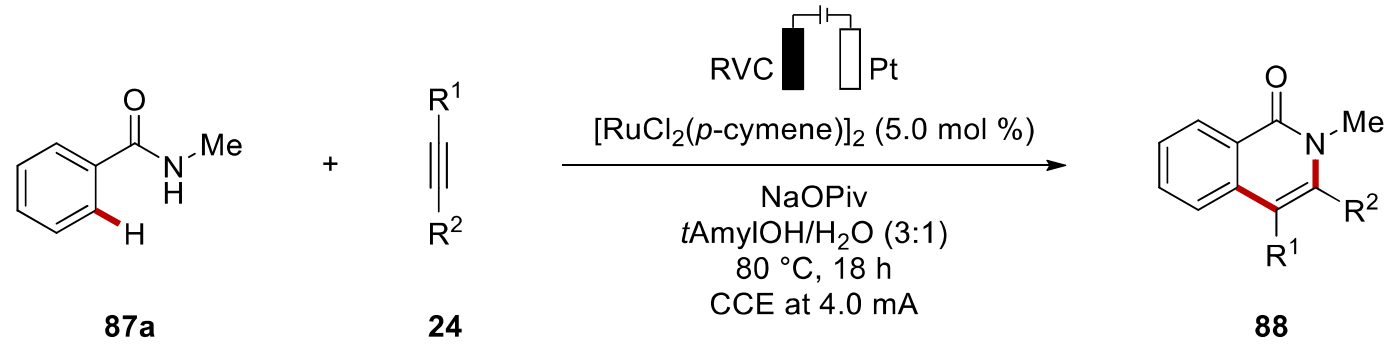<smiles>CCCc1c(-c2ccc(C(=O)OCC)cc2)n(C)c(=O)c2ccccc12</smiles>

88ag: $42 \%$<smiles>Cn1c(-c2ccccc2)c(-c2ccccc2)c2ccccc2c1=O</smiles>

88aa: $74 \%[a]$<smiles>Cc1c(-c2ccccc2)n(C)c(=O)c2ccccc12</smiles>

88ah: $54 \%^{[b]}$

Scheme 3.2.3 Scope of the electrochemical ruthenium-catalyzed C-H/O-H alkyne annulation by benzamides 87. [a] Performed by Dr. Youai Qiu. [b] Performed by Dr. Cong Tian.

Further, phenylacetylene (117a) was submitted to the optimized reaction conditions in order to test if terminal alkynes are feasible substrates (Scheme 3.2.4). Unfortunately, no desired product 189aa was detected.<smiles>O=C(O)c1ccccc1</smiles>

$89 a$

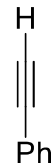

$117 \mathrm{a}$

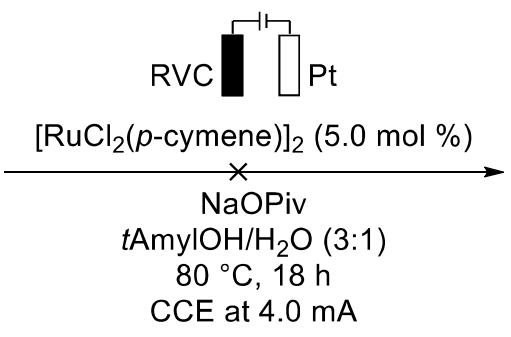

CCE at $4.0 \mathrm{~mA}$<smiles>O=c1oc(-c2ccccc2)cc2ccccc12</smiles>

189aa

Scheme 3.2.4 Attempt for the electrochemical ruthenium-catalyzed $\mathrm{C}-\mathrm{H} / \mathrm{O}-\mathrm{H}$ annulation of phenylacetylene 117a.

\subsubsection{Mechanistic Studies and Proposed Catalytic Cycle}

The mechanistic studies were performed by Dr. Youai Qiu. The H/D exchange experiment showed the presence of deuterium incorporation in both the recovered starting material and the product. This 
indicates a reversible $\mathrm{C}-\mathrm{H}$ cleavage by the ruthenium catalyst. Moreover, intermolecular competition experiments showed a preferential reactivity of the electron-rich arenes and alkynes. With these insights in hand, we proposed a plausible catalytic cycle (Scheme 3.2.5) that starts from the $\mathrm{C}-\mathrm{H}$ activation by the ruthenium catalyst on the arene $\mathbf{8 9}$, followed by a regio-determining migratory insertion step. After reductive elimination, the ruthenium(0) intermediate 193 undergoes an anodic oxidation to yield the desired product 90 and to regenerate the active catalyst $\mathbf{1 8 8 b}$.

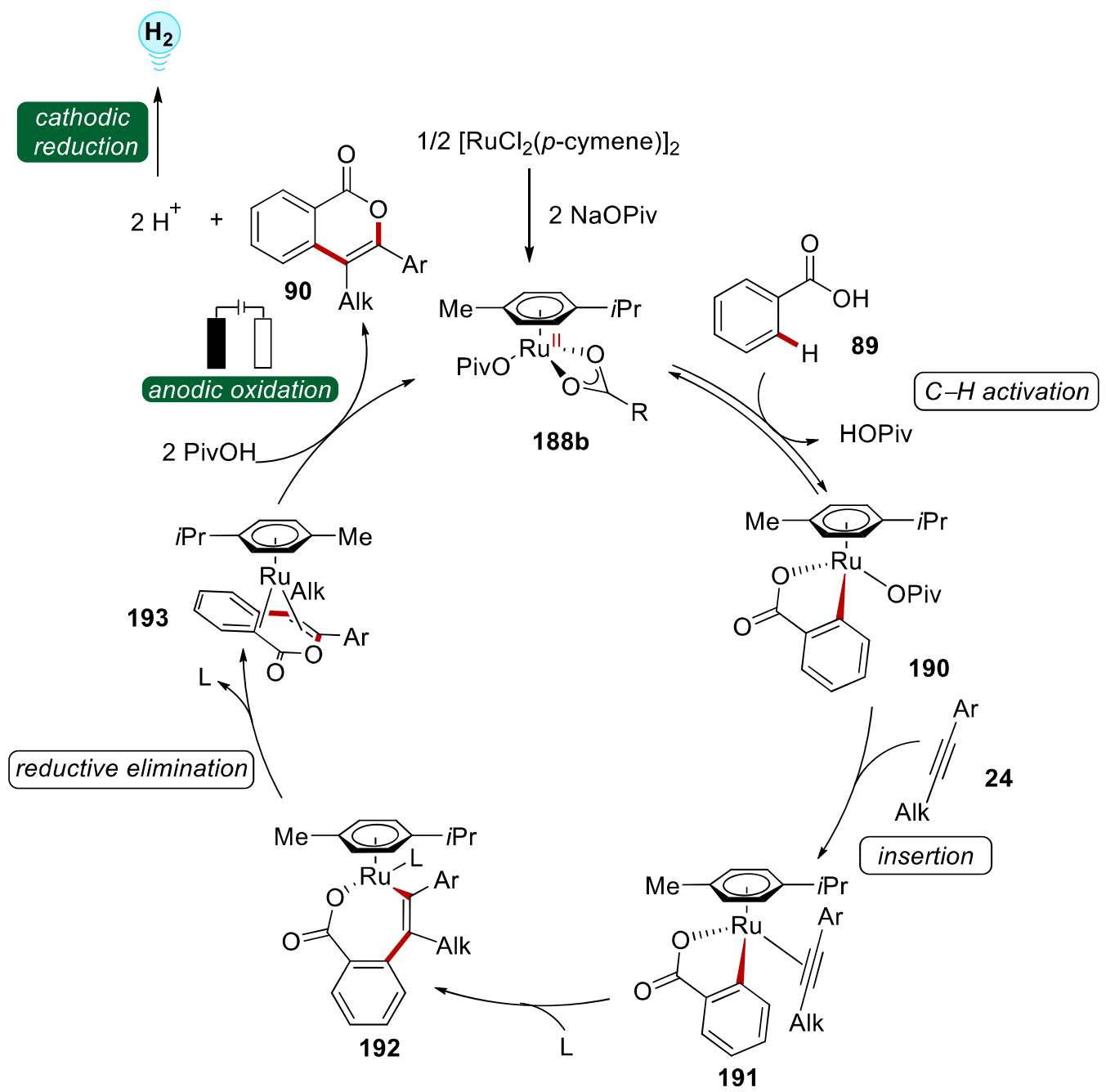

Scheme 3.2.5 Proposed catalytic cycle for the electrochemical ruthenium-catalyzed C-H/O-H alkyne annulation. 


\subsection{C-H Oxygenation Reactions Enabled by Dual Catalysis with} Electrogenerated Hypervalent Iodine Species and Ruthenium Complexes

The electrochemical oxidation of aryl iodides was revealed to be a valuable approach for the in-situ synthesis of hypervalent iodine species, thus allowing for a safer chemistry that eliminates the need for hazardous and expensive chemical oxidants. ${ }^{[165 \mathrm{~d}]}$ The first example was published by Fuchigami and Fujita in 1994, where they could remarkably employ catalytic amounts of 4-iodoanisole for the formation of hypervalent iodobenzene difluoride to allow a gem-difluorination reaction. ${ }^{[165 \mathrm{~g}]}$ Lately, this methodology has been used for several transformation, but always with stoichiometric amounts of the aryl iodide precursor. ${ }^{[165 a-c, 165 e-f]}$ In this context, our efforts focused on the coupling of the electrochemical generated hypervalent iodine from catalytic amounts of iodobenzene with ruthenium-catalyzed $\mathrm{C}-\mathrm{H}$ oxygenation.

\subsubsection{Optimization}

The project started with the optimization of reaction conditions for the electrochemical formation of hypervalent iodine 195 (Table 3.3.1). The identified solvents for the formation of hypervalent iodine were acetic acid, trifluoroacetic acid, TFE, and HFIP. The reactions were initially performed with $4 \AA$ molecular sieves and under nitrogen. The yields were obtained by ${ }^{1} \mathrm{H}-\mathrm{NMR}$ analysis of the reaction with the addition of an internal standard. The classical 1,3,5-trimethoxybenene could not be employed since it would react with the hypervalent iodine. Dibromomethane was thus used instead.

First, TFE was employed as solvent, obtaining $42 \%$ of the desired product after 2 hours, and $75 \%$ after 4 hours (entries 1-2). The use of tetrabutylammonium hexafluorophosphate as the electrolyte yielded $60 \%$ over 4 hours (entry 3), while there was no reaction in the absence of an electrolyte (entry 4). Interestingly, when HFIP was used as the solvent, the reaction was yielding trace amounts of the desired product in presence of lithium perchlorate as electrolyte, while a promising $65 \%$ yield was obtained with tetrabutylammonium hexafluorophosphate (entries 5-6). Trifluoroacetic acid was also a solvent of interest, therefore the electrochemical formation of (bis(trifluoroacetoxy)iodo)benzene 195aa was investigated in TFA. Under the same previous conditions , 69\% yield was obtained with $\mathrm{LiClO}_{4}$, and $68 \%$ using $n \mathrm{Bu}_{4} \mathrm{NPF}_{6}$ as the electrolytes 
(entries 7-8). The removal of the molecular sieves proved beneficial, as well as performing the reaction under air, which gave $88 \%$ yield (entries 9-10). Different currents were then attempted. The reaction worked with $7.0 \mathrm{~mA}$ for 5 hours, but the yield decreased to $42 \%$ (entry 11). When the current was lowered to $4.0 \mathrm{~mA}$ for 16 hours, it resulted in an $88 \%$ yield (entry 12). Lastly, control reactions were performed and confirmed the necessity of both the electrolyte and the current (entries 13-14). The idea of substituting the electrolyte with sodium trifluoroacetate did not prove successful (entry 15).

As shown in Figure 3.3.1, the formation of the hypervalent iodine species was easily followed by ${ }^{1} \mathrm{H}-$ NMR spectroscopy, since the aromatic resonances of the product are clearly shifted towards low fields. ${ }^{[165 e]}$

Table 3.3.1 Optimization for the electrochemical formation of hypervalent iodine. ${ }^{[a]}$

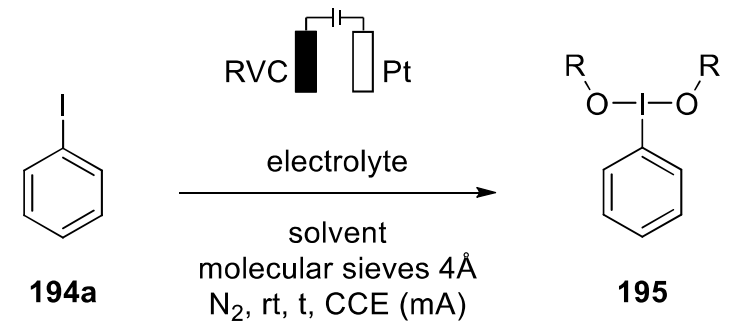

\begin{tabular}{ccccccc}
\hline Entry & Solvent & Electrolyte & $\mathbf{m A}$ & $\mathbf{t}$ & notes & Yield $^{[\mathbf{b}]}$ \\
\hline 1 & TFE & $\mathrm{LiClO}_{4}$ & 10 & $2 \mathrm{~h}$ & $42 \%$ \\
2 & TFE & $\mathrm{LiClO}_{4}$ & 10 & $4 \mathrm{~h}$ & $75 \%$ \\
3 & TFE & $n \mathrm{Bu}_{4} \mathrm{NPF}_{6}$ & 10 & $4 \mathrm{~h}$ & $60 \%$ \\
4 & TFE & - & 10 & $4 \mathrm{~h}$ & - \\
5 & HFIP & $\mathrm{LiClO}_{4}$ & 10 & $4 \mathrm{~h}$ & traces \\
6 & HFIP & $n \mathrm{Bu}_{4} \mathrm{NPF}_{6}$ & 10 & $4 \mathrm{~h}$ & $65 \%$ \\
7 & TFA & $\mathrm{LiClO}_{4}$ & 10 & $4 \mathrm{~h}$ & & $69 \%$ \\
8 & TFA & $n \mathrm{Bu}_{4} \mathrm{NPF}_{6}$ & 10 & $5 \mathrm{~h}$ & & $68 \%$ \\
$9^{[\mathrm{c}]}$ & TFA & $n \mathrm{Bu}_{4} \mathrm{NPF}_{6}$ & 10 & $5 \mathrm{~h}$ & Without mol. sieves & $75 \%{ }^{[\mathrm{c}]}$ \\
$10^{[\mathrm{c}]}$ & TFA & $n \mathrm{Bu}_{4} \mathrm{NPF}_{6}$ & 10 & $5 \mathrm{~h}$ & Without mol. sieves, under air & $88 \%{ }^{[\mathrm{c}]}$ \\
$11^{[\mathrm{c}]}$ & TFA & $n \mathrm{Bu}_{4} \mathrm{NPF}_{6}$ & 7 & $5 \mathrm{~h}$ & & $42 \%{ }^{[\mathrm{c}]}$ \\
$12^{[\mathrm{c}]}$ & TFA & $n \mathrm{Bu}_{4} \mathrm{NPF}_{6}$ & 4 & $16 \mathrm{~h}$ & & $84 \%{ }^{[\mathrm{c}]}$ \\
$13^{[\mathrm{cc}]}$ & TFA & - & 10 & $5 \mathrm{~h}$ & - & $-[\mathrm{c}]$
\end{tabular}




\begin{tabular}{|c|c|c|c|c|c|c|}
\hline $14^{[\mathrm{c}]}$ & TFA & $n \mathrm{Bu}_{4} \mathrm{NPF}_{6}$ & 10 & $5 \mathrm{~h}$ & Without current & - [c] \\
\hline $15^{[\mathrm{c}]}$ & TFA & $\begin{array}{c}\text { NaOTFA (2.0 } \\
\text { equiv) }\end{array}$ & 10 & $5 \mathrm{~h}$ & & $-[c]$ \\
\hline
\end{tabular}

${ }^{\text {[a] }}$ Reaction conditions: Undivided cell, 194a ( $\left.0.50 \mathrm{mmol}\right)$, electrolyte (1.00 equiv), solvent (5.0 mL), $23{ }^{\circ} \mathrm{C}, \mathrm{CCE}, \mathrm{N}_{2}$, molecular sieves $4 \AA$, RVC anode $(10 \mathrm{~mm} \times 15 \mathrm{~mm} \times 6 \mathrm{~mm})$, Pt-plate cathode $(10$ $\mathrm{mm} \times 15 \mathrm{~mm} \times 0.125 \mathrm{~mm}) .{ }^{[\mathrm{b}]}{ }^{1} \mathrm{H}-\mathrm{NMR}$ yield with dibromomethane as internal standard. ${ }^{[\mathrm{c}]}$ Without molecular sieves.

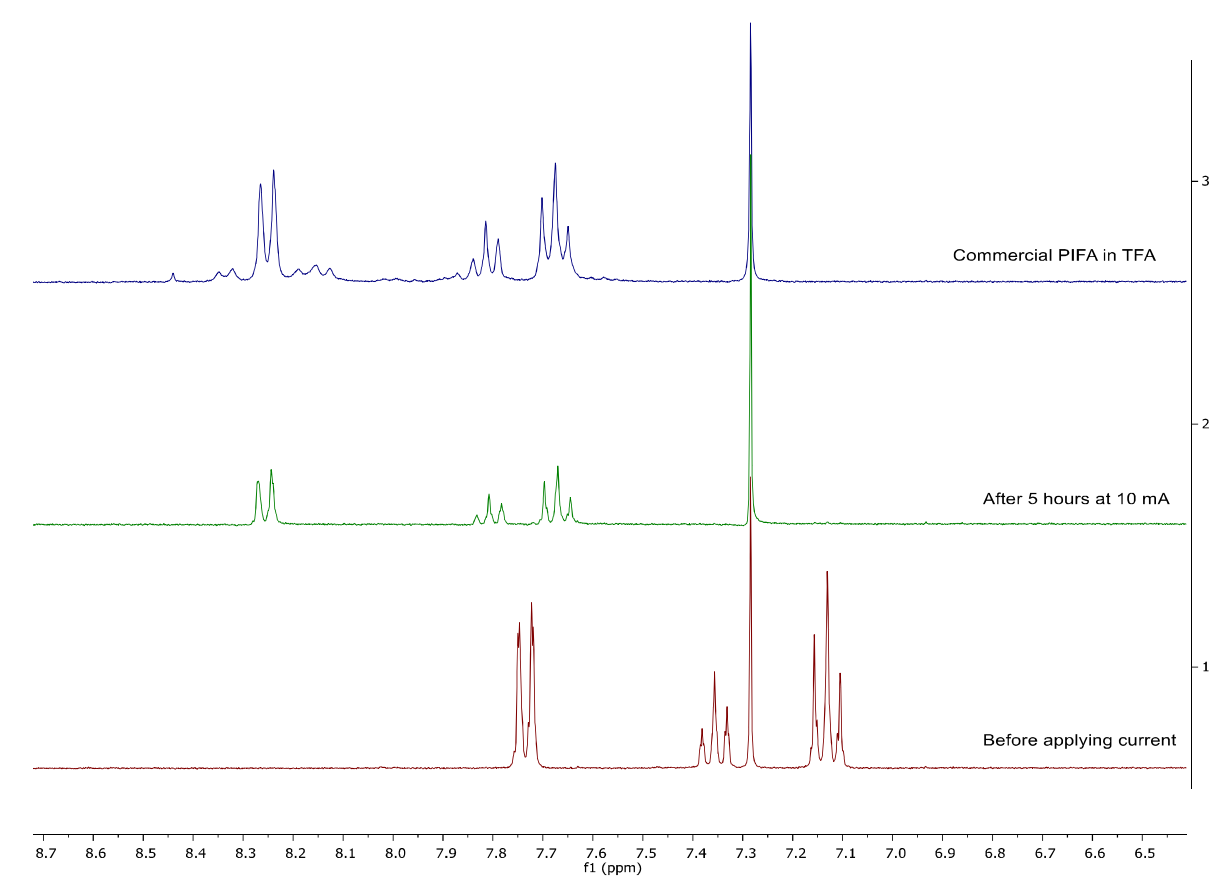

Figure 3.3.1 Analysis of $i n-s i t u$ generation of PIFA 195aa with TFA, ${ }^{1} \mathrm{H}-\mathrm{NMR}(300 \mathrm{MHz})$.

The aim of the project was to ideally couple the study on electrochemical-generated hypervalent iodine with mediated electrolysis for transition metal catalysis. Therefore, based on literature precedents from the Ackermann group,$^{[110-113,115]}$ we identified Weinreb amides, carbamates, and aldehydes as suitable substrates for the desired reaction. In these reports, the solvents used were a mixture of trifluoroacetic acid and trifluoroacetic anhydride, or 1,2-dichloroethane. The first media was considered to be more easily applicable, since the hypervalent iodine species is formed in TFA. In the case of DCE, another solvent would need to be added. Hence, the ruthenium oxygenation of weakly-coordinating Weinreb amides 196 was studied in electrochemical conditions, with the in-situ 
generation of hypervalent iodine as oxidant from catalytic amounts of iodobenzene 194a and TFA as solvent.

The initial tests were performed with a two steps procedure, where first the hypervalent iodine 195aa formed in TFA, and then, after the addition of substrate 196a, catalyst, and TFAA, the $\mathrm{C}-\mathrm{H}$ activation reaction occurred to yield the desired product 106a (Table 3.3.2). When the reaction was performed under air no product could be observed, even when the iodobenzene 194a was used in excess (entry 1). The second reaction was conducted under an inert atmosphere, but no improvement was noticed (entry 2).

Table 3.3.2 Attempts for the two-step procedure for ruthenium oxygenation with $\mathrm{LiClO}_{4}$ as electrolyte. ${ }^{[\mathrm{a}]}$

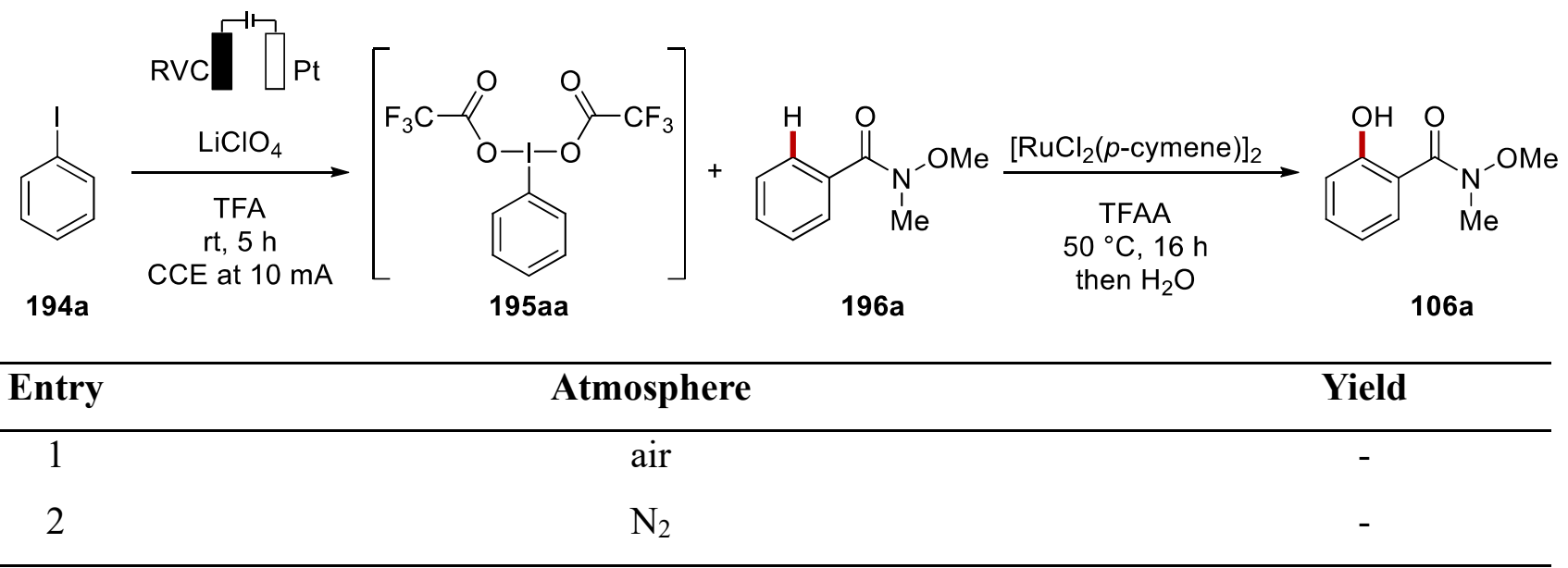

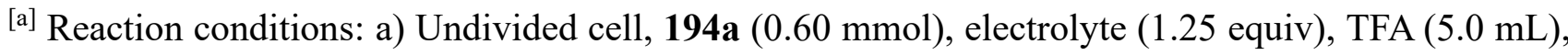
$23{ }^{\circ} \mathrm{C}, 5 \mathrm{~h} \mathrm{CCE}$ at $10 \mathrm{~mA}, \mathrm{RVC}$ anode $(10 \mathrm{~mm} \times 15 \mathrm{~mm} \times 6 \mathrm{~mm})$, Pt-plate cathode $(10 \mathrm{~mm} \times 15 \mathrm{~mm}$ $\times 0.125 \mathrm{~mm})$; b) $196 \mathrm{a}(0.25 \mathrm{mmol}),\left[\mathrm{RuCl}_{2}(p \text {-cymene })\right]_{2}(2.5 \mathrm{~mol} \%)$, TFAA $(1.0 \mathrm{~mL}), 50{ }^{\circ} \mathrm{C}, 16 \mathrm{~h}$.

Next, the reaction was carefully analyzed. The only differences between the above shown reaction (Table 3.3.2) and the literature precedent ${ }^{[112]}$ lied in the use of PIFA instead of PIDA and in the presence of the electrolyte. Consequently, the reaction with the commercial chemical oxidant was analyzed (Table 3.3.3). First, the oxygenation with PIDA was repeated, yielding $80 \%$ of the desired product 106a (entry 1). Then, a test reaction with PIFA instead of PIDA, gave a comparable yield (entry 2). Subsequently, the reaction with the chemical oxidant and without current was tried in the 
presence of the lithium perchlorate, to evaluate its effect (entry 3). Interestingly, the reactivity was completely suppressed in the presence of this electrolyte. The same reaction was also tried with tetrabutylammonium hexafluorophosphate, and - to our great delight - succeeded with $84 \%$ of the isolated desired product 106a (entry 4).

Table 3.3.3 Effect of the electrolyte on oxygenation reaction with chemical oxidant. ${ }^{\text {a] }}$

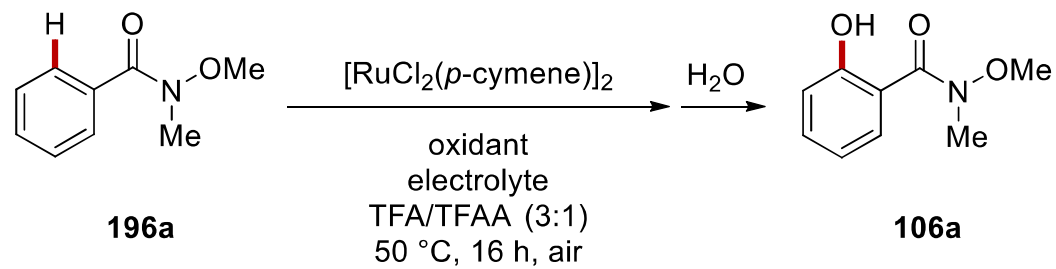

\begin{tabular}{cccc}
\hline Entry & Oxidant & Electrolyte & Yield \\
\hline 1 & PIDA & - & $80 \%[\mathrm{~b}]$ \\
2 & PIFA & - & $75 \%[\mathrm{~b}]$ \\
3 & PIFA & $\mathrm{LiClO}_{4}$ & - \\
4 & PIFA & $n \mathrm{Bu}_{4} \mathrm{NPF}_{6}$ & $84 \%$ \\
\hline
\end{tabular}

${ }^{[a]}$ Reaction conditions: Undivided cell, 196a $(0.25 \mathrm{mmol}),\left[\mathrm{RuCl}_{2}(p \text {-cymene })\right]_{2}(2.5 \mathrm{~mol} \%)$, oxidant (1.00 equiv), electrolyte (1.25 equiv), TFA/TFAA $(3: 1,4.0 \mathrm{~mL}), 50{ }^{\circ} \mathrm{C}, 16 \mathrm{~h}$, air. ${ }^{\mathrm{b}]}{ }^{1} \mathrm{H}-\mathrm{NMR}$ yield with dibromomethane as internal standard.

With these insights in hand, the two-step procedure was attempted with tetrabutylammonium hexafluorophosphate as the electrolyte (Table 3.3.4). This change proved to be successful, and the oxygenated product 106a was obtained in 75\% yield under nitrogen atmosphere and in $80 \%$ under air (entries 1-2). In the same reaction conditions, the concentration of the Weinreb amide 196a and the catalyst were increased, with a benefit for the yield of product 106a (entry 3).

Table 3.3.4 Two-step procedure for ruthenium oxygenation with $n \mathrm{Bu}_{4} \mathrm{NPF}_{6}{ }^{[\mathrm{a}]}$ 


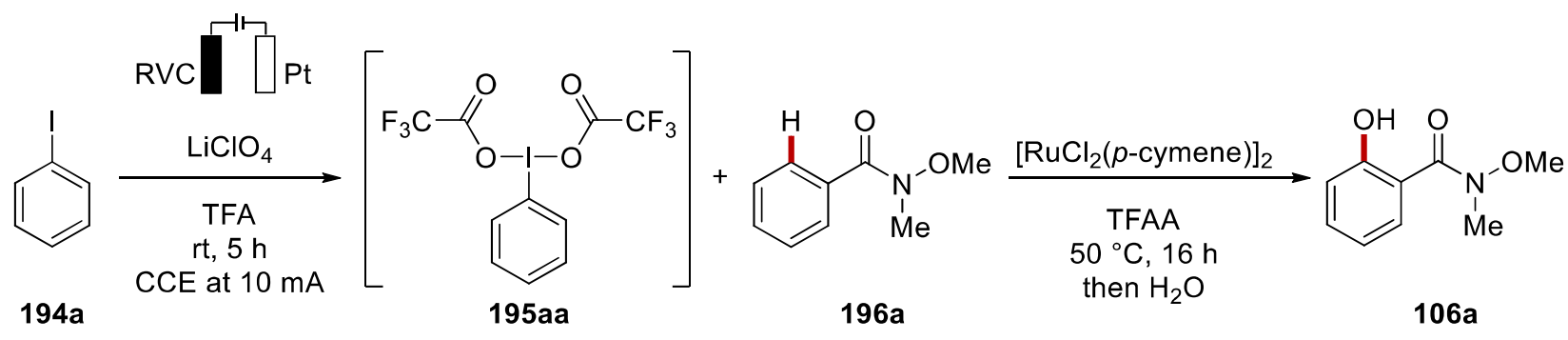

\begin{tabular}{cccc}
\hline Entry & Atmosphere & note & Yield \\
\hline 1 & $\mathrm{~N}_{2}$ & - & $75 \%$ \\
2 & air & - & $80 \%$ \\
3 & air & $0.50 \mathrm{mmol}$ of 196a & $84 \%$ \\
\hline
\end{tabular}

${ }^{[a]}$ Reaction conditions: a) Undivided cell, 194a (0.60 mmol), electrolyte (1.25 equiv), TFA (5.0 mL), $23{ }^{\circ} \mathrm{C}, 5 \mathrm{~h}, \mathrm{CCE}$ at $10 \mathrm{~mA}, \mathrm{RVC}$ anode $(10 \mathrm{~mm} \times 15 \mathrm{~mm} \times 6 \mathrm{~mm})$, Pt-plate cathode $(10 \mathrm{~mm} \times 15$ $\mathrm{mm} \times 0.125 \mathrm{~mm})$; b) 196a $(0.25 \mathrm{mmol}),\left[\mathrm{RuCl}_{2}(p \text {-cymene })\right]_{2}(2.5 \mathrm{~mol} \%)$, TFAA $(1.0 \mathrm{~mL}), 50{ }^{\circ} \mathrm{C}$, $16 \mathrm{~h}$.

The desired reaction would form the hypervalent iodine in-situ and possibly with catalytic amounts of iodobenzene 194a. The experiments above showed that all the components of the first step are tolerated in the ruthenium-catalyzed oxygenation, so the attempt on performing the reaction in onestep was tried (Table 3.3.5). Unfortunately, both the iodobenzene 194a in stoichiometric amounts (1.2 equiv) or in catalytic (20 mol \%), provided only traces amount of the desired product 106a (entry 1-2).

Table 3.3.5 Attempts for the in-situ ruthenium catalyzed oxygenation. ${ }^{[a]}$
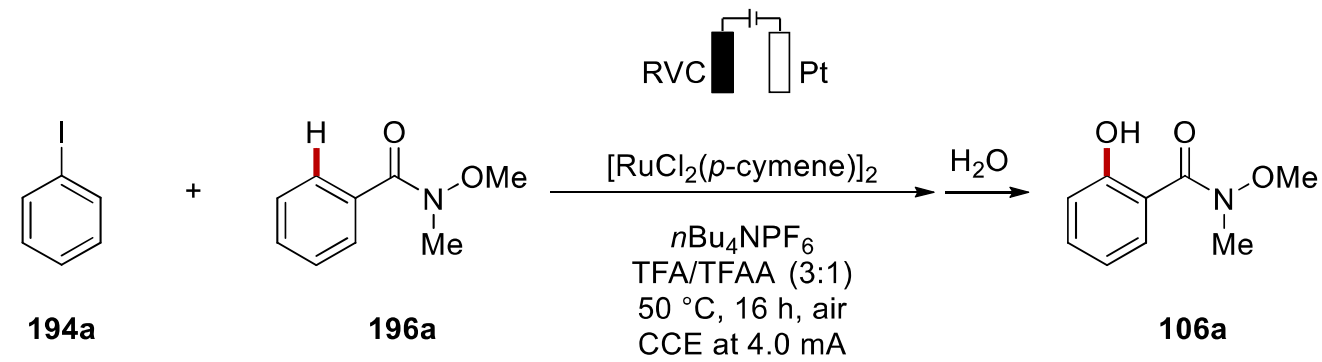

\begin{tabular}{ccc}
\hline Entry & 194a & Yield \\
\hline 1 & $120 \mathrm{~mol} \mathrm{\%}$ & traces
\end{tabular}


${ }^{[a]}$ Reaction conditions: Undivided cell, 194a (as specified), 196a (0.5 mmol), $\left[\mathrm{RuCl}_{2}(p \text {-cymene) }]_{2}\right.$ (2.5 mol \%), $n \mathrm{Bu}_{4} \mathrm{NPF}_{6}\left(1.25\right.$ equiv), TFA/TFAA $(3: 1,4.0 \mathrm{~mL}), 50{ }^{\circ} \mathrm{C}, 16 \mathrm{~h}$, air, CCE at $4.0 \mathrm{~mA}$, RVC anode $(10 \mathrm{~mm} \times 15 \mathrm{~mm} \times 6 \mathrm{~mm})$, Pt-plate cathode $(10 \mathrm{~mm} \times 15 \mathrm{~mm} \times 0.125 \mathrm{~mm})$.

Since the two-step reaction worked, while the one-step reaction was thus far unsuccessful, the attention was focused on the differences between the conditions for the electrochemical formation of PIFA (as in Scheme 3.3.1) and the one for the one-step reaction (as in Scheme 3.3.5). Two differences were the temperature of the reaction and the nature of the solvent mixture. These different conditions were then separately tested for the electrochemical synthesis of PIFA 195aa (Table 3.3.6). The reaction worked well both at $50{ }^{\circ} \mathrm{C}$ as well as with a TFA/TFAA mixture (3:1) as the solvent media (entries 1-2), proving that the differences in the conditions were not prohibitive to the product formation. Another hypothesis could be related to the oxidation potentials of the components of the reactions. As shown by cyclic voltammetry (Figure 3.3.2, performed by Dr. T. H. Meyer), ruthenium 188a was indeed having a lower oxidation potential as compared to iodobenzene 194a. Thus, the reason for the one-pot procedure failure might lie in the preferential oxidation of the metal complex rather than the iodobenzene. In the previous project on electrochemical rutheniumcatalyzed $\mathrm{C}-\mathrm{H} / \mathrm{C}-\mathrm{O}$ annulation, ${ }^{[130]}$ it was found that the ruthenium catalysis worked with a $\mathrm{RVC}$ anode, but not with a platinum-plate anode. It was deductible that the direct oxidation of this metal on such an electrode is not optimal. Therefore, the formation of the hypervalent iodine 195aa was tried with a platinum-platinum electrodes setup, giving $80 \%$ NMR conversion (entry 3 ).

Table 3.3.6 Further optimization for the electrochemical formation of hypervalent iodine. ${ }^{[a]}$

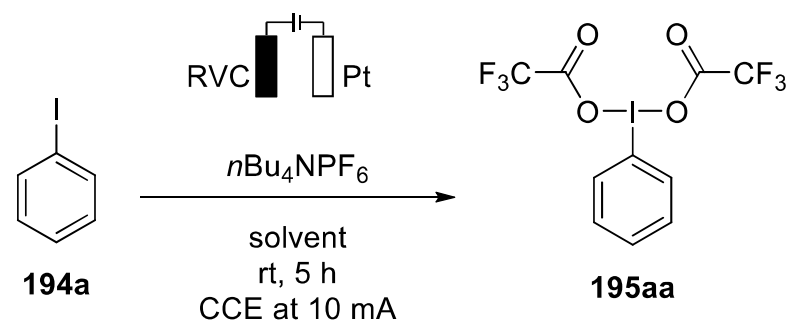

\begin{tabular}{llll}
\hline Entry & Solvent & Note & Yield $^{[\mathrm{a}]}$ \\
\hline
\end{tabular}


TFA

$50{ }^{\circ} \mathrm{C}$

$95 \%$

2

TFA/TFAA $(3: 1)$

TFA

Pt-Pt electrodes

$80 \%$

${ }^{[\mathrm{a}]}$ Reaction conditions: Undivided cell, 194a $(0.50 \mathrm{mmol})$, electrolyte $(1.25$ equiv), solvent $(3.0 \mathrm{~mL})$, $23{ }^{\circ} \mathrm{C}, 5 \mathrm{~h}$, air, CCE at $10 \mathrm{~mA}$, RVC anode $(10 \mathrm{~mm} \times 15 \mathrm{~mm} \times 6 \mathrm{~mm})$, Pt-plate cathode $(10 \mathrm{~mm} \times 15$ $\mathrm{mm} \times 0.125 \mathrm{~mm}) .{ }^{[\mathrm{b}]}{ }^{1} \mathrm{H}-\mathrm{NMR}$ yield with $\mathrm{CH}_{2} \mathrm{Cl}_{2}$ as the internal standard.

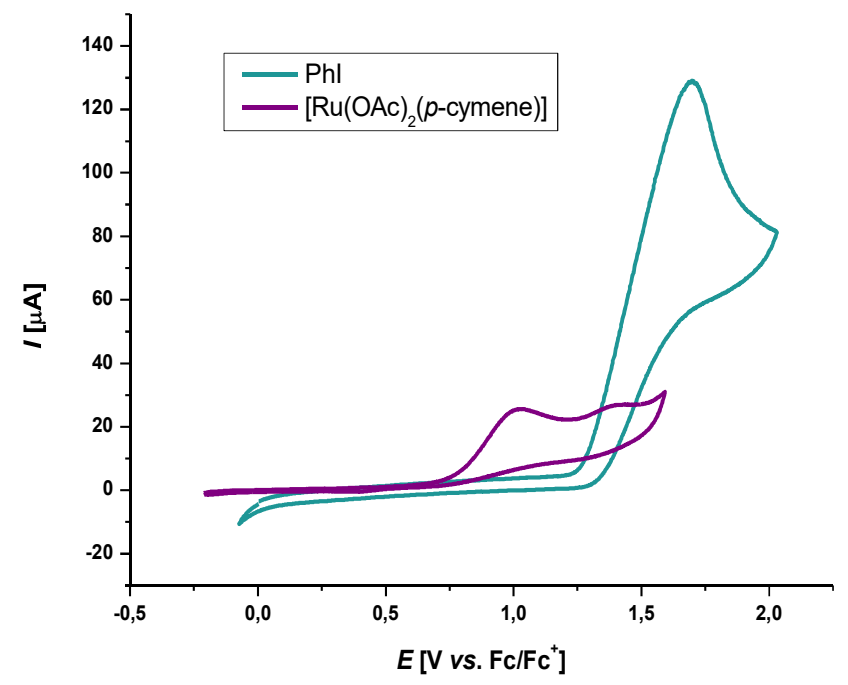

Figure 3.3.2 Selected data from the cyclic voltammograms performed by Dr. T. H. Meyer at a scan rate of $100 \mathrm{mVs}^{-1}$ with TFA and $n \mathrm{Bu}_{4} \mathrm{NPF}_{6}(0.1 \mathrm{M})$ as the electrolyte and a GC working electrode; the concentration of all substrates was $5.0 \mathrm{mM}$. (green) iodobenzene 194a, (purple) $\left[\mathrm{Ru}(\mathrm{OAc})_{2}(p-\right.$ cymene)] 188a.

After detailed optimization, the reaction conditions were found to be with $20 \mathrm{~mol} \%$ of iodobenzene 194a, $2.5 \mathrm{~mol} \%$ of $\left[\mathrm{RuCl}_{2}(p \text {-cymene })\right]_{2}$, tetrabutylammonium hexafluorophosphate as electrolyte, TFA/TFAA (3:1) as solvent mixure, $50{ }^{\circ} \mathrm{C}$, with platinum electrodes. The desired product 106a could thus be obtained in a one-step procedure in $70 \%$ isolated yield (Scheme 3.3.1). 


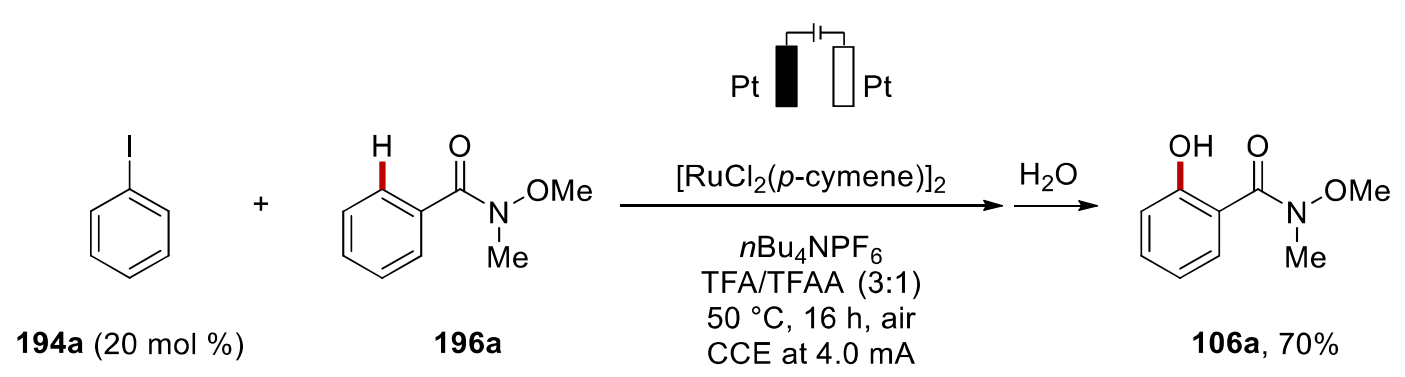

Scheme 3.3.1 Successful electrochemical ruthenium oxygenation mediated by in-situ formed PIFA from catalytic iodobenzene.

After this successful breakthrough, the further optimization of the reaction was started. Firstly, different ruthenium catalysts were tried for the envisioned $\mathrm{C}-\mathrm{H}$ oxygenation (Table 3.3.7). $\left[\mathrm{Ru}(\mathrm{OAc})_{2}(p\right.$-cymene $\left.)\right]$ and $\left[\mathrm{Ru}\left(\mathrm{O}_{2} \mathrm{CMes}\right)_{2}(p\right.$-cymene $\left.)\right]$ were suitable catalysts, with the former being the best with $80 \%$ yield (entries 2-3). Other ruthenium sources did not prove to be viable for the desired transformation (entries 4-5). Thus, $\left[\mathrm{Ru}(\mathrm{OAc})_{2}(p\right.$-cymene) $]$ (188a) in 5.0 mol \% loading was selected as the best catalyst and further optimization studies were performed with complex 188a.

Table 3.3.7 Optimization of the ruthenium catalyst for $\mathrm{C}-\mathrm{H}$ oxygenation. ${ }^{[\mathrm{a}]}$

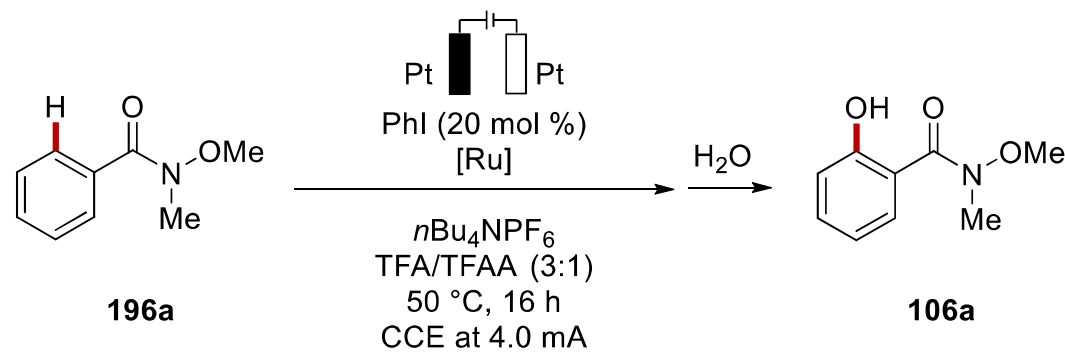

\begin{tabular}{|c|c|c|}
\hline Entry & {$[\mathbf{R u}]$} & Yield \\
\hline 1 & {$\left[\mathrm{RuCl}_{2}(p \text {-cymene })\right]_{2}(2.5 \mathrm{~mol} \%)$} & $77 \% \%^{[b]}$ \\
\hline 2 & {$\left[\mathrm{Ru}(\mathrm{OAc})_{2}(p\right.$-cymene $\left.)\right](5.0 \mathrm{~mol} \%)$} & $80 \%$ \\
\hline 3 & {$\left[\mathrm{Ru}\left(\mathrm{O}_{2} \mathrm{CMes}\right)_{2}(p\right.$-cymene $\left.)\right](5.0 \mathrm{~mol} \%)$} & $59 \%$ \\
\hline 4 & {$\left[\mathrm{Ru}(\mathrm{NC} t \mathrm{Bu})_{6}\right]\left[\mathrm{PF}_{6}\right]_{2}(5.0 \mathrm{~mol} \%)$} & - \\
\hline 5 & $\mathrm{RuCl}_{3}(5.0 \mathrm{~mol} \%)$ & - \\
\hline
\end{tabular}


${ }^{[a]}$ Reaction conditions: Undivided cell, 196a (0.25 mmol), PhI 194a (20 mol \%), [Ru] (as specified), $n \mathrm{Bu}_{4} \mathrm{NPF}_{6}\left(1.00\right.$ equiv), TFA/TFAA $(3: 1,3.0 \mathrm{~mL}), 50{ }^{\circ} \mathrm{C}, 16 \mathrm{~h}$, air, CCE at $4.0 \mathrm{~mA}$, Pt-plate electrodes $(10 \mathrm{~mm} \times 15 \mathrm{~mm} \times 0.125 \mathrm{~mm})$.

Furthermore, the optimization was extended to gain a better understanding of the reaction (Table 3.3.8). Initially, control reactions in the absence of current, or in the absence of the ruthenium catalyst $188 \mathrm{a}$ or iodobenzene 194a, were independently checked and all the three components proved to be essential (entries 1-4). The reaction performed under an inert atmosphere of nitrogen gave a comparable result, showing that air had no influence on the reactivity (entry 5). The reaction temperature was lowered to room temperature, which gave $50 \%$ yield of the product 106a (entry 6). Diminishing the electrolyte loading to 0.5 equivalents resulted in $52 \%$ of the desired product (entry 7). In the complete absence of the tetrabutylammonium salt the yield was $55 \%$ (entry 8 ). The reaction was thus clearly benefiting from a temperature of $50{ }^{\circ} \mathrm{C}$ and from the presence of the electrolyte. Moreover, 4-iodoanisole 194b was used instead of iodobenzene to see if a lower oxidation potential of the mediator could be beneficial for the reaction but it proved to be less efficient (entry 9). Several redox mediators were added as additives instead of iodobenzene, but all of them did not furnish any desired product (entries 10-14). Chemical oxidants were employed instead of electricity to compare their efficacy, and both meta-chloroperoxybenzoic acid and oxone gave a poor conversion (entries 15-16). Afterwards, the focus was shifted towards the electrochemical features of the reaction. CCE was attempted at 6.0 and $2.0 \mathrm{~mA}$, giving only $51 \%$ and $37 \%$ of $\mathbf{1 0 6 a}$, respectively (entries 17-18). Likewise, CPE was investigated at 2.0, 1.5, and $1.0 \mathrm{~V}$ vs. $\mathrm{Ag} / \mathrm{Ag}^{+}$, yielding $86 \%$ and $60 \%$, respectively, for the first two reactions, while no reaction occurred with the lowest voltage applied (entries 19-21). This meant that $1.0 \mathrm{~V} v s . \mathrm{Ag} / \mathrm{Ag}^{+}$was probably too low for the efficient oxidation of iodobenzene 194a. Even though the reaction worked very well also at $2.0 \mathrm{~V}$ vs. $\mathrm{Ag} / \mathrm{Ag}^{+}$, the scope of the reaction was performed under CCE conditions as a comparable result was obtained and the set-up is more user-friendly. Lastly, the electrodes were tested. RVC anode was again tried in the new optimized conditions and only $24 \%$ of the desired product was obtained (entry 22). A reaction with RVC anode and without iodobenzene was tried to understand if in absence of the 
mediator the catalyst could efficiently be reoxidize directly on the carbon-based electrode, but it resulted in only $28 \%$ isolated yield (entry 23 ). The platinum electrodes were then substituted with stainless steel and nickel-plate, but in both cases the reaction failed (entry 24-25).

Table 3.3.8 General optimization for the ruthenium catalyzed $\mathrm{C}-\mathrm{H}$ oxygenation. ${ }^{[a]}$

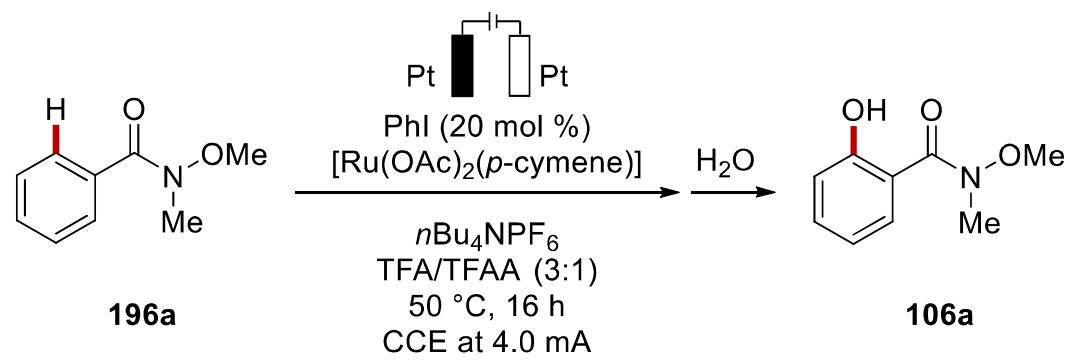

\begin{tabular}{|c|c|c|}
\hline Entry & Deviation from standard conditions & Yield \\
\hline 1 & ( & $80 \%$ \\
\hline 2 & No current & - \\
\hline 3 & Without $[\mathrm{Ru}]$ & - \\
\hline 4 & Without PhI & - \\
\hline 5 & Under $\mathrm{N}_{2}$ & $70 \%$ \\
\hline 6 & $25^{\circ} \mathrm{C}$ instead of $50{ }^{\circ} \mathrm{C}$ & $50 \%$ \\
\hline 7 & Electrolyte ( 0.50 equiv) & $52 \%$ \\
\hline 8 & Without electrolyte & $55 \%$ \\
\hline 9 & 4- $\mathrm{MeOC}_{6} \mathrm{H}_{4} \mathrm{I}$ instead of $\mathrm{PhI}$ & $55 \%$ \\
\hline 10 & $\mathrm{PhBr}$ instead of $\mathrm{PhI}$ & - \\
\hline 11 & $\mathrm{PhCl}$ instead of $\mathrm{PhI}$ & - \\
\hline 12 & 1,4-BQ instead of $\mathrm{PhI}$ & - \\
\hline 13 & $\mathrm{PhS}-\mathrm{SPh}$ instead of $\mathrm{PhI}$ & - \\
\hline 14 & $\mathrm{PhSe}-\mathrm{SePh}$ instead of $\mathrm{PhI}$ & - \\
\hline 15 & $m \mathrm{CPBA}$ (1.0 equiv) instead of electricity & $15 \%$ \\
\hline 16 & Oxone (1.0 equiv) instead of electricity & $32 \%$ \\
\hline 17 & $6.0 \mathrm{~mA}$ & $51 \%$ \\
\hline 18 & $2.0 \mathrm{~mA}$ & $37 \%$ \\
\hline 19 & $\mathrm{CPE}$ at $2.0 \mathrm{~V} v s . \mathrm{Ag} / \mathrm{Ag}^{+}$ & $86 \%$ \\
\hline 20 & $\mathrm{CPE}$ at $1.5 \mathrm{~V} v s . \mathrm{Ag} / \mathrm{Ag}^{+}$ & $60 \%$ \\
\hline 21 & $\mathrm{CPE}$ at $1.0 \mathrm{~V} v s . \mathrm{Ag} / \mathrm{Ag}^{+}$ & - \\
\hline
\end{tabular}


24 Stainless Steel electrodes instead of $\mathrm{Pt}$

${ }^{[a]}$ Reaction conditions: Undivided cell, 196a (0.25 mmol), PhI 194a (20 mol \%), $\left[\mathrm{Ru}(\mathrm{OAc})_{2}(p-\right.$ cymene)] $188 \mathrm{a}(5.0 \mathrm{~mol} \%), n \mathrm{Bu}_{4} \mathrm{NPF}_{6}\left(1.00\right.$ equiv), TFA/TFAA $(3: 1,3.0 \mathrm{~mL}), 50{ }^{\circ} \mathrm{C}, 16 \mathrm{~h}$, air, $\mathrm{CCE}$ at $4.0 \mathrm{~mA}$, Pt-plate electrodes $(10 \mathrm{~mm} \times 15 \mathrm{~mm} \times 0.125 \mathrm{~mm})$. Yields of the isolated products.

\subsubsection{Robustness}

Having the optimized reaction conditions in hand, the scope was investigated with a variety of weakly-coordinating Weinreb amides 196 in collaboration with Dr. X. Tan (Scheme 3.3.2). The reaction proved to be very robust on amides $\mathbf{1 9 6 b}-\mathbf{d}$ bearing both electron-rich and electron-deficient para-substituents, furnishing the desired products in good yields. 3,4-dimethyl and 3,4-dichloro arenes 196e-f were successfully employed giving 59\% and $62 \%$ yield, respectively. Electron-rich meta-substituents were well tolerated by the system, even though the minor regioisomer was detected in $2 \%$ yield for product $\mathbf{1 0 6 \mathbf { j }}$. In the case of the isopropyl substituent in meta (106k), we could not detect any minor regioisomer. The same held true for electron-deficient substituents (1061-n), which were functionalized only in the more accessible position. Moreover, products $\mathbf{1 0 6 0}$ and $\mathbf{1 0 6 p}$ could also be obtained with the envisioned mediated ruthenium catalysis, underlying the compatibility of this reaction with electrophilic functional groups that are useful for subsequent late-stage modifications. As proved during the optimization, the reaction was also feasible in the absence of the electrolyte (Table 3.3.8). Some compounds were tested in these conditions also in the scope, showing that the desired products could be obtained likewise without tetrabutylammonium hexafluorophosphate with decent yields, around 20\% lower than with the optimized reaction conditions. 


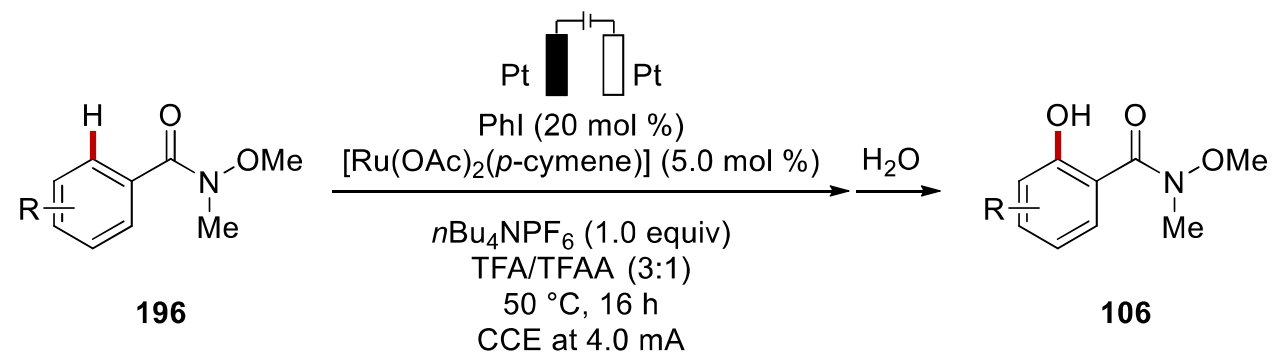

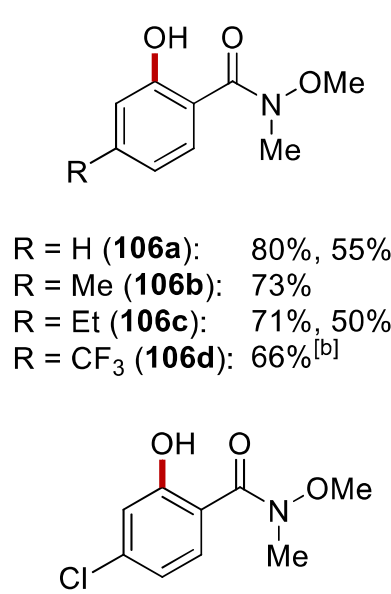

106h: $81 \%^{[\mathrm{b}]}$<smiles>CON(C)C(=O)c1cc(C(C)C)ccc1O</smiles>

106k: $74 \%{ }^{[\mathrm{b}]}$<smiles>CON(C)C(=O)c1cc(Br)ccc1O</smiles>

106n: $75 \%$<smiles>[R]c1cc(O)c(C(=O)N(C)OC)cc1[R]</smiles>

$\mathrm{R}=\mathrm{Me}(\mathbf{1 0 6 e}): \quad 59 \%$

$\mathrm{R}=\mathrm{Cl}(106 \mathrm{f}): \quad 62 \%, 46 \%{ }^{[a]}$<smiles>CON(C)C(=O)c1ccc(Br)cc1O</smiles>

106i: $82 \%, 58 \%$ [a]<smiles>CON(C)C(=O)c1cc(C(F)(F)F)ccc1O</smiles>

106I: $45 \%$<smiles>CON(C)C(=O)c1ccc(I)cc1O</smiles>

1060: $65 \%$<smiles>CON(C)C(=O)c1ccc(F)cc1O</smiles>

106g: $73 \%{ }^{[b]}$<smiles>CON(C)C(=O)c1cc(C)ccc1O</smiles>

106j: $59 \%(2 \%)^{[\mathrm{b}]}$<smiles>CON(C)C(=O)c1cc(Cl)ccc1O</smiles>

106m: $84 \%$<smiles>CON(C)C(=O)c1ccc(CCl)cc1O</smiles>

106p: $77 \%$

Scheme 3.3.2 Scope of electrochemical ruthenium-catalyzed $\mathrm{C}-\mathrm{H}$ oxygenation of Weinreb amides 196. ${ }^{[\mathrm{a}]}$ Without $n \mathrm{Bu}_{4} \mathrm{NPF}_{6}{ }^{[\mathrm{b}]}$ Performed by Dr. X. Tan.

The reaction was further tested on other tertiary amides $\mathbf{1 0 3}$ (Scheme 3.3.3). The presence of a methyl group in para to dimethyl amide or in meta to diethyl amide was well tolerated, yielding product 104b and 104c in $84 \%$ and 64\%, respectively. Further robustness studies were investigated 
by Dr. X. Tan, showing that different substituted amides 103 were similarly oxygenated. Especially, product 104f was obtained in 91\% yield in the optimized conditions and in an interesting $61 \%$ yield when the electrolyte was omitted.

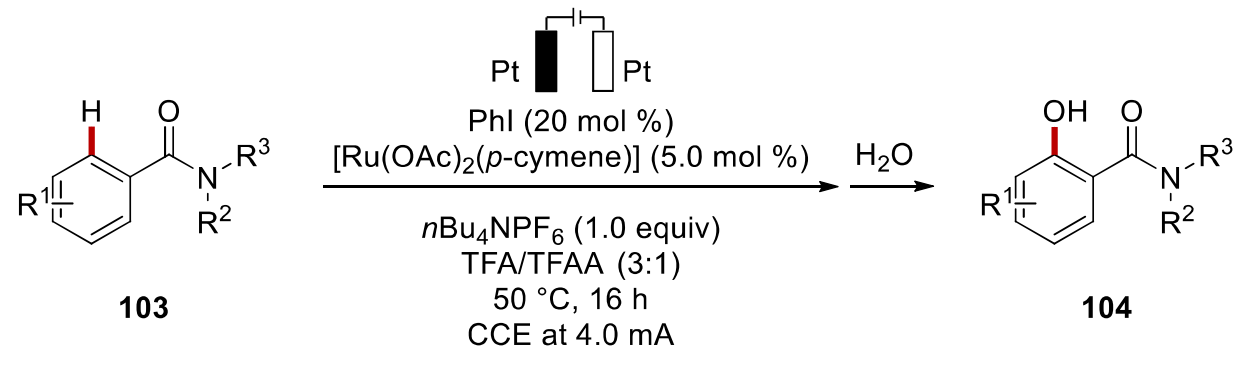<smiles>CN(C)C(=O)c1ccccc1O</smiles>

104a: $62 \%[\mathrm{a}]$<smiles>[R]c1ccc(C(=O)N(C)C)c(O)c1</smiles>

$\mathrm{R}=\mathrm{Me}(\mathbf{1 0 4 b}): \quad 84 \%$ $\mathrm{R}=\operatorname{Br}(\mathbf{1 0 4 c}): \quad 83 \%{ }^{[a]}$<smiles>O=C(c1ccccc1O)N1CCCC1</smiles>

104f: $91 \%{ }^{[a]} 61 \%{ }^{[a][b]}$<smiles>CCN(CC)C(=O)c1cc(C)ccc1O</smiles>

104d: $64 \%$<smiles>CC(C)N(C(=O)c1ccccc1O)C(C)C</smiles>

104e: $55 \%[$ [a]<smiles>O=C(c1ccccc1O)N1CCOCC1</smiles>

104g: $60 \%$ [a]

Scheme 3.3.3 Scope of electrochemical ruthenium-catalyzed $\mathrm{C}-\mathrm{H}$ oxygenation of various amides 103. ${ }^{[\mathrm{a}]}$ Performed by Dr. X. Tan. ${ }^{[\mathrm{b}]}$ Without $n \mathrm{Bu}_{4} \mathrm{NPF}_{6}$.

We further aimed to extend the applicability of the reaction to more weakly coordinating directing groups. Interestingly, we found that the electrochemical mediated ruthenium oxygenation was also suitable for ketones 77 (Scheme 3.3.4). Ketones were converted slightly more efficiently by $\left[\mathrm{RuCl}_{2}(p \text {-cymene })\right]_{2}$, which was thus used for this part of the scope. Differently decorated ketones 77 successfully underwent the reaction, such as tert-butyl phenyl ketone (77a) and acetophenone(77c). Electron-rich and -poor substrates were well tolerated (197e-h), as well as a methyl substituent in meta (197i). Moreover, the excellent selectivity of the envisioned reaction was demonstrated on the 
substrate $\mathbf{7 7 k}$, for which the mono-arylated product $\mathbf{1 9 7} \mathbf{k}$ could be selectively obtained after 8 hours, while the diarylated one $\mathbf{1 9 7 1}$ was selectively obtained after a 24-hour reaction. Similarly, for the unsymmetrical substrate, the electron-rich arene reacted preferentially, yielding the sole product $197 \mathrm{~m}$.

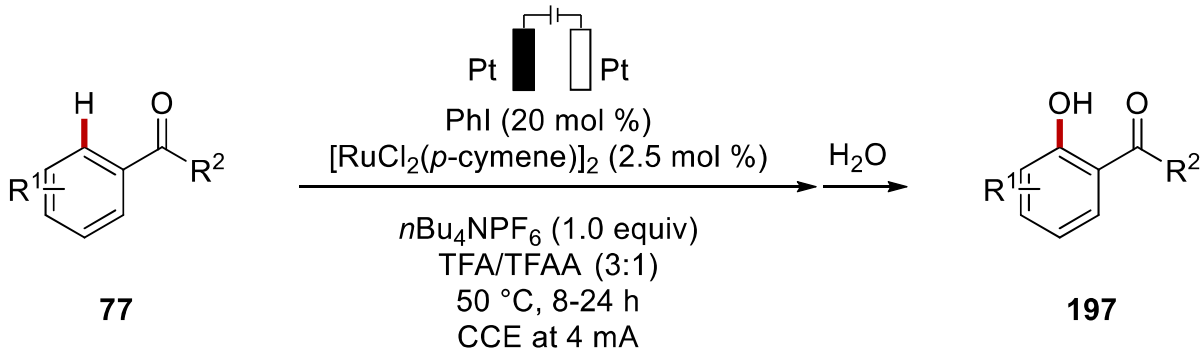<smiles>CC(C)(C)C(=O)c1ccccc1O</smiles>

197a: $85 \%[a]$<smiles>CC(C)C(=O)c1ccccc1O</smiles>

197d: $66 \%$<smiles>CC(C)(C)C(=O)c1ccc(Cl)cc1O</smiles>

197h: $61 \%$<smiles>CCC(=O)c1ccccc1O</smiles>

197b: $60 \%$<smiles>[R]c1ccc(C(=O)C(C)(C)C)c(O)c1</smiles>

$\mathrm{R}=\mathrm{Me}(\mathbf{1 9 7 e )}): 51 \%$ $R=t B u(197 f): \quad 68 \%{ }^{[a]}$<smiles>Cc1ccc(O)c(C(=O)C(C)(C)C)c1</smiles>

197i: $64 \%{ }^{[a][b]}$<smiles>CC(=O)c1ccccc1O</smiles>

197c: $66 \%$<smiles>CC(C)(C)C(=O)c1ccc(C(F)(F)F)cc1O</smiles>

197g: $65 \%{ }^{[a]}$<smiles>CC(C)(C)C(=O)c1ccc(F)cc1O</smiles>

197j: $65 \%$<smiles>[R]c1ccccc1C(=O)c1ccccc1O</smiles>

$8 \mathrm{~h}: \mathrm{R}=\mathrm{H}(197 \mathbf{k}): \quad 57 \%[\mathrm{a}]$ $24 \mathrm{~h}: \mathrm{R}=\mathrm{OH}(197 \mathrm{I}): 59 \%{ }^{[\mathrm{a}]}$<smiles>O=C(c1ccccc1O)c1ccccc1Cl</smiles>

$197 \mathrm{~m}: 78 \%^{[\mathrm{a}]}$ 
Scheme 3.3.4 Scope of electrochemical ruthenium-catalyzed C-H oxygenation of ketones 77. [a] Performed by Dr. X. Tan. ${ }^{[b]}$ CCE at $3.0 \mathrm{~mA}$.

The power of the iodine(III)/ruthenium(II)-catalyzed $\mathrm{C}-\mathrm{H}$ oxygenation was highlighted by the reactivity of more challenging substrates. After considerable experimentation, Dr. X. Tan could prove the viability of the designed reaction for pyrazole containing substrates 198 (Scheme 3.3.5).
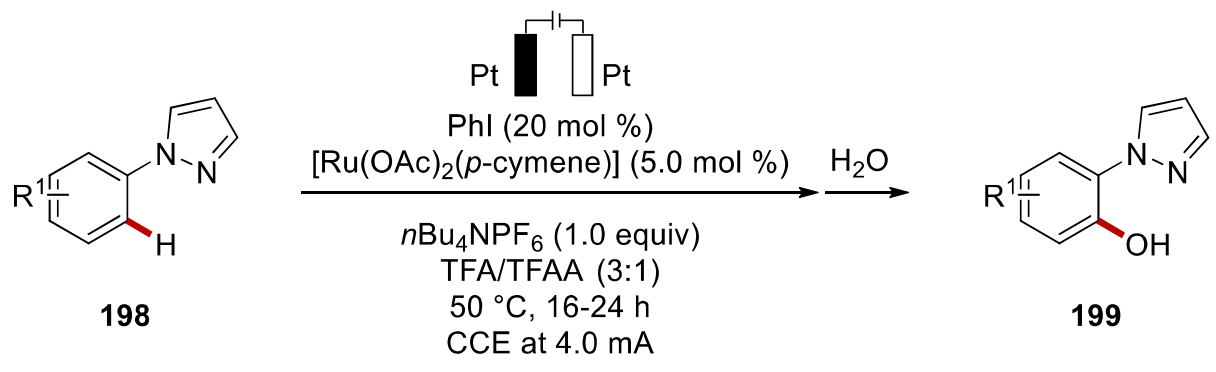<smiles>Cc1cccc(O)c1-n1cccn1</smiles>

199a: $53 \%$<smiles>CC(C)c1cccc(O)c1-n1cccn1</smiles>

199b: $47 \%$<smiles>Cc1ccc(O)c(-n2cccn2)c1C</smiles>

199c: $46 \%$

Scheme 3.3.5 Scope of electrochemical ruthenium-catalyzed $\mathrm{C}-\mathrm{H}$ oxygenation of pyrazole substrates 198. Performed by Dr. X. Tan.

The challenging remote functionalization of differently substituted anisoles $\mathbf{2 0 0}$ was achieved with few modifications to the methodology (Scheme 3.3.6). This showed that the power of the presented ruthena-electrocatalysis is not restricted to chelating directing groups but is also viable on directinggroup-free substrates. Due to the lower oxidation potential of anisole compared to iodobenzene, ${ }^{[170]}$ the procedure has to be changed to circumvent the unfruitful oxidation of the substrate $\mathbf{2 0 0}$ on the anode. A sequential two-step/one-pot procedure was devised, where the hypervalent iodine was firstly generated in stoichiometric amounts, and then the substrate $\mathbf{2 0 0}$ and the catalyst $\mathbf{1 8 8 a}$ were added into the reaction. The desired products $\mathbf{1 0 9}$ were obtained as a sole regioisomer with good 
yields. In the case of the anisole 200c, the reaction was tested also without the addition of the ruthenium catalyst, but no product was obtained.

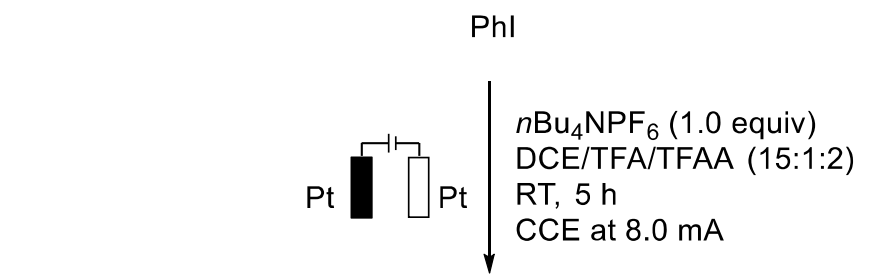

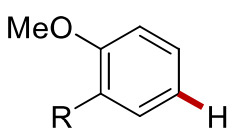

200

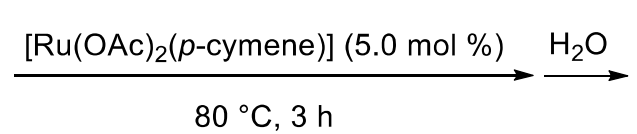

$80^{\circ} \mathrm{C}, 3 \mathrm{~h}$

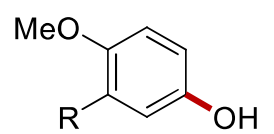

109<smiles>COc1ccc(O)cc1Br</smiles>

109a: $52 \%$<smiles>COc1ccc(O)cc1Cl</smiles>

109b: $40 \%$<smiles>COc1ccc(O)cc1</smiles>

109c: $53 \%[\mathrm{a}]$ without $[\mathrm{Ru}]: 0 \%$

Scheme 3.3.6 Remote C-H oxygenation directing-group free. ${ }^{\text {[a] }}$ Performed by Dr. X. Tan.

The robustness of the reaction was further proven by the gram-scale synthesis of the product 106a (Scheme 3.3.7). Starting from $8.50 \mathrm{mmol}(1.40 \mathrm{~g})$, we could achieve an excellent $84 \%$ isolated yield $(1.29 \mathrm{~g})$, that testifies the great efficiency of the reaction also on larger scale.
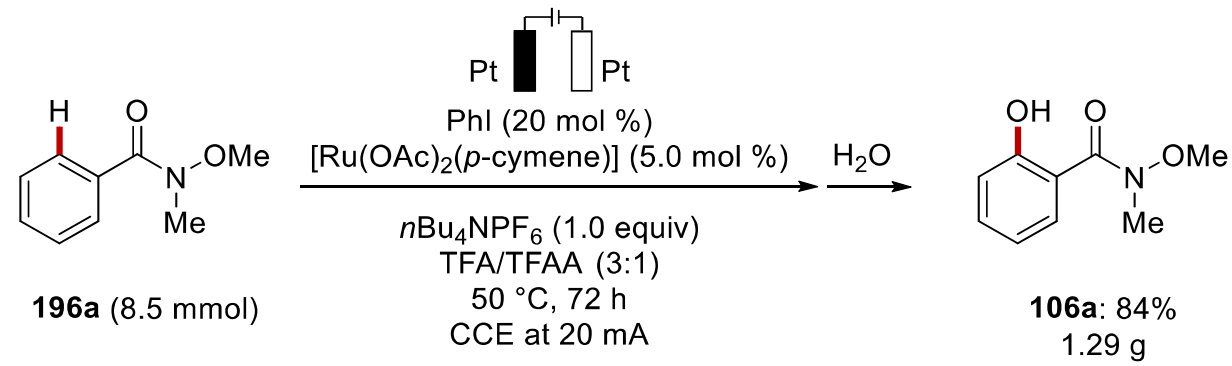

Scheme 3.3.7 Gram-scale electrochemical ruthenium-catalyzed C-H oxygenation. 


\subsubsection{Mechanistic Studies}

To elucidate the catalytic cycle for the iodine(III)/ruthenium(II)-catalyzed $\mathrm{C}-\mathrm{H}$ oxygenation, extensive mechanistic studies were carried out. First, the H/D exchange on the recovered starting material and on the obtained product was studied after 6 hours of CCE (Scheme 3.3.8,a). For substrate $[\mathrm{D}]_{\mathrm{n}}-\mathbf{1 9 6 a}$ each ortho-position had $44 \%$ of deuterium incorporation, while the product $[\mathrm{D}]_{\mathrm{n}}{ }^{-}$ 106a had $20 \%$ of deuterium incorporation. This clearly indicated the reversibility of the $\mathrm{C}-\mathrm{H}$ activation step. The same study was performed with the optimized condition for the chemical oxidant reaction (Scheme 3.3.8,b). In this case electricity was absent and commercially available PIDA was employed as oxidant. The deuterium incorporation for both the product and the starting material was detected only in traces.

(a) Electrochemical reaction

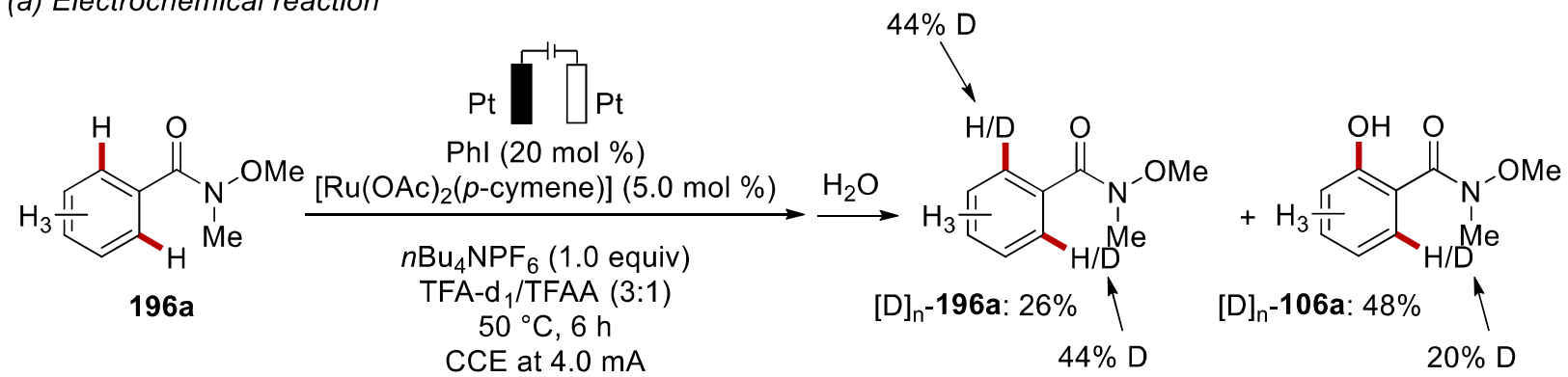

(b) Chemical oxidant reaction

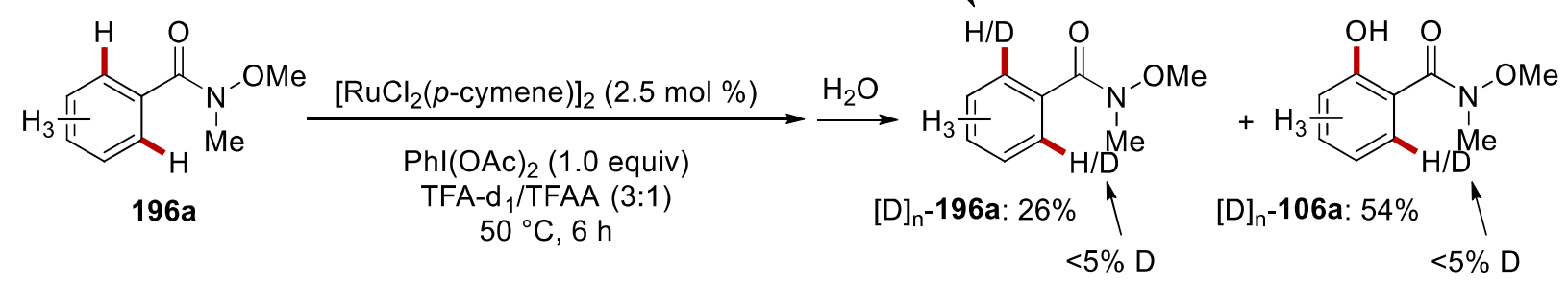

Scheme 3.3.8 H/D exchange studies for (a) the electrochemical iodine(III)/ruthenium(II)-catalyzed $\mathrm{C}-\mathrm{H}$ oxygenation and (b) the ruthenium-catalyzed oxygenation with PIDA.

Afterwards, the kinetic isotope effect was evaluated (Scheme 3.3.9). The KIE was found to be $k_{\mathrm{H}} / k_{\mathrm{D}}$ $\approx 1.6$, which indicated a fast $\mathrm{C}-\mathrm{H}$ metalation. The comparison of this result with the $\mathrm{KIE}$ of $k_{\mathrm{H}} / k_{\mathrm{D}} \approx$ 3.0 reported in the literature ${ }^{[112]}$ for the chemical oxidant reaction suggests a change in the rate- 
determining step between the two approaches. In the Ackermann report from 2013, the C-H activation was indeed indicated as the rate-limiting step while, in the current electrochemical study, the oxidation of the cyclometalated species seems to be the slow step. These conclusions are in good agreement with the above shown deuterium incorporation studies, delineating the electrochemical iodine(III)/ruthenium(II)-catalyzed oxygenation to have a fast and reversible $\mathrm{C}-\mathrm{H}$ activation and a slow oxidation step.

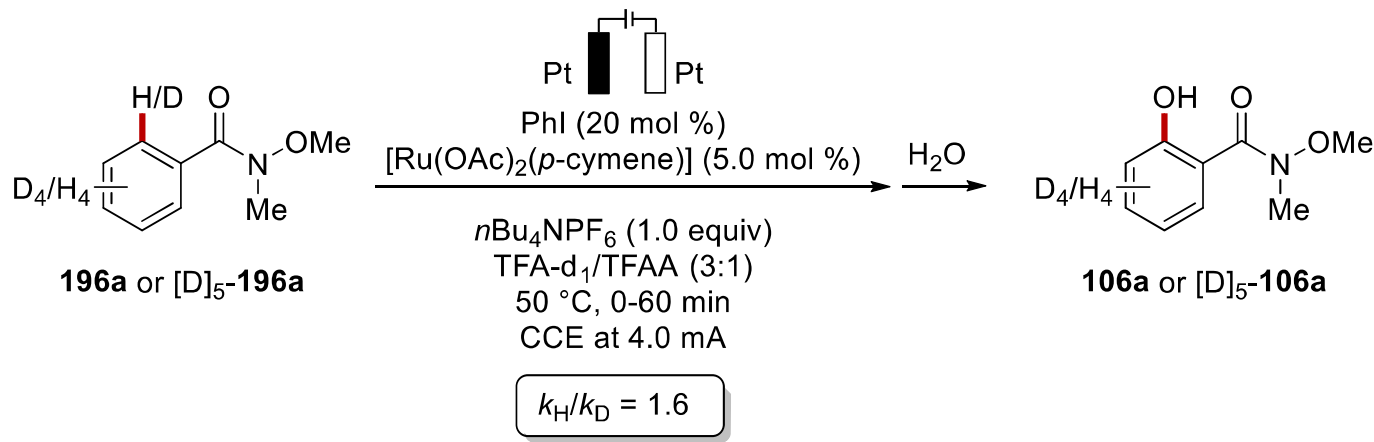

Scheme 3.3.9 KIE study for the iodine(III)/ruthenium(II)-catalyzed C-H oxygenation.

Moreover, competition experiments were performed both for Weinreb amides 196 as well as for ketones 77 (Scheme 3.3.10). In the first case, para-methyl and para-trifluoromethyl amides 196b and $\mathbf{1 9 6 \mathbf { d }}$ were used. The product $\mathbf{1 0 6} \mathbf{b}$ was obtained in $38 \%$ yield, while the product $\mathbf{1 0 6} \mathbf{d}$ was only detected in traces (Scheme 3.3.10,a). As for ketones 77, an intramolecular competition has been carried on with phenyl[4-(trifluoromethyl)phenyl]methanone (77n). Similarly, the more electron-rich arene was mainly functionalized (Scheme 3.3.10,b). These results are suggestive of a BIES ${ }^{[29,32]}$ for the $\mathrm{C}-\mathrm{H}$ metalation. 
(a) Competition experiment for Weinreb amides
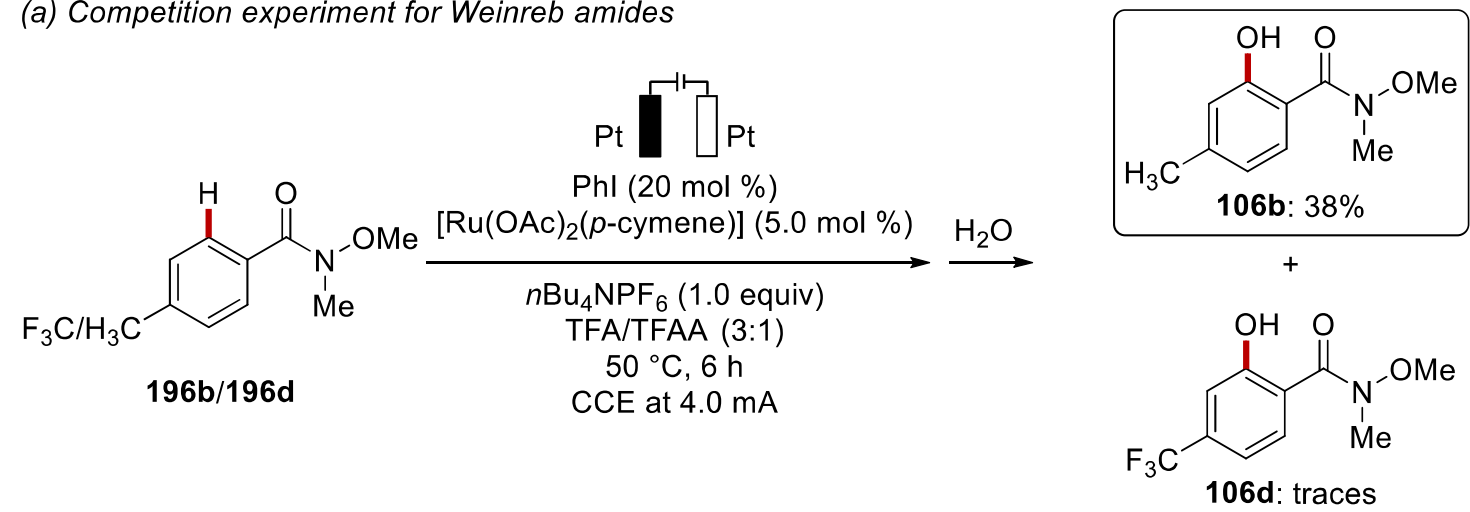

(b) Competition experiment for ketone ${ }^{[\mathrm{a}]}$<smiles>O=C(c1ccccc1)c1ccc(C(F)(F)F)cc1</smiles>
$77 n$

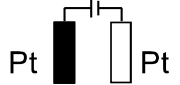

$\mathrm{Phl}(20 \mathrm{~mol} \%)$

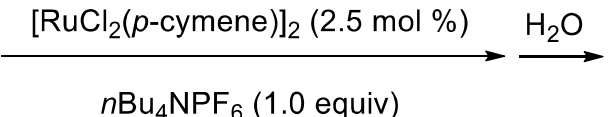

TFA/TFAA (3:1)

$50^{\circ} \mathrm{C}, 16 \mathrm{~h}$

CCE at $4.0 \mathrm{~mA}$

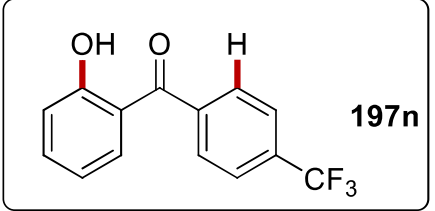

$+$<smiles>O=C(c1ccccc1)c1ccc(C(F)(F)F)cc1O</smiles>

$90 \%,\left(197 n / 197 n^{\prime} 9: 1^{1} H-N M R\right)$

Scheme 3.3.10 Competition experiments for Weinreb amides 196 and for ketones 77. ${ }^{\text {a] }}$ Performed by Dr. X. Tan.

An intramolecular competition between the amide and the ketone as directing groups was next designed (Scheme 3.3.11). 4-Acetyl- $N$-methoxy- $N$-methylbenzamide (196q) has been synthesized as the starting material. After the reaction a sole product $\mathbf{1 0 6 q}$ was obtained, and it was functionalized in ortho to the amide group.

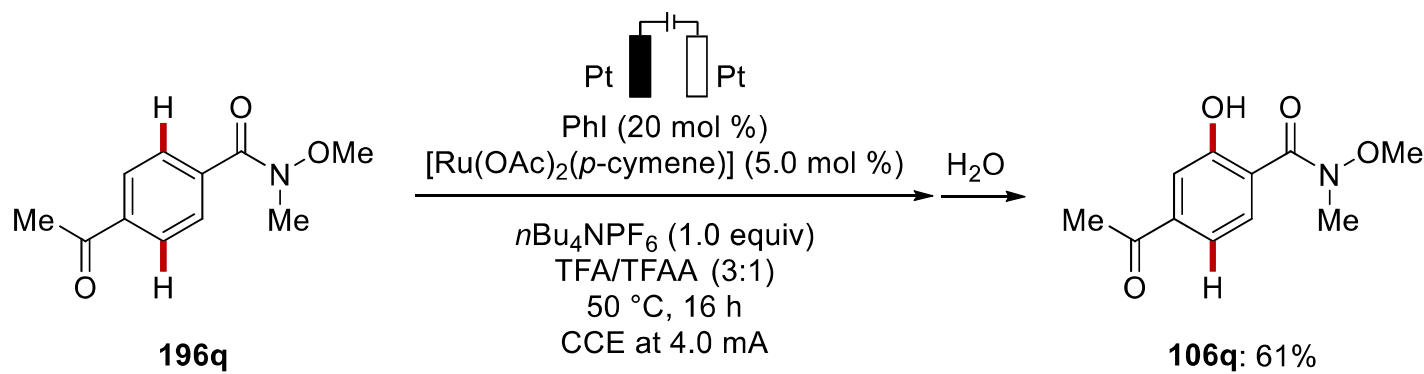

Scheme 3.3.11 Directing group comparison for the iodine(III)/ruthenium(II)-catalyzed C-H oxygenation. 
In addition to these studies, we performed a gas-chromatographic headspace analysis after $16 \mathrm{~h}$ of reaction (Scheme 3.3.12). Herein, hydrogen gas could be detected in the Schlenk tube after completion of the electrolysis. With this insight in hand, we could assert that the other half reaction is the reduction of protons to molecular $\mathrm{H}_{2}$.

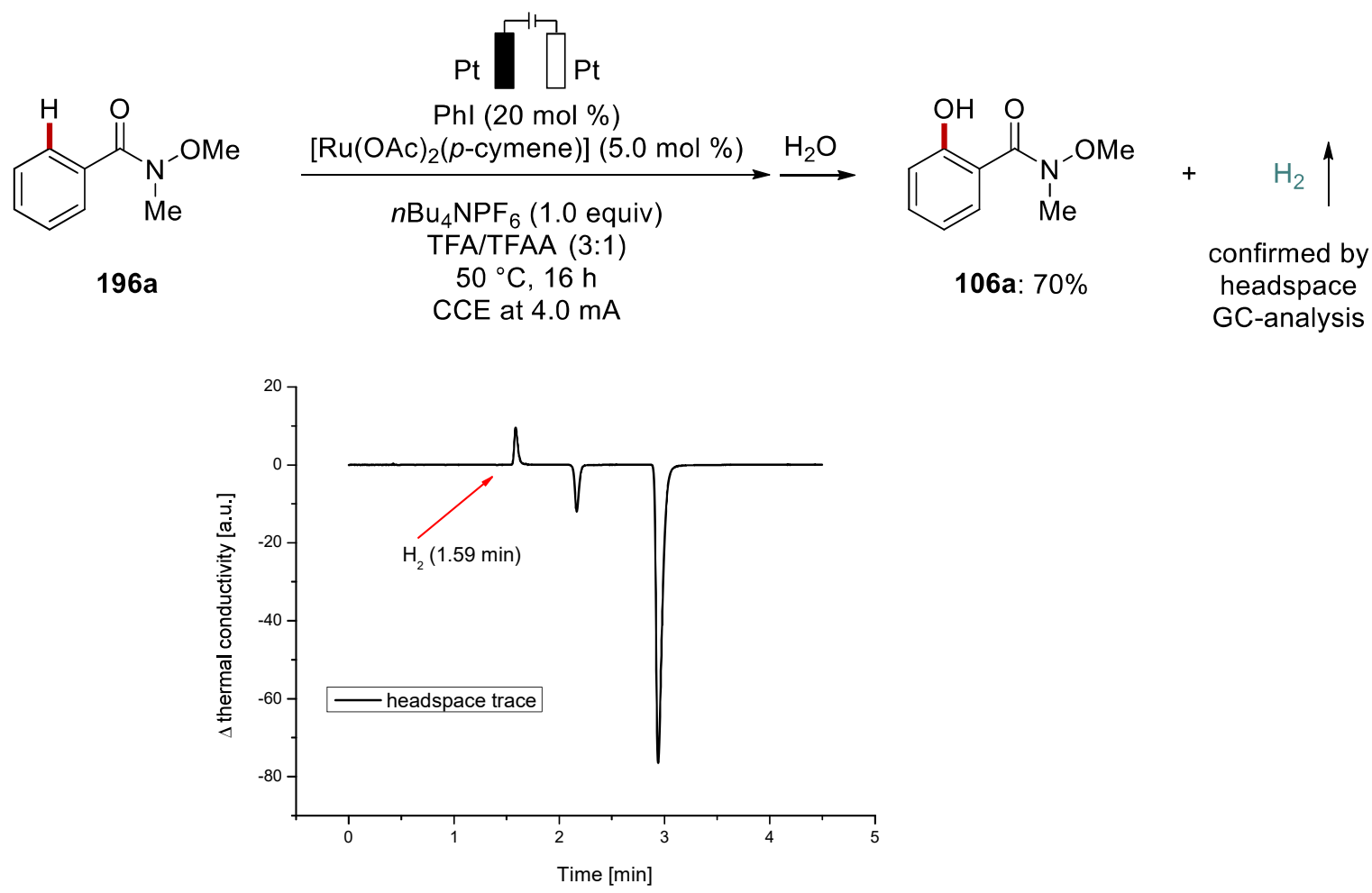

Scheme 3.3.12 Gas-chromatographic headspace analysis for the iodine(III)/ruthenium(II)-catalyzed C-H oxygenation.

Moreover, the trifluoroacetate product 201f could be detected as intermediate in the reaction (Scheme 3.3.13, performed by Dr. X. Tan). This supported the proposed catalytic cycle (vide infra) where first the $\mathrm{C}-\mathrm{H}$ esterification takes place and then the oxygenated product $\mathbf{1 0 6}$ is obtained via hydrolysis. 


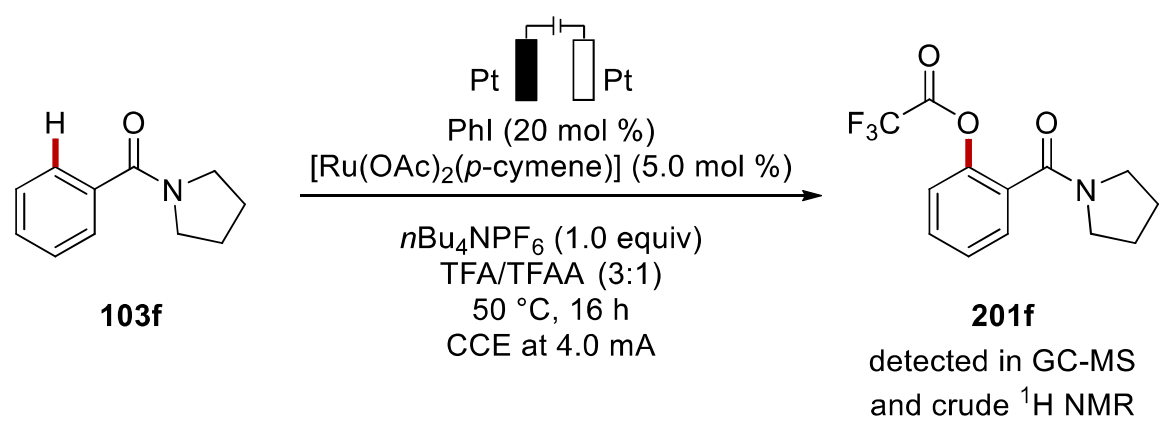

Scheme 3.3.13 Trifluoroacetate intermediate detection. Performed by Dr. X. Tan.

With the assistance of Dr. T. H. Meyer, we could obtain the kinetic profile of the reaction for the formation of the hypervalent iodine 195 via in-operando NMR spectroscopy (Scheme 3.3.14). By employing this approach, we could follow the formation of the rather unstable hypervalent iodine(III) species. The profile of the reaction with TFE as well as the one with the TFA/TFAA mixture used in the optimized conditions were recorded. The former profile showed almost a full conversion in only 2.5 hours at $10 \mathrm{~mA}$ at room temperature, while the formation of $195 \mathrm{ca}$ was slightly slower under the same conditions.
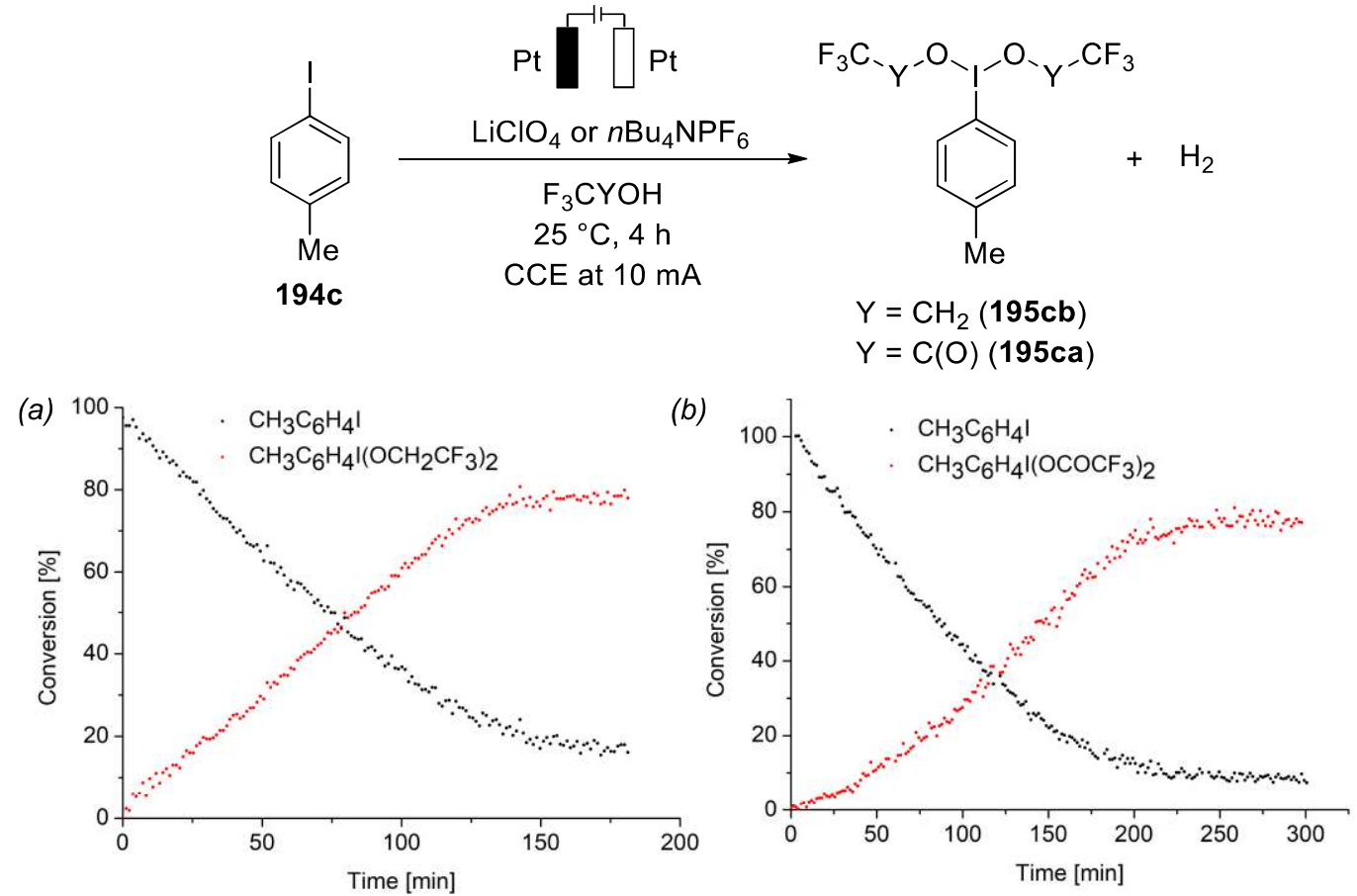

Scheme 3.3.14 In-operando NMR $(60 \mathrm{MHz})$ studies for the formation of hypervalent iodine(III) reagents with (a) TFE or (b) TFA/TFAA (3:1). Performed with Dr. T. H. Meyer. 
Dr. T. H. Meyer also performed the cyclic voltammetry studies for the envisioned reaction (Figure 3.3.15). The studies suggested that iodobenzene 194a is oxidized before the amide 196a. Other iodoarenes were also tested and as expected, the electron-rich 4-iodotoluene 194c had a slightly lower oxidation potential, while methyl 4-iodobenzoate 194d did not show a clear oxidation peak. Furthermore, DFT studies performed by Dr. R. Kuniyil, confirmed that the oxidation potential of the ruthenium(II/IV) manifold was $200 \mathrm{mV}$ higher than the iodobenzene 194a.

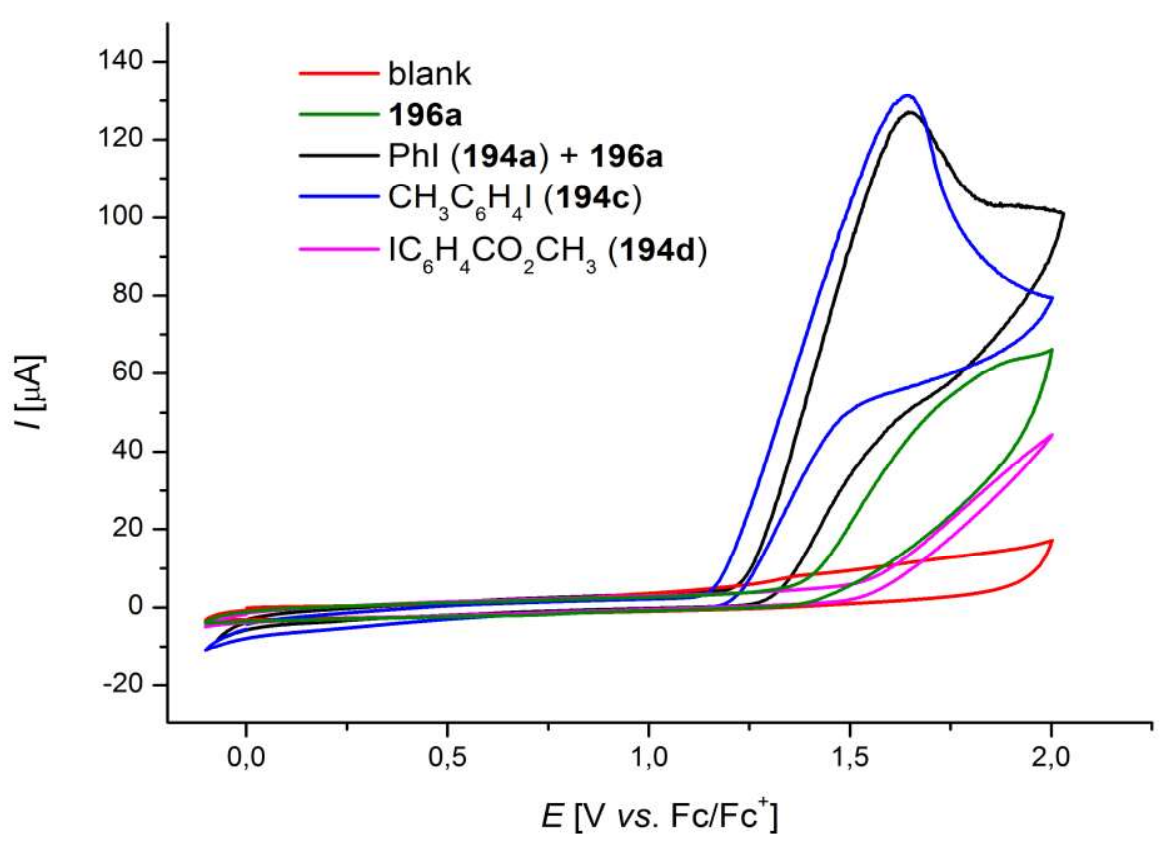

Figure 3.3.15 Selected data from the cyclic voltammograms performed by Dr. T. H. Meyer at a scan rate of $100 \mathrm{mVs}^{-1}$ with TFA and $n \mathrm{Bu}_{4} \mathrm{NPF}_{6}(0.1 \mathrm{M})$ as the electrolyte and a GC working electrode; the concentration of all substrates was 5.0 mM. (red) blank, (green) 194a, (black) 194a + 196a, (blue) 4-iodotoluene 194c, (magenta) methyl 4-iodobenzoate 194d.

With the data from the experimental mechanistic studies, the cyclic voltammetry analysis, and the computational studies, we propose a feasible catalytic cycle (Scheme 3.3.16). The mechanism commences with the $\mathrm{C}-\mathrm{H}$ activation on the amide 196 by a ruthenium(II) carboxylate species $\mathbf{9 1 b}$. In 
the meantime, the iodobenzene 194a is oxidize on the anode to form [bis(trifluoroacetoxy)iodo]benzene 195aa that subsequently oxidizes the cyclometalated complex 203 to furnish a ruthenium(IV) complex 204 by group transfer. This mediated oxidation is suggested to be the rate limiting step. Subsequently, an oxidatively-induced reductive elimination yields the trifluoro ester product 201 and regenerates the active catalyst $\mathbf{9 1 b}$. The desired product $\mathbf{1 0 6}$ is obtained after hydrolysis. As aforementioned, the cathodic reduction forms molecular hydrogen, detectable by gas chromatography.

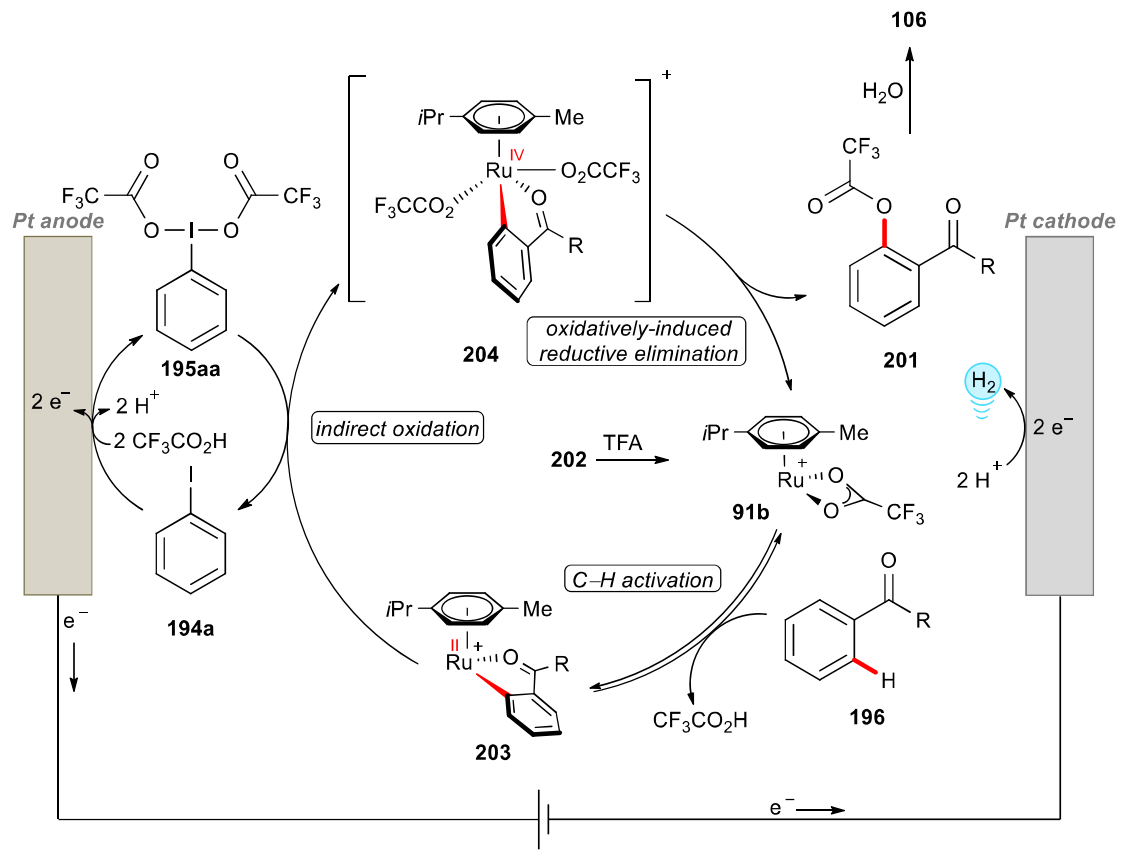

Scheme 3.3.16 Proposed catalytic cycle. 


\subsection{Rhoda-Electrocatalyzed Bimetallic $\mathrm{C}-\mathrm{H}$ Oxygenation by Weak $O$ - Coordination}

Rhodium was discovered to be a suitable and versatile metal for electrochemical transformations and many reports have recently been published. ${ }^{[171]}$

\subsubsection{Optimization}

The optimization of the rhoda-electrocatalyzed $\mathrm{C}-\mathrm{H}$ oxygenation started with the screening of typical supporting electrolytes (Table 3.4.1). Sodium trifluoroacetate did not yield the desired product 106a, while tetrabutylammonium hexafluorophosphate gave the best result (entries 1-4). Changing the ratio of TFA/TFAA from 3:1 to 1:1 increased the yield, as well as running the reaction at room temperature did (entries 5-6). The influence of different amounts of trifluoroacetic anhydride was then explored. A 1:2 solvent mixture gave a similar result as with a 1:1 ratio, while increasing ratio to 1:3 TFA/TFAA furnished only traces of the desired product 106a (entries 7-8). The poor solubility, hence, the poor conductivity, of the electrolyte were deemed responsible for the failure of this reaction. At this point, test reactions were performed, showing that the reaction did not work in the absence of electricity or the catalyst, while running the so-far optimized conditions under nitrogen gave the same result (entries 9-11). To resolve the solubility issue, we devised a different electrolyte. The liquid and easily available TFA $\mathrm{NEt}_{3}$ salt was used as electrolyte, allowing us to increase the amount of TFAA in the solvent mixture. Thus, with a 1:20 TFA/TFAA mixture and TFA $\cdot \mathrm{NEt}_{3}$ as the electrolyte, the highest yield was obtained with a CCE of $2.0 \mathrm{~mA}$, furnishing $82 \%$ isolated yield of the desired product 106a (entries12-13). Importantly, other catalyst did not prove more efficient (entries 14-16).

Table 3.4.1 Optimization of the electrochemical rhodium-catalyzed C-H oxygenation. ${ }^{[a]}$

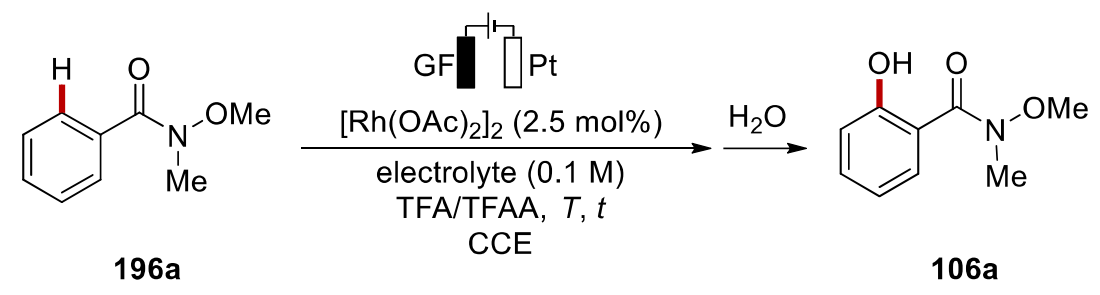




\begin{tabular}{|c|c|c|c|c|c|c|}
\hline Entry & Electrolyte & TFA/TFAA & I (mA) & t (h) & $\mathrm{T}\left({ }^{\circ} \mathrm{C}\right)$ & Yield (\%) \\
\hline 1 & $\mathrm{NaO}_{2} \mathrm{CCF}_{3}$ & $3: 1$ & 4 & 16 & 50 & $\operatorname{trace}^{[\mathrm{b}]}$ \\
\hline 2 & $\mathrm{LiClO}_{4}$ & $3: 1$ & 4 & 16 & 50 & $24^{[\mathrm{b}]}$ \\
\hline 3 & $n \mathrm{Bu}_{4} \mathrm{NBF}_{4}$ & $3: 1$ & 4 & 16 & 50 & $22^{[\mathrm{b}]}$ \\
\hline 4 & $n \mathrm{Bu}_{4} \mathrm{NPF}_{6}$ & $3: 1$ & 4 & 16 & 50 & $28^{[\mathrm{b}]}$ \\
\hline 5 & $n \mathrm{Bu}_{4} \mathrm{NPF}_{6}$ & $1: 1$ & 4 & 16 & 50 & $42^{[b]}$ \\
\hline 6 & $n \mathrm{Bu}_{4} \mathrm{NPF}_{6}$ & $1: 1$ & 4 & 16 & $\mathrm{RT}$ & $54^{[\mathrm{b}]}$ \\
\hline 7 & $n \mathrm{Bu}_{4} \mathrm{NPF}_{6}$ & $1: 2$ & 4 & 16 & $\mathrm{RT}$ & 52 \\
\hline 8 & $n \mathrm{Bu}_{4} \mathrm{NPF}_{6}$ & $1: 3$ & 4 & 16 & $\mathrm{RT}$ & $\operatorname{trace}^{[\mathrm{c}]}$ \\
\hline 9 & $n \mathrm{Bu}_{4} \mathrm{NPF}_{6}$ & $1: 1$ & - & 16 & $\mathrm{RT}$ & ND \\
\hline 10 & $n \mathrm{Bu}_{4} \mathrm{NPF}_{6}$ & $1: 1$ & 4 & 16 & $\mathrm{RT}$ & $\operatorname{trace}^{[\mathrm{d}]}$ \\
\hline 11 & $n \mathrm{Bu}_{4} \mathrm{NPF}_{6}$ & $1: 1$ & 4 & 16 & $\mathrm{RT}$ & $57^{[\mathrm{b}, \mathrm{e}]}$ \\
\hline 12 & $\mathrm{TFA} \cdot \mathrm{NEt}_{3}$ & $1: 20$ & 4 & 8 & $\mathrm{RT}$ & $76^{[\mathrm{b}, \mathrm{e}, \mathrm{f}]}$ \\
\hline 13 & TFA $\cdot$ NEt $_{3}$ & $1: 20$ & 2 & 15 & RT & $82^{[b, e, f]}$ \\
\hline 14 & $\mathrm{TFA} \cdot \mathrm{NEt}_{3}$ & $1: 20$ & 2 & 15 & RT & $\mathrm{ND}^{[\mathrm{f}, \mathrm{g}]}$ \\
\hline 15 & $n \mathrm{Bu}_{4} \mathrm{NPF}_{6}$ & $3: 1$ & 4 & 16 & 50 & $28^{[\mathrm{h}]}$ \\
\hline 16 & $\mathrm{TFA} \cdot \mathrm{NEt}_{3}$ & $1: 20$ & 2 & 15 & RT & $52^{[\mathrm{f}, \mathrm{i}]}$ \\
\hline
\end{tabular}

[a] Reaction conditions: 196a $(0.50 \mathrm{mmol}),\left[\mathrm{Rh}(\mathrm{OAc})_{2}\right]_{2}(2.5 \mathrm{~mol} \%)$, electrolyte $(0.10 \mathrm{M})$, TFA/TFAA (3 mL), graphite felt (GF) anode $(10 \mathrm{~mm} \times 10 \mathrm{~mm} \times 6 \mathrm{~mm})$, Pt-plate cathode $(10 \mathrm{~mm} \times$ $15 \mathrm{~mm} \times 0.125 \mathrm{~mm})$, CCE as specified. ${ }^{[\mathrm{b}]}$ Performed by Dr. X. Tan. ${ }^{[\mathrm{c}]}$ Poor conductivity due to poor solubility of electrolyte. ${ }^{[\mathrm{d}]}$ Without $\left[\mathrm{Rh}(\mathrm{OAc})_{2}\right]_{2}$. ${ }^{[\mathrm{e}]}$ Under $\mathrm{N}_{2}$. ${ }^{[\mathrm{f}]} \mathrm{TFA} \cdot \mathrm{NEt}_{3}(0.33 \mathrm{M})$. ${ }^{[\mathrm{g}]}$ $\left[\mathrm{RhCp}^{*} \mathrm{Cl}_{2}\right]_{2}$ or $\mathrm{RhCl}_{3} \cdot 3 \mathrm{H}_{2} \mathrm{O}$ instead of $\left[\mathrm{Rh}(\mathrm{OAc})_{2}\right]_{2}$ as the catalyst. ${ }^{\mathrm{h}]}\left[\mathrm{Ru}(\mathrm{OAc})_{2}(p\right.$-cymene $\left.)\right]$ 188a $(5.0 \mathrm{~mol} \%)$ as the catalyst. ${ }^{[i]}\left[\mathrm{Rh}(\mathrm{OPiv})_{2}\right]_{2}$ as the catalyst. Piv $=$ pivalate.

\subsubsection{Substrate Scope}

Once the system was optimized, its versatility was tested with a broad substrate range, which was performed together with Dr. X. Tan. We started the investigation with Weinreb amides 196 (Scheme 3.4.1). Electron-rich substituents in the para-position were nicely tolerated and also electron-poor ones gave excellent results (106b-q). Among these are some notable examples. The para-methoxy group, that was not tolerated for the mediated ruthenium electrochemical oxygenation, gave $50 \%$ isolated yield of product 106r. Halogen substituents were very efficiently converted to the desired products $(\mathbf{1 0 6 g - i , 0})$, and both ester (196u) and ketone (196q) moieties on the arene were feasible and 
each yielded a sole product, since the amide was a better directing group. The substrates with electron-rich meta-substituents performed slightly less efficiently in rhodium catalysis compared to the ruthenium catalysis, giving between $3 \%$ and $7 \%$ of the minor regioisomer for products $\mathbf{1 0 6 \mathbf { j }}$, 106v, and 106e. The minor product was present only for electron-rich substrates, probably due to their high reactivity (vide infra). However, electron-deficient groups in the meta-position yielded only one regioisomer at the least hindered position $(\mathbf{1 0 6 m - n , f})$.
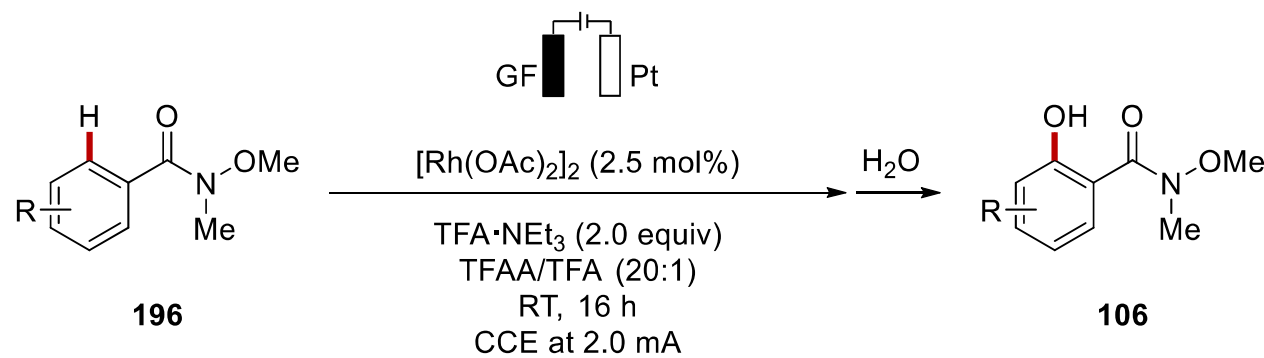<smiles>[R]c1ccc(C(=O)N(C)OC)c(O)c1</smiles>

$\mathrm{R}=\mathrm{H}(\mathbf{1 0 6 a}): \quad 78 \%{ }^{[\mathrm{a}]}$

$\mathrm{R}=\mathrm{Me}(\mathbf{1 0 6 b}): 73 \%$

$\mathrm{R}=\mathrm{OMe}(106 \mathrm{r}): 50 \%{ }^{[\mathrm{a}]}$

$R=t B u(106 s): 80 \%{ }^{[a]}$<smiles>CON(C)C(=O)c1ccc(C(C)=O)cc1O</smiles>

106q: $50 \%$<smiles>[R]c1ccc(O)c(C(=O)N(C)C)c1</smiles>

$\mathrm{R}=\mathrm{Cl}(106 \mathrm{~m}): \quad 52 \%$

$\mathrm{R}=\mathrm{Br}(\mathbf{1 0 6 n}): \quad 67 \%^{[\mathrm{a}]}$<smiles>[R]c1ccc(C(=O)N(C)OC)c(O)c1</smiles>

$\mathrm{R}=\mathrm{Ph}(\mathbf{1 0 6 t}): \quad \quad 70 \%$

$\mathrm{R}=\mathrm{CO}_{2} \mathrm{Me} \mathrm{(106u):62 \%}$<smiles>CON(C)C(=O)c1cc(C)ccc1O</smiles>

106j: $51 \%$<smiles>CON(C)C(=O)c1cc(C)c(C)cc1O</smiles>

106e: $65 \%(5 \%)^{[a]}$<smiles>[R]c1ccc(C(=O)N(C)OC)c(O)c1</smiles>

$\mathrm{R}=\mathrm{F}(106 \mathrm{~g}): \quad 80 \%{ }^{[\mathrm{a}]}$

$\mathrm{R}=\mathrm{Cl}(106 \mathrm{~h}): \quad 79 \%{ }^{[\mathrm{a}]}$

$\mathrm{R}=\mathrm{Br}(106 \mathrm{i}): \quad 81 \%{ }^{[\mathrm{a}]}$

$R=I(1060): \quad 61 \%$<smiles>CON(C)C(=O)c1cc2ccccc2cc1O</smiles>

106v: $59 \%(7 \%)^{[a]}$<smiles>CN(C)C(=O)c1cc(Cl)c(Cl)cc1O</smiles>

106f: $77 \%$

Scheme 3.4.1 Scope of electrochemical rhodium-catalyzed C-H oxygenation of Weinreb amides 196.

${ }^{[a]}$ Performed by Dr. X. Tan. 
The broad applicability of the approach enabled $\mathrm{C}-\mathrm{H}$ oxygenations on tertiary amides $\mathbf{1 0 3}$ (Scheme 3.4.2). For this part of the scope and the following one, also MSc X. Hou joined the project. The reaction proved very robust on dimethyl amides. Since the para-methyl-substituted substrate underwent the reaction with an excellent yield, it was then tried with lower amounts of the catalyst. Product 104b could be obtained in high yields with just $1.0 \mathrm{~mol} \%$ or $0.5 \mathrm{~mol} \%$ loading of the rhodium dimer. Other substituents in the para-position, as methoxy (103h), chloro (103i), bromo $(\mathbf{1 0 3 c})$, and trifluoromethyl (103j), furnished high yields of the desired products. An electron-rich substituent in the meta-position showed again the formation of 5\% of the minor regioisomer (104k), while with a halogen in that position products $\mathbf{1 0 4 I}$ and $\mathbf{1 0 4 n}$ were obtained selectively. Other tertiary amides, like diethyl and diisopropyl amides $\mathbf{1 0 3 m}$ and $\mathbf{1 0 3 e}$, were efficiently converted, as well as morpholino(phenyl)methanone (103g) and phenyl(pyrrolidin-1-yl)methanone (103f), which gave excellent results. 


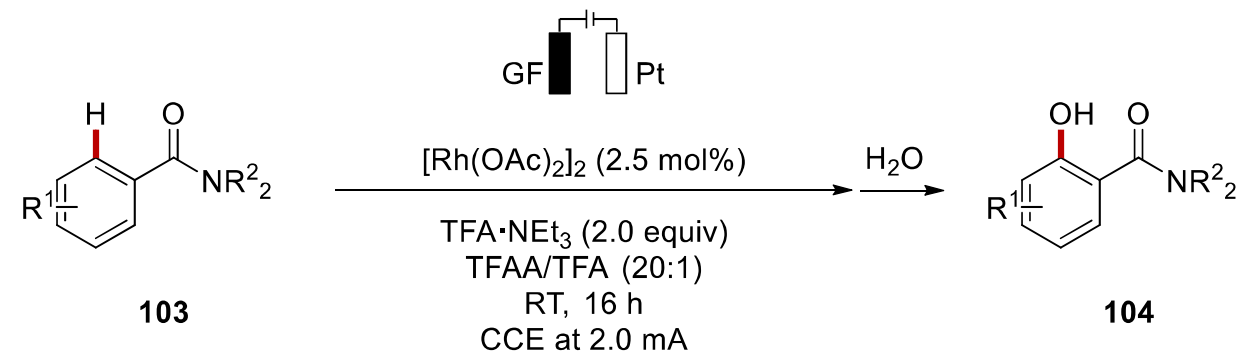<smiles>Cc1ccc(C(=O)N(C)C)c(O)c1</smiles>

104b: $[\mathrm{Rh}](2.5 \mathrm{~mol} \%)=91 \%$ [Rh] $(1.0 \mathrm{~mol} \%)=66 \%$ [Rh] $(0.5 \mathrm{~mol} \%)=60 \%$<smiles>CC(=O)c1cc(O)ccc1C</smiles>

104k: $76 \%$<smiles>CC(=O)c1cc(Br)ccc1O</smiles>

104n: $86 \%$<smiles>[R]c1ccc(C(=O)N(C)C)c(O)c1</smiles><smiles>[R]c1ccc(C(=O)N(C)C)c(O)c1</smiles>

$\mathrm{R}=\mathrm{H}(104 \mathrm{a}): \quad 84 \%[\mathrm{a}]$ $\mathrm{R}=\mathrm{OMe}(104 \mathrm{~h}): \quad 77 \%$<smiles>CC(=O)c1cc(Cl)ccc1O</smiles>

104I: $80 \%{ }^{[b]}$<smiles>O=C(c1ccccc1O)N1CCOCC1</smiles>

104g: $79 \%[$ [a]<smiles>NC(=O)c1ccccc1O</smiles>

$R=E t(\mathbf{1 0 4 m}): \quad 85 \%[\mathrm{bb}]$ $\mathrm{R}=\operatorname{Pr}(104 \mathrm{e}): \quad 66 \%{ }^{[\mathrm{a}]}$<smiles>O=C(c1ccccc1O)N1CCCC1</smiles>

104f: $82 \%$ [a]

Scheme 3.4.2 Scope of the electrochemical rhodium-catalyzed C-H oxygenation of various amides 103. ${ }^{[a]}$ Performed by Dr. X. Tan. ${ }^{[b]}$ Performed by MSc X. Hou.

The rhodium-catalyzed electrochemical $\mathrm{C}-\mathrm{H}$ oxygenation was likewise viable on ketones 77 (Scheme 3.4.3). Acetophenone (77c) gave product $197 \mathrm{c}$ in good yield. In the presence of 4-methyl or 4-chloro substituents the expected products $197 \mathbf{n}$ and $197 \mathbf{o}$ were also obtained in good yields. Propiophenone (77b) and phenyl tert-butyl ketone (77a) were likewise tolerated by the envisioned reaction. 


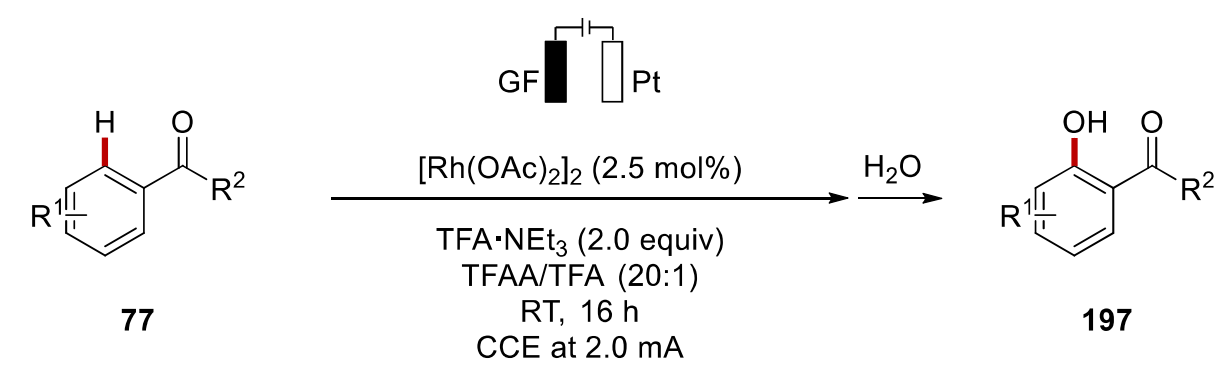<smiles>CC(=O)c1ccc(C)cc1O</smiles>

197n: $53 \%$<smiles>CCC(=O)c1ccccc1O</smiles>

197b: $68 \%{ }^{[b]}$<smiles>CC(=O)c1ccccc1O</smiles>

197c: $76 \%[$ [b]<smiles>CC(C)CC(=O)c1ccccc1O</smiles>

197a: $66 \%^{[\mathrm{a}]}$<smiles>CC(=O)c1ccc(Cl)cc1O</smiles>

1970: $53 \%{ }^{[b]}$<smiles>CC(C)(C)C(=O)c1ccc(Cl)cc1O</smiles>

197f: $77 \%[\mathrm{a}]$

Scheme 3.4.3 Scope of the electrochemical rhodium-catalyzed $\mathrm{C}-\mathrm{H}$ oxygenation of various ketones 77. ${ }^{[\mathrm{a}]}$ Performed by Dr. X. Tan. ${ }^{[\mathrm{b}]}$ Performed by MSc X. Hou.

During the optimization studies, we sometimes encountered small amounts of $N$-demethylated product 206a (Scheme 3.4.4). This finding was further investigated, and we proposed that the formation occurs due to a Shono-type $\mathrm{C}-\mathrm{H}$ oxidation. Tuning the conditions, Dr. X. Tan could take advantage of this alternative path to access dihydrooxazinones 207. 
(a) Strategy of rhoda-electrocatalyzed cascade for the synthesis of dihydrooxazinone

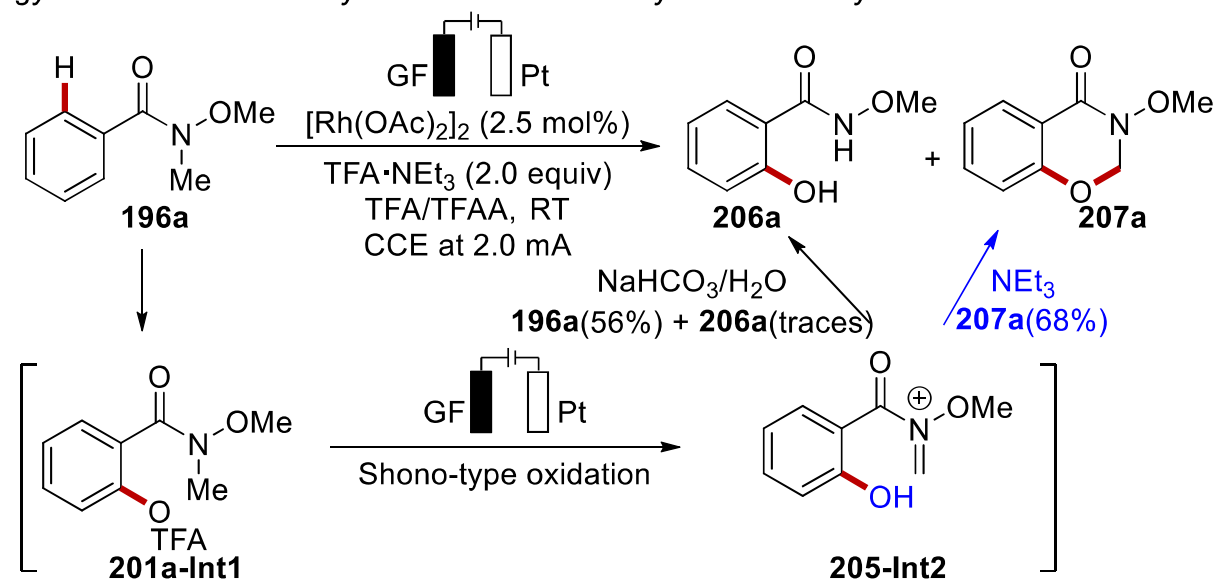

(b) Substrate scope for rhoda-electrocatalyzed double $\mathrm{C}-\mathrm{H}$ functionalization

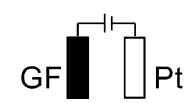<smiles>[R]N(C)C(=O)c1cc[R1]cc1</smiles>

196 or 103

1) $\left[\mathrm{Rh}(\mathrm{OAc})_{2}\right]_{2}(2.5 \mathrm{~mol} \%)$

TFA $\cdot \mathrm{NEt}_{3}, \mathrm{TFAA} / \mathrm{TFA}, \mathrm{RT}, \mathrm{CCE}$ at $2.0 \mathrm{~mA}$

2) TFA (5.2 equiv), RT, CCE at $5.0 \mathrm{~mA}$

3) $\mathrm{NEt}_{3}$<smiles>[R]N1COc2c[R1]#ccc2C1=O</smiles>

207<smiles>[R]c1ccc2c(c1)OCN(C)C2=O</smiles>

$\mathrm{R}=\mathrm{H}(\mathbf{2 0 6 b}): \quad 62 \%$

$\mathrm{R}=\mathrm{OMe}(206 \mathrm{c}): \quad 62 \%$<smiles>CN1COc2ccc(Cl)cc2C1=O</smiles>

206d: $61 \%$<smiles>[R]c1ccc2c(c1)OCN(OC)C2=O</smiles>

$\mathrm{R}=\mathrm{Br}(\mathbf{2 0 6 e}): \quad 67 \%$

$\mathrm{R}=t \mathrm{Bu}(\mathbf{2 0 6 f}): \quad 55 \%$

Scheme 3.4.4 (a) Strategy for the cascade synthesis of dihydrooxazinone 207 and (b) selected example from the scope performed by Dr. X. Tan.

\subsubsection{Mechanistic Studies}

Subsequently, we focused on the mechanistic studies to better understand the process and to shine light on the possible catalytic pathway. First, a competition experiment showed a preferential reactivity of the electron-rich substrate $\mathbf{1 9 6 b}$ compared to the electron-poor one 196d (Scheme 3.4.5). 


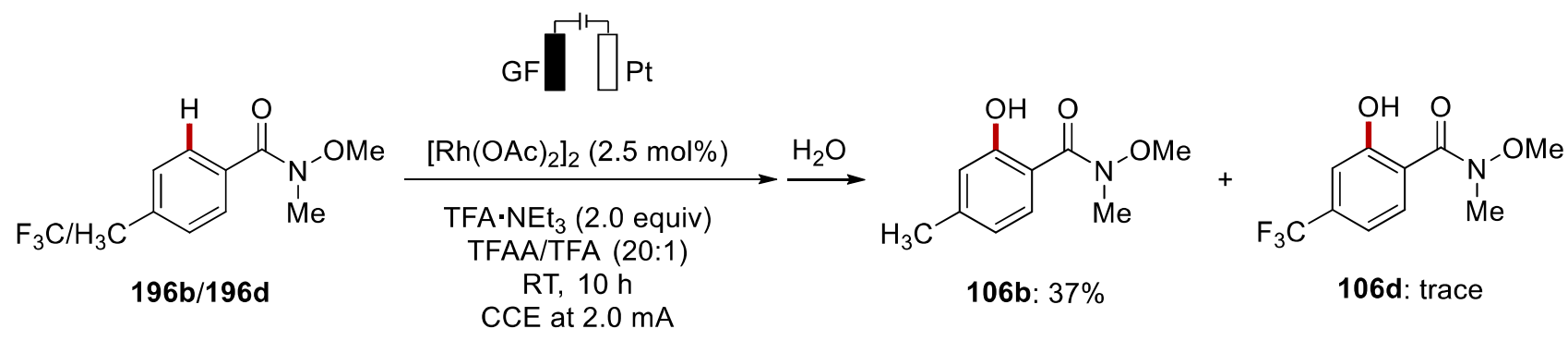

Scheme 3.4.5 Competition experiment for the electrochemical rhodium-catalyzed C-H oxygenation.

Furthermore, when the reaction was performed in the presence of deuterated trifluoroacetic acid, the deuterium incorporation was only detected in traces in both the starting material 196a and the product 106a (Scheme 3.4.6,a). This would suggest that the $\mathrm{C}-\mathrm{H}$ metalation happens irreversibly. At the same time, the kinetic isotope effect was found to be $k_{\mathrm{H}} / k_{\mathrm{D}} \approx 1.1$, indicating that the $\mathrm{C}-\mathrm{H}$ activation is not the rate-limiting step (Scheme 3.4.6,b). Moreover, the profile of the reaction at different constant current electrolyses showed a clear dependence of the rate of the reaction on the applied current (Scheme 3.4.6,c). The data thus implied that the oxidation is the rate-determining step, as it was for the iodo(III)/ruthenium(II) electrochemical oxygenation. 
(a) $H / D$ exchange

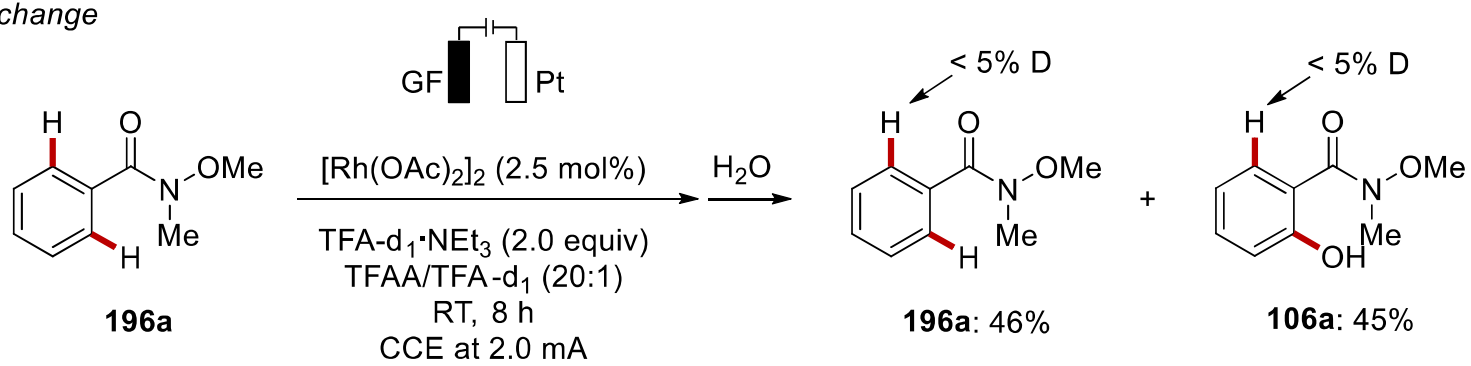

(b) KIE studies ${ }^{[a]}$
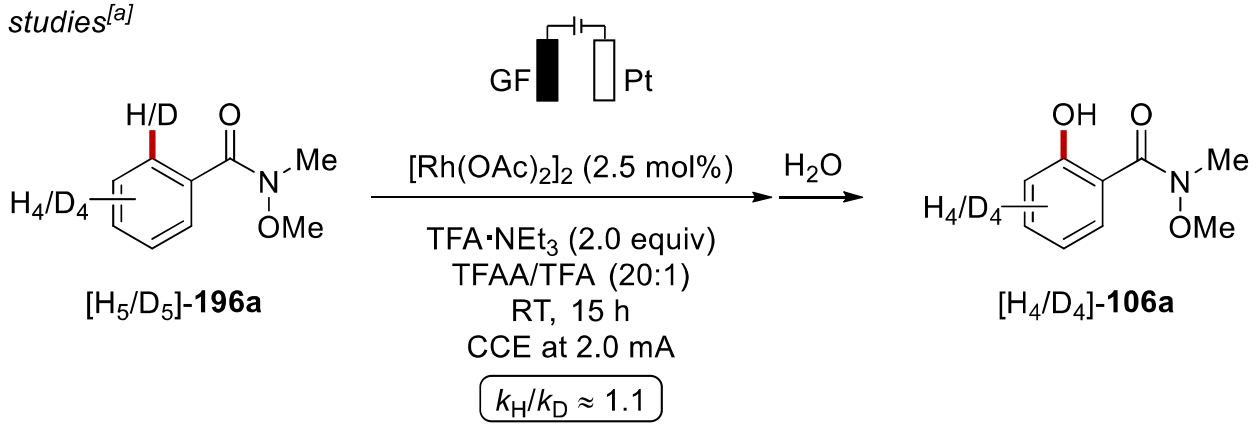

$\left[\mathrm{H}_{4} / \mathrm{D}_{4}\right]-106 \mathrm{a}$

(c) Reaction profile at different currents ${ }^{[a]}$
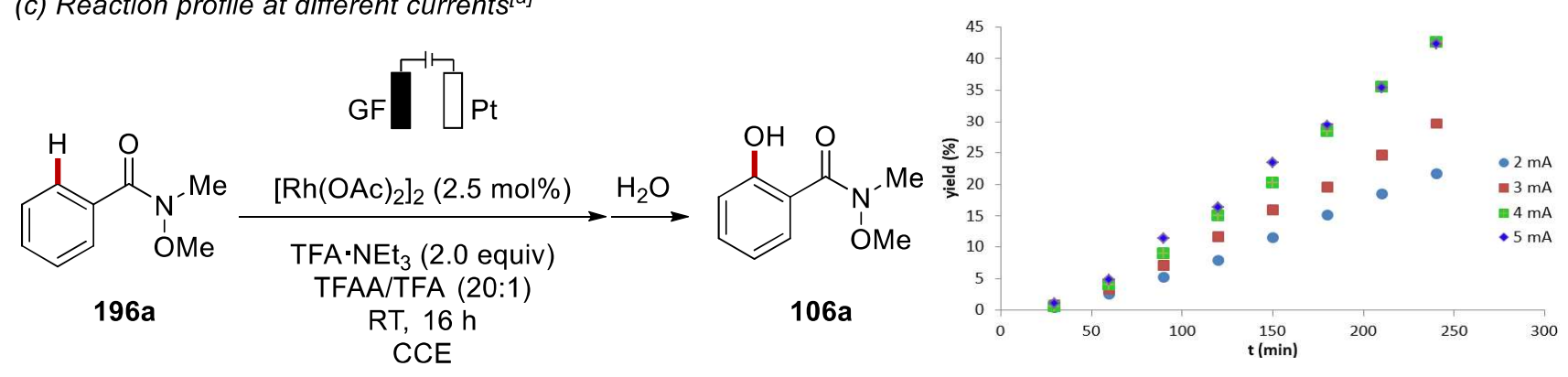

Scheme 3.4.6 (a) H/D exchange experiment, (b) KIE studies, and (c) reaction profile at different currents for the electrochemical rhodium-catalyzed $\mathrm{C}-\mathrm{H}$ oxygenation. ${ }^{[\mathrm{a}]}$ Performed by Dr. X. Tan.

The reaction was studied with different catalysts to understand which kind of influence the ligands can have and, therefore, if ligand exchange with trifluoroacetic acid happens in the reaction conditions (Scheme 3.4.7,a). For this purpose, $\left[\mathrm{Rh}(\mathrm{OTFA})_{2}\right]_{2}$ and $\left[\mathrm{Rh}(\mathrm{OPiv})_{2}\right]_{2}$ were tested as the catalysts. The former furnished the desired product only in trace amounts, while the latter yielded $52 \%$ of 106a. The absence of reactivity for $\left[\mathrm{Rh}(\mathrm{OTFA})_{2}\right]_{2}$ could be explained by its higher oxidation potential that makes this catalyst less efficient. This has been shown by cyclic voltammetry studies conducted by M. N. Hussain, were the oxidation potential of $\left[\mathrm{Rh}(\mathrm{OTFA})_{2}\right]_{2}$ was found to be $0.5 \mathrm{~V} v s$. $\mathrm{Ag} / \mathrm{AgCl}$ higher than the acetate catalyst (Figure 3.4.1). Additionally, mass spectroscopic analyses of 
$\left[\mathrm{Rh}(\mathrm{OAc})_{2}\right]_{2}$ in TFA/TFAA 1:1 and TFA/TFAA 1:20 solvent mixtures, conducted by Dr. X. Tan, showed a fast ligand exchange between acetate and trifluoroacetate for the catalyst in the 1:1 mixture, while a slow one was observed in the 1:20 mixture. As presented in the optimization table (Table 3.4.1, entry 6), a solvent mixture with equal parts of the trifluoroacetic acid and anhydride lowered the reaction yield. The effect of the solvent could be clearly observed also by the same cyclic voltammetry study discussed above, where the rhodium acetate dimer had a higher oxidation potential when recorded in a 1:1 mixture of TFA/TFAA. The oxidation potential also increased over time due to the increment in the ligand exchange (Figure 3.4.1). Regarding the more electron rich catalyst $\left[\mathrm{Rh}(\mathrm{OPiv})_{2}\right]_{2}$, a higher reactivity than $\left[\mathrm{Rh}(\mathrm{OAc})_{2}\right]_{2}$ would be expected, but instead only $52 \%$ of the desired product 106a was obtained. This was rationalized by the fact that the catalyst is more prone to be oxidized. However, the corresponding complex could also have a lower oxidation ability to drive a fast oxidative induced $\mathrm{C}-\mathrm{H}$ activation. Indeed, the reaction rate comparison between $\left[\mathrm{Rh}(\mathrm{OAc})_{2}\right]_{2}$ and $\left[\mathrm{Rh}(\mathrm{OPiv})_{2}\right]_{2}$ showed clearly slower kinetics for the latter (Scheme 3.4.7,b).

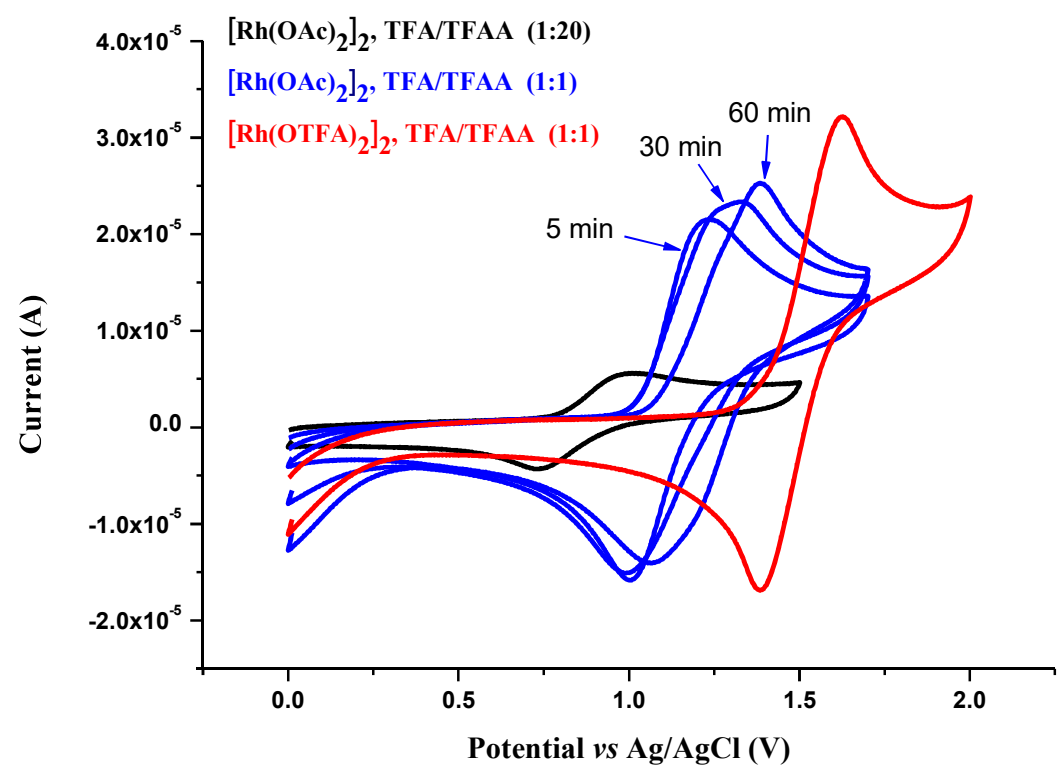

Figure 3.4.1 Cyclic voltammetry measurements with GC working electrode in TFA/TFAA with 0.15 $\mathrm{M} \mathrm{TFA} \cdot \mathrm{NEt}_{3}$ and $5.0 \mathrm{mM}$ rhodium catalyst at RT with a scan rate of $100 \mathrm{mVs}^{-1}$ : black, $\left[\mathrm{Rh}(\mathrm{OAc})_{2}\right]_{2}$ in TFA/TFAA (1:20), stirred $10 \mathrm{~min}$, poor solubility; blue, $\left[\mathrm{Rh}(\mathrm{OAc})_{2}\right]_{2}$ in TFA/TFAA $(1: 1)$, measured at stirring 5, 30 and $60 \mathrm{~min}$; red, $\left[\mathrm{Rh}(\mathrm{OTFA})_{2}\right]_{2}$ in TFA/TFAA $(1: 1)$. 
(a) Reactions with different catalysts

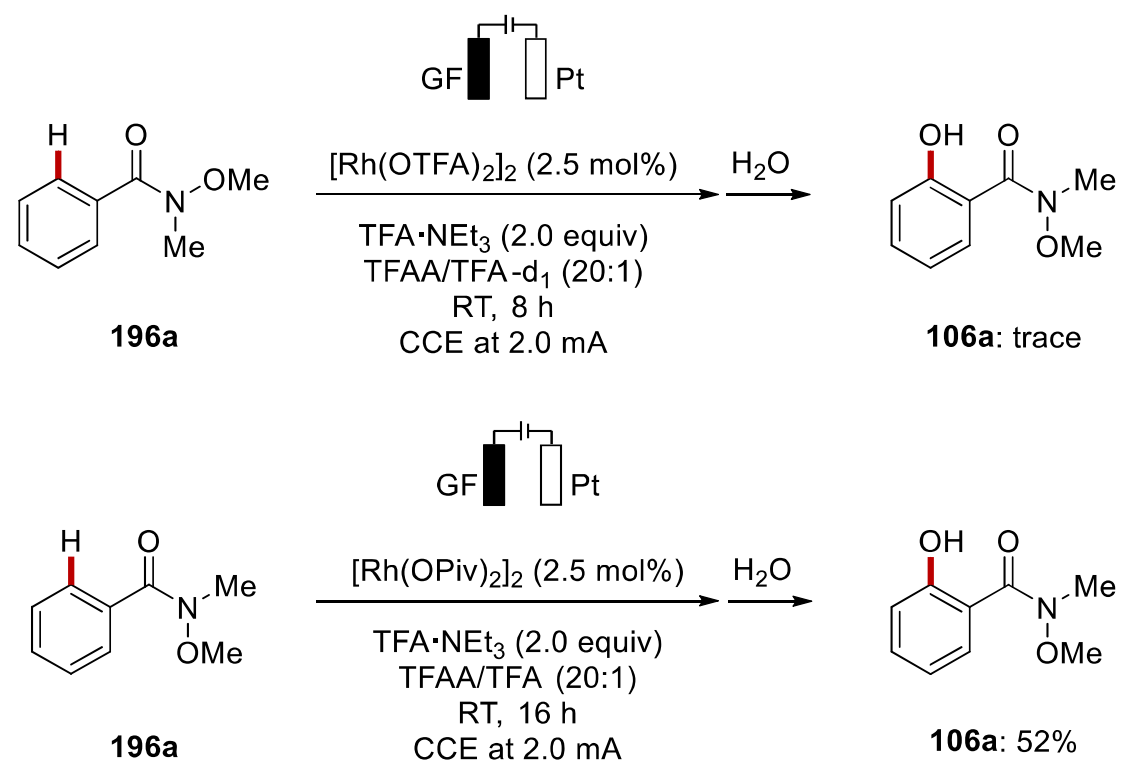

(b) Reactions profiles with different catalysts

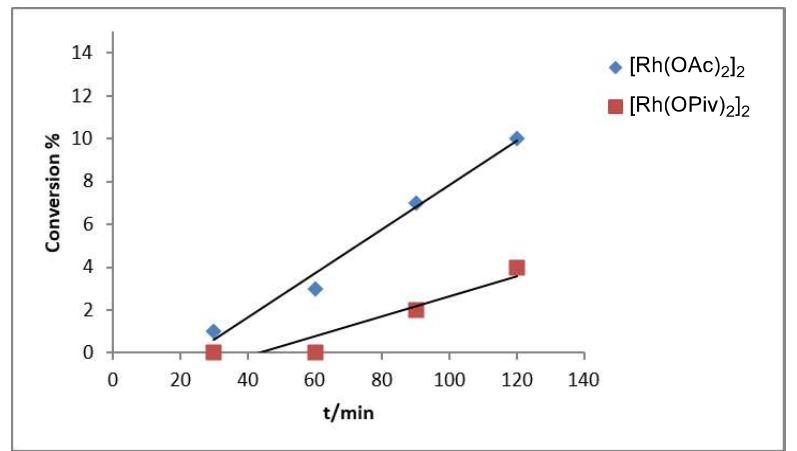

Scheme 3.4.7 (a) Reactions with $\left[\mathrm{Rh}(\mathrm{OTFA})_{2}\right]_{2}$ and $\left[\mathrm{Rh}(\mathrm{OPiv})_{2}\right]_{2}$ and (b) relative initial rate profile with $\left[\mathrm{Rh}(\mathrm{OAc})_{2}\right]_{2}$ and $\left[\mathrm{Rh}(\mathrm{OPiv})_{2}\right]_{2}$ for the electrochemical rhodium-catalyzed $\mathrm{C}-\mathrm{H}$ oxygenation.

Since the peaks in the mass spectroscopy were ascribable to bimetallic complexes, we started to wonder if a bimetallic rhodium/rhodium species could be the active catalyst in the oxygenation reaction. To have some insights, Dr. X. Tan tried the reaction with stoichiometric amounts of $\mathrm{Rh}(\mathrm{OAc})_{3}$ without electricity, and no reaction was obtained. Moreover, a mass spectrometric analysis performed after electrolysis of the sole catalyst showed that $\left[\mathrm{Rh}(\mathrm{OAc})_{2}(\mathrm{OTFA})_{2}\right]_{2}$ could be a plausible intermediate. At this point, if bimetallic species were involved, the possibilities are that we are in presence of a rhodium(III)/rhodium(III) monocationic or dicationic species, or a rhodium(II)/rhodium(III) monocationic species. To clarify the situation, Dr. J. C. A. Oliveira 
performed DFT calculations on the $\mathrm{C}-\mathrm{H}$ activation step, which showed that the most plausible pathway was through a bimetallic rhodium $\mathrm{Rh}(\mathrm{III})-\mathrm{Rh}(\mathrm{III})$ dicationic species with a barrier of 25.1 $\mathrm{kcal} \mathrm{mol}^{-1}$ for the $\mathrm{C}-\mathrm{H}$ activation step (Figure 3.4.2). The calculated barrier for the $\mathrm{C}-\mathrm{H}$ activation elementary step for both the other bimetallic complexes in this study was significantly higher, at approximately $29 \mathrm{kcal} \mathrm{mol}^{-1}$.

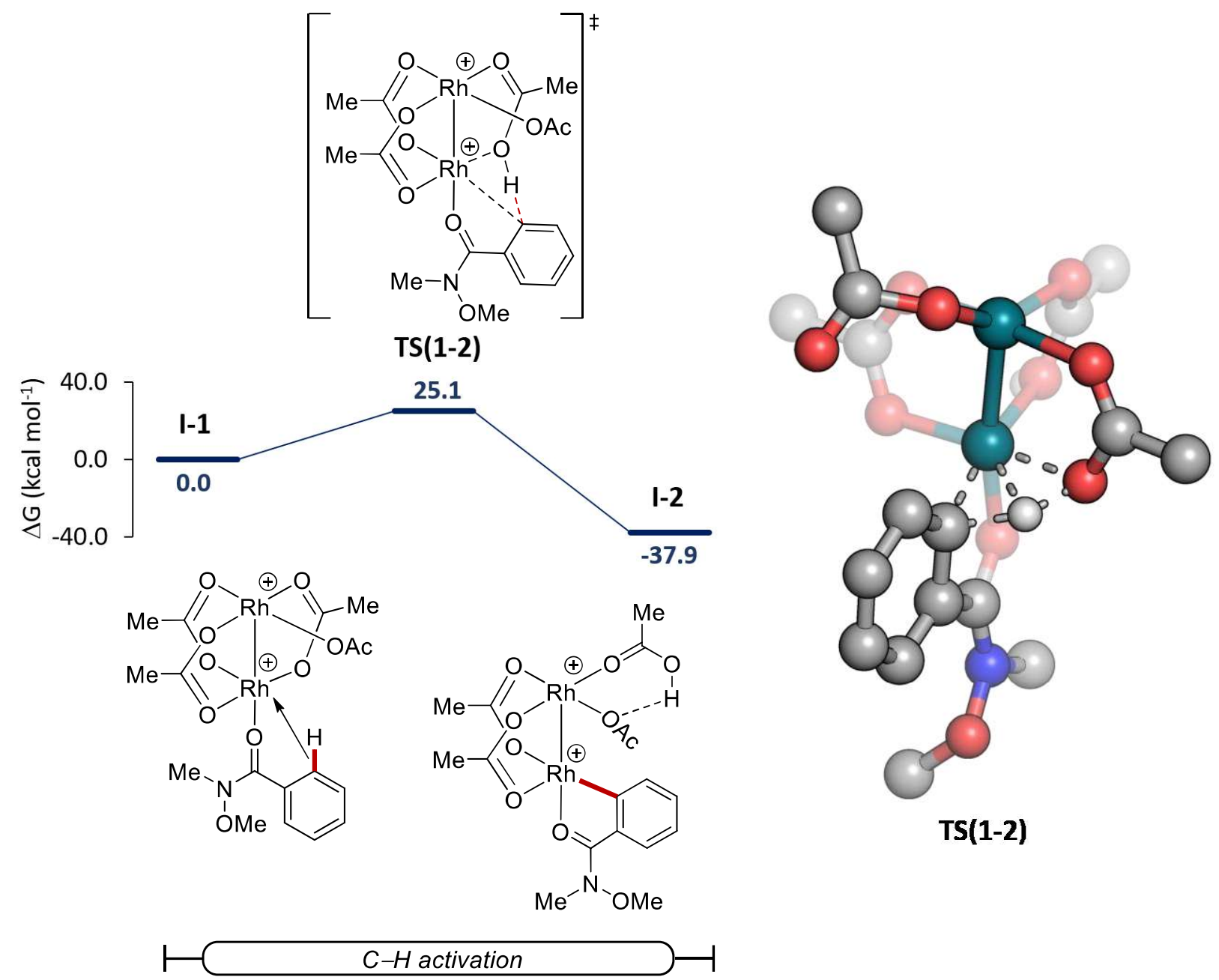

Figure 3.4.2 Calculated relative Gibbs free energies $\left(\Delta \mathrm{G}_{298.15}\right)$ in $\mathrm{kcal} \mathrm{mol}^{-1}$ for the $\mathrm{C}-\mathrm{H}$ activation elementary step at the B3LYP-D4/6-311++G**,Rh/SDD+SMD(DCE)//B3LYP-D3BJ/6$31 \mathrm{G}^{* *}, \mathrm{Rh} / \mathrm{SDD}$ level of theory for a dicationic $\mathrm{Rh}(\mathrm{III})-\mathrm{Rh}(\mathrm{III})$ complex. In the computed transition state structure, non-relevant hydrogens are omitted for clarity. Performed by Dr. J. C. A. Oliveira.

To further prove our hypothesis, additional cyclic voltammetry studies were conducted by M. N. Hussain, showing no differences in the oxidation potential of the catalyst, neither alone nor in the 
presence of the substrate 196a (Figure 3.4.3,a). This could suggest that the catalyst did not interact with the substrate prior to its oxidation. To prove this, Dr. X. Tan performed a stepwise reaction, firstly oxidizing the catalyst and, once the current was turned off, adding the substrate to perform the $\mathrm{C}-\mathrm{H}$ activation (Scheme 3.4.3,b). The product formation proved an oxidatively-induced $\mathrm{C}-\mathrm{H}$ activation and oxygenation.

(a) Cyclic Voltammetry

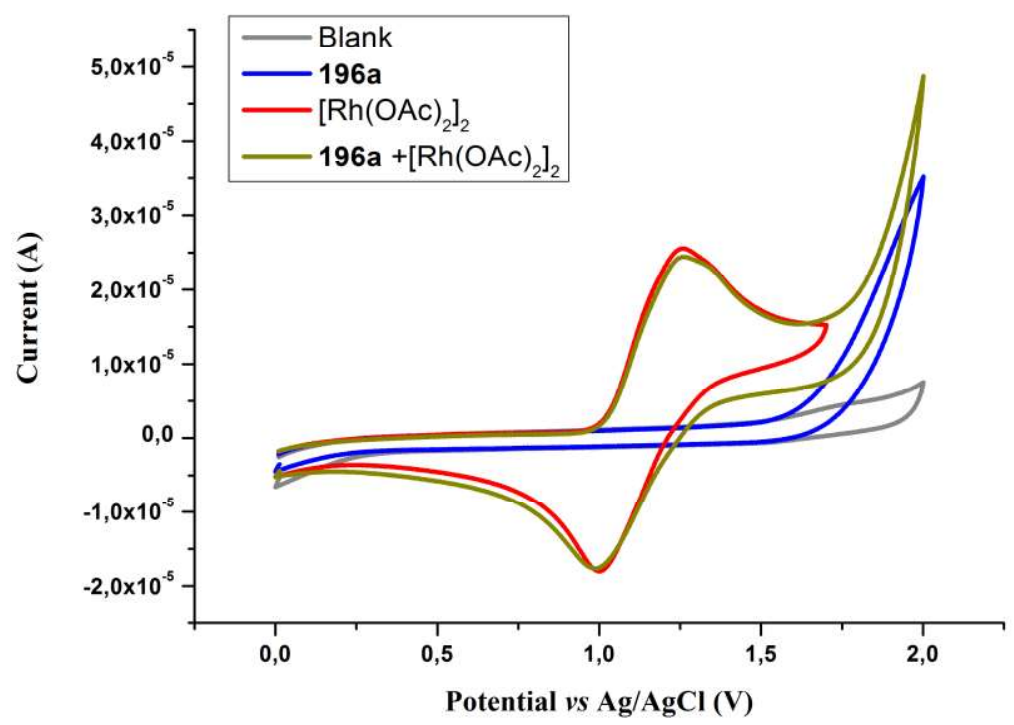

(b) Stepwise oxidation/oxygenation
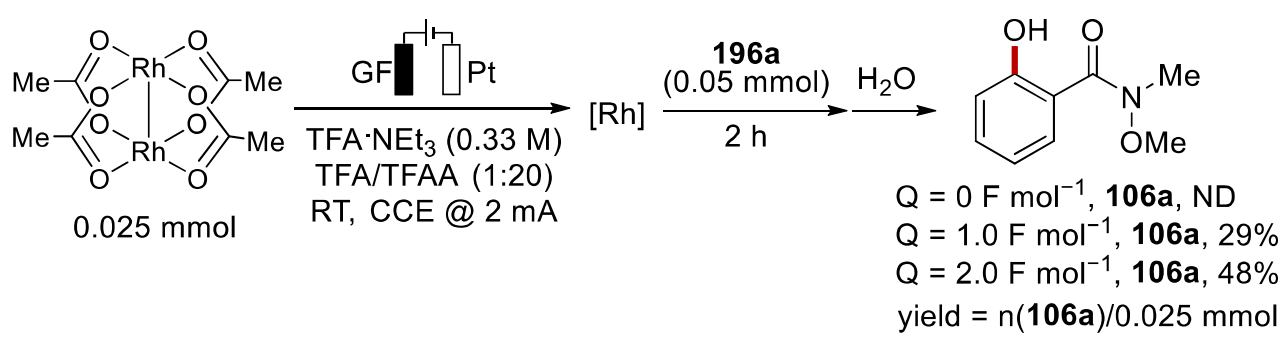

Figure 3.4.3 (a) Cyclic voltammetry measurements with GC working electrode in TFA/TFAA (1:1) with $0.15 \mathrm{M} \mathrm{TFA} \cdot \mathrm{NEt}_{3}$ at r.t. with a scan rate of $100 \mathrm{mVs}^{-1}$; concentrations of substrates were 5.0 $\mathrm{mM}$; (b) stepwise oxidation experiment.

Lastly, the trifluoroacetate ester $\mathbf{2 0 1}$ that should form prior to the hydrolysis at the end of the reaction, was detected by GC-MS for substrate $\mathbf{1 0 3 f}$ (Scheme 3.4.8), as similarly performed in the previous 
project (vide supra). The ester is very susceptible to hydrolysis, so further purification and isolation were not possible.

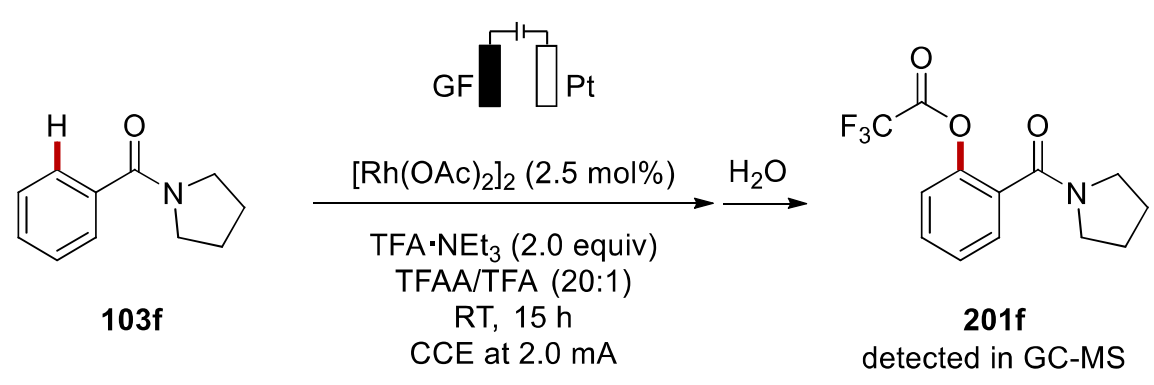

Scheme 3.4.8 Detection of the trifluoroacetate intermediate.

With the data obtained from experiments, mass spectroscopy, cyclic voltammetry, and computation, we could propose a plausible catalytic cycle for the envisioned rhodium oxygenation reaction (Scheme 3.4.9). The mechanism commences with the oxidation of the rhodium acetate dimer to generate a monocationic rhodium(III)/rhodium(II) species 208. A subsequent oxidation drives to what the DFT calculations proposed to be the active catalyst, the dicationic rhodium(III)/rhodium(III) species 209. Hence, after coordination of the substrate, the facile, but irreversible, $\mathrm{C}-\mathrm{H}$ activation takes place. Finally, a reductive elimination yields the trifluoroacetate ester 201 of the desired product 106, which is then obtained by aqueous workup. At the same time, anodic oxidation regenerates the catalyst 209. 


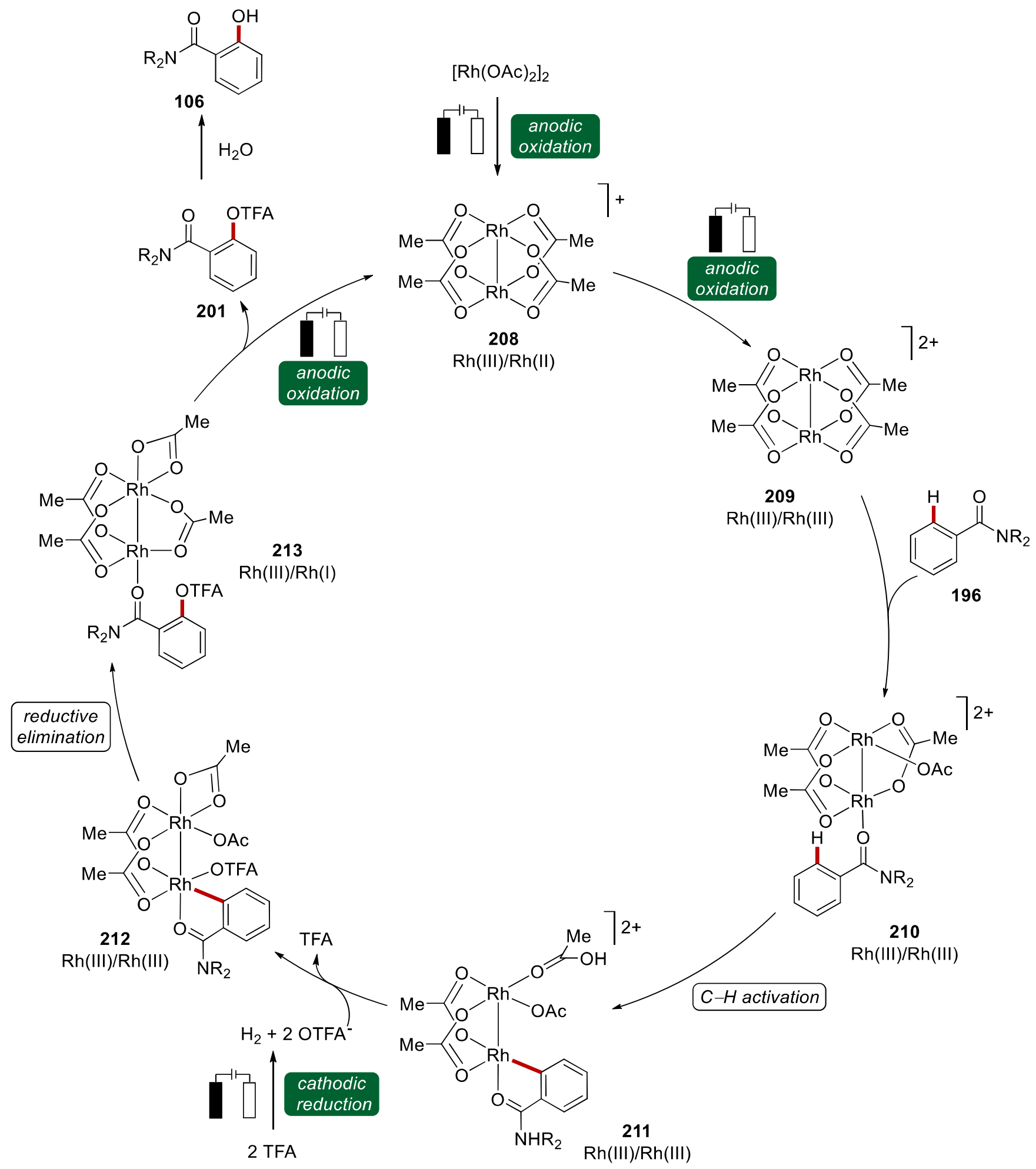

Scheme 3.4.9 Plausible catalytic cycle for the electrochemical rhodium-catalyzed C-H oxygenation. 


\subsection{Manganaelectro-Catalyzed Azine $\mathrm{C}-\mathrm{H}$ Arylations and $\mathrm{C}-\mathrm{H}$ Alkylations by Assistance of Weakly-Coordinating Amides}

Electrochemical manganese-catalyzed $\mathrm{C}-\mathrm{H}$ activation is underdeveloped and represented a challenge that we wanted to address. Indeed, besides the electrochemical olefin functionalizations ${ }^{[156-157]}$ and azidation reactions, ${ }^{[158,159]}$ no reports on electrochemical manganese-catalyzed $\mathrm{C}-\mathrm{H}$ activation were published, to the best of my knowledge. Due to our experience in low-valent manganese-catalysis ${ }^{[151,}$ 153-154] and our accomplishment in electrochemical low-valent iron catalysis, ${ }^{[48 f]}$ we planned to develop an electrochemical approach for the low-valent mangasese catalysis.

\subsubsection{Optimization}

At the outset of the project, our goal was to use a weakly coordinating mono-dentate amide in order to more easily access electrochemical $\mathrm{C}-\mathrm{H}$ arylations. The optimization was carried out together with Dr. C. Zhu. For this purpose, benzamide 172a was employed under the optimized reaction conditions of an earlier former project on iron-electro-catalyzed $\mathrm{C}-\mathrm{H}$ arylations of TAM-benzamides (Table 3.5.1). ${ }^{[48 f]}$ The first attempt was unsuccessful and a modification of the conditions with the use of different ligands, namely dppe, neocuproine, or 1,10 phenantroline, of different currents (3.0 or $5.0 \mathrm{~mA}$ ), of $\mathrm{FeCl}_{3}$ instead of $\mathrm{Fe}(\mathrm{acac})_{3}$, or of different temperatures, did not provide any breakthrough (entries 1-7). At the same time, Dr. C. Zhu studied the reaction with different catalysts. Nickel, ruthenium, and palladium fell short in providing the desired product 176aa (entries 8-10). Only manganese was efficiently delivering the arylated benzamide in a discrete manner and the testing of different ligands, such as 2,2'-dipyridyl, 1,10-phenantroline, and neocuproine, revealed neocuproine to be the best one, giving $70 \%$ of the isolated desired product 176aa (entries 11-14). Manganese(I)pentacarbonyl bromide, manganese(II) acetate, and manganese(II) acetylacetonate were tested with a good outcome for each catalyst, but not as good as the inexpensive manganese(II) chloride (entries 15-17). To improve the efficiency of the electrocatalysis system, we tried supporting electrolytes, such as tetrabutylammonium hexafluorophosphate or lithium perchlorate, but these were not beneficial for the reaction (entries 18-19). Control experiments were performed to probe the essential role of the catalyst, TMEDA, and electricity, and all the components proved to be 
essential for the reactivity (entries 20-22). Moreover, the reaction gave a similar result when the CCE was set at $2.5 \mathrm{~mA}$ (entry 23). Lastly, a 1:1 mixture of tetrahydrofuran and $N$-methyl-2pyrrolidone, or $\gamma$-valerolactone were tested as alternative solvents, but neither provided any product (entries 24-25).

Table 3.5.1 Optimization of the electrochemical manganese-catalyzed C-H arylation. ${ }^{\text {[a] }}$

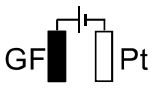

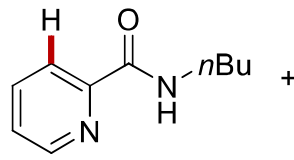

$172 a$
ArMgBr

$175 a$

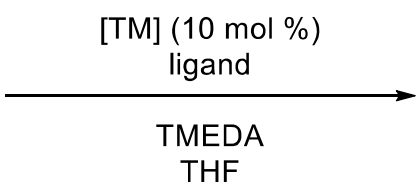

$60^{\circ} \mathrm{C}, 18 \mathrm{~h}, \mathrm{~N}_{2}$ CCE at $3.0 \mathrm{~mA}$

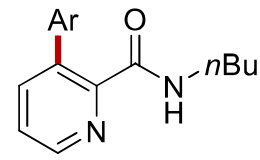

$176 a a$

entry $\quad$ ligand

Deviation from standard

conditions

yield

(\%)

\begin{tabular}{|c|c|c|c|c|}
\hline 1 & $\mathrm{Fe}(\mathrm{acac})_{3}$ & dppe (10 mol \%) & $40^{\circ} \mathrm{C}, 6 \mathrm{~h}, 5.0 \mathrm{~mA}$ & traces \\
\hline 2 & $\mathrm{Fe}(\mathrm{acac})_{3}$ & dppe (10 mol \%) & $40{ }^{\circ} \mathrm{C}, 5.0 \mathrm{~mA}$ & 11 \\
\hline 3 & $\mathrm{Fe}(\mathrm{acac})_{3}$ & dppe $(10$ mol \%) & $5.0 \mathrm{~mA}$ & traces \\
\hline 4 & $\mathrm{Fe}(\mathrm{acac})_{3}$ & neocuproine (20 $\mathrm{mol} \%)$ & --- & --- \\
\hline 5 & $\mathrm{Fe}(\mathrm{acac})_{3}$ & neocuproine (20 mol \%) & $5.0 \mathrm{~mA}$ & --- \\
\hline 6 & $\mathrm{Fe}(\mathrm{acac})_{3}$ & 1,10-phenanthroline (20 mol \%) & $40{ }^{\circ} \mathrm{C}, 5.0 \mathrm{~mA}$ & 7 \\
\hline 7 & $\mathrm{FeCl}_{3}$ & dppe (10 mol \%) & $40{ }^{\circ} \mathrm{C}, 5.0 \mathrm{~mA}$ & 10 \\
\hline 8 & $\mathrm{Ni}(\mathrm{DME}) \mathrm{Cl}_{2}$ & neocuproine (20 mol \%) & --- & $---[b]$ \\
\hline 9 & $\mathrm{RuCl}_{3} \cdot\left(\mathrm{H}_{2} \mathrm{O}\right)_{\mathrm{n}}$ & neocuproine (20 $\mathrm{mol} \%)$ & --- & $---[b]$ \\
\hline 10 & $\mathrm{PdCl}_{2}$ & neocuproine (20 mol \%) & --- & $---[b]$ \\
\hline 11 & $\mathrm{MnCl}_{2}$ & 2,2'-dipyridyl (20 mol \%) & --- & $40^{[\mathrm{b}]}$ \\
\hline 12 & $\mathrm{MnCl}_{2}$ & 1,10-phenanthroline (20 mol \%) & --- & $61^{[\mathrm{b}]}$ \\
\hline 13 & $\mathrm{MnCl}_{2}$ & neocuproine ( $20 \mathrm{~mol} \%)$ & --- & $70^{[b]}$ \\
\hline 14 & $\mathrm{MnCl}_{2}$ & --- & --- & $34^{[b]}$ \\
\hline 15 & $\mathrm{MnBr}(\mathrm{CO})_{5}$ & neocuproine (20 mol \%) & --- & 47 \\
\hline 16 & $\mathrm{Mn}(\mathrm{OAc})_{2}$ & neocuproine (20 mol \%) & --- & 50 \\
\hline 17 & $\operatorname{Mn}(\operatorname{acac})_{2}$ & neocuproine (20 mol \%) & --- & 55 \\
\hline 18 & $\mathrm{MnCl}_{2}$ & neocuproine (20 mol \%) & $n \mathrm{Bu}_{4} \mathrm{NPF}_{6}$ & --- \\
\hline
\end{tabular}




\begin{tabular}{|c|c|c|c|c|}
\hline 19 & $\mathrm{MnCl}_{2}$ & neocuproine (20 mol \%) & $\mathrm{LiClO}_{4}$ & $30^{[\mathrm{b}]}$ \\
\hline 20 & --- & neocuproine (20 $\mathrm{mol} \%)$ & --- & $---[b]$ \\
\hline 21 & $\mathrm{MnCl}_{2}$ & neocuproine (20 $\mathrm{mol} \%)$ & without TMEDA & $---[b]$ \\
\hline 22 & $\mathrm{MnCl}_{2}$ & neocuproine (20 $\mathrm{mol} \%)$ & without electricity & $10^{[\mathrm{b}]}$ \\
\hline 23 & $\mathrm{MnCl}_{2}$ & neocuproine (20 mol \%) & $2.5 \mathrm{~mA}$ & $67^{[\mathrm{b}]}$ \\
\hline 24 & $\mathrm{MnCl}_{2}$ & neocuproine (20 $\mathrm{mol} \%)$ & THF/NMP & $\ldots[b]$ \\
\hline 25 & $\mathrm{MnCl}_{2}$ & neocuproine (20 mol \%) & GVL & $---[b]$ \\
\hline
\end{tabular}

${ }^{[a]}$ Reaction conditions: undivided cell, 172a $(0.25 \mathrm{mmol}), 175 \mathrm{a}(1.00 \mathrm{mmol}),[\mathrm{TM}](10 \mathrm{~mol} \%)$, ligand (as specified), TMEDA $(0.50 \mathrm{mmol})$, solvent $(4.0 \mathrm{~mL}), 60^{\circ} \mathrm{C}, 18 \mathrm{~h}, \mathrm{~N}_{2}, \mathrm{CCE}$ at $3.0 \mathrm{~mA}$, graphite felt $(\mathrm{GF})$ anode $(10 \mathrm{~mm} \times 15 \mathrm{~mm} \times 6 \mathrm{~mm})$, Pt-plate cathode $(10 \mathrm{~mm} \times 15 \mathrm{~mm} \times 0.125 \mathrm{~mm})$, yield of isolated products. $\mathrm{Ar}=4-\mathrm{MeOC}_{6} \mathrm{H}_{4}, \mathrm{TMEDA}=N^{1}, N^{1}, N^{2}, N^{2}$-tetra-methylethane-1,2-diamine. dppe $=1$,2-bis(diphenylphosphino) ethane. ${ }^{[b]}$ Performed by Dr. C. Zhu.

\subsubsection{Substrate Scope}

The optimized conditions were then applied to a broad range of secondary amides $\mathbf{1 7 2}$ to prove the robustness of the reaction (Scheme 3.5.1). Several groups were acceptable on the amide moiety, such as benzyl (172b) and $n$-hexyl substituents (172c). Also, para-substituents on the benzyl group did not alter the course of the arylation reaction, and both a methoxy (172d) and a fluoro (172e) substituents were used in that position. The bulkier ortho-fluoro benzyl derivative $\mathbf{1 7 2 f}$ was likewise converted to product 176fa. Moreover, 1,2,3,4-tetrahydronaphthalene or cyclohexene groups were tolerated (176ga, 176ha). Regarding the pyridine moiety, the para-phenyl substrate $\mathbf{1 7 2} \mathbf{j}$ was efficiently converted. Interestingly, the manganese-catalyzed electrochemical approach was also feasible for nicotinic and isonicotinic amides (172k-n). For the former, both the unsubstituted and the bulkier meta-methyl substrate provided the desired products 176ka and 176la, as well two examples 176ma and 176na were successfully obtained for the latter. 

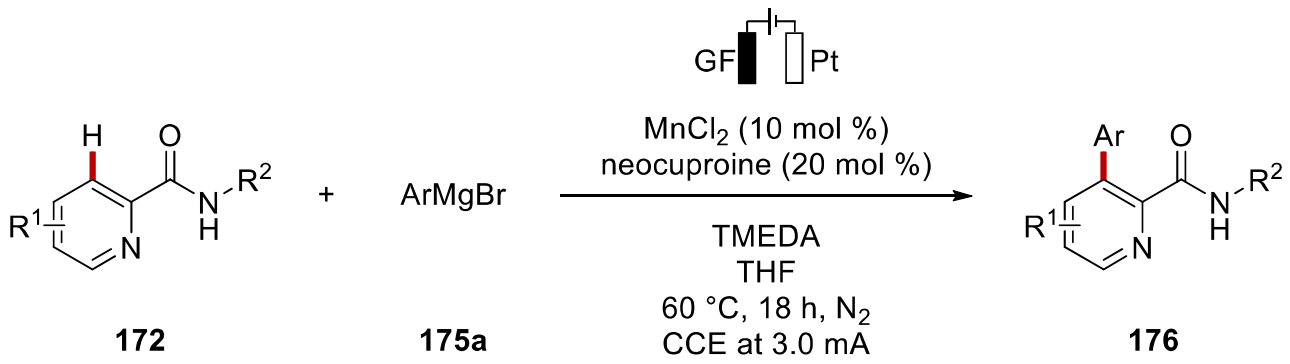<smiles>CCCCNC(=O)c1ncccc1Br</smiles>

176aa: $70 \%{ }^{[a]}$<smiles>COc1ccc(CNC(=O)c2ncccc2Br)cc1</smiles>

176da: $51 \%$<smiles>O=C(NC1CCCc2ccccc21)c1ncccc1Br</smiles>

176ga: $74 \%$<smiles>CCCCNC(=O)c1ncc(-c2ccccc2)cc1Br</smiles>

176ja: $59 \%^{[a]}$<smiles>O=C(NCc1ccccc1)c1ncccc1Br</smiles>

176ba: $58 \%$<smiles>O=C(NCc1ccc(F)cc1)c1ncccc1Cl</smiles>

176ea: $46 \%$<smiles>O=C(NC1CCCCC1)c1ncccc1Br</smiles>

176ha: $61 \%$<smiles>CCCCNC(=O)c1cnccc1Br</smiles>

176ka: $51 \%^{[a]}$

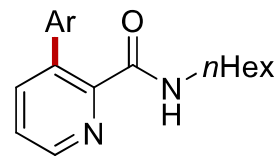

176ca: $77 \%^{[a]}$<smiles>O=C(NCc1ccccc1F)c1ncccc1Br</smiles>

176fa: $56 \%$<smiles>O=C(NCCc1ccccc1)c1ncccc1Br</smiles>

176ia: $70 \%{ }^{[a]}$<smiles>CCCCNC(=O)c1cncc(C)c1Br</smiles>

176la: $60 \%{ }^{[a]}$<smiles>CCCCNC(=O)c1ccncc1Br</smiles>

176ma: $65 \%^{[\mathrm{a}]}$<smiles>O=C(NCc1ccccc1)c1ccncc1Br</smiles>

176na: $56 \%^{[\mathrm{a}]}$

Scheme 3.5.1 Scope of electrochemical manganese-catalyzed C-H arylation of amides 172. [a] Performed by Dr. C. Zhu. $\mathrm{Ar}=4-\mathrm{MeOC}_{6} \mathrm{H}_{4}$.

The scope was further extended with the probing of diverse aryl Grignard reagents $\mathbf{1 7 5}$ as the arylating agents (Scheme 3.5.2). Besides the anisole moiety (172a), the unsubstituted phenyl group 
(172b) could also be easily installed. Other substrates with electron-rich groups, including methyl, tert-butyl, and phenyl substituents, were converted with excellent yields (172c-e). The 4fluorobenzylmagnesiumbromide furnished likewise $60 \%$ of the product $\mathbf{1 7 2 f}$. Good yields were also obtained with methoxy or fluoro groups in the meta-position (176ag-ah) The challenging thiophene motif (172i) succeeded in the arylation reaction giving a modest yield for product 176ai. Lastly, the naphthyl-substituted Grignard reagent $\mathbf{1 7 2} \mathbf{j}$ also provided the arylated product 176aj in good amounts.

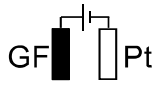

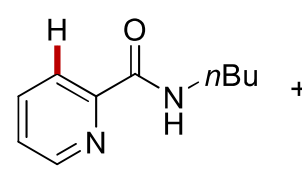

$172 a$
[TM] $(10 \mathrm{~mol} \%)$ $\mathrm{ArMgBr}$ 175

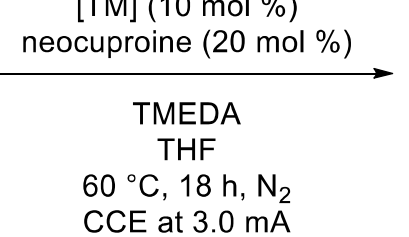<smiles>CCCCNC(=O)c1ncccc1Br</smiles>

176<smiles>CCCCNC(=O)c1ncccc1-c1ccc(OC)cc1</smiles>

176aa: $70 \%{ }^{[a]}$<smiles>CCCCNC(=O)c1ncccc1-c1ccc(C(C)(C)C)cc1</smiles>

176ad: $73 \%$<smiles>[R]c1cccc(-c2cccnc2C(=O)NCCCC)c1</smiles>

$\mathrm{R}=-\mathrm{OMe}$ (176ag): $76 \%$ $\mathrm{R}=-\mathrm{F}(\mathbf{1 7 6} \mathrm{ah}): \quad 70 \%$<smiles>CCCCNC(=O)c1ncccc1-c1ccccc1</smiles>

176ab: $75 \%$<smiles>CCCCNC(=O)c1ncccc1-c1ccc(-c2ccccc2)cc1</smiles>

176ae: $57 \%^{[a]}$<smiles>CCCCNC(=O)c1ncccc1-c1ccsc1</smiles>

176ai: $21 \%^{[\mathrm{a}]}$<smiles>CCCCNC(=O)c1ncccc1-c1ccc(C)cc1</smiles>

176ac: $78 \%$<smiles>CCCCNC(=O)c1ncccc1-c1ccc(F)cc1</smiles>

176af: $60 \%{ }^{[a]}$<smiles>CCCCNC(=O)c1ncccc1-c1ccc2ccccc2c1</smiles>

176aj: $52 \%$ [a] 
Scheme 3.5.2 Scope of electrochemical manganese-catalyzed $\mathrm{C}-\mathrm{H}$ arylation with different arylating agents 172. ${ }^{[a]}$ Performed by Dr. C. Zhu.

During the attempts to expand the scope, we were delighted to discover that the envisioned manganese-catalyzed methodology was also feasible for unprecedented electrochemical $\mathrm{C}-\mathrm{H}$ alkylations (Scheme 3.5.3). With this approach we were able to perform the $\mathrm{C}-\mathrm{H}$ methylation reaction (214aa), that is considered a very important reaction for pharmaceutical industries due to the so-called 'magic methyl effect', which can lead to an enhancement in bioactivity or selectivity of a drug candidate after the insertion of a sole $\mathrm{CH}_{3}$ group. ${ }^{[172]}$ The isopropyl group was also successfully introduced, yielding the desired product 214ab. Moreover, the reaction proved amenable for benzylation likewise (214hc).

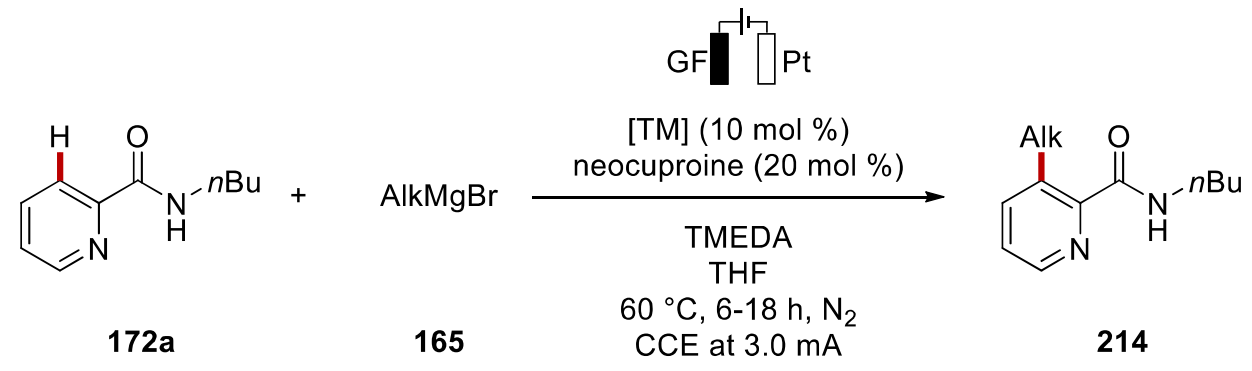<smiles>CCCCNC(=O)c1ncccc1C</smiles>

214aa: $60 \%$<smiles>CCCCNC(=O)c1ncccc1C(C)C</smiles>

214ab: $57 \%$<smiles>O=C(NC1CCCCC1)c1ncccc1Cc1ccccc1</smiles>

214hc: $45 \%$

Scheme 3.5.3 Scope of electrochemical manganese-catalyzed C-H alkylation of amides $\mathbf{1 7 2}$.

\subsubsection{Mechanistic Studies}

Subsequently, mechanistic studies were performed, starting with competition experiments between the Grignard reagents $\mathbf{1 7 5 c}$ and $\mathbf{1 7 5 f}$. The more electron-rich Grignard $\mathbf{1 7 5 c}$ reacted preferentially, with a $31 \%$ yield of product 176ac, while the electron-poor one gave $17 \%$ of $\mathbf{1 7 6 a f}$ (Scheme $3.5 .4, a)$. The preference for the electron-rich substrate $\mathbf{1 7 5 c}$ is in accordance with the proposal of a ligand-to- 
ligand hydrogen transfer (vide infra). Another competition experiment was conducted between the picolinic and nicotinic amides $\mathbf{1 7 2 a}$ and $\mathbf{1 7 2} \mathbf{k}$, with the former reacting faster. Moreover, the kinetic isotope effect, studied on parallel reactions, was found to be $k_{\mathrm{H}} / k_{\mathrm{D}} \approx 1.1$, suggesting that the $\mathrm{C}-\mathrm{H}$ activation is not the rate determining step (Scheme 3.5.4,b, performed by Dr. C. Zhu).

(a) Competition experiments
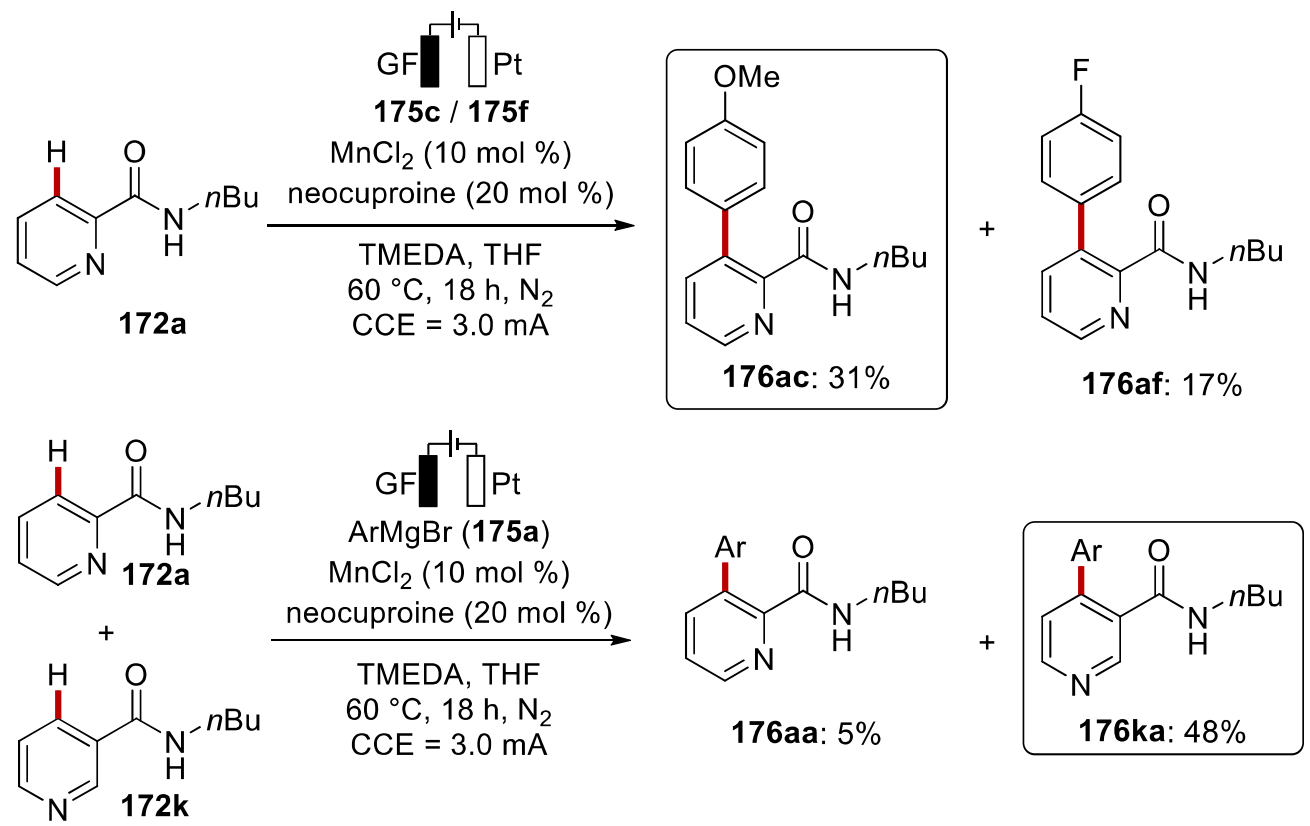

(b) KIE studies ${ }^{[a]}$<smiles>O=C(NCc1ccccc1F)c1ncccc1Br</smiles>

$172 f /[D]_{1}-172 f$
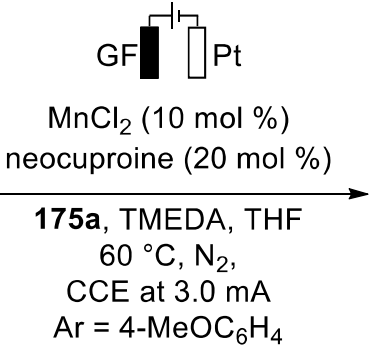

$k_{\mathrm{H}} / k_{\mathrm{D}}=1.1$

Scheme 3.5.4 Mechanistic findings for the electrochemical manganese-catalyzed $\mathrm{C}-\mathrm{H}$ activation. ${ }^{\text {[a] }}$ Performed by Dr. C. Zhu. $\mathrm{Ar}=4-\mathrm{MeOC}_{6} \mathrm{H}_{4}$.

Since the $\mathrm{C}-\mathrm{H}$ activation did not seem to be the slow step, the dependence of the rate on the current was tested next (Figure 3.5.1). The profiles clearly showed an increasing rate with increasing currents. 


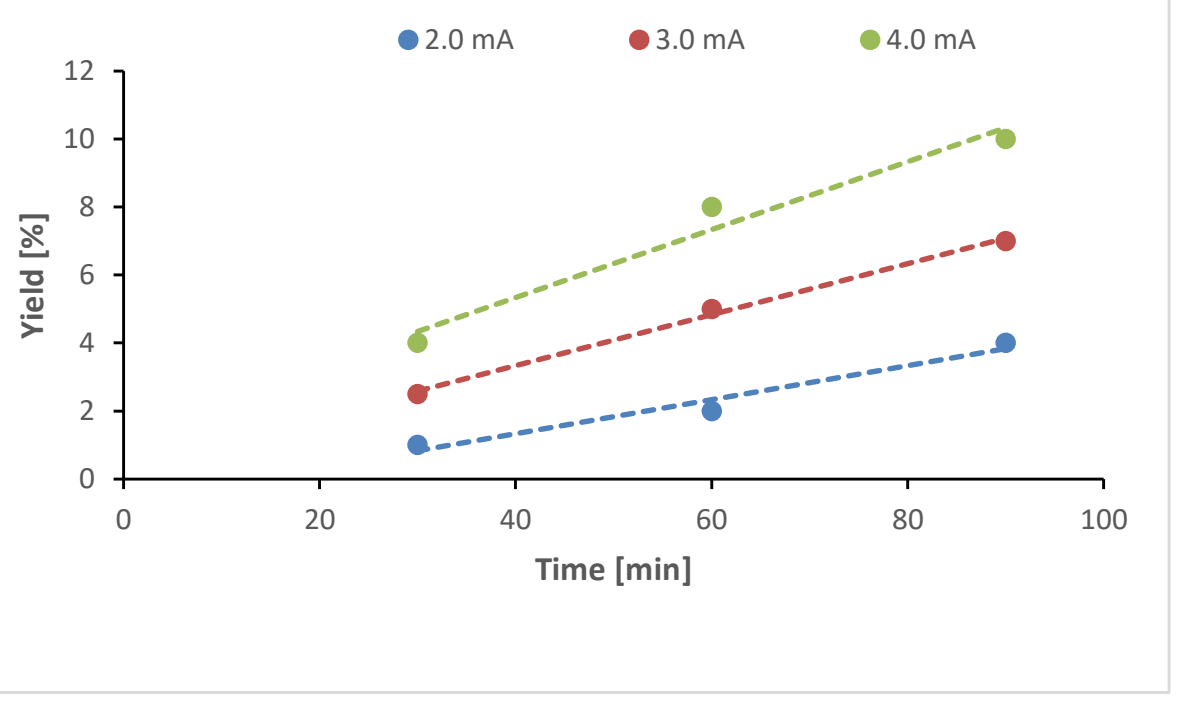

Figure 3.5.1 Profile of the manganese-catalyzed $\mathrm{C}-\mathrm{H}$ activation at different currents.

Then, the well-defined manganese complex 215 was synthesized and tested under the reaction conditions (Scheme 3.5.5). The complex 215 gave a comparable yield, confirming its catalytic activity. Together with MSc A. Salamé, we analyzed the manganese-neocuproine complex by cyclic voltammetry, and it showed a reversible oxidation, supposedly manganese(II)/(III), at $\mathrm{E}_{1 / 2}=+0.80 \mathrm{~V}$ vs. $\mathrm{Ag} / \mathrm{AgCl}$ (Figure 3.5.2). The addition of the amide 172a did not modify the oxidation event. The presence of all the reaction compounds, caused the irreversibility of the mentioned oxidation, due to plausible transmetalation.

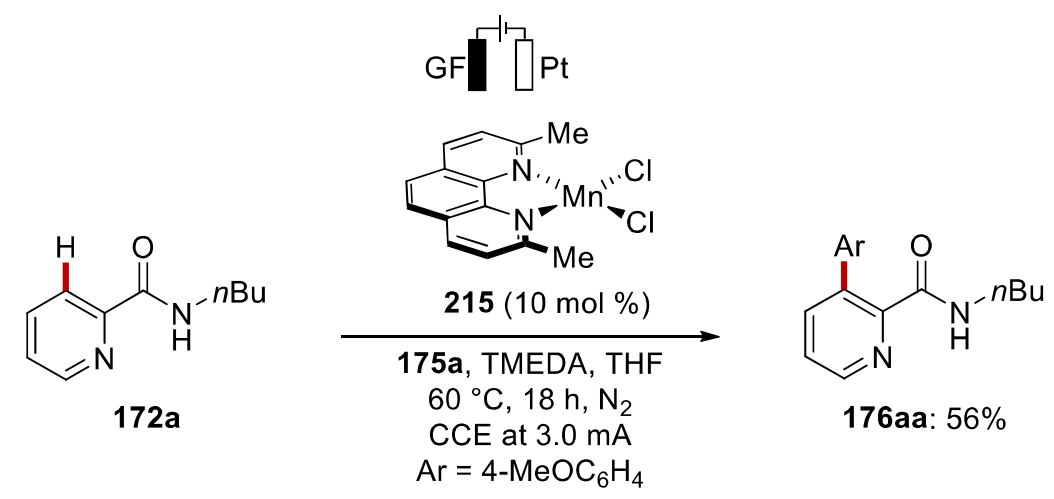

Scheme 3.5.5 Manganese complex 215 in the electrochemical manganese-catalyzed C-H activation. 


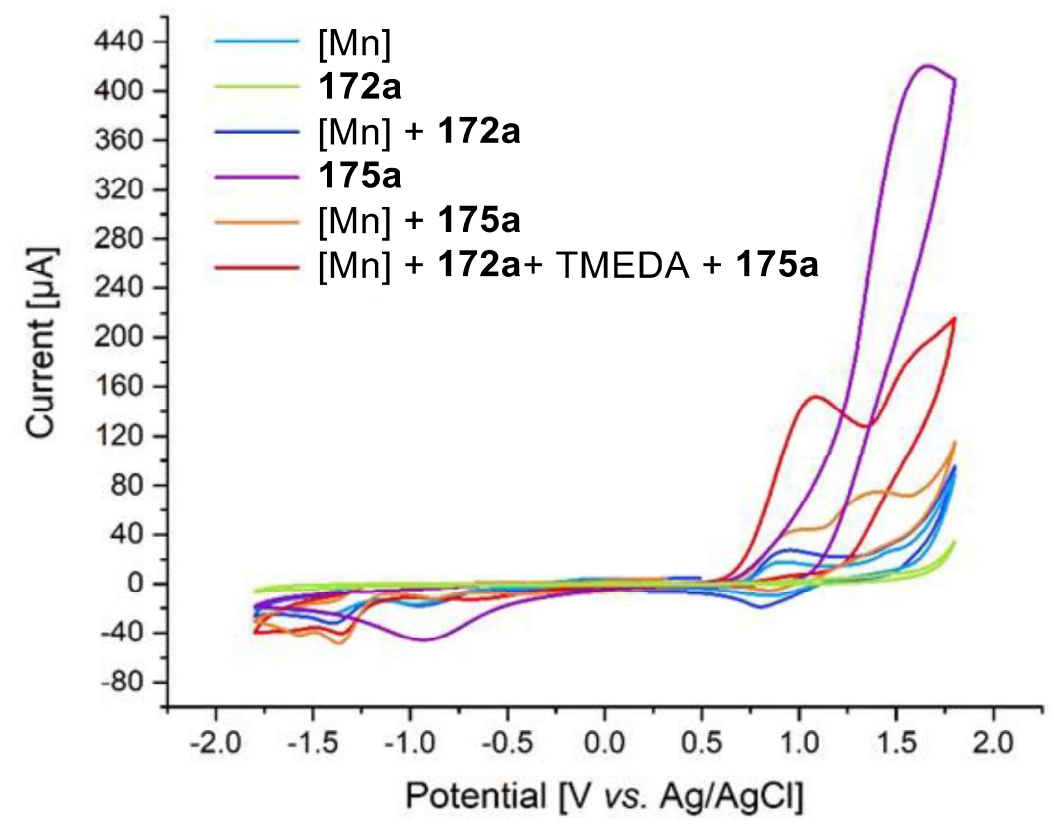

Figure 3.5.2 Cyclic voltammograms recorded with GC working electrode at $100 \mathrm{mVs}^{-1}$ with $n \mathrm{Bu}_{4} \mathrm{NBF}_{4}\left(0.2 \mathrm{mM}\right.$ in THF); concentration of substrates $5.0 \mathrm{mM}(\mathbf{1 7 5 a} 20 \mathrm{mM}){ }^{[173]}=$ complex 215. Performed with MSc A. Salamé.

Having clarified the oxidative event, the reductive event had to be investigated. Thus, Dr. P. Liu performed scanning electron microscopy energy-dispersive X-ray spectroscopy (SEM-EDS) on the platinum cathode after the electrocatalysis (Figure 3.5.3). From this analysis, magnesium was found on the surface of the cathode, suggesting that magnesium ions were directly reduced on the platinum surface. This finding underlined one of the dissimilarities with the iron-catalyzed electrochemical C$\mathrm{H}$ arylation where zinc was deposit on the cathode. Indeed, in the iron-electrocatalyzed $\mathrm{C}-\mathrm{H}$ activation, zinc was preferentially reduced due to its redox potential of $-0.76 \mathrm{~V} v s$. NHE that is higher than the one of magnesium of $-2.36 \mathrm{~V} v$. NHE. ${ }^{[174]}$ 

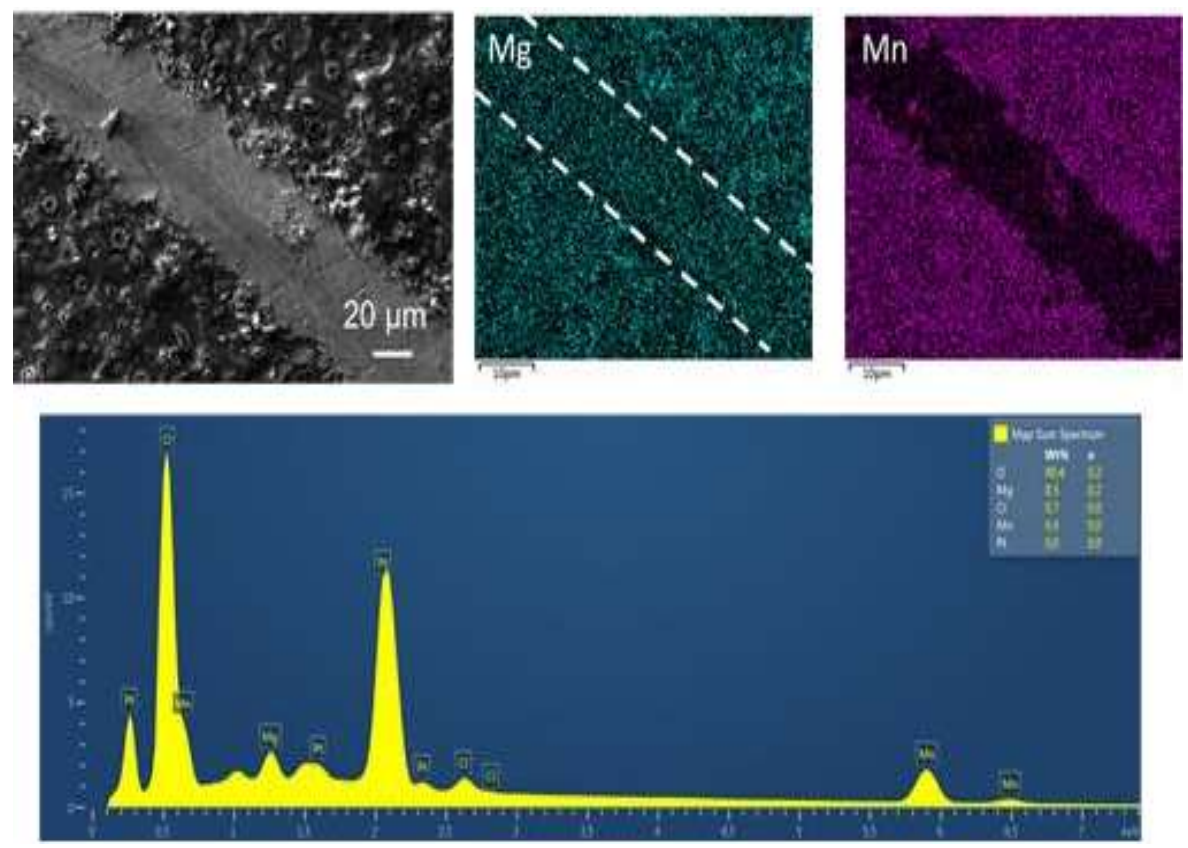

Figure 3.5.3 SEM-EDS studies on the post-catalysis cathodic material. Performed by Dr. P. Liu.

Based on our detailed mechanistic observations, a plausible catalytic cycle has been deduced (Scheme 3.5.6). Initially, the active catalyst $\mathbf{2 1 6}$ is formed upon coordination the ligand and the Grignard reagent. Subsequently, C-H activation through a ligand-to-ligand hydrogen transfer (LLHT) takes place. After a transmetalation event, an anodic oxidation induces the reductive elimination from a manganese(III) intermediate 220. Lastly, another trasmetalation yields the product $\mathbf{1 7 6}$ and the manganese(I) complex 222. An anodic oxidation then regenerates the active catalyst 216. 


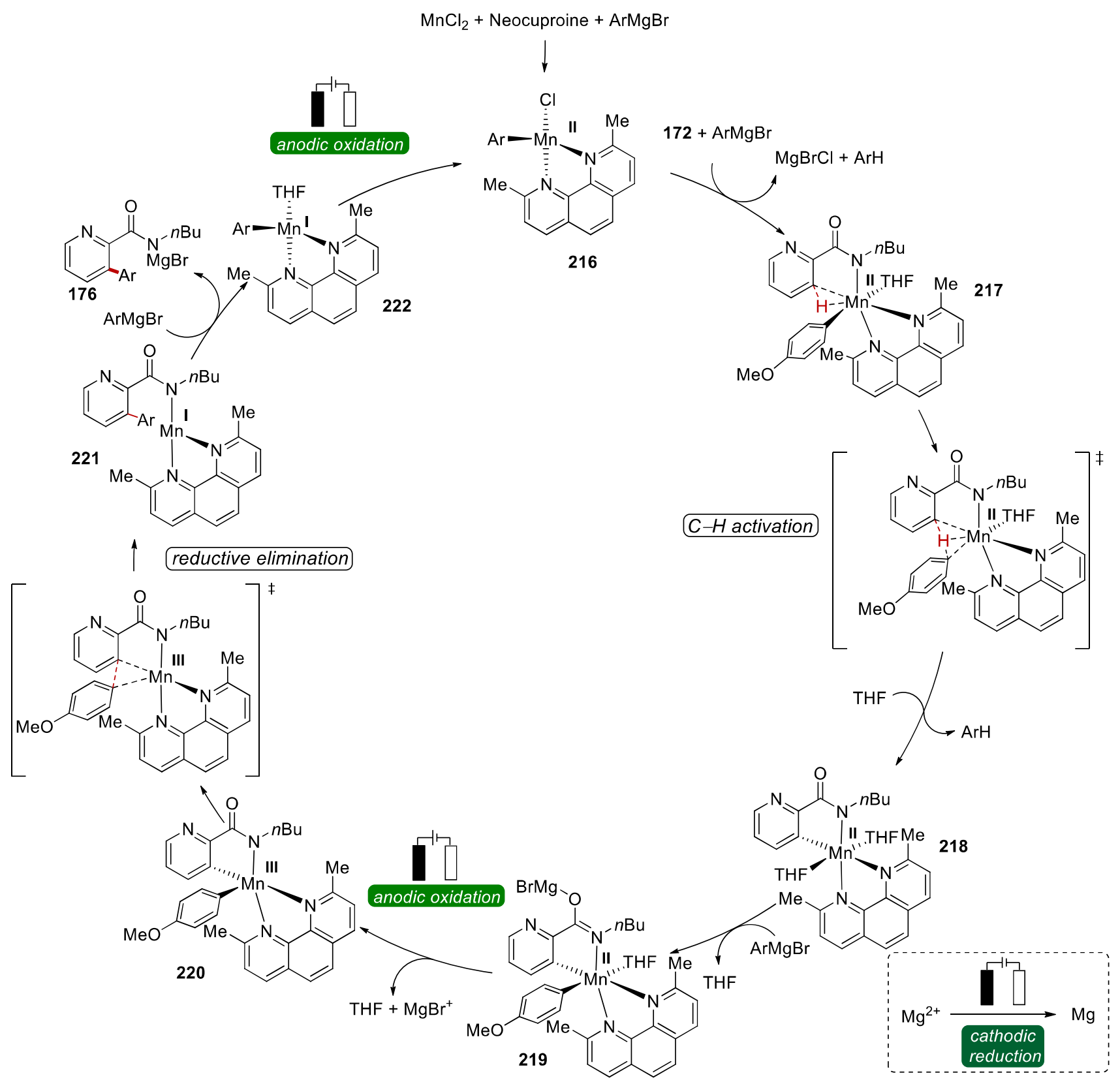

Scheme 3.5.6 Plausible catalytic cycle for the electrochemical manganese-catalyzed C-H arylation. 


\section{Summary and Outlook}

The oxidative metal-catalyzed $\mathrm{C}-\mathrm{H}$ activation of inert bonds is a powerful tool for the functionalization of complex molecules. This platform allows broadening of the organic chemists' toolbox and to improve the resource-economy of synthetic routes, avoiding prefunctionalizations of starting materials. Nevertheless, its applications were constrained by the use of stoichiometric oxidants, which limited the sustainability of this approach. In contrast, the use of electricity as environmental-friendly and versatile oxidant enhanced the sustainability of oxidative metal-catalyzed $\mathrm{C}-\mathrm{H}$ activation and opened the way to the study of novel reactivities and selectivities.

In the first project, an electrochemical strategy was studied for the $\mathrm{C}-\mathrm{H} / \mathrm{N}-\mathrm{H}$ annulation reaction with a cost-effective cobalt(II) salts as the catalyst (Scheme 4.1). ${ }^{[175]}$ The approach occurred under extremely mild conditions, allowing the electrolysis to occur at room temperature with water as the cosolvent. The newly established electrochemical procedure proved to be user-friendly, with an undivided cell setup and constant current electrolysis at $4.0 \mathrm{~mA}$. A variety of alkynes 117, including heteroarenes, furnished the desired products $\mathbf{3 4}$ with excellent levels of positional selectivity.

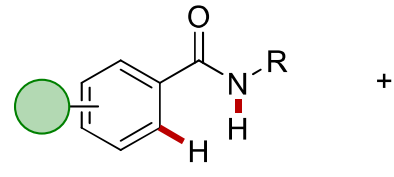

33

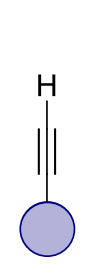

117

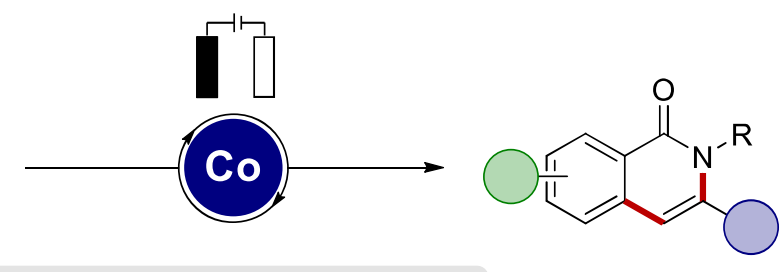

electrochemical oxidation no $\mathrm{Cu}(I I)$ or $\mathrm{Ag}(\mathrm{I})$ salts Earth-abundant cobalt catalyst $\mathrm{H}_{2}$ as the sole byproduct mild reaction conditions

Scheme 4.1 Electrochemical cobalt-catalyzed $\mathrm{C}-\mathrm{H} / \mathrm{N}-\mathrm{H}$ alkyne annulations.

The electrochemical oxidative metal-catalyzed annulation approach was then applied to internal unsymmetrical alkynes 24 by mean of ruthenium-catalysis (Scheme 4.2). ${ }^{[130]}$ This project represented the first ruthenaelectro-catalysis with weakly $O$-coordinating directing groups. The scope proved broad with examples of diaryl-, diheteroaryl-, dialkyl-substituted, and unsymmetrical alkynes 24. 
<smiles>O=C(O)c1ccc2ccccc2c1</smiles>

89

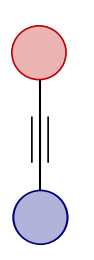

24

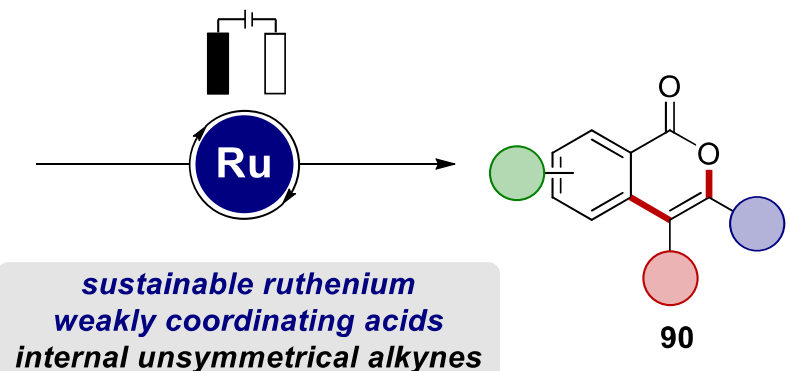

no $\mathrm{Cu}(\mathrm{II})$, no $\mathrm{Ag}(\mathrm{I})$

electricity as green oxidant

Scheme 4.2 Electrochemical ruthenium-catalyzed C-H/O-H alkyne annulations.

Having established a robust platform for electrooxidative $\mathrm{C}-\mathrm{H}$ activations, we aimed to broaden its applicability. Therefore, a study on the electrosynthesis of hypervalent iodine as mediator in ruthenium-catalyzed oxygenations was carried out (Scheme 4.3). ${ }^{[176]}$ The use of electricity allowed the use of catalytic amounts of iodoarenes 194a, without the need for other stoichiometric oxidants. The environmental footprint of such approach was thus minimized, as only $\mathrm{H}_{2}$ was generated as byproduct. The reaction featured a broad scope, selectively delivering the desired products 106, 104, 197, and 199 with Weinreb amides 196, tertiary amides 103, ketones 77, and even pyrazoles 198 as directing groups. The reaction was also tolerant of electron-rich as well as electron-poor arenes, and electrophilic functional groups, useful for late-stage modifications. Remarkably, the same reaction could be conducted for a two-step/one-pot remote undirected functionalization (109). 
<smiles>[R]C(=O)c1ccc2ccccc2c1</smiles>

$196,103,77$ 198 , or 200

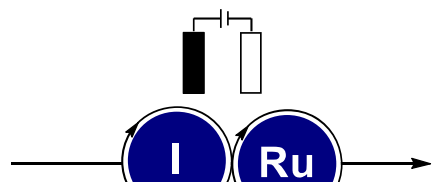

sustainable ruthenium(II) mild reaction conditions iodobenzene as mediator electrochemical formation of PIFA weakly coordinating ketones remote functionalization

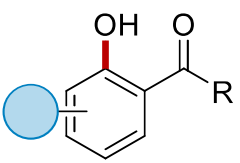

$106,104,197$ 199 , or 109<smiles>CC(C)(F)C(=O)OI(I)OC(=O)C(F)(F)F</smiles>

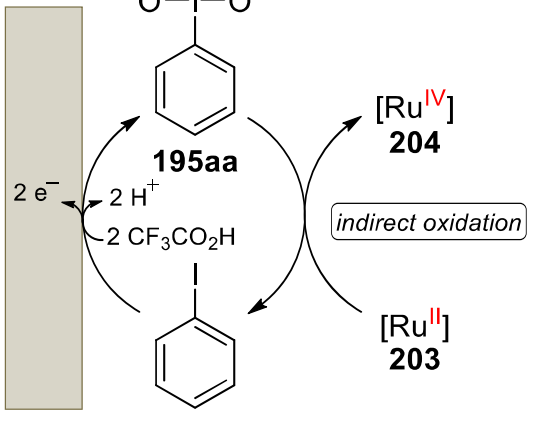

$194 a$<smiles>CON(C)C(=O)c1ccccc1O</smiles>

106a: $80 \%$<smiles>O=C(c1ccccc1O)N1CCCC1</smiles>

104f: $91 \%$<smiles>CC(=O)c1ccccc1O</smiles>

197c: $66 \%$<smiles>Cc1cccc(O)c1-n1cccn1</smiles>

199a: $53 \%$<smiles>COc1ccc(O)cc1Br</smiles>

109a: $52 \%$

Scheme 4.3 Electrochemical hypervalent iodine formation for the ruthenium-catalyzed C-H oxygenation reaction.

Subsequently, we focused on rhodium catalysis to attain an effective oxidation of the metal catalyst directly at the anode (Scheme 4.4). ${ }^{[177]}$ For this approach, the substrate scope proved similarly good to the ruthenium-catalyzed reaction. By taking advantage of the presence of electricity, it was also possible to access the cascade synthesis of dihydrooxazinone via a Shono oxidation. Comprehensive mechanistical studies, including CV analysis and DFT calculcations, demonstrated the bimetallic nature of the active rhodium catalyst and an oxidatively-induced $\mathrm{C}-\mathrm{H}$ activation event.

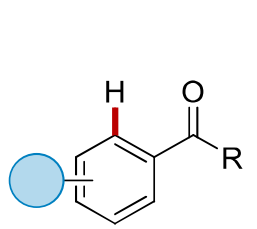

$\mathrm{R}=-\mathrm{NR}_{2}$, -alkyl, -aryl

196,103 , or 77

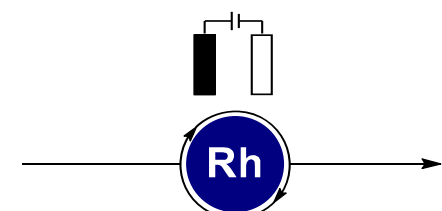

room temperature no mediator required oxidatively-induced $\mathrm{C}-\mathrm{H}$ activation weakly coordinating ketones bimetallic catalysis<smiles></smiles>

106,104 , or 197

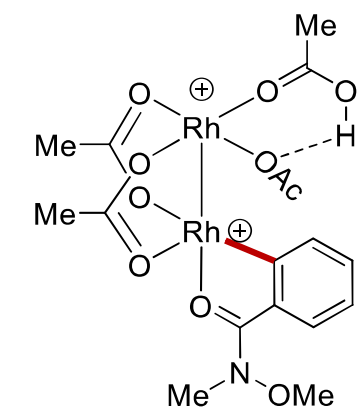


Scheme 4.4 Electrochemical rhodium-catalyzed $\mathrm{C}-\mathrm{H}$ oxygenation and computed cyclometalated bimetallic intermediate.

Finally, the $\mathrm{C}-\mathrm{H}$ arylation by earth-abundant manganese as catalyst and electricity as sustainable oxidant in a user-friendly undivided cell setup was developed (Scheme 4.5$).{ }^{[178]}$ In contrast to an iron-electrocatalyzed $\mathrm{C}-\mathrm{H}$ arylation, ${ }^{[48 \mathrm{f}]}$ weakly coordinating mono-dentate azinylamides $\mathbf{1 7 2}$ could be employed. During the development of the project, it was possible to expand the approach to $\mathrm{C}-\mathrm{H}$ alkylations, allowing for the introduction of the relevant methyl group (214). ${ }^{[172]}$ Insights in the electrochemical events were accessed by means of experimental studies, CV, and SEM-EDS analysis, providing support for the proposed oxidation of the cyclometalated species and the reduction of magnesium.

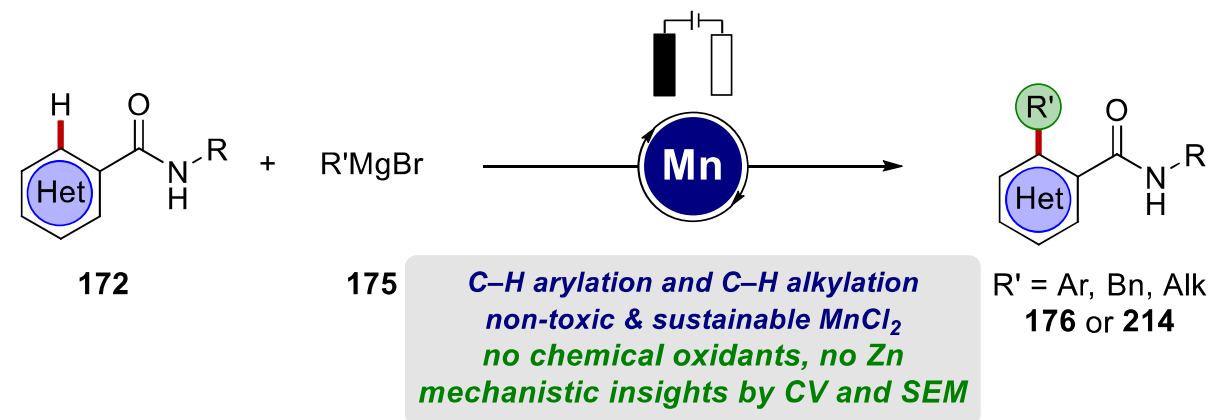

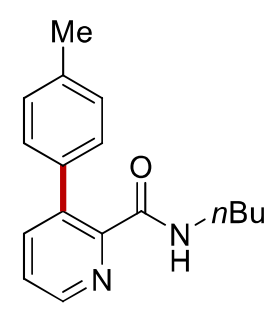

176ac: $78 \%$<smiles>COc1ccc(-c2cccnc2C(=O)NCc2ccccc2)cc1</smiles>

176ba: $58 \%$<smiles>CCCCNC(=O)c1ncccc1C</smiles>

214aa: $60 \%$

Scheme 4.5 Electrochemical manganese-catalyzed C-H arylations.

The application of electrochemistry in $\mathrm{C}-\mathrm{H}$ activation was successful with diverse transition metal catalysts. Nevertheless, many challenges still need to be addressed to further develop this approach. ${ }^{[163 a]}$ First, electricity could be used to further enhance the sustainability of these reactions, with the replacement or the in-situ synthesis of different toxic or hazardous chemicals. Novel 
strategies, such as paired electrolysis, can moreover improve the atom-efficiency. ${ }^{[179]}$ The development of enantioselective electrochemical transformation is also of utmost importance to the scientific community. ${ }^{[180]}$ Other interesting approaches can be envisioned in photoelectrocatalysis, ${ }^{[181]}$ flow-electrocatalysis, ${ }^{[182]}$ the design of electrode materials, ${ }^{[183]}$ and by the aid from artificial intelligence. ${ }^{[184]}$ Electrocatalysis is thus still a novel area of research with important challenges but a bright future ahead. 


\section{Experimental Data}

\subsection{General Remarks}

Reactions involving air- or moisture-sensitive compounds were conducted under an atmosphere of nitrogen using pre-dried glassware and standard Schlenk or glovebox techniques. Liquids and solutions were transferred via nitrogen-flushed syringes by BRAUN, with oven-dried stainless-steel cannulas (pre-dried at $120^{\circ} \mathrm{C}$ ). Solids were added under counter flow of nitrogen (standard Schlenk technique). Solutions were concentrated under reduced pressure by rotary evaporation at $40{ }^{\circ} \mathrm{C}$ with a HEIDOLPH Hei-VAP Core. Non-volatile products were dried under OPV for $14 \mathrm{~h}$. Air and moisture sensitive substances were stored in a MBRAUN glovebox. If not otherwise noted, yields refer to isolated compounds, estimated to be $>95 \%$ pure by GC and NMR.

\section{Vacuum}

The following average pressure was measured on the used rotary vane pump RD4 from VACUUBRAND ${ }^{\circledR}: 0.8 \times 10^{-1}$ mbar (uncorrected value).

\section{Melting points}

Melting points were measured on a Stuart ${ }^{\circledR}$ Melting Point Apparatus SMP3 from BARLOWORLD SCIENTIFIC and are uncorrected.

\section{Chromatography}

Analytical thin-layer chromatography (TLC) was used for reaction monitoring, analysis of column chromatography, and determination of $R_{\mathrm{f}}$ values. TLC was performed on silica gel 60 coated aluminium-sheets, with fluorescence indicator F-254 (MACHEREY NAGEL, by MERCK). The plates were either visualized by UV light $(\lambda=254 \mathrm{~nm}$ or $366 \mathrm{~nm})$, if applicable, or by staining solution $\left(\mathrm{KMnO}_{4}\right.$ aq. solution) followed by gentle heating by heat-gun.

Chromatographic purification of crude products was accomplished by flash column chromatography using MERCK silica gel, grade 60 (40-63 $\mu \mathrm{m}, 70-230$ mesh ASTM, Geduran SI 60). The crude 
products were loaded in the column with the respective eluent. For acid-sensitive compounds the silica gel was neutralized with $\mathrm{Et}_{3} \mathrm{~N}$ prior to use.

\section{Gas Chromatography}

Gas chromatographic analysis (GC) was performed on an AGILENT 7890A GC System or AGILENT $7890 B$ GC System equipped with an AgILENT HP-5MS column $(30 \mathrm{~m} \times 0.25 \mathrm{~mm}$ diameter, $0.25 \mu \mathrm{m}$ film thickness) and a flame-ionization detector (FID) using hydrogen as the carrier gas. Gas chromatography coupled with mass spectrometry (GC-MS) was performed on the same instrument equipped with an AgILENT 5875C Triple-Axis-Detector or AGILENT 5977B MSD. Mass spectra were obtained with electron-ionization (EI) at $70 \mathrm{eV}$ in positive ion mode. Gas-chromatogrphical analysis of the headspace after reaction was performed on a SHIMADZU S2014 GC System using a Thermal Conductivity Detector and a 5A MS column.

\section{Mass Spectrometry}

Electrospray-ionization (ESI) mass spectra were recorded on a quadrupole time-of-flight on a micrOTOF or a maXis from BRUKER DALTONICS or a LTQ Orbitrab XL from THERMO SCIENTIFIC. Electron-ionization (EI) mass spectra were recorded on a time-of flight mass spectrometer JEOL AccuTOF instrument at $70 \mathrm{eV}$. The ratio of mass to charge $(\mathrm{m} / \mathrm{z})$ is given, intensities $I$ relative to the base signal $(I=100)$ are written in parentheses.

\section{Infrared Spectroscopy (IR)}

Infrared (IR) spectra of were measured on a BRUKER Alpha-P FT-IR spectrometer with a diamond ATR probe in the range of $\tilde{v}=4000-400 \mathrm{~cm}^{-1}$. Analysis of the spectra was performed with the software Opus 6.5 from BRUKER. In-situ IR measurements were performed with a ReactIR 15 from MetTLER TOLEDO equipped with a diamond ATR probe and an MCT detector. Spectra were acquired using METTLER TOLEDO iC IR software version 7.0.297 in the range of $650-2200 \mathrm{~cm}^{-1}$ with a $4 \mathrm{~cm}^{-1}$ resolution. A Pearson's Correction was applied as baseline correction in all measurements. 


\section{Nuclear Magnetic Resonance (NMR) Spectroscopy}

Nuclear magnetic resonance (NMR) spectra were recorded on BRUKER Avance 300, Avance III HD 400, Avance Neo 400, Avance III HD 500; VARIAN Mercury VX 300, Inova 500 or Inova 600 spectrometer at $300 \mathrm{MHz}, 400 \mathrm{MHz}, 500 \mathrm{MHz}, 600 \mathrm{MHz}\left({ }^{1} \mathrm{H}-\mathrm{NMR}\right), 75 \mathrm{MHz}, 100 \mathrm{MHz}, 125 \mathrm{MHz}$ $\left({ }^{13} \mathrm{C}-\mathrm{NMR}\right)$ and $282 \mathrm{MHz}\left({ }^{19} \mathrm{~F}-\mathrm{NMR}\right)$. Unless stated otherwise, all measurements were performed at $298 \mathrm{~K}$. Chemical shifts $(\delta)$ are reported relative to tetramethylsilane and are referenced using the residual proton peak or the carbon peak of the deuterated solvent (Table 5.1.1).

Table 5.1.1 Chemical shifts of residual proton signals or carbon signals of common deuterated solvents.

\begin{tabular}{lll} 
Solvent & ${ }^{\mathbf{1}} \mathbf{H}-\mathbf{N M R}$ & ${ }^{\mathbf{1 3}} \mathbf{C}-\mathbf{N M R}$ \\
\hline $\mathrm{CDCl}_{3}$ & $7.26 \mathrm{ppm}$ & $77.16 \mathrm{ppm}$ \\
DMSO-d $_{6}$ & $2.50 \mathrm{ppm}$ & $39.52 \mathrm{ppm}$ \\
Acetone-d 6 & $2.05 \mathrm{ppm}$ & $206.7,29.92 \mathrm{ppm}$ \\
Methanol-d $_{4}$ & $4.78,3.31 \mathrm{ppm}$ & $49.15 \mathrm{ppm}$ \\
THF-d $_{8}$ & $3.58,1.73 \mathrm{ppm}$ & $67.57,25.37 \mathrm{ppm}$
\end{tabular}

The measured resonance multiplicities were reported using the following abbreviations: $s$ (singlet), $d$ (doublet), t (triplet), q (quartet), quint (quintet), sext (sextet), sept (septet), dd (doublet of doublets), dt (doublet of triplets), ddd (doublet of doublets of doublets), td (triplet of doublets), dddd (doublet of doublets of doublets of doublets), m (multiplet) and br (broad singlet). The coupling constants $J$ are reported in Hertz (Hz). Analysis of all spectra until February 2019 was performed with MestReNova v10.0.2 and from February onwards with MestReNova v14.1.0 from MestRELAB RESEARCH S.L.

${ }^{1} \mathrm{H}-\mathrm{NMR}$ spectroscopic experiments in flow were performed on a Magritek Spinsolve $60^{\text {ULTRA }}$ from MAGRITEK GmbH, Germany. These spectra were batch-processed with the reaction monitoring wizard of the MestReNova v12.0.3 software. Arbitrary integral values were transformed to mmol and percentage values by referencing with dibromomethane as the internal standard.

\section{Data Analysis and Plots}


Data analysis and plotting were performed using Microsoft ${ }^{\circledR}$ Excel 2016 software. CVs were analyzed and plotted using OriginLab ${ }^{\odot}$ OriginPro 8.5G software.

\section{Electrochemistry}

\section{Constant Current Electrolysis (CCE)}

The electrocatalytic reactions were performed in undivided electrochemical cells $(10 \mathrm{~mL})$ using pre-dried glassware, unless stated otherwise. Platinum electrodes $(10 \mathrm{~mm} \times 15 \mathrm{~mm} \times 0.125 \mathrm{~mm}$, 99.9\%, ChemPur Karlsruhe, Germany or 99.95\%; ESG-Edelmetall-Handel GMBH \& Co. KG), graphite felt electrodes $\left(10 \mathrm{~mm} \times 15 \mathrm{~mm} \times 6 \mathrm{~mm}\right.$, SIGRACELL ${ }^{\circledR} G F A 6$ EA, SGL CARBON, Wiesbaden, Germany) and reticulated vitreous carbon (RVC) (40 mm x $5.0 \mathrm{~mm}$ x $6.0 \mathrm{~mm}$, Duocel $\mathbb{}$ Reticulated Vitreous Carbon RVC100 (100 PPI) ERG AEROSPACE CORPORATION, Oakland, United States of America) were connected using stainless steel adapters, following the published protocol. ${ }^{[185]}$ Electrolysis was conducted using an AXIOMET $A X$-3003P galvanostat in constant current mode. Divided cells, separated by a P4 glass frit, were custom-made and obtained from GlasgerÄtebau Ochs LaborfachHANDEL e. K. (Bovenden, Germany). For reactions performed with the standardized electrochemistry kit, ElectraSyn 2.0 from IKA, the commercialized electrodes and $10 \mathrm{~mL}$ undivided cells were used, if not stated otherwise. If reactions were performed at temperatures other than room temperature, the vial was connected via the IKA ElectraSyn GOGO Module ${ }^{\circledR}$ and mounted in a silicon oil bath.

For reactions in flow, an ISMATEC REGLO Digital MS-2/12 (ISM 596) peristaltic pump and a KEYSIGHT E36104A galvanostat was employed. The flow-electrocatalysis was performed with a commercially available IKA ElectraSyn flow system and the respective half-cell electrodes.

\section{Constant Potential Reactions under Amperometric Detection}

The constant potential electrolyses (CPE) were performed using a METROHM Autolab PGSTAT204 or a Metrohm Dropsense $8000 P$ workstation and Nova 2.1 or the Dropview 8400 software, respectively. A silver wire $(d=1 \mathrm{~mm})$ was used as the pseudo-reference electrode in close proximity to the working electrode. To ensure comparable constant potential conditions with the results gained by 
cyclic voltammetry, calibration of the pseudo-reference electrode versus ferrocene was performed for each reaction system. If applicable, an aqueous $\mathrm{Ag} / \mathrm{AgCl}$ reference electrode was used instead of the silver wire.

\section{Cyclic Voltammetry}

The cyclic voltammetry measurements were carried out using a METROHM Autolab PGSTAT204 workstation, and the following data analysis was performed with Nova 2.1 software. For the experiments, a glassy carbon (GC) disc electrode $(d=3 \mathrm{~mm})$ was used as the working electrode (WE). Either a saturated calomel electrode (SCE); a $3 \mathrm{M}$ aq. $\mathrm{Ag} / \mathrm{AgCl}$ or a non-aqueous $\mathrm{Ag} / \mathrm{AgNO}{ }_{3}$ (solution of $\mathrm{MeCN}$ with $\mathrm{AgNO}_{3}(0.01 \mathrm{M})$ and $n \mathrm{Bu}_{4} \mathrm{NClO}_{4}(0.1 \mathrm{M})$ ) was used as the reference electrode (RE), if not stated otherwise. If a silver-wire $(d=1 \mathrm{~mm})$ was used as the pseudo-reference electrode, the voltammograms were referenced internally versus ferrocene. The counter electrode (CE) was a coiled platinum wire $(d=1 \mathrm{~mm})$. The electrodes were purchased from ALS JAPAN Co., Ltd. Measurements were recorded at a scan rate of $100 \mathrm{mV} \cdot \mathrm{s}^{-1}$, if not indicated otherwise. The working temperature was $298 \mathrm{~K}$, if not indicated otherwise. All solutions were degassed via freeze-pumpthaw method prior to use and dry nitrogen was bubbled through the solutions for at least $5 \mathrm{~min}$ before the experiment was performed. During the voltammetric measurements, an overpressure of dry nitrogen was maintained. The rotating-disc electrode (RDE) experiments were performed using a METROHм Autolab PGSTAT204 workstation and a RRDE-3A Rotating Ring Disk Electrode Apparatus Ver.2.0 purchased from ALS JAPAN Co., Ltd. For the RDE experiments, a glassy carbon disc electrode ( $d=4 \mathrm{~mm}$, disc-electrode) was used as the working electrode, a coiled platinum wire $\left(d=1 \mathrm{~mm}\right.$ ) was used as the counter electrode and a non-aqueous $\mathrm{Ag} / \mathrm{AgNO}_{3}$ (solution of $\mathrm{MeCN}$ with $\mathrm{AgNO}_{3}(0.01 \mathrm{M})$ and $\left.n \mathrm{Bu}_{4} \mathrm{NClO}_{4}(0.1 \mathrm{M})\right)$ was used as the reference electrode. The operation temperature was $25^{\circ} \mathrm{C}$ and dry nitrogen was bubbled through the solution for at least 5 min before the analytical experiment was performed.

\section{Solvents}


All solvents used for work-up and purification were distilled prior to use. Solvents used in reactions involving air- or moisture-sensitive compounds were dried and stored under an inert atmosphere of nitrogen or argon according to the following standard procedures: Solvents purified by solvent purification system (SPS-800) from MBRAUN: toluene, THF, diethyl ether, DCM, and DMF. Solvents dried and distilled over $\mathrm{CaH}_{2}$ : DCE, DMA, and NMP. Solvents dried over $4 \AA$ molecular sieves and degassed using multiple cycles of freeze-pump-thaw: $t \mathrm{AmOH}, o-, m-, p$-xylene, 1,4-dioxane, DME, methanol, TFE, and HFIP, 2-methyltetrahydrofuran, $n$ hexane, toluene- $\mathrm{d}_{8}$, and THF- $\mathrm{d}_{8}$. Water was degassed before its use applying repeated freeze-pump-thaw cycles.

\section{Reagents}

Reagents obtained from commercial sources with a purity $>99 \%$ were used without further purification unless stated otherwise. The following compounds were synthesized according to previously reported procedures: 33, 106, 104, 197, 199, 172, 175.

The following compounds were kindly synthesized and/or provided by the persons listed below:

Karsten Rauch: $\left[\mathrm{RuCl}_{2}(p \text {-cymene })\right]_{2}$ and $\left[\mathrm{Ru}(\mathrm{OAc})_{2}(p\right.$-cymene $\left.)\right]$ 188a

Dr. Xuefeng Tan: 103f, 103h, 103i, 103n, and 196t.

Dr. Cuiju Zhu: 172c, 172e, 172f, 172i, 172k, and $172 \mathrm{l}$.

Dr. Nikolaos Kaplaneris: 24d, and 24e. 


\subsection{General Procedures}

\subsubsection{General Procedure A: Electrochemical Cobalt-Catalyzed C-H/N-H Annulation}

The electrolysis was carried out in an undivided cell, with a RVC anode $(10 \mathrm{~mm} \times 15 \mathrm{~mm} \times 6 \mathrm{~mm})$ and a platinum cathode $(10 \mathrm{~mm} \times 15 \mathrm{~mm} \times 0.125 \mathrm{~mm})$. Benzamide $33(0.50 \mathrm{mmol}, 1.00$ equiv $)$, alkyne 117 (1.00 mmol, 2.00 equiv), NaOPiv (124 mg, $1.00 \mathrm{mmol}, 2.00$ equiv) and $\mathrm{Co}(\mathrm{OAc})_{2} \cdot 4 \mathrm{H}_{2} \mathrm{O}$ $(12.7 \mathrm{mg}, 10 \mathrm{~mol} \%)$ were placed in a $20 \mathrm{~mL}$ cell and dissolved in $10 \mathrm{~mL}$ of $\mathrm{H}_{2} \mathrm{O} / \mathrm{MeOH}(1: 1)$. The electrolysis was performed at ambient temperature with a constant current of $4.0 \mathrm{~mA}$ maintained for $16 \mathrm{~h}$. The reaction was quenched by adding saturated aqueous $\mathrm{NaHCO}_{3}(10 \mathrm{~mL})$. The $\mathrm{RVC}$ anode was washed with $\mathrm{CH}_{2} \mathrm{Cl}_{2}(3 \times 10 \mathrm{~mL})$ with the aid of an ultrasonic bath. The mixture of organic phases and of the aqueous one, was separated and further extracted with $\mathrm{CH}_{2} \mathrm{Cl}_{2}(3 \times 10 \mathrm{~mL})$, then dried over $\mathrm{Na}_{2} \mathrm{SO}_{4}$. Evaporation of the solvent and subsequent column chromatography on silica gel afforded the desired products 34 .

\subsubsection{General Procedure B: Electrochemical Cobalt-Catalyzed C-H/N-H Annulation}

The electrolysis was carried out in an undivided cell, with a RVC anode $(10 \mathrm{~mm} \times 15 \mathrm{~mm} \times 6 \mathrm{~mm})$ and a platinum cathode $(10 \mathrm{~mm} \times 15 \mathrm{~mm} \times 0.125 \mathrm{~mm})$. Benzamide $33(0.50 \mathrm{mmol}, 1.00$ equiv $)$, alkyne 117 (1.00 mmol, 2.00 equiv), NaOPiv (124 mg, 1.00 mmol, 2.00 equiv) and $\mathrm{Co}(\mathrm{OAc})_{2} \cdot 4 \mathrm{H}_{2} \mathrm{O}$ ( $25.7 \mathrm{mg}, 20 \mathrm{~mol} \%$ ) were placed in a $20 \mathrm{~mL}$ cell and dissolved in $10 \mathrm{~mL}$ of $\mathrm{H}_{2} \mathrm{O} / \mathrm{MeOH}(1: 1)$. The electrolysis was performed at ambient temperature with a constant current of $4.0 \mathrm{~mA}$ maintained for $16 \mathrm{~h}$. The reaction was quenched by adding saturated aqueous $\mathrm{NaHCO}_{3}(10 \mathrm{~mL})$. The $\mathrm{RVC}$ anode was washed with $\mathrm{CH}_{2} \mathrm{Cl}_{2}(3 \times 10 \mathrm{~mL})$ with the aid of an ultrasonic bath. The mixture of organic phases and of the aqueous one, was separated and further extracted with $\mathrm{CH}_{2} \mathrm{Cl}_{2}(3 \times 10 \mathrm{~mL})$, then dried over $\mathrm{Na}_{2} \mathrm{SO}_{4}$. Evaporation of the solvent and subsequent column chromatography on silica gel afforded the desired products 34 . 


\subsubsection{General Procedure C: Electrochemical Ruthenium-Catalyzed C-H/Het-H Annulation}

The electrolysis was carried out in an undivided cell with a RVC anode $(10 \mathrm{~mm} \times 15 \mathrm{~mm} \times 6 \mathrm{~mm})$ and a platinum cathode $(10 \mathrm{~mm} \times 15 \mathrm{~mm} \times 0.125 \mathrm{~mm})$. Benzoic acids 89 or benzamide $87(1.0$ mmol, 2.0 equiv), alkyne 24 ( $0.5 \mathrm{mmol}, 1.0$ equiv), NaOPiv (62 mg, $0.5 \mathrm{mmol}, 1.0$ equiv) and $\left[\mathrm{RuCl}_{2}(p \text {-cymene })\right]_{2}(15.3 \mathrm{mg}, 5.0 \mathrm{~mol} \%)$ were dissolved in $t \mathrm{AmOH} / \mathrm{H}_{2} \mathrm{O}(3 / 1,4.0 \mathrm{~mL})$. The electrolysis was performed at $80-100{ }^{\circ} \mathrm{C}$ with a constant current of $4.0 \mathrm{~mA}$ maintained for $18-24 \mathrm{~h}$. The RVC anode was washed with $\mathrm{CH}_{2} \mathrm{Cl}_{2}(3 \times 10 \mathrm{~mL})$ with the aid of an ultrasonic bath and the organic phases were combined. Evaporation of the solvent and subsequent column chromatography on silica gel afforded the corresponding products $\mathbf{9 0}$ or $\mathbf{8 8}$.

\subsubsection{General Procedure D: Electrochemical Ruthenium-Catalyzed C-H Oxygenation of} Amides

The electrolysis was carried out in an undivided cell with platinum electrodes $(10 \mathrm{~mm} \times 15 \mathrm{~mm} \times$ $0.125 \mathrm{~mm})$. The cell was charged with amide 196 or $103(0.50 \mathrm{mmol}, 1.0$ equiv), iodobenzene 194a $(11 \mu \mathrm{L}, 20.4 \mathrm{mg}, 20 \mathrm{~mol} \%),\left[\mathrm{Ru}(\mathrm{OAc})_{2}(p\right.$-cymene $\left.)\right]$ 188a $(8.8 \mathrm{mg}, 5.0 \mathrm{~mol} \%)$, and $n \mathrm{Bu}_{4} \mathrm{NPF}_{6}(194$ mg, 1.0 equiv) in TFA/TFAA $(3: 1,3.0 \mathrm{~mL})$. The electrolysis was performed at $50{ }^{\circ} \mathrm{C}$ with a constant current of $4.0 \mathrm{~mA}$ maintained for $16 \mathrm{~h}$. After the reaction was completed, a saturated aqueous solution of $\mathrm{NaHCO}_{3}(25 \mathrm{~mL})$ was added and the reaction mixture was extracted with EtOAc $(3 \times 15$ $\mathrm{mL})$. The combined organic layers were washed with brine $(25 \mathrm{~mL})$, dried over $\mathrm{Na}_{2} \mathrm{SO}_{4}$, filtered, and concentrated in vacuo. The crude product 106 or 104 was purified by column chromatography on silica gel.

\subsubsection{General Procedure E: Electrochemical Ruthenium-Catalyzed C-H Oxygenation of}

\section{Ketones}

The electrolysis was carried out in an undivided cell with platinum electrodes $(10 \mathrm{~mm} \times 15 \mathrm{~mm} \times$ $0.125 \mathrm{~mm})$. The cell was charged with ketone 77 (0.50 mmol, 1.0 equiv), iodobenzene 194a $(11 \mu \mathrm{L}$, $20.4 \mathrm{mg}, 20 \mathrm{~mol} \%)$, $\left[\mathrm{RuCl}_{2}(p \text {-cymene) }]_{2}(7.7 \mathrm{mg}, 2.5 \mathrm{~mol} \%)\right.$, and $n \mathrm{Bu}_{4} \mathrm{NPF}_{6}(194 \mathrm{mg}, 1.0$ equiv) in TFA/TFAA $(3: 1,3.0 \mathrm{~mL})$. The electrolysis was performed at $50{ }^{\circ} \mathrm{C}$ with a constant current of $4.0 \mathrm{~mA}$ 
maintained for 16-24 h. After the reaction was completed, a saturated aqueous solution of $\mathrm{NaHCO}_{3}$ $(25 \mathrm{~mL})$ was added and the reaction mixture was extracted with EtOAc $(3 \times 15 \mathrm{~mL})$. The combined organic layers were washed with brine $(25 \mathrm{~mL})$, dried over $\mathrm{Na}_{2} \mathrm{SO}_{4}$, filtered, and concentrated in vacuo. The crude product 197 was purified by column chromatography on silica gel.

\subsubsection{General Procedure F: Electrochemical Ruthenium-Catalyzed C-H Oxygenation in para- Position}

The electrolysis was carried out in an undivided cell with platinum electrodes $(10 \mathrm{~mm} \times 15 \mathrm{~mm} \times$ $0.125 \mathrm{~mm})$. The cell was charged with iodobenzene $194 \mathrm{a}\left(68 \mu \mathrm{L}, 122 \mathrm{mg}, 1.2\right.$ equiv), and $n \mathrm{Bu}_{4} \mathrm{NPF}_{6}$ (194 mg, 1.0 equiv) in TFA/TFAA/DCE $(1: 2: 15,3.6 \mathrm{~mL})$. The electrolysis was performed at room temperature with a constant current of $8.0 \mathrm{~mA}$ for $5 \mathrm{~h}$. Subsequently, anisole $200(0.50 \mathrm{mmol}$, 1.0 equiv) and $\left[\mathrm{Ru}(\mathrm{OAc})_{2}(p\right.$-cymene $\left.)\right] \mathbf{1 8 8 a}(8.8 \mathrm{mg}, 5.0 \mathrm{~mol} \%)$ were added and the reaction was heated at $80{ }^{\circ} \mathrm{C}$ for $3 \mathrm{~h}$. After the reaction was completed, water $(25 \mathrm{~mL})$ was added, and the reaction mixture was extracted with EtOAc $(3 \times 15 \mathrm{~mL})$. The combined organic layers were washed with brine $(25 \mathrm{~mL})$, dried over $\mathrm{Na}_{2} \mathrm{SO}_{4}$, filtered, and concentrated in vacuo. The crude product 109 was purified by column chromatography on silica gel.

\subsubsection{General Procedure G: Electrochemical Rhodium-Catalyzed C-H Oxygenation of Amides}

The electrolysis was carried out in an undivided cell $(10 \mathrm{~mL})$ equipped with a graphite felt $(\mathrm{GF})$ anode $(10 \mathrm{~mm} \times 10 \mathrm{~mm} \times 6 \mathrm{~mm})$ and a platinum cathode $(10 \mathrm{~mm} \times 15 \mathrm{~mm} \times 0.125 \mathrm{~mm})$. $\left[\mathrm{Rh}(\mathrm{OAc})_{2}\right]_{2}(5.5 \mathrm{mg}, 0.0125 \mathrm{mmol}, 2.5 \mathrm{~mol} \%)$, TFA $\cdot \mathrm{NEt}_{3}(215 \mathrm{mg}, 1.0 \mathrm{mmol}), \mathrm{TFA}(0.15 \mathrm{~mL})$, amide 196 or $103(0.50 \mathrm{mmol})$ and TFAA $(3.0 \mathrm{~mL})$ were successively added. The electrolysis was performed at $2.0 \mathrm{~mA}$ at ambient temperature for $15-17 \mathrm{~h}\left(2.2-2.5 \mathrm{~F} \mathrm{~mol}^{-1}\right)$. After completion, the reaction mixture was transferred into a separatory funnel and the electrodes were rinsed with EtOAc $(10 \mathrm{~mL})$. A saturated aqueous $\mathrm{NaHCO}_{3}$ solution $(50 \mathrm{~mL})$ was added slowly, and the mixture was extracted with ethyl acetate $(3 \times 20 \mathrm{~mL})$. The combined organic layers were dried over $\mathrm{Na}_{2} \mathrm{SO}_{4}$ and concentrated under vacuum. The crude reaction mixture was purified column chromatography on silica gel to yield the desired product 106 or 104. 


\subsubsection{General Procedure H: Electrochemical Rhodium-Catalyzed C-H Oxygenation of Ketones}

The electrolysis was carried out in an undivided cell $(10 \mathrm{~mL})$ equipped with a graphite felt (GF) anode $(10 \mathrm{~mm} \times 10 \mathrm{~mm} \times 6 \mathrm{~mm})$ and a platinum cathode $(10 \mathrm{~mm} \times 15 \mathrm{~mm} \times 0.125 \mathrm{~mm})$. $\left[\mathrm{Rh}(\mathrm{OAc})_{2}\right]_{2}(5.5 \mathrm{mg}, 0.0125 \mathrm{mmol}, 2.5 \mathrm{~mol} \%)$, TFA $\cdot \mathrm{NEt}_{3}(215 \mathrm{mg}, 1.0 \mathrm{mmol}), \mathrm{TFA}(0.20 \mathrm{~mL})$, ketone $77(0.50 \mathrm{mmol})$ and TFAA $(3.0 \mathrm{~mL})$ were successively added. The electrolysis was performed at $2.0 \mathrm{~mA}$ at ambient temperature for $17 \mathrm{~h}\left(2.5 \mathrm{~F} \mathrm{~mol}^{-1}\right)$. After completion, the reaction mixture was transferred into a separatory funnel and the electrodes were rinsed with EtOAc $(10 \mathrm{~mL})$. A saturated aqueous $\mathrm{NaHCO}_{3}$ solution $(50 \mathrm{~mL})$ was added slowly, and the mixture was extracted with ethyl acetate $(3 \times 20 \mathrm{~mL})$. The combined organic layers were dried over $\mathrm{Na}_{2} \mathrm{SO}_{4}$ and concentrated under vacuum. The crude reaction mixture was purified column chromatography on silica gel to yield the desired product 197.

\subsubsection{General Procedure I: Electrochemical Manganese(II/III/I)-Catalyzed C-H Arylation}

The electrolysis was carried out in an undivided cell with a graphite felt $(\mathrm{GF})$ anode $(10 \mathrm{~mm} \times 15$ $\mathrm{mm} \times 6 \mathrm{~mm})$ and a platinum cathode $(10 \mathrm{~mm} \times 15 \mathrm{~mm} \times 0.125 \mathrm{~mm})$. A mixture of amide $172(0.25$ mmol, 1.00 equiv), $\mathrm{MnCl}_{2}$ (3.1 mg, $10 \mathrm{~mol} \%$ ), neocuproine (10.4 mg, $20 \mathrm{~mol} \%$ ), and TMEDA (74 $\mu \mathrm{L}, 2.0$ equiv) were placed in a $10 \mathrm{~mL}$ cell under nitrogen atmosphere and dissolved in THF (4.0 $\mathrm{mL}$ ). A solution of ArMgBr 175 or AlkMgBr 165 (4.0 equiv, in THF) was slowly added. Electrolysis was performed at $60{ }^{\circ} \mathrm{C}$ with a constant current of $3.0 \mathrm{~mA}$ maintained for $18 \mathrm{~h}$. At ambient temperature, a saturated aqueous $\mathrm{NH}_{4} \mathrm{Cl}$ solution $(10 \mathrm{~mL})$ was added, and the $\mathrm{GF}$ anode was washed with EtOAc $(3 \times 2.0 \mathrm{~mL})$ in an ultrasonic bath. The mixture of organic phases and of the aqueous one, was separated and further extracted with EtOAc $(3 \times 10 \mathrm{~mL})$ and then dried over $\mathrm{Na}_{2} \mathrm{SO}_{4}$. Evaporation of the solvents and purification by column chromatography on silica gel yielded the desired product $\mathbf{1 7 6}$ or $\mathbf{2 1 4}$. 


\subsection{Electrochemical $\mathrm{C}-\mathrm{H} / \mathrm{N}-\mathrm{H}$ Activation by Water-Tolerant Cobalt-Catalysis at Room Temperature}

\subsubsection{Characterization Data}

\section{2-[1-Oxo-3-phenylisoquinolin-2(1H)-yl]-pyridine-2-oxide (34aa)}<smiles>O=c1c2ccccc2cc(-c2ccccc2)n1-c1cccc[n+]1[O-]</smiles>

The general procedure A was followed using benzamide 33a (107 mg, $0.50 \mathrm{mmol})$ and alkyne 117a (102 mg, $1.00 \mathrm{mmol}$ ). Purification by column chromatography on silica gel (dichloromethane/acetone: 3/1) yielded 34aa (119 $\mathrm{mg}, 76 \%$ ) as a white solid.

M. p.: $225-226^{\circ} \mathrm{C}$.

${ }^{1}$ H-NMR $\left(300 \mathrm{MHz}, \mathrm{CDCl}_{3}\right): \delta=8.46-8.37(\mathrm{~m}, 1 \mathrm{H}), 8.23-8.14(\mathrm{~m}, 1 \mathrm{H}), 7.73-7.63(\mathrm{~m}, 1 \mathrm{H}), 7.53$ $(\mathrm{dt}, J=7.2,0.7 \mathrm{~Hz}, 1 \mathrm{H}), 7.51-7.44(\mathrm{~m}, 1 \mathrm{H}), 7.44-7.35(\mathrm{~m}, 2 \mathrm{H}), 7.28-7.16(\mathrm{~m}, 3 \mathrm{H}), 7.16-7.08(\mathrm{~m}$, 2H), 7.08-7.00 (m, 1H), 6.59 (s, 1H).

${ }^{13}$ C-NMR $\left(125 \mathrm{MHz}, \mathrm{CDCl}_{3}\right): \delta=161.7\left(\mathrm{C}_{\mathrm{q}}\right), 145.3\left(\mathrm{C}_{\mathrm{q}}\right), 142.4\left(\mathrm{C}_{\mathrm{q}}\right), 139.8(\mathrm{CH}), 136.9\left(\mathrm{C}_{\mathrm{q}}\right), 134.7$ $\left(\mathrm{C}_{\mathrm{q}}\right), 133.2(\mathrm{CH}), 128.9(\mathrm{CH}), 128.2(\mathrm{CH}), 128.0(\mathrm{CH}), 127.8(\mathrm{CH}), 127.5(\mathrm{CH}), 126.9(\mathrm{CH}), 126.2$ $(\mathrm{CH}), 125.3(\mathrm{CH}), 124.9(\mathrm{CH}), 124.8\left(\mathrm{C}_{\mathrm{q}}\right), 107.9(\mathrm{CH})$.

IR (ATR): 1664, 1624, 1490, 1261, 889, 843, 764, $526 \mathrm{~cm}^{-1}$.

MS (ESI) m/z (relative intensity): 353 (5), $337(30)[\mathrm{M}+\mathrm{Na}]^{+}, 315(60)[\mathrm{M}+\mathrm{H}]^{+}, 221(20)$.

HR-MS (ESI) $m / z$ calc. for $\mathrm{C}_{20} \mathrm{H}_{15} \mathrm{~N}_{2} \mathrm{O}_{2}[\mathrm{M}+\mathrm{H}]^{+}: 315.1128$, found: 315.1128 .

The analytical data are in accordance with those previously reported in the literature. ${ }^{[62]}$

2-[6-Methyl-1-oxo-3-phenylisoquinolin-2(1H)-yl]-pyridine-2-oxide (34ba) 
<smiles>Cc1ccc2c(=O)n(-c3cccc[n+]3[O-])c(-c3ccccc3)cc2c1</smiles>

The general procedure $\mathbf{A}$ was followed using benzamide $\mathbf{3 3 b}(114 \mathrm{mg}, 0.50 \mathrm{mmol})$ and alkyne $\mathbf{1 1 7} \mathbf{a}$ (102 mg, $1.00 \mathrm{mmol}$ ). Purification by column chromatography on silica gel (dichloromethane/acetone: $3 / 1$ ) yielded 34ba (121 mg, 73\%) as a white solid.

M. p.: $220-221^{\circ} \mathrm{C}$

${ }^{1}$ H-NMR $\left(300 \mathrm{MHz}, \mathrm{CDCl}_{3}\right): \delta=8.29(\mathrm{~d}, J=8.0 \mathrm{~Hz}, 1 \mathrm{H}), 8.21-8.10(\mathrm{~m}, 1 \mathrm{H}), 7.43-7.36(\mathrm{~m}, 2 \mathrm{H})$, 7.34-7.27 (m, 2H), 7.25-7.17 (m, 3H), 7.17-7.10 (m, 2H), 7.06-6.97 (m, 1H), $6.52(\mathrm{~s}, 1 \mathrm{H}), 2.48(\mathrm{~s}$, $3 \mathrm{H})$.

${ }^{13}$ C-NMR (125 MHz, $\left.\mathrm{CDCl}_{3}\right): \delta=161.8\left(\mathrm{C}_{\mathrm{q}}\right), 145.7\left(\mathrm{C}_{\mathrm{q}}\right), 143.9\left(\mathrm{C}_{\mathrm{q}}\right), 142.5\left(\mathrm{C}_{\mathrm{q}}\right), 140.0(\mathrm{CH}), 137.0$ $\left(\mathrm{C}_{\mathrm{q}}\right), 134.8\left(\mathrm{C}_{\mathrm{q}}\right), 128.8(\mathrm{CH}), 128.5(\mathrm{CH}), 128.2(\mathrm{CH}), 128.0(\mathrm{CH}), 127.8(\mathrm{CH}), 127.6(\mathrm{CH}), 126.0$ $(\mathrm{CH}), 125.1(\mathrm{CH}), 125.0(\mathrm{CH}), 122.6\left(\mathrm{C}_{\mathrm{q}}\right), 107.8(\mathrm{CH}), 21.9\left(\mathrm{CH}_{3}\right)$.

IR (ATR): 3059, 1664, 1626, 1486, 1260, 909, 769, $727 \mathrm{~cm}^{-1}$.

MS (EI) $m / z$ (relative intensity): 328 (25) [M] $]^{+}, 283$ (15), 208 (25), 181 (100), 165 (15), 78 (65).

HR-MS (EI) $m / z$ calc. for $\mathrm{C}_{21} \mathrm{H}_{16} \mathrm{~N}_{2} \mathrm{O}_{2}[\mathrm{M}]^{+}: 328.1212$, found: 328.1213 .

The analytical data are in accordance with those previously reported in the literature. ${ }^{[62]}$

\section{2-[6-Trifluoromethyl-1-oxo-3-phenylisoquinolin-2(1H)-yl]-pyridine-2-oxide (34ca)}<smiles></smiles>

The general procedure $\mathbf{B}$ was followed using benzamide 33c $(141 \mathrm{mg}, 0.50 \mathrm{mmol})$ and alkyne $\mathbf{1 1 7 a}$ (102 mg, $1.00 \mathrm{mmol}$ ). Purification by column chromatography on silica gel (dichloromethane/acetone: $3 / 1$ ) yielded 34ca (97.2 $\mathrm{mg}, 51 \%$ ) as a white solid.

M. p.: $190-191{ }^{\circ} \mathrm{C}$. 
${ }^{1} \mathbf{H}-N M R\left(400 \mathrm{MHz}, \mathrm{CDCl}_{3}\right): \delta=8.57-8.52(\mathrm{~m}, 1 \mathrm{H}), 8.24(\mathrm{~d}, J=6.4 \mathrm{~Hz}, 1 \mathrm{H}), 7.87-7.82(\mathrm{~m}, 1 \mathrm{H})$, 7.74-7.66 (m, 1H), 7.44-7.37 (m, 2H), 7.32-7.22 (m, 3H), 7.21-7.14 (m, 2H), 7.13-7.07 (m, 1H), $6.66(\mathrm{~s}, 1 \mathrm{H})$.

${ }^{13}$ C-NMR $\left(100 \mathrm{MHz}, \mathrm{CDCl}_{3}\right): \delta=161.1\left(\mathrm{C}_{\mathrm{q}}\right), 145.1\left(\mathrm{C}_{\mathrm{q}}\right), 144.3\left(\mathrm{C}_{\mathrm{q}}\right), 140.1(\mathrm{CH}), 137.1\left(\mathrm{C}_{\mathrm{q}}\right), 134.9$ $\left(\mathrm{q},{ }^{2} J_{\mathrm{C}-\mathrm{F}}=32.6 \mathrm{~Hz}, \mathrm{C}_{\mathrm{q}}\right), 134.3\left(\mathrm{C}_{\mathrm{q}}\right), 129.5(\mathrm{CH}), 129.5(\mathrm{CH}), 128.4(\mathrm{CH}), 127.9(\mathrm{CH}), 127.6(\mathrm{CH})$, $127.1\left(\mathrm{C}_{\mathrm{q}}\right), 125.7(\mathrm{CH}), 125.3(\mathrm{CH}), 125.0\left(\mathrm{q},{ }^{1} J_{\mathrm{C}-\mathrm{F}}=273.4 \mathrm{~Hz}, \mathrm{C}_{\mathrm{q}}\right), 123.6\left(\mathrm{q},{ }^{3} J_{\mathrm{C}-\mathrm{F}}=3.9 \mathrm{~Hz}, \mathrm{CH}\right)$, $123.1\left(\mathrm{q},{ }^{3} J_{\mathrm{C}-\mathrm{F}}=3.2 \mathrm{~Hz}, \mathrm{CH}\right), 107.5(\mathrm{CH})$.

${ }^{19}$ F-NMR $\left(376 \mathrm{MHz}, \mathrm{CDCl}_{3}\right) \delta=-63.13$ (s).

IR (ATR): 1672, 1490, 1431, 1319, 1126, 920, 729, $698 \mathrm{~cm}^{-1}$.

MS (EI) $m / z$ (relative intensity): $382(30)[\mathrm{M}]^{+}, 365$ (20), 337 (20), 262 (30), 181 (100), 78 (85).

HR-MS (EI) $m / z$ calc. for $\mathrm{C}_{21} \mathrm{H}_{13} \mathrm{~F}_{3} \mathrm{~N}_{2} \mathrm{O}_{2}[\mathrm{M}]^{+}: 382.0929$, found: 382.0928 .

The analytical data are in accordance with those previously reported in the literature. ${ }^{[164 c]}$

\section{2-[6-Bromo-1-oxo-3-phenylisoquinolin-2(1H)-yl]-pyridine-2-oxide (34da)}<smiles></smiles>

The general procedure $\mathbf{B}$ was followed using benzamide 33d (146 mg, $0.50 \mathrm{mmol})$ and alkyne 117a (102 mg, $1.00 \mathrm{mmol}$ ). Purification by column chromatography on silica gel (dichloromethane/acetone: $3 / 1$ ) yielded 34da (127 mg, 65\%) as a white solid.

M. p.: $212-215^{\circ} \mathrm{C}$.

${ }^{1}$ H-NMR $\left(300 \mathrm{MHz}, \mathrm{CDCl}_{3}\right): \delta=8.24(\mathrm{~d}, J=8.6 \mathrm{~Hz}, 1 \mathrm{H}), 8.19(\mathrm{~d}, J=6.2 \mathrm{~Hz}, 1 \mathrm{H}), 7.69(\mathrm{~d}, J=1.9$ $\mathrm{Hz}, 1 \mathrm{H}), 7.56(\mathrm{dd}, J=8.6,1.9 \mathrm{~Hz}, 1 \mathrm{H}), 7.41-7.34(\mathrm{~m}, 2 \mathrm{H}), 7.30-7.17(\mathrm{~m}, 3 \mathrm{H}), 7.17-7.09$ (m, 2H), 7.09-7.00 (m, 1H), 6.49 (s, 1H).

${ }^{13}$ C-NMR $\left(125 \mathrm{MHz}, \mathrm{CDCl}_{3}\right): \delta=161.2\left(\mathrm{C}_{\mathrm{q}}\right), 145.1\left(\mathrm{C}_{\mathrm{q}}\right), 144.0\left(\mathrm{C}_{\mathrm{q}}\right), 139.9(\mathrm{CH}), 138.3\left(\mathrm{C}_{\mathrm{q}}\right), 134.3$ $\left(\mathrm{C}_{\mathrm{q}}\right), 130.2(\mathrm{CH}), 130.0(\mathrm{CH}), 129.2(\mathrm{CH}), 128.6(\mathrm{CH}), 128.4\left(\mathrm{C}_{\mathrm{q}}\right), 128.1(\mathrm{CH}), 127.7(\mathrm{CH}), 127.5$ $(\mathrm{CH}), 125.4(\mathrm{CH}), 124.9(\mathrm{CH}), 123.5\left(\mathrm{C}_{\mathrm{q}}\right), 106.7(\mathrm{CH})$. 
IR (ATR): 1666, 1627, 1491, 1428, 1368, 1255, 900, $727 \mathrm{~cm}^{-1}$.

MS (EI) $m / z$ (relative intensity): $394(10)\left[\mathrm{M}^{+}\right]\left({ }^{81} \mathrm{Br}\right), 392(10)\left[\mathrm{M}^{+}\right]\left({ }^{79} \mathrm{Br}\right), 377$ (15), 349 (15), 274 (10), 268 (15), 181 (100), 165 (10), 78 (55).

HR-MS (EI) $m / z$ calc. for $\mathrm{C}_{20} \mathrm{H}_{13}{ }^{79} \mathrm{BrN}_{2} \mathrm{O}_{2}\left[\mathrm{M}^{+}\right]$392.0160, found 392.0160.

The analytical data are in accordance with those previously reported in the literature. ${ }^{[62]}$

\section{2-[5,7-Dimethoxy-1-oxo-3-phenylisoquinolin-2(1H)-yl]-pyridine-2-oxide (34ea)}<smiles>COc1cc(OC)c2cc(-c3ccccc3)n(-c3cccc[n+]3[O-])c(=O)c2c1</smiles>

The general procedure A was followed using benzamide 33e (137 mg, $0.50 \mathrm{mmol})$ and alkyne 117a (102 mg, $1.00 \mathrm{mmol}$ ). Purification by column chromatography on silica gel (dichloromethane/acetone: $3 / 1$ ) yielded 34ea (150 $\mathrm{mg}, 80 \%)$ as a white solid.

M. p.: $246-247^{\circ} \mathrm{C}$.

${ }^{1}$ H-NMR $\left(300 \mathrm{MHz}, \mathrm{CDCl}_{3}\right): \delta=8.25-8.18(\mathrm{~m}, 1 \mathrm{H}), 7.42(\mathrm{~d}, J=2.4 \mathrm{~Hz}, 1 \mathrm{H}), 7.40-7.34(\mathrm{~m}, 2 \mathrm{H})$, 7.23-7.15 (m, 3H), 7.15-7.06 (m, 2H), 7.06-6.99 (m, 1H), $6.92(\mathrm{~d}, J=0.6 \mathrm{~Hz}, 1 \mathrm{H}), 6.73(\mathrm{~d}, J=2.3$ Hz, 1H), 3.89 (s, 3H), 3.88 (s, 3H).

${ }^{13}$ C-NMR (125 MHz, $\left.\mathrm{CDCl}_{3}\right): \delta=161.2\left(\mathrm{C}_{\mathrm{q}}\right), 159.4\left(\mathrm{C}_{\mathrm{q}}\right), 155.9\left(\mathrm{C}_{\mathrm{q}}\right), 145.7\left(\mathrm{C}_{\mathrm{q}}\right), 139.8(\mathrm{CH}), 139.4$ $\left(\mathrm{C}_{\mathrm{q}}\right), 135.2\left(\mathrm{C}_{\mathrm{q}}\right), 128.6(\mathrm{CH}), 128.0(\mathrm{CH}), 127.9(\mathrm{CH}), 127.4(\mathrm{CH}), 126.4\left(\mathrm{C}_{\mathrm{q}}\right), 125.2(\mathrm{CH}), 124.7$ $(\mathrm{CH}), 122.6\left(\mathrm{C}_{\mathrm{q}}\right), 103.8(\mathrm{CH}), 102.4(\mathrm{CH}), 99.6(\mathrm{CH}), 55.9\left(\mathrm{CH}_{3}\right), 55.6\left(\mathrm{CH}_{3}\right)$.

IR (ATR): 1664, 1606, 1488, 1433, 1366, 1046, 784, $753 \mathrm{~cm}^{-1}$.

MS (EI) $m / z$ (relative intensity): 374 (15) [M] $]^{+}, 330$ (10), 269 (10), 254 (15), 181 (100), 78 (60).

HR-MS (EI) $m / z$ calc. for $\mathrm{C}_{22} \mathrm{H}_{18} \mathrm{~N}_{2} \mathrm{O}_{4}[\mathrm{M}]^{+}: 374.1267$, found: 374.1264 .

\section{2-[4-Oxo-6-phenylthieno[3,2-c]pyridin-5(4H)-yl]-pyridine-2-oxide (34fa)}


<smiles></smiles>

The general procedure $\mathbf{B}$ was followed using 2-(thiophene-3-carboxamido)pyridine 1-oxide 33f (110 $\mathrm{mg}, 0.50 \mathrm{mmol})$ and alkyne $\mathbf{1 1 7 a}(102 \mathrm{mg}, 1.00 \mathrm{mmol})$. Purification by column chromatography on silica gel (dichloromethane/acetone: $5 / 1)$ yielded $\mathbf{3 4 f a}(87.0 \mathrm{mg}, 54 \%)$ as a white solid.

M. p.: $215-218^{\circ} \mathrm{C}$

${ }^{1}$ H-NMR $\left(300 \mathrm{MHz}, \mathrm{CDCl}_{3}\right): \delta=8.22-8.17(\mathrm{~m}, 1 \mathrm{H}), 7.67(\mathrm{dd}, J=5.3,0.7 \mathrm{~Hz}, 1 \mathrm{H}), 7.40-7.35(\mathrm{~m}$, 2H), $7.30(\mathrm{~d}, J=5.3 \mathrm{~Hz}, 1 \mathrm{H}), 7.25-7.19(\mathrm{~m}, 3 \mathrm{H}), 7.16-7.09(\mathrm{~m}, 2 \mathrm{H}), 7.09-7.03(\mathrm{~m}, 1 \mathrm{H}), 6.78(\mathrm{~d}, J=$ $0.6 \mathrm{~Hz}, 1 \mathrm{H})$.

${ }^{13}$ C-NMR $\left(125 \mathrm{MHz}, \mathrm{CDCl}_{3}\right): \delta=158.1\left(\mathrm{C}_{\mathrm{q}}\right), 148.5\left(\mathrm{C}_{\mathrm{q}}\right), 145.3\left(\mathrm{C}_{\mathrm{q}}\right), 143.5\left(\mathrm{C}_{\mathrm{q}}\right), 140.0(\mathrm{CH}), 134.5$ $\left(\mathrm{C}_{\mathrm{q}}\right), 129.4\left(\mathrm{C}_{\mathrm{q}}\right), 129.3(\mathrm{CH}), 128.3(\mathrm{CH}), 127.9(\mathrm{CH}), 127.7(\mathrm{CH}), 125.6(\mathrm{CH}), 125.5(\mathrm{CH}), 125.0$ $(\mathrm{CH}), 124.8(\mathrm{CH}), 103.8(\mathrm{CH})$.

IR (ATR): 3072, 1664, 1584, 1267, 768, 727, $522 \mathrm{~cm}^{-1}$

MS (EI) $m / z$ (relative intensity): 320 (15) [M] $]^{+}, 275$ (15), 200 (35), 181 (100), 171 (20), 78 (60).

HR-MS (EI) $m / z$ calc. for $\mathrm{C}_{18} \mathrm{H}_{12} \mathrm{~N}_{2} \mathrm{O}_{2} \mathrm{~S}[\mathrm{M}]^{+}: 320.0619$, found: 320.0616 .

\section{2-[1-Oxo-3-(4-methoxy)-isoquinolin-2(1H)-yl]-pyridine-2-oxide (34ab)}<smiles></smiles>

The general procedure $\mathbf{B}$ was followed using benzamide 33a $(107 \mathrm{mg}, 0.50 \mathrm{mmol})$ and alkyne $\mathbf{1 1 7 b}$ (132 mg, $1.00 \mathrm{mmol})$. Purification by column chromatography on silica gel (dichloromethane/acetone: $3 / 1$ ) yielded 34ab (141 $\mathrm{mg}, 82 \%$ ) as a white solid.

M. p.: $228-230{ }^{\circ} \mathrm{C}$. 
${ }^{1}$ H-NMR (300 MHz, $\left.\mathrm{CDCl}_{3}\right): \delta=8.44-8.38(\mathrm{~m}, 1 \mathrm{H}), 8.25-8.19(\mathrm{~m}, 1 \mathrm{H}), 7.72-7.64(\mathrm{~m}, 1 \mathrm{H}), 7.56-$ $7.51(\mathrm{~m}, 1 \mathrm{H}), 7.50-7.45(\mathrm{~m}, 1 \mathrm{H}), 7.35-7.30(\mathrm{~m}, 2 \mathrm{H}), 7.18-7.11(\mathrm{~m}, 2 \mathrm{H}), 7.11-7.05(\mathrm{~m}, 1 \mathrm{H}), 6.76-$ $6.70(\mathrm{~m}, 2 \mathrm{H}), 6.57(\mathrm{~s}, 1 \mathrm{H}), 3.74(\mathrm{~s}, 3 \mathrm{H})$.

${ }^{13}$ C-NMR $\left(125 \mathrm{MHz}, \mathrm{CDCl}_{3}\right): \delta=162.0\left(\mathrm{C}_{\mathrm{q}}\right), 160.0\left(\mathrm{C}_{\mathrm{q}}\right), 145.6\left(\mathrm{C}_{\mathrm{q}}\right), 142.4\left(\mathrm{C}_{\mathrm{q}}\right), 140.0(\mathrm{CH}), 137.2$ $\left(\mathrm{C}_{\mathrm{q}}\right), 133.3(\mathrm{CH}), 129.3(\mathrm{CH}), 128.3(\mathrm{CH}), 127.7(\mathrm{CH}), 127.3\left(\mathrm{C}_{\mathrm{q}}\right), 126.9(\mathrm{CH}), 126.2(\mathrm{CH}), 125.4$ $(\mathrm{CH}), 125.1(\mathrm{CH}), 124.8\left(\mathrm{C}_{\mathrm{q}}\right), 113.6(\mathrm{CH}), 107.8(\mathrm{CH}), 55.1\left(\mathrm{CH}_{3}\right)$.

IR (ATR): 2359, 2010, 1670, 1511, 1251, 1028, 762, $561 \mathrm{~cm}^{-1}$.

MS (ESI) $m / z$ (relative intensity): 368 (23), 367 (100) $[\mathrm{M}+\mathrm{Na}]^{+}, 345(30)[\mathrm{M}+\mathrm{H}]^{+}, 337$ (5).

HR-MS (ESI) $m / z$ calc. for $\mathrm{C}_{21} \mathrm{H}_{17} \mathrm{~N}_{2} \mathrm{O}_{3}[\mathrm{M}+\mathrm{H}]^{+}: 345.1234$, found: 345.1232 .

\section{2-[3-(4-(tert-Butyl)phenyl)-1-oxoisoquinolin-2(1H)-yl]-pyridine-2-oxide (34ac)}<smiles></smiles>

The general procedure $\mathbf{B}$ was followed using benzamide 33a (136 mg, $0.50 \mathrm{mmol})$ and alkyne 117c (158 mg, $1.00 \mathrm{mmol}$ ). Purification by column chromatography on silica gel (dichloromethane/acetone: 4/1) yielded 34ac (119 mg, 64\%) as a white solid.

M. p.: $162-165^{\circ} \mathrm{C}$.

${ }^{1}$ H-NMR (400 MHz, $\left.\mathrm{CDCl}_{3}\right): \delta=8.41(\mathrm{ddt}, J=8.0,1.4,0.7 \mathrm{~Hz}, 1 \mathrm{H}), 8.21(\mathrm{dd}, J=6.9,1.5 \mathrm{~Hz}, 1 \mathrm{H})$, 7.67 (ddd, $J=8.0,7.1,1.4 \mathrm{~Hz}, 1 \mathrm{H}), 7.53(\mathrm{ddd}, J=8.3,1.1,0.5 \mathrm{~Hz}, 1 \mathrm{H}), 7.47$ (ddd, $J=8.2,7.1,1.2$ $\mathrm{Hz}, 1 \mathrm{H}), 7.32-7.28(\mathrm{~m}, 2 \mathrm{H}), 7.23-7.19(\mathrm{~m}, 2 \mathrm{H}), 7.16-7.11(\mathrm{~m}, 2 \mathrm{H}), 7.06$ (ddd, $J=8.6,6.9,1.5 \mathrm{~Hz}$, $1 \mathrm{H}), 6.60-6.56(\mathrm{~m}, 1 \mathrm{H}), 1.22(\mathrm{~s}, 9 \mathrm{H})$.

${ }^{13}$ C-NMR $\left(100 \mathrm{MHz}, \mathrm{CDCl}_{3}\right): \delta=162.0\left(\mathrm{C}_{\mathrm{q}}\right), 152.2\left(\mathrm{C}_{\mathrm{q}}\right), 145.6\left(\mathrm{C}_{\mathrm{q}}\right), 142.7\left(\mathrm{C}_{\mathrm{q}}\right), 140.0(\mathrm{CH}), 137.2$ $\left(\mathrm{C}_{\mathrm{q}}\right), 133.3(\mathrm{CH}), 132.0\left(\mathrm{C}_{\mathrm{q}}\right), 128.4(\mathrm{CH}), 127.8(\mathrm{CH}), 127.7(\mathrm{CH}), 127.0(\mathrm{CH}), 126.2(\mathrm{CH}), 125.3$ $(\mathrm{CH}), 125.1(\mathrm{CH}), 124.9(\mathrm{CH}), 124.9\left(\mathrm{C}_{\mathrm{q}}\right), 108.0(\mathrm{CH}), 34.6\left(\mathrm{C}_{\mathrm{q}}\right), 31.1\left(\mathrm{CH}_{3}\right)$.

IR (ATR): 3063, 2962, 1671, 1626, 1482, 1432, 1272, $759 \mathrm{~cm}^{-1}$.

MS (EI) $m / z$ (relative intensity): 370 (20) [M] $]^{+}, 238$ (20), 237 (100), 194 (25), 78 (40), 43 (30). 
HR-MS (EI) $m / z$ calc. for $\mathrm{C}_{24} \mathrm{H}_{22} \mathrm{~N}_{2} \mathrm{O}_{2}[\mathrm{M}]^{+}: 370.1681$, found: 370.1688 .

\section{2-[3-n-Pentyl-1-oxoisoquinolin-2(1H)-yl]-pyridine-2-oxide (34ad)}<smiles></smiles>

The general procedure $\mathbf{B}$ was followed using benzamide 33a $(107 \mathrm{mg}, 0.50 \mathrm{mmol})$ and alkyne 117d (96.2 $\mathrm{mg}, \quad 1.00 \mathrm{mmol})$. Purification by column chromatography on silica gel (dichloromethane/acetone: $3 / 1$ ) yielded 34ad (85.2 $\mathrm{mg}, 55 \%)$ as a yellow oil.

${ }^{1}$ H-NMR $\left(400 \mathrm{MHz}, \mathrm{CDCl}_{3}\right): \delta=8.43-8.37(\mathrm{~m}, 1 \mathrm{H}), 8.36-8.29(\mathrm{~m}, 1 \mathrm{H}), 7.69-7.60(\mathrm{~m}, 1 \mathrm{H}), 7.50-$ $7.44(\mathrm{~m}, 2 \mathrm{H}), 7.44-7.40(\mathrm{~m}, 1 \mathrm{H}), 7.40-7.36(\mathrm{~m}, 2 \mathrm{H}), 6.44(\mathrm{~s}, 1 \mathrm{H}), 2.41-2.09(\mathrm{~m}, 2 \mathrm{H}), 1.62-1.47$ (m, 2H), $1.28-1.18(\mathrm{~m}, 4 \mathrm{H}), 0.84(\mathrm{t}, J=6.9 \mathrm{~Hz}, 3 \mathrm{H})$.

${ }^{13}$ C-NMR $\left(100 \mathrm{MHz}, \mathrm{CDCl}_{3}\right): \delta=162.6\left(\mathrm{C}_{\mathrm{q}}\right), 144.5\left(\mathrm{C}_{\mathrm{q}}\right), 142.5\left(\mathrm{C}_{\mathrm{q}}\right), 140.6(\mathrm{CH}), 137.5\left(\mathrm{C}_{\mathrm{q}}\right), 133.2$ $(\mathrm{CH}), 128.2(\mathrm{CH}), 128.0(\mathrm{CH}), 126.3(\mathrm{CH}), 126.0(\mathrm{CH}), 125.7(\mathrm{CH}), 125.3(\mathrm{CH}), 124.4\left(\mathrm{C}_{\mathrm{q}}\right), 104.9$ $(\mathrm{CH}), 31.9\left(\mathrm{CH}_{2}\right), 31.2\left(\mathrm{CH}_{2}\right), 27.2\left(\mathrm{CH}_{2}\right), 22.2\left(\mathrm{CH}_{2}\right), 13.8\left(\mathrm{CH}_{3}\right)$.

IR (ATR): 2358, 2001, 1667, 1634, 1258, 824, 773, $749 \mathrm{~cm}^{-1}$.

MS (EI) $m / z$ (relative intensity): 308 (45) [M] $]^{+}, 291$ (80), 251 (60), 234 (100), 171 (35), 78 (60).

HR-MS (EI) $m / z$ calc. for $\mathrm{C}_{19} \mathrm{H}_{20} \mathrm{~N}_{2} \mathrm{O}_{2}[\mathrm{M}]^{+}: 308.1525$, found: 308.1529 .

\section{2-(2-(phenylethynyl)benzamido)pyridine 1-oxide (184)}<smiles></smiles>

M. p.: $126-128^{\circ} \mathrm{C}$. 
${ }^{1}$ H-NMR $\left(300 \mathrm{MHz}, \mathrm{CDCl}_{3}\right): \delta=11.42(\mathrm{~s}, 1 \mathrm{H}), 8.67(\mathrm{dd}, J=8.5,1.8 \mathrm{~Hz}, 1 \mathrm{H}), 8.26(\mathrm{dd}, J=6.5,1.5$ Hz, 1H), 8.09-7.94 (m, 1H), 7.71-7.62 (m, 3H), 7.57-7.39 (m, 2H), 7.36-7.29 (m, 4H), 6.98 (ddd, $J$ $=8.0,6.4,2.0 \mathrm{~Hz}, 1 \mathrm{H})$

${ }^{13}$ C-NMR $\left(100 \mathrm{MHz}, \mathrm{CDCl}_{3}\right): \delta=165.5\left(\mathrm{C}_{\mathrm{q}}\right), 144.8\left(\mathrm{C}_{\mathrm{q}}\right), 137.2(\mathrm{CH}), 135.1\left(\mathrm{C}_{\mathrm{q}}\right), 134.2(\mathrm{CH})$, $132.0(\mathrm{CH}), 131.6(\mathrm{CH}), 129.7(\mathrm{CH}), 128.9(\mathrm{CH}), 128.6(\mathrm{CH}), 128.3(\mathrm{CH}), 127.6(\mathrm{CH}), 122.6\left(\mathrm{C}_{\mathrm{q}}\right)$, $121.2\left(\mathrm{C}_{\mathrm{q}}\right), 118.9(\mathrm{CH}), 115.4(\mathrm{CH}), 96.8\left(\mathrm{C}_{\mathrm{q}}\right), 86.4\left(\mathrm{C}_{\mathrm{q}}\right)$.

IR (ATR): 3055, 1672, 1503, 1426, 1265, 1208, 757, $735 \mathrm{~cm}^{-1}$.

MS (EI) $m / z$ (relative intensity): $651(70)[2 \mathrm{M}+\mathrm{Na}]^{+}, 337(100)[\mathrm{M}+\mathrm{Na}]^{+}, 315(90)[\mathrm{M}+\mathrm{H}]^{+}$.

HR-MS (EI) $m / z$ calc. for $\mathrm{C}_{24} \mathrm{H}_{22} \mathrm{~N}_{2} \mathrm{O}_{2}[\mathrm{M}]^{+}: 315.1128$, found: 315.1121 . 


\subsection{Electrooxidative Ruthenium-Catalyzed $\mathrm{C}-\mathrm{H} / \mathrm{O}-\mathrm{H}$ Annulation by Weak $\boldsymbol{O}$-Coordination}

\subsubsection{Characterization Data}

\section{8-Methyl-3,4-diphenyl-1H-isochromen-1-one (90ca)}<smiles>Cc1cccc2c(-c3ccccc3)c(-c3ccccc3)oc(=O)c12</smiles>

The general procedure $\mathbf{C}$ was followed using carboxylic acid 89c (136 mg, $1.0 \mathrm{mmol})$ and $\mathbf{2 4 a}(89.1$ $\mathrm{mg}, 0.5 \mathrm{mmol})$ at $80{ }^{\circ} \mathrm{C}$ for $18 \mathrm{~h}$. Purification by column chromatography on silica gel (nhexane/ethyl acetate: 20/1) yielded 90ca (140 mg, 90\%) as a white solid.

M. p.: $143-144{ }^{\circ} \mathrm{C}$.

${ }^{1}$ H-NMR (400 MHz, $\left.\mathrm{CDCl}_{3}\right): \delta=7.44(\mathrm{dd}, J=8.1,7.4 \mathrm{~Hz}, 1 \mathrm{H}), 7.41-7.35(\mathrm{~m}, 3 \mathrm{H}), 7.34-7.27(\mathrm{~m}$, 3H), 7.25-7.13 (m, 5H), 6.99 (dd, $J=8.1,1.3 \mathrm{~Hz}, 1 \mathrm{H}), 2.90(\mathrm{~s}, 3 \mathrm{H})$.

${ }^{13} \mathrm{C}-N M R\left(100 \mathrm{MHz}, \mathrm{CDCl}_{3}\right): \delta=161.4\left(\mathrm{C}_{\mathrm{q}}\right), 150.6\left(\mathrm{C}_{\mathrm{q}}\right), 143.4\left(\mathrm{C}_{\mathrm{q}}\right), 140.4\left(\mathrm{C}_{\mathrm{q}}\right), 134.9\left(\mathrm{C}_{\mathrm{q}}\right), 133.6$ $(\mathrm{CH}), 132.9(\mathrm{Cq}), 131.3(\mathrm{CH}), 131.0(\mathrm{CH}), 129.0(\mathrm{CH}), 129.0(\mathrm{CH}), 128.7(\mathrm{CH}), 127.9(\mathrm{CH}), 127.7$ $(\mathrm{CH}), 123.6(\mathrm{CH}), 118.9\left(\mathrm{C}_{\mathrm{q}}\right), 116.9\left(\mathrm{C}_{\mathrm{q}}\right), 23.5\left(\mathrm{CH}_{3}\right)$.

IR (ATR): 1719, 1616, 1317, 1489, 1264, $732 \mathrm{~cm}^{-1}$.

MS (ESI) $m / z$ (relative intensity): $325(100)[\mathrm{M}+\mathrm{Na}]^{+}, 313(60)[\mathrm{M}+\mathrm{H}]^{+}$.

HR-MS (ESI) $m / z$ calc. for $\mathrm{C}_{22} \mathrm{H}_{17} \mathrm{O}_{2}[\mathrm{M}+\mathrm{H}]^{+}: 313.1223$, found: 313.1224 .

The analytical data are in accordance with those previously reported in the literature. ${ }^{[95]}$

\section{6-Methoxy-3,4-diphenyl-1H-isochromen-1-one (90ba)}<smiles>COc1ccc2c(=O)oc(-c3ccccc3)c(-c3ccccc3)c2c1</smiles> 
The general procedure $\mathbf{C}$ was followed using carboxylic acid $\mathbf{8 9 b}(152 \mathrm{mg}, 1.0 \mathrm{mmol})$ and $\mathbf{2 4 a}(89.1$ $\mathrm{mg}, 0.5 \mathrm{mmol}$ ) at $100{ }^{\circ} \mathrm{C}$ for $24 \mathrm{~h}$. Purification by column chromatography on silica gel (nhexane/ethyl acetate: $10 / 1)$ yielded $90 \mathrm{ba}(98.5 \mathrm{mg}, 60 \%)$ as a white solid.

M. p.: $178-180{ }^{\circ} \mathrm{C}$.

${ }^{1}$ H-NMR (400 MHz, $\left.\mathrm{CDCl}_{3}\right): \delta=8.28(\mathrm{~d}, J=8.0 \mathrm{~Hz}, 1 \mathrm{H}), 7.43-7.37$ (m, 3H), 7.34-7.28 (m, 3H), 7.26-7.21 (m, 2H), 7.21-7.13 (m, 3H), 6.95 (d, J=1.5 Hz, 1H), 2.35 (s, 3H).

${ }^{13}$ C-NMR $\left(125 \mathrm{MHz}, \mathrm{CDCl}_{3}\right): \delta=164.6\left(\mathrm{C}_{\mathrm{q}}\right), 161.9\left(\mathrm{C}_{\mathrm{q}}\right), 151.5\left(\mathrm{C}_{\mathrm{q}}\right), 141.1\left(\mathrm{C}_{\mathrm{q}}\right), 134.3\left(\mathrm{C}_{\mathrm{q}}\right), 133.0$ $\left(\mathrm{C}_{\mathrm{q}}\right), 131.9(\mathrm{CH}), 131.1(\mathrm{CH}), 129.2(\mathrm{CH}), 129.0(\mathrm{CH}), 128.9(\mathrm{CH}), 128.1(\mathrm{CH}), 127.8(\mathrm{CH}), 116.7$ $\left(\mathrm{C}_{\mathrm{q}}\right), 115.6(\mathrm{CH}), 113.6\left(\mathrm{C}_{\mathrm{q}}\right), 108.4(\mathrm{CH}), 55.4\left(\mathrm{CH}_{3}\right)$.

IR (ATR): 1717, 1604, 1488, 1264, 905, $728 \mathrm{~cm}^{-1}$.

MS (ESI) $m / z$ (relative intensity): $351(30)[\mathrm{M}+\mathrm{Na}]^{+}, 329(100)[\mathrm{M}+\mathrm{H}]^{+}$.

HR-MS (ESI) $m / z$ calc. for $\mathrm{C}_{22} \mathrm{H}_{17} \mathrm{O}_{3}[\mathrm{M}+\mathrm{H}]^{+}:$329.1172, found: 329.1176.

The analytical data are in accordance with those previously reported in the literature. ${ }^{[95]}$

\section{3,4-Diethyl-8-methyl-1 $H$-isochromen-1-one (90cb)}<smiles>CCc1oc(=O)c2c(C)cccc2c1CC</smiles>

The general procedure $\mathbf{C}$ was followed using carboxylic acid $89 \mathrm{c}(136 \mathrm{mg}, 1.00 \mathrm{mmol})$ and alkyne 24b (41.1 mg, $0.50 \mathrm{mmol}$ ). Purification by column chromatography on silica gel (nhexane/ethyl acetate: $20 / 1)$ yielded $90 \mathrm{cb}(91.9 \mathrm{mg}, 85 \%)$ as a colourless oil.

${ }^{1}$ H-NMR (300 MHz, $\left.\mathrm{CDCl}_{3}\right): \delta=7.51(\mathrm{dd}, J=8.1,7.4 \mathrm{~Hz}, 1 \mathrm{H}), 7.32(\mathrm{~d}, 1 \mathrm{H}), 7.18$ (dt, $J=7.4,0.9$ $\mathrm{Hz}, 1 \mathrm{H}), 2.61-2.50(\mathrm{~m}, 4 \mathrm{H}), 1.23(\mathrm{t}, J=7.5 \mathrm{~Hz}, 3 \mathrm{H}), 1.13(\mathrm{t}, J=7.5 \mathrm{~Hz}, 3 \mathrm{H})$.

${ }^{13}$ C-NMR $\left(125 \mathrm{MHz}, \mathrm{CDCl}_{3}\right): \delta=161.90\left(\mathrm{C}_{\mathrm{q}}\right), 154.42\left(\mathrm{C}_{\mathrm{q}}\right), 143.47\left(\mathrm{C}_{\mathrm{q}}\right), 138.99\left(\mathrm{C}_{\mathrm{q}}\right), 133.45(\mathrm{CH})$, $129.85(\mathrm{CH}), 120.25(\mathrm{CH}), 119.19\left(\mathrm{C}_{\mathrm{q}}\right), 112.70\left(\mathrm{C}_{\mathrm{q}}\right), 23.94\left(\mathrm{CH}_{2}\right), 23.60\left(\mathrm{CH}_{3}\right), 19.58\left(\mathrm{CH}_{2}\right), 14.17$ $\left(\mathrm{CH}_{3}\right), 12.47\left(\mathrm{CH}_{3}\right)$.

IR (ATR): 2967, 2932, 2716, 2648, 2571, 1469, 1268, 1023, 806, $707 \mathrm{~cm}^{-1}$.

MS (ESI) $m / z$ (relative intensity): $216(100)[\mathrm{M}]^{+}, 201$ (90). 
HR-MS (ESI) $m / z$ calc. for $\mathrm{C}_{14} \mathrm{H}_{16} \mathrm{O}_{2}[\mathrm{M}]^{+}: 216.1150$, found: 216.1147 .

The analytical data are in accordance with those previously reported in the literature. ${ }^{[95]}$

\section{4-Ethyl-8-methyl-3-phenyl-1H-isochromen-1-one (90cc)}<smiles>CCc1c(-c2ccccc2)oc(=O)c2c(C)cccc12</smiles>

The general procedure $\mathbf{C}$ was followed using carboxylic acid 89c (136 $\mathrm{mg}, 1.00 \mathrm{mmol})$ and alkyne 24c $(65.1 \mathrm{mg}, 0.50 \mathrm{mmol})$. Purification by column chromatography on silica gel ( $n$ hexane/ethyl acetate: 20/1) yielded 90cc (123 mg, 93\%) and 90ce' (6.6 mg, 5\%) as white solids.

M. p.: $119-121^{\circ} \mathrm{C}$.

${ }^{1}$ H-NMR $\left(300 \mathrm{MHz}, \mathrm{CDCl}_{3}\right): \delta=7.69-7.61(\mathrm{~m}, 1 \mathrm{H}), 7.61-7.55(\mathrm{~m}, 2 \mathrm{H}), 7.55-7.51(\mathrm{~m}, 1 \mathrm{H}), 7.51-$ $7.42(\mathrm{~m}, 3 \mathrm{H}), 7.37-7.32(\mathrm{~m}, 1 \mathrm{H}), 2.90(\mathrm{~s}, 3 \mathrm{H}), 2.79-2.64(\mathrm{~m}, 2 \mathrm{H}), 1.28(\mathrm{t}, J=7.4 \mathrm{~Hz}, 3 \mathrm{H})$.

${ }^{13}$ C-NMR $\left(100 \mathrm{MHz}, \mathrm{CDCl}_{3}\right): \delta=161.65\left(\mathrm{C}_{\mathrm{q}}\right), 151.11\left(\mathrm{C}_{\mathrm{q}}\right), 143.89\left(\mathrm{C}_{\mathrm{q}}\right), 139.11\left(\mathrm{C}_{\mathrm{q}}\right), 133.81(\mathrm{CH})$, $133.62\left(\mathrm{C}_{\mathrm{q}}\right), 130.87(\mathrm{CH}), 129.26(\mathrm{CH}), 128.93(\mathrm{CH}), 128.31(\mathrm{CH}), 121.44(\mathrm{CH}), 119.82\left(\mathrm{C}_{\mathrm{q}}\right)$, $115.10\left(\mathrm{C}_{\mathrm{q}}\right), 23.74\left(\mathrm{CH}_{3}\right), 20.38\left(\mathrm{CH}_{2}\right), 14.66\left(\mathrm{CH}_{3}\right)$.

IR (ATR): 3058, 2967, 2930, 1717, 1467, 1094, 1031, $699 \mathrm{~cm}^{-1}$.

MS (EI) $m / z$ (relative intensity): 264 (100), 249 (40), 221 (90).

HR-MS (ESI) $m / z$ calc. for $\mathrm{C}_{18} \mathrm{H}_{16} \mathrm{O}_{2}[\mathrm{M}+\mathrm{H}]^{+}: 264.1150$, found: 264.1161 .

\section{3-Ethyl-8-methyl-4-phenyl-1 $H$-isochromen-1-one (90cc')}<smiles>CCc1oc(=O)c2c(C)cccc2c1-c1ccccc1</smiles>

M. p.: $119-121^{\circ} \mathrm{C}$.

${ }^{1}$ H-NMR $\left(400 \mathrm{MHz}, \mathrm{CDCl}_{3}\right): \delta=7.47-7.35(\mathrm{~m}, 4 \mathrm{H}), 7.26-7.21(\mathrm{~m}, 3 \mathrm{H}), 6.78-6.72(\mathrm{~m}, 1 \mathrm{H}), 2.85(\mathrm{~s}$, $3 \mathrm{H}), 2.35-2.27(\mathrm{~m}, 2 \mathrm{H}), 1.15(\mathrm{t}, J=7.6 \mathrm{~Hz}, 3 \mathrm{H})$. 
${ }^{13}$ C-NMR $\left(100 \mathrm{MHz}, \mathrm{CDCl}_{3}\right): \delta=162.1\left(\mathrm{C}_{\mathrm{q}}\right), 155.8\left(\mathrm{C}_{\mathrm{q}}\right), 143.3\left(\mathrm{C}_{\mathrm{q}}\right), 140.4\left(\mathrm{C}_{\mathrm{q}}\right), 135.1\left(\mathrm{C}_{\mathrm{q}}\right), 133.6$ $(\mathrm{CH}), 130.6(\mathrm{CH}), 130.3(\mathrm{CH}), 128.9(\mathrm{CH}), 127.9(\mathrm{CH}), 123.0(\mathrm{CH}), 118.6\left(\mathrm{C}_{\mathrm{q}}\right), 115.7\left(\mathrm{C}_{\mathrm{q}}\right), 24.9$ $\left(\mathrm{CH}_{2}\right), 23.5\left(\mathrm{CH}_{3}\right), 12.4\left(\mathrm{CH}_{3}\right)$.

IR (ATR): 3057, 2970, 2932, 1720, 1648, 1470, 1185, 1021, 805, $704 \mathrm{~cm}^{-1}$.

MS (EI) $m / z$ (relative intensity): 264 (100) [M]+, 235 (80), 179 (70).

HR-MS (ESI) $m / z$ calc. for $\mathrm{C}_{18} \mathrm{H}_{16} \mathrm{O}_{2}[\mathrm{M}]^{+}: 264.1150$, found: 264.1147 .

4-Butyl-3-(4-methylphenyl)-8-methyl-1H-isochromen-1-one (90cd)

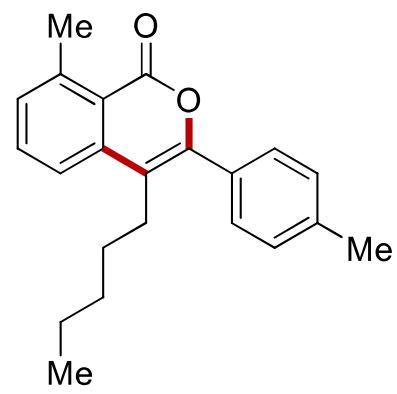

The general procedure $\mathbf{C}$ was followed using carboxylic acid 89c (136 mg, $1.00 \mathrm{mmol})$ and alkyne 24d (93.2 $\mathrm{mg}, 0.50 \mathrm{mmol})$. Purification by column chromatography on silica gel ( $n$ hexane/ethyl acetate: $20 / 1)$ yielded 90cd (130 mg, 81\%) and 90cd' (9.6 mg, 6\%) as white solids.

M. p.: $110-113^{\circ} \mathrm{C}$.

${ }^{1}$ H-NMR $\left(300 \mathrm{MHz}, \mathrm{CDCl}_{3}\right): \delta=7.64(\mathrm{t}, J=7.8 \mathrm{~Hz}, 1 \mathrm{H}), 7.52-7.43(\mathrm{~m}, 3 \mathrm{H}), 7.35-7.26(\mathrm{~m}, 3 \mathrm{H})$, $2.89(\mathrm{~s}, 3 \mathrm{H}), 2.76-2.58(\mathrm{~m}, 2 \mathrm{H}), 2.44(\mathrm{~s}, 3 \mathrm{H}), 1.75-1.52(\mathrm{~m}, 2 \mathrm{H}), 1.45-1.26(\mathrm{~m}, 4 \mathrm{H}), 0.95-0.84(\mathrm{~m}$, $3 \mathrm{H})$.

${ }^{13}$ C-NMR $\left(75 \mathrm{MHz}, \mathrm{CDCl}_{3}\right): \delta=161.78\left(\mathrm{C}_{\mathrm{q}}\right), 151.45\left(\mathrm{C}_{\mathrm{q}}\right), 143.79\left(\mathrm{C}_{\mathrm{q}}\right), 139.49\left(\mathrm{C}_{\mathrm{q}}\right), 139.22\left(\mathrm{C}_{\mathrm{q}}\right)$, $133.70(\mathrm{CH}), 130.81\left(\mathrm{C}_{\mathrm{q}}\right), 130.68(\mathrm{CH}), 128.94(\mathrm{CH}), 128.91(\mathrm{CH}), 121.41(\mathrm{CH}), 119.74\left(\mathrm{C}_{\mathrm{q}}\right)$, $113.69\left(\mathrm{C}_{\mathrm{q}}\right), 31.83\left(\mathrm{CH}_{2}\right), 29.61\left(\mathrm{CH}_{2}\right), 27.21\left(\mathrm{CH}_{2}\right), 23.74\left(\mathrm{CH}_{3}\right), 22.32\left(\mathrm{CH}_{2}\right), 21.41\left(\mathrm{CH}_{3}\right), 14.02$ $\left(\mathrm{CH}_{3}\right)$.

IR (ATR): 2954, 2925, 1720, 1591, 1471, 1081, 1036, 803, 731, $499 \mathrm{~cm}^{-1}$.

MS (ESI) $m / z$ (relative intensity): 320 (70) [M]+, 292 (10), 263 (95), 235 (100).

HR-MS (ESI) $m / z$ calc. for $\mathrm{C}_{22} \mathrm{H}_{24} \mathrm{O}_{2}[\mathrm{M}]^{+}: 320.1776$, found: 320.1779 .

\section{8-Methyl-3-pentyl-4-(p-methylphenyl)-1H-isochromen-1-one (90cd')}




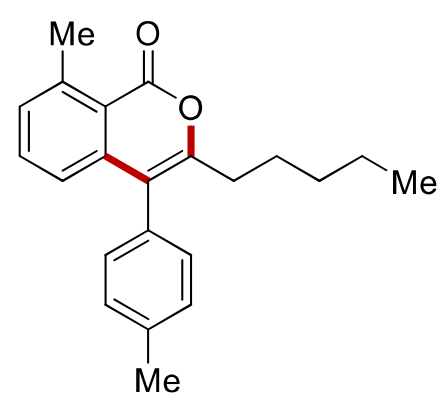

M. p.: $110-113^{\circ} \mathrm{C}$.

${ }^{1}$ H-NMR $\left(400 \mathrm{MHz}, \mathrm{CDCl}_{3}\right): \delta=7.36(\mathrm{t}, J=7.8 \mathrm{~Hz}, 1 \mathrm{H}), 7.26-7.24(\mathrm{~m}, 2 \mathrm{H}), 7.20(\mathrm{~d}, J=7.4 \mathrm{~Hz}$, 1H), 7.11-7.08 (m, 2H), $6.76(\mathrm{~d}, J=8.0 \mathrm{~Hz}, 1 \mathrm{H}), 2.84(\mathrm{~s}, 3 \mathrm{H}), 2.42(\mathrm{~s}, 3 \mathrm{H}), 2.31-2.27(\mathrm{~m}, 2 \mathrm{H})$, $1.65-1.57(\mathrm{~m}, 2 \mathrm{H}), 1.22-1.16(\mathrm{~m}, 4 \mathrm{H}), 0.83-0.79(\mathrm{~m}, 3 \mathrm{H})$.

${ }^{13}$ C-NMR $\left(100 \mathrm{MHz}, \mathrm{CDCl}_{3}\right): \delta=162.2\left(\mathrm{C}_{\mathrm{q}}\right), 154.9\left(\mathrm{C}_{\mathrm{q}}\right), 143.3\left(\mathrm{C}_{\mathrm{q}}\right), 140.6\left(\mathrm{C}_{\mathrm{q}}\right), 137.6\left(\mathrm{C}_{\mathrm{q}}\right), 133.5$ $(\mathrm{CH}), 132.0\left(\mathrm{C}_{\mathrm{q}}\right), 130.5(\mathrm{CH}), 130.2(\mathrm{CH}), 129.5(\mathrm{CH}), 128.9(\mathrm{CH}), 123.0(\mathrm{CH}), 118.6\left(\mathrm{C}_{\mathrm{q}}\right), 116.1$ $\left(\mathrm{C}_{\mathrm{q}}\right), 31.3\left(\mathrm{CH}_{2}\right), 31.2\left(\mathrm{CH}_{2}\right), 27.3\left(\mathrm{CH}_{2}\right), 23.5\left(\mathrm{CH}_{3}\right), 22.3\left(\mathrm{CH}_{2}\right), 21.3\left(\mathrm{CH}_{3}\right), 13.9\left(\mathrm{CH}_{3}\right)$.

IR (ATR): 2955, 2926, 2857, 1726, 1645, 1591, 1496, 1022, 805, $520 \mathrm{~cm}^{-1}$.

MS (ESI) $m / z$ (relative intensity): 320 (100) [M] $]^{+}, 263$ (20), 249 (90), 235 (30).

HR-MS (ESI) $m / z$ calc. for $\mathrm{C}_{22} \mathrm{H}_{24} \mathrm{O}_{2}[\mathrm{M}]^{+}: 320.1776$, found: 320.1776 .

\section{4-Butyl-3-(4-chlorophenyl)-8-methyl-1H-isochromen-1-one (90ce)}<smiles>CCCCc1c(-c2ccc(Cl)cc2)oc(=O)c2c(C)cccc12</smiles>

The general procedure $\mathbf{C}$ was followed using carboxylic acid $\mathbf{8 9 c}(136 \mathrm{mg}, 1.00 \mathrm{mmol})$ and alkyne 24e (103 mg, $0.50 \mathrm{mmol})$. Purification by column chromatography on silica gel ( $n$ hexane/ethyl acetate: 20/1) yielded 90ce (128 $\mathrm{mg}, 78 \%$ ) as a white solid.

M. p.: $96-100{ }^{\circ} \mathrm{C}$.

${ }^{1}$ H-NMR $\left(300 \mathrm{MHz}, \mathrm{CDCl}_{3}\right): \delta=7.60(\mathrm{t}, J=8.1 \mathrm{~Hz}, 1 \mathrm{H}), 7.49-7.37(\mathrm{~m}, 5 \mathrm{H}), 7.30(\mathrm{~d}, J=7.4,1.0$ $\mathrm{Hz}, 1 \mathrm{H}), 2.83(\mathrm{~s}, 3 \mathrm{H}), 2.65-2.55(\mathrm{~m}, 2 \mathrm{H}), 1.63-1.51(\mathrm{~m}, 2 \mathrm{H}), 1.40-1.26(\mathrm{~m}, 2 \mathrm{H}), 0.87(\mathrm{t}, J=7.3 \mathrm{~Hz}$ $3 \mathrm{H})$. 
${ }^{13}$ C-NMR $\left(125 \mathrm{MHz}, \mathrm{CDCl}_{3}\right): \delta=161.17\left(\mathrm{C}_{\mathrm{q}}\right), 149.84\left(\mathrm{C}_{\mathrm{q}}\right), 143.73\left(\mathrm{C}_{\mathrm{q}}\right), 138.93\left(\mathrm{C}_{\mathrm{q}}\right), 135.11\left(\mathrm{C}_{\mathrm{q}}\right)$, $133.67(\mathrm{CH}), 131.94\left(\mathrm{C}_{\mathrm{q}}\right), 130.92(\mathrm{CH}), 130.26(\mathrm{CH}), 128.43(\mathrm{CH}), 121.40(\mathrm{CH}), 119.66\left(\mathrm{C}_{\mathrm{q}}\right)$, $114.19\left(\mathrm{C}_{\mathrm{q}}\right), 31.98\left(\mathrm{CH}_{2}\right), 26.88\left(\mathrm{CH}_{2}\right), 23.66\left(\mathrm{CH}_{3}\right), 22.70\left(\mathrm{CH}_{2}\right), 13.76\left(\mathrm{CH}_{3}\right)$.

IR (ATR): 2956, 2928, 2869, 1720, 1489, 1470, 1229, 1093, 1032, $803 \mathrm{~cm}^{-1}$.

MS (EI) $m / z$ (relative intensity): 326 (60) [M] $]^{+}, 283$ (50), 255 (30), 248 (100).

HR-MS (ESI) $m / z$ calc. for $\mathrm{C}_{20} \mathrm{H}_{19} \mathrm{ClO}_{2}[\mathrm{M}]^{+}: 326.1074$, found: 326.1069 .

The analytical data are in accordance with those previously reported in the literature. ${ }^{[95]}$

\section{4-Butyl-3-(4-methoxyphenyl)-8-methyl-1H-isochromen-1-one (90cf)}<smiles>CCCCc1c(-c2ccc(OC)cc2)oc(=O)c2c(C)cccc12</smiles>

The general procedure $\mathbf{C}$ was followed using carboxylic acid 89c (136 mg, $1.00 \mathrm{mmol})$ and alkyne 24f $(101 \mathrm{mg}, 0.50 \mathrm{mmol})$. Purification by column chromatography on silica gel (nhexane/ethyl acetate: $20 / 1)$ yielded 90cf (105 mg, 65\%) and 90cf' $(11.3 \mathrm{mg}, 7 \%)$ as white solids.

M. p.: $72-76^{\circ} \mathrm{C}$.

${ }^{1}$ H-NMR $\left(300 \mathrm{MHz}, \mathrm{CDCl}_{3}\right): \delta=7.59(\mathrm{dd}, J=8.1,7.4 \mathrm{~Hz}, 1 \mathrm{H}), 7.50-7.42(\mathrm{~m}, 3 \mathrm{H}), 7.30-7.25(\mathrm{~m}$, $1 \mathrm{H}), 6.99-6.91(\mathrm{~m}, 2 \mathrm{H}), 3.84(\mathrm{~s}, 3 \mathrm{H}), 2.85(\mathrm{~s}, 3 \mathrm{H}), 2.66-2.57(\mathrm{~m}, 2 \mathrm{H}), 1.63-1.53(\mathrm{~m}, 2 \mathrm{H}), 1.42-1.28$ $(\mathrm{m}, 2 \mathrm{H}), 0.88(\mathrm{t}, J=7.3 \mathrm{~Hz}, 3 \mathrm{H})$.

${ }^{13}$ C-NMR $\left(125 \mathrm{MHz}, \mathrm{CDCl}_{3}\right): \delta=161.61\left(\mathrm{C}_{\mathrm{q}}\right), 160.04\left(\mathrm{C}_{\mathrm{q}}\right), 151.09\left(\mathrm{C}_{\mathrm{q}}\right), 143.60\left(\mathrm{C}_{\mathrm{q}}\right), 139.42\left(\mathrm{C}_{\mathrm{q}}\right)$, $133.53(\mathrm{CH}), 130.46(\mathrm{CH}), 130.31(\mathrm{CH}), 126.02\left(\mathrm{C}_{\mathrm{q}}\right), 121.27(\mathrm{CH}), 119.57\left(\mathrm{C}_{\mathrm{q}}\right), 113.57(\mathrm{CH})$, $113.31\left(\mathrm{C}_{\mathrm{q}}\right), 55.32\left(\mathrm{CH}_{3}\right), 32.03\left(\mathrm{CH}_{2}\right), 27.00\left(\mathrm{CH}_{2}\right), 23.71\left(\mathrm{CH}_{3}\right), 22.75\left(\mathrm{CH}_{2}\right), 13.81\left(\mathrm{CH}_{3}\right)$.

IR (ATR): 2956, 2927, 1717, 1510, 1252, 1176, 1032, 842, 804, $522 \mathrm{~cm}^{-1}$.

MS (ESI) $m / z$ (relative intensity): 322 (40) [M] $]^{+}, 294$ (30), 279 (35), 251 (100).

HR-MS (ESI) $m / z$ calc. for $\mathrm{C}_{21} \mathrm{H}_{22} \mathrm{O}_{3}[\mathrm{M}]^{+}: 322.1569$, found: 322.1566 .

The analytical data are in accordance with those previously reported in the literature. ${ }^{[95]}$ 


\section{3-Butyl-4-(4-methoxyphenyl)-8-methyl-1H-isochromen-1-one (90cf')}<smiles>CCCCc1oc(=O)c2c(C)cccc2c1-c1ccc(OC)cc1</smiles>

M. p.: $72-76^{\circ} \mathrm{C}$.

${ }^{1} \mathrm{H}-\mathrm{NMR}\left(400 \mathrm{MHz}, \mathrm{CDCl}_{3}\right): \delta=7.37(\mathrm{t}, J=7.8 \mathrm{~Hz}, 1 \mathrm{H}), 7.22-7.18(\mathrm{~m}, 1 \mathrm{H}), 7.14-7.11(\mathrm{~m}, 2 \mathrm{H})$, 7.00-6.96 (m, 2H), $6.77(\mathrm{ddd}, J=8.0,1.3,0.7 \mathrm{~Hz}, 1 \mathrm{H}), 3.86(\mathrm{~s}, 3 \mathrm{H}), 2.84(\mathrm{~d}, J=0.9 \mathrm{~Hz}, 3 \mathrm{H}), 2.33-$ $2.28(\mathrm{~m}, 2 \mathrm{H}), 1.60-1.54(\mathrm{~m}, 2 \mathrm{H}), 1.26-1.22(\mathrm{~m}, 2 \mathrm{H}), 0.80(\mathrm{t}, J=7.3 \mathrm{~Hz}, 3 \mathrm{H})$.

${ }^{13}$ C-NMR $\left(100 \mathrm{MHz}, \mathrm{CDCl}_{3}\right): \delta=162.1(\mathrm{Cq}), 159.2\left(\mathrm{C}_{\mathrm{q}}\right), 155.1\left(\mathrm{C}_{\mathrm{q}}\right), 143.3\left(\mathrm{C}_{\mathrm{q}}\right), 140.8\left(\mathrm{C}_{\mathrm{q}}\right), 133.5$ $(\mathrm{CH}), 131.8(\mathrm{CH}), 130.2(\mathrm{CH}), 127.1\left(\mathrm{C}_{\mathrm{q}}\right), 123.0(\mathrm{CH}), 118.6(\mathrm{Cq}), 115.8(\mathrm{Cq}), 114.3(\mathrm{CH}), 55.3$ $\left(\mathrm{CH}_{2}\right), 31.0\left(\mathrm{CH}_{2}\right), 29.7\left(\mathrm{CH}_{3}\right), 23.5\left(\mathrm{CH}_{3}\right), 22.6\left(\mathrm{CH}_{2}\right), 13.8\left(\mathrm{CH}_{3}\right)$.

IR (ATR): 2957, 2928, 2860, 1721, 1512, 1468, 1245, 1176, 1029, $842 \mathrm{~cm}^{-1}$.

MS (ESI) $m / z$ (relative intensity): 322 (90) [M] $]^{+}, 265$ (100), 253 (50), 237 (70).

HR-MS (ESI) $m / z$ calc. for $\mathrm{C}_{21} \mathrm{H}_{22} \mathrm{O}_{3}[\mathrm{M}]^{+}: 322.1569$, found: 322.1582 .

The analytical data are in accordance with those previously reported in the literature. ${ }^{[95]}$

\section{Ethyl 4-(4-butyl-8-methyl-1-oxo-1 $H$-isochromen-3-yl)benzoate $(90 \mathrm{cg})$}<smiles>CCCCc1c(-c2ccc(C(=O)OCC)cc2)oc(=O)c2c(C)cccc12</smiles>

The general procedure $\mathbf{C}$ was followed using carboxylic acid 89c (136 $\mathrm{mg}, 1.00 \mathrm{mmol})$ and alkyne 24g (115 mg, $0.50 \mathrm{mmol})$. Purification by column chromatography on silica gel ( $n$ hexane/ethyl acetate: 20/1) yielded 90cg (160 mg, 88\%) and 90cg' (12.8 mg, 7\%) as white solids.

M. p.: $106-109{ }^{\circ} \mathrm{C}$. 
${ }^{1}$ H-NMR (300 MHz, $\left.\mathrm{CDCl}_{3}\right): \delta=8.14-8.08(\mathrm{~m}, 2 \mathrm{H}), 7.67-7.57(\mathrm{~m}, 3 \mathrm{H}), 7.47(\mathrm{~d}, J=8.2 \mathrm{~Hz}, 1 \mathrm{H})$, $7.35-7.29(\mathrm{~m}, 1 \mathrm{H}), 4.39(\mathrm{q}, J=7.2 \mathrm{~Hz}, 2 \mathrm{H}), 2.85(\mathrm{~s}, 3 \mathrm{H}), 2.65-2.58(\mathrm{~m}, 2 \mathrm{H}), 1.63-1.53(\mathrm{~m}, 2 \mathrm{H})$, $1.40(\mathrm{t}, J=7.1 \mathrm{~Hz}, 3 \mathrm{H}), 1.37-1.28(\mathrm{~m}, 2 \mathrm{H}), 0.86(\mathrm{t}, J=7.3 \mathrm{~Hz}, 3 \mathrm{H})$.

${ }^{13}$ C-NMR $\left(125 \mathrm{MHz}, \mathrm{CDCl}_{3}\right): \delta=165.84\left(\mathrm{C}_{\mathrm{q}}\right), 161.15\left(\mathrm{C}_{\mathrm{q}}\right), 149.98\left(\mathrm{C}_{\mathrm{q}}\right), 143.84\left(\mathrm{C}_{\mathrm{q}}\right), 138.90\left(\mathrm{C}_{\mathrm{q}}\right)$, $137.65\left(\mathrm{C}_{\mathrm{q}}\right), 133.74(\mathrm{CH}), 131.11(\mathrm{CH}), 130.92\left(\mathrm{C}_{\mathrm{q}}\right), 129.37(\mathrm{CH}), 128.95(\mathrm{CH}), 121.50(\mathrm{CH})$, $119.78\left(\mathrm{C}_{\mathrm{q}}\right), 114.69\left(\mathrm{C}_{\mathrm{q}}\right), 61.20\left(\mathrm{CH}_{2}\right), 32.05\left(\mathrm{CH}_{2}\right), 26.89\left(\mathrm{CH}_{2}\right), 23.71\left(\mathrm{CH}_{3}\right), 22.72\left(\mathrm{CH}_{2}\right), 14.38$ $\left(\mathrm{CH}_{3}\right), 13.78\left(\mathrm{CH}_{3}\right)$.

IR (ATR): 2957, 2929, 2871, 1716, 1608, 1469, 1270, 1100, 772, 705 $\mathrm{cm}^{-1}$.

MS (ESI) $m / z$ (relative intensity): 364 (90) [M] $]^{+}, 321$ (10), 293 (25), 249 (100).

HR-MS (ESI) $m / z$ calc. for $\mathrm{C}_{23} \mathrm{H}_{24} \mathrm{O}_{4}[\mathrm{M}]^{+}: 364.1675$, found: 364.1684 .

\section{Ethyl 4-(3-butyl-8-methyl-1-oxo-1H-isochromen-4-yl)benzoate (90cg')}<smiles>CCCCc1oc(=O)c2c(C)cccc2c1-c1ccc(C(=O)OCC)cc1</smiles>

M. p.: $106-109{ }^{\circ} \mathrm{C}$.

${ }^{1} \mathbf{H}-N M R\left(300 \mathrm{MHz}, \mathrm{CDCl}_{3}\right): \delta=8.14(\mathrm{dd}, J=8.3,1.9 \mathrm{~Hz}, 2 \mathrm{H}), 7.37(\mathrm{t}, J=7.7 \mathrm{~Hz}, 1 \mathrm{H}), 7.34-7.29$ $(\mathrm{m}, 2 \mathrm{H}), 7.24(\mathrm{~s}, 1 \mathrm{H}), 6.67(\mathrm{~d}, J=8.0 \mathrm{~Hz}, 1 \mathrm{H}), 4.44-4.38(\mathrm{~m}, 2 \mathrm{H}), 2.84(\mathrm{~s}, 3 \mathrm{H}), 2.30-2.24(\mathrm{~m}, 2 \mathrm{H})$, $1.61-1.56(\mathrm{~m}, 2 \mathrm{H}), 1.44-1.39(\mathrm{~m}, 3 \mathrm{H}), 1.25-1.19(\mathrm{~m}, 2 \mathrm{H}), 0.79(\mathrm{t}, J=7.3 \mathrm{~Hz}, 3 \mathrm{H})$.

${ }^{13}$ C-NMR $\left(100 \mathrm{MHz}, \mathrm{CDCl}_{3}\right): \delta=165.84\left(\mathrm{C}_{\mathrm{q}}\right), 161.15\left(\mathrm{C}_{\mathrm{q}}\right), 149.98\left(\mathrm{C}_{\mathrm{q}}\right), 143.84\left(\mathrm{C}_{\mathrm{q}}\right), 138.90\left(\mathrm{C}_{\mathrm{q}}\right)$, $137.65\left(\mathrm{C}_{\mathrm{q}}\right), 133.74(\mathrm{CH}), 131.11(\mathrm{CH}), 130.92\left(\mathrm{C}_{\mathrm{q}}\right), 129.37(\mathrm{CH}), 128.95(\mathrm{CH}), 121.50(\mathrm{CH}), 119.78$ $\left(\mathrm{C}_{\mathrm{q}}\right), 114.69\left(\mathrm{C}_{\mathrm{q}}\right), 61.20\left(\mathrm{CH}_{2}\right), 32.05\left(\mathrm{CH}_{2}\right), 26.89\left(\mathrm{CH}_{2}\right), 23.71\left(\mathrm{CH}_{3}\right), 22.72\left(\mathrm{CH}_{2}\right), 14.38\left(\mathrm{CH}_{3}\right)$, $13.78\left(\mathrm{CH}_{3}\right)$.

IR (ATR): 2958, 2928, 2870, 1717, 1470, 1270, 1100, 1020, 773, 713 $\mathrm{cm}^{-1}$. MS (ESI) $m / z$ (relative intensity): 364 (100) [M] $]^{+}, 307$ (20), 280 (25).

HR-MS (ESI) $m / z$ calc. for $\mathrm{C}_{23} \mathrm{H}_{24} \mathrm{O}_{4}[\mathrm{M}]^{+}: 364.1675$, found: 364.1670 . 


\section{Ethyl 4-(4-butyl-2,8-dimethyl-1-oxo-1,2-dihydroisoquinolin-3-yl)benzoate (88ag)}<smiles>CCCCc1c(-c2ccc(C(=O)OCC)cc2)n(C)c(=O)c2ccccc12</smiles>

The general procedure $\mathbf{C}$ was followed using amide $\mathbf{8 7 a}$ (136 mg, $1.00 \mathrm{mmol}$ ) and alkyne $\mathbf{2 4 g}$ (115 mg, $0.50 \mathrm{mmol}$ ). Purification by column chromatography on silica gel ( $n$ hexane/ethyl acetate: 20/1) yielded 88ag (76.3 $\mathrm{mg}, 42 \%)$ as an oil.

${ }^{1}$ H-NMR (400 MHz, $\left.\mathrm{CDCl}_{3}\right): \delta=8.55-8.49(\mathrm{~m}, 1 \mathrm{H}), 8.21-8.15(\mathrm{~m}, 2 \mathrm{H}), 7.70-7.66(\mathrm{~m}, 2 \mathrm{H}), 7.53-$ 7.47 (m, 1H), 7.39-7.34 (m, 2H), 4.42 (q, $J=7.1 \mathrm{~Hz}, 2 \mathrm{H}), 3.19$ (s, 3H), 2.37-2.31 (m, 2H), 1.42 (t, $J$ $=7.1 \mathrm{~Hz}, 5 \mathrm{H}), 1.21(\mathrm{~s}, 3 \mathrm{H}), 1.20-1.13(\mathrm{~m}, 2 \mathrm{H}), 0.75(\mathrm{t}, J=7.3 \mathrm{~Hz}, 3 \mathrm{H})$.

${ }^{13}$ C-NMR $\left(100 \mathrm{MHz}, \mathrm{CDCl}_{3}\right): \delta=165.97\left(\mathrm{C}_{\mathrm{q}}\right), 162.40\left(\mathrm{C}_{\mathrm{q}}\right), 139.98\left(\mathrm{C}_{\mathrm{q}}\right), 139.16\left(\mathrm{C}_{\mathrm{q}}\right), 136.12\left(\mathrm{C}_{\mathrm{q}}\right)$, $132.17(\mathrm{CH}), 130.92\left(\mathrm{C}_{\mathrm{q}}\right), 130.17\left(\mathrm{C}_{\mathrm{q}}\right), 129.48(\mathrm{CH}), 128.43(\mathrm{CH}), 126.63(\mathrm{CH}), 125.73\left(\mathrm{C}_{\mathrm{q}}\right), 123.28$ $(\mathrm{CH}), 115.57\left(\mathrm{C}_{\mathrm{q}}\right), 61.35\left(\mathrm{CH}_{2}\right), 34.15\left(\mathrm{CH}_{3}\right), 32.56\left(\mathrm{CH}_{2}\right), 28.16\left(\mathrm{CH}_{2}\right), 27.06\left(\mathrm{CH}_{3}\right), 22.83\left(\mathrm{CH}_{2}\right)$, $14.34\left(\mathrm{CH}_{3}\right), 13.71\left(\mathrm{CH}_{3}\right)$.

IR (ATR): 2956, 2931, 2871, 1716, 1648, 1608, 1271, 1100, 1019, $771 \mathrm{~cm}^{-1}$.

MS (ESI) $m / z$ (relative intensity): 363 (50) [M] $]^{+}, 247$ (100).

HR-MS (ESI) $m / z$ calc. for $\mathrm{C}_{23} \mathrm{H}_{25} \mathrm{NO}_{3}[\mathrm{M}]^{+}: 363.1834$, found: 363.1843 . 
5.5 C-H Oxygenation Reactions Enabled by Dual Catalysis with Electrogenerated Hypervalent Iodine Species and Ruthenium Complexes

\subsubsection{Characterization Data}

\section{2-Hydroxy- $N$-methoxy- $N$-methylbenzamide (106a)}<smiles>CON(C)C(=O)c1ccccc1O</smiles>

The general procedure D was followed using $N$-methoxy- $N$-methylbenzamide 196a $(82.5 \mathrm{mg}, 0.50$ mmol). Isolation by column chromatography ( $n$ hexane/ethyl acetate: $5 / 1 \rightarrow 3 / 1)$ yielded 106a $(72.5$ $\mathrm{mg}, 80 \%)$ as a colourless oil. The same procedure without the addition of electrolyte $\left(n \mathrm{Bu}_{4} \mathrm{NPF}_{6}\right)$ yielded 106a (49.8 $\mathrm{mg}, 55 \%)$ as a colourless oil.

${ }^{1} \mathbf{H}-\mathbf{N M R}\left(400 \mathrm{MHz}, \mathrm{CDCl}_{3}\right) \delta=10.40(\mathrm{~s}, 1 \mathrm{H}), 7.89(\mathrm{dd}, J=8.1,1.7 \mathrm{~Hz}, 1 \mathrm{H}), 7.34(\mathrm{ddd}, J=8.4$, 7.2, $1.7 \mathrm{~Hz}, 1 \mathrm{H}), 6.95(\mathrm{dd}, J=8.4,1.3 \mathrm{~Hz}, 1 \mathrm{H}), 6.82(\mathrm{ddd}, J=8.1,7.2,1.3 \mathrm{~Hz}, 1 \mathrm{H}), 3.61(\mathrm{~s}, 3 \mathrm{H})$, $3.37(\mathrm{~s}, 3 \mathrm{H})$.

${ }^{13}$ C-NMR $\left(100 \mathrm{MHz}, \mathrm{CDCl}_{3}\right) \delta=169.8\left(\mathrm{C}_{\mathrm{q}}\right), 160.9\left(\mathrm{C}_{\mathrm{q}}\right), 133.7(\mathrm{CH}), 129.4(\mathrm{CH}), 118.5(\mathrm{CH}), 117.9$ $(\mathrm{CH}), 114.3\left(\mathrm{C}_{\mathrm{q}}\right), 61.1\left(\mathrm{CH}_{3}\right), 34.0\left(\mathrm{CH}_{3}\right)$.

IR (ATR): 2936, 1625, 1590, 1452, 1249, 973, 754, $527 \mathrm{~cm}^{-1}$.

MS (ESI) $m / z$ (relative intensity): $385(30)[2 \mathrm{M}+\mathrm{Na}]^{+}, 204(100)[\mathrm{M}+\mathrm{Na}]^{+}, 182(100)[\mathrm{M}+\mathrm{H}]^{+}$.

HR-MS (ESI) $m / z$ calc. for $\mathrm{C}_{9} \mathrm{H}_{12} \mathrm{NO}_{3}{ }^{+}[\mathrm{M}+\mathrm{H}]^{+}$182.0814, found 182.0812 .

The analytical data are in accordance with those previously reported in the literature. ${ }^{[12]}$

\section{2-Hydroxy- $N$-methoxy- $N$,4-dimethylbenzamide (106b)}<smiles>CON(C)C(=O)c1ccc(C)cc1O</smiles> 
The general procedure D was followed using $N$-methoxy- $N, 4$-dimethylbenzamide 196b $(89.6 \mathrm{mg}$, $0.50 \mathrm{mmol}$ ). Isolation by column chromatography ( $n$ hexane/ethyl acetate: $5 / 1 \rightarrow 3 / 1$ ) yielded 106b $(71.6 \mathrm{mg}, 73 \%)$ as a pale yellow oil.

${ }^{1}$ H-NMR $\left(400 \mathrm{MHz}, \mathrm{CDCl}_{3}\right) \delta=11.36(\mathrm{~s}, 1 \mathrm{H}), 7.88(\mathrm{~d}, J=8.3 \mathrm{~Hz}, 1 \mathrm{H}), 6.82(\mathrm{~d}, J=1.8 \mathrm{~Hz}, 1 \mathrm{H})$, $6.67(\mathrm{dd}, J=8.3,1.8 \mathrm{~Hz}, 1 \mathrm{H}), 3.67(\mathrm{~s}, 3 \mathrm{H}), 3.41(\mathrm{~s}, 3 \mathrm{H}), 2.34(\mathrm{~s}, 3 \mathrm{H})$.

${ }^{13}$ C-NMR $\left(100 \mathrm{MHz}, \mathrm{CDCl}_{3}\right) \delta=170.0\left(\mathrm{C}_{\mathrm{q}}\right), 161.2\left(\mathrm{C}_{\mathrm{q}}\right), 144.9\left(\mathrm{C}_{\mathrm{q}}\right), 129.3(\mathrm{CH}), 119.7(\mathrm{CH}), 118.2$ $(\mathrm{CH}), 111.5\left(\mathrm{C}_{\mathrm{q}}\right), 61.1\left(\mathrm{CH}_{3}\right), 34.0\left(\mathrm{CH}_{3}\right), 21.6\left(\mathrm{CH}_{3}\right)$.

IR (ATR): 2933, 1584, 1502, 1432, 1351, 1201, 949, $594 \mathrm{~cm}^{-1}$.

MS (ESI) $m / z$ (relative intensity): $413(10)[2 \mathrm{M}+\mathrm{Na}]^{+}, 218(90)[\mathrm{M}+\mathrm{Na}]^{+}, 196(100)[\mathrm{M}+\mathrm{H}]^{+}$.

HR-MS (ESI) $m / z$ calc. for $\mathrm{C}_{10} \mathrm{H}_{14} \mathrm{NO}_{3}{ }^{+}[\mathrm{M}+\mathrm{H}]^{+}$196.0969, found 196.0968.

The analytical data are in accordance with those previously reported in the literature. ${ }^{[12]}$

\section{4-Ethyl-2-hydroxy- $N$-methoxy- $N$-methylbenzamide (106c)}<smiles>CCc1ccc(C(=O)N(C)OC)c(O)c1</smiles>

The general procedure D was followed using 4-ethyl- $N$-methoxy- $N$-methylbenzamide 196c (96.6 $\mathrm{mg}, 0.50 \mathrm{mmol}$ ). Isolation by column chromatography ( $n$ hexane/ethyl acetate: $5 / 1 \rightarrow 3 / 1$ ) yielded 106c $(74.5 \mathrm{mg}, 71 \%)$ as a yellow oil. The same procedure without the addition of electrolyte $\left(n \mathrm{Bu}_{4} \mathrm{NPF}_{6}\right)$ yielded $\mathbf{1 0 6 c}(52.3 \mathrm{mg}, 50 \%)$ as yellow oil.

${ }^{1}$ H-NMR (400 MHz, $\left.\mathrm{CDCl}_{3}\right) \delta=11.37(\mathrm{br}, 1 \mathrm{H}), 7.90(\mathrm{~d}, J=8.4 \mathrm{~Hz}, 1 \mathrm{H}), 6.84(\mathrm{~d}, J=1.7 \mathrm{~Hz}, 1 \mathrm{H})$, $6.70(\mathrm{dd}, J=8.4,1.7 \mathrm{~Hz}, 1 \mathrm{H}), 3.67(\mathrm{~s}, 3 \mathrm{H}), 3.41(\mathrm{~s}, 3 \mathrm{H}), 2.64(\mathrm{q}, J=7.6 \mathrm{~Hz}, 2 \mathrm{H}), 1.25(\mathrm{t}, J=7.6 \mathrm{~Hz}$, 3H). ${ }^{13}$ C-NMR $\left(100 \mathrm{MHz}, \mathrm{CDCl}_{3}\right) \delta=170.0\left(\mathrm{C}_{\mathrm{q}}\right), 161.4\left(\mathrm{C}_{\mathrm{q}}\right), 151.0\left(\mathrm{C}_{\mathrm{q}}\right), 129.4(\mathrm{CH}), 118.5(\mathrm{CH})$, $116.9(\mathrm{CH}), 111.7\left(\mathrm{C}_{\mathrm{q}}\right), 61.1\left(\mathrm{CH}_{3}\right), 34.1\left(\mathrm{CH}_{3}\right), 28.8\left(\mathrm{CH}_{2}\right), 14.7\left(\mathrm{CH}_{3}\right)$.

IR (ATR): 2968, 1632, 1584, 1499, 1433, 1356, 1202, $974 \mathrm{~cm}^{-1}$.

MS (ESI) $m / z$ (relative intensity): $232(100)[\mathrm{M}+\mathrm{Na}]^{+}, 210(100)[\mathrm{M}+\mathrm{H}]^{+}$.

HR-MS (ESI) $m / z$ calc. for $\mathrm{C}_{11} \mathrm{H}_{16} \mathrm{NO}_{3}{ }^{+}[\mathrm{M}+\mathrm{H}]^{+} 210.1129$, found 210.1125 .

The analytical data are in accordance with those previously reported in the literature. ${ }^{[12]}$ 


\section{2-Hydroxy- $N$-methoxy- $N$-4,5-trimethylbenzamide (106e)}<smiles>CON(C)C(=O)c1cc(C)c(C)cc1O</smiles>

The general procedure D was followed using $N$-methoxy- $N$-3,4-trimethylbenzamide 196e $(96.5 \mathrm{mg}$, $0.50 \mathrm{mmol})$. Purification by column chromatography on silica gel ( $n$ hexane/ethyl acetate: $5 / 1)$ yielded 106e (61.5 $\mathrm{mg}, 59 \%)$ as a white solid.

M.p.: $102-104{ }^{\circ} \mathrm{C}$.

${ }^{1}$ H-NMR $\left(400 \mathrm{MHz}, \mathrm{CDCl}_{3}\right) \delta=10.38(\mathrm{br}, 1 \mathrm{H}), 7.67(\mathrm{~s}, 1 \mathrm{H}), 6.76(\mathrm{~s}, 1 \mathrm{H}), 3.63(\mathrm{~s}, 3 \mathrm{H}), 3.36(\mathrm{~s}, 3 \mathrm{H})$, $2.21(\mathrm{~s}, 3 \mathrm{H}), 2.16(\mathrm{~s}, 3 \mathrm{H})$.

${ }^{13}$ C-NMR $\left(100 \mathrm{MHz}, \mathrm{CDCl}_{3}\right) \delta=170.2\left(\mathrm{C}_{\mathrm{q}}\right), 159.1\left(\mathrm{C}_{\mathrm{q}}\right), 143.5\left(\mathrm{C}_{\mathrm{q}}\right), 129.7(\mathrm{CH}), 126.6\left(\mathrm{C}_{\mathrm{q}}\right), 118.6$ $(\mathrm{CH}), 111.7\left(\mathrm{C}_{\mathrm{q}}\right), 61.0\left(\mathrm{CH}_{3}\right), 34.2\left(\mathrm{CH}_{3}\right), 20.1\left(\mathrm{CH}_{3}\right), 19.0\left(\mathrm{CH}_{3}\right)$.

IR (ATR): 2985, 1736, 1373, 1235, 1044, 916, 730, $607 \mathrm{~cm}^{-1}$.

MS (ESI) $m / z$ (relative intensity): $438(26)[2 \mathrm{M}+\mathrm{Na}]^{+}, 232(100)[\mathrm{M}+\mathrm{Na}]^{+}, 210(90)[\mathrm{M}+\mathrm{H}]^{+}$.

HR-MS (ESI) $m / z$ calc. for $\mathrm{C}_{11} \mathrm{H}_{16} \mathrm{NO}_{3}{ }^{+}[\mathrm{M}+\mathrm{H}]^{+} 210.1127$, found 210.1125 .

\section{4,5-Dichloro-2-hydroxy- $N$-methoxy- $N$-methylbenzamide (106f)}<smiles>CON(C)C(=O)c1cc(Cl)c(Cl)cc1O</smiles>

The general procedure D was followed using 3,4-dichloro- $N$-methoxy- $N$-methylbenzamide $196 \mathbf{f}$ (117 $\mathrm{mg}, 0.50 \mathrm{mmol})$. Purification by column chromatography on silica gel (nhexane/ethyl acetate: $5 / 1)$ yielded 106f (77.2 mg, 62\%) as a white solid. The same procedure without the addition of electrolyte $\left(n \mathrm{Bu}_{4} \mathrm{NPF}_{6}\right)$ yielded $\mathbf{1 0 6 f}(57.5 \mathrm{mg}, 46 \%)$ as a white solid.

M.p.: $114-117^{\circ} \mathrm{C}$.

${ }^{1}$ H-NMR $\left(400 \mathrm{MHz}, \mathrm{CDCl}_{3}\right) \delta=11.51(\mathrm{~s}, 1 \mathrm{H}), 8.17(\mathrm{~s}, 1 \mathrm{H}), 7.14(\mathrm{~s}, 1 \mathrm{H}), 3.70(\mathrm{~s}, 3 \mathrm{H}), 3.42(\mathrm{~s}, 3 \mathrm{H})$.

${ }^{13}$ C-NMR $\left(100 \mathrm{MHz}, \mathrm{CDCl}_{3}\right) \delta=167.8\left(\mathrm{C}_{\mathrm{q}}\right), 160.4\left(\mathrm{C}_{\mathrm{q}}\right), 137.6\left(\mathrm{C}_{\mathrm{q}}\right), 130.7(\mathrm{CH}), 121.9\left(\mathrm{C}_{\mathrm{q}}\right), 119.8$ $(\mathrm{CH}), 113.7\left(\mathrm{C}_{\mathrm{q}}\right), 61.5\left(\mathrm{CH}_{3}\right), 33.7\left(\mathrm{CH}_{3}\right)$. 
IR (ATR): 2936, 1625, 1570, 1454, 1334, 1180, 978, $649 \mathrm{~cm}^{-1}$.

MS (ESI) $m / z$ (relative intensity): $521(10)[2 \mathrm{M}+\mathrm{Na}]^{+}\left({ }^{35} \mathrm{Cl}\right), 251(100)[\mathrm{M}+\mathrm{H}]^{+}\left({ }^{35} \mathrm{Cl}\right)$.

HR-MS (ESI) $m / z$ calc. for $\mathrm{C}_{9} \mathrm{H}_{10}{ }^{35} \mathrm{Cl}_{2} \mathrm{NO}_{3}{ }^{+}[\mathrm{M}+\mathrm{H}]^{+} 250.0030$, found 250.0032 .

\section{4-Bromo-2-hydroxy- $N$-methoxy- $N$-methylbenzamide (106h)}<smiles>CN(C)C(=O)c1ccc(Br)cc1O</smiles>

The general procedure D was followed using 4-bromo- $N$-methoxy- $N$-methylbenzamide 196h (121 mg, $0.50 \mathrm{mmol}$ ). Purification by column chromatography on silica gel ( $n$ hexane/ethyl acetate: $5 / 1$ ) yielded 106h (107 $\mathrm{mg}, 82 \%)$ as a white solid. The same procedure without the addition of electrolyte $\left(n \mathrm{Bu}_{4} \mathrm{NPF}_{6}\right)$ yielded $\mathbf{1 0 6 h}(74.8 \mathrm{mg}, 58 \%)$ as a white solid.

M.p.: $92-95^{\circ} \mathrm{C}$.

${ }^{1} \mathbf{H}-\mathbf{N M R}\left(300 \mathrm{MHz}, \mathrm{CDCl}_{3}\right) \delta=11.21(\mathrm{br}, 1 \mathrm{H}), 7.89(\mathrm{~d}, J=8.7 \mathrm{~Hz}, 1 \mathrm{H}), 7.19(\mathrm{~d}, J=2.0 \mathrm{~Hz}, 1 \mathrm{H})$, $6.99(\mathrm{dd}, J=8.7,2.0 \mathrm{~Hz}, 1 \mathrm{H}), 3.66(\mathrm{~s}, 3 \mathrm{H}), 3.41(\mathrm{~s}, 3 \mathrm{H})$.

${ }^{13}$ C-NMR $\left(100 \mathrm{MHz}, \mathrm{CDCl}_{3}\right) \delta=169.0\left(\mathrm{C}_{\mathrm{q}}\right), 161.9\left(\mathrm{C}_{\mathrm{q}}\right), 130.6(\mathrm{CH}), 127.8\left(\mathrm{C}_{\mathrm{q}}\right), 121.9(\mathrm{CH}), 121.2$ $(\mathrm{CH}), 113.0\left(\mathrm{C}_{\mathrm{q}}\right), 61.3\left(\mathrm{CH}_{3}\right), 33.8\left(\mathrm{CH}_{3}\right)$.

IR (ATR): 2935, 1621, 1481, 1343, 1236, 1075, 861, $590 \mathrm{~cm}^{-1}$.

MS (ESI) $m / z$ (relative intensity): $543(35)[2 \mathrm{M}+\mathrm{Na}]^{+}\left({ }^{81} \mathrm{Br}\right), 280(10)[\mathrm{M}+\mathrm{Na}]^{+}\left({ }^{81} \mathrm{Br}\right), 262(100)$ $[\mathrm{M}+\mathrm{H}]^{+}\left({ }^{81} \mathrm{Br}\right)$.

HR-MS (ESI) $m / z$ calc. for $\mathrm{C}_{9} \mathrm{H}_{11}{ }^{81} \mathrm{BrNO}_{3}{ }^{+}[\mathrm{M}+\mathrm{H}]^{+}$261.9898, found 261.9897.

\section{2-Hydroxy- $N$-methoxy- $N$-methyl-5-(trifluoromethyl)benzamide (1061)}<smiles>CON(C)C(=O)c1cc(C(F)(F)F)ccc1O</smiles> 
The general procedure D was followed using $N$-methoxy- $N$-methyl-3-(trifluoromethyl)benzamide 1961 (117 mg, $0.50 \mathrm{mmol}$ ). Purification by column chromatography on silica gel ( $n$ hexane/ethyl acetate: 5/1) yielded $\mathbf{1 0 6 1}(56.0 \mathrm{mg}, 45 \%)$ as a yellow oil.

${ }^{1}$ H-NMR $\left(400 \mathrm{MHz}, \mathrm{CDCl}_{3}\right) \delta=11.83(\mathrm{~s}, 1 \mathrm{H}), 8.37(\mathrm{~d}, J=2.3 \mathrm{~Hz}, 1 \mathrm{H}), 7.63(\mathrm{dd}, J=8.8,2.3 \mathrm{~Hz}$, 1H), 7.12-7.06 (m, 1H), $3.70(\mathrm{~s}, 3 \mathrm{H}), 3.45(\mathrm{~s}, 3 \mathrm{H})$.

${ }^{13}$ C-NMR $\left(100 \mathrm{MHz}, \mathrm{CDCl}_{3}\right) \delta=168.5\left(\mathrm{C}_{\mathrm{q}}\right), 163.9\left(\mathrm{C}_{\mathrm{q}}\right), 130.5\left(\mathrm{q},{ }^{3} J_{\mathrm{C}-\mathrm{F}}=3.4 \mathrm{~Hz}, \mathrm{CH}\right), 127.5(\mathrm{q}$, $\left.{ }^{3} J_{\mathrm{C}-\mathrm{F}}=3.4 \mathrm{~Hz}, \mathrm{CH}\right), 124.1\left(\mathrm{q},{ }^{1} J_{\mathrm{C}-\mathrm{F}}=271.1 \mathrm{~Hz}, \mathrm{C}_{\mathrm{q}}\right), 120.8\left(\mathrm{q},{ }^{2} J_{\mathrm{C}-\mathrm{F}}=33.0 \mathrm{~Hz}, \mathrm{C}_{\mathrm{q}}\right), 118.7(\mathrm{CH})$, $113.8\left(\mathrm{C}_{\mathrm{q}}\right), 61.4\left(\mathrm{CH}_{3}\right), 33.8\left(\mathrm{CH}_{3}\right)$.

${ }^{19}$ F-NMR $\left(376 \mathrm{MHz}, \mathrm{CDCl}_{3}\right) \delta=-61.74(\mathrm{~s})$.

IR (ATR): 2956, 1747, 1460, 1374, 1237, 1048, 742, $385 \mathrm{~cm}^{-1}$.

MS (ESI) $m / z$ (relative intensity): $271(80)[\mathrm{M}+\mathrm{Na}]^{+}, 250(100)[\mathrm{M}+\mathrm{H}]^{+}$.

HR-MS (ESI) $m / z$ calc. for $\mathrm{C}_{10} \mathrm{H}_{11} \mathrm{~F}_{3} \mathrm{NO}_{3}{ }^{+}[\mathrm{M}+\mathrm{H}]^{+}$250.0684, found 250.0686.

\section{5-Chloro-2-hydroxy- $N$-methoxy- $N$-methylbenzamide (106m)}<smiles>CN(C)C(=O)c1cc(Cl)ccc1O</smiles>

The general procedure D was followed using 3-chloro- $N$-methoxy- $N$-methylbenzamide 196m $(99.8$ $\mathrm{mg}, 0.50 \mathrm{mmol})$. Purification by column chromatography on silica gel ( $n$ hexane/ethyl acetate: $5 / 1$ ) yielded 106m (90.3 $\mathrm{mg}, 84 \%)$ as a white solid.

M.p.: $74-77^{\circ} \mathrm{C}$.

${ }^{1}$ H-NMR $\left(400 \mathrm{MHz}, \mathrm{CDCl}_{3}\right) \delta=11.21(\mathrm{~s}, 1 \mathrm{H}), 8.00(\mathrm{~d}, J=2.6 \mathrm{~Hz}, 1 \mathrm{H}), 7.5(\mathrm{dd}, J=8.9,2.6 \mathrm{~Hz}$, 1H), 6.95 (d, $J=8.9 \mathrm{~Hz}, 1 \mathrm{H}), 3.69$ (s, 3H), 3.42 (s, 3H).

${ }^{13}$ C-NMR $\left(100 \mathrm{MHz}, \mathrm{CDCl}_{3}\right) \delta=168.5\left(\mathrm{C}_{\mathrm{q}}\right), 159.7\left(\mathrm{C}_{\mathrm{q}}\right), 133.7(\mathrm{CH}), 129.0(\mathrm{CH}), 123.3\left(\mathrm{C}_{\mathrm{q}}\right), 119.6$ $(\mathrm{CH}), 115.1\left(\mathrm{C}_{\mathrm{q}}\right), 61.4\left(\mathrm{CH}_{3}\right), 33.8\left(\mathrm{CH}_{3}\right)$.

IR (ATR): 2958, 2253, 1630, 1586, 1469, 1249, 903, $722 \mathrm{~cm}^{-1}$.

MS (ESI) $m / z$ (relative intensity): $453(15)[2 \mathrm{M}+\mathrm{Na}]^{+}\left({ }^{35} \mathrm{Cl}\right), 238(30)[\mathrm{M}+\mathrm{Na}]^{+}\left({ }^{35} \mathrm{Cl}\right), 216(100)$ $[\mathrm{M}+\mathrm{H}]^{+}\left({ }^{35} \mathrm{Cl}\right)$. 
HR-MS (ESI) $m / z$ calc. for $\mathrm{C}_{9} \mathrm{H}_{11}{ }^{35} \mathrm{ClNO}_{3}{ }^{+}[\mathrm{M}+\mathrm{H}]^{+} 216.0415$, found 216.0422 .

\section{5-Bromo-2-hydroxy- $N$-methoxy- $N$-methylbenzamide (106n)}<smiles>CON(C)C(=O)c1cc(Br)ccc1O</smiles>

The general procedure D was followed using 3-bromo- $N$-methoxy- $N$-methylbenzamide 196n (121 mg, $0.50 \mathrm{mmol}$ ). Purification by column chromatography on silica gel ( $n$ hexane/ethyl acetate: $5 / 1$ ) yielded 106n (97.4 mg, 75\%) as a yellow oil.

${ }^{1}$ H-NMR $\left(400 \mathrm{MHz}, \mathrm{CDCl}_{3}\right) \delta=11.19(\mathrm{~s}, 1 \mathrm{H}), 8.10(\mathrm{~d}, J=2.5 \mathrm{~Hz}, 1 \mathrm{H}), 7.43(\mathrm{dd}, J=8.9,2.5 \mathrm{~Hz}$, $1 \mathrm{H}), 6.86(\mathrm{~d}, J=8.9 \mathrm{~Hz}, 1 \mathrm{H}), 3.65(\mathrm{~s}, 3 \mathrm{H}), 3.38(\mathrm{~s}, 3 \mathrm{H})$.

${ }^{13}$ C-NMR $\left(100 \mathrm{MHz}, \mathrm{CDCl}_{3}\right) \delta=168.4\left(\mathrm{C}_{\mathrm{q}}\right), 160.1\left(\mathrm{C}_{\mathrm{q}}\right), 136.5(\mathrm{CH}), 131.9(\mathrm{CH}), 119.9(\mathrm{CH}), 115.7$ $\left(\mathrm{C}_{\mathrm{q}}\right), 110.2\left(\mathrm{C}_{\mathrm{q}}\right), 61.4\left(\mathrm{CH}_{3}\right), 33.8\left(\mathrm{CH}_{3}\right)$.

IR (ATR): 2985, 1737, 1447, 1372, 1233, 1043, 847, $608 \mathrm{~cm}^{-1}$.

MS (ESI) $m / z$ (relative intensity): $543(20)[2 \mathrm{M}+\mathrm{Na}]]^{+}\left({ }^{79} \mathrm{Br}\right), 260(100)[\mathrm{M}+\mathrm{H}]^{+}\left({ }^{79} \mathrm{Br}\right)$.

HR-MS (ESI) $m / z$ calc. for $\mathrm{C}_{9} \mathrm{H}_{11}{ }^{79} \mathrm{BrNO}_{3}{ }^{+}[\mathrm{M}+\mathrm{H}]^{+}$259.9914, found 259.9917 .

\section{4-Iodo-2-hydroxy- $N$-methoxy- $N$-methylbenzamide (1060)}<smiles>CN(C)C(=O)c1ccc(I)cc1O</smiles>

The general procedure D was followed using 4-iodo- $N$-methoxy- $N$-methylbenzamide 1960 (146 mg, $0.50 \mathrm{mmol}$ ). Purification by column chromatography on silica gel ( $n$ hexane/ethyl acetate: $5 / 1)$ yielded $1060(99.7 \mathrm{mg}, 65 \%)$ as a yellow liquid.

${ }^{1}$ H-NMR $\left(400 \mathrm{MHz}, \mathrm{CDCl}_{3}\right) \delta=10.68(\mathrm{br}, 1 \mathrm{H}), 7.65(\mathrm{~d}, J=8.6 \mathrm{~Hz}, 1 \mathrm{H}), 7.36(\mathrm{~d}, J=1.8 \mathrm{~Hz}, 1 \mathrm{H})$, $7.16(\mathrm{dd}, J=8.6,1.8 \mathrm{~Hz}, 1 \mathrm{H}), 3.61(\mathrm{~s}, 3 \mathrm{H}), 3.36(\mathrm{~s}, 3 \mathrm{H})$.

${ }^{13}$ C-NMR $\left(100 \mathrm{MHz}, \mathrm{CDCl}_{3}\right) \delta=169.1\left(\mathrm{C}_{\mathrm{q}}\right), 161.2\left(\mathrm{C}_{\mathrm{q}}\right), 130.4(\mathrm{CH}), 127.8(\mathrm{CH}), 127.2(\mathrm{CH}), 113.6$ $\left(\mathrm{C}_{\mathrm{q}}\right), 100.3\left(\mathrm{C}_{\mathrm{q}}\right), 61.3\left(\mathrm{CH}_{3}\right), 33.8\left(\mathrm{CH}_{3}\right)$. 
IR (ATR): 2934, 1618, 1476, 1341, 1233, 972, 809, $586 \mathrm{~cm}^{-1}$.

MS (ESI) $m / z$ (relative intensity): 634 (16) $[2 \mathrm{M}+\mathrm{Na}]^{+}, 330(16)[\mathrm{M}+\mathrm{Na}]^{+}, 308(100)[\mathrm{M}+\mathrm{H}]^{+}$.

HR-MS (ESI) $m / z$ calc. for $\mathrm{C}_{9} \mathrm{H}_{11} \mathrm{INO}_{3}{ }^{+}[\mathrm{M}+\mathrm{H}]^{+} 307.9780$, found 307.9778 .

The analytical data are in accordance with those previously reported in the literature. ${ }^{[112]}$

4-(Chloromethyl)-2-hydroxy- $N$-methoxy- $N$-methylbenzamide (106p)<smiles>CON(C)C(=O)c1ccc(CCl)cc1O</smiles>

The general procedure D was followed using 4-(chloromethyl)- $N$-methoxy- $N$-methylbenzamide 196p (107 mg, $0.50 \mathrm{mmol})$. Purification by column chromatography on silica gel ( $n$ hexane/ethyl acetate: $5 / 1)$ yielded $\mathbf{1 0 6 p}(88.2 \mathrm{mg}, 77 \%)$ as an orange oil.

${ }^{1}$ H-NMR (400 MHz, $\left.\mathrm{CDCl}_{3}\right) \delta=11.36(\mathrm{~s}, 1 \mathrm{H}), 7.99(\mathrm{~d}, J=8.4 \mathrm{~Hz}, 1 \mathrm{H}), 7.02(\mathrm{~d}, J=1.8 \mathrm{~Hz}, 1 \mathrm{H})$, $6.89(\mathrm{dd}, J=8.4,1.8 \mathrm{~Hz}, 1 \mathrm{H}), 4.54(\mathrm{~s}, 2 \mathrm{H}), 3.67(\mathrm{~s}, 3 \mathrm{H}), 3.42(\mathrm{~s}, 3 \mathrm{H})$.

${ }^{13}$ C-NMR $\left(100 \mathrm{MHz}, \mathrm{CDCl}_{3}\right) \delta=169.3\left(\mathrm{C}_{\mathrm{q}}\right), 161.3\left(\mathrm{C}_{\mathrm{q}}\right), 143.2\left(\mathrm{C}_{\mathrm{q}}\right), 130.1(\mathrm{CH}), 118.5(\mathrm{CH}), 117.8$ $(\mathrm{CH}), 114.0\left(\mathrm{C}_{\mathrm{q}}\right), 61.3\left(\mathrm{CH}_{3}\right), 45.3\left(\mathrm{CH}_{2}\right), 33.9\left(\mathrm{CH}_{3}\right)$.

IR (ATR): 2985, 1636, 1589, 1265, 904, 724, 650, $534 \mathrm{~cm}^{-1}$.

MS (ESI) $m / z$ (relative intensity): $252(20)[\mathrm{M}+\mathrm{Na}]+\left({ }^{35} \mathrm{Cl}\right), 230(100)[\mathrm{M}+\mathrm{H}]+\left({ }^{35} \mathrm{Cl}\right)$.

HR-MS (ESI) $m / z$ calc. for $\mathrm{C}_{10} \mathrm{H}_{13}{ }^{35} \mathrm{ClNO}_{3}{ }^{+}[\mathrm{M}+\mathrm{H}]^{+} 230.0585$, found 230.0578 .

The analytical data are in accordance with those previously reported in the literature. ${ }^{[12]}$

\section{2-Hydroxy- $N, N, 4$-trimethylbenzamide (104b)}<smiles>Cc1ccc(C(=O)N(C)C)c(O)c1</smiles>

The general procedure $\mathbf{D}$ was followed using $N, N, 4$-trimethylbenzamide $\mathbf{1 0 3 b}(81.5 \mathrm{mg}, 0.50 \mathrm{mmol})$. Purification by column chromatography on silica gel ( $n$ hexane/ethyl acetate: $5 / 1 \rightarrow 3 / 1$ ) yielded $\mathbf{1 0 4 b}$ (75.2 $\mathrm{mg}, 84 \%)$ as a white solid.

M.p.: $118-120^{\circ} \mathrm{C}$. 
${ }^{1}$ H-NMR $\left(300 \mathrm{MHz}, \mathrm{CDCl}_{3}\right) \delta=9.05(\mathrm{br}, 1 \mathrm{H}), 7.22(\mathrm{~d}, J=8.0 \mathrm{~Hz}, 1 \mathrm{H}), 6.82(\mathrm{~d}, J=1.6 \mathrm{~Hz}, 1 \mathrm{H})$, $6.67(\mathrm{dd}, J=8.0,1.6 \mathrm{~Hz}, 1 \mathrm{H}), 3.16(\mathrm{~s}, 6 \mathrm{H}), 2.33(\mathrm{~s}, 3 \mathrm{H})$.

${ }^{13}$ C-NMR $\left(100 \mathrm{MHz}, \mathrm{CDCl}_{3}\right) \delta=172.1\left(\mathrm{C}_{\mathrm{q}}\right), 159.1\left(\mathrm{C}_{\mathrm{q}}\right), 143.4\left(\mathrm{C}_{\mathrm{q}}\right), 128.4(\mathrm{CH}), 119.2(\mathrm{CH}), 118.1$ $(\mathrm{CH}), 114.2\left(\mathrm{C}_{\mathrm{q}}\right), 38.4\left(\mathrm{CH}_{3}\right), 21.5\left(\mathrm{CH}_{3}\right)$.

IR (ATR): 2935, 1595, 1494, 1452, 1400, 1262, 1199, $754 \mathrm{~cm}^{-1}$.

MS (ESI) $m / z$ (relative intensity): $202(100)[\mathrm{M}+\mathrm{Na}]^{+}, 180(85)[\mathrm{M}+\mathrm{H}]^{+}$.

HR-MS (ESI) $m / z$ calc. for $\mathrm{C}_{10} \mathrm{H}_{14} \mathrm{NO}_{2}{ }^{+}[\mathrm{M}+\mathrm{H}]^{+} 180.1017$, found 180.1019 .

The analytical data are in accordance with those previously reported in the literature. ${ }^{[86]}$

\section{$N, N$-Diethyl-2-hydroxy-5-methylbenzamide (104d)}<smiles>CCNC(=O)c1cc(C)ccc1O</smiles>

The general procedure D was followed using $N, N$-diethyl-3-methylbenzamide 103d (95.6 mg, 0.50 mmol). Purification by column chromatography on silica gel ( $n$ hexane/ethyl acetate: $5 / 1 \rightarrow 3 / 1$ ) yielded 104d (66.3 $\mathrm{mg}, 64 \%)$ as a white solid.

M.p.: $116-119^{\circ} \mathrm{C}$.

${ }^{1}$ H-NMR $\left(400 \mathrm{MHz}, \mathrm{CDCl}_{3}\right) \delta=9.19(\mathrm{br}, 1 \mathrm{H}), 7.13(\mathrm{dd}, J=8.3,2.1 \mathrm{~Hz}, 1 \mathrm{H}), 7.07(\mathrm{~d}, J=2.1 \mathrm{~Hz}$, $1 \mathrm{H}), 6.91(\mathrm{~d}, J=8.3 \mathrm{~Hz}, 1 \mathrm{H}), 3.54(\mathrm{q}, J=7.1 \mathrm{~Hz}, 4 \mathrm{H}), 2.30(\mathrm{~s}, 3 \mathrm{H}), 1.29$ (t, $J=7.1 \mathrm{~Hz}, 6 \mathrm{H})$.

${ }^{13}$ C-NMR $\left(100 \mathrm{MHz}, \mathrm{CDCl}_{3}\right) \delta=171.5\left(\mathrm{C}_{\mathrm{q}}\right), 156.1\left(\mathrm{C}_{\mathrm{q}}\right), 132.9(\mathrm{CH}), 127.6\left(\mathrm{C}_{\mathrm{q}}\right), 127.4(\mathrm{CH}), 118.2$ $\left(\mathrm{C}_{\mathrm{q}}\right), 117.7(\mathrm{CH}), 42.1\left(\mathrm{CH}_{2}\right), 20.6\left(\mathrm{CH}_{3}\right), 13.4\left(\mathrm{CH}_{3}\right)$.

IR (ATR): 3160, 2973, 1586, 1486, 1440, 1286, 1244, $820 \mathrm{~cm}^{-1}$.

MS (ESI) $m / z$ (relative intensity): $437(10)[\mathrm{M}+2 \mathrm{Na}]^{+}, 230(108)[\mathrm{M}+\mathrm{Na}]^{+}, 208(80)[\mathrm{M}+\mathrm{H}]^{+}$.

HR-MS (ESI) $m / z$ calc. for $\mathrm{C}_{12} \mathrm{H}_{18} \mathrm{NO}_{2}{ }^{+}[\mathrm{M}+\mathrm{H}]^{+} 208,1337$, found 208.1332.

The analytical data are in accordance with those previously reported in the literature. ${ }^{[187]}$

\section{4-Acetyl-2-hydroxy- $N$-methoxy- $N$-methylbenzamide (106q)}




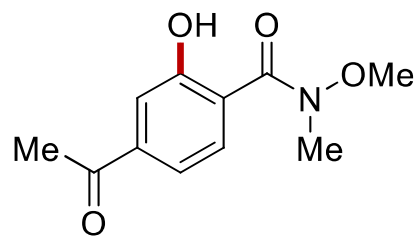

The general procedure D was followed using 4-acetyl- $N$-methoxy- $N$-methylbenzamide 196q (104 $\mathrm{mg}, 0.50 \mathrm{mmol}$ ). Isolation by column chromatography ( $n$ hexane/ethyl acetate: $8 / 1 \rightarrow 3 / 1$ ) yielded 106q (67.8 $\mathrm{mg}, 61 \%)$ as a colourless liquid.

${ }^{1}$ H-NMR $\left(400 \mathrm{MHz}, \mathrm{CDCl}_{3}\right) \delta=10.97(\mathrm{~s}, 1 \mathrm{H}), 8.06-7.90(\mathrm{~d}, J=8.4 \mathrm{~Hz}, 1 \mathrm{H}), 7.49$ (d, $J=1.8 \mathrm{~Hz}$, $1 \mathrm{H}), 7.38(\mathrm{dd}, J=8.4,1.8 \mathrm{~Hz}, 1 \mathrm{H}), 3.61(\mathrm{~s}, 3 \mathrm{H}), 3.39(\mathrm{~s}, 3 \mathrm{H}), 2.56(\mathrm{~s}, 3 \mathrm{H})$.

${ }^{13}$ C-NMR $\left(100 \mathrm{MHz}, \mathrm{CDCl}_{3}\right) \delta=197.6\left(\mathrm{C}_{\mathrm{q}}\right), 168.7\left(\mathrm{C}_{\mathrm{q}}\right), 160.7\left(\mathrm{C}_{\mathrm{q}}\right), 140.8\left(\mathrm{C}_{\mathrm{q}}\right), 129.8(\mathrm{CH}), 118.0$ $\left(\mathrm{C}_{\mathrm{q}}\right), 117.9(\mathrm{CH}), 117.7(\mathrm{CH}), 61.4\left(\mathrm{CH}_{3}\right), 33.8\left(\mathrm{CH}_{3}\right), 26.7\left(\mathrm{CH}_{3}\right)$.

IR (ATR): 2937, 1684, 1630, 1582, 1415, 1298, 1205, $823 \mathrm{~cm}^{-1}$.

MS (ESI) $m / z$ (relative intensity): $246(30)[\mathrm{M}+\mathrm{Na}]^{+}, 224(100)[\mathrm{M}+\mathrm{H}]^{+}$.

HR-MS (ESI) $m / z$ calc. for $\mathrm{C}_{11} \mathrm{H}_{14} \mathrm{NO}_{4}{ }^{+}[\mathrm{M}+\mathrm{H}]^{+} 224.0917$, found 224.0917

\section{1-(2-Hydroxyphenyl)propan-1-one (197b)}<smiles>CCC(=O)c1ccccc1O</smiles>

The general procedure $\mathbf{E}$ was followed using propiophenone $\mathbf{7 7 b}(67.0 \mathrm{mg}, 0.50 \mathrm{mmol})$. Purification by column chromatography on silica gel (nhexane/ethyl acetate: $80 / 1)$ yielded $197 \mathbf{b}(45.1 \mathrm{mg}, 60 \%)$ as a colorless liquid.

${ }^{1}$ H-NMR $\left(400 \mathrm{MHz}, \mathrm{CDCl}_{3}\right) \delta=12.33(\mathrm{~s}, 1 \mathrm{H}), 7.74$ (dd, $\left.J=8.0,1.6 \mathrm{~Hz}, 1 \mathrm{H}\right), 7.43$ (ddd, $J=8.4,7.2$, $1.6 \mathrm{~Hz}, 1 \mathrm{H}), 6.95(\mathrm{dd}, J=8.4,1.2 \mathrm{~Hz}, 1 \mathrm{H}), 6.87(\mathrm{ddd}, J=8.0,7.2,1.2 \mathrm{~Hz}, 1 \mathrm{H}), 3.02(\mathrm{q}, J=7.3 \mathrm{~Hz}$, $2 \mathrm{H}), 1.22(\mathrm{t}, J=7.3 \mathrm{~Hz}, 3 \mathrm{H})$.

${ }^{13}$ C-NMR $\left(100 \mathrm{MHz}, \mathrm{CDCl}_{3}\right) \delta=207.1\left(\mathrm{C}_{\mathrm{q}}\right), 162.3\left(\mathrm{C}_{\mathrm{q}}\right), 136.1(\mathrm{CH}), 129.8(\mathrm{CH}), 119.2\left(\mathrm{C}_{\mathrm{q}}\right), 118.8$ $(\mathrm{CH}), 118.4(\mathrm{CH}), 31.5\left(\mathrm{CH}_{2}\right), 8.16\left(\mathrm{CH}_{3}\right)$.

IR (ATR): 2984, 1641, 1488, 1265, 1206, 906, 272, $649 \mathrm{~cm}^{-1}$.

MS (ESI) $m / z$ (relative intensity): $323(50)[2 \mathrm{M}+\mathrm{Na}]^{+}, 151(100)[\mathrm{M}+\mathrm{H}]^{+}$. 
HR-MS (ESI) $m / z$ calc. for $\mathrm{C}_{9} \mathrm{H}_{11} \mathrm{O}_{2}{ }^{+}[\mathrm{M}+\mathrm{H}]^{+}$151.0753, found 151.0754.

The analytical data are in accordance with those previously reported in the literature. ${ }^{[114 a]}$

\section{1-(2-Hydroxyphenyl)ethan-1-one (197c)}<smiles>CC(=O)c1ccccc1O</smiles>

The general procedure $\mathbf{E}$ was followed using acetophenone $77 \mathbf{c}(60.0 \mathrm{mg}, 0.50 \mathrm{mmol})$. Purification by column chromatography on silica gel (nhexane/ethyl acetate: $50 / 1)$ yielded $197 \mathrm{c}(45.0 \mathrm{mg}, 66 \%)$ as a colorless liquid.

${ }^{1}$ H-NMR $\left(400 \mathrm{MHz}, \mathrm{CDCl}_{3}\right) \delta=12.24(\mathrm{~s}, 1 \mathrm{H}), 7.72(\mathrm{dd}, J=8.1,1.7 \mathrm{~Hz}, 1 \mathrm{H}), 7.45(\mathrm{ddd}, J=8.7,7.2$, $1.7 \mathrm{~Hz}, 1 \mathrm{H}), 6.96$ (dd, $J=8.7,1.2 \mathrm{~Hz}, 1 \mathrm{H}), 6.88$ (ddd, $J=8.1,7.2,1.2 \mathrm{~Hz}, 1 \mathrm{H}), 2.62$ (s, 3H).

${ }^{13}$ C-NMR $\left(100 \mathrm{MHz}, \mathrm{CDCl}_{3}\right) \delta=204.5\left(\mathrm{C}_{\mathrm{q}}\right), 162.4\left(\mathrm{C}_{\mathrm{q}}\right), 136.4(\mathrm{CH}), 130.7(\mathrm{CH}), 119.7\left(\mathrm{C}_{\mathrm{q}}\right), 118.9$ $(\mathrm{CH}), 118.4(\mathrm{CH}), 26.6\left(\mathrm{CH}_{3}\right)$.

IR (ATR): 3054, 1637, 1615, 1446, 1243, 1218, 752, $619 \mathrm{~cm}^{-1}$.

MS (ESI) $m / z$ (relative intensity): 283 (8), 157 (7), 135 (100) [M-H] $]^{-}, 121$ (5).

HR-MS (ESI) $m / z$ calc. for $\mathrm{C}_{8} \mathrm{H}_{7} \mathrm{O}_{2}^{-}[\mathrm{M}-\mathrm{H}]^{-}$135.0452, found 135.0443.

The analytical data are in accordance with those previously reported in the literature. ${ }^{[14 a]}$

\section{1-(2-Hydroxyphenyl)-2-methylpropan-1-one (197d)}<smiles>CC(C)C(=O)c1ccccc1O</smiles>

The general procedure $\mathbf{E}$ was followed using 2-methyl-1-phenylpropan-1-one $\mathbf{7 7 d}$ (74.0 $\mathrm{mg}, 0.50$ mmol). Purification by column chromatography on silica gel ( $n$ hexane/ethyl acetate: 100/1) yielded 197d (54.2 $\mathrm{mg}, 66 \%)$ as a yellow oil.

${ }^{1}$ H-NMR $\left(300 \mathrm{MHz}, \mathrm{CDCl}_{3}\right) \delta=12.55(\mathrm{~s}, 1 \mathrm{H}), 7.82(\mathrm{dd}, J=8.1,1.5 \mathrm{~Hz}, 1 \mathrm{H}), 7.56-7.43(\mathrm{~m}, 1 \mathrm{H})$, $7.02(\mathrm{~d}, J=8.4 \mathrm{~Hz}, 1 \mathrm{H}), 6.93(\mathrm{dd}, J=8.1,7.1 \mathrm{~Hz}, 1 \mathrm{H}), 3.63(\mathrm{~h}, J=6.9 \mathrm{~Hz}, 1 \mathrm{H}), 1.28(\mathrm{~d}, J=6.8 \mathrm{~Hz}$, $6 \mathrm{H})$. 
${ }^{13}$ C-NMR $\left(100 \mathrm{MHz}, \mathrm{CDCl}_{3}\right) \delta=210.8\left(\mathrm{C}_{\mathrm{q}}\right), 163.1\left(\mathrm{C}_{\mathrm{q}}\right), 136.2(\mathrm{CH}), 129.8(\mathrm{CH}), 118.8(\mathrm{CH}), 118.7$

$(\mathrm{CH}), 118.2\left(\mathrm{C}_{\mathrm{q}}\right), 34.9(\mathrm{CH}), 19.3\left(\mathrm{CH}_{3}\right)$.

IR (ATR): 2975, 1636, 1446, 1273, 1208, 1151, 982, $754 \mathrm{~cm}^{-1}$.

MS (ESI) $m / z$ (relative intensity): $351(50)[2 \mathrm{M}+\mathrm{Na}]^{+}, 165(100)[\mathrm{M}+\mathrm{H}]^{+}$.

HR-MS (ESI) $m / z$ calc. for $\mathrm{C}_{10} \mathrm{H}_{13} \mathrm{O}_{2}{ }^{+}[\mathrm{M}+\mathrm{H}]^{+} 165.0904$, found 165.0910 .

The analytical data are in accordance with those previously reported in the literature. ${ }^{[11]}$

\section{1-(2-Hydroxy-4-methylphenyl)-2,2-dimethylpropan-1-one (197e)}<smiles>Cc1ccc(C(=O)C(C)(C)C)c(O)c1</smiles>

The general procedure $\mathbf{E}$ was followed using 2,2-dimethyl-1-( $p$-tolyl)propan-1-one 77e (88.0 mg, $0.50 \mathrm{mmol}$ ). Purification by column chromatography on silica gel ( $n$ hexane/ethyl acetate: 50/1) yielded 197e (49.2 $\mathrm{mg}, 51 \%)$ as a colorless liquid.

${ }^{1}$ H-NMR (400 MHz, $\left.\mathrm{CDCl}_{3}\right) \delta=12.77(\mathrm{~s}, 1 \mathrm{H}), 7.88(\mathrm{~d}, J=8.4 \mathrm{~Hz}, 1 \mathrm{H}), 6.79(\mathrm{~d}, J=1.8 \mathrm{~Hz}, 1 \mathrm{H})$, $6.64(\mathrm{dd}, J=8.4,1.8 \mathrm{~Hz}, 1 \mathrm{H}), 2.31(\mathrm{~s}, 3 \mathrm{H}), 1.42(\mathrm{~s}, 9 \mathrm{H})$.

${ }^{13}$ C-NMR $\left(100 \mathrm{MHz}, \mathrm{CDCl}_{3}\right) \delta=211.5\left(\mathrm{C}_{\mathrm{q}}\right), 163.9\left(\mathrm{C}_{\mathrm{q}}\right), 146.7\left(\mathrm{C}_{\mathrm{q}}\right), 130.7(\mathrm{CH}), 119.2(\mathrm{CH}), 119.0$ $(\mathrm{CH}), 115.1\left(\mathrm{C}_{\mathrm{q}}\right), 44.4\left(\mathrm{C}_{\mathrm{q}}\right), 28.7\left(\mathrm{CH}_{3}\right), 21.7\left(\mathrm{CH}_{3}\right)$.

IR (ATR): 2978, 1632, 1301, 1190, 1136, 973, 801, $403 \mathrm{~cm}^{-1}$.

MS (ESI) $m / z$ (relative intensity): $407(30)[2 \mathrm{M}+\mathrm{Na}]^{+}, 215(20)[\mathrm{M}+\mathrm{Na}]^{+}, 193(100)[\mathrm{M}+\mathrm{H}]^{+}$.

HR-MS (ESI) $m / z$ calc. for $\mathrm{C}_{12} \mathrm{H}_{17} \mathrm{O}_{2}{ }^{+}[\mathrm{M}+\mathrm{H}]^{+}$193.1225, found 193.1223.

The analytical data are in accordance with those previously reported in the literature. ${ }^{[111]}$

\section{1-(4-Chloro-2-hydroxyphenyl)-2,2-dimethylpropan-1-one (197h)}<smiles>CC(C)(C)C(=O)c1ccc(Cl)cc1O</smiles> 
The general procedure $\mathbf{E}$ was followed using 1-(4-chlorophenyl)-2,2-dimethylpropan-1-one 77k (98.4 mg, $0.50 \mathrm{mmol})$. Purification by column chromatography on silica gel ( $n$ hexane/ethyl acetate: $50 / 1)$ yielded 197k (65.0 mg, 61\%) as a colorless liquid.

${ }^{1} \mathbf{H}-N M R\left(400 \mathrm{MHz}, \mathrm{CDCl}_{3}\right) \delta=12.83(\mathrm{~s}, 1 \mathrm{H}), 7.92(\mathrm{~d}, J=8.8 \mathrm{~Hz}, 1 \mathrm{H}), 6.99(\mathrm{~d}, J=2.2 \mathrm{~Hz}, 1 \mathrm{H})$, $6.80(\mathrm{dd}, J=8.8,2.2 \mathrm{~Hz}, 1 \mathrm{H}), 1.41(\mathrm{~s}, 9 \mathrm{H})$.

${ }^{13}$ C-NMR $\left(100 \mathrm{MHz}, \mathrm{CDCl}_{3}\right) \delta=211.4\left(\mathrm{C}_{\mathrm{q}}\right), 164.5\left(\mathrm{C}_{\mathrm{q}}\right), 140.9\left(\mathrm{C}_{\mathrm{q}}\right), 131.8(\mathrm{CH}), 119.2(\mathrm{CH}), 118.4$ $(\mathrm{CH}), 115.9\left(\mathrm{C}_{\mathrm{q}}\right), 44.6\left(\mathrm{C}_{\mathrm{q}}\right), 28.6\left(\mathrm{CH}_{3}\right)$.

IR (ATR): 2970, 1625, 1561, 1487, 1343, 1179, 960, $799 \mathrm{~cm}^{-1}$.

MS (ESI) $m / z$ (relative intensity): 279 (10), 245 (8), $211(100)[\mathrm{M}-\mathrm{H}]^{-}\left({ }^{35} \mathrm{Cl}\right)$.

HR-MS (ESI) $m / z$ calc. for $\mathrm{C}_{11} \mathrm{H}_{12}{ }^{35} \mathrm{ClO}_{2}{ }^{-}[\mathrm{M}-\mathrm{H}]^{-} 211.0531$, found 211.0525 .

The analytical data are in accordance with those previously reported in the literature. ${ }^{[111]}$

\section{1-(4-Fluoro-2-hydroxyphenyl)-2,2-dimethylpropan-1-one (197j)}<smiles>CC(C)(C)C(=O)c1ccc(F)cc1O</smiles>

The general procedure $\mathbf{E}$ was followed using 1-(4-fluorophenyl)-2,2-dimethylpropan-1-one 77j (90.1 mg, $0.50 \mathrm{mmol}$ ). Purification by column chromatography on silica gel ( $n$ hexane/ethyl acetate: 50/1) yielded 197j (63.9 mg, 65\%) as a colorless liquid.

${ }^{1}$ H-NMR $\left(400 \mathrm{MHz}, \mathrm{CDCl}_{3}\right) \delta=13.06(\mathrm{~d}, J=1.5 \mathrm{~Hz}, 1 \mathrm{H}), 8.01(\mathrm{dd}, J=9.2,6.5 \mathrm{~Hz}, 1 \mathrm{H}), 6.65(\mathrm{dd}$, $J=10.4,2.7 \mathrm{~Hz}, 1 \mathrm{H}), 6.54(\mathrm{ddd}, J=9.2,7.9,2.7 \mathrm{~Hz}, 1 \mathrm{H}), 1.41(\mathrm{~s}, 9 \mathrm{H})$.

${ }^{13}$ C-NMR $\left(100 \mathrm{MHz}, \mathrm{CDCl}_{3}\right) \delta=211.0\left(\mathrm{C}_{\mathrm{q}}\right), 166.5\left(\mathrm{~d},{ }^{3} J_{\mathrm{C}-\mathrm{F}}=14.1 \mathrm{~Hz}, \mathrm{C}_{\mathrm{q}}\right), 166.4\left(\mathrm{~d},{ }^{1} J_{\mathrm{C}-\mathrm{F}}=256.2\right.$ $\left.\mathrm{Hz}, \mathrm{C}_{\mathrm{q}}\right), 133.2\left(\mathrm{~d},{ }^{3} J_{\mathrm{C}-\mathrm{F}}=11.5 \mathrm{~Hz}, \mathrm{CH}\right), 114.4\left(\mathrm{~d},{ }^{4} J_{\mathrm{C}-\mathrm{F}}=2.6 \mathrm{~Hz}, \mathrm{C}_{\mathrm{q}}\right), 106.0\left(\mathrm{~d},{ }^{2} J_{\mathrm{C}-\mathrm{F}}=22.5 \mathrm{~Hz}, \mathrm{CH}\right)$, $105.5\left(\mathrm{~d},{ }^{2} J_{\mathrm{C}-\mathrm{F}}=23.1 \mathrm{~Hz}, \mathrm{CH}\right), 44.5\left(\mathrm{C}_{\mathrm{q}}\right), 28.7\left(\mathrm{CH}_{3}\right)$.

${ }^{19}$ F-NMR $\left(376 \mathrm{MHz}, \mathrm{CDCl}_{3}\right) \delta=-100.81(\mathrm{ddd}, J=10.4,7.9,6.5 \mathrm{~Hz})$.

IR (ATR): 2975, 1632, 1693, 1259, 1188, 1148, 986, $576 \mathrm{~cm}^{-1}$.

MS (ESI) $m / z$ (relative intensity): 195 (100) $[\mathrm{M}-\mathrm{H}]^{-}$.

HR-MS (ESI) $m / z$ calc. for $\mathrm{C}_{11} \mathrm{H}_{12} \mathrm{FO}_{2}^{-}[\mathrm{M}-\mathrm{H}]^{-}$195.0827, found 195.0828.

The analytical data are in accordance with those previously reported in the literature. ${ }^{[186]}$ 


\section{3-Bromo-4-methoxyphenol (109a)}<smiles>COc1ccc(O)cc1Br</smiles>

The general procedure $\mathbf{F}$ was followed using 1-bromo-2-methoxybenzene $\mathbf{2 0 0 a}(93.0 \mathrm{mg}, 0.50$ mmol). Purification by column chromatography on silica gel (nhexane/ethyl acetate: 5/1) yielded 109a (52.8 $\mathrm{mg}, 52 \%)$ as a green oil.

${ }^{1}$ H-NMR $\left(600 \mathrm{MHz}, \mathrm{CDCl}_{3}\right) \delta=7.06(\mathrm{~d}, J=2.8 \mathrm{~Hz}, 1 \mathrm{H}), 6.77(\mathrm{~d}, J=8.8 \mathrm{~Hz}, 1 \mathrm{H}), 6.74(\mathrm{dd}, J=8.8$, $2.8 \mathrm{~Hz}, 1 \mathrm{H}), 4.47(\mathrm{~s}, 1 \mathrm{H}), 3.81(\mathrm{~s}, 3 \mathrm{H})$.

${ }^{13}$ C-NMR $\left(150 \mathrm{MHz}, \mathrm{CDCl}_{3}\right) \delta=150.4\left(\mathrm{C}_{\mathrm{q}}\right), 149.8\left(\mathrm{C}_{\mathrm{q}}\right), 120.5(\mathrm{CH}), 115.0(\mathrm{CH}), 113.2(\mathrm{CH}), 112.0$ $\left(\mathrm{C}_{\mathrm{q}}\right), 56.9\left(\mathrm{CH}_{3}\right)$.

IR (ATR): 3363, 2942, 2837, 1495, 1276, 1206, 1048, $744 \mathrm{~cm}^{-1}$.

MS (ESI) $m / z$ (relative intensity): $203(95)[\mathrm{M}+\mathrm{H}]^{+}\left({ }^{79} \mathrm{Br}\right), 201$ (100).

HR-MS (ESI) $m / z$ calc. for $\mathrm{C}_{7} \mathrm{H}_{8}{ }^{79} \mathrm{BrO}_{2}{ }^{+}[\mathrm{M}+\mathrm{H}]^{+} 202.9537$, found 202.9536. ${ }^{[188]}$

\section{3-Chloro-4-methoxyphenol (109b)}<smiles>COc1ccc(O)cc1Cl</smiles>

The general procedure $\mathbf{F}$ was followed using 1-chloro-2-methoxybenzene 200b $(71.0 \mathrm{mg}, 0.50$ mmol). Purification by column chromatography on silica gel ( $n$ hexane/ethyl acetate: 5/1) yielded 109b (31.7 mg, 40\%) as a green oil.

${ }^{1} \mathrm{H}-\mathrm{NMR}\left(600 \mathrm{MHz}, \mathrm{CDCl}_{3}\right) \delta=6.89(\mathrm{~d}, J=3.0 \mathrm{~Hz}, 1 \mathrm{H}), 6.79(\mathrm{~d}, J=8.8 \mathrm{~Hz}, 1 \mathrm{H}), 6.68(\mathrm{dd}, J=8.8$, $3.0 \mathrm{~Hz}, 1 \mathrm{H}), 4.35(\mathrm{~s}, 1 \mathrm{H}), 3.82(\mathrm{~s}, 3 \mathrm{H})$.

${ }^{13}$ C-NMR $\left(150 \mathrm{MHz}, \mathrm{CDCl}_{3}\right) \delta=149.6\left(\mathrm{C}_{\mathrm{q}}\right), 149.4\left(\mathrm{C}_{\mathrm{q}}\right), 123.0\left(\mathrm{C}_{\mathrm{q}}\right), 117.6(\mathrm{CH}), 114.2(\mathrm{CH}), 113.5$ $(\mathrm{CH}), 56.8\left(\mathrm{CH}_{3}\right)$.

IR (ATR): 3125, 2916, 1501, 1265, 1059, 908, 729, $650 \mathrm{~cm}^{-1}$.

MS (ESI) $m / z$ (relative intensity): $157(100)[\mathrm{M}-\mathrm{H}]^{-}\left({ }^{35} \mathrm{Cl}\right), 142(50)$.

HR-MS (ESI) $m / z$ calc. for $\mathrm{C}_{7} \mathrm{H}_{6}{ }^{35} \mathrm{ClO}_{2}^{-}[\mathrm{M}-\mathrm{H}]^{-} 157.0062$, found 157.0062 . 
The analytical data are in accordance with those previously reported in the literature. ${ }^{[189]}$

\subsubsection{Gram-Scale Synthesis of $106 a$}

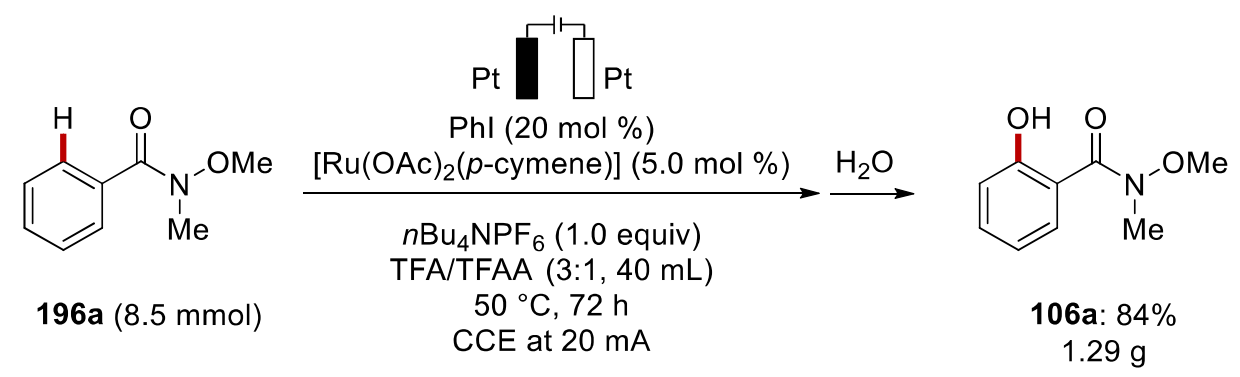

To an undivided two-necked flask (diameter: $40 \mathrm{~mm}$; length: $130 \mathrm{~mm}$; volume: $120 \mathrm{~mL}$ ) equipped with a teflon-coated magnetic stirring bar and teflon cap, platinum electrodes $(25 \mathrm{~mm} \times 50 \mathrm{~mm} \times$ $0.125 \mathrm{~mm}), 196 \mathrm{a}(1.40 \mathrm{~g}, 8.5 \mathrm{mmol}), \mathrm{PhI}$ 194a $(347 \mathrm{mg}, 1.7 \mathrm{mmol}),\left[\mathrm{Ru}(\mathrm{OAc})_{2}(p\right.$-cymene $\left.)\right]$ 188a (150 mg, $0.43 \mathrm{mmol}), n \mathrm{Bu}_{4} \mathrm{NPF}_{6}(3.29 \mathrm{~g}, 8.4 \mathrm{mmol})$ were added in TFA/TFAA $(3: 1,40 \mathrm{~mL})$. Electrocatalysis was performed at $50{ }^{\circ} \mathrm{C}$ with a constant current of $20 \mathrm{~mA}$ maintained for $72 \mathrm{~h}$. Thereafter, saturated aqueous $\mathrm{NaHCO}_{3}(200 \mathrm{~mL})$ was added and the reaction mixture was extracted with EtOAc $(3 \times 50 \mathrm{~mL})$. The combined organic layers were washed with brine $(100 \mathrm{~mL})$, dried over $\mathrm{Na}_{2} \mathrm{SO}_{4}$, filtered, and concentrated in vacuo. The crude product was purified by column chromatography on silica gel (nhexane/ethyl acetate: 6/1) and yielded 106a $(1.29 \mathrm{~g}, 84 \%)$ as a colorless oil.

\subsubsection{H/D Exchange Experiment}

(a) Electrochemical reaction
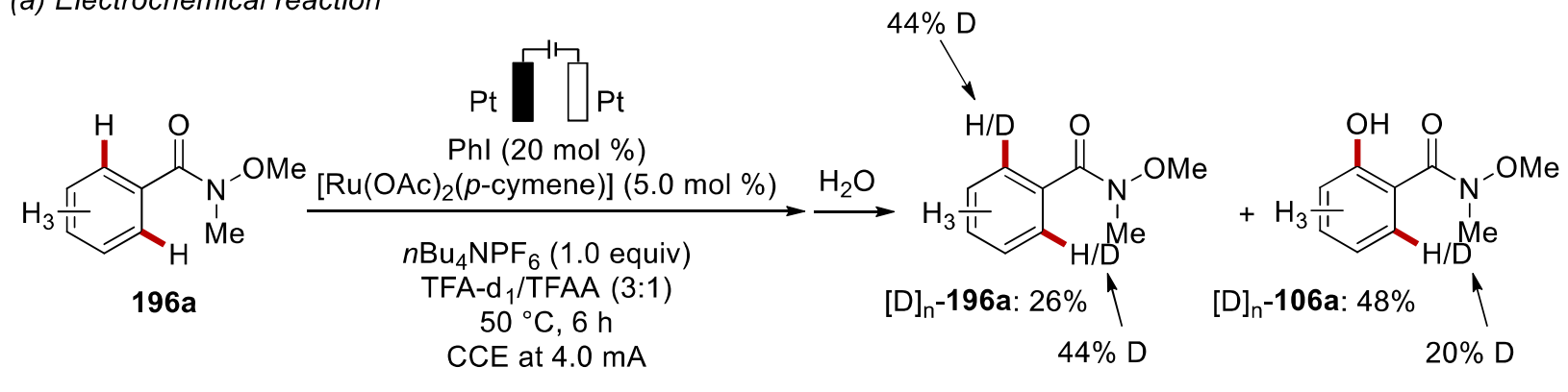
to an undivided cell equipped with Pt electrodes (10 mm x $15 \mathrm{~mm} \times 0.125 \mathrm{~mm}), \mathbf{1 9 6 a}(82.5 \mathrm{mg}, 0.50$ mmol), PhI 194a (20.4 mg, 20 mol \%), [Ru(OAc) $2\left(p\right.$-cymene)] 188a (8.8 mg, 5.0 mol \%), $n \mathrm{Bu}_{4} \mathrm{NPF}_{6}$ (194 mg, 1.0 equiv), and TFA-d 1 /TFAA (3:1, $3.0 \mathrm{~mL})$ were added. Electrocatalysis was performed at $50{ }^{\circ} \mathrm{C}$ with a constant current of $4.0 \mathrm{~mA}$ maintained for $6 \mathrm{~h}$. Thereafter, saturated aqueous $\mathrm{NaHCO}_{3}$ $(25 \mathrm{~mL})$ was added, and the reaction mixture was extracted with EtOAc $(3 \times 15 \mathrm{~mL})$. The combined organic layers were washed with brine $(25 \mathrm{~mL})$, dried over $\mathrm{Na}_{2} \mathrm{SO}_{4}$, filtered, and concentrated in vacuo. Column chromatography (nhexane/ethyl acetate: $5 / 1)$ yielded $[\mathrm{D}]_{\mathrm{n}}-196 \mathbf{a}(21.5 \mathrm{mg}, 26 \%)$ as a colourless oil and $[\mathrm{D}]_{\mathrm{n}}$-106a $(43.4 \mathrm{mg}, 48 \%)$ as a colorless oil. The D-incorporation was determined by ${ }^{1}$ H-NMR spectroscopy (Figures 5.5.1-2).
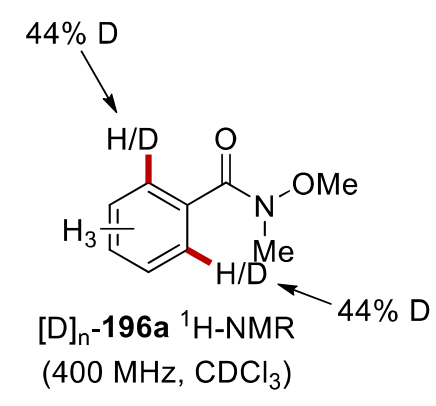
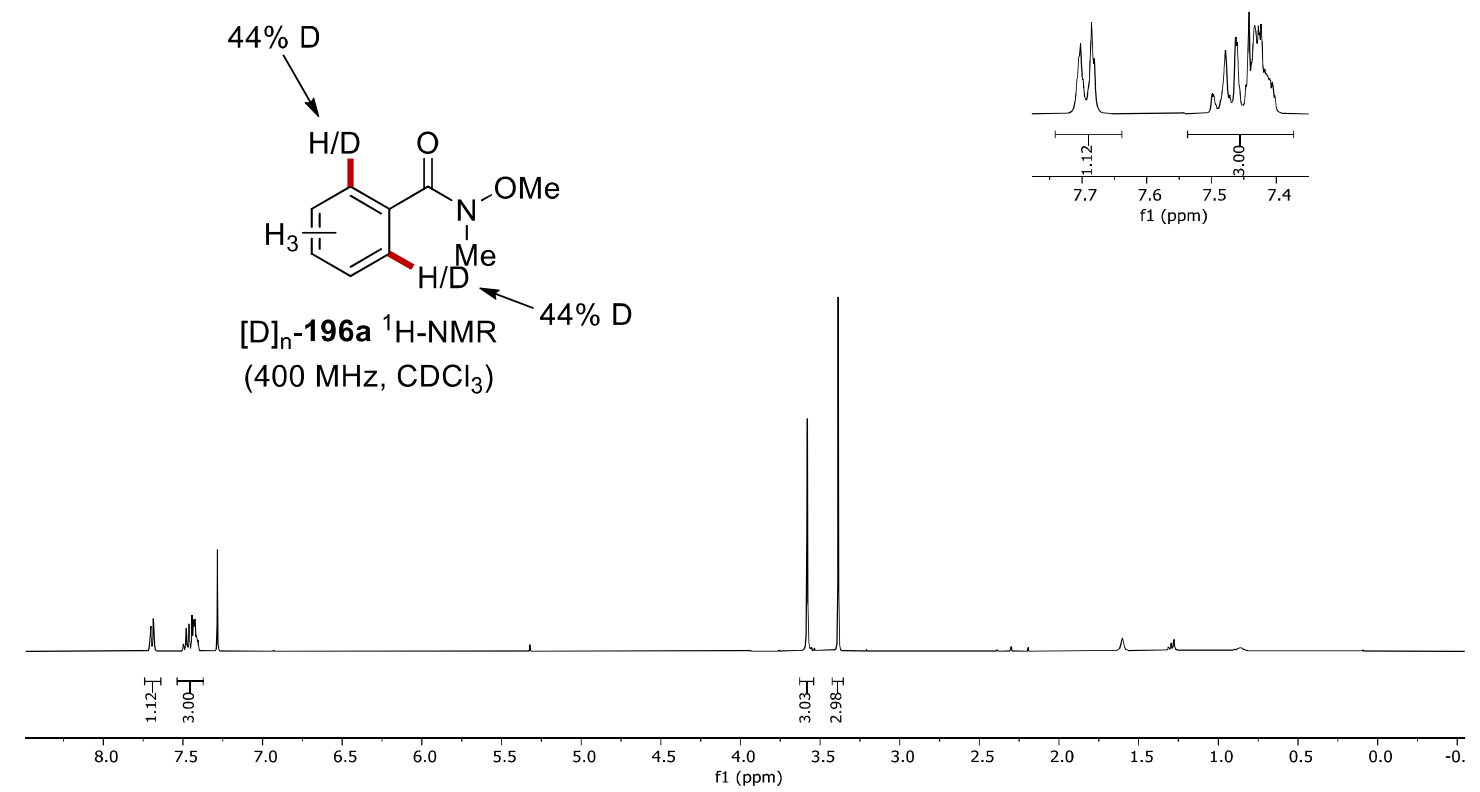

Figure 5.5.1 ${ }^{1} \mathrm{H}-\mathrm{NMR}$ of $[\mathrm{D}]_{\mathrm{n}}-\mathbf{1 9 6 a}$ from the deuteration study with electricity. 

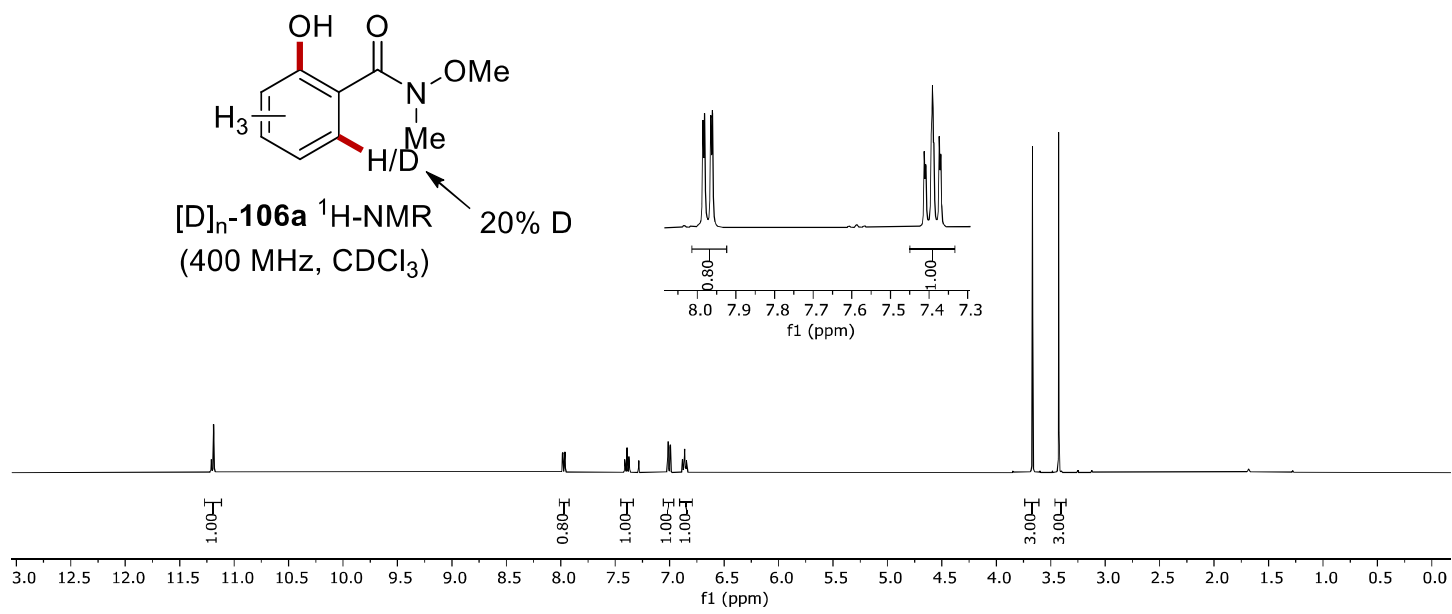

Figure 5.5.2 ${ }^{1} \mathrm{H}-\mathrm{NMR}$ of $[\mathrm{D}]_{\mathrm{n}}$-106a from the deuteration study with electricity.

(b) Chemical oxidant reaction

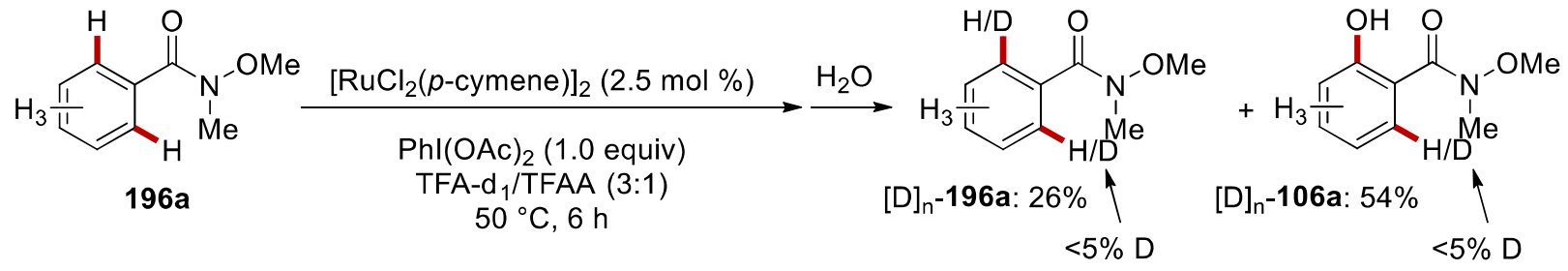

To an undivided cell, 196a (82.5 mg, $0.50 \mathrm{mmol}), \mathrm{PhI}$ 194a (20.4 mg, $20 \mathrm{~mol} \%),\left[\mathrm{RuCl}_{2}\right.$ (p-cymene)] (8.8 mg, $5.0 \mathrm{~mol} \%), \mathrm{PhI}(\mathrm{OAc})_{2}\left(161 \mathrm{mg}, 1.0\right.$ equiv) $n \mathrm{Bu}_{4} \mathrm{NPF}_{6}$ (194 mg, 1.0 equiv), and TFA$\mathrm{d}_{1} /$ TFAA $(3: 1,3.0 \mathrm{~mL})$ were added. The reaction was performed at $50{ }^{\circ} \mathrm{C}$ for $6 \mathrm{~h}$. Thereafter, saturated aqueous $\mathrm{NaHCO}_{3}(25 \mathrm{~mL})$ was added and the reaction mixture was extracted with EtOAc $(3 \times 15 \mathrm{~mL})$. The combined organic layers were washed with brine $(25 \mathrm{~mL})$, dried over $\mathrm{Na}_{2} \mathrm{SO}_{4}$, filtered, and concentrated in vacuo. Column chromatography (nhexane/ethyl acetate: 5/1) yielded $[D]_{\mathrm{n}}-196 \mathrm{a}(21.5 \mathrm{mg}, 26 \%)$ as a colourless oil and $[\mathrm{D}]_{\mathrm{n}}-\mathbf{1 0 6 a}(48.9 \mathrm{mg}, 54 \%)$ as a colorless oil. The D-incorporation was determined by ${ }^{1} \mathrm{H}-\mathrm{NMR}$ spectroscopy (Figures 5.5.3-4). 

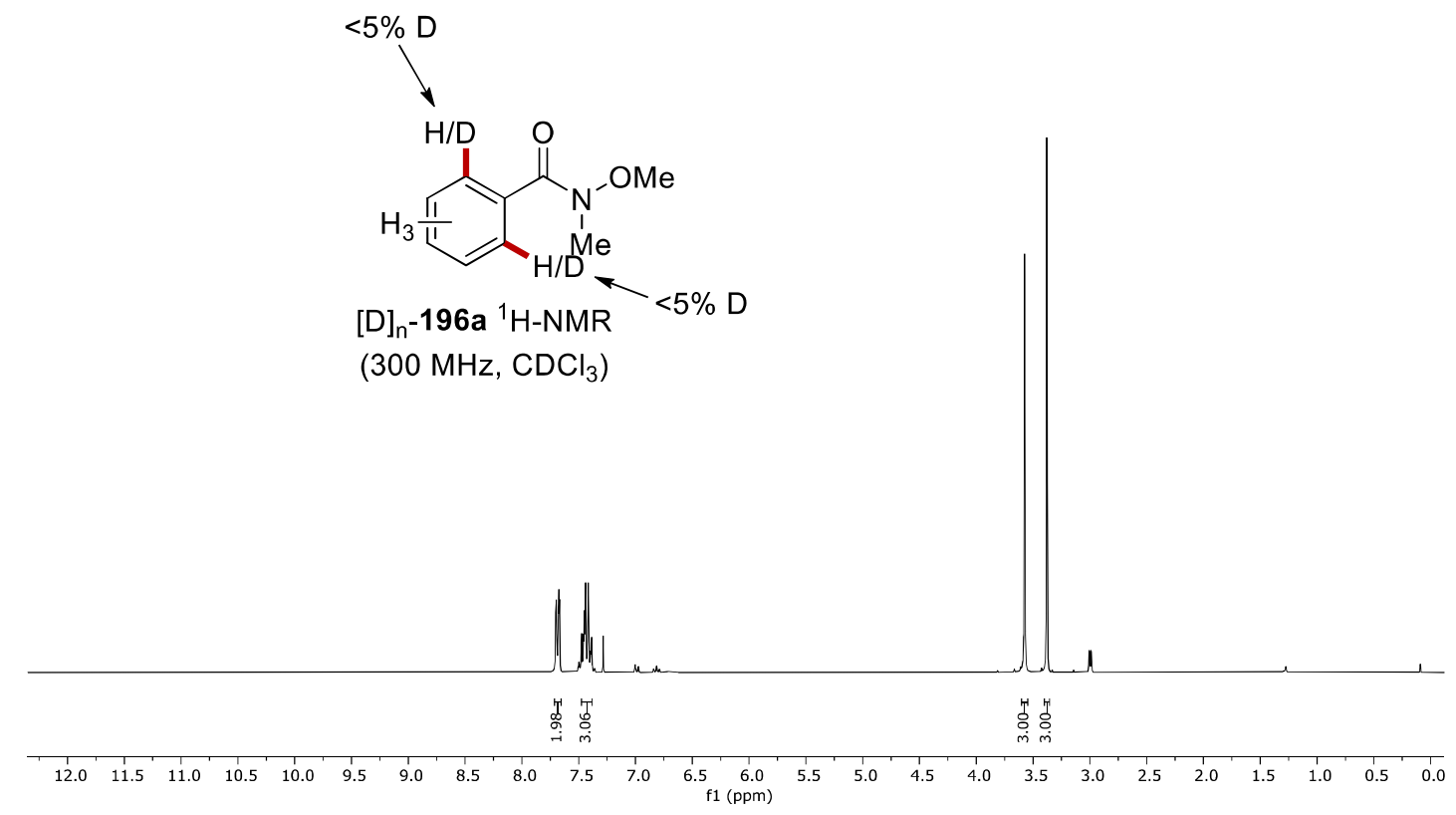

Figure 5.5.3 ${ }^{1} \mathrm{H}-\mathrm{NMR}$ of $[\mathrm{D}]_{\mathrm{n}}-\mathbf{1 9 6 a}$ from the deuteration study with chemical oxidant.

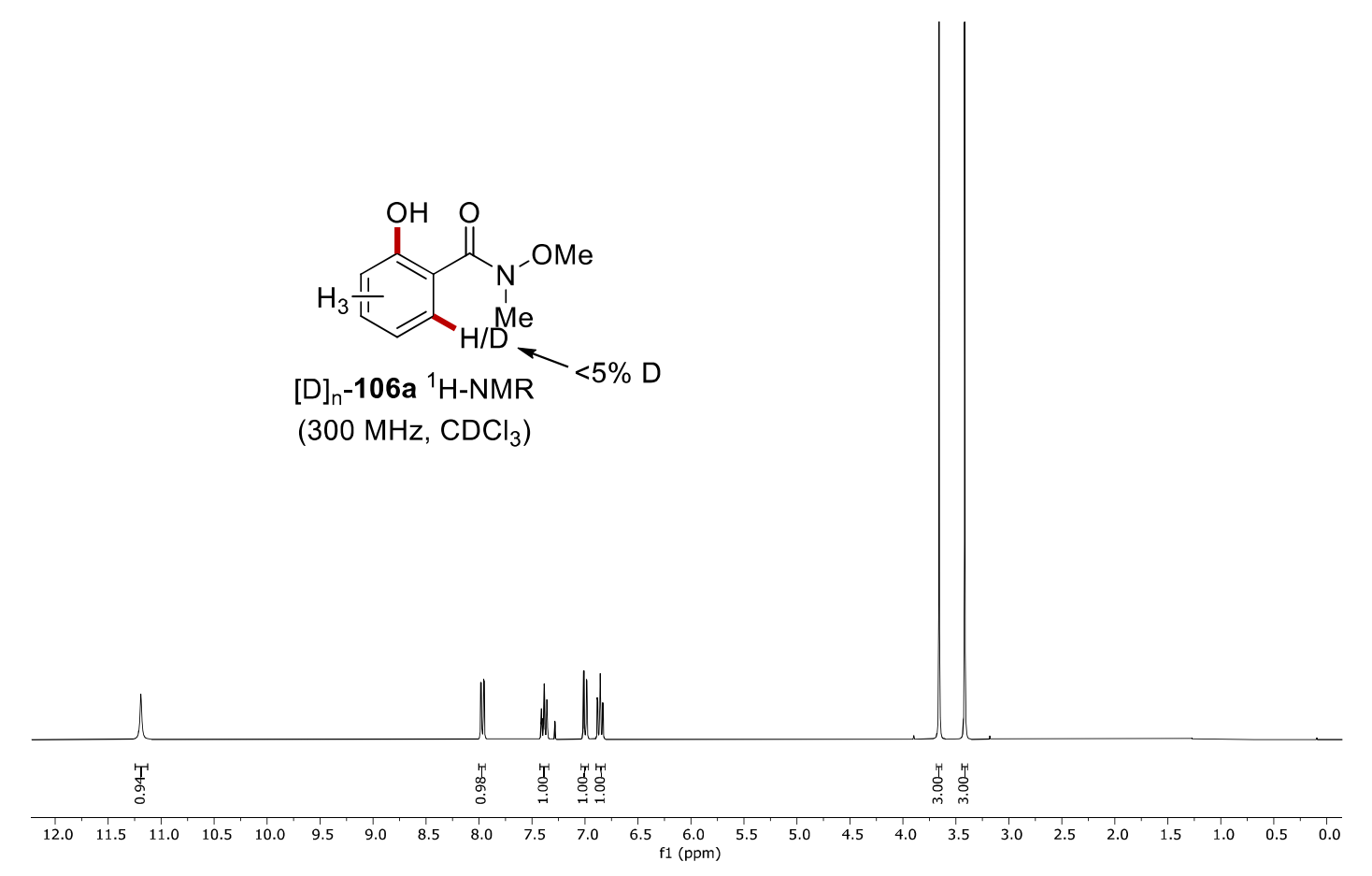

Figure 5.5.4 ${ }^{1} \mathrm{H}-\mathrm{NMR}$ of $[\mathrm{D}]_{\mathrm{n}}$-106a from the deuteration study with chemical oxidant. 


\subsubsection{Kinetic Isotope Effect (KIE)}

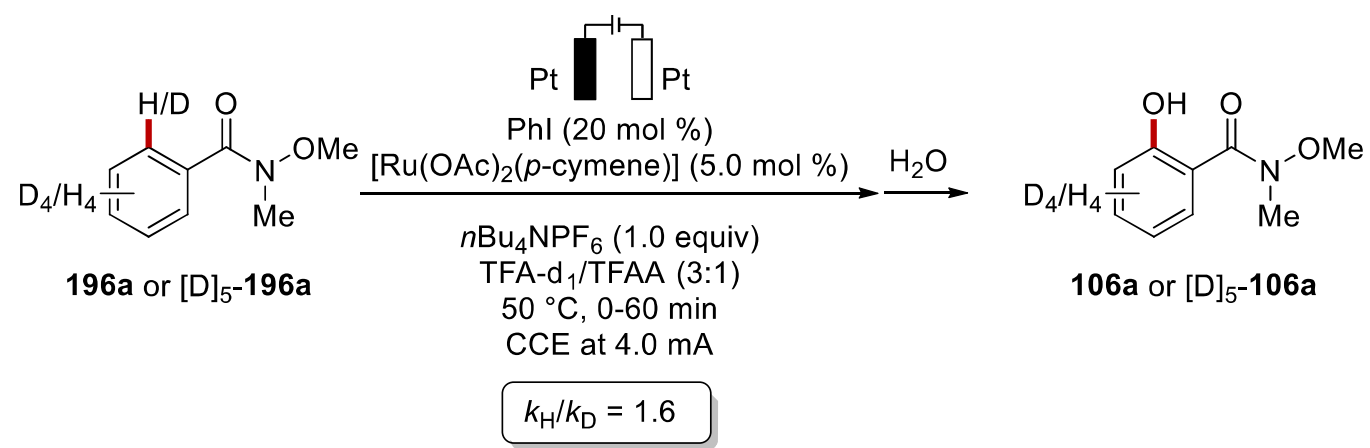

Two parallel reactions using substrates $196 \mathbf{a}$ and $[\mathrm{D}]_{5}-\mathbf{1 9 6 a}(0.50 \mathrm{mmol}$ each $)$ were carried out to determine the KIE by comparison of the initial rates. To undivided cells equipped with Pt electrodes $(10 \mathrm{~mm} \times 15 \mathrm{~mm} \times 0.125 \mathrm{~mm}), \mathbf{1 9 6 a}(82.5 \mathrm{mg}, 0.50 \mathrm{mmol})$ or $[\mathrm{D}]_{5}-\mathbf{1 9 6 a}(85.1 \mathrm{mg}, 0.50 \mathrm{mmol})$ respectevely, $\mathrm{PhI}$ 194a (20.4 mg, $20 \mathrm{~mol} \%)$, [Ru(OAc) $2(p$-cymene)] 188a (8.8 mg, $5.0 \mathrm{~mol} \%)$ $n \mathrm{Bu}_{4} \mathrm{NPF}_{6}(194 \mathrm{mg}, 1.0$ equiv), and TFA/TFAA $(3: 1,4.0 \mathrm{~mL})$ were added. Electrocatalysis was performed at $50{ }^{\circ} \mathrm{C}$ with a constant current of $4.0 \mathrm{~mA}$. After 20,40 and 60 minutes, aliquots of 0.2 $\mathrm{mL}$ were collected from the cell. Each aliquot was then treated with saturated aqueous $\mathrm{NaHCO}_{3}(2.0$ $\mathrm{mL})$ and extracted with $\mathrm{CH}_{2} \mathrm{Cl}_{2}(3 \times 1.0 \mathrm{~mL})$. After evaporation of the solvents, the crude mixture was analyzed by ${ }^{1} \mathrm{H}-\mathrm{NMR}$ spectroscopy using $\mathrm{CH}_{2} \mathrm{Br}_{2}$ as the internal standard. The measured yields of 106a and [D] $]_{5}-\mathbf{1 0 6 a}$ were plotted and a linear fit revealed a KIE of $k_{\mathrm{H}} / k_{\mathrm{D}} \approx 1.6$ (Figure 5.5.5).

\begin{tabular}{llll}
\hline $\boldsymbol{t} / \mathbf{m i n}$ & $\mathbf{2 0}$ & $\mathbf{4 0}$ & $\mathbf{6 0}$ \\
\hline $\mathbf{1 0 6 a} / \%$ & 1 & 3 & 6 \\
{$[\mathrm{D}]_{\mathrm{n}}-\mathbf{1 0 6 a} / \%$} & 0 & 1.6 & 3 \\
\hline
\end{tabular}




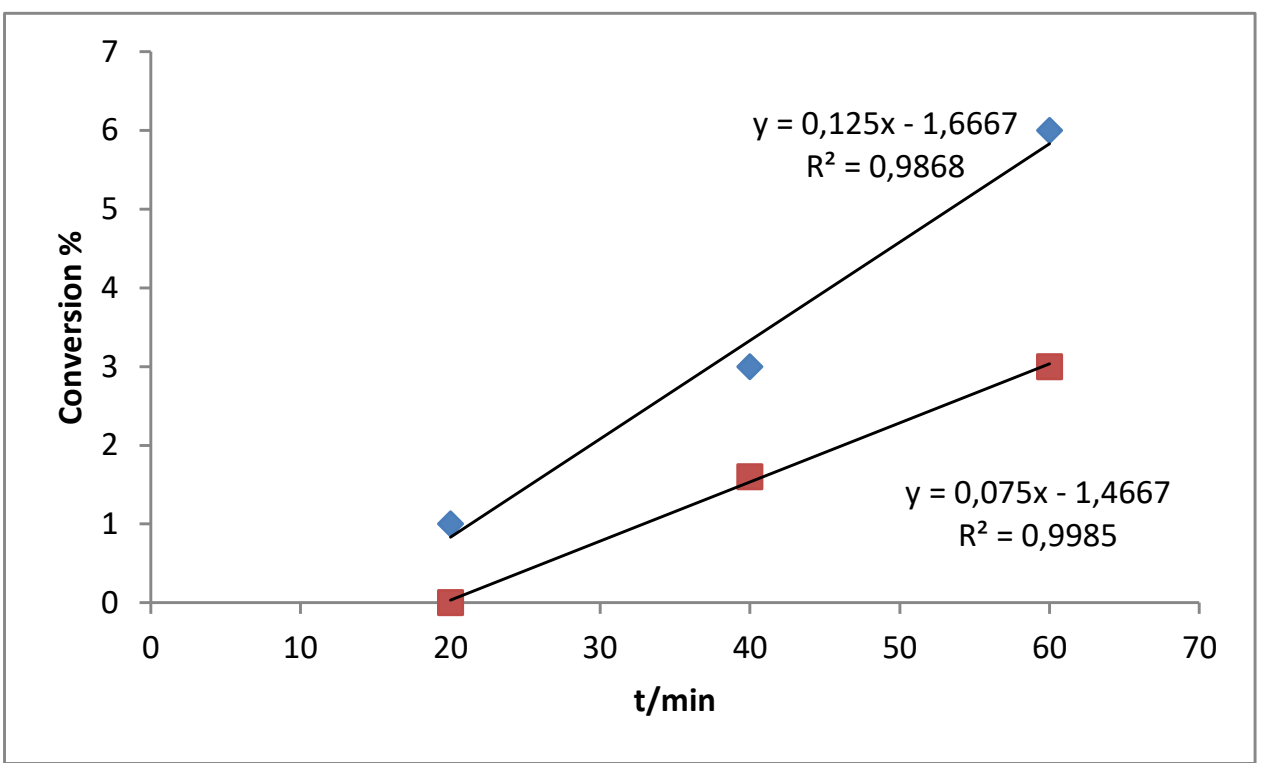

Figure 5.5.5 Linear fit for the reaction rates of 196a and $[D]_{5}-\mathbf{1 9 6 a}$.

\subsubsection{Competition Experiment}
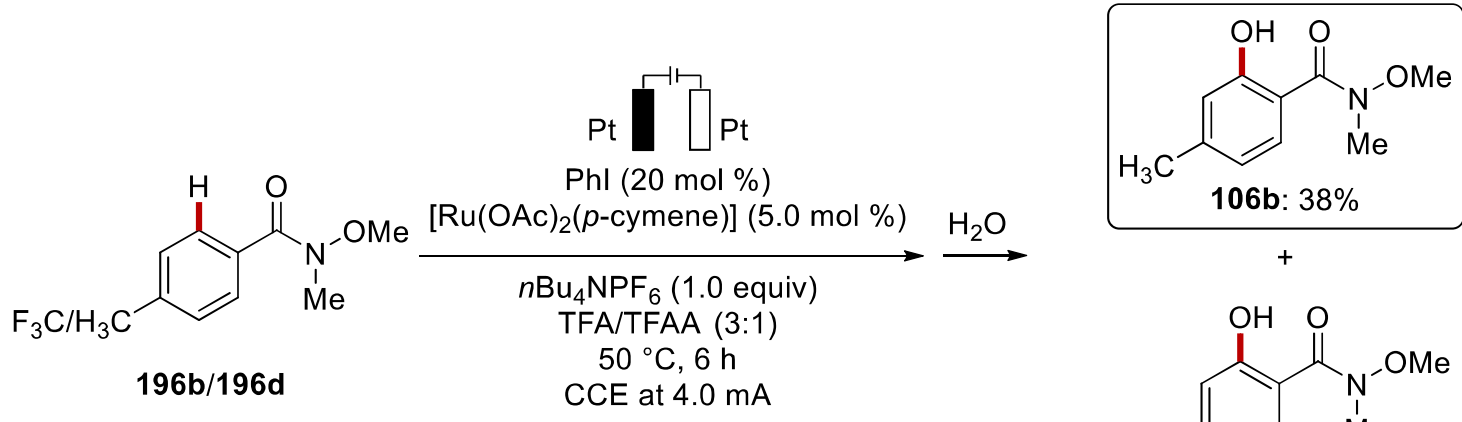<smiles>CN(C)C(=O)c1ccc(C(F)(F)F)cc1O</smiles>

To an undivided cell equipped with Pt electrodes (10 mm x $15 \mathrm{~mm}$ x $0.125 \mathrm{~mm}), \mathbf{1 9 6 b}(44.8 \mathrm{mg}$, $0.25 \mathrm{mmol}), 196 \mathrm{~d}$ (58.5 mg, $0.25 \mathrm{mmol}), \mathrm{PhI}$ 194a (20.4 mg, $20 \mathrm{~mol} \%)$, [Ru(OAc) $2(p$-cymene)] 188a (8.8 mg, $5.0 \mathrm{~mol} \%) n \mathrm{Bu}_{4} \mathrm{NPF}_{6}$ (194 mg, 1.0 equiv), and TFA/TFAA (3:1, $\left.3.0 \mathrm{~mL}\right)$ were added. Electrocatalysis was performed at $50{ }^{\circ} \mathrm{C}$ with a constant current of $4.0 \mathrm{~mA}$ maintained for $6 \mathrm{~h}$. Thereafter, saturated aqueous $\mathrm{NaHCO}_{3}(25 \mathrm{~mL})$ was added, and the reaction mixture was extracted with EtOAc $(3 \times 15 \mathrm{~mL})$. The combined organic layers were washed with brine $(25 \mathrm{~mL})$, dried over $\mathrm{Na}_{2} \mathrm{SO}_{4}$, filtered, and concentrated in vacuo. Purification by column chromatography on silica gel 
(nhexane/ethyl acetate: $10 / 1 \rightarrow 5 / 1)$ yielded $\mathbf{1 0 6 b}(31.8 \mathrm{mg}, 38 \%)$ as a colourless solid. 106d was obtained only in trace amount.

\subsubsection{Directing Group Competition}

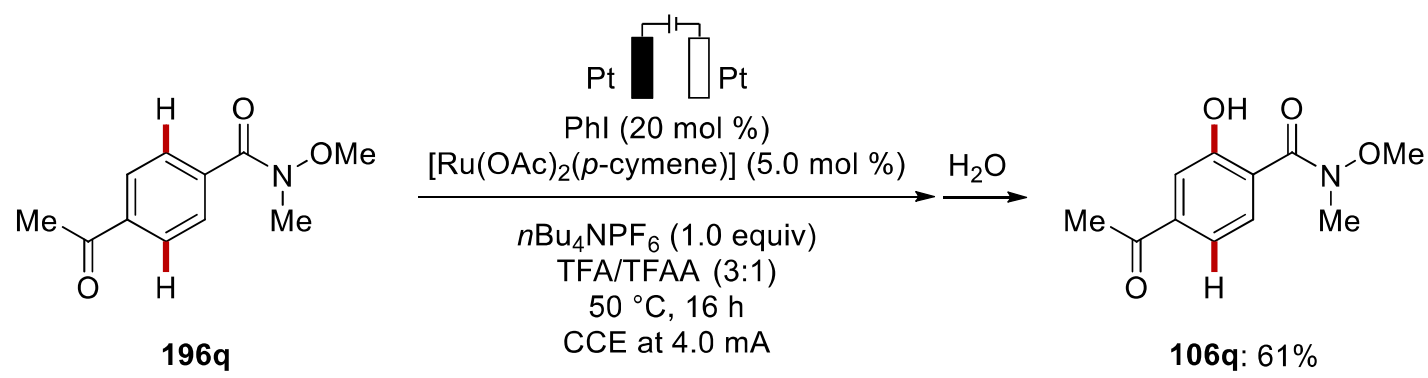

The general procedure D was followed using 4-acetyl- $N$-methoxy- $N$-methylbenzamide 196q (104 $\mathrm{mg}, 0.50 \mathrm{mmol}$ ) to evaluate the competition in directing the $\mathrm{C}-\mathrm{H}$ activation between the two directing groups. Isolation by column chromatography ( $n$ hexane/ethyl acetate: $8 / 1 \rightarrow 3 / 1$ ) yielded 106q (67.8 $\mathrm{mg}, 61 \%)$ as a colourless liquid.

\subsubsection{Gas-Chromatographical Analysis of Headspace}

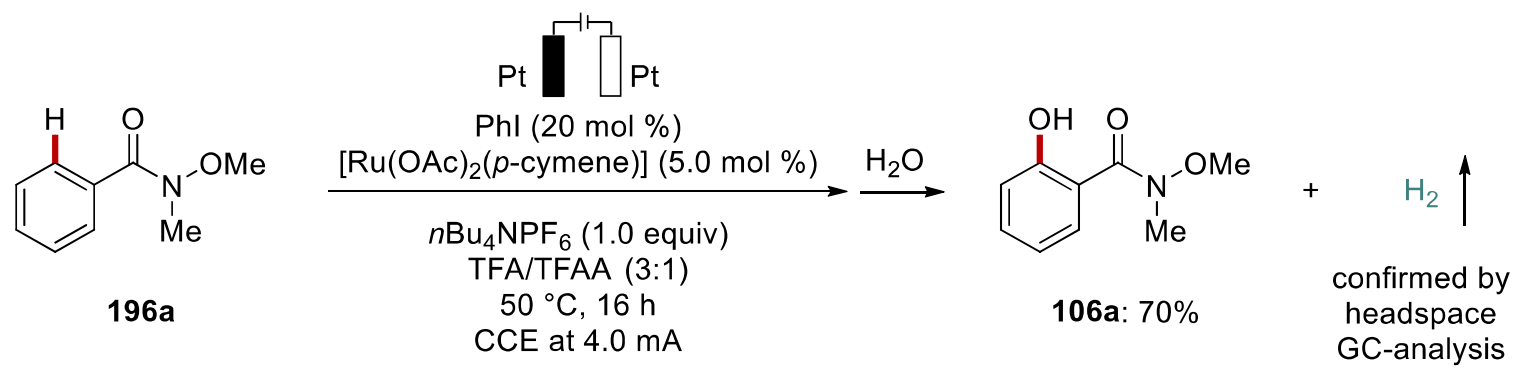

To a Schlenk tube equipped with platinum electrodes $(10 \mathrm{~mm}$ x $15 \mathrm{~mm}$ x $0.125 \mathrm{~mm}), \mathbf{1 9 6 a}(82.5 \mathrm{mg}$, $0.50 \mathrm{mmol}), \mathrm{PhI}$ 194a $(20.4 \mathrm{mg}, 20 \mathrm{~mol} \%),\left[\mathrm{Ru}(\mathrm{OAc})_{2}(p\right.$-cymene $\left.)\right]$ 188a $(8.8 \mathrm{mg}, 5.0 \mathrm{~mol} \%)$ $n \mathrm{Bu}_{4} \mathrm{NPF}_{6}(194 \mathrm{mg}, 1.0$ equiv), and degassed TFA/TFAA $(3: 1,3.0 \mathrm{~mL})$ were added under nitrogen atmosphere. Electrocatalysis was performed at $50{ }^{\circ} \mathrm{C}$ with a constant current of $4.0 \mathrm{~mA}$ maintained for $16 \mathrm{~h}$. After cooling to ambient temperature, $1.0 \mathrm{~mL}$ of the gas-phase above the reaction mixture 
was analyzed by GC (Figure 5.5.6). Next, a saturated aqueous $\mathrm{NaHCO}_{3}(25 \mathrm{~mL})$ was added, and the reaction mixture was extracted with EtOAc $(3 \times 15 \mathrm{~mL})$. The combined organic layers were washed with brine $(25 \mathrm{~mL})$, dried over $\mathrm{Na}_{2} \mathrm{SO}_{4}$, filtered, and concentrated in vacuo. The crude product was purified by column chromatography on silica gel ( $n$ hexane/ethyl acetate: $5 / 1)$ yielding 106a $(63.4$ mg, 70\%) as yellow oil.

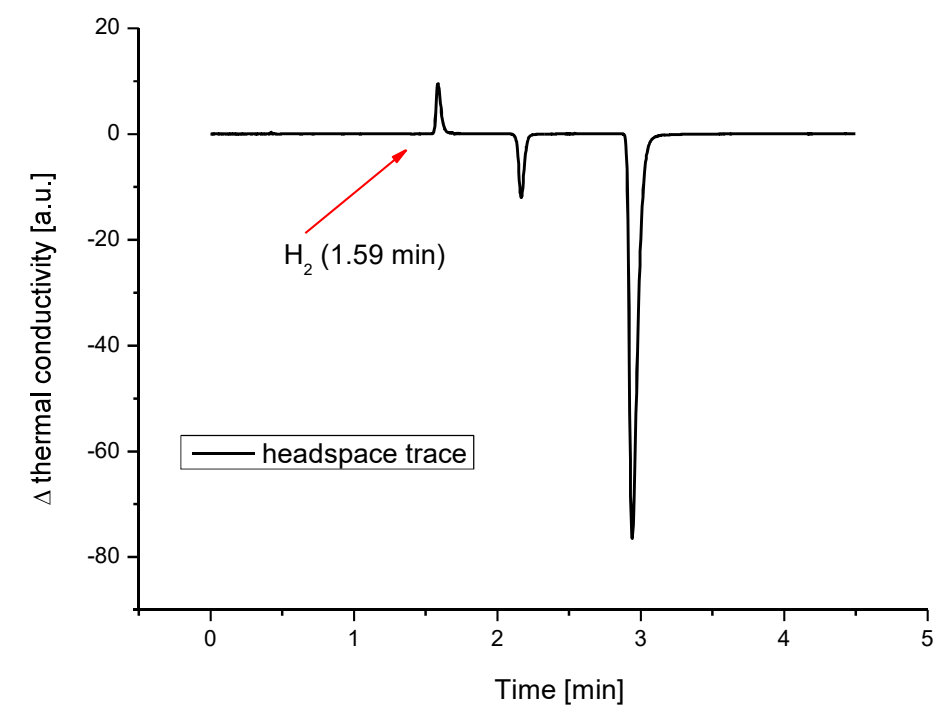

Figure 5.5.6 Gas chromatographic analysis. 


\subsection{Rhoda-Electrocatalyzed Bimetallic C-H Oxygenation by Weak $O$-Coordination}

\subsubsection{Characterization Data}

\section{2-Hydroxy- $N$-methoxy- $N$,4-dimethylbenzamide (106b)}<smiles>CON(C)C(=O)c1ccc(C)cc1O</smiles>

The general procedure $\mathbf{G}(15 \mathrm{~h})$ was followed using $N$-methoxy- $N$,4-dimethylbenzamide $\mathbf{1 9 6} \mathbf{b}$ (89.6 $\mathrm{mg}, 0.50 \mathrm{mmol}$ ). Purification by column chromatography ( $n$ hexane/ethyl acetate: $5 / 1 \rightarrow 3 / 1$ ) yielded 106b (71.3 $\mathrm{mg}, 73 \%)$ as a yellow oil.

${ }^{1}$ H-NMR $\left(300 \mathrm{MHz}, \mathrm{CDCl}_{3}\right) \delta=11.38(\mathrm{~s}, 1 \mathrm{H}), 7.88(\mathrm{~d}, J=8.3 \mathrm{~Hz}, 1 \mathrm{H}), 6.86-6.79(\mathrm{~m}, 1 \mathrm{H}), 6.67$ (dd, $J=8.3,1.8 \mathrm{~Hz}, 1 \mathrm{H}), 3.67$ (s, 3H), 3.41 (s, 3H), 2.34 (s, 3H).

${ }^{13}$ C-NMR $\left(100 \mathrm{MHz}, \mathrm{CDCl}_{3}\right) \delta=170.0\left(\mathrm{C}_{\mathrm{q}}\right), 161.3\left(\mathrm{C}_{\mathrm{q}}\right), 144.9\left(\mathrm{C}_{\mathrm{q}}\right), 129.4(\mathrm{CH}), 119.7(\mathrm{CH}), 118.2$ $(\mathrm{CH}), 111.5\left(\mathrm{C}_{\mathrm{q}}\right), 61.1\left(\mathrm{CH}_{3}\right), 34.1\left(\mathrm{CH}_{3}\right), 21.6\left(\mathrm{CH}_{3}\right)$.

IR (ATR): 3069, 1634, 1586, 1350, 1265, 949, 735, $533 \mathrm{~cm}^{-1}$.

MS (ESI) $m / z$ (relative intensity): $413(20)[2 \mathrm{M}+\mathrm{Na}]^{+}, 218(30)[\mathrm{M}+\mathrm{H}]^{+}, 196(100)[\mathrm{M}+\mathrm{H}]^{+}$.

HR-MS (ESI) $m / z$ calc. for $\mathrm{C}_{10} \mathrm{H}_{14} \mathrm{NO}_{3}{ }^{+}[\mathrm{M}+\mathrm{H}]^{+}$196.0968, found 196.0974.

The analytical data are in accordance with those previously reported in the literature. ${ }^{[176]}$

\section{3-Hydroxy- $N$-methoxy- $N$-methyl-[1,1'-biphenyl]-4-carboxamide (106t)}<smiles>CON(C)C(=O)c1ccc(-c2ccccc2)cc1O</smiles>

The general procedure $\mathbf{G}(15 \mathrm{~h})$ was followed using $N$-methoxy- $N$-methyl-[1,1'-biphenyl]-4carboxamide 196t $(121 \mathrm{mg}, 0.50 \mathrm{mmol})$. Purification by column chromatography on silica gel ( $n$ hexane/ethyl acetate: $5 / 1)$ yielded $\mathbf{1 0 6 t}(90.1 \mathrm{mg}, 70 \%)$ as a light viscous liquid.

${ }^{1}$ H-NMR $\left(300 \mathrm{MHz}, \mathrm{CDCl}_{3}\right) \delta=11.49(\mathrm{~s}, 1 \mathrm{H}), 8.08(\mathrm{~d}, J=8.4 \mathrm{~Hz}, 1 \mathrm{H}), 7.68-7.62(\mathrm{~m}, 2 \mathrm{H}), 7.51-$ $7.38(\mathrm{~m}, 3 \mathrm{H}), 7.26(\mathrm{~d}, J=1.8 \mathrm{~Hz}, 1 \mathrm{H}), 7.12(\mathrm{dt}, J=8.4,1.3 \mathrm{~Hz}, 1 \mathrm{H}), 3.72(\mathrm{~s}, 3 \mathrm{H}), 3.46(\mathrm{~s}, 3 \mathrm{H})$. 
${ }^{13}$ C-NMR $\left(100 \mathrm{MHz}, \mathrm{CDCl}_{3}\right) \delta=169.8\left(\mathrm{C}_{\mathrm{q}}\right), 161.6\left(\mathrm{C}_{\mathrm{q}}\right), 146.5\left(\mathrm{C}_{\mathrm{q}}\right), 139.7\left(\mathrm{C}_{\mathrm{q}}\right), 130.0(\mathrm{CH}), 128.9$ $(\mathrm{CH}), 128.3(\mathrm{CH}), 127.1(\mathrm{CH}), 117.5(\mathrm{CH}), 116.2(\mathrm{CH}), 113.0\left(\mathrm{C}_{\mathrm{q}}\right), 61.3\left(\mathrm{CH}_{3}\right), 34.1\left(\mathrm{CH}_{3}\right)$.

IR (ATR): 2935, 1632, 1579, 1353, 1210, 972, 755, $696 \mathrm{~cm}^{-1}$.

MS (ESI) $m / z$ (relative intensity): $537(30)[2 \mathrm{M}+\mathrm{Na}]^{+}, 280(30)[\mathrm{M}+\mathrm{H}]^{+}, 258(100)[\mathrm{M}+\mathrm{H}]^{+}$.

HR-MS (ESI) $m / z$ calc. for $\mathrm{C}_{15} \mathrm{H}_{16} \mathrm{NO}_{3}{ }^{+}[\mathrm{M}+\mathrm{H}]^{+} 258.1125$, found 258.1126.

\section{Methyl 3-hydroxy-4-[methoxy(methyl)carbamoyl]benzoate (106u)}<smiles>COC(=O)c1ccc(C(=O)N(C)C)c(O)c1</smiles>

The general procedure $\mathbf{G}$ (15 h) was followed using methyl 4-[methoxy(methyl)carbamoyl]benzoate 196u (112 mg, $0.50 \mathrm{mmol})$. Purification by column chromatography on silica gel (nhexane/ethyl acetate: $5 / 1)$ yielded $106 u(74.2 \mathrm{mg}, 62 \%)$ as white solid.

M.p.: $108-110^{\circ} \mathrm{C}$.

${ }^{1}$ H-NMR $\left(300 \mathrm{MHz}, \mathrm{CDCl}_{3}\right) \delta=11.01(\mathrm{~s}, 1 \mathrm{H}), 8.02(\mathrm{~d}, J=8.4 \mathrm{~Hz}, 1 \mathrm{H}), 7.64(\mathrm{~d}, J=1.8 \mathrm{~Hz}, 1 \mathrm{H})$, $7.50(\mathrm{dd}, J=8.4,1.8 \mathrm{~Hz}, 1 \mathrm{H}), 3.93(\mathrm{~s}, 3 \mathrm{H}), 3.65(\mathrm{~s}, 3 \mathrm{H}), 3.42(\mathrm{~s}, 3 \mathrm{H})$.

${ }^{13}$ C-NMR $\left(100 \mathrm{MHz}, \mathrm{CDCl}_{3}\right) \delta=168.8\left(\mathrm{C}_{\mathrm{q}}\right), 166.2\left(\mathrm{C}_{\mathrm{q}}\right), 160.5\left(\mathrm{C}_{\mathrm{q}}\right), 134.5\left(\mathrm{C}_{\mathrm{q}}\right), 129.6(\mathrm{CH}), 119.3$ $(\mathrm{CH}), 119.1(\mathrm{CH}), 118.1\left(\mathrm{C}_{\mathrm{q}}\right), 61.4\left(\mathrm{CH}_{3}\right), 52.4\left(\mathrm{CH}_{3}\right), 33.8\left(\mathrm{CH}_{3}\right)$.

IR (ATR): 3055, 2987, 1722, 1594, 1264, 1098, 990, $732 \mathrm{~cm}^{-1}$.

MS (ESI) $m / z$ (relative intensity): $501(30)[2 \mathrm{M}+\mathrm{Na}]^{+}, 262(30)[\mathrm{M}+\mathrm{H}]^{+}, 240(100)[\mathrm{M}+\mathrm{H}]^{+}$.

HR-MS (ESI) $m / z$ calc. for $\mathrm{C}_{11} \mathrm{H}_{14} \mathrm{NO}_{5}{ }^{+}[\mathrm{M}+\mathrm{H}]^{+} 240.0866$, found 240.0868 .

\section{2-Hydroxy-4-iodo- $N$-methoxy- $N$-methylbenzamide (1060)}<smiles>CON(C)C(=O)c1ccc(I)cc1O</smiles> 
The general procedure $\mathbf{G}(15 \mathrm{~h})$ was followed using 4-iodo- $N$-methoxy- $N$-methylbenzamide 1960 (146 mg, $0.50 \mathrm{mmol}$ ). Purification by column chromatography on silica gel ( $n$ hexane/ethyl acetate: 5/1) yielded $1060(93.7 \mathrm{mg}, 61 \%)$ as a yellow oil.

${ }^{1}$ H-NMR $\left(300 \mathrm{MHz}, \mathrm{CDCl}_{3}\right) \delta=11.42(\mathrm{~s}, 1 \mathrm{H}), 7.71(\mathrm{~d}, J=8.6 \mathrm{~Hz}, 1 \mathrm{H}), 7.42(\mathrm{~d}, J=1.8 \mathrm{~Hz}, 1 \mathrm{H})$, $7.21(\mathrm{dd}, J=8.6,1.8 \mathrm{~Hz}, 1 \mathrm{H}), 3.66(\mathrm{~s}, 3 \mathrm{H}), 3.41(\mathrm{~s}, 3 \mathrm{H})$.

${ }^{13}$ C-NMR $\left(100 \mathrm{MHz}, \mathrm{CDCl}_{3}\right) \delta=169.2\left(\mathrm{C}_{\mathrm{q}}\right), 161.4\left(\mathrm{C}_{\mathrm{q}}\right), 130.4(\mathrm{CH}), 127.8(\mathrm{CH}), 127.3(\mathrm{CH}), 113.6$ $\left(\mathrm{C}_{\mathrm{q}}\right), 100.3\left(\mathrm{C}_{\mathrm{q}}\right), 61.3\left(\mathrm{CH}_{3}\right), 33.8\left(\mathrm{CH}_{3}\right)$.

IR (ATR): 3203, 2933, 1631, 1477, 1303, 1007, 877, $751 \mathrm{~cm}^{-1}$.

MS (ESI) $m / z$ (relative intensity): $307(20)[\mathrm{M}+\mathrm{H}]^{+}, 278(100)$.

HR-MS (ESI) $m / z$ calc. for $\mathrm{C}_{9} \mathrm{H}_{11} \mathrm{INO}_{3}{ }^{+}[\mathrm{M}+\mathrm{H}]^{+} 307.9778$, found 307.9784 .

The analytical data are in accordance with those previously reported in the literature. ${ }^{[176]}$

\section{4-Acetyl-2-hydroxy- $N$-methoxy- $N$-methylbenzamide (106q)}<smiles>CC(=O)c1ccc(C(=O)N(C)C)c(O)c1</smiles>

The general procedure $\mathbf{G}$ (15 h) was followed using 4 -acetyl- $N$-methoxy- $N$-methylbenzamide $\mathbf{1 9 6 q}$ (104 mg, $0.50 \mathrm{mmol}$ ). Purification by column chromatography on silica gel ( $n$ hexane/ethyl acetate: 5/1) yielded 106q (55.8 $\mathrm{mg}, 50 \%)$ as a colourless liquid.

${ }^{1}$ H-NMR $\left(300 \mathrm{MHz}, \mathrm{CDCl}_{3}\right) \delta=11.08(\mathrm{~s}, 1 \mathrm{H}), 8.04(\mathrm{~d}, J=8.4 \mathrm{~Hz}, 1 \mathrm{H}), 7.53(\mathrm{~d}, J=1.8 \mathrm{~Hz}, 1 \mathrm{H})$, $7.42(\mathrm{dd}, J=8.4,1.8 \mathrm{~Hz}, 1 \mathrm{H}), 3.65(\mathrm{~s}, 3 \mathrm{H}), 3.43(\mathrm{~s}, 3 \mathrm{H}), 2.60(\mathrm{~s}, 3 \mathrm{H})$.

${ }^{13}$ C-NMR $\left(100 \mathrm{MHz}, \mathrm{CDCl}_{3}\right) \delta=197.5\left(\mathrm{C}_{\mathrm{q}}\right), 168.7\left(\mathrm{C}_{\mathrm{q}}\right), 160.8\left(\mathrm{C}_{\mathrm{q}}\right), 140.8\left(\mathrm{C}_{\mathrm{q}}\right), 129.8(\mathrm{CH}), 118.0$ $\left(\mathrm{C}_{\mathrm{q}}\right), 117.9(\mathrm{CH}), 117.7(\mathrm{CH}), 61.4\left(\mathrm{CH}_{3}\right), 33.8\left(\mathrm{CH}_{3}\right), 26.8\left(\mathrm{CH}_{3}\right)$.

IR (ATR): 3204, 2939, 1690, 1518, 1266, 1043, 884, $747 \mathrm{~cm}^{-1}$.

MS (ESI) $m / z$ (relative intensity): $224(30)[\mathrm{M}+\mathrm{H}]^{+}, 194$ (100).

HR-MS (ESI) $m / z$ calc. for $\mathrm{C}_{11} \mathrm{H}_{14} \mathrm{NO}_{4}{ }^{+}[\mathrm{M}+\mathrm{H}]^{+} 224.0917$, found 224.0914.

The analytical data are in accordance with those previously reported in the literature. ${ }^{[176]}$ 


\section{2-Hydroxy- $N$-methoxy- $N, 5$-dimethylbenzamide (106j)}<smiles>CON(C)C(=O)c1cc(C)ccc1O</smiles>

The general procedure $\mathbf{G}(15 \mathrm{~h})$ was followed using $N$-methoxy- $N, 3$-dimethylbenzamide 196j $(89.5$ mg, $0.50 \mathrm{mmol})$. Purification by column chromatography on silica gel (nhexane/ethyl acetate: $5 / 1)$ yielded 106j (52.0 mg, 53\%) and 106j' (2.9 mg, 3\%) as colorless liquids.

${ }^{1} \mathrm{H}-\mathrm{NMR}\left(400 \mathrm{MHz}, \mathrm{CDCl}_{3}\right) \delta=10.76(\mathrm{~s}, 1 \mathrm{H}), 7.69(\mathrm{~d}, J=2.3 \mathrm{~Hz}, 1 \mathrm{H}), 7.16(\mathrm{dd}, J=8.4 \mathrm{~Hz}, 2.3 \mathrm{~Hz}$, $1 \mathrm{H}), 6.86(\mathrm{~d}, J=8.4 \mathrm{~Hz}, 1 \mathrm{H}), 3.62(\mathrm{~s}, 3 \mathrm{H}), 3.37(\mathrm{~s}, 3 \mathrm{H}), 2.25(\mathrm{~s}, 3 \mathrm{H})$.

${ }^{13}$ C-NMR $\left(100 \mathrm{MHz}, \mathrm{CDCl}_{3}\right) \delta=170.0\left(\mathrm{C}_{\mathrm{q}}\right), 158.4\left(\mathrm{C}_{\mathrm{q}}\right), 134.5(\mathrm{CH}), 129.3(\mathrm{CH}), 127.5\left(\mathrm{C}_{\mathrm{q}}\right), 117.6$ $(\mathrm{CH}), 114.2\left(\mathrm{C}_{\mathrm{q}}\right), 61.1\left(\mathrm{CH}_{3}\right), 34.1\left(\mathrm{CH}_{3}\right), 20.6\left(\mathrm{CH}_{3}\right)$.

IR (ATR): 2937, 1633, 1572, 1486, 1423, 1348, 1246, 1179, 974, $822 \mathrm{~cm}^{-1}$.

MS (ESI) $m / z$ (relative intensity): $413(20)[2 \mathrm{M}+\mathrm{Na}]^{+}, 218(40)[\mathrm{M}+\mathrm{Na}]^{+}, 196(100)[\mathrm{M}+\mathrm{H}]^{+}$.

HR-MS (ESI) $m / z$ calc. for $\mathrm{C}_{10} \mathrm{H}_{14} \mathrm{NO}_{3}{ }^{+}[\mathrm{M}+\mathrm{H}]^{+}$196.0968, found 196.0969.

The analytical data are in accordance with those previously reported in the literature. ${ }^{[176]}$

\section{2-Hydroxy- $N$-methoxy- $N, 3-$ dimethylbenzamide (106j')}<smiles>CON(C)C(=O)c1cccc(C)c1O</smiles>

${ }^{1} \mathbf{H}-N M R\left(400 \mathrm{MHz}, \mathrm{CDCl}_{3}\right) \delta=11.28(\mathrm{~s}, 1 \mathrm{H}), 7.75(\mathrm{dd}, J=8.2,1.7 \mathrm{~Hz}, 1 \mathrm{H}), 7.22(\mathrm{dd}, J=7.3,1.7$ Hz, 1H), 6.73 (dd, $J=8.2,7.3 \mathrm{~Hz}, 1 \mathrm{H}), 3.62$ (s, 3H), 3.39 (s, 3H), 2.25 (s, 3H).

${ }^{13}$ C-NMR $\left(100 \mathrm{MHz}, \mathrm{CDCl}_{3}\right) \delta=170.4\left(\mathrm{C}_{\mathrm{q}}\right), 159.2\left(\mathrm{C}_{\mathrm{q}}\right), 134.6(\mathrm{CH}), 127.0(\mathrm{CH}), 126.8\left(\mathrm{C}_{\mathrm{q}}\right), 117.8$ $(\mathrm{CH}), 113.6\left(\mathrm{C}_{\mathrm{q}}\right), 61.2\left(\mathrm{CH}_{3}\right), 34.3\left(\mathrm{CH}_{3}\right), 16.0\left(\mathrm{CH}_{3}\right)$.

IR (ATR): 2962, 1587, 1474, 1401, 1292, 1193, 1052, $747 \mathrm{~cm}^{-1}$.

MS (ESI) $m / z$ (relative intensity): $218(100)[\mathrm{M}+\mathrm{Na}]^{+}, 196(90)[\mathrm{M}+\mathrm{H}]^{+}$.

HR-MS (ESI) $m / z$ calc. for $\mathrm{C}_{10} \mathrm{H}_{14} \mathrm{NO}_{3}{ }^{+}[\mathrm{M}+\mathrm{H}]^{+}$196.0968, found 196.0968.

The analytical data are in accordance with those previously reported in the literature. ${ }^{[176]}$ 


\section{5-Chloro-2-hydroxy- $N$-methoxy- $N$-methylbenzamide (106m)}<smiles>CON(C)C(=O)c1cc(Cl)ccc1O</smiles>

The general procedure $\mathbf{G}$ (15 h) was followed using 3-chloro- $N$-methoxy- $N$-methylbenzamide 196m (99.8 mg, $0.50 \mathrm{mmol})$. Purification by column chromatography ( $n$ hexane/ethyl acetate: $5 / 1$ ) yielded 106m (56.1 $\mathrm{mg}, 52 \%)$ as as yellow solid.

M.p.: $97-99^{\circ} \mathrm{C}$.

${ }^{1}$ H-NMR (400 MHz, $\left.\mathrm{CDCl}_{3}\right) \delta=11.22(\mathrm{~s}, 1 \mathrm{H}), 8.00(\mathrm{~d}, J=3.2 \mathrm{~Hz}, 1 \mathrm{H}), 7.34(\mathrm{dd}, J=9.0,3.2 \mathrm{~Hz}$, 1H), $6.95(\mathrm{~d}, J=9.0 \mathrm{~Hz}, 1 \mathrm{H}), 3.69(\mathrm{~s}, 3 \mathrm{H}), 3.42(\mathrm{~s}, 3 \mathrm{H})$.

${ }^{13}$ C-NMR $\left(100 \mathrm{MHz}, \mathrm{CDCl}_{3}\right) \delta=168.5\left(\mathrm{C}_{\mathrm{q}}\right), 159.7\left(\mathrm{C}_{\mathrm{q}}\right), 133.7(\mathrm{CH}), 129.0(\mathrm{CH}), 123.2\left(\mathrm{C}_{\mathrm{q}}\right), 119.5$ $(\mathrm{CH}), 115.1\left(\mathrm{C}_{\mathrm{q}}\right), 61.4\left(\mathrm{CH}_{3}\right), 33.8\left(\mathrm{CH}_{3}\right)$.

IR (ATR): 2937, 1587, 1468, 1250, 1182, 974, 735, $651 \mathrm{~cm}^{-1}$.

MS (ESI) $m / z$ (relative intensity): $238(30)[\mathrm{M}+\mathrm{Na}]^{+}, 216(100)[\mathrm{M}+\mathrm{H}]^{+}$.

HR-MS (ESI) $m / z$ calc. for $\mathrm{C}_{9} \mathrm{H}_{11}{ }^{35} \mathrm{ClNO}_{3}{ }^{+}[\mathrm{M}+\mathrm{H}]^{+}$216.0422, found 216.0423 .

The analytical data are in accordance with those previously reported in the literature. ${ }^{[176]}$

\section{4,5-Dichloro-2-hydroxy- $N$-methoxy- $N$-methylbenzamide (106f)}<smiles>CN(C)C(=O)c1cc(Cl)c(Cl)cc1O</smiles>

The general procedure $\mathbf{G}(15 \mathrm{~h})$ was followed using 3,4-dichloro- $N$-methoxy- $N$-methylbenzamide $196 f(117 \mathrm{mg}, 0.50 \mathrm{mmol})$. Purification by column chromatography ( $n$ hexane/ethyl acetate: $5 / 1$ ) yielded $\mathbf{1 0 6 f}(96.3 \mathrm{mg}, 77 \%)$ as a white solid.

M.p.: $100-102{ }^{\circ} \mathrm{C}$.

${ }^{1} \mathrm{H}-\mathrm{NMR}\left(300 \mathrm{MHz}, \mathrm{CDCl}_{3}\right) \delta=11.51(\mathrm{~s}, 1 \mathrm{H}), 8.16(\mathrm{~s}, 1 \mathrm{H}), 7.13(\mathrm{~s}, 1 \mathrm{H}), 3.70(\mathrm{~s}, 3 \mathrm{H}), 3.42(\mathrm{~s}, 3 \mathrm{H})$. 
${ }^{13}$ C-NMR $\left(100 \mathrm{MHz}, \mathrm{CDCl}_{3}\right) \delta=167.8\left(\mathrm{C}_{\mathrm{q}}\right), 160.4\left(\mathrm{C}_{\mathrm{q}}\right), 137.6\left(\mathrm{C}_{\mathrm{q}}\right), 130.7(\mathrm{CH}), 121.9\left(\mathrm{C}_{\mathrm{q}}\right), 119.8$ $(\mathrm{CH}), 113.7\left(\mathrm{C}_{\mathrm{q}}\right), 61.5\left(\mathrm{CH}_{3}\right), 33.7\left(\mathrm{CH}_{3}\right)$.

IR (ATR): 2937, 1628, 1457, 1339, 1181, 978, 649, $447 \mathrm{~cm}^{-1}$.

MS (ESI) $m / z$ (relative intensity): $521(10)[2 \mathrm{M}+\mathrm{Na}]^{+}, 272(10)[\mathrm{M}+\mathrm{Na}]^{+}, 250(100)[\mathrm{M}+\mathrm{H}]^{+}$.

HR-MS (ESI) $m / z$ calc. for $\mathrm{C}_{9} \mathrm{H}_{9}{ }^{35} \mathrm{Cl}_{2} \mathrm{NO}_{3}{ }^{+}[\mathrm{M}+\mathrm{H}]^{+} 250.0032$, found 250.0037 .

The analytical data are in accordance with those previously reported in the literature. ${ }^{[176]}$

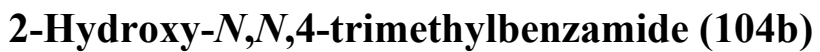<smiles>Cc1ccc(C(=O)N(C)C)c(O)c1</smiles>

The general procedure $\mathbf{G}(15 \mathrm{~h})$ was followed using $N, N, 4$-trimethylbenzamide $\mathbf{1 0 3 b}(81.6 \mathrm{mg}, 0.50$ mmol). Purification by column chromatography (nhexane/ethyl acetate: $3 / 1)$ yielded 104b (81.6 mg, 91\%) as a yellow oil.

The general procedure $\mathbf{G}(15 \mathrm{~h})$ was followed using $N, N, 4$-trimethylbenzamide $\mathbf{1 0 3 b}(81.6 \mathrm{mg}, 0.50$ $\mathrm{mmol})$ with $\left[\mathrm{Rh}(\mathrm{OAc})_{2}\right]_{2}(2.2 \mathrm{mg}, 0.005 \mathrm{mmol}, 1.0 \mathrm{~mol} \%)$. Purification by column chromatography ( $n$ hexane/EtOAc: $3 / 1$ ) yielded $\mathbf{1 0 4 b}(59.2 \mathrm{mg}, 66 \%)$ as a yellow oil.

The general procedure $\mathbf{G}(15 \mathrm{~h})$ was followed using $N, N, 4$-trimethylbenzamide $\mathbf{1 0 3 b}(81.6 \mathrm{mg}, 0.50$ mmol) with $\left[\mathrm{Rh}(\mathrm{OAc})_{2}\right]_{2} \quad(1.1 \mathrm{mg}, 0.0025 \mathrm{mmol}, 0.5 \mathrm{~mol} \%)$. Purification by column chromatography (nhexane/EtOAc: $3 / 1)$ yielded 104b $(53.8 \mathrm{mg}, 60 \%)$ as a yellow oil.

${ }^{1}$ H-NMR $\left(300 \mathrm{MHz}, \mathrm{CDCl}_{3}\right) \delta=9.96(\mathrm{~s}, 1 \mathrm{H}), 7.22(\mathrm{~d}, J=8.0 \mathrm{~Hz}, 1 \mathrm{H}), 6.8(\mathrm{~s}, 1 \mathrm{H}), 6.67(\mathrm{~d}, J=8.0$ $\mathrm{Hz}, 1 \mathrm{H}), 3.16$ (s, 6H), 2.33 (s, 3H).

${ }^{13}$ C-NMR $\left(100 \mathrm{MHz}, \mathrm{CDCl}_{3}\right) \delta=172.1\left(\mathrm{C}_{\mathrm{q}}\right), 159.5\left(\mathrm{C}_{\mathrm{q}}\right), 143.5\left(\mathrm{C}_{\mathrm{q}}\right), 128.5(\mathrm{CH}), 119.2(\mathrm{CH}), 118.2$ $(\mathrm{CH}), 114.1\left(\mathrm{C}_{\mathrm{q}}\right), 38.5\left(\mathrm{CH}_{3}\right), 21.6\left(\mathrm{CH}_{3}\right)$.

IR (ATR): 3156, 2930, 1621, 1398, 1265, 1127, 954, $812 \mathrm{~cm}^{-1}$.

MS (ESI) $m / z$ (relative intensity): $381(10)[2 \mathrm{M}+\mathrm{Na}]^{+}, 202(20)[\mathrm{M}+\mathrm{Na}]^{+}, 180(100)[\mathrm{M}+\mathrm{H}]^{+}$.

HR-MS (ESI) $m / z$ calc. for $\mathrm{C}_{10} \mathrm{H}_{14} \mathrm{NO}_{2}{ }^{+}[\mathrm{M}+\mathrm{H}]^{+} 180.1019$, found 180.1026 .

The analytical data are in accordance with those previously reported in the literature. ${ }^{[176]}$ 


\section{2-Hydroxy-4-methoxy- $N, N$-dimethylbenzamide (104h)}<smiles>COc1ccc(C(=O)N(C)C)c(O)c1</smiles>

The general procedure $\mathbf{G}(15 \mathrm{~h})$ was followed using 4-methoxy- $N, N$-dimethylbenzamide $\mathbf{1 0 3 h}(89.6$ mg, $0.50 \mathrm{mmol}$ ). Purification by column chromatography (nhexane/ethyl acetate: $3 / 1$ ) yielded $\mathbf{1 0 4 h}$ (75.2 $\mathrm{mg}, 77 \%)$ as a yellow oil.

${ }^{1}$ H-NMR $\left(400 \mathrm{MHz}, \mathrm{CDCl}_{3}\right) \delta=9.51(\mathrm{br}, 1 \mathrm{H}), 7.26(\mathrm{~d}, J=8.8 \mathrm{~Hz}, 1 \mathrm{H}), 6.50(\mathrm{~s}, 1 \mathrm{H}), 6.40(\mathrm{~d}, J=$ $8.8 \mathrm{~Hz}, 1 \mathrm{H}), 3.80(\mathrm{~s}, 3 \mathrm{H}), 3.15(\mathrm{~s}, 6 \mathrm{H})$.

${ }^{13}$ C-NMR $\left(100 \mathrm{MHz}, \mathrm{CDCl}_{3}\right) \delta=172.3\left(\mathrm{C}_{\mathrm{q}}\right), 163.1\left(\mathrm{C}_{\mathrm{q}}\right), 162.0\left(\mathrm{C}_{\mathrm{q}}\right), 130.1(\mathrm{CH}), 109.3\left(\mathrm{C}_{\mathrm{q}}\right), 105.6$ $(\mathrm{CH}), 101.8(\mathrm{CH}), 55.3\left(\mathrm{CH}_{3}\right), 38.6\left(\mathrm{CH}_{3}\right)$.

IR (ATR): 3022, 2925, 1626, 1390, 1268, 1078, 743, $642 \mathrm{~cm}^{-1}$.

MS (ESI) $m / z$ (relative intensity): $413(10)[2 \mathrm{M}+\mathrm{Na}]^{+}, 218(30)[\mathrm{M}+\mathrm{Na}]^{+}, 196(100)[\mathrm{M}+\mathrm{H}]^{+}$.

HR-MS (ESI) $m / z$ calc. for $\mathrm{C}_{10} \mathrm{H}_{14} \mathrm{NO}_{3}{ }^{+}[\mathrm{M}+\mathrm{H}]^{+}$196.0974, found 196.0979.

The analytical data are in accordance with those previously reported in the literature. ${ }^{[190]}$

\section{4-Chloro-2-hydroxy- $N, N$-dimethylbenzamide (104i)}<smiles>CNC(=O)c1ccc(Cl)cc1O</smiles>

The general procedure $\mathbf{G}(15 \mathrm{~h})$ was followed using 4-chloro- $N, N$-dimethylbenzamide $\mathbf{1 0 3 i}$ (91.8 mg, $0.50 \mathrm{mmol}$ ). Purification by column chromatography (nhexane/ethyl acetate: $3 / 1$ ) yielded 104i (92.8 $\mathrm{mg}, 93 \%)$ as a yellow oil.

${ }^{1} \mathrm{H}-\mathrm{NMR}\left(400 \mathrm{MHz}, \mathrm{CDCl}_{3}\right) \delta=7.26(\mathrm{~d}, J=8.5 \mathrm{~Hz}, 1 \mathrm{H}), 7.02(\mathrm{~s}, 1 \mathrm{H}), 6.85(\mathrm{~d}, J=8.5 \mathrm{~Hz}, 1 \mathrm{H})$, $3.17(\mathrm{~s}, 6 \mathrm{H})$

${ }^{13}$ C-NMR $\left(100 \mathrm{MHz}, \mathrm{CDCl}_{3}\right) \delta=171.2\left(\mathrm{C}_{\mathrm{q}}\right), 160.2\left(\mathrm{C}_{\mathrm{q}}\right), 138.1\left(\mathrm{C}_{\mathrm{q}}\right), 129.5(\mathrm{CH}), 118.7(\mathrm{CH}), 118.2$ $(\mathrm{CH}), 115.5\left(\mathrm{C}_{\mathrm{q}}\right), 38.4\left(\mathrm{CH}_{3}\right)$.

IR (ATR): 3093, 2936, 1580, 1398, 1254, 1094, 926, $734 \mathrm{~cm}^{-1}$.

MS (ESI) $m / z$ (relative intensity): $421(10)[2 \mathrm{M}+\mathrm{Na}]^{+}, 222(40)[\mathrm{M}+\mathrm{Na}]^{+}, 200(100)[\mathrm{M}+\mathrm{H}]^{+}$. 
HR-MS (ESI) $m / z$ calc. for $\mathrm{C}_{9} \mathrm{H}_{11}{ }^{35} \mathrm{ClNO}_{2}{ }^{+}[\mathrm{M}+\mathrm{H}]^{+}$200.0473, found 200.0475 .

\section{2-Hydroxy- $N, N, 5$-trimethylbenzamide (104k)}<smiles>Cc1ccc(O)c(C(=O)N(C)C)c1</smiles>

The general procedure $\mathbf{G}(15 \mathrm{~h})$ was followed using $N, N, 3$-trimethylbenzamide $\mathbf{1 0 3 k}(81.6 \mathrm{mg}, 0.50$ mmol). Purification by column chromatography (nhexane/ethyl acetate: 3/1) yielded 104k (68.1 mg, $76 \%$ ) and $104 \mathrm{k}^{\prime}(4.5 \mathrm{mg}, 5 \%)$ as yellow liquids.

${ }^{1}$ H-NMR (300 MHz, $\left.\mathrm{CDCl}_{3}\right) \delta=9.50(\mathrm{br}, 1 \mathrm{H}), 7.17-7.06(\mathrm{~m}, 2 \mathrm{H}), 6.89(\mathrm{~d}, J=8.2 \mathrm{~Hz}, 1 \mathrm{H}), 3.16(\mathrm{~s}$, $6 \mathrm{H}), 2.28(\mathrm{~s}, 3 \mathrm{H})$.

${ }^{13}$ C-NMR $\left(100 \mathrm{MHz}, \mathrm{CDCl}_{3}\right) \delta=171.9\left(\mathrm{C}_{\mathrm{q}}\right), 156.6\left(\mathrm{C}_{\mathrm{q}}\right), 133.2(\mathrm{CH}), 128.6(\mathrm{CH}), 127.5\left(\mathrm{C}_{\mathrm{q}}\right), 117.6$ $(\mathrm{CH}), 117.2\left(\mathrm{C}_{\mathrm{q}}\right), 38.3\left(\mathrm{CH}_{3}\right), 20.5\left(\mathrm{CH}_{3}\right)$.

IR (ATR): 3161, 2925, 1589, 1492, 1399, 1265, 1172, $734 \mathrm{~cm}^{-1}$.

MS (ESI) $m / z$ (relative intensity): $381(30)[2 \mathrm{M}+\mathrm{Na}]^{+}, 202(50)[\mathrm{M}+\mathrm{Na}]^{+}, 180(100)[\mathrm{M}+\mathrm{H}]^{+}$.

HR-MS (ESI) $m / z$ calc. for $\mathrm{C}_{10} \mathrm{H}_{14} \mathrm{NO}_{2}{ }^{+}[\mathrm{M}+\mathrm{H}]^{+} 180.1019$, found 180.1023 .

\section{2-Hydroxy- $N, N, 3$-trimethylbenzamide (104k')}<smiles>CNC(=O)c1cccc(C)c1O</smiles>

${ }^{1}$ H-NMR $\left(300 \mathrm{MHz}, \mathrm{CDCl}_{3}\right) \delta=10.13(\mathrm{~s}, 1 \mathrm{H}), 7.25-7.13(\mathrm{~m}, 2 \mathrm{H}), 6.77(\mathrm{t}, J=7.6 \mathrm{~Hz}, 1 \mathrm{H}), 3.18(\mathrm{~s}$, $6 \mathrm{H}), 2.29(\mathrm{~s}, 3 \mathrm{H})$.

${ }^{13}$ C-NMR $\left(100 \mathrm{MHz}, \mathrm{CDCl}_{3}\right) \delta=172.5\left(\mathrm{C}_{\mathrm{q}}\right), 157.6\left(\mathrm{C}_{\mathrm{q}}\right), 133.5(\mathrm{CH}), 127.0\left(\mathrm{C}_{\mathrm{q}}\right), 126.2(\mathrm{CH}), 117.6$ $(\mathrm{CH}), 116.2\left(\mathrm{C}_{\mathrm{q}}\right), 16.0\left(\mathrm{CH}_{3}\right)$.

IR (ATR): 2929, 1602, 1502, 1410, 1253, 1115, 759, $691 \mathrm{~cm}^{-1}$.

MS (ESI) $m / z$ (relative intensity): $381(20)[2 \mathrm{M}+\mathrm{Na}]^{+}, 202(50)[\mathrm{M}+\mathrm{Na}]^{+}, 180(100)[\mathrm{M}+\mathrm{H}]^{+}$.

HR-MS (ESI) $m / z$ calc. for $\mathrm{C}_{10} \mathrm{H}_{14} \mathrm{NO}_{2}{ }^{+}[\mathrm{M}+\mathrm{H}]^{+} 180.1019$, found 180.1019 . 
The analytical data are in accordance with those previously reported in the literature. ${ }^{[191]}$

\section{5-Bromo- $N, N$-diethyl-2-hydroxybenzamide (104n)}<smiles>CCNC(=O)c1cc(Br)ccc1O</smiles>

The general procedure $\mathbf{G}$ (16 h) was followed using 3-bromo- $N, N$-diethylbenzamide 103n (128 mg, $0.50 \mathrm{mmol})$. Purification by column chromatography on silica gel ( $n$ hexane/ethyl acetate: $3 / 1 \rightarrow 2 / 1)$ yielded 104n (117 $\mathrm{mg}, 66 \%)$ as a white solid.

M.p.: $151-153^{\circ} \mathrm{C}$.

${ }^{1}$ H-NMR $\left(400 \mathrm{MHz}, \mathrm{CDCl}_{3}\right) \delta=9.59(\mathrm{~s}, 1 \mathrm{H}), 7.38-7.31(\mathrm{~m}, 2 \mathrm{H}), 6.83(\mathrm{~d}, J=8.3 \mathrm{~Hz}, 1 \mathrm{H}), 3.47$ (q, $J$ $=7.1 \mathrm{~Hz}, 4 \mathrm{H}), 1.24(\mathrm{t}, J=7.1 \mathrm{~Hz}, 6 \mathrm{H})$.

${ }^{13}$ C-NMR $\left(100 \mathrm{MHz}, \mathrm{CDCl}_{3}\right) \delta=169.9\left(\mathrm{C}_{\mathrm{q}}\right), 157.2\left(\mathrm{C}_{\mathrm{q}}\right), 134.7(\mathrm{CH}), 129.7(\mathrm{CH}), 120.3\left(\mathrm{C}_{\mathrm{q}}\right), 119.8$ $(\mathrm{CH}), 110.3\left(\mathrm{C}_{\mathrm{q}}\right), 42.2\left(\mathrm{CH}_{2}\right), 13.3\left(\mathrm{CH}_{3}\right)$.

IR (ATR): 2984, 2935, 1583, 1444, 1404, 1357, 1280, 1234, 1096, $822 \mathrm{~cm}^{-1}$.

MS (ESI) $m / z$ (relative intensity): $567(50)[2 \mathrm{M}+\mathrm{Na}]^{+}, 294(80)[\mathrm{M}+\mathrm{Na}]^{+}, 272(100)[\mathrm{M}+\mathrm{H}]^{+}$.

HR-MS (ESI) $m / z$ calc. for $\mathrm{C}_{11} \mathrm{H}_{15} \mathrm{BrNO}_{2}{ }^{+}[\mathrm{M}+\mathrm{H}]^{+} 272.0281$, found 272.0285.

\section{1-(2-Hydroxy-4-methylphenyl)ethan-1-one (197n)}<smiles>CC(=O)c1ccc(C)cc1O</smiles>

The general procedure $\mathbf{H}$ was followed using 4'-methyl-acetophenone $77 \mathbf{n}(67.1 \mathrm{mg}, 0.50 \mathrm{mmol})$. Purification by column chromatography (nhexane/ethyl acetate: $200 / 1)$ yielded 197n (39.8 mg, 53\%) as a colourless liquid.

${ }^{1}$ H-NMR $\left(300 \mathrm{MHz} \mathrm{CDCl}_{3}\right) \delta=12.30(\mathrm{~s}, 1 \mathrm{H}), 7.63(\mathrm{~d}, J=8.1 \mathrm{~Hz}, 1 \mathrm{H}), 6.80(\mathrm{~s}, 1 \mathrm{H}), 6.73(\mathrm{~d}, J=$ $8.1 \mathrm{~Hz}, 1 \mathrm{H}), 2.61(\mathrm{~s}, 3 \mathrm{H}), 2.37(\mathrm{~s}, 3 \mathrm{H})$. 
${ }^{13}$ C-NMR $\left(100 \mathrm{MHz}, \mathrm{CDCl}_{3}\right) \delta=203.9\left(\mathrm{C}_{\mathrm{q}}\right), 162.5\left(\mathrm{C}_{\mathrm{q}}\right), 148.1\left(\mathrm{C}_{\mathrm{q}}\right), 130.6(\mathrm{CH}), 120.2(\mathrm{CH}), 118.4$ $(\mathrm{CH}), 117.6\left(\mathrm{C}_{\mathrm{q}}\right), 265\left(\mathrm{CH}_{3}\right), 22.0\left(\mathrm{CH}_{3}\right)$.

IR (ATR): 2923, 1635, 1366, 1224, 1149, 977, 792, $561 \mathrm{~cm}^{-1}$.

MS (ESI) $m / z$ (relative intensity): $173(10)[\mathrm{M}+\mathrm{Na}]^{+}, 151(100)[\mathrm{M}+\mathrm{H}]^{+}$.

HR-MS (ESI) $m / z$ calc. for $\mathrm{C}_{9} \mathrm{H}_{11} \mathrm{O}_{2}{ }^{+}[\mathrm{M}+\mathrm{H}]^{+}$151.0754, found 151.0756.

The analytical data are in accordance with those previously reported in the literature. ${ }^{[192]}$

\subsubsection{Competition Experiment}

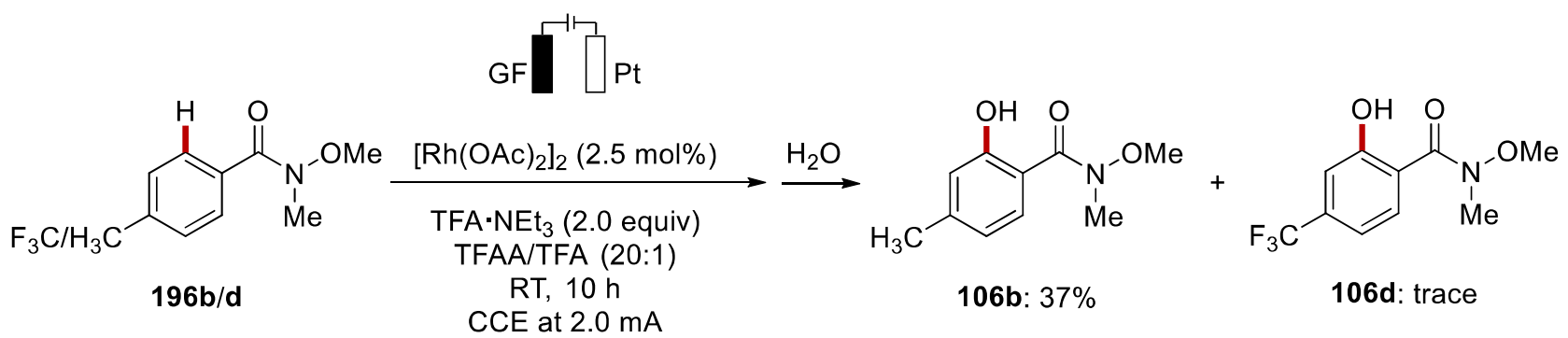

To an undivided cell equipped with graphite felt anode $(10 \mathrm{~mm} \times 10 \mathrm{~mm} \times 6 \mathrm{~mm})$ and platinum cathode $(10 \mathrm{~mm} \times 15 \mathrm{~mm} \times 0.125 \mathrm{~mm}), \mathbf{1 9 6 b}(44.8 \mathrm{mg}, 0.25 \mathrm{mmol}), \mathbf{1 9 6 d}(58.5 \mathrm{mg}, 0.25 \mathrm{mmol})$, $\left[\mathrm{Rh}(\mathrm{OAc})_{2}\right]_{2}(5.5 \mathrm{mg}, 0.0125 \mathrm{mmol}, 2.5 \mathrm{~mol} \%), \mathrm{TFA} \cdot \mathrm{NEt}_{3}(215 \mathrm{mg}, 1.0 \mathrm{mmol}), \mathrm{TFA}(0.15 \mathrm{~mL})$, and TFAA $(3.0 \mathrm{~mL})$ were added. The electrolysis was performed at $2.0 \mathrm{~mA}$ at ambient temperature for 10 h. After completion, the reaction mixture was transferred into a separatory funnel and the electrodes were rinsed with EtOAc $(10 \mathrm{~mL})$. A saturated aqueous $\mathrm{NaHCO}_{3}$ solution $(50 \mathrm{~mL})$ was added slowly, and the mixture was extracted with ethyl acetate $(20 \mathrm{~mL} \times 3)$. The combined organic layers were dried over $\mathrm{Na}_{2} \mathrm{SO}_{4}$, filtered, and concentrated under vacuum. The crude reaction mixture was purified by silica gel column chromatography ( $n$ hexane/ethyl acetate: $10 / 1 \rightarrow 5 / 1)$ yielding $\mathbf{1 0 6}$ b $(31.0$ mg, 37\%) as a colourless solid. 106d was obtained only in trace amounts.

\subsubsection{H/D Exchange Experiment}




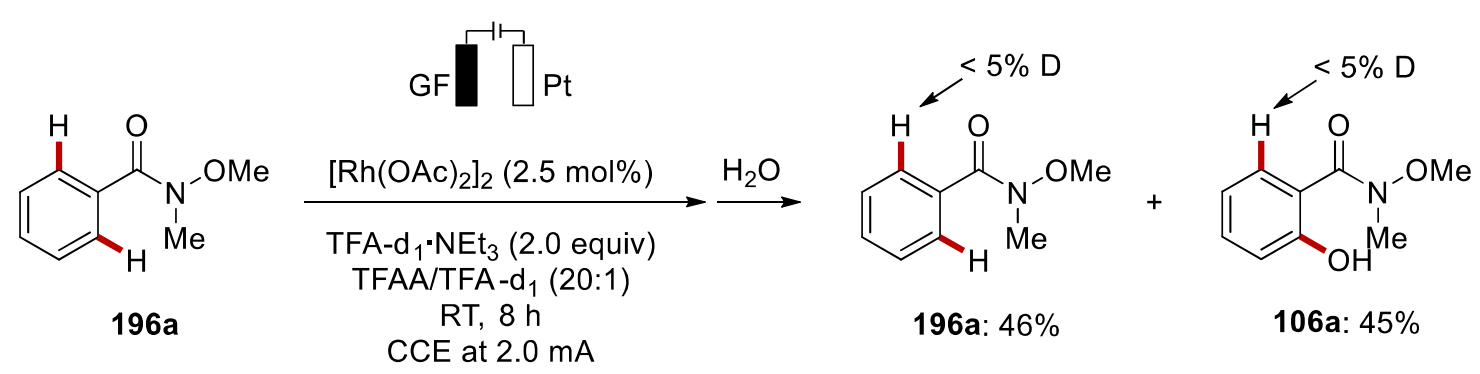

The electrolysis was carried out in an undivided cell $(10 \mathrm{~mL})$ equipped with a graphite felt anode $(10$ $\mathrm{mm} \times 10 \mathrm{~mm} \times 6 \mathrm{~mm})$ and a platinum cathode $(10 \mathrm{~mm} \times 15 \mathrm{~mm} \times 0.125 \mathrm{~mm}) .\left[\mathrm{Rh}(\mathrm{OAc})_{2}\right]_{2}(5.5 \mathrm{mg}$, $0.0125 \mathrm{mmol}, 2.5 \mathrm{~mol} \%)$, [D]1-TFA $\mathrm{NEt}_{3}(215 \mathrm{mg}, 1.0 \mathrm{mmol}),[\mathrm{D}]_{1}-\mathrm{TFA}(0.15 \mathrm{~mL})$, Weinreb amide 196a $(82.5 \mathrm{mg}, 0.50 \mathrm{mmol})$ and TFAA $(3.0 \mathrm{~mL})$ were successively added. The electrolysis was performed at $2.0 \mathrm{~mA}$ at ambient temperature for $8 \mathrm{~h}\left(2.2-2.5 \mathrm{~F} \mathrm{~mol}^{-1}\right)$. After completion, the reaction mixture was transferred into a separatory funnel and the electrodes were rinsed with EtOAc $(10 \mathrm{~mL})$. A saturated aqueous $\mathrm{NaHCO}_{3}$ solution $(50 \mathrm{~mL})$ was added slowly, and the mixture was extracted with ethyl acetate $(20 \mathrm{~mL} \times 3)$. The combined organic layers were dried over $\mathrm{Na}_{2} \mathrm{SO}_{4}$ and concentrated. The crude reaction mixture was purified by silica gel column chromatography ( $n$ hexane/ethyl acetate: $5 / 1 \rightarrow 4 / 1)$ yielded 196a (38.0 mg, 46\%) and 106a (41.0 mg, 45\%) without obvious H/D exchange (Figure 5.6.1-2). 


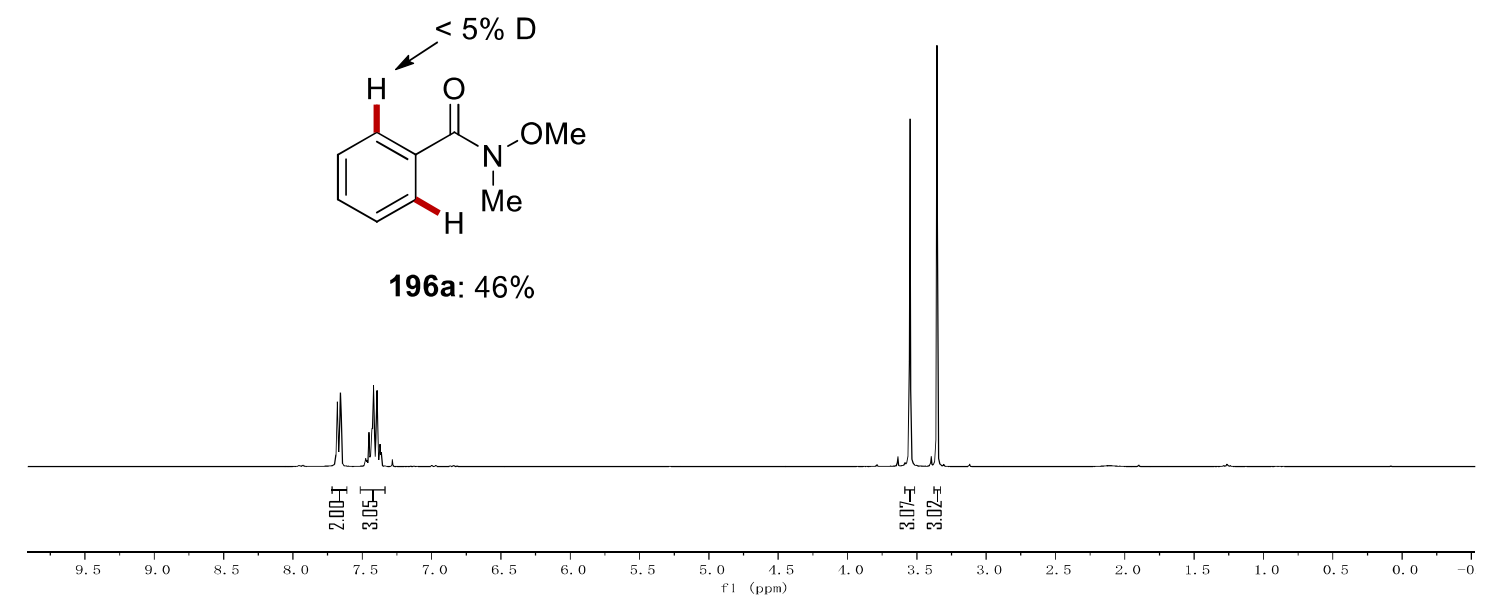

Figure 5.6.1 ${ }^{1} \mathrm{H}-\mathrm{NMR}$ of $[\mathrm{D}]_{\mathrm{n}}-\mathbf{1 9 6 a}$ from the deuteration study.

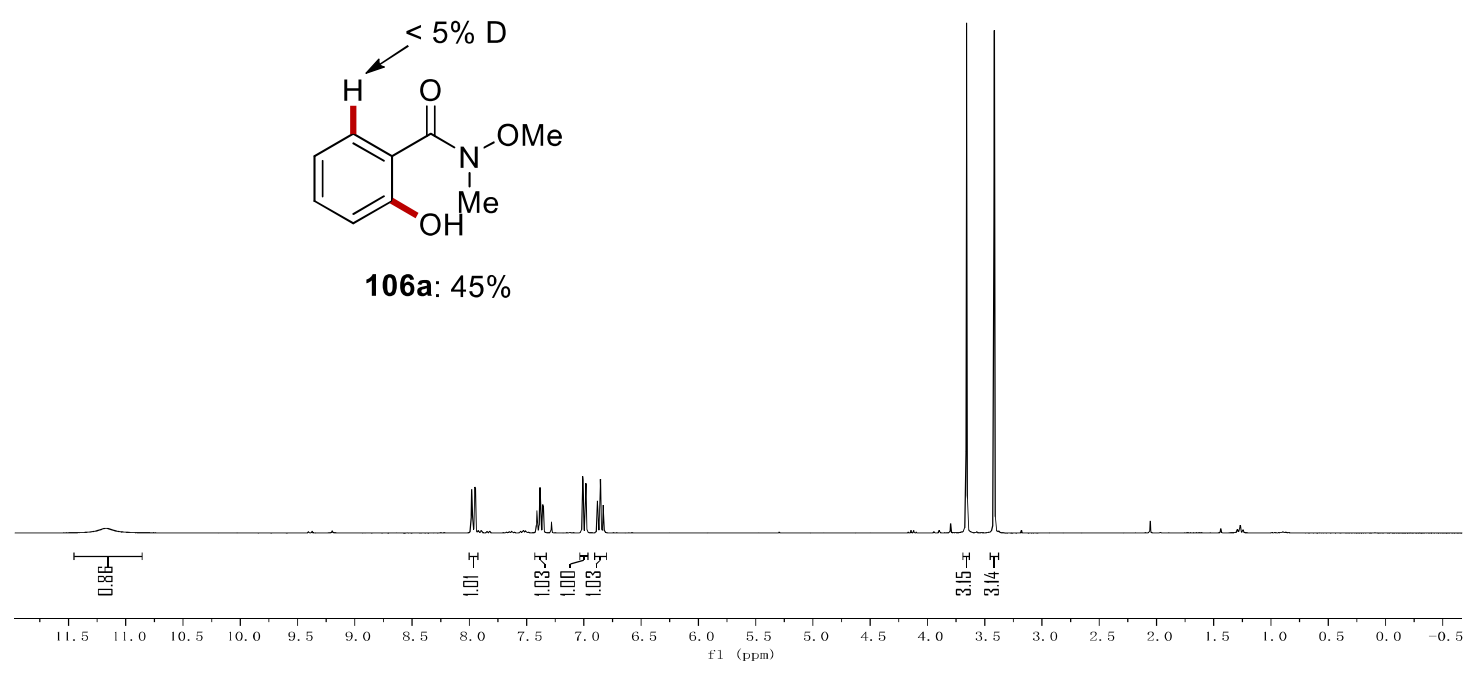

Figure 5.6.2 ${ }^{1} \mathrm{H}-\mathrm{NMR}$ of $[\mathrm{D}]_{\mathrm{n}} \mathbf{- 1 0 6 a}$ from the deuteration study. 


\subsubsection{Reactions with Different Catalysts}

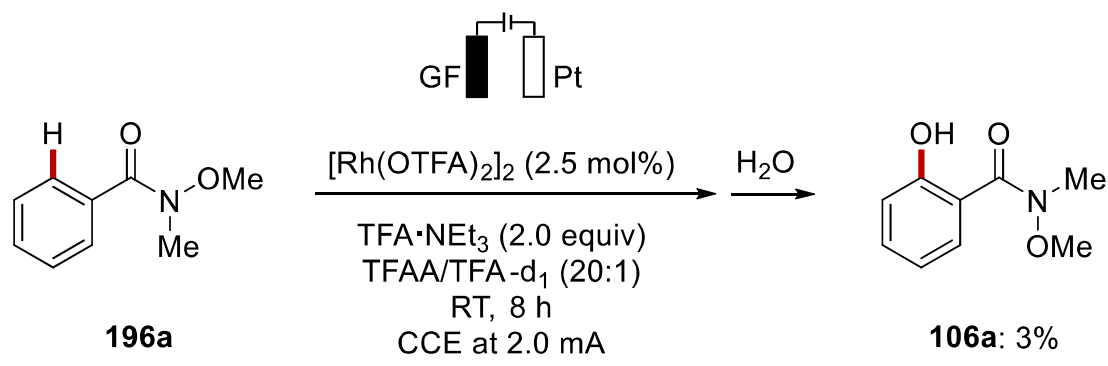

The electrolysis was carried out in an undivided cell $(10 \mathrm{~mL})$ equipped with a graphite felt anode $(10$ $\mathrm{mm} \times 10 \mathrm{~mm} \times 6 \mathrm{~mm})$ and a platinum cathode $(10 \mathrm{~mm} \times 15 \mathrm{~mm} \times 0.125 \mathrm{~mm}) .\left[\mathrm{Rh}(\mathrm{OTFA})_{2}\right]_{2}(8.2$ $\mathrm{mg}, 0.0125 \mathrm{mmol}, 2.5 \mathrm{~mol} \%)$, TFA $\cdot \mathrm{NEt}_{3}(215 \mathrm{mg}, 1.0 \mathrm{mmol})$, TFA $(0.15 \mathrm{~mL})$, Weinreb amide 196a (82.5 mg, $0.50 \mathrm{mmol})$ and TFAA $(3.0 \mathrm{~mL})$ were successively added. The electrolysis was performed at $2.0 \mathrm{~mA}$ at ambient temperature for $16 \mathrm{~h}$. After completion, the reaction mixture was transferred into a separatory funnel and the electrodes were rinsed with EtOAc $(10 \mathrm{~mL})$. A saturated aqueous $\mathrm{NaHCO}_{3}$ solution $(50 \mathrm{~mL})$ was added slowly, and the mixture was extracted with ethyl acetate $(20$ $\mathrm{mL} \times 3$ ). The combined organic layers were dried over $\mathrm{Na}_{2} \mathrm{SO}_{4}$, filtered, and concentrated. The crude reaction mixture was purified by silica gel column chromatography ( $n$ hexane/ethyl acetate: $5 / 1 \rightarrow 4 / 1$ ) yielding 106a (2.6 mg, 3\%) as a colourless oil.

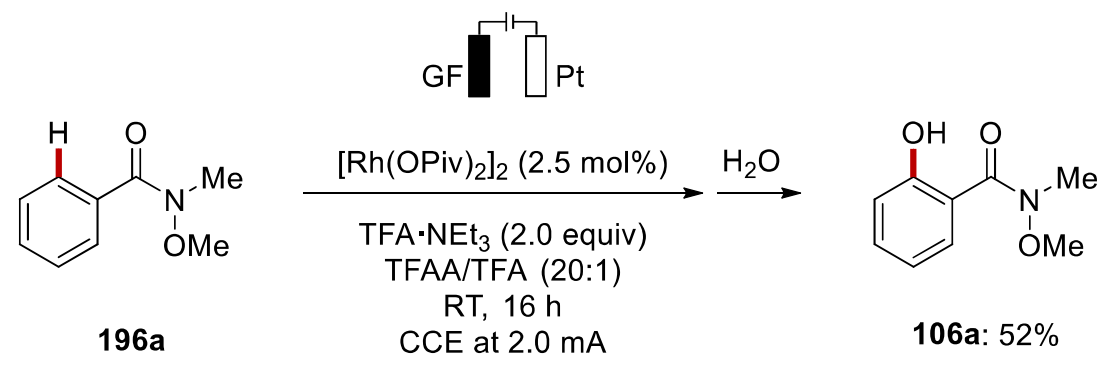

The electrolysis was carried out in an undivided cell $(10 \mathrm{~mL})$ equipped with a graphite felt anode $(10$ $\mathrm{mm} \times 10 \mathrm{~mm} \times 6 \mathrm{~mm})$ and a platinum cathode $(10 \mathrm{~mm} \times 15 \mathrm{~mm} \times 0.125 \mathrm{~mm}) .\left[\mathrm{Rh}(\mathrm{OPiv})_{2}\right]_{2}(7.6 \mathrm{mg}$, $0.0125 \mathrm{mmol}, 2.5 \mathrm{~mol} \%)$, TFA $\cdot \mathrm{NEt}_{3}(215 \mathrm{mg}, 1.0 \mathrm{mmol})$, TFA $(0.15 \mathrm{~mL})$, Weinreb amide 196a (82.5 $\mathrm{mg}, 0.50 \mathrm{mmol})$ and TFAA $(3.0 \mathrm{~mL})$ were successively added. The electrolysis was performed 
at $2.0 \mathrm{~mA}$ at ambient temperature for $16 \mathrm{~h}$. After completion, the reaction mixture was transferred into a separatory funnel and the electrodes were rinsed with EtOAc $(10 \mathrm{~mL})$. A saturated aqueous $\mathrm{NaHCO}_{3}$ solution $(50 \mathrm{~mL})$ was added slowly, and the mixture was extracted with ethyl acetate (20 $\mathrm{mL} \times 3$ ). The combined organic layers were dried over $\mathrm{Na}_{2} \mathrm{SO}_{4}$, filtered, and concentrated. The crude reaction mixture was purified by silica gel column chromatography ( $n$ hexane/ethyl acetate: $5 / 1 \rightarrow 4 / 1$ ) yielding 106a (47.1 mg, 52\%) as a colourless oil.

\subsubsection{Initial Rate Comparison between $\left[\mathrm{Rh}(\mathrm{OAc})_{2}\right]_{2}$ and $\left[\mathrm{Rh}(\mathrm{OPiv})_{2}\right]_{2}$}

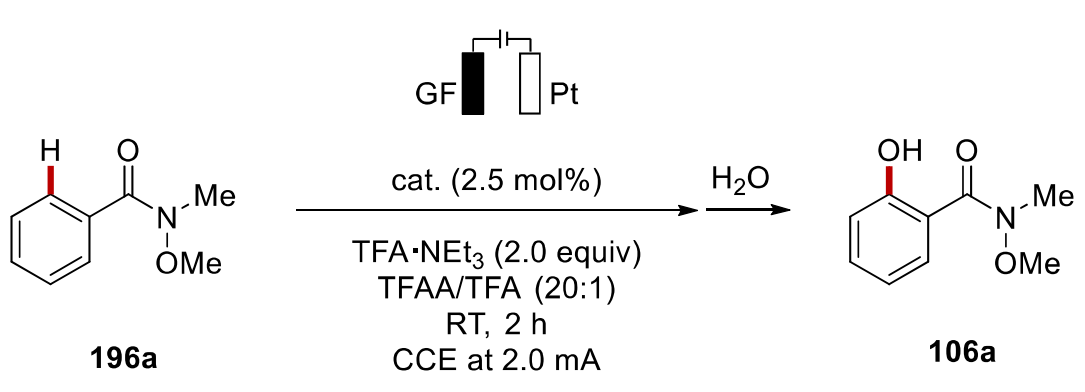

Two parallel electrolyses were carried out in undivided cells $(10 \mathrm{~mL})$, each equipped with graphite felt anode $(10 \mathrm{~mm} \times 10 \mathrm{~mm} \times 6 \mathrm{~mm})$ and platinum cathode $(10 \mathrm{~mm} \times 15 \mathrm{~mm} \times 0.125 \mathrm{~mm})$. $\left[\mathrm{Rh}(\mathrm{OAc})_{2}\right]_{2}(5.5 \mathrm{mg}, 0.0125 \mathrm{mmol}, 2.5 \mathrm{~mol} \%)$ or $\left[\mathrm{Rh}(\mathrm{OPiv})_{2}\right]_{2}(7.6 \mathrm{mg}, 0.0125 \mathrm{mmol}, 2.5 \mathrm{~mol} \%)$ respectevely, TFA $\cdot \mathrm{NEt}_{3}(215 \mathrm{mg}, 1.0 \mathrm{mmol})$, TFA $(0.15 \mathrm{~mL})$, Weinreb amide 196a $(82.5 \mathrm{mg}, 0.50$ mmol), and TFAA (4.0 mL) were successively added. The electrolysis was performed at $2.0 \mathrm{~mA}$ at ambient temperature. In the time range of 30-120 min, aliquots of $0.1 \mathrm{~mL}$ were taken from each reaction mixture every $30 \mathrm{~min}$. To each aliquot was added $0.1 \mathrm{~mL}$ of an internal standard solution ( $0.5 \mathrm{mmol}$ of $\mathrm{CH}_{2} \mathrm{Br}_{2}$ in $4.0 \mathrm{~mL}$ of TFAA), then treated with a saturated aqueous $\mathrm{NaHCO}_{3}(2.0 \mathrm{~mL})$ and extracted with $\mathrm{CH}_{2} \mathrm{Cl}_{2}(3 \times 1.0 \mathrm{~mL})$. After evaporation of the solvents, the crude mixture was analyzed by ${ }^{1} \mathrm{H}-\mathrm{NMR}$ spectroscopy. The determined yields of $\mathbf{1 0 6}$ a were plotted in Figure 5.6.3. 


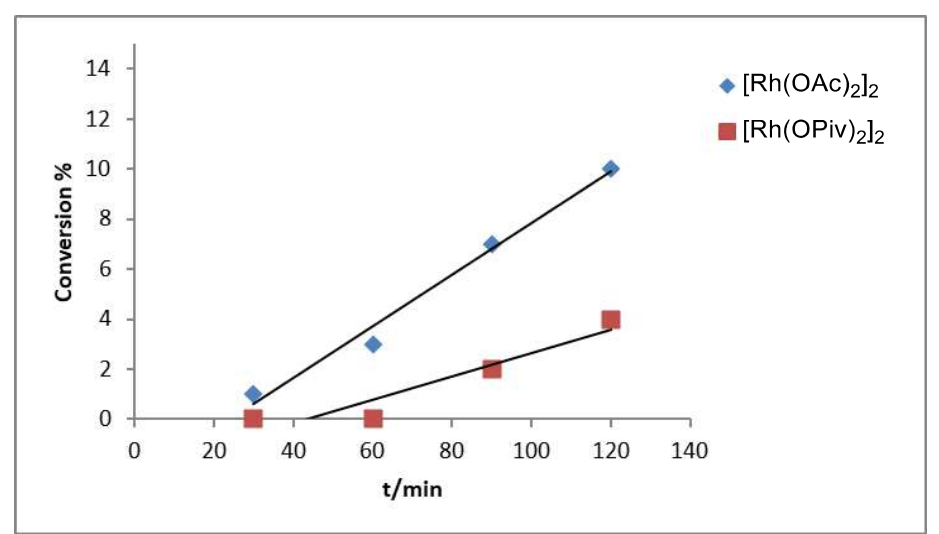

Figure 5.6.3 Reaction profiles of 106a with different catalysts.

\subsubsection{Identification of the Trifluoroacetate Product after C-H Acyloxylation}

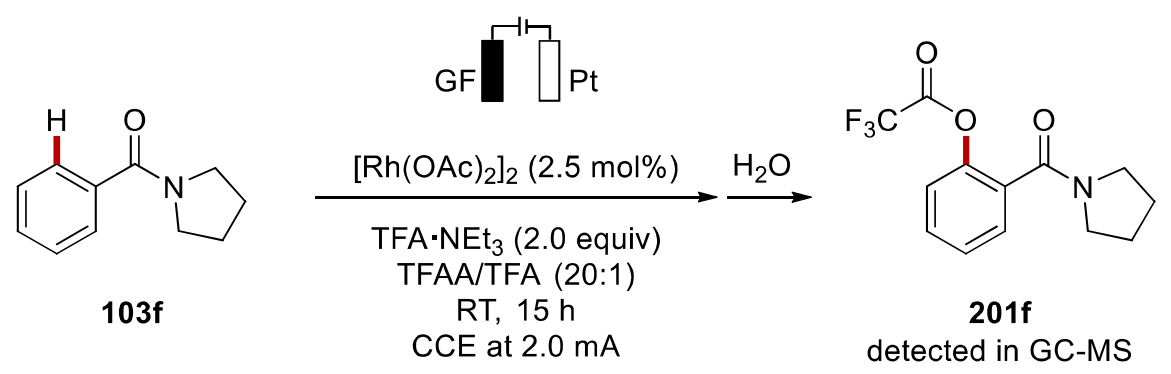

The electrolysis was carried out in an undivided cell $(10 \mathrm{~mL})$ equipped with a graphite felt anode (10 $\mathrm{mm} \times 10 \mathrm{~mm} \times 6 \mathrm{~mm})$ and a platinum cathode $(10 \mathrm{~mm} \times 15 \mathrm{~mm} \times 0.125 \mathrm{~mm}) .\left[\mathrm{Rh}(\mathrm{OAc})_{2}\right]_{2}(5.5 \mathrm{mg}$, $0.0125 \mathrm{mmol}, 2.5 \mathrm{~mol} \%)$, TFA $\cdot \mathrm{NEt}_{3}(215 \mathrm{mg}, 1.0 \mathrm{mmol})$, TFA $(0.15 \mathrm{~mL})$, phenyl(pyrrolidin-1yl)methanone $103 f(87.6 \mathrm{mg}, 0.50 \mathrm{mmol})$ and TFAA $(3.0 \mathrm{~mL})$ were successively added. The electrolysis was performed at $2.0 \mathrm{~mA}$ at ambient temperature for $16 \mathrm{~h}$. The crude reaction mixture was analyzed by GC-MS. As expected, the desired trifluoroacetate ester 201f was detected as the only product after the rhodaelectro-catalyzed $\mathrm{C}-\mathrm{H}$ acyloxylation (Figure 5.6.4). However, attempts to isolate the pure form of the acyloxylated product failed due to the sensitibility to moisture. 


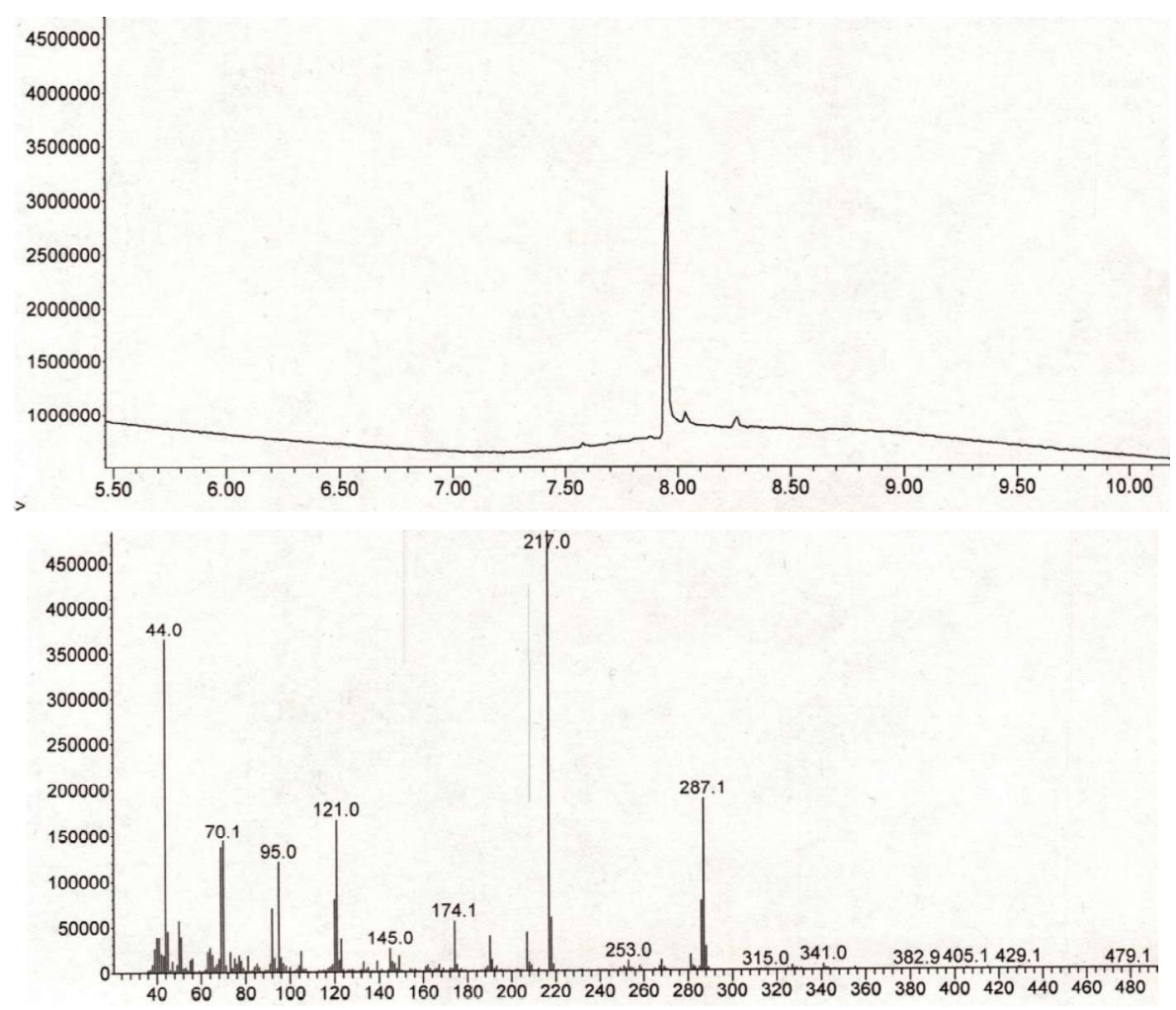

Figure 5.6.4 GC-MS data of the reaction mixture. 
5.7 Manganaelectro-Catalyzed Azine C-H Arylations and C-H Alkylations by Assistance of Weakly Coordinating Amides

\subsubsection{Characterization Data}

N-n-Butyl-3-(4-methoxyphenyl)picolinamide (176aa)<smiles>CCCCNC(=O)c1ncccc1-c1ccc(OC)cc1</smiles>

The general procedure was followed using $172 \mathbf{a}(44.5 \mathrm{mg}, 0.25 \mathrm{mmol})$ and $\mathbf{1 7 5 a}(0.40 \mathrm{~mL}, 1.0 \mathrm{mmol}$, 2.5 $\mathrm{M}$ in THF). Isolation by column chromatography ( $n$ hexane/ethyl acetate: $2 / 1 \rightarrow 1 / 1$ ) yielded 176aa (49.8 $\mathrm{mg}, 70 \%)$ as a white solid.

M. p.: $96-97^{\circ} \mathrm{C}$.

${ }^{1} \mathbf{H}-\mathrm{NMR}\left(300 \mathrm{MHz}, \mathrm{CDCl}_{3}\right) \delta=8.54(\mathrm{dd}, J=4.6,1.7 \mathrm{~Hz}, 1 \mathrm{H}), 7.69(\mathrm{dd}, J=7.8,1.7 \mathrm{~Hz}, 2 \mathrm{H}), 7.43$ $(\mathrm{dd}, J=7.8,4.6 \mathrm{~Hz}, 1 \mathrm{H}), 7.28(\mathrm{~m}, 2 \mathrm{H}), 7.01-6.93(\mathrm{~m}, 2 \mathrm{H}), 3.86(\mathrm{~s}, 3 \mathrm{H}), 3.38(\mathrm{td}, J=7.1,6.0 \mathrm{~Hz}$, $2 \mathrm{H}), 1.64-1.50(\mathrm{~m}, 2 \mathrm{H}), 1.45-1.32(\mathrm{~m}, 2 \mathrm{H}), 0.94(\mathrm{t}, J=7.1 \mathrm{~Hz}, 3 \mathrm{H})$.

${ }^{13}$ C-NMR $\left(125 \mathrm{MHz}, \mathrm{CDCl}_{3}\right) \delta=165.2\left(\mathrm{C}_{\mathrm{q}}\right), 159.0\left(\mathrm{C}_{\mathrm{q}}\right), 148.2\left(\mathrm{C}_{\mathrm{q}}\right), 146.4(\mathrm{CH}), 139.9(\mathrm{CH}), 137.7$ $\left(\mathrm{C}_{\mathrm{q}}\right), 131.6\left(\mathrm{C}_{\mathrm{q}}\right), 129.5(\mathrm{CH}), 124.9(\mathrm{CH}), 113.4(\mathrm{CH}), 55.2\left(\mathrm{CH}_{3}\right), 39.2\left(\mathrm{CH}_{2}\right), 31.7\left(\mathrm{CH}_{2}\right), 20.2$ $\left(\mathrm{CH}_{2}\right), 13.8\left(\mathrm{CH}_{3}\right)$.

IR (ATR): 3200, 2957, 1648, 1511,1247, 1178, 1035, $804 \mathrm{~cm}^{-1}$.

MS (ESI) $m / z$ (relative intensity): $591(100)[2 \mathrm{M}+\mathrm{Na}]^{+}, 307(90)[\mathrm{M}+\mathrm{Na}]^{+}, 285(90)[\mathrm{M}+\mathrm{H}]^{+}$.

HR-MS (ESI) $m / z$ calc. for $\mathrm{C}_{17} \mathrm{H}_{21} \mathrm{~N}_{2} \mathrm{O}_{2}[\mathrm{M}+\mathrm{H}]^{+}$285.1598, found 285.1600.

The analytical data are in accordance with those previously reported in the literature. ${ }^{[54]}$

$N$-Benzyl-3-(4-methoxyphenyl)picolinamide (176ba) 
<smiles>COc1ccc(-c2cccnc2C(=O)NCc2ccccc2)cc1</smiles>

The general procedure I was followed using $N$-benzylpicolinamide $\mathbf{1 7 6 b}(53.1 \mathrm{mg}, 0.25 \mathrm{mmol})$ and 175a $(0.40 \mathrm{~mL}, 1.0 \mathrm{mmol}, 2.5 \mathrm{M}$ in THF). Isolation by column chromatography ( $n$ hexane/ethyl acetate: $2 / 1 \rightarrow 1 / 1)$ yielded $\mathbf{1 7 6 b a}(46.2 \mathrm{mg}, 58 \%)$ as a white solid.

M. p.: $133-135^{\circ} \mathrm{C}$

${ }^{1}$ H-NMR $\left(300 \mathrm{MHz}, \mathrm{CDCl}_{3}\right) \delta=8.53(\mathrm{dd}, J=4.6,1.6 \mathrm{~Hz}, 1 \mathrm{H}), 8.04(\mathrm{~s}, 1 \mathrm{H}), 7.71(\mathrm{dd}, J=7.8,1.6$ $\mathrm{Hz}, 1 \mathrm{H}), 7.45(\mathrm{dd}, J=7.8,4.6 \mathrm{~Hz}, 1 \mathrm{H}), 7.37-7.27(\mathrm{~m}, 7 \mathrm{H}), 7.02-6.94(\mathrm{~m}, 2 \mathrm{H}), 4.59(\mathrm{~d}, J=6.0 \mathrm{~Hz}$, $2 \mathrm{H}), 3.88(\mathrm{~s}, 3 \mathrm{H})$.

${ }^{13}$ C-NMR $\left(100 \mathrm{MHz}, \mathrm{CDCl}_{3}\right) \delta=165.2\left(\mathrm{C}_{\mathrm{q}}\right), 159.2\left(\mathrm{C}_{\mathrm{q}}\right), 148.0\left(\mathrm{C}_{\mathrm{q}}\right), 146.7(\mathrm{CH}), 140.2(\mathrm{CH}), 138.4$ $\left(\mathrm{C}_{\mathrm{q}}\right), 138.1\left(\mathrm{C}_{\mathrm{q}}\right), 131.6\left(\mathrm{C}_{\mathrm{q}}\right), 129.7(\mathrm{CH}), 128.6(\mathrm{CH}), 127.9(\mathrm{CH}), 127.4(\mathrm{CH}), 125.2(\mathrm{CH}), 113.5$ $(\mathrm{CH}), 55.3\left(\mathrm{CH}_{3}\right), 43.5\left(\mathrm{CH}_{2}\right)$.

IR (ATR): 3055, 1711, 1673, 1512, 1361, 1222, 737, $531 \mathrm{~cm}^{-1}$

MS (EI) $m / z$ (relative intensity): $659(80)[2 \mathrm{M}+\mathrm{Na}]^{+}, 341(70)[\mathrm{M}+\mathrm{Na}]^{+}, 319(100)[\mathrm{M}+\mathrm{H}]^{+}$.

HR-MS (ESI) $m / z$ calc. for $\mathrm{C}_{20} \mathrm{H}_{19} \mathrm{~N}_{2} \mathrm{O}_{2}[\mathrm{M}+\mathrm{H}]^{+} 319.1441$, found 319.1441 .

The analytical data are in accordance with those previously reported in the literature. ${ }^{[154]}$

\section{$N$-(4-Methoxybenzyl)-3-(4-methoxyphenyl)picolinamide (176da)}<smiles>COc1ccc(CNC(=O)c2ncccc2-c2ccc(OC)cc2)cc1</smiles>

The general procedure I was followed using $N$-(4-methoxybenzyl)picolinamide 172d (60.6 mg, 0.25 mmol) and 175a $(0.40 \mathrm{~mL}, 1.0 \mathrm{mmol}, 2.5 \mathrm{M}$ in THF). Isolation by column chromatography ( $n$ hexane/ethyl acetate: $2 / 1 \rightarrow 1 / 1$ ) yielded 176da (44.4 $\mathrm{mg}, 51 \%$ ) as a white solid.

M. p.: $97-98^{\circ} \mathrm{C}$. 
${ }^{1}$ H-NMR $\left(300 \mathrm{MHz}, \mathrm{CDCl}_{3}\right) \delta=8.47(\mathrm{dd}, J=4.6,1.7 \mathrm{~Hz}, 1 \mathrm{H}), 7.89(\mathrm{~s}, 1 \mathrm{H}), 7.65(\mathrm{dd}, J=7.8,1.7$ Hz, 1H), 7.39 (dd, $J=7.8,4.6 \mathrm{~Hz}, 1 \mathrm{H}), 7.28-7.20(\mathrm{~m}, 4 \mathrm{H}), 6.97-6.91(\mathrm{~m}, 2 \mathrm{H}), 6.86-6.81(\mathrm{~m}, 2 \mathrm{H})$, $4.47(\mathrm{~d}, J=5.9 \mathrm{~Hz}, 2 \mathrm{H}), 3.83(\mathrm{~s}, 3 \mathrm{H}), 3.77(\mathrm{~s}, 3 \mathrm{H})$.

${ }^{13}$ C-NMR $\left(125 \mathrm{MHz}, \mathrm{CDCl}_{3}\right) \delta=165.3\left(\mathrm{C}_{\mathrm{q}}\right), 159.3\left(\mathrm{C}_{\mathrm{q}}\right), 159.0\left(\mathrm{C}_{\mathrm{q}}\right), 148.1\left(\mathrm{C}_{\mathrm{q}}\right), 146.7(\mathrm{CH}), 140.2$ $(\mathrm{CH}), 138.1\left(\mathrm{C}_{\mathrm{q}}\right), 131.7\left(\mathrm{C}_{\mathrm{q}}\right), 130.6\left(\mathrm{C}_{\mathrm{q}}\right), 129.8(\mathrm{CH}), 129.4(\mathrm{CH}), 125.3(\mathrm{CH}), 114.1(\mathrm{CH}), 113.6$ $(\mathrm{CH}), 55.4\left(\mathrm{CH}_{3}\right), 55.4\left(\mathrm{CH}_{3}\right), 43.0\left(\mathrm{CH}_{2}\right)$.

IR (ATR): 3056, 1712, 1674, 1513, 1361, 1222, 737, $531 \mathrm{~cm}^{-1}$.

MS (EI) $m / z$ (relative intensity): $719(60)[2 \mathrm{M}+\mathrm{Na}]^{+}, 371(70)[\mathrm{M}+\mathrm{Na}]^{+}, 349(100)[\mathrm{M}+\mathrm{H}]^{+}$.

HR-MS (EI) $m / z$ calc. for $\mathrm{C}_{21} \mathrm{H}_{21} \mathrm{~N}_{2} \mathrm{O}_{3}[\mathrm{M}]^{+} 349.1547$, found 349.1548 .

The analytical data are in accordance with those previously reported in the literature. ${ }^{[154]}$

\section{$N$-(4-Fluorobenzyl)-3-(4-methoxyphenyl)picolinamide (176ea)}<smiles>COc1ccc(-c2cccnc2C(=O)NCc2ccc(F)cc2)cc1</smiles>

The general procedure I was followed using $N$-(4-fluorobenzyl)picolinamide 172e (57.6 mg, 0.25 mmol) and 175a $(0.40 \mathrm{~mL}, 1.0 \mathrm{mmol}, 2.5 \mathrm{M}$ in THF). Isolation by column chromatography ( $n$ hexane/ethyl acetate: $2 / 1 \rightarrow 1 / 1$ ) yielded 176 ea $(38.7 \mathrm{mg}, 46 \%$ ) as a white solid.

M. p.: $127-130{ }^{\circ} \mathrm{C}$.

${ }^{1}$ H-NMR $\left(300 \mathrm{MHz}, \mathrm{CDCl}_{3}\right) \delta=8.53(\mathrm{dd}, J=4.6,1.6 \mathrm{~Hz}, 1 \mathrm{H}), 8.04(\mathrm{~s}, 1 \mathrm{H}), 7.71(\mathrm{dd}, J=7.8,1.6$ Hz, 1H), 7.45 (dd, $J=7.8,4.6 \mathrm{~Hz}, 1 \mathrm{H}), 7.33-7.26(\mathrm{~m}, 4 \mathrm{H}), 7.07-6.95(\mathrm{~m}, 4 \mathrm{H}), 4.55$ (d, $J=6.1 \mathrm{~Hz}$, 2H), $3.88(\mathrm{~s}, 3 \mathrm{H})$.

${ }^{13}$ C-NMR $\left(100 \mathrm{MHz}, \mathrm{CDCl}_{3}\right) \delta=165.2\left(\mathrm{C}_{\mathrm{q}}\right), 163.4\left(\mathrm{~d},{ }^{1} J_{\mathrm{C}-\mathrm{F}}=245.4 \mathrm{~Hz}, \mathrm{C}_{\mathrm{q}}\right), 161.0\left(\mathrm{~d},{ }^{1} J_{\mathrm{C}-\mathrm{F}}=245.4\right.$ $\left.\mathrm{Hz}, \mathrm{C}_{\mathrm{q}}\right), 159.2\left(\mathrm{C}_{\mathrm{q}}\right), 147.8\left(\mathrm{C}_{\mathrm{q}}\right), 146.7(\mathrm{CH}), 140.2(\mathrm{CH}), 138.1\left(\mathrm{C}_{\mathrm{q}}\right), 134.3\left(\mathrm{~d},{ }^{4} J_{\mathrm{C}-\mathrm{F}}=3.1 \mathrm{~Hz}, \mathrm{C}_{\mathrm{q}}\right)$, $131.5\left(\mathrm{C}_{\mathrm{q}}\right), 129.7(\mathrm{CH}), 129.5\left(\mathrm{~d},{ }^{3} J_{\mathrm{C}-\mathrm{F}}=8.1 \mathrm{~Hz}, \mathrm{CH}\right), 125.3(\mathrm{CH}), 115.5\left(\mathrm{~d},{ }^{2} J_{\mathrm{C}-\mathrm{F}}=21.6 \mathrm{~Hz}, \mathrm{CH}\right)$, $113.5(\mathrm{CH}), 55.3\left(\mathrm{CH}_{3}\right), 42.7\left(\mathrm{CH}_{2}\right)$.

${ }^{19}$ F-NMR $\left(282 \mathrm{MHz}, \mathrm{CDCl}_{3}\right) \delta=-115.4(\mathrm{tt}, J=9.0,5.3 \mathrm{~Hz})$. 
IR (ATR): 2984, 2906, 1734, 1373, 1241, 1045, 913, $736 \mathrm{~cm}^{-1}$.

MS (ESI) $m / z$ (relative intensity): $695(70)[2 \mathrm{M}+\mathrm{Na}]^{+}, 359(100)[\mathrm{M}+\mathrm{Na}]^{+}, 337(90)[\mathrm{M}+\mathrm{H}]^{+}$.

HR MS (ESI) $m / z$ calc. for $\mathrm{C}_{20} \mathrm{H}_{18} \mathrm{FN}_{2} \mathrm{O}_{2}[\mathrm{M}+\mathrm{H}]^{+} 337.1347$, found 337.1349.

The analytical data are in accordance with those previously reported in the literature. ${ }^{[154]}$

\section{$N$-(2-Fluorobenzyl)-3-(4-methoxyphenyl)picolinamide (176fa)}<smiles>COc1ccc(-c2cccnc2C(=O)NCc2ccccc2F)cc1</smiles>

The general procedure was followed using $N$-(2-fluorobenzyl)picolinamide 172f $(57.6 \mathrm{mg}, 0.25$ $\mathrm{mmol})$ and 175a $(0.40 \mathrm{~mL}, 1.0 \mathrm{mmol}, 2.5 \mathrm{M}$ in THF). Isolation by column chromatography (nhexane/ethyl acetate: $2 / 1 \rightarrow 1 / 1$ ) yielded $\mathbf{1 7 6 f a}(47.1 \mathrm{mg}, 56 \%$ ) as a white solid.

M. p.: $114-116^{\circ} \mathrm{C}$.

${ }^{1}$ H-NMR $\left(300 \mathrm{MHz}, \mathrm{CDCl}_{3}\right) \delta=8.54(\mathrm{dd}, J=4.7,1.6 \mathrm{~Hz}, 1 \mathrm{H}), 8.06(\mathrm{~s}, 1 \mathrm{H}), 7.70(\mathrm{dd}, J=7.8,1.6$ $\mathrm{Hz}, 1 \mathrm{H}), 7.45(\mathrm{dd}, J=7.8,4.7 \mathrm{~Hz}, 1 \mathrm{H}), 7.41-7.34(\mathrm{~m}, 1 \mathrm{H}), 7.30-7.27(\mathrm{~m}, 3 \mathrm{H}), 7.16-7.01(\mathrm{~m}, 2 \mathrm{H})$, 7.00-6.90 (m, 2H), 4.71-4.57 (m, 2H), 3.87 (s, 3H).

${ }^{13}$ C-NMR $\left(125 \mathrm{MHz}, \mathrm{CDCl}_{3}\right)_{\delta}=165.1\left(\mathrm{C}_{\mathrm{q}}\right), 160.9\left(\mathrm{~d},{ }^{1} J_{\mathrm{C}-\mathrm{F}}=246.2 \mathrm{~Hz}, \mathrm{C}_{\mathrm{q}}\right), 159.0\left(\mathrm{C}_{\mathrm{q}}\right), 147.8\left(\mathrm{C}_{\mathrm{q}}\right)$, $146.5(\mathrm{CH}), 140.0(\mathrm{CH}), 137.9\left(\mathrm{C}_{\mathrm{q}}\right), 131.4\left(\mathrm{C}_{\mathrm{q}}\right), 130.1\left(\mathrm{~d},{ }^{3} J_{\mathrm{C}-\mathrm{F}}=4.5 \mathrm{~Hz}, \mathrm{CH}\right), 129.6(\mathrm{CH}), 129.0(\mathrm{~d}$, $\left.{ }^{3} J_{\mathrm{C}-\mathrm{F}}=8.1 \mathrm{~Hz}, \mathrm{CH}\right), 125.3\left(\mathrm{~d},{ }^{2} J_{\mathrm{C}-\mathrm{F}}=15.0 \mathrm{~Hz}, \mathrm{C}_{\mathrm{q}}\right), 125.1(\mathrm{CH}), 124.1\left(\mathrm{~d},{ }^{4} J_{\mathrm{C}-\mathrm{F}}=3.6 \mathrm{~Hz}, \mathrm{CH}\right), 115.2$ $\left(\mathrm{d},{ }^{2} J_{\mathrm{C}-\mathrm{F}}=21.4 \mathrm{~Hz}, \mathrm{CH}\right), 113.4(\mathrm{CH}), 55.2\left(\mathrm{CH}_{2}\right), 37.3\left(\mathrm{~d},{ }^{3} J_{\mathrm{C}-\mathrm{F}}=4.1 \mathrm{~Hz}, \mathrm{CH}_{2}\right)$.

${ }^{19} \mathbf{F}-\mathrm{NMR}\left(282 \mathrm{MHz}, \mathrm{CDCl}_{3}\right) \delta=-118.8(\mathrm{ddd}, J=10.2,7.6,5.6 \mathrm{~Hz})$.

IR (ATR): 3057, 2984, 1733, 1373, 1242, 1046, 736, $608 \mathrm{~cm}^{-1}$.

MS (ESI) $m / z$ (relative intensity): $695(40)[2 \mathrm{M}+\mathrm{Na}]^{+}, 359(60)[\mathrm{M}+\mathrm{Na}]^{+}, 337(100)[\mathrm{M}+\mathrm{H}]^{+}$.

HR-MS (ESI) $m / z$ calc. for $\mathrm{C}_{20} \mathrm{H}_{18} \mathrm{FN}_{2} \mathrm{O}_{2}[\mathrm{M}+\mathrm{H}]^{+} 337.1347$, found 337.1349.

The analytical data are in accordance with those previously reported in the literature. ${ }^{[54]}$ 
<smiles>COc1ccc(-c2cccnc2C(=O)NC2CCCc3ccccc32)cc1</smiles>

The general procedure was followed using $N$-(1,2,3,4-tetrahydronaphthalen-1-yl)picolinamide 172g (63.1 $\mathrm{mg}, 0.25 \mathrm{mmol})$ and $175 \mathrm{a}(0.40 \mathrm{~mL}, 1.0 \mathrm{mmol}, 2.5 \mathrm{M}$ in THF). Isolation by column chromatography ( $n$ hexane/ethyl acetate: $2 / 1 \rightarrow 1 / 1)$ yielded $176 \mathrm{ga}(66.4 \mathrm{mg}, 74 \%$ ) as a white solid. M. p.: $125-126^{\circ} \mathrm{C}$.

${ }^{1}$ H-NMR $\left(400 \mathrm{MHz}, \mathrm{CDCl}_{3}\right) \delta=8.50(\mathrm{dd}, J=4.7,1.7 \mathrm{~Hz}, 1 \mathrm{H}), 7.86(\mathrm{~d}, J=8.9 \mathrm{~Hz}, 1 \mathrm{H}), 7.70(\mathrm{dd}, J$ = 7.9, 1.7 Hz, 1H), $7.43(\mathrm{dd}, J=7.9,4.7 \mathrm{~Hz}, 1 \mathrm{H}), 7.34(\mathrm{~d}, J=8.9 \mathrm{~Hz}, 2 \mathrm{H}), 7.28-7.24(\mathrm{~m}, 1 \mathrm{H}), 7.21-$ $7.10(\mathrm{~m}, 3 \mathrm{H}), 7.01(\mathrm{~d}, J=8.9 \mathrm{~Hz}, 2 \mathrm{H}), 5.28(\mathrm{dt}, J=9.9,5.6 \mathrm{~Hz}, 1 \mathrm{H}), 3.89(\mathrm{~s}, 3 \mathrm{H}), 2.90-2.74(\mathrm{~m}, 2 \mathrm{H})$, 2.16-2.04 (m, 1H), 1.94-1.79 (m, 3H).

${ }^{13}$ C-NMR $\left(100 \mathrm{MHz}, \mathrm{CDCl}_{3}\right) \delta=164.8\left(\mathrm{C}_{\mathrm{q}}\right), 159.3\left(\mathrm{C}_{\mathrm{q}}\right), 148.4\left(\mathrm{C}_{\mathrm{q}}\right), 146.8(\mathrm{CH}), 140.0(\mathrm{CH}), 137.8$ $\left(\mathrm{C}_{\mathrm{q}}\right), 137.6\left(\mathrm{C}_{\mathrm{q}}\right), 136.8\left(\mathrm{C}_{\mathrm{q}}\right), 131.6\left(\mathrm{C}_{\mathrm{q}}\right), 129.8(\mathrm{CH}), 129.1(\mathrm{CH}), 128.9(\mathrm{CH}), 127.2(\mathrm{CH}), 126.2$ $(\mathrm{CH}), 125.1(\mathrm{CH}), 113.6(\mathrm{CH}), 55.3\left(\mathrm{CH}_{3}\right), 47.4(\mathrm{CH}), 30.1\left(\mathrm{CH}_{2}\right), 29.3\left(\mathrm{CH}_{2}\right), 20.1\left(\mathrm{CH}_{2}\right)$.

IR (ATR): 2984, 2905, 1734, 1373, 1241, 1046, 737, $608 \mathrm{~cm}^{-1}$.

MS (EI) $m / z$ (relative intensity): $739(100)[2 \mathrm{M}+\mathrm{Na}]^{+}, 381(70)[\mathrm{M}+\mathrm{Na}]^{+}, 359(80)[\mathrm{M}+\mathrm{H}]^{+}$.

HR-MS (EI) $m / z$ calc. for $\mathrm{C}_{23} \mathrm{H}_{23} \mathrm{~N}_{2} \mathrm{O}_{2}[\mathrm{M}+\mathrm{H}]^{+} 359.1754$, found 359.1756.

The analytical data are in accordance with those previously reported in the literature. ${ }^{[154]}$

\section{$\mathrm{N}$-Cyclohexyl-3-(4-methoxyphenyl)picolinamide (176ha)}<smiles>COc1ccc(-c2cccnc2C(=O)NC2CCCCC2)cc1</smiles>

The general procedure was followed using $N$-cyclohexylpicolinamide $\mathbf{1 7 2 h}(51.1 \mathrm{mg}, 0.25 \mathrm{mmol})$ and $175 \mathrm{a}(0.40 \mathrm{~mL}, 1.0 \mathrm{mmol}, 2.5 \mathrm{M}$ in THF). Isolation by column chromatography ( $n$ hexane/ethyl acetate: $2 / 1 \rightarrow 1 / 1)$ yielded $\mathbf{1 7 6 h a}(47.3 \mathrm{mg}, 61 \%)$ as a white solid. 
M. p.: $95-96^{\circ} \mathrm{C}$.

${ }^{1}$ H-NMR $\left(300 \mathrm{MHz}, \mathrm{CDCl}_{3}\right) \delta=8.49(\mathrm{dd}, J=4.6,1.7 \mathrm{~Hz}, 1 \mathrm{H}), 7.63(\mathrm{dd}, J=7.8,1.7 \mathrm{~Hz}, 1 \mathrm{H}), 7.57-$ $7.47(\mathrm{~m}, 1 \mathrm{H}), 7.38(\mathrm{dd}, J=7.8,4.7 \mathrm{~Hz}, 1 \mathrm{H}), 7.24(\mathrm{~d}, J=8.8 \mathrm{~Hz}, 2 \mathrm{H}), 6.92(\mathrm{~d}, J=8.8 \mathrm{~Hz}, 2 \mathrm{H}), 3.82$ (s, 3H), 1.97-1.88 (m, 2H), 1.71-1.69 (m, 2H), 1.62-1.55 (m, 1H), 1.38-1.15 (m, 5H).

${ }^{13}$ C-NMR (125 MHz, $\left.\mathrm{CDCl}_{3}\right) \delta=164.3\left(\mathrm{C}_{\mathrm{q}}\right), 159.0\left(\mathrm{C}_{\mathrm{q}}\right), 148.4\left(\mathrm{C}_{\mathrm{q}}\right), 146.4(\mathrm{CH}), 139.9(\mathrm{CH}), 137.7$ $\left(\mathrm{C}_{\mathrm{q}}\right), 131.7\left(\mathrm{C}_{\mathrm{q}}\right), 129.5(\mathrm{CH}), 124.8(\mathrm{CH}), 113.4(\mathrm{CH}), 55.2\left(\mathrm{CH}_{3}\right), 48.1(\mathrm{CH}), 33.0\left(\mathrm{CH}_{2}\right), 25.7$ $\left(\mathrm{CH}_{2}\right), 25.0\left(\mathrm{CH}_{2}\right)$.

IR (ATR): 3059, 2984, 1735, 1373, 1240, 1046, 737, $608 \mathrm{~cm}^{-1}$.

MS (EI) $m / z$ (relative intensity): $643(80)[2 \mathrm{M}+\mathrm{Na}]^{+}, 333(90)[\mathrm{M}+\mathrm{Na}]^{+}, 311(100)[\mathrm{M}+\mathrm{H}]^{+}$.

HR-MS (EI) $m / z$ calc. for $\mathrm{C}_{19} \mathrm{H}_{23} \mathrm{~N}_{2} \mathrm{O}_{2}[\mathrm{M}+\mathrm{H}]^{+} 311.1754$, found 310.1755 .

The analytical data are in accordance with those previously reported in the literature. ${ }^{[154]}$

\section{$N$-n-Butyl-3-phenylpicolinamide (176ab)}<smiles>CCCCNC(=O)c1ncccc1-c1ccccc1</smiles>

The general procedure was followed using 172a $(44.5 \mathrm{mg}, 0.25 \mathrm{mmol})$ and phenylmagnesium bromide $175 \mathbf{b}(0.38 \mathrm{~mL}, 1.0 \mathrm{mmol}, 2.6 \mathrm{M}$ in THF). Isolation by column chromatography (nhexane/ethyl acetate: $2 / 1 \rightarrow 1 / 1)$ yielded 176ab $(47.7 \mathrm{mg}, 75 \%$ ) as a white solid.

M. p.: $59-61^{\circ} \mathrm{C}$.

${ }^{1}$ H-NMR $\left(400 \mathrm{MHz}, \mathrm{CDCl}_{3}\right) \delta=8.54(\mathrm{dd}, J=4.7,1.7 \mathrm{~Hz}, 1 \mathrm{H}), 7.72(\mathrm{~s}, 1 \mathrm{H}), 7.67$ (dd, $J=7.8,1.7$ $\mathrm{Hz}, 1 \mathrm{H}), 7.45-7.35(\mathrm{~m}, 4 \mathrm{H}), 7.34-7.31(\mathrm{~m}, 2 \mathrm{H}), 3.35(\mathrm{td}, J=7.2,6.0 \mathrm{~Hz}, 2 \mathrm{H}), 1.59-1.50(\mathrm{~m}, 2 \mathrm{H})$, $1.42-1.31(\mathrm{~m}, 2 \mathrm{H}), 0.92(\mathrm{t}, J=7.3 \mathrm{~Hz}, 3 \mathrm{H})$.

${ }^{13}$ C-NMR $\left(100 \mathrm{MHz}, \mathrm{CDCl}_{3}\right) \delta=165.0\left(\mathrm{C}_{\mathrm{q}}\right), 148.2\left(\mathrm{C}_{\mathrm{q}}\right), 146.8(\mathrm{CH}), 140.0(\mathrm{CH}), 139.5\left(\mathrm{C}_{\mathrm{q}}\right), 138.1$ $\left(\mathrm{C}_{\mathrm{q}}\right), 128.3(\mathrm{CH}), 127.8(\mathrm{CH}), 127.4(\mathrm{CH}), 125.0(\mathrm{CH}), 39.1\left(\mathrm{CH}_{2}\right), 31.6\left(\mathrm{CH}_{2}\right), 20.1\left(\mathrm{CH}_{2}\right), 13.7$ $\left(\mathrm{CH}_{3}\right)$.

IR (ATR): 3250, 3060, 2957, 1649, 1510, 1313, 757, $698 \mathrm{~cm}^{-1}$.

MS (ESI) $m / z$ (relative intensity): $531(100)[2 \mathrm{M}+\mathrm{Na}]^{+}, 277(90)[\mathrm{M}+\mathrm{Na}]^{+}, 255(100)[\mathrm{M}+\mathrm{H}]^{+}$. 
HR-MS (ESI) $m / z$ calc. for $\mathrm{C}_{16} \mathrm{H}_{19} \mathrm{~N}_{2} \mathrm{O}[\mathrm{M}+\mathrm{H}]^{+}$255.1492, found 255.1494.

The analytical data are in accordance with those previously reported in the literature. ${ }^{[54]}$

\section{$N$-n-Butyl-3-(p-tolyl)picolinamide (176ac)}<smiles>CCCCNC(=O)c1ncccc1-c1ccc(C)cc1</smiles>

The general procedure was followed using 172a $(44.5 \mathrm{mg}, 0.25 \mathrm{mmol})$ and $p$-tolylmagnesium bromide $\mathbf{x x 1 7 5 \mathrm { cx }}(0.42 \mathrm{~mL}, 1.0 \mathrm{mmol}, 2.4 \mathrm{M}$ in THF). Isolation by column chromatography (nhexane/ethyl acetate: $2 / 1 \rightarrow 1 / 1)$ yielded 176ac $(52.3 \mathrm{mg}, 78 \%$ ) as a white solid.

M. p.: $110-111^{\circ} \mathrm{C}$.

${ }^{1}$ H-NMR $\left(400 \mathrm{MHz}, \mathrm{CDCl}_{3}\right) \delta=8.52(\mathrm{dd}, J=4.6,1.6 \mathrm{~Hz}, 1 \mathrm{H}), 7.66(\mathrm{dd}, J=7.8,1.6 \mathrm{~Hz}, 2 \mathrm{H}), 7.41$ $(\mathrm{dd}, J=7.8,4.6 \mathrm{~Hz}, 1 \mathrm{H}), 7.22(\mathrm{~m}, 4 \mathrm{H}), 3.36(\mathrm{td}, J=7.2,6.0 \mathrm{~Hz}, 2 \mathrm{H}), 2.39(\mathrm{~s}, 3 \mathrm{H}), 1.62-1.48(\mathrm{~m}$, 2H), 1.41-1.30 (m, 2H), $0.92(\mathrm{t}, J=7.2 \mathrm{~Hz}, 3 \mathrm{H})$.

${ }^{13}$ C-NMR $\left(100 \mathrm{MHz}, \mathrm{CDCl}_{3}\right) \delta=165.2\left(\mathrm{C}_{\mathrm{q}}\right), 148.3\left(\mathrm{C}_{\mathrm{q}}\right), 146.7(\mathrm{CH}), 140.0(\mathrm{CH}), 138.1\left(\mathrm{C}_{\mathrm{q}}\right), 137.2$ $\left(\mathrm{C}_{\mathrm{q}}\right), 136.5\left(\mathrm{C}_{\mathrm{q}}\right), 128.7(\mathrm{CH}), 128.2(\mathrm{CH}), 125.0(\mathrm{CH}), 39.1\left(\mathrm{CH}_{2}\right), 31.6\left(\mathrm{CH}_{2}\right), 21.3\left(\mathrm{CH}_{3}\right), 20.1$ $\left(\mathrm{CH}_{2}\right), 13.8\left(\mathrm{CH}_{3}\right)$.

IR (ATR): 3250, 2958, 2920, 1665, 1550, 1315, 803, $696 \mathrm{~cm}^{-1}$.

MS (EI) $m / z$ (relative intensity): 268 (100) $[\mathrm{M}]^{+}, 211$ (40), 168 (70).

HR-MS (ESI) $m / z$ calc. for $\mathrm{C}_{17} \mathrm{H}_{21} \mathrm{~N}_{2} \mathrm{O}[\mathrm{M}+\mathrm{H}]^{+} 269.1648$, found 269.1647 .

The analytical data are in accordance with those previously reported in the literature. ${ }^{[54]}$

\section{$N$-n-Butyl-3-[4-(tert-butyl)phenyl]picolinamide (176ad)}<smiles>CCCCNC(=O)c1ncccc1-c1ccc(C(C)(C)C)cc1</smiles> 
The general procedure was followed using 172a $(44.5 \mathrm{mg}, 0.25 \mathrm{mmol})$ and (4-(tertbutyl)phenyl)magnesium bromide $\mathbf{1 7 5 d}(0.40 \mathrm{~mL}, 1.0 \mathrm{mmol}, 2.5 \mathrm{M}$ in THF). Isolation by column chromatography ( $n$ hexane/ethyl acetate: $2 / 1 \rightarrow 1 / 1$ ) yielded 176ad (56.6 mg, $73 \%$ ) as a white solid.

M. p.: $106-109{ }^{\circ} \mathrm{C}$.

${ }^{1}$ H-NMR $\left(400 \mathrm{MHz}, \mathrm{CDCl}_{3}\right) \delta=8.52(\mathrm{dd}, J=4.6,1.6 \mathrm{~Hz}, 1 \mathrm{H}), 7.67(\mathrm{dd}, J=7.8,1.6 \mathrm{~Hz}, 2 \mathrm{H}), 7.45-$ $7.38(\mathrm{~m}, 3 \mathrm{H}), 7.32-7.26(\mathrm{~m}, 2 \mathrm{H}), 3.36(\mathrm{td}, J=7.2,6.0 \mathrm{~Hz}, 2 \mathrm{H}), 1.58-1.50(\mathrm{~m}, 2 \mathrm{H}), 1.39-1.32(\mathrm{~m}$, $11 \mathrm{H}), 0.92(\mathrm{t}, J=7.2 \mathrm{~Hz}, 3 \mathrm{H})$.

${ }^{13}$ C-NMR $\left(100 \mathrm{MHz}, \mathrm{CDCl}_{3}\right) \delta=165.2\left(\mathrm{C}_{\mathrm{q}}\right), 150.1\left(\mathrm{C}_{\mathrm{q}}\right), 148.2\left(\mathrm{C}_{\mathrm{q}}\right), 146.6(\mathrm{CH}), 140.1(\mathrm{CH}), 137.9$ $\left(\mathrm{C}_{\mathrm{q}}\right), 136.3\left(\mathrm{C}_{\mathrm{q}}\right), 128.1(\mathrm{CH}), 124.9(\mathrm{CH}), 124.8(\mathrm{CH}), 39.1\left(\mathrm{CH}_{2}\right), 34.5\left(\mathrm{C}_{\mathrm{q}}\right), 31.5\left(\mathrm{CH}_{2}\right), 31.3\left(\mathrm{CH}_{3}\right)$, $20.1\left(\mathrm{CH}_{2}\right), 13.7\left(\mathrm{CH}_{3}\right)$.

IR (ATR): 3280, 2961, 2871, 1649, 1510, 1002, 804, $584 \mathrm{~cm}^{-1}$.

MS (ESI) $m / z$ (relative intensity): $643(70)[2 \mathrm{M}+\mathrm{Na}]^{+}, 621(10)[2 \mathrm{M}+\mathrm{H}]^{+}, 333(40)[\mathrm{M}+\mathrm{Na}]^{+}, 311$ (100) $[\mathrm{M}+\mathrm{H}]^{+}$.

HR-MS (ESI) $m / z$ calc. for $\mathrm{C}_{20} \mathrm{H}_{27} \mathrm{~N}_{2} \mathrm{O}[\mathrm{M}+\mathrm{H}]^{+} 311.2118$, found 311.2117.

The analytical data are in accordance with those previously reported in the literature. ${ }^{[54]}$

N-n-Butyl-3-(3-methoxyphenyl)picolinamide (176ag)

$\mathrm{MeO}$<smiles>CCCCNC(=O)c1ncccc1-c1cccc(C)c1</smiles>

The general procedure was followed using 172a (44.5 $\mathrm{mg}, 0.25 \mathrm{mmol}$ ) and (3methoxyphenyl)magnesium bromide $\mathbf{1 7 5 g}(0.40 \mathrm{~mL}, 1.0 \mathrm{mmol}, 2.5 \mathrm{M}$ in THF). Isolation by column chromatography ( $n$ hexane/ethyl acetate: $2 / 1 \rightarrow 1 / 1)$ yielded 176ag $(54.0 \mathrm{mg}, 76 \%$ ) as a white solid.

M. p.: $100-102{ }^{\circ} \mathrm{C}$.

${ }^{1}$ H-NMR $\left(400 \mathrm{MHz}, \mathrm{CDCl}_{3}\right) \delta=8.52(\mathrm{dd}, J=4.7,1.7 \mathrm{~Hz}, 1 \mathrm{H}), 7.66(\mathrm{dd}, J=7.8,1.7 \mathrm{~Hz}, 1 \mathrm{H}), 7.60$ (s, 1H), $7.40(\mathrm{dd}, J=7.8,4.7 \mathrm{~Hz}, 1 \mathrm{H}), 7.34-7.26(\mathrm{~m}, 1 \mathrm{H}), 6.92-6.83(\mathrm{~m}, 3 \mathrm{H}), 3.80(\mathrm{~s}, 3 \mathrm{H}), 3.34(\mathrm{td}$, $J=7.1,6.0 \mathrm{~Hz}, 2 \mathrm{H}), 1.57-1.48(\mathrm{~m}, 2 \mathrm{H}), 1.39-1.29(\mathrm{~m}, 2 \mathrm{H}), 0.90(\mathrm{t}, J=7.1 \mathrm{~Hz}, 3 \mathrm{H})$. 
${ }^{13}$ C-NMR $\left(100 \mathrm{MHz}, \mathrm{CDCl}_{3}\right) \delta=165.2\left(\mathrm{C}_{\mathrm{q}}\right), 159.2\left(\mathrm{C}_{\mathrm{q}}\right), 148.6\left(\mathrm{C}_{\mathrm{q}}\right), 147.1(\mathrm{CH}), 140.9\left(\mathrm{C}_{\mathrm{q}}\right), 139.9$ $(\mathrm{CH}), 137.9\left(\mathrm{C}_{\mathrm{q}}\right), 129.0(\mathrm{CH}), 125.0(\mathrm{CH}), 121.1(\mathrm{CH}), 114.3(\mathrm{CH}), 113.0(\mathrm{CH}), 55.3\left(\mathrm{CH}_{3}\right), 39.3$ $\left(\mathrm{CH}_{2}\right), 31.7\left(\mathrm{CH}_{2}\right), 20.2\left(\mathrm{CH}_{2}\right), 13.9\left(\mathrm{CH}_{3}\right)$.

IR (ATR): 3300, 2957, 2872, 1649, 1511, 1227, 779, $697 \mathrm{~cm}^{-1}$.

MS (ESI) $m / z$ (relative intensity): $591(100)[2 \mathrm{M}+\mathrm{Na}]^{+}, 307(60)[\mathrm{M}+\mathrm{Na}]^{+}, 285(90)[\mathrm{M}+\mathrm{H}]^{+}$.

HR-MS (ESI) $m / z$ calc. for $\mathrm{C}_{17} \mathrm{H}_{21} \mathrm{~N}_{2} \mathrm{O}_{2}[\mathrm{M}+\mathrm{H}]^{+} 285.1598$, found 285.1602.

The analytical data are in accordance with those previously reported in the literature. ${ }^{[154]}$

\section{$N$-n-Butyl-3-(3-fluorophenyl)picolinamide (176ah)}<smiles>CCCCNC(=O)c1ncccc1-c1cccc(F)c1</smiles>

The general procedure was followed using 172a (44.5 $\mathrm{mg}, 0.25 \mathrm{mmol})$ and (3fluorophenyl)magnesium bromide $175 \mathrm{~h}(0.44 \mathrm{~mL}, 1.0 \mathrm{mmol}, 2.3 \mathrm{M}$ in THF). Isolation by column chromatography ( $n$ hexane/ethyl acetate: $2 / 1 \rightarrow 1 / 1)$ yielded 176ah $(47.7 \mathrm{mg}, 70 \%$ ) as a white solid. M. p.: $80-82{ }^{\circ} \mathrm{C}$.

${ }^{1}$ H-NMR $\left(400 \mathrm{MHz}, \mathrm{CDCl}_{3}\right) \delta=8.56(\mathrm{~d}, J=4.6 \mathrm{~Hz}, 1 \mathrm{H}), 7.82(\mathrm{~s}, 1 \mathrm{H}), 7.64(\mathrm{dd}, J=7.8,1.2 \mathrm{~Hz}$, 1H), $7.44(\mathrm{dd}, J=7.8,4.6 \mathrm{~Hz}, 1 \mathrm{H}), 7.38-7.32(\mathrm{~m}, 1 \mathrm{H}), 7.11-7.00(\mathrm{~m}, 3 \mathrm{H}), 3.35$ (td, $J=7.3,6.3 \mathrm{~Hz}$, 2H) $1.61-1.50(\mathrm{~m}, 2 \mathrm{H}), 1.44-1.32(\mathrm{~m}, 2 \mathrm{H}), 0.92(\mathrm{t}, J=7.3 \mathrm{~Hz}, 3 \mathrm{H})$.

${ }^{13}$ C-NMR $\left(100 \mathrm{MHz}, \mathrm{CDCl}_{3}\right) \delta=164.6\left(\mathrm{C}_{\mathrm{q}}\right), 162.2\left(\mathrm{~d},{ }^{1} J_{\mathrm{C}-\mathrm{F}}=245.6 \mathrm{~Hz}, \mathrm{C}_{\mathrm{q}}\right), 147.8\left(\mathrm{C}_{\mathrm{q}}\right), 147.2(\mathrm{CH})$, $141.8\left(\mathrm{~d},{ }^{3} J_{\mathrm{C}-\mathrm{F}}=8.1 \mathrm{~Hz}, \mathrm{C}_{\mathrm{q}}\right), 139.8(\mathrm{CH}), 137.0\left(\mathrm{C}_{\mathrm{q}}\right), 129.3\left(\mathrm{~d},{ }^{3} J_{\mathrm{C}-\mathrm{F}}=8.4 \mathrm{~Hz}, \mathrm{CH}\right), 125.0(\mathrm{CH})$, $124.2\left(\mathrm{~d},{ }^{4} J_{\mathrm{C}-\mathrm{F}}=3.0 \mathrm{~Hz}, \mathrm{CH}\right), 115.4\left(\mathrm{~d},{ }^{2} J_{\mathrm{C}-\mathrm{F}}=22.4 \mathrm{~Hz}, \mathrm{CH}\right), 114.2\left(\mathrm{~d},{ }^{2} J_{\mathrm{C}-\mathrm{F}}=21.1 \mathrm{~Hz}, \mathrm{CH}\right), 39.1$ $\left(\mathrm{CH}_{2}\right), 31.6\left(\mathrm{CH}_{2}\right), 20.1\left(\mathrm{CH}_{2}\right), 13.7\left(\mathrm{CH}_{3}\right)$.

${ }^{19} \mathbf{F}-\mathbf{N M R}\left(282 \mathrm{MHz}, \mathrm{CDCl}_{3}\right) \delta=-113.7$.

IR (ATR): 3330, 3058, 2958, 2873, 1649, 1518, 783, $694 \mathrm{~cm}^{-1}$.

MS (ESI) $m / z$ (relative intensity): $567(100)[2 \mathrm{M}+\mathrm{Na}]^{+}, 295(70)[\mathrm{M}+\mathrm{Na}]^{+}, 273(80)[\mathrm{M}+\mathrm{H}]^{+}$.

HR-MS (ESI) $m / z$ calc. for $\mathrm{C}_{16} \mathrm{H}_{18} \mathrm{~N}_{2} \mathrm{OF}[\mathrm{M}+\mathrm{H}]^{+} 273.1398$, found 273.1398 .

The analytical data are in accordance with those previously reported in the literature. ${ }^{[154]}$ 


\section{$N$-butyl-3-methylpicolinamide (214aa)}<smiles>CCCCNC(=O)c1ncccc1C</smiles>

The general procedure was followed for $6 \mathrm{~h}$ using $\mathbf{1 7 2 a}(44.5 \mathrm{mg}, 0.25 \mathrm{mmol})$ and methylmagnesium bromide $165 \mathrm{a}(0.33 \mathrm{~mL}, 1.0 \mathrm{mmol}, 3.0 \mathrm{M}$ in diethyl ether). Isolation by column chromatography ( $n$ hexane/ethyl acetate: $2 / 1 \rightarrow 1 / 1$ ) yielded 214 aa $(28.8 \mathrm{mg}, 60 \%$ ) as a colourless liquid.

${ }^{1}$ H-NMR $\left(400 \mathrm{MHz}, \mathrm{CDCl}_{3}\right) \delta=8.39(\mathrm{~d}, J=4.6 \mathrm{~Hz}, 1 \mathrm{H}), 8.14(\mathrm{~s}, 1 \mathrm{H}), 7.59(\mathrm{~d}, J=7.7 \mathrm{~Hz}, 1 \mathrm{H})$, $7.33-7.27(\mathrm{~m}, 1 \mathrm{H}), 3.45(\mathrm{q}, J=6.8 \mathrm{~Hz}, 2 \mathrm{H}), 2.76(\mathrm{~s}, 3 \mathrm{H}), 1.67-1.60(\mathrm{~m}, 2 \mathrm{H}), 1.49-1.40(\mathrm{~m}, 2 \mathrm{H})$, $0.98(\mathrm{t}, J=7.6 \mathrm{~Hz} 3 \mathrm{H})$.

${ }^{13}$ C-NMR $\left(100 \mathrm{MHz}, \mathrm{CDCl}_{3}\right) \delta=166.0\left(\mathrm{C}_{\mathrm{q}}\right), 147.5\left(\mathrm{C}_{\mathrm{q}}\right), 145.4(\mathrm{CH}), 140.8(\mathrm{CH}), 135.3\left(\mathrm{C}_{\mathrm{q}}\right), 125.5$ $(\mathrm{CH}), 39.0\left(\mathrm{CH}_{2}\right), 31.8\left(\mathrm{CH}_{2}\right), 20.6\left(\mathrm{CH}_{3}\right), 20.3\left(\mathrm{CH}_{2}\right), 13.8\left(\mathrm{CH}_{3}\right)$.

IR (ATR): 3390, 3054, 2959, 1670, 1517, 1448, 734, $468 \mathrm{~cm}^{-1}$.

MS (ESI) $m / z$ (relative intensity): $215(70)[\mathrm{M}+\mathrm{Na}]^{+}, 193(100)[\mathrm{M}+\mathrm{H}]^{+}$.

HR-MS (ESI) $m / z$ calc. for $\mathrm{C}_{11} \mathrm{H}_{17} \mathrm{~N}_{2} \mathrm{O}[\mathrm{M}+\mathrm{H}]^{+}$193.1335, found 193.1336.

The analytical data are in accordance with those previously reported in the literature. ${ }^{[193]}$

\section{$N$-butyl-3-isopropylpicolinamide (214ab)}<smiles>CCCCNC(=O)c1ncccc1C(C)C</smiles>

The general procedure was followed using 172a $(44.5 \mathrm{mg}, 0.25 \mathrm{mmol})$ and isopropylmagnesium chloride $165 \mathrm{~b}(0.50 \mathrm{~mL}, 1.0 \mathrm{mmol}, 2.0 \mathrm{M}$ in THF). Isolation by column chromatography (nhexane/ethyl acetate: $2 / 1 \rightarrow 1 / 1)$ yielded 214ab $(31.3 \mathrm{mg}, 57 \%$ ) as a yellow liquid.

${ }^{1}$ H-NMR $\left(400 \mathrm{MHz}, \mathrm{CDCl}_{3}\right) \delta=8.37(\mathrm{dd}, J=4.5,1.6 \mathrm{~Hz}, 1 \mathrm{H}), 7.97$ (s, 1H), 7.80 (dd, $J=8.1,1.7$ $\mathrm{Hz}, 1 \mathrm{H}), 7.37(\mathrm{dd}, J=8.0,4.5 \mathrm{~Hz}, 1 \mathrm{H}), 4.45$ (hept, $J=6.9 \mathrm{~Hz}, 1 \mathrm{H}), 3.45$ (td, $J=7.1,6.4 \mathrm{~Hz}, 2 \mathrm{H})$, $1.67-1.59(\mathrm{~m}, 2 \mathrm{H}), 1.49-1.41(\mathrm{~m}, 2 \mathrm{H}), 1.28(\mathrm{~d}, J=6.9 \mathrm{~Hz}, 6 \mathrm{H}), 0.98(\mathrm{t}, J=7.3 \mathrm{~Hz}, 3 \mathrm{H})$. 
${ }^{13}$ C-NMR $\left(100 \mathrm{MHz}, \mathrm{CDCl}_{3}\right) \delta=166.3\left(\mathrm{C}_{\mathrm{q}}\right), 147.2\left(\mathrm{C}_{\mathrm{q}}\right), 145.7\left(\mathrm{C}_{\mathrm{q}}\right), 145.1(\mathrm{CH}), 135.5(\mathrm{CH}), 125.7$ $(\mathrm{CH}), 39.1\left(\mathrm{CH}_{2}\right), 31.7\left(\mathrm{CH}_{2}\right), 27.6(\mathrm{CH}), 23.7\left(\mathrm{CH}_{3}\right), 20.3\left(\mathrm{CH}_{2}\right), 13.8\left(\mathrm{CH}_{3}\right)$.

IR (ATR): 3386, 3051, 2963, 1667, 1518, 1428, 735, $656 \mathrm{~cm}^{-1}$.

MS (ESI) $m / z$ (relative intensity): $463(5)[2 \mathrm{M}+\mathrm{Na}]^{+}, 243(50)[\mathrm{M}+\mathrm{Na}]^{+}, 221(100)[\mathrm{M}+\mathrm{H}]^{+}$.

HR-MS (ESI) $m / z$ calc. for $\mathrm{C}_{13} \mathrm{H}_{21} \mathrm{~N}_{2} \mathrm{O}[\mathrm{M}+\mathrm{H}]^{+} 221.1648$, found 221.1652 .

The analytical data are in accordance with those previously reported in the literature. ${ }^{[153]}$

\section{3-benzyl- $N$-cyclohexylpicolinamide (214hc)}<smiles>O=C(NC1CCCCC1)c1ncccc1Cc1ccccc1</smiles>

The general procedure was followed using $N$-cyclohexylpicolinamide $\mathbf{1 7 2 h}(51.1 \mathrm{mg}, 0.25 \mathrm{mmol})$ and benzylmagnesium chloride $165 \mathrm{c}(0.70 \mathrm{~mL}, 1.0 \mathrm{mmol}, 1.4 \mathrm{M}$ in THF). Isolation by column chromatography ( $n$ hexane/ethyl acetate: $2 / 1 \rightarrow 1 / 1)$ yielded 214 hc $(33.1 \mathrm{mg}, 45 \%)$ as a white solid.

M. p.: $98-100^{\circ} \mathrm{C}$.

${ }^{1}$ H-NMR $\left(400 \mathrm{MHz}, \mathrm{CDCl}_{3}\right) \delta=8.43(\mathrm{~d}, J=5.0 \mathrm{~Hz}, 1 \mathrm{H}), 8.10(\mathrm{~d}, J=1.8 \mathrm{~Hz}, 1 \mathrm{H}), 7.96(\mathrm{~d}, J=8.6$ $\mathrm{Hz}, 1 \mathrm{H}), 7.36-7.25(\mathrm{~m}, 3 \mathrm{H}), 7.24-7.17(\mathrm{~m}, 3 \mathrm{H}), 4.05(\mathrm{~s}, 2 \mathrm{H}), 4.02-3.93(\mathrm{~m}, 1 \mathrm{H}), 2.02$ (dt, $J=12.0$, $4.1 \mathrm{~Hz}, 2 \mathrm{H}), 1.84-1.74(\mathrm{~m}, 2 \mathrm{H}), 1.67$ (dt, $J=12.9,4.1 \mathrm{~Hz}, 1 \mathrm{H}), 1.50-1.22(\mathrm{~m}, 5 \mathrm{H})$.

${ }^{13}$ C-NMR $\left(100 \mathrm{MHz}, \mathrm{CDCl}_{3}\right) \delta=163.4\left(\mathrm{C}_{\mathrm{q}}\right), 151.8\left(\mathrm{C}_{\mathrm{q}}\right), 150.4\left(\mathrm{C}_{\mathrm{q}}\right), 148.1(\mathrm{CH}), 138.6\left(\mathrm{C}_{\mathrm{q}}\right), 129.0$ $(\mathrm{CH}), 128.8(\mathrm{CH}), 126.8(\mathrm{CH}), 126.3(\mathrm{CH}), 122.7(\mathrm{CH}), 48.1(\mathrm{CH}), 41.4\left(\mathrm{CH}_{2}\right), 33.1\left(\mathrm{CH}_{2}\right), 25.6$ $\left(\mathrm{CH}_{2}\right), 24.9\left(\mathrm{CH}_{2}\right)$.

IR (ATR): 3377, 3051, 2932, 1669, 1521, 1414, 734, $460 \mathrm{~cm}^{-1}$. MS (ESI) $m / z$ (relative intensity): $611(15)[2 \mathrm{M}+\mathrm{Na}]^{+}, 317(20)[\mathrm{M}+\mathrm{Na}]^{+}, 295(100)[\mathrm{M}+\mathrm{H}]^{+}$. HR-MS (ESI) $m / z$ calc. for $\mathrm{C}_{19} \mathrm{H}_{23} \mathrm{~N}_{2} \mathrm{O}[\mathrm{M}+\mathrm{H}]^{+} 295.1805$, found 295.1806.

\subsubsection{Competition Experiment}




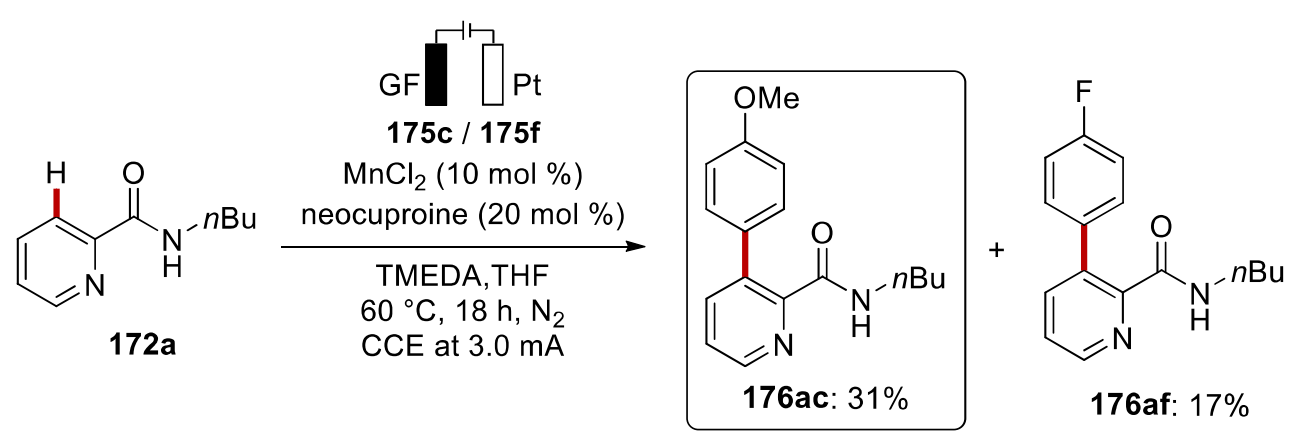

A solution of $172 \mathrm{a}(44.5 \mathrm{mg}, 0.25 \mathrm{mmol}), \mathrm{MnCl}_{2}(3.1 \mathrm{mg}, 10 \mathrm{~mol} \%)$, neocuproine (10.4 $\mathrm{mg}, 20$ mol \%), and TMEDA $(74 \mu \mathrm{L}, 0.5 \mathrm{mmol})$ in THF $(4.0 \mathrm{~mL})$ was place in a $10 \mathrm{~mL}$ cell. $\mathbf{1 7 5 c}(0.40 \mathrm{~mL}$, $1.0 \mathrm{mmol}, 2.5 \mathrm{M}$ in THF) and $\mathbf{1 7 5 f}(0.38 \mathrm{~mL}, 1.0 \mathrm{mmol}, 2.6 \mathrm{M}$ in THF) were added dropwise. The electrolysis was performed at $60{ }^{\circ} \mathrm{C}$ with a constant current of $3.0 \mathrm{~mA}$ for $18 \mathrm{~h}$. After that, a saturated aqueous $\mathrm{NH}_{4} \mathrm{Cl}$ solution $(10 \mathrm{~mL})$ was added, and the $\mathrm{GF}$ anode was washed with EtOAc $(3 \times 2 \mathrm{~mL})$ in an ultrasonic bath. The reaction mixture was extracted with EtOAc $(3 \times 15 \mathrm{~mL})$. The combined organic layers were dried over $\mathrm{Na}_{2} \mathrm{SO}_{4}$, filtered, and concentrated in vacuo. The crude product was purified by column chromatography ( $n$ hexane/ethyl acetate: $2 / 1 \rightarrow 1 / 1)$ to yield 176ac $(22.0 \mathrm{mg}, 31 \%)$ and 176af (11.6 mg, 17\%).

\subsubsection{Well-defined Manganese Complex 215 as Catalyst}

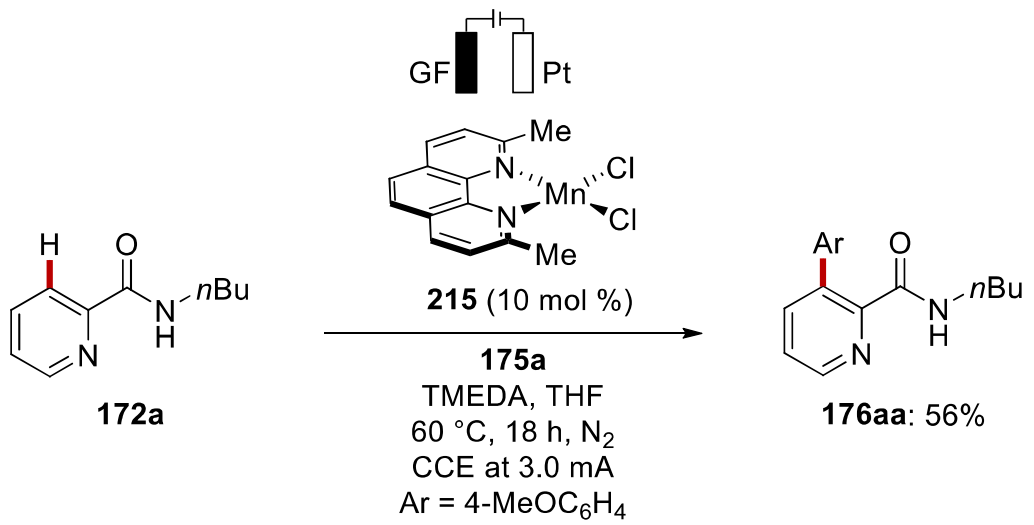

A solution of 172a (44.5 mg, $0.25 \mathrm{mmol})$, manganese complex 215 (8.3 $\mathrm{mg}, 10 \mathrm{~mol} \%$ ), and TMEDA $(74 \mu \mathrm{L}, 0.5 \mathrm{mmol})$ in THF $(4.0 \mathrm{~mL})$ was place in a $10 \mathrm{~mL}$ cell. 175a $(0.40 \mathrm{~mL}, 1.0 \mathrm{mmol}$, 
2.5 $\mathrm{M}$ in THF) was added dropwise. The electrolysis was performed at $60{ }^{\circ} \mathrm{C}$ with a constant current of $3.0 \mathrm{~mA}$. for $18 \mathrm{~h}$. After that, a saturated aqueous $\mathrm{NH}_{4} \mathrm{Cl}$ solution $(10 \mathrm{~mL})$ was added, and the GF anode was washed with EtOAc $(3 \times 2 \mathrm{~mL})$ in an ultrasonic bath. The reaction mixture was extracted with EtOAc $(3 \times 15 \mathrm{~mL})$. The combined organic layers were dried over $\mathrm{Na}_{2} \mathrm{SO}_{4}$, filtered, and concentrated in vacuo. The crude product was purified by column chromatography (nhexane/ethyl acetate: $2 / 1 \rightarrow 1 / 1)$ to yield $\mathbf{1 7 6 a a}(39.8 \mathrm{mg}, 56 \%)$.

\subsubsection{Dependence on the Current}

Three parallel electrolyses were carried out in undivided cells $(10 \mathrm{~mL})$, each equipped with graphite felt anode $(10 \mathrm{~mm} \times 10 \mathrm{~mm} \times 6 \mathrm{~mm})$ and platinum cathode $(10 \mathrm{~mm} \times 15 \mathrm{~mm} \times 0.125 \mathrm{~mm})$. Substrate 172a (44.5 mg, $0.25 \mathrm{mmol}), \mathrm{MnCl}_{2}(3.1 \mathrm{mg}, 10 \mathrm{~mol} \%)$, neocuproine (10.4 mg, $\left.20 \mathrm{~mol} \%\right)$, TMEDA (74 $\mu \mathrm{L}, 0.5 \mathrm{mmol})$, and THF $(4.0 \mathrm{~mL})$ were successively added. 175a $(0.40 \mathrm{~mL}, 1.0 \mathrm{mmol}$, 2.5 $\mathrm{M}$ in THF). The electrolysis was performed at $60^{\circ} \mathrm{C}$. In the time range of 30-90 min, aliquots of $0.1 \mathrm{~mL}$ were taken from each reaction mixture every $30 \mathrm{~min}$. To each aliquot was added $0.1 \mathrm{~mL}$ of an internal standard solution ( $0.5 \mathrm{mmol}$ of 1,3,5-trimethoxybenzene in $4.0 \mathrm{~mL}$ of THF), then treated with saturated aqueous $\mathrm{NH}_{4} \mathrm{Cl}(2.0 \mathrm{~mL})$ and extracted with EtOAc $(3 \times 1.0 \mathrm{~mL})$. The combined organic layers were dried over $\mathrm{Na}_{2} \mathrm{SO}_{4}$, filtered, and concentrated in vacuo. After evaporation of the solvents, the crude mixture was analyzed by ${ }^{1} \mathrm{H}-\mathrm{NMR}$ spectroscopy. The determined yields of 176aa were plotted in Figure 5.7.1. 


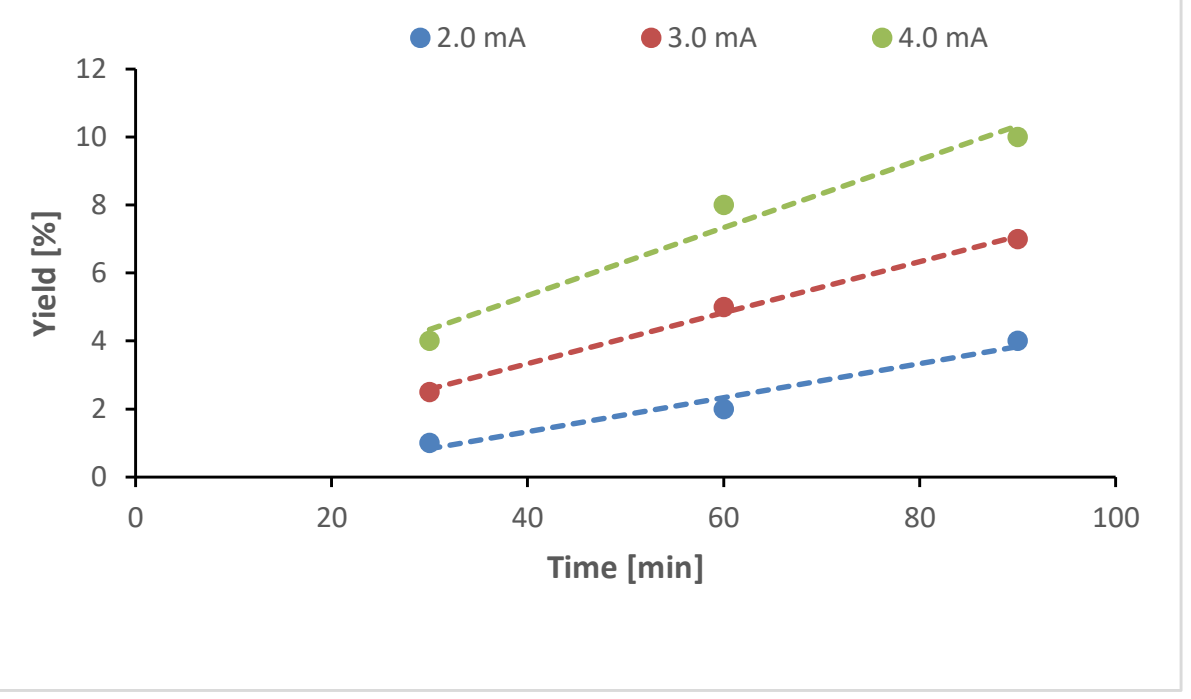

Figure 5.7.1 Manganaelectro-catalyzed $\mathrm{C}-\mathrm{H}$ arylation at different currents, 1,3,5-trimethoxybenzene as internal standard.

\subsubsection{Cyclic Voltammetry Studies}

The cyclic voltammetry (Figure 5.7.2) was carried out with MSc Aude Salamé using a METROHM Autolab PGSTAT204 workstation and the following analysis was performed with Nova 2.0 software. A glassy-carbon (GC) electrode (3 mm diameter, disc-electrode) was used as the working electrode, a Pt wire was employed as the counter electrode and an $\mathrm{Ag} / \mathrm{Ag}^{+}$electrode was used as a quasireference electrode with ferrocene as an internal standard. The measurements were carried out at a scan rate of $100 \mathrm{mVs}^{-1}$. The operation temperature was $298 \mathrm{~K}$. All solutions were degassed via freeze-pump-thaw method prior to use and nitrogen was bubbled through the solutions for at least 5 min before the experiment was performed. The experiments were performed under inert conditions (constant flow of dry nitrogen). 


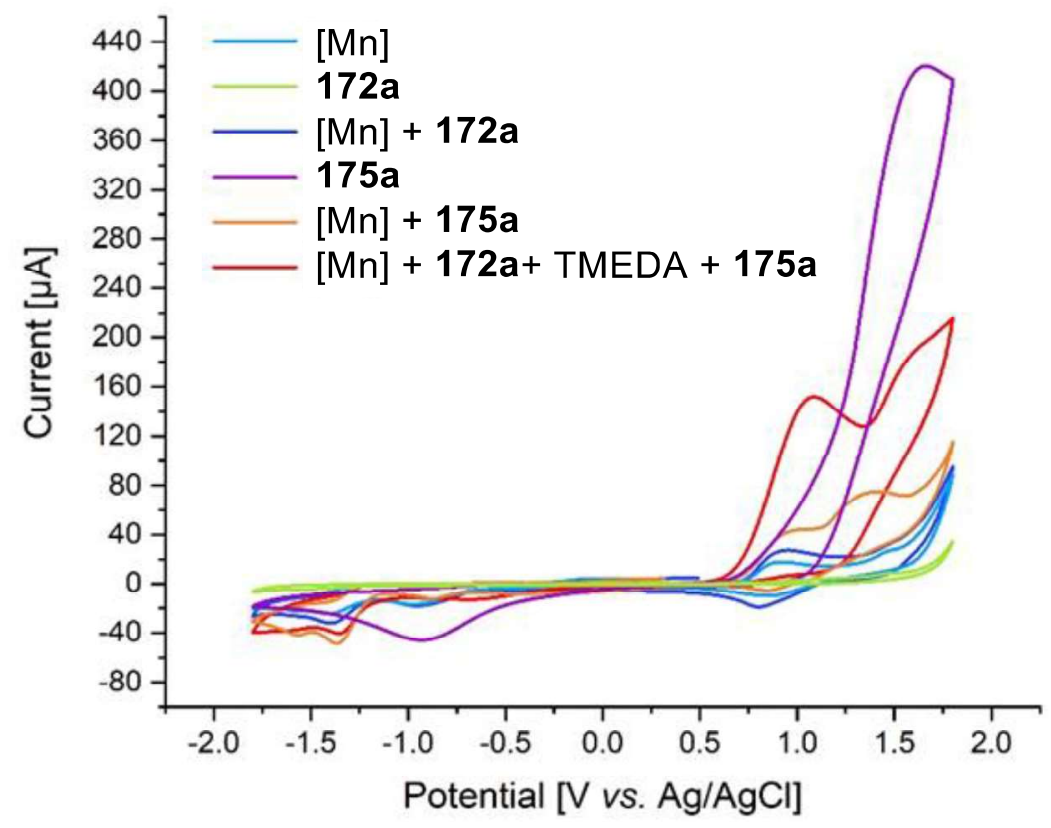

Figure 5.7.2 Cyclic voltammograms of reactants at $100 \mathrm{mVs}^{-1}$ with $n \mathrm{Bu}_{4} \mathrm{NPF}_{6}(0.2 \mathrm{mM}$ in THF); concentrations of substrates $5 \mathrm{mM}$ (Grignard 175a $20 \mathrm{mM}$ ). ${ }^{[173]}$ (light blue), 172a (green), ${ }^{[173]}+$ 172a (blue), 175a (purple), ${ }^{[173]}+\mathbf{1 7 5 a}$ (orange), ${ }^{[173]}+\mathbf{1 7 2} \mathbf{a}+$ TMEDA $+\mathbf{1 7 5 a}$ (red). ${ }^{[173]}=$ complex 215. 


\section{References}

[1] a) P. T. Anastas, M. M. Kirchhoff, Acc. Chem. Res. 2002, 35, 686-694; b) B. Trost, Science 1991, 254, $1471-1477$.

[2] a) C. Jimenez-Gonzalez, C. S. Ponder, Q. B. Broxterman, J. B. Manley, Org. Process Res. Dev. 2011, 15, 912-917; b) D. J. C. Constable, A. D. Curzons, V. L. Cunningham, Green Chem. 2002, 4, 521-527.

[3] J. C. W. P. T. Anastas, Green Chemistry: Theory and Practice, Oxford University Press, New York, 1998.

[4] a) P. Gandeepan, L. H. Finger, T. H. Meyer, L. Ackermann, Chem. Soc. Rev. 2020, 49, 4254-4272; b) T. H. Meyer, L. H. Finger, P. Gandeepan, L. Ackermann, Trends Chem. 2019, 1, 63-76.

[5] a) F. Ullmann, J. Bielecki, Ber. Dtsch. Chem. Ges. 1901, 34, 2174-2185; b) C. Glaser, Ber. Dtsch. Chem. Ges. 1869, 2, 422-424.

[6] a) N. Miyaura, A. Suzuki, Chem. Rev. 1995, 95, 2457-2483; b) A. Suzuki, Acc. Chem. Res. 1982, 15, 178-184; c) N. Miyaura, A. Suzuki, J. Chem. Soc., Chem. Commun. 1979, 866-867; d) N. Miyaura, K. Yamada, A. Suzuki, Tetrahedron Lett. 1979, 20, 3437-3440.

[7] a) E.-i. Negishi, T. Takahashi, S. Baba, D. E. Van Horn, N. Okukado, J. Am. Chem. Soc. 1987, 109, 2393-2401; b) E.i. Negishi, Acc. Chem. Res. 1982, 15, 340-348; c) A. O. King, N. Okukado, E.-i. Negishi, J. Chem. Soc., Chem. Commun. 1977, 683-684; d) E.-i. Negishi, A. O. King, N. Okukado, J. Org. Chem. 1977, 42, 1821-1823.

[8] a) H. A. Dieck, R. F. Heck, J. Org. Chem. 1975, 40, 1083-1090; b) H. A. Dieck, R. F. Heck, J. Am. Chem. Soc. 1974, 96, 1133-1136; c) R. F. Heck, J. P. Nolley, J. Org. Chem. 1972, 37, 2320-2322; d) T. Mizoroki, K. Mori, A. Ozaki, Bull. Chem. Soc. Jpn. 1971, 44, 581-581.

[9] a) R. J. P. Corriu, J. P. Masse, J. Chem. Soc., Chem. Commun. 1972, 144a-144a; b) K. Tamao, K. Sumitani, M. Kumada, J. Am. Chem. Soc. 1972, 94, 4374-4376.

[10] a) T. Hiyama, J. Organomet. Chem. 2002, 653, 58-61; b) Y. Hatanaka, T. Hiyama, J. Org. Chem. 1988, 53, 918-920.

[11] a) J. K. Stille, Angew. Chem. Int. Ed. 1986, 25, 508-524; b) D. Milstein, J. K. Stille, J. Am. Chem. Soc. 1979, 101, 4992-4998; c) D. Milstein, J. K. Stille, J. Am. Chem. Soc. 1978, 100, 3636-3638; d) K. Masanori, S. Kazuo, S. Yutaka, M. Toshihiko, Chem. Lett. 1977, 6, 301-302; e) K. Masanori, S. Yutaka, M. Toshihiko, Chem. Lett. 1977, 6, 1423-1424.

[12] a) K. Sonogashira, J. Organomet. Chem. 2002, 653, 46-49; b) L. Cassar, J. Organomet. Chem. 1975, 93, 253-257; c) H. A. Dieck, F. R. Heck, J. Organomet. Chem. 1975, 93, 259-263; d) K. Sonogashira, Y. Tohda, N. Hagihara, Tetrahedron Lett. 1975, 16, 4467-4470.

[13] a) J. Tsuji, Tetrahedron 1986, 42, 4361-4401; b) B. M. Trost, Acc. Chem. Res. 1980, 13, 385-393; c) B. M. Trost, T. J. Fullerton, J. Am. Chem. Soc. 1973, 95, 292-294; d) J. Tsuji, H. Takahashi, M. Morikawa, Tetrahedron Lett. 1965, 6, 4387-4388.

[14] a) A. S. Guram, S. L. Buchwald, J. Am. Chem. Soc. 1994, 116, 7901-7902; b) F. Paul, J. Patt, J. F. Hartwig, J. Am. Chem. Soc. 1994, 116, 5969-5970.

[15] Nobel Prize Home Page: https://www.nobelprize.org/prizes/chemistry/2010/summary/ (accessed on 13.Sep.2021).

[16] P. A. Wender, V. A. Verma, T. J. Paxton, T. H. Pillow, Acc. Chem. Res. 2008, 41, 40-49.

[17] P. Gandeepan, T. Müller, D. Zell, G. Cera, S. Warratz, L. Ackermann, Chem. Rev. 2019, 119, $2192-2452$.

[18] a) C.-Y. Huang, H. Kang, J. Li, C.-J. Li, J. Org. Chem. 2019, 84, 12705-12721; b) Y. Yang, J. Lan, J. You, Chem. Rev. 2017, 117, 8787-8863; c) S. H. Cho, J. Y. Kim, J. Kwak, S. Chang, Chem. Soc. Rev. 2011, 40, 5068-5083; d) C. S. Yeung, V. M. Dong, Chem. Rev. 2011, 111, 1215-1292; e) C.-J. Li, Acc. Chem. Res. 2009, 42, 335-344.

[19] S. J. Blanksby, G. B. Ellison, Acc. Chem. Res. 2003, 36, 255-263. 
[20] a) Z. Huang, G. Dong, Acc. Chem. Res. 2017, 50, 465-471; b) L. Ackermann, in Directed Metallation (Ed.: N. Chatani), Springer Berlin Heidelberg, Berlin, Heidelberg, 2007, pp. 35-60.

[21] E. M. Beck, M. J. Gaunt, in C-H Activation (Eds.: J.-Q. Yu, Z. Shi), Springer Berlin Heidelberg, 2010, pp. 85-121.

[22] T. P. Pabst, P. J. Chirik, Organometallics 2021, 40, 813-831.

[23] a) U. Dhawa, N. Kaplaneris, L. Ackermann, Org. Chem. Front. 2021, 8, 4886-4913; b) M. Zhang, Y. Zhang, X. Jie, H. Zhao, G. Li, W. Su, Org. Chem. Front. 2014, 1, 843-895.

[24] S. De Sarkar, W. Liu, S. I. Kozhushkov, L. Ackermann, Adv. Synth. Catal. 2014, 356, 1461-1479.

[25] P. Gandeepan, L. Ackermann, Chem 2018, 4, 199-222.

[26] W. Ma, P. Gandeepan, J. Li, L. Ackermann, Org. Chem. Front. 2017, 4, 1435-1467.

[27] a) H. Yi, G. Zhang, H. Wang, Z. Huang, J. Wang, A. K. Singh, A. Lei, Chem. Rev. 2017, 117, 9016-9085; b) J.-T. Yu, C. Pan, Chem. Commun. 2016, 52, 2220-2236.

[28] a) L. Ackermann, Chem. Rev. 2011, 111, 1315-1345; b) D. Balcells, E. Clot, O. Eisenstein, Chem. Rev. 2010, 110, 749-823.

[29] T. Rogge, J. C. A. Oliveira, R. Kuniyil, L. Hu, L. Ackermann, ACS Catal. 2020, 10, 10551-10558.

[30] a) D. Lapointe, K. Fagnou, Chem. Lett. 2010, 39, 1118-1126; b) S. I. Gorelsky, D. Lapointe, K. Fagnou, J. Am. Chem. Soc. 2008, 130, 10848-10849; c) L.-C. Campeau, M. Parisien, A. Jean, K. Fagnou, J. Am. Chem. Soc. 2006, 128, 581-590.

[31] a) Y. Boutadla, D. L. Davies, S. A. Macgregor, A. I. Poblador-Bahamonde, Dalton Trans. 2009, 5887-5893; b) D. L. Davies, S. M. A. Donald, S. A. Macgregor, J. Am. Chem. Soc. 2005, 127, 13754-13755.

[32] a) D. Zell, M. Bursch, V. Müller, S. Grimme, L. Ackermann, Angew. Chem. Int. Ed. 2017, 56, 10378-10382; b) D. Santrač, S. Cella, W. Wang, L. Ackermann, Eur. J. Org. Chem. 2016, 5429-5436; c) H. Wang, M. Moselage, M. J. González, L. Ackermann, ACS Catal. 2016, 6, 2705-2709; d) W. Ma, R. Mei, G. Tenti, L. Ackermann, Chem. Eur. J. 2014, 20, 15248-15251.

[33] a) H. J. Schäfer, C. R. Chimie 2011, 14, 745-765; b) B. A. Frontana-Uribe, R. D. Little, J. G. Ibanez, A. Palma, R. Vasquez-Medrano, Green Chem. 2010, 12, 2099.

[34] M. Faraday, Ann. Phys. 1834, 109, 481-520.

[35] H. Kolbe, Justus Liebigs Ann. Chem. 1849, 69, 257-294.

[36] T. Shono, Tetrahedron 1984, 40, 811-850.

[37] J. H. Simons, J. Electrochem. Soc. 1949, 95, 47-52.

[38] a) A. K. Fazlur-Rahman, J.-C. Tsai, K. M. Nicholas, J. Chem. Soc., Chem. Commun. 1992, 1334-1335; b) M. Bressan, A. Morvillo, Inorg. Chim. Acta 1989, 166, 177-179; c) H. Mimoun, Angew. Chem. Int. Ed. 1982, 21, 734 750; d) H. Mimoun, M. M. Perez Machirant, I. Seree de Roch, J. Am. Chem. Soc. 1978, 100, 5437-5444; e) M. M. Baizer, J. Electrochem. Soc. 1964, 111, 215.

[39] C. Amatore, C. Cammoun, A. Jutand, Adv. Synth. Catal. 2007, 349, 292-296.

[40] F. Kakiuchi, T. Kochi, H. Mutsutani, N. Kobayashi, S. Urano, M. Sato, S. Nishiyama, T. Tanabe, J. Am. Chem. Soc. 2009, 131, 11310-11311.

[41] H. Aiso, T. Kochi, H. Mutsutani, T. Tanabe, S. Nishiyama, F. Kakiuchi, J. Org. Chem. 2012, 77, 7718-7724.

[42] Q.-L. Yang, X.-Y. Wang, T.-L. Wang, X. Yang, D. Liu, X. Tong, X.-Y. Wu, T.-S. Mei, Org. Lett. 2019, 21, $2645-2649$.

[43] Y. B. Dudkina, D. Y. Mikhaylov, T. V. Gryaznova, A. I. Tufatullin, O. N. Kataeva, D. A. Vicic, Y. H. Budnikova, Organometallics 2013, 32, 4785-4792.

[44] Q.-L. Yang, Y.-Q. Li, C. Ma, P. Fang, X.-J. Zhang, T.-S. Mei, J. Am. Chem. Soc. 2017, 139, 3293-3298.

[45] Y.-Q. Li, Q.-L. Yang, P. Fang, T.-S. Mei, D. Zhang, Org. Lett. 2017, 19, 2905-2908. 
[46] A. Shrestha, M. Lee, A. L. Dunn, M. S. Sanford, Org. Lett. 2018, 20, 204-207.

[47] C. Ma, C.-Q. Zhao, Y.-Q. Li, L.-P. Zhang, X.-T. Xu, K. Zhang, T.-S. Mei, Chem. Commun. 2017, 53, 12189-12192.

[48] a) L. Ackermann, Acc. Chem. Res. 2020, 53, 84-104; b) R. Mei, U. Dhawa, R. C. Samanta, W. Ma, J. WencelDelord, L. Ackermann, ChemSusChem 2020, 13, 3306-3356; c) R. C. Samanta, T. H. Meyer, I. Siewert, L. Ackermann, Chem. Sci. 2020, 11, 8657-8670; d) S.-K. Zhang, R. C. Samanta, A. Del Vecchio, L. Ackermann, Chem. Eur. J. 2020, 26, 10936-10947; e) Y. Qiu, J. Struwe, L. Ackermann, Synlett 2019, 30, 1164-1173; f) C. Zhu, M. Stangier, J. C. A. Oliveira, L. Massignan, L. Ackermann, Chem. Eur. J. 2019, 25, 16382-16389; g) N. Sauermann, T. H. Meyer, L. Ackermann, Chem. Eur. J. 2018, 24, 16209-16217; h) N. Sauermann, T. H. Meyer, Y. Qiu, L. Ackermann, ACS Catal. 2018, 8, 7086-7103.

[49] a) P. Wang, X. Gao, P. Huang, A. Lei, ChemCatChem 2020, 12, 27-40; b) H. Wang, X. Gao, Z. Lv, T. Abdelilah, A. Lei, Chem. Rev. 2019, 119, 6769-6787; c) Y. Yuan, A. Lei, Acc. Chem. Res. 2019, 52, 3309-3324; d) S. Tang, L. Zeng, A. Lei, J. Am. Chem. Soc. 2018, 140, 13128-13135.

[50] a) K.-J. Jiao, Y.-K. Xing, Q.-L. Yang, H. Qiu, T.-S. Mei, Acc. Chem. Res. 2020, 53, 300-310; b) Q.-L. Yang, C.-Z. Li, L.-W. Zhang, Y.-Y. Li, X. Tong, X.-Y. Wu, T.-S. Mei, Organometallics 2019, 38, 1208-1212; c) C. Ma, P. Fang, T.-S. Mei, ACS Catal. 2018, 8, 7179-7189; d) Q.-L. Yang, P. Fang, T.-S. Mei, Chin. J. Chem . 2018, 36, 338-352; e) K.-J. Jiao, C.-Q. Zhao, P. Fang, T.-S. Mei, Tetrahedron Lett. 2017, 58, 797-802.

[51] a) Z.-J. Wu, F. Su, W. Lin, J. Song, T.-B. Wen, H.-J. Zhang, H.-C. Xu, Angew. Chem. Int. Ed. 2019, 58, 16770-16774; b) F. Xu, Y.-J. Li, C. Huang, H.-C. Xu, ACS Catal. 2018, 8, 3820-3824.

[52] a) Y. H. Budnikova, Chem. Rec. 2021, 21, 2148-2163; b) X. Ye, C. Wang, S. Zhang, J. Wei, C. Shan, L. Wojtas, Y. Xie, X. Shi, ACS Catal. 2020, 10, 11693-11699; c) S. Kathiravan, S. Suriyanarayanan, I. A. Nicholls, Org. Lett. 2019, 21, 1968-1972; d) M.-J. Luo, M. Hu, R.-J. Song, D.-L. He, J.-H. Li, Chem. Commun. 2019, 55, 1124-1127; e) M.-J. Luo, T.-T. Zhang, F.-J. Cai, J.-H. Li, D.-L. He, Chem. Commun. 2019, 55, 7251-7254; f) Z.-Q. Wang, C. Hou, Y.-F. Zhong, Y.X. Lu, Z.-Y. Mo, Y.-M. Pan, H.-T. Tang, Org. Lett. 2019, 21, 9841-9845.

[53] M. S. Kharasch, E. K. Fields, J. Am. Chem. Soc. 1941, 63, 2316-2320.

[54] S. Murahashi, J. Am. Chem. Soc. 1955, 77, 6403-6404.

[55] S. Murahashi, S. Horiie, J. Am. Chem. Soc. 1956, 78, 4816-4817.

[56] a) R. Beck, H. Sun, X. Li, S. Camadanli, H.-F. Klein, Eur. J. Inorg. Chem. 2008, 3253-3257; b) S. Camadanli, R. Beck, U. Flörke, H.-F. Klein, Dalton Trans. 2008, 5701-5704; c) H.-F. Klein, S. Camadanli, R. Beck, D. Leukel, U. Flörke, Angew. Chem. Int. Ed. 2005, 44, 975-977; d) H.-F. Klein, R. Beck, U. Flörke, H.-J. Haupt, Eur. J. Inorg. Chem. 2003, 1380-1387; e) H.-F. Klein, S. Schneider, M. He, U. Floerke, H.-J. Haupt, Eur. J. Inorg. Chem. 2000, 2295-2301; f) H.-F. Klein, M. Helwig, U. Koch, U. Flörke, H.-J. Haupt, Z. Naturforsch. B 1993, 48, 778-784.

[57] G. Halbritter, F. Knoch, A. Wolski, H. Kisch, Angew. Chem. Int. Ed. 1994, 33, 1603-1605.

[58] L. Grigorjeva, O. Daugulis, Angew. Chem. Int. Ed. 2014, 53, 10209-10212.

[59] S. Rej, Y. Ano, N. Chatani, Chem. Rev. 2020, 120, 1788-1887.

[60] L. Grigorjeva, O. Daugulis, Org. Lett. 2014, 16, 4684-4687.

[61] a) T. T. Nguyen, L. Grigorjeva, O. Daugulis, Angew. Chem. Int. Ed. 2018, 57, 1688-1691; b) S. Zhai, S. Qiu, X. Chen, J. Wu, H. Zhao, C. Tao, Y. Li, B. Cheng, H. Wang, H. Zhai, Chem. Commun. 2018, 54, 98-101; c) Á. M. Martínez, N. Rodríguez, R. Gómez-Arrayás, J. C. Carretero, Chem. Eur. J. 2017, 23, 11669-11676.

[62] R. Mei, H. Wang, S. Warratz, S. A. Macgregor, L. Ackermann, Chem. Eur. J. 2016, 22, 6759-6763.

[63] A. Dey, N. Thrimurtulu, C. M. R. Volla, Org. Lett. 2019, 21, 3871-3875.

[64] W. Ma, L. Ackermann, ACS Catal. 2015, 5, 2822-2825.

[65] N. Thrimurtulu, A. Dey, D. Maiti, C. M. R. Volla, Angew. Chem. Int. Ed. 2016, 55, 12361-12365. 
[66] R. Boobalan, R. Kuppusamy, R. Santhoshkumar, P. Gandeepan, C.-H. Cheng, ChemCatChem 2017, 9, $273-277$.

[67] a) S. Maity, R. Kancherla, U. Dhawa, E. Hoque, S. Pimparkar, D. Maiti, ACS Catal. 2016, 6, 5493-5499; b) R. Manoharan, G. Sivakumar, M. Jeganmohan, Chem. Commun. 2016, 52, 10533-10536; c) T. Yamaguchi, Y. Kommagalla, Y. Aihara, N. Chatani, Chem. Commun. 2016, 52, 10129-10132.

[68] V. G. Landge, G. Jaiswal, E. Balaraman, Org. Lett. 2016, 18, 812-815.

[69] L.-B. Zhang, X.-Q. Hao, S.-K. Zhang, Z.-J. Liu, X.-X. Zheng, J.-F. Gong, J.-L. Niu, M.-P. Song, Angew. Chem. Int. Ed. 2015, 54, 272-275.

[70] J. Lan, H. Xie, X. Lu, Y. Deng, H. Jiang, W. Zeng, Org. Lett. 2017, 19, 4279-4282.

[71] X. Wu, K. Yang, Y. Zhao, H. Sun, G. Li, H. Ge, Nat. Commun. 2015, 6, 6462.

[72] L.-B. Zhang, S.-K. Zhang, D. Wei, X. Zhu, X.-Q. Hao, J.-H. Su, J.-L. Niu, M.-P. Song, Org. Lett. 2016, 18, 1318-1321.

[73] N. Sauermann, T. H. Meyer, C. Tian, L. Ackermann, J. Am. Chem. Soc. 2017, 139, 18452-18455.

[74] S. Tang, D. Wang, Y. Liu, L. Zeng, A. Lei, Nat. Commun. 2018, 9, 798.

[75] R. Mei, N. Sauermann, J. C. A. Oliveira, L. Ackermann, J. Am. Chem. Soc. 2018, 140, 7913-7921.

[76] T. H. Meyer, J. C. A. Oliveira, S. C. Sau, N. W. J. Ang, L. Ackermann, ACS Catal. 2018, 8, 9140-9147.

[77] R. Mei, W. Ma, Y. Zhang, X. Guo, L. Ackermann, Org. Lett. 2019, 21, 6534-6538.

[78] Y. Cao, Y. Yuan, Y. Lin, X. Jiang, Y. Weng, T. Wang, F. Bu, L. Zeng, A. Lei, Green Chem. 2020, 22, $1548-1552$.

[79] T. H. Meyer, J. C. A. Oliveira, D. Ghorai, L. Ackermann, Angew. Chem. Int. Ed. 2020, 59, 10955-10960.

[80] L. Zeng, H. Li, S. Tang, X. Gao, Y. Deng, G. Zhang, C.-W. Pao, J.-L. Chen, J.-F. Lee, A. Lei, ACS Catal. 2018, 8, 54485453.

[81] S. C. Sau, R. Mei, J. Struwe, L. Ackermann, ChemSusChem 2019, 12, 3023-3027.

[82] U. Dhawa, C. Tian, W. Li, L. Ackermann, ACS Catal. 2020, 10, 6457-6462.

[83] N. Sauermann, R. Mei, L. Ackermann, Angew. Chem. Int. Ed. 2018, 57, 5090-5094.

[84] X. Gao, P. Wang, L. Zeng, S. Tang, A. Lei, J. Am. Chem. Soc. 2018, 140, 4195-4199.

[85] C. Tian, U. Dhawa, J. Struwe, L. Ackermann, Chin. J. Chem . 2019, 37, 552-556.

[86] a) A. Fürstner, J. Am. Chem. Soc. 2019, 141, 11-24; b) O. M. Ogba, N. C. Warner, D. J. O'Leary, R. H. Grubbs, Chem. Soc. Rev. 2018, 47, 4510-4544; c) P. Nareddy, F. Jordan, M. Szostak, ACS Catal. 2017, 7, 5721-5745; d) L. Ackermann, Acc. Chem. Res. 2014, 47, 281-295; e) P. B. Arockiam, C. Bruneau, P. H. Dixneuf, Chem. Rev. 2012, 112, 5879-5918; f) L. Ackermann, R. Vicente, Top. Curr. Chem. 2010, 292, 211-229; g) B. M. Trost, F. D. Toste, A. B. Pinkerton, Chem. Rev. 2001, 101, 2067-2096.

[87] a) K. S. Singh, Catalysts 2019, 9, 173; b) R. Manikandan, M. Jeganmohan, Chem. Commun. 2017, 53, 8931-8947; c) R. Manikandan, M. Jeganmohan, Org. Biomol. Chem. 2015, 13, 10420-10436.

[88] J. Chatt, J. M. Davidson, J. Chem. Soc. 1965, 843-855.

[89] L. N. Lewis, J. F. Smith, J. Am. Chem. Soc. 1986, 108, 2728-2735.

[90] E. J. Moore, W. R. Pretzer, T. J. O'Connell, J. Harris, L. LaBounty, L. Chou, S. S. Grimmer, J. Am. Chem. Soc. 1992, 114, 5888-5890.

[91] S. Murai, F. Kakiuchi, S. Sekine, Y. Tanaka, A. Kamatani, M. Sonoda, N. Chatani, Nature 1993, 366, 529-531.

[92] a) C. Jia, T. Kitamura, Y. Fujiwara, Acc. Chem. Res. 2001, 34, 633-639; b) Y. Fujiwara, I. Moritani, S. Danno, R. Asano, S. Teranishi, J. Am. Chem. Soc. 1969, 91, 7166-7169; c) I. Moritani, Y. Fujiwara, Tetrahedron Lett. 1967, 8 , 1119-1122.

[93] H. Weissman, X. Song, D. Milstein, J. Am. Chem. Soc. 2001, 123, 337-338.

[94] L. Ackermann, A. V. Lygin, N. Hofmann, Angew. Chem. Int. Ed. 2011, 50, 6379-6382.

[95] L. Ackermann, J. Pospech, K. Graczyk, K. Rauch, Org. Lett. 2012, 14, 930-933. 
[96] R. K. Chinnagolla, M. Jeganmohan, Chem. Commun. 2012, 48, 2030-2032.

[97] S. Warratz, C. Kornhaaß, A. Cajaraville, B. Niepötter, D. Stalke, L. Ackermann, Angew. Chem. Int. Ed. 2015, 54, 5513-5517.

[98] H. Tan, H. Li, J. Wang, L. Wang, Chem. Eur. J. 2015, 21, 1904-1907.

[99] a) S. Rajkumar, S. Antony Savarimuthu, R. Senthil Kumaran, C. M. Nagaraja, T. Gandhi, Chem. Commun. 2016, 52, 2509-2512; b) K. S. Singh, S. G. Sawant, P. H. Dixneuf, ChemCatChem 2016, 8, 1046-1050; c) Y. Zhao, Z. He, S. Li, J. Tang, G. Gao, J. Lan, J. You, Chem. Commun. 2016, 52, 4613-4616; d) A. Banerjee, S. K. Santra, P. R. Mohanta, B. K. Patel, Org. Lett. 2015, 17, 5678-5681; e) R. Li, Y. Hu, R. Liu, R. Hu, B. Li, B. Wang, Adv. Synth. Catal. 2015, 357, 3885-3892; f) R. Manoharan, M. Jeganmohan, Chem. Commun. 2015, 51, 2929-2932; g) R. Prakash, K. Shekarrao, S. Gogoi, Org. Lett. 2015, 17, 5264-5267; h) Y. Zheng, W.-B. Song, S.-W. Zhang, L.-J. Xuan, Org. Biomol. Chem. 2015, 13, 6474-6478; i) Z. Zuo, X. Yang, J. Liu, J. Nan, L. Bai, Y. Wang, X. Luan, J. Org. Chem. 2015, 80, 3349-3356; j) R. K. Arigela, R. Kumar, T. Joshi, R. Mahar, B. Kundu, RSC Adv. 2014, 4, 57749-57753; k) C.-H. Hung, P. Gandeepan, C.-H. Cheng, ChemCatChem 2014, 6, 2692-2697; I) S. Nakanowatari, L. Ackermann, Chem. Eur. J. 2014, 20, 5409-5413; m) J. D. Dooley, S. Reddy Chidipudi, H. W. Lam, J. Am. Chem. Soc. 2013, 135, 10829-10836.

[100] L. Ackermann, J. Pospech, Org. Lett. 2011, 13, 4153-4155.

[101] A. Bechtoldt, M. E. Baumert, L. Vaccaro, L. Ackermann, Green Chem. 2018, 20, 398-402.

[102] a) L. Ackermann, L. Wang, R. Wolfram, A. V. Lygin, Org. Lett. 2012, 14, 728-731; b) J. Li, C. Kornhaaß, L. Ackermann, Chem. Commun. 2012, 48, 11343-11345.

[103] B. Li, J. Ma, Y. Liang, N. Wang, S. Xu, H. Song, B. Wang, Eur. J. Org. Chem. 2013, 1950-1962.

[104] M. C. Reddy, M. Jeganmohan, Eur. J. Org. Chem. 2013, 1150-1157.

[105] I. Choi, A. M. Messinis, L. Ackermann, Angew. Chem. Int. Ed. 2020, 59, 12534-12540.

[106] V. S. Thirunavukkarasu, S. I. Kozhushkov, L. Ackermann, Chem. Commun. 2014, 50, 29-39.

[107] a) M. Drees, T. Strassner, J. Org. Chem. 2006, 71, 1755-1760; b) J. M. Bakke, A. E. Frøhaug, J. Phys. Org. Chem. 1996, 9, 310-318.

[108] a) E. McNeill, J. Du Bois, Chem. Sci. 2012, 3, 1810-1813; b) E. McNeill, J. Du Bois, J. Am. Chem. Soc. 2010, 132, 10202-10204.

[109] Y. Yang, Y. Lin, Y. Rao, Org. Lett. 2012, 14, 2874-2877.

[110] V. S. Thirunavukkarasu, J. Hubrich, L. Ackermann, Org. Lett. 2012, 14, 4210-4213.

[111] V. S. Thirunavukkarasu, L. Ackermann, Org. Lett. 2012, 14, 6206-6209.

[112] F. Yang, L. Ackermann, Org. Lett. 2013, 15, 718-720.

[113] W. Liu, L. Ackermann, Org. Lett. 2013, 15, 3484-3486.

[114] a) G. Shan, X. Han, Y. Lin, S. Yu, Y. Rao, Org. Biomol. Chem. 2013, 11, 2318-2322; b) X. Yang, G. Shan, Y. Rao, Org. Lett. 2013, 15, 2334-2337.

[115] F. Yang, K. Rauch, K. Kettelhoit, L. Ackermann, Angew. Chem. Int. Ed. 2014, 53, 11285-11288.

[116] a) D. A. Colby, R. G. Bergman, J. A. Ellman, Chem. Rev. 2010, 110, 624-655; b) B. de Bruin, P. H. M. Budzelaar, A. W. Gal, Angew. Chem. Int. Ed. 2004, 43, 4142-4157.

[117] J. M. Kisenyi, G. J. Sunley, J. A. Cabeza, A. J. Smith, H. Adams, N. J. Salt, P. M. Maitlis, J. Chem. Soc., Dalton Trans. 1987, 2459-2466.

[118] a) T. Matsumoto, R. A. Periana, D. J. Taube, H. Yoshida, J. Catal. 2002, 206, 272-280; b) T. Matsumoto, H. Yoshida, Chem. Lett. 2000, 29, 1064-1065.

[119] a) K. Ueura, T. Satoh, M. Miura, Org. Lett. 2007, 9, 1407-1409; b) K. Ueura, T. Satoh, M. Miura, J. Org. Chem. 2007, 72, 5362-5367. 
[120] M. Shimizu, K. Hirano, T. Satoh, M. Miura, J. Org. Chem. 2009, 74, 3478-3483.

[121] S. Mochida, K. Hirano, T. Satoh, M. Miura, J. Org. Chem. 2009, 74, 6295-6298.

[122] M. Shimizu, H. Tsurugi, T. Satoh, M. Miura, Chem. Asian J. 2008, 3, 881-886.

[123] H. Zeng, C.-J. Li, Angew. Chem. Int. Ed. 2014, 53, 13862-13865.

[124] a) L. Cai, X. Zhu, J. Chen, A. Lin, H. Yao, Org. Chem. Front. 2019, 6, 3688-3692; b) P. Sun, S. Gao, C. Yang, S. Guo, A. Lin, H. Yao, Org. Lett. 2016, 18, 6464-6467; c) S. Mochida, M. Shimizu, K. Hirano, T. Satoh, M. Miura, Chem. Asian J. 2010, 5, 847-851; d) T. Uto, M. Shimizu, K. Ueura, H. Tsurugi, T. Satoh, M. Miura, J. Org. Chem. 2008, 73, 298-300.

[125] D. R. Stuart, M. Bertrand-Laperle, K. M. N. Burgess, K. Fagnou, J. Am. Chem. Soc. 2008, 130, 16474-16475.

[126] T. Fukutani, N. Umeda, K. Hirano, T. Satoh, M. Miura, Chem. Commun. 2009, 5141-5143.

[127] K. Kim, J. Hyun, J. Kim, H. Kim, Asian J. Org. Chem. 2017, 6, 907-912.

[128] Y. Wu, B. Zhou, Org. Lett. 2017, 19, 3532-3535.

[129] W. Zhai, B. Li, B. Wang, ChemistrySelect 2018, 3, 8035-8039.

[130] Y. Qiu, C. Tian, L. Massignan, T. Rogge, L. Ackermann, Angew. Chem. Int. Ed. 2018, 57, 5818-5822.

[131] Y. Qiu, W.-J. Kong, J. Struwe, N. Sauermann, T. Rogge, A. Scheremetjew, L. Ackermann, Angew. Chem. Int. Ed. 2018, 57, 5828-5832.

[132] Y. Zhang, J. Struwe, L. Ackermann, Angew. Chem. Int. Ed. 2020, 59, 15076-15080.

[133] Z. Shen, I. Maksso, R. Kuniyil, T. Rogge, L. Ackermann, Chem. Commun. 2021, 57, 3668-3671.

[134] Y. Qiu, A. Scheremetjew, L. Ackermann, J. Am. Chem. Soc. 2019, 141, 2731-2738.

[135] W.-J. Kong, L. H. Finger, J. C. A. Oliveira, L. Ackermann, Angew. Chem. Int. Ed. 2019, 58, 6342-6346.

[136] W.-J. Kong, Z. Shen, L. H. Finger, L. Ackermann, Angew. Chem. Int. Ed. 2020, 59, 5551-5556.

[137] W.-J. Kong, L. H. Finger, A. M. Messinis, R. Kuniyil, J. C. A. Oliveira, L. Ackermann, J. Am. Chem. Soc. 2019, 141, 17198-17206.

[138] J. Kim, K. Shin, S. Jin, D. Kim, S. Chang, J. Am. Chem. Soc. 2019, 141, 4137-4146.

[139] Y. Wang, J. C. A. Oliveira, Z. Lin, L. Ackermann, Angew. Chem. Int. Ed. 2021, 60, 6419-6424.

[140] Y.-K. Xing, X.-R. Chen, Q.-L. Yang, S.-Q. Zhang, H.-M. Guo, X. Hong, T.-S. Mei, Nat. Commun. 2021, $12,930$.

[141] M. Stangier, A. M. Messinis, J. C. A. Oliveira, H. Yu, L. Ackermann, Nat. Commun. 2021, 12, 4736.

[142] W. Liu, L. Ackermann, ACS Catal. 2016, 6, 3743-3752.

[143] a) P. B. Tchounwou, C. G. Yedjou, A. K. Patlolla, D. J. Sutton, in Molecular, Clinical and Environmental Toxicology: Volume 3: Environmental Toxicology (Ed.: A. Luch), Springer Basel, 2012, pp. 133-164; b) S. H. Gilani, Y. Alibhai, J. Toxicol. Environ. Health 1990, 30, 23-31.

[144] M. I. Bruce, M. Z. Iqbal, F. G. A. Stone, J. Chem. Soc. A 1970, 3204-3209.

[145] a) G. J. Depree, L. Main, B. K. Nicholson, J. Organomet. Chem. 1998, 551, 281-291; b) W. Tully, L. Main, B. K. Nicholson, J. Organomet. Chem. 1995, 503, 75-92; c) N. P. Robinson, L. Main, B. K. Nicholson, J. Organomet. Chem. 1988, 349, 209-218; d) L. H. P. Gommans, L. Main, B. K. Nicholson, J. Chem. Soc., Chem. Commun. 1987, 761-762.

[146] a) R. C. Cambie, L. C. Mui Mui, P. S. Rutledge, P. D. Woodgate, J. Organomet. Chem. 1994, 464, 171-182; b) R. C. Cambie, M. R. Metzler, P. S. Rutledge, P. D. Woodgate, J. Organomet. Chem. 1992, 429, 41-57; c) R. C. Cambie, M. R. Metzler, P. S. Rutledge, P. D. Woodgate, J. Organomet. Chem. 1990, 381, C26-C30; d) R. C. Cambie, M. R. Metzler, P. S. Rutledge, P. D. Woodgate, J. Organomet. Chem. 1990, 398, C22-C24.

[147] L. S. Liebeskind, J. R. Gasdaska, J. S. McCallum, S. J. Tremont, J. Org. Chem. 1989, 54, 669-677. 
[148] a) G. J. Depree, L. Main, B. K. Nicholson, N. P. Robinson, G. B. Jameson, J. Organomet. Chem. 2006, 691, 667679; b) J. Albert, J. M. Cadena, J. Granell, X. Solans, M. Font-Bardia, J. Organomet. Chem. 2004, 689, 4889-4896; C) D. Lafrance, J. L. Davis, R. Dhawan, B. A. Arndtsen, Organometallics 2001, 20, 1128-1136; d) M. A. Leeson, B. K. Nicholson, M. R. Olsen, J. Organomet. Chem. 1999, 579, 243-251; e) G. J. Depree, N. D. Childerhouse, B. K. Nicholson, J. Organomet. Chem. 1997, 533, 143-151; f) J.-P. Djukic, A. Maisse, M. Pfeffer, A. de Cian, J. Fischer, Organometallics 1997, 16, 657-667; g) C. Morton, D. J. Duncalf, J. P. Rourke, J. Organomet. Chem. 1997, 530, 19-25; h) J. M. Cooney, L. H. P. Gommans, L. Main, B. K. Nicholson, J. Organomet. Chem. 1988, 349, 197-207; i) J. M. Ressner, P. C. Wernett, C. S. Kraihanzel, A. L. Rheingold, Organometallics 1988, 7, 1661-1663; j) A. Suárez, J. Manuel Vila, M. Teresa Pereira, E. Gayoso, M. Gayoso, J. Organomet. Chem. 1987, 335, 359-363; k) M. I. Bruce, B. L. Goodall, M. Z. Iqbal, F. G. A. Stone, R. J. Doedens, R. G. Little, J. Chem. Soc. D 1971, 1595-1596.

[149] Y. Kuninobu, Y. Nishina, T. Takeuchi, K. Takai, Angew. Chem. Int. Ed. 2007, 46, 6518-6520.

[150] B. Zhou, Y. Hu, C. Wang, Angew. Chem. Int. Ed. 2015, 54, 13659-13663.

[151] W. Liu, G. Cera, J. C. A. Oliveira, Z. Shen, L. Ackermann, Chem. Eur. J. 2017, 23, 11524-11528.

[152] T. Sato, T. Yoshida, H. H. Al Mamari, L. Ilies, E. Nakamura, Org. Lett. 2017, 19, 5458-5461.

[153] Z. Shen, H. Huang, C. Zhu, S. Warratz, L. Ackermann, Org. Lett. 2019, 21, 571-574.

[154] C. Zhu, J. C. A. Oliveira, Z. Shen, H. Huang, L. Ackermann, ACS Catal. 2018, 8, 4402-4407.

[155] I. Choi, Z. Shen, E. Ronge, V. Karius, C. Jooss, L. Ackermann, Chem. Eur. J. 2021, 27, 12737-12741.

[156] a) L. F. T. Novaes, S. Lin, Trends Chem. 2020, 2, 84-85; b) J. C. Siu, N. Fu, S. Lin, Acc Chem Res 2020, 53, 547-560; c) N. Fu, Y. Shen, A. R. Allen, L. Song, A. Ozaki, S. Lin, ACS Catal. 2019, 9, 746-754; d) L. Lu, N. Fu, S. Lin, Synlett 2019, 30, 1199-1203; e) J. B. Parry, N. Fu, S. Lin, Synlett 2018, 29, 257-265; f) K.-Y. Ye, G. Pombar, N. Fu, G. S. Sauer, I. Keresztes, S. Lin, J. Am. Chem. Soc. 2018, 140, 2438-2441; g) N. Fu, G. S. Sauer, S. Lin, J. Am. Chem. Soc. 2017, 139, 15548-15553; h) N. Fu, G. S. Sauer, A. Saha, A. Loo, S. Lin, Science 2017, 357, 575-579.

[157] H. Schäfer, Angew. Chem. Int. Ed. 1970, 9, 158-159.

[158] L. Niu, C. Jiang, Y. Liang, D. Liu, F. Bu, R. Shi, H. Chen, A. D. Chowdhury, A. Lei, J. Am. Chem. Soc. 2020, 142, 17693-17702.

[159] T. H. Meyer, R. C. Samanta, A. Del Vecchio, L. Ackermann, Chem. Sci. 2021, 12, 2890-2897.

[160] a) C. L. Hill, J. A. Smegal, T. J. Henly, J. Org. Chem. 1983, 48, 3277-3281; b) C. L. Hill, B. C. Schardt, J. Am. Chem. Soc. 1980, 102, 6374-6375.

[161] X. Huang, T. M. Bergsten, J. T. Groves, J. Am. Chem. Soc. 2015, 137, 5300-5303.

[162] T. Rogge, N. Kaplaneris, N. Chatani, J. Kim, S. Chang, B. Punji, L. L. Schafer, D. G. Musaev, J. Wencel-Delord, C. A. Roberts, R. Sarpong, Z. E. Wilson, M. A. Brimble, M. J. Johansson, L. Ackermann, Nat. Rev. Methods Primers 2021, 1, 43.

[163] a) C. Zhu, N. W. J. Ang, T. H. Meyer, Y. Qiu, L. Ackermann, ACS Cent. Sci. 2021, 7, 415-431; b) T. H. Meyer, I. Choi, C. Tian, L. Ackermann, Chem 2020, 6, 2484-2496.

[164] a) T. T. Nguyen, L. Grigorjeva, O. Daugulis, Chem. Commun. 2017, 53, 5136-5138; b) O. Planas, S. Roldán-Gómez, V. Martin-Diaconescu, T. Parella, J. M. Luis, A. Company, X. Ribas, J. Am. Chem. Soc. 2017, 139, 14649-14655; c) X.-Q. Hao, C. Du, X. Zhu, P.-X. Li, J.-H. Zhang, J.-L. Niu, M.-P. Song, Org. Lett. 2016, 18, 3610-3613; d) T. T. Nguyen, L. Grigorjeva, O. Daugulis, ACS Catal. 2016, 6, 551-554; e) O. Planas, C. J. Whiteoak, V. Martin-Diaconescu, I. Gamba, J. M. Luis, T. Parella, A. Company, X. Ribas, J. Am. Chem. Soc. 2016, 138, 14388-14397; f) O. Daugulis, J. Roane, L. D. Tran, Acc. Chem. Res. 2015, 48, 1053-1064; g) O. Planas, C. J. Whiteoak, A. Company, X. Ribas, Adv. Synth. Catal. 2015, 357, 4003-4012; h) B. Sun, T. Yoshino, M. Kanai, S. Matsunaga, Angew. Chem. Int. Ed. 2015, 54, 12968-12972; i) L.-B. Zhang, X.-Q. Hao, Z.-J. Liu, X.-X. Zheng, S.-K. Zhang, J.-L. Niu, M.-P. Song, Angew. Chem. 
Int. Ed. 2015, 54, 10012-10015; j) H. Ikemoto, T. Yoshino, K. Sakata, S. Matsunaga, M. Kanai, J. Am. Chem. Soc. 2014, 136, 5424-5431.

[165] a) S. Doobary, A. T. Sedikides, H. P. Caldora, D. L. Poole, A. J. J. Lennox, Angew. Chem. Int. Ed. 2020, 59, 11551160; b) W.-C. Gao, Z.-Y. Xiong, S. Pirhaghani, T. Wirth, Synthesis 2019, 51, 276-284; c) J. D. Herszman, M. Berger, S. R. Waldvogel, Org. Lett. 2019, 21, 7893-7896; d) M. Elsherbini, T. Wirth, Chem. Eur. J. 2018, 24, 13399-13407; e) T. Broese, R. Francke, Org. Lett. 2016, 18, 5896-5899; f) S. Nishiyama, Y. Amano, Heterocycles 2008, 75, 1997; g) T. Fuchigami, T. Fujita, J. Org. Chem. 1994, 59, 7190-7192.

[166] G. P. McGlacken, L. M. Bateman, Chem. Soc. Rev. 2009, 38, 2447-2464.

[167] a) S. R. Yetra, T. Rogge, S. Warratz, J. Struwe, W. Peng, P. Vana, L. Ackermann, Angew. Chem. Int. Ed. 2019, 58, 7490-7494; b) S. Handa, J. D. Smith, M. S. Hageman, M. Gonzalez, B. H. Lipshutz, ACS Catal. 2016, 6, 8179-8183; c) S. Handa, E. D. Slack, B. H. Lipshutz, Angew. Chem. Int. Ed. 2015, 54, 11994-11998; d) S. Handa, Y. Wang, F. Gallou, B. H. Lipshutz, Science 2015, 349, 1087-1091; e) T. Nishikata, A. R. Abela, S. Huang, B. H. Lipshutz, J. Am. Chem. Soc. 2010, 132, 4978-4979.

[168] a) J. M. Ramos-Villaseñor, E. Rodríguez-Cárdenas, C. E. Barrera Díaz, B. A. Frontana-Uribe, J. Electrochem. Soc. 2020, 167, 155509; b) L. Schulz, S. R. Waldvogel, Synlett 2019, 30, 275-286; c) S. K. Sinha, T. Bhattacharya, D. Maiti, React. Chem. Eng. 2019, 4, 244-253; d) O. Hollóczki, A. Berkessel, J. Mars, M. Mezger, A. Wiebe, S. R. Waldvogel, B. Kirchner, ACS Catal. 2017, 7, 1846-1852.

[169] a) M. Deponti, S. I. Kozhushkov, D. S. Yufit, L. Ackermann, Org. Biomol. Chem. 2013, 11, 142-148; b) L. Ackermann, A. V. Lygin, Org. Lett. 2012, 14, 764-767; c) L. Ackermann, L. Wang, A. V. Lygin, Chem. Sci. 2012, 3, 177-180; d) K. Parthasarathy, N. Senthilkumar, J. Jayakumar, C.-H. Cheng, Org. Lett. 2012, 14, 3478-3481; e) V. S. Thirunavukkarasu, M. Donati, L. Ackermann, Org. Lett. 2012, 14, 3416-3419.

[170] D. Nicewicz, H. Roth, N. Romero, Synlett 2016, 27, 714-723.

[171] Y. Qiu, C. Zhu, M. Stangier, J. Struwe, L. Ackermann, CCS Chem. 2021, 3, 1529-1552.

[172] a) D. Aynetdinova, M. C. Callens, H. B. Hicks, C. Y. X. Poh, B. D. A. Shennan, A. M. Boyd, Z. H. Lim, J. A. Leitch, D. J. Dixon, Chem. Soc. Rev. 2021, 50, 5517-5563; b) K. Feng, R. E. Quevedo, J. T. Kohrt, M. S. Oderinde, U. Reilly, M. C. White, Nature 2020, 580, 621-627; c) S. D. Friis, M. J. Johansson, L. Ackermann, Nat. Chem. 2020, 12, 511519; d) H. Schönherr, T. Cernak, Angew. Chem. Int. Ed. 2013, 52, 12256-12267.

[173] A. F. B. Räder, M. Weinmüller, F. Reichart, A. Schumacher-Klinger, S. Merzbach, C. Gilon, A. Hoffman, H. Kessler, Angew. Chem. Int. Ed. 2018, 57, 14414-14438.

[174] L. R. F. A. J. Bard, Electrochemical Methods - Fundamentals and Applications, 2nd Ed., John Wiley \& Sons, US, 2001.

[175] C. Tian, L. Massignan, T. H. Meyer, L. Ackermann, Angew. Chem. Int. Ed. 2018, 57, 2383-2387.

[176] L. Massignan, X. Tan, T. H. Meyer, R. Kuniyil, A. M. Messinis, L. Ackermann, Angew. Chem. Int. Ed. 2020, 59, 3184-3189.

[177] X. Tan, L. Massignan, X. Hou, J. Frey, J. C. A. Oliveira, M. N. Hussain, L. Ackermann, Angew. Chem. Int. Ed. 2021, 60, 13264-13270.

[178] L. Massignan, C. Zhu, X. Hou, J. C. A. Oliveira, A. Salamé, L. Ackermann, ACS Catal. 2021, 11, 11639-11649.

[179] a) W. Zhang, N. Hong, L. Song, N. Fu, Chem Rec. 2021, 21, 2574-2584; b) N. P. Martínez, M. Isaacs, K. K. Nanda, New J. Chem. 2020, 44, 5617-5637; c) R. S. Sherbo, R. S. Delima, V. A. Chiykowski, B. P. MacLeod, C. P. Berlinguette, Nat. Catal. 2018, 1, 501-507.

[180] a) X. Chang, Q. Zhang, C. Guo, Angew. Chem. Int. Ed. 2020, 59, 12612-12622; b) A. M. F. Phillips, A. J. L. Pombeiro, Org. Biomol. Chem. 2020, 18, 7026-7055; c) Q. Lin, L. Li, S. Luo, Chem. Eur. J. 2019, 25, 10033-10044. 
[181] a) Y. Qiu, A. Scheremetjew, L. H. Finger, L. Ackermann, Chem. Eur. J. 2020, 26, 3241-3246; b) H. Yan, Z.-W. Hou, H.-C. Xu, Angew. Chem. Int. Ed. 2019, 58, 4592-4595.

[182] a) D. Pletcher, R. A. Green, R. C. D. Brown, Chem. Rev. 2018, 118, 4573-4591; b) A. A. Folgueiras-Amador, T. Wirth, J. Flow Chem. 2017, 7, 94-95.

[183] a) D. M. Heard, A. J. J. Lennox, Angew. Chem. Int. Ed. 2020, 59, 18866-18884; b) A. Das, S. S. Stahl, Angew. Chem. 2017, 129, 9018-9023; c) D. Bélanger, J. Pinson, Chem. Soc. Rev. 2011, 40, 3995-4048.

[184] M. Zhong, K. Tran, Y. Min, C. Wang, Z. Wang, C.-T. Dinh, P. De Luna, Z. Yu, A. S. Rasouli, P. Brodersen, S. Sun, O. Voznyy, C.-S. Tan, M. Askerka, F. Che, M. Liu, A. Seifitokaldani, Y. Pang, S.-C. Lo, A. Ip, Z. Ulissi, E. H. Sargent, Nature 2020, 581, 178-183.

[185] C. Tian, T. H. Meyer, M. Stangier, U. Dhawa, K. Rauch, L. H. Finger, L. Ackermann, Nat. Protoc. 2020, 15, 17601774.

[186] K. C. Nicolaou, J. Becker, Y. H. Lim, A. Lemire, T. Neubauer, A. Montero, J. Am. Chem. Soc. 2009, 131, 1481214826.

[187] Y. Zhao, V. Snieckus, J. Am. Chem. Soc. 2014, 136, 11224-11227.

[188] D. R. Henton, K. Anderson, M. J. Manning, J. S. Swenton, J. Org. Chem. 1980, 45, 3422-3433.

[189] K. V. Chuang, R. Navarro, S. E. Reisman, Chem. Sci. 2011, 2, 1086-1089.

[190] S. Mavel, N. Meheux, D. Guilloteau, P. Emond, Bioorg. Med. Chem. 2010, 18, 236-241.

[191] M. A. J. Miah, M. P. Sibi, S. Chattopadhyay, O. B. Familoni, V. Snieckus, Eur. J. Org. Chem. 2018, $2018,440-446$.

[192] G. Shan, X. Yang, L. Ma, Y. Rao, Angew. Chem. Int. Ed. 2012, 51, 13070-13074.

[193] H. Xie, Z. Ye, Z. Ke, J. Lan, H. Jiang, W. Zeng, Chem. Sci. 2018, 9, 985-989. 


\section{Appendix: NMR Spectra}

7.1 Electrochemical $\mathrm{C}-\mathrm{H} / \mathrm{N}-\mathrm{H}$ Activation by Water-Tolerant Cobalt-Catalysis at Room Temperature

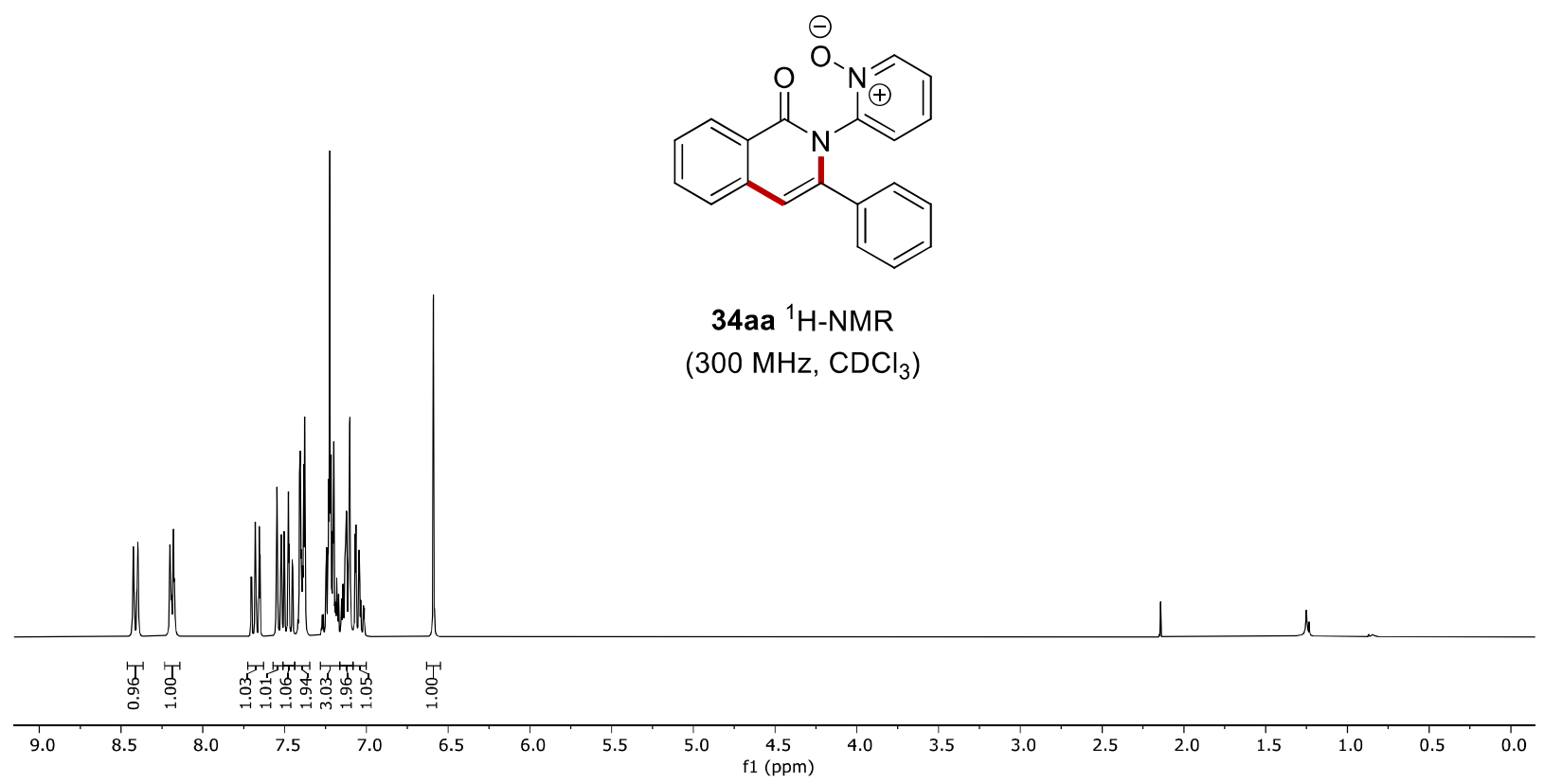




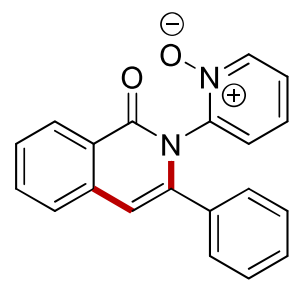

34aa ${ }^{13} \mathrm{C}-\mathrm{NMR}$

$\left(125 \mathrm{MHz}, \mathrm{CDCl}_{3}\right)$

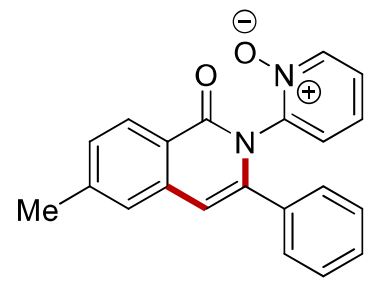

34ba ${ }^{1} \mathrm{H}-\mathrm{NMR}$

(300 MHz, $\mathrm{CDCl}_{3}$ )

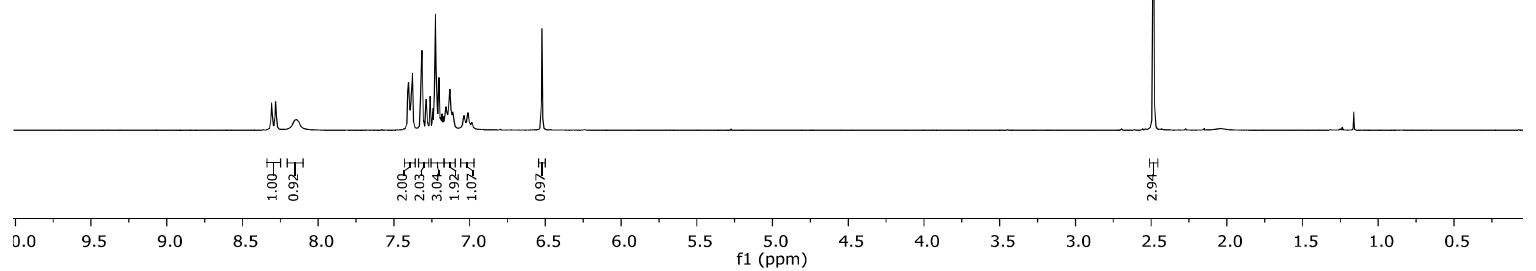




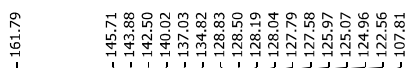

$11 / 111$<smiles>Cc1ccc2c(=O)n(-c3cccc[n+]3[O-])c(-c3ccccc3)cc2c1</smiles>

34ba ${ }^{13} \mathrm{C}-\mathrm{NMR}$

$\left(125 \mathrm{MHz} \mathrm{CDCl}_{3}\right)$

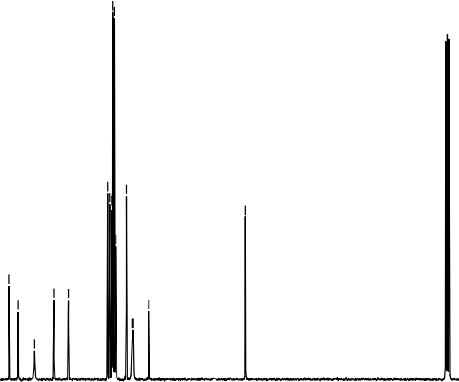

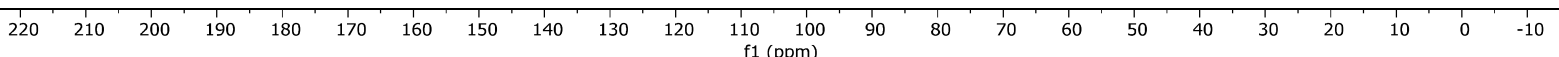<smiles></smiles>

34ca ${ }^{1} \mathrm{H}-\mathrm{NMR}$

(400 MHz, $\mathrm{CDCl}_{3}$ )

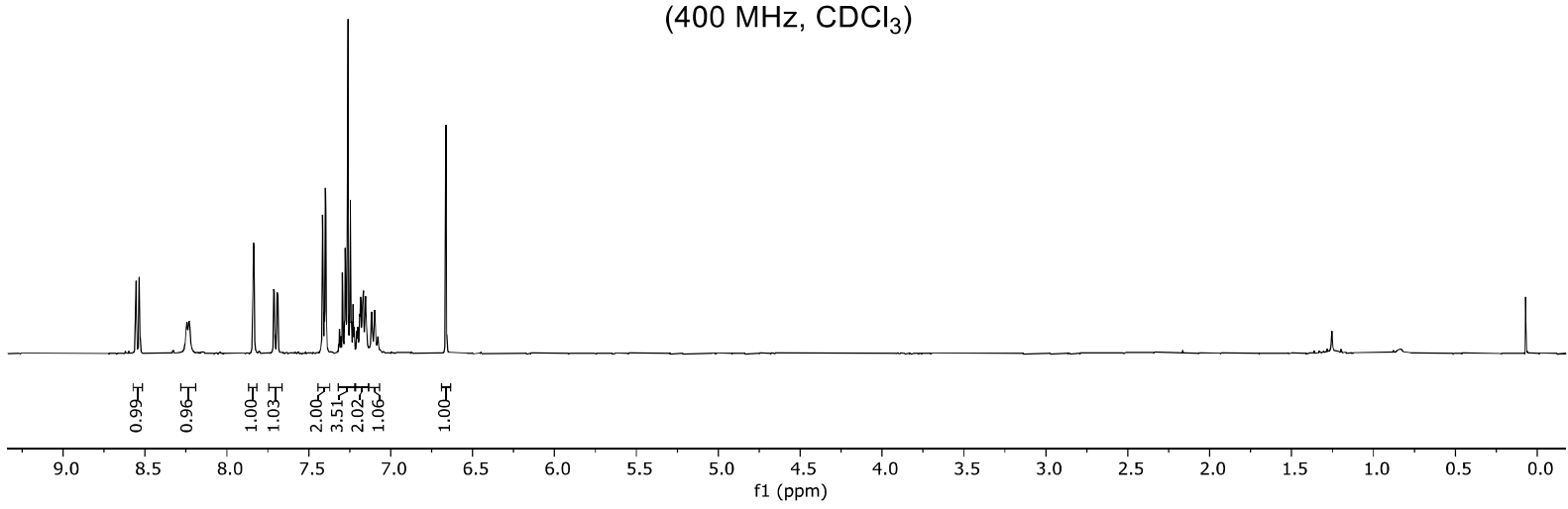




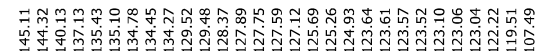

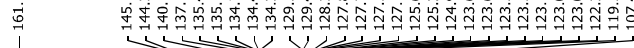<smiles></smiles>

34ca ${ }^{13} \mathrm{C}-\mathrm{NMR}$

(100 MHz, $\mathrm{CDCl}_{3}$ )
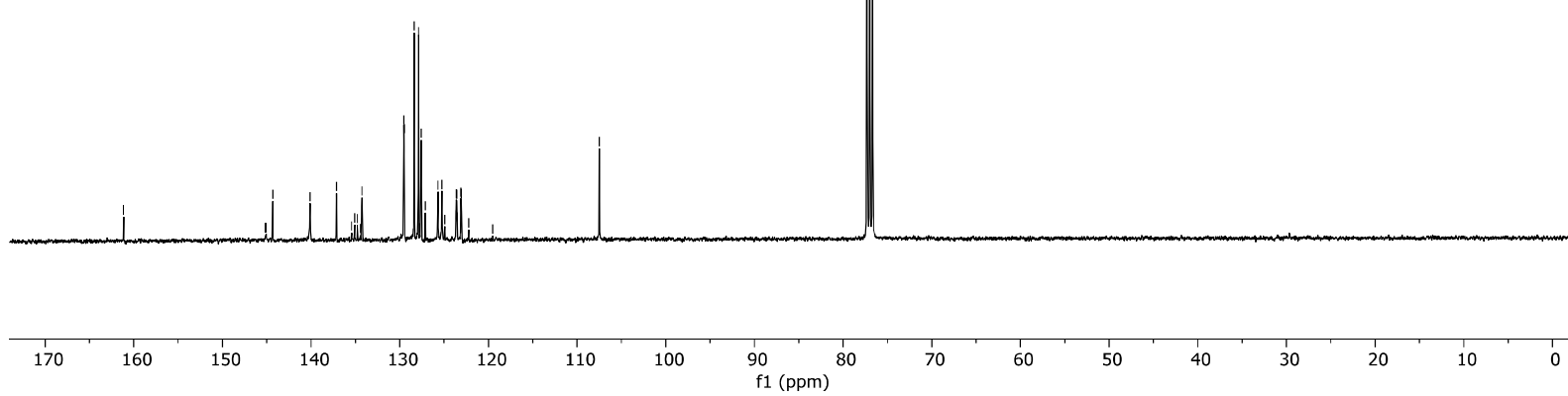

i

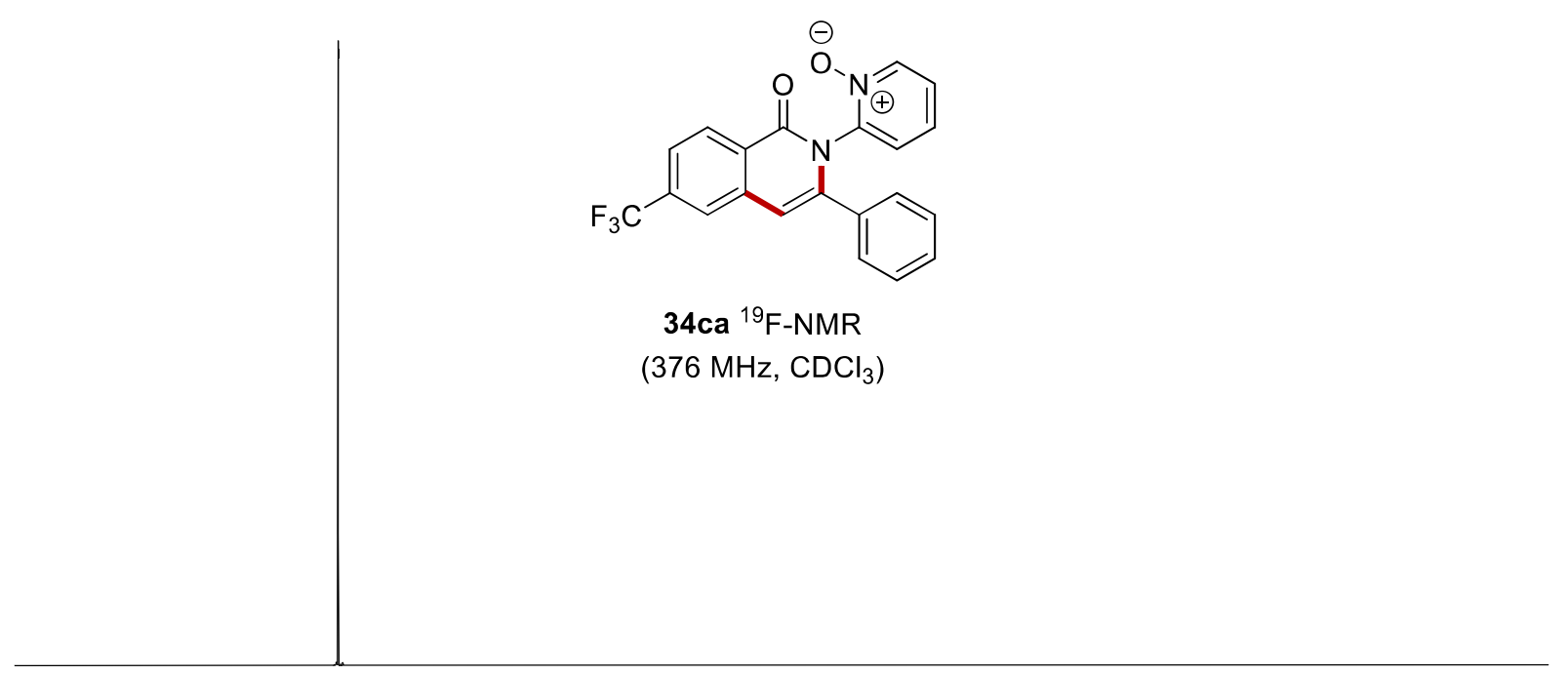

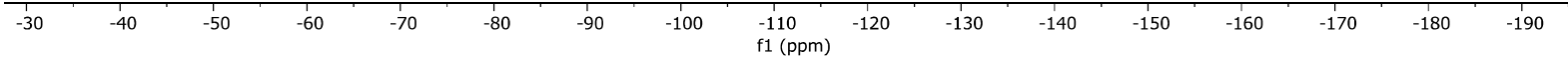




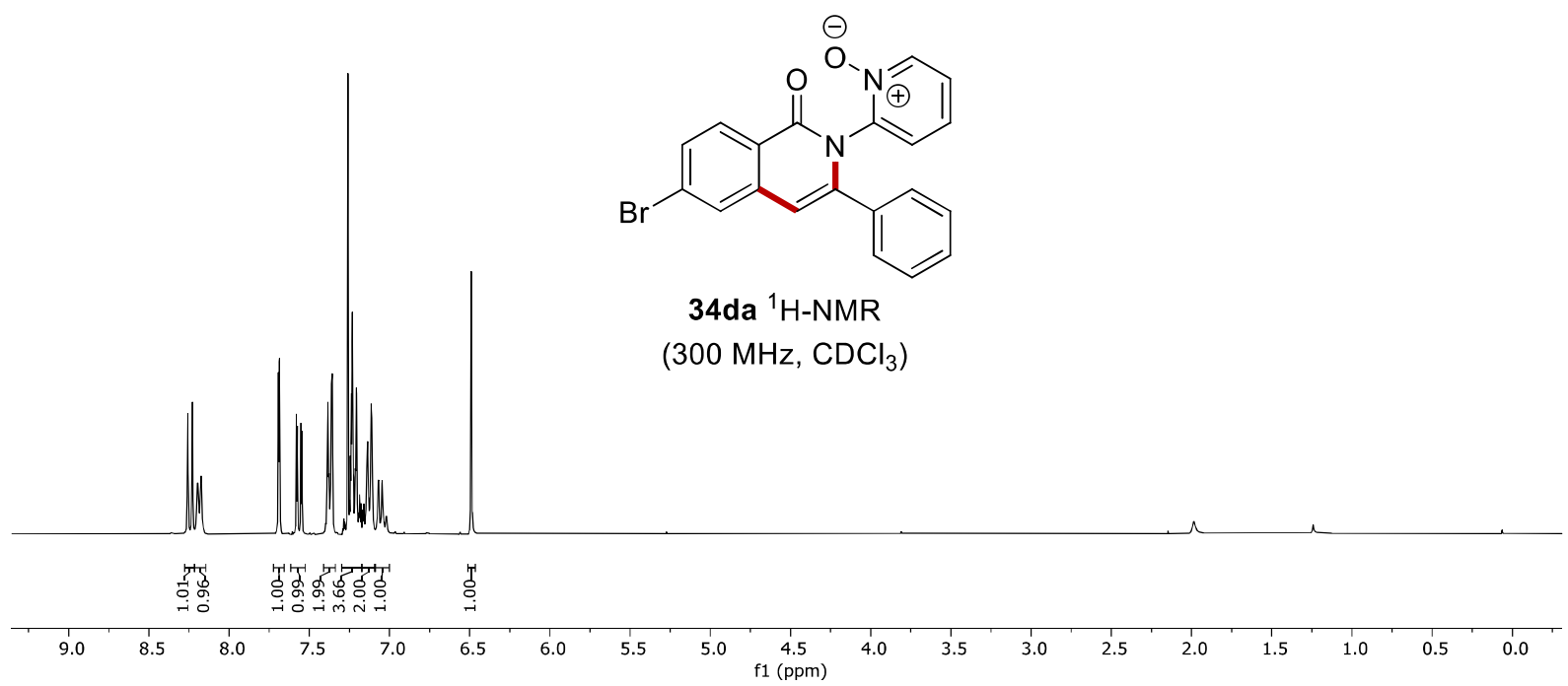

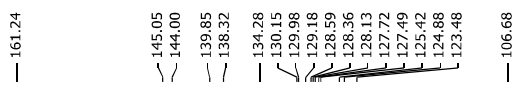

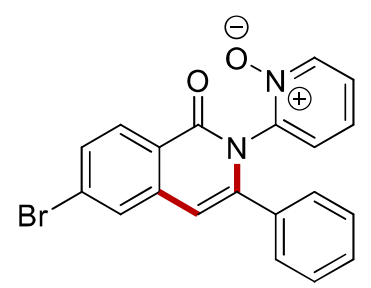

34da ${ }^{13} \mathrm{C}-\mathrm{NMR}$

$\left(125 \mathrm{MHz}, \mathrm{CDCl}_{3}\right)$

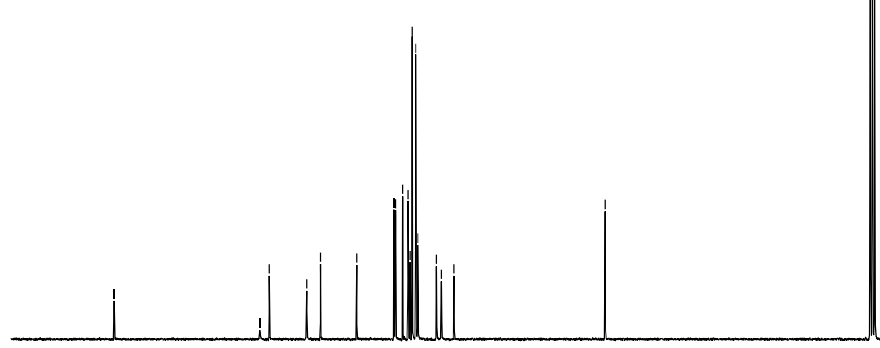

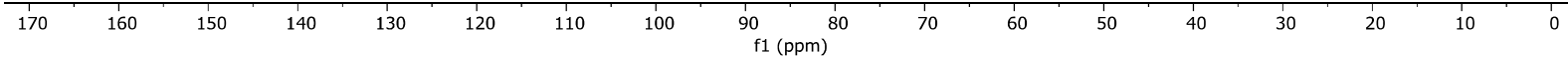




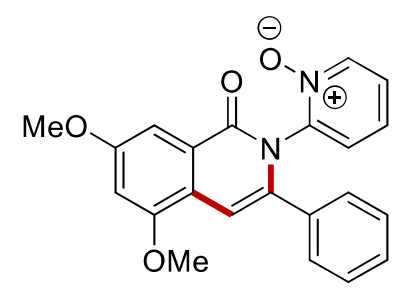

34ea ${ }^{1} \mathrm{H}-\mathrm{NMR}$

$\left(300 \mathrm{MHz}, \mathrm{CDCl}_{3}\right)$

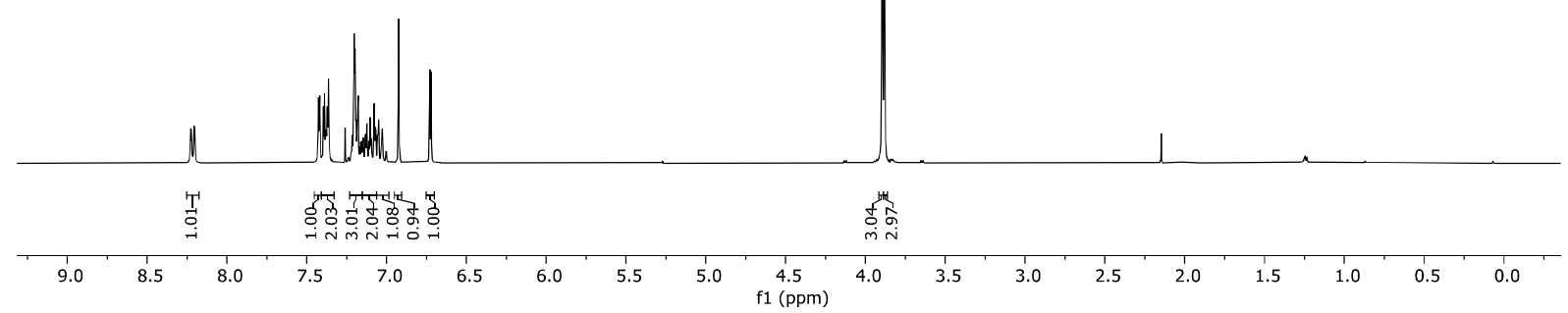

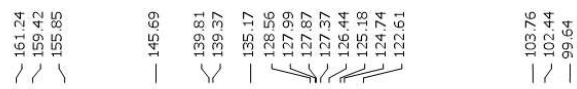

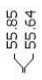

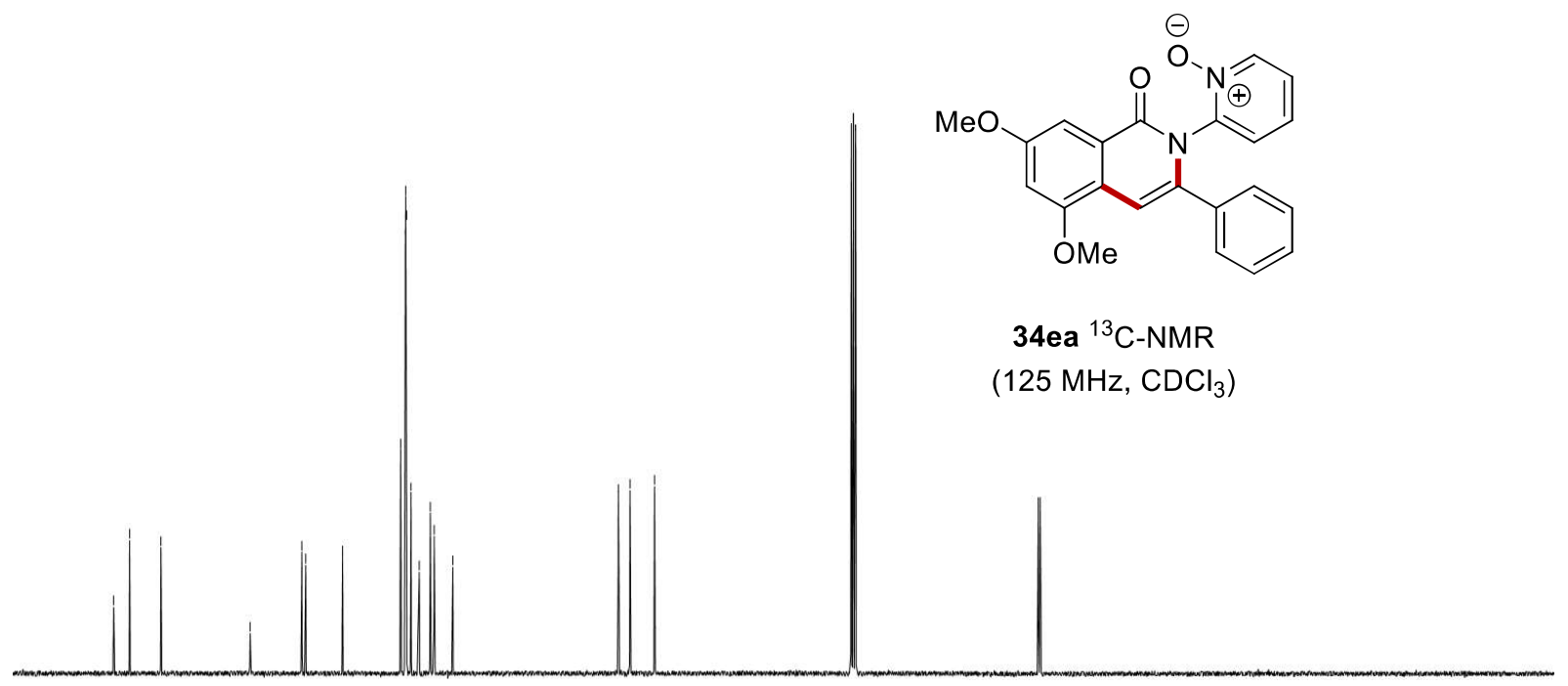

\begin{tabular}{lllllllll}
\hline 170 & 160 & 150 & 140 & 130 & 120 & 110 & 100 & 90 \\
$\mathrm{f} 1(\mathrm{ppm})$
\end{tabular} 


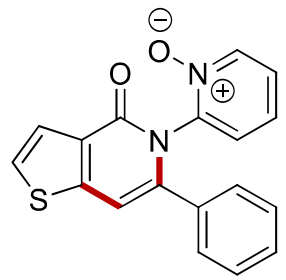

34fa ${ }^{1} \mathrm{H}-\mathrm{NMR}$

(300 MHz, $\mathrm{CDCl}_{3}$ )
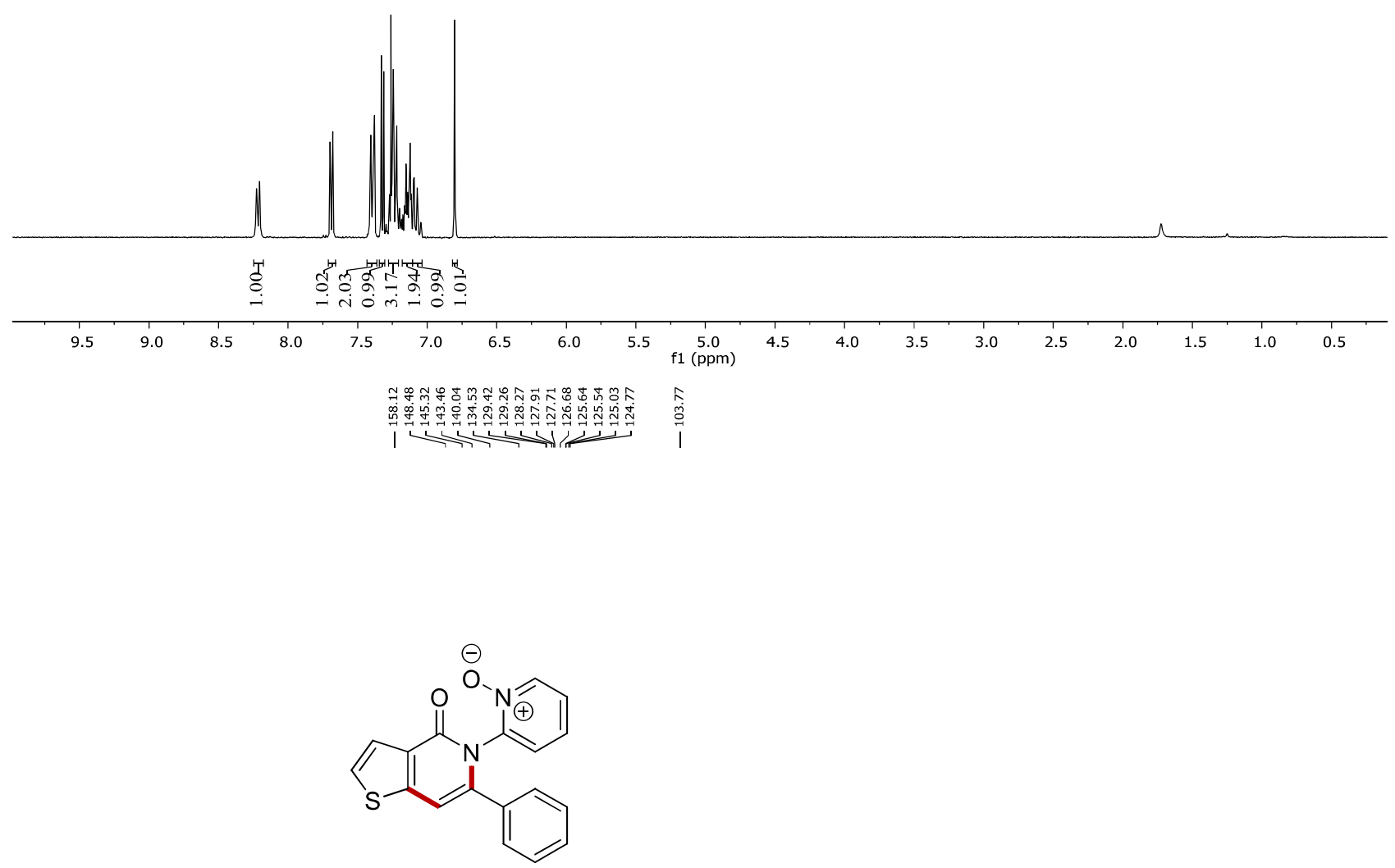

$34 \mathrm{fa}{ }^{13} \mathrm{C}-\mathrm{NMR}$

(125 MHz, $\mathrm{CDCl}_{3}$ )

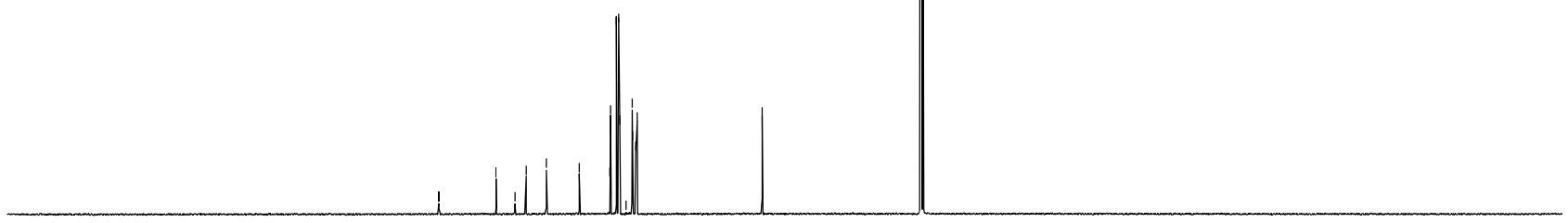

$\begin{array}{llllllllllllllllllllllllllll}30 & 220 & 210 & 200 & 190 & 180 & 170 & 160 & 150 & 140 & 130 & 120 & 110 & 100 & 90 & 80 & 70 & 60 & 50 & 40 & 30 & 20 & 10 & 0 & -10 & -20 & -3\end{array}$ 


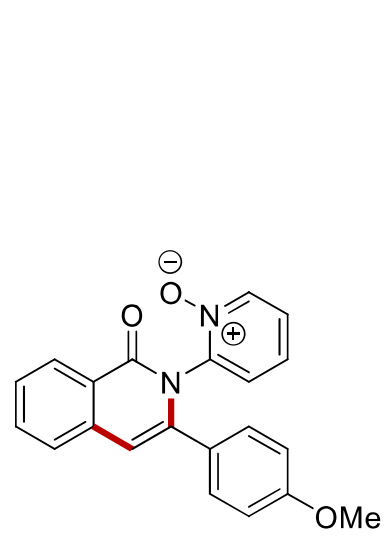

34ab ${ }^{1} \mathrm{H}-\mathrm{NMR}$

$\left(300 \mathrm{MHz}, \mathrm{CDCl}_{3}\right)$

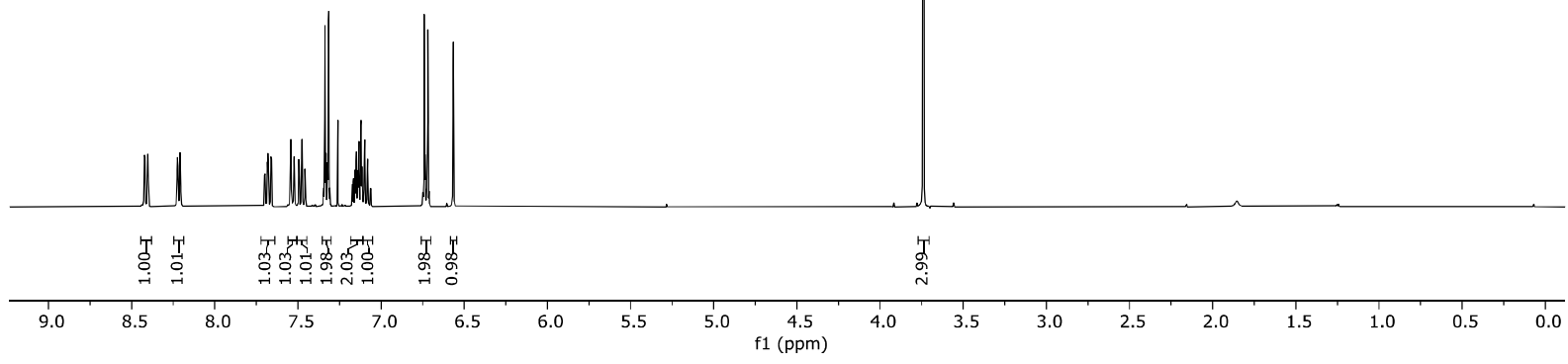

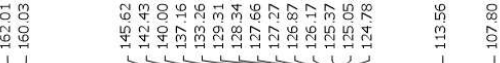

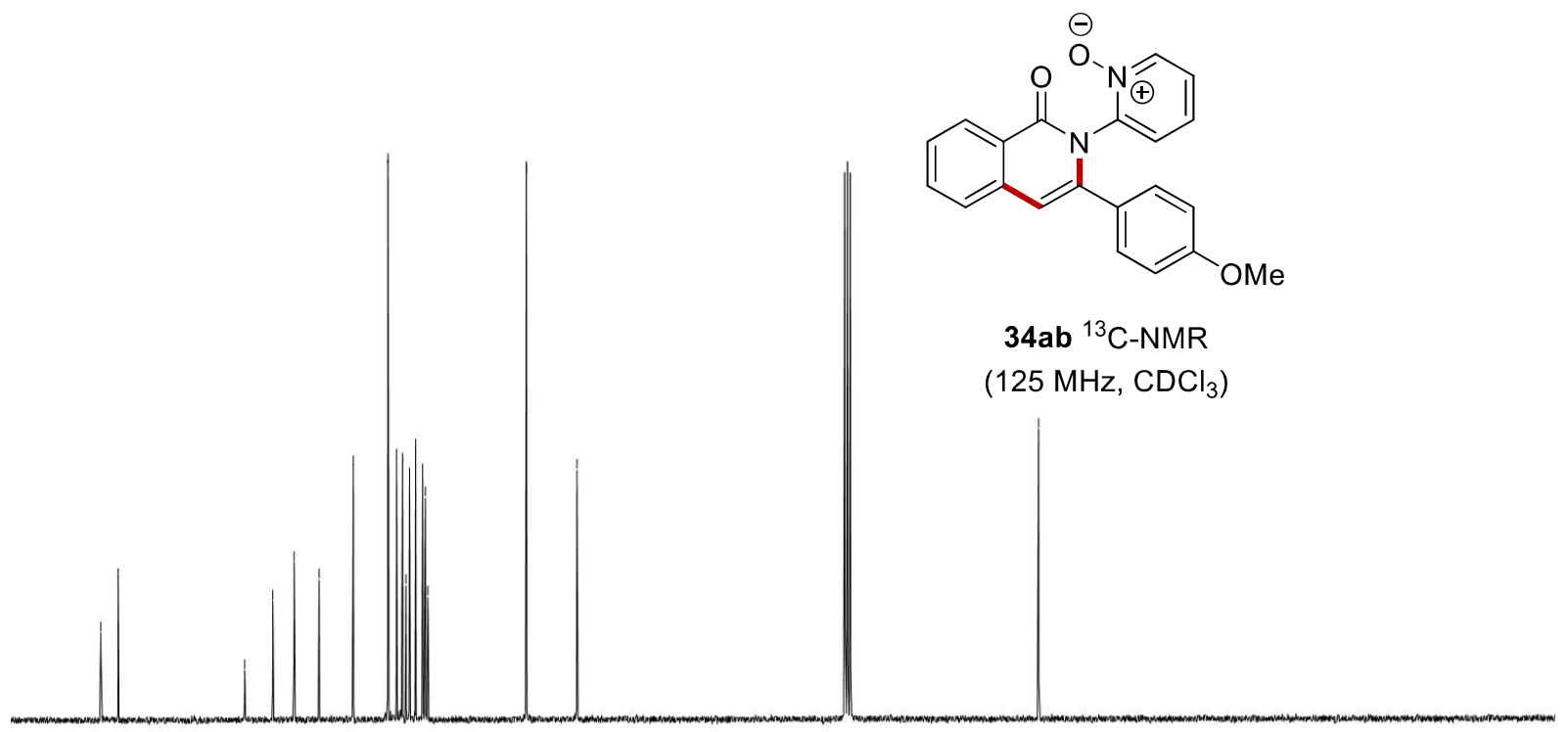




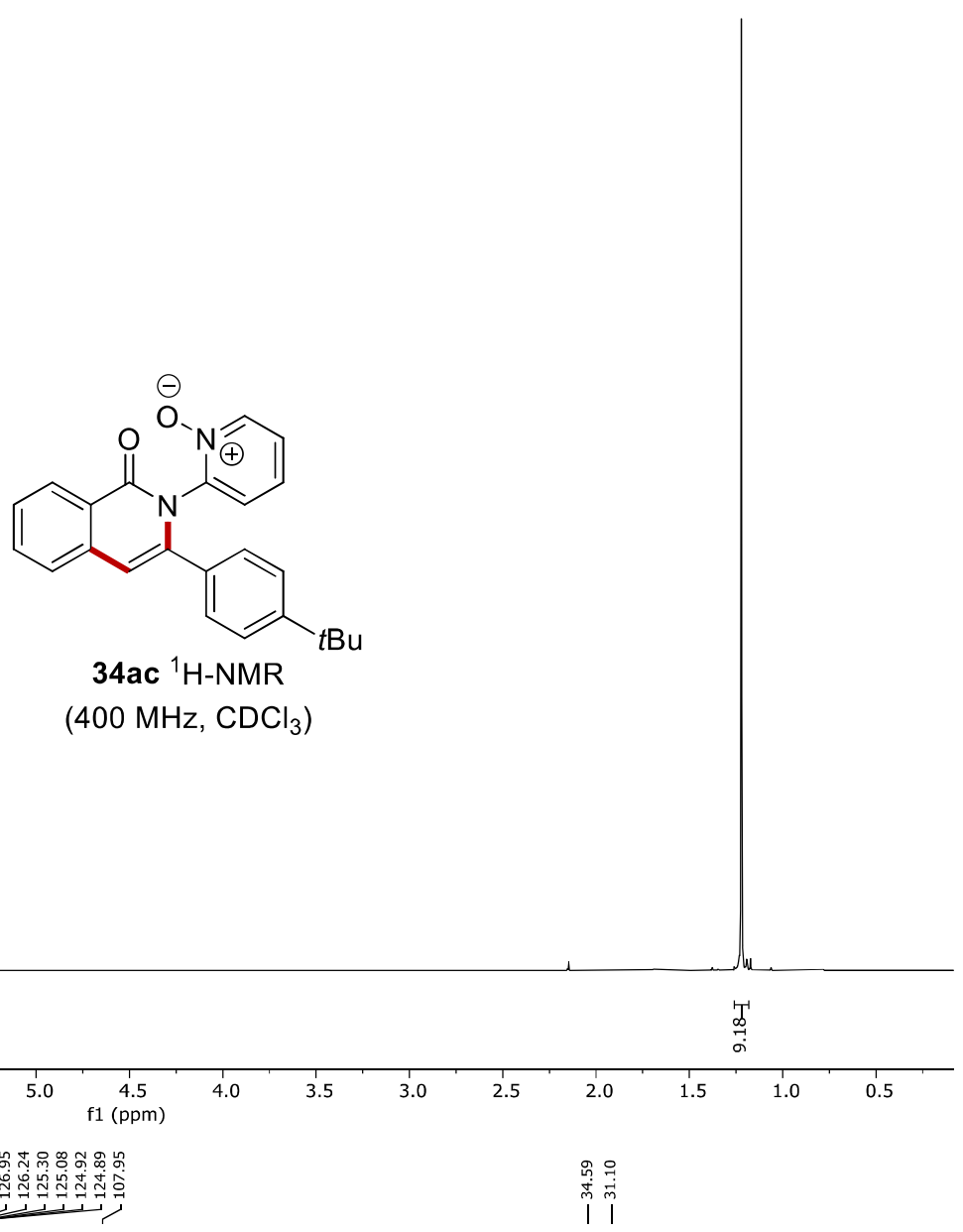

|

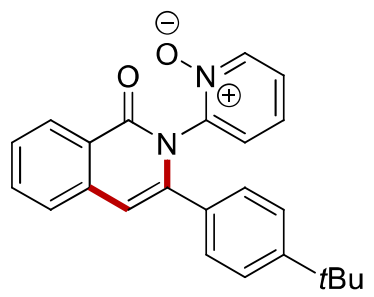

34ac ${ }^{13} \mathrm{C}-\mathrm{NMR}$

$\left(100 \mathrm{MHz} \mathrm{CDCl}_{3}\right)$

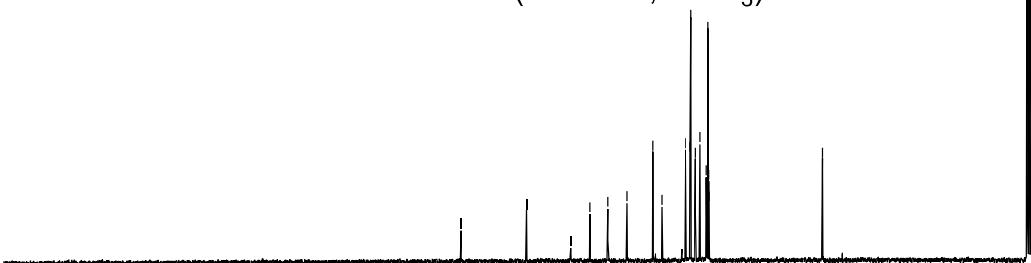

\begin{tabular}{lllllllllllllllllllllllllllllllllllll}
\hline 30 & 220 & 210 & 200 & 190 & 180 & 170 & 160 & 150 & 140 & 130 & 120 & $\begin{array}{c}110 \\
\mathrm{f} 1(\mathrm{ppm})\end{array}$ & 100 & 90 & 70 & 60 & 50 & 40 & 30 & 20 & 10 & 0 & -10 & -2
\end{tabular} 

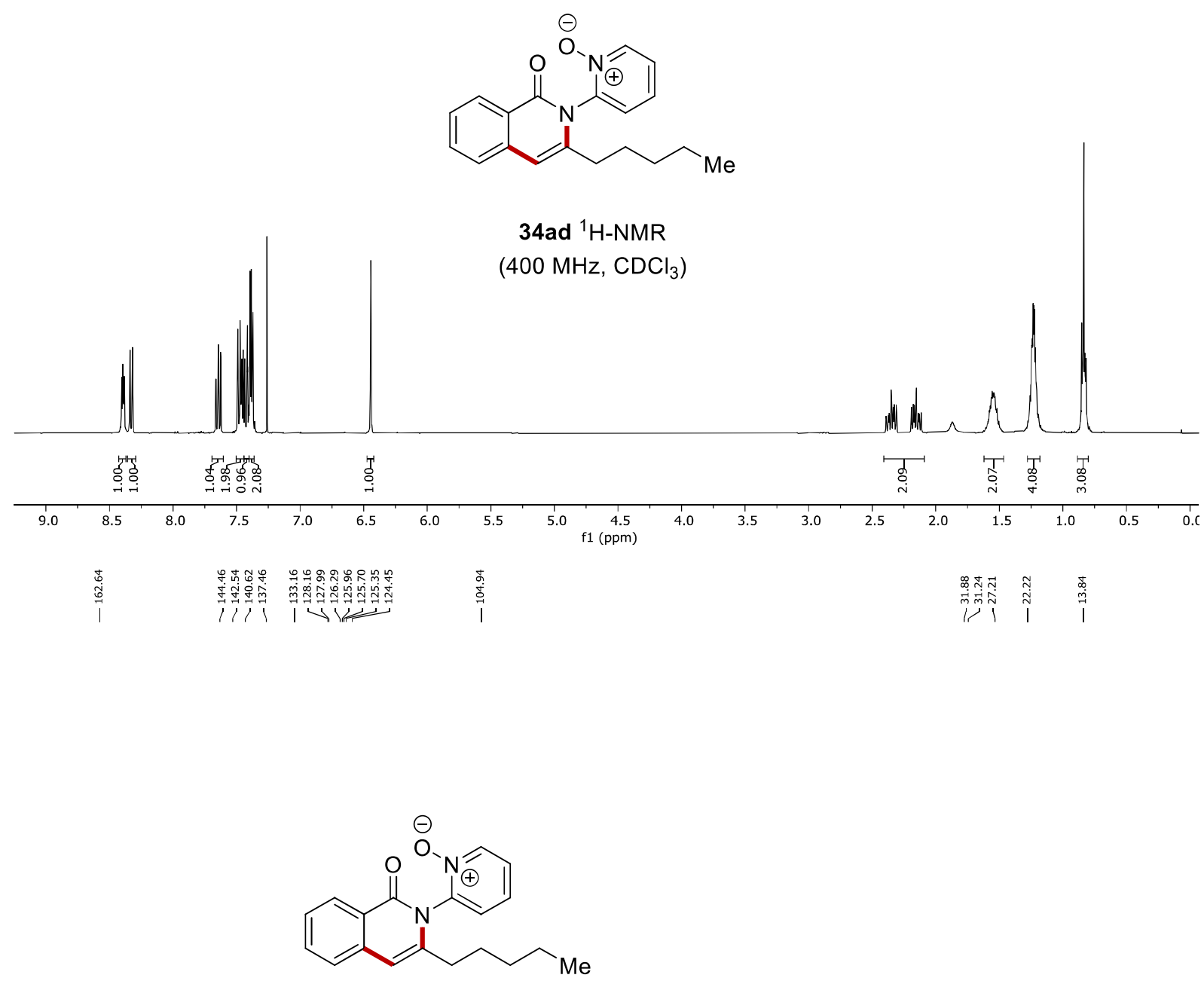

34ad ${ }^{13} \mathrm{C}-\mathrm{NMR}$

$\left(100 \mathrm{MHz}, \mathrm{CDCl}_{3}\right.$ )

$\begin{array}{lllllllll}170 & 160 & 150 & 140 & 130 & 120 & 110 & 100 & 90 \\ & & & & & & & & \end{array}$ 


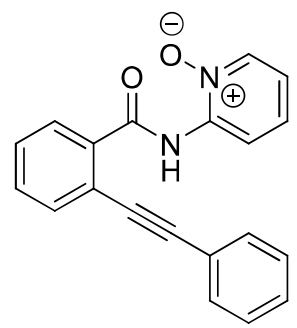

$184^{1} \mathrm{H}-\mathrm{NMR}$

$\left(300 \mathrm{MHz}, \mathrm{CDCl}_{3}\right.$ )

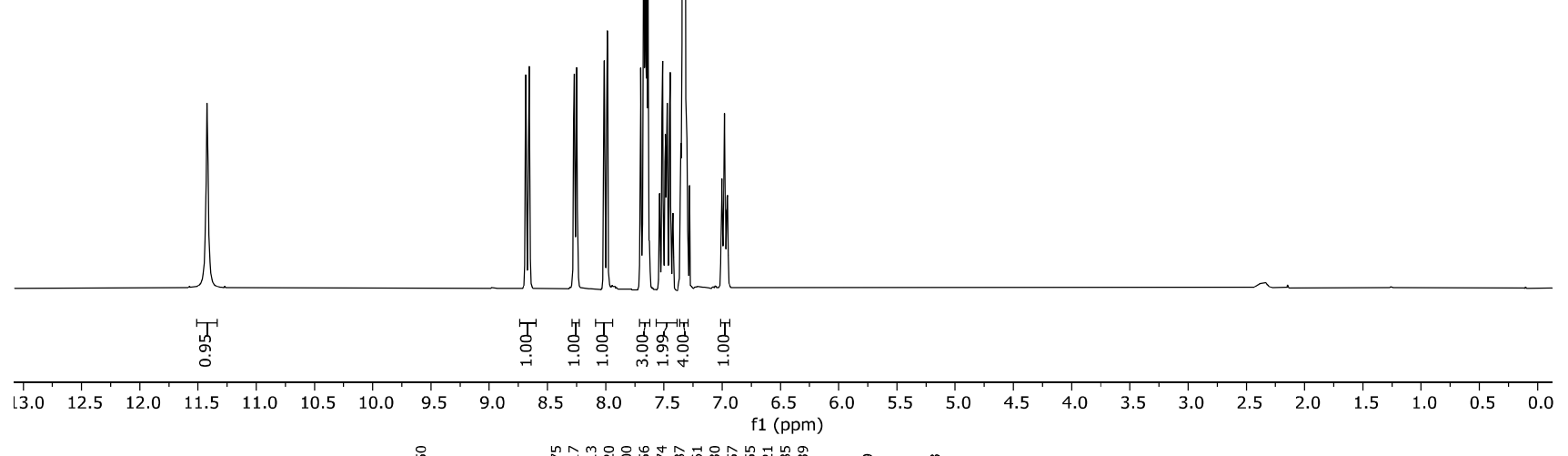
|

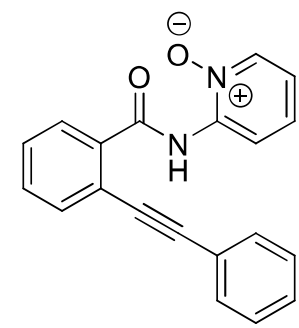

$184{ }^{13} \mathrm{C}-\mathrm{NMR}$

$\left(100 \mathrm{MHz}, \mathrm{CDCl}_{3}\right.$ )

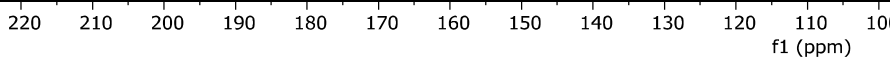


7.2 Electrooxidative Ruthenium-Catalyzed $\mathrm{C}-\mathrm{H} / \mathrm{O}-\mathrm{H}$ Annulation by Weak $\boldsymbol{O}$-Coordination

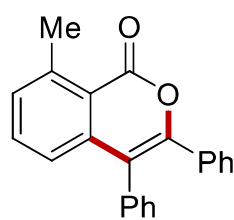

90ca ${ }^{1} \mathrm{H}-\mathrm{NMR}$

$\left(400 \mathrm{MHz}, \mathrm{CDCl}_{3}\right.$ )
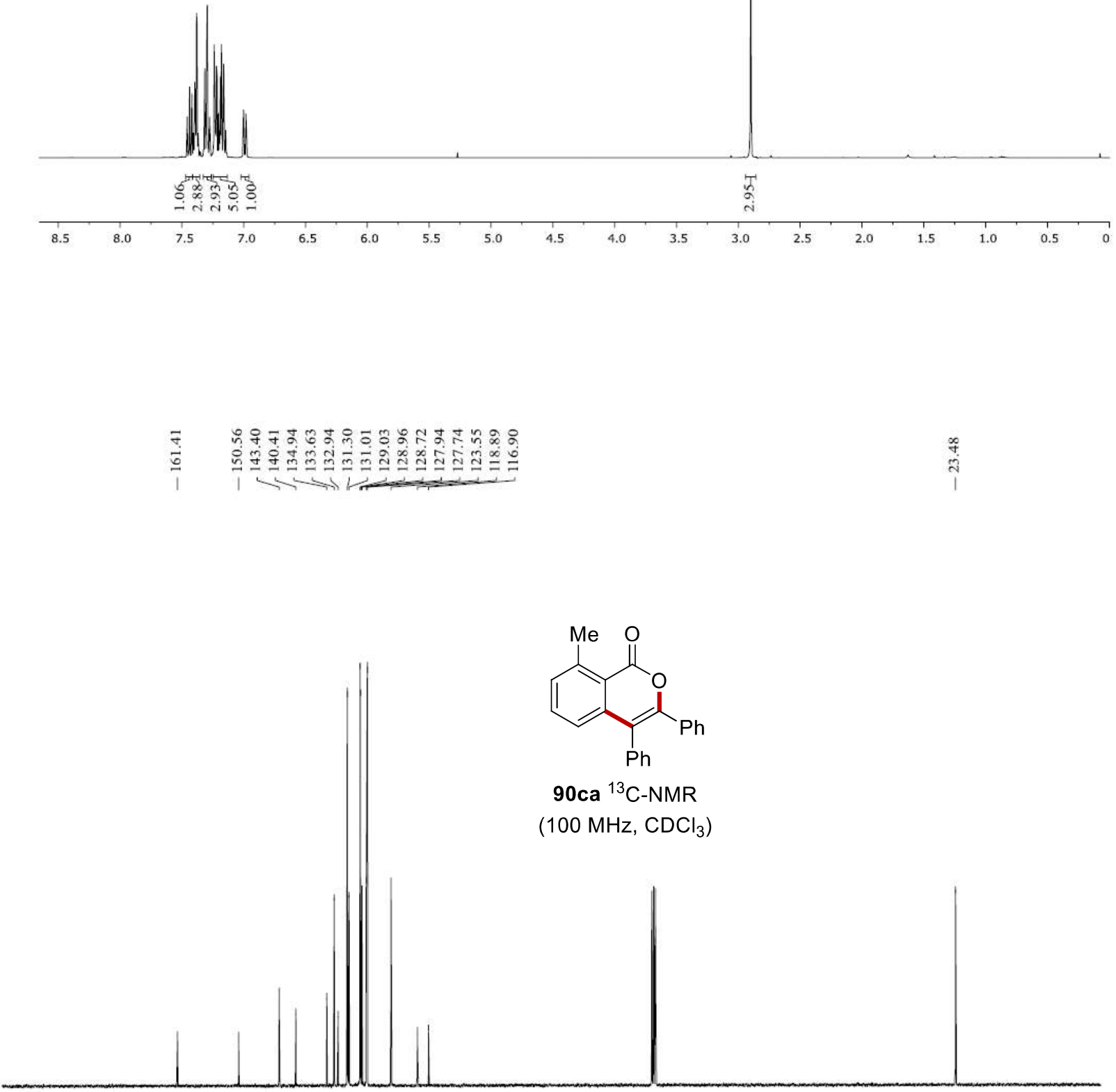


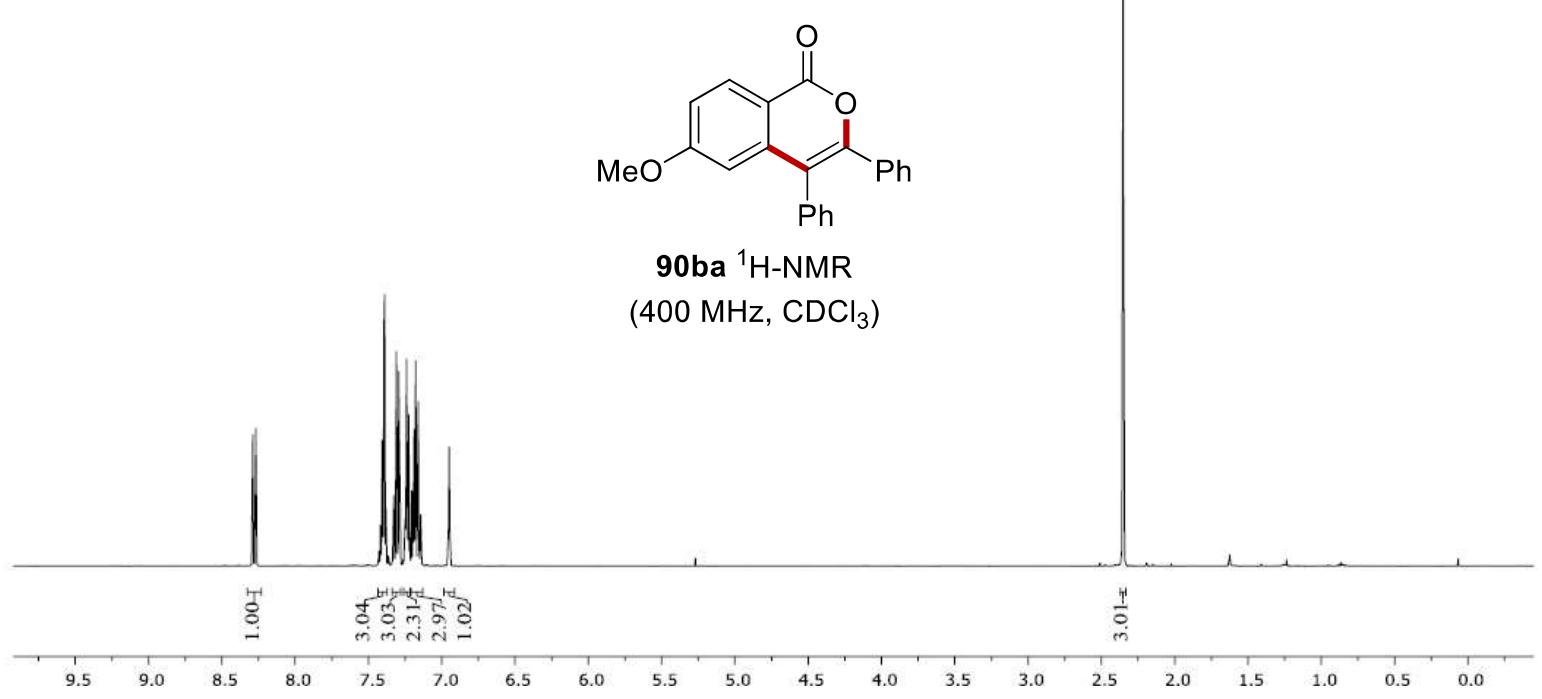

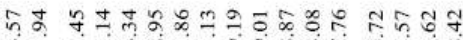

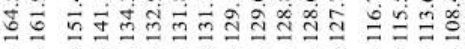
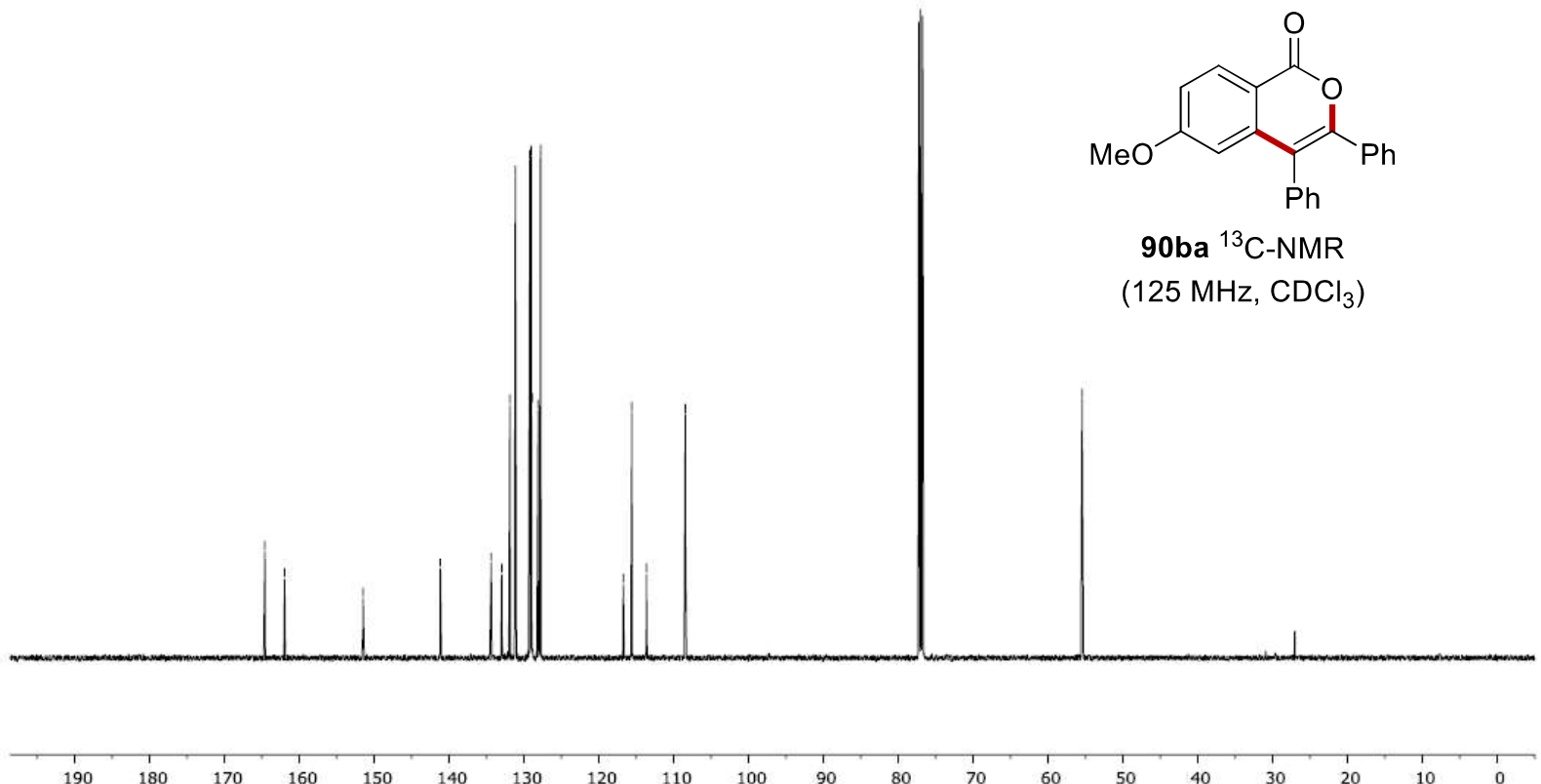


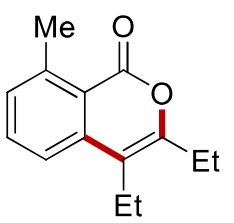

90cb ${ }^{1} \mathrm{H}-\mathrm{NMR}$

$\left(300 \mathrm{MHz}, \mathrm{CDCl}_{3}\right)$

Iliv

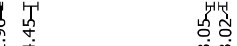

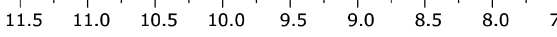

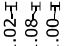

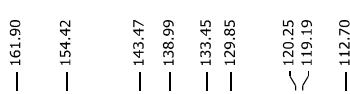

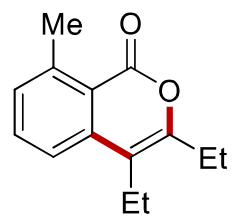

$90 \mathrm{cb}{ }^{13} \mathrm{C}-\mathrm{NMR}$

(125 MHz, $\mathrm{CDCl}_{3}$ )

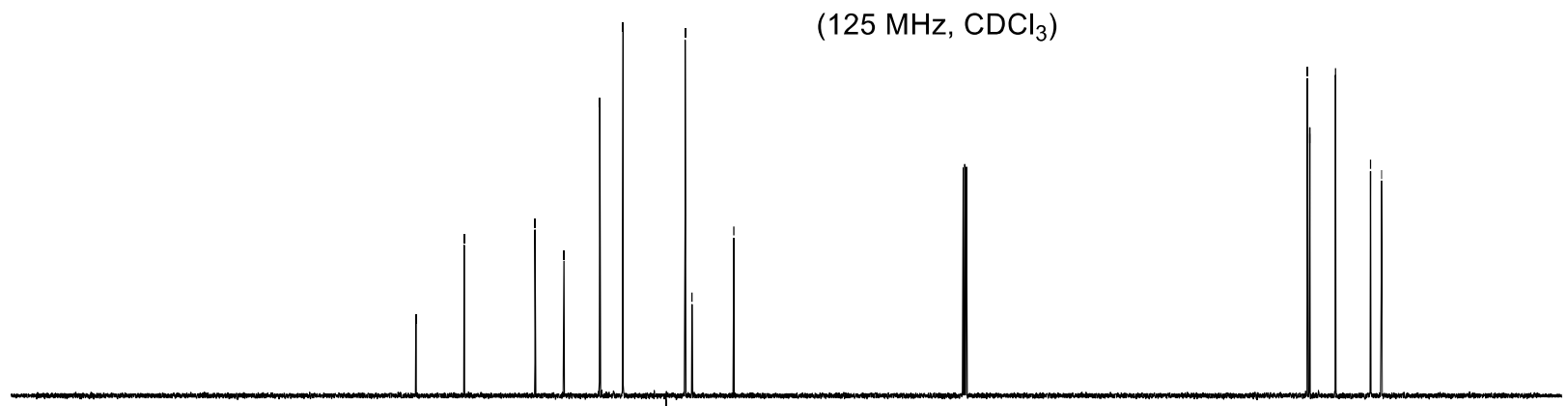

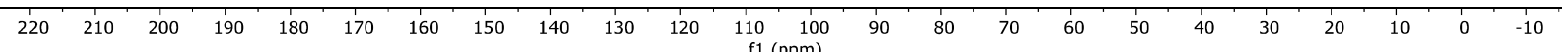




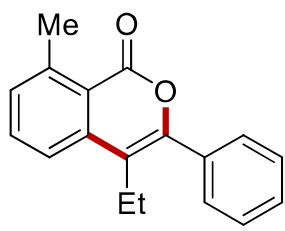

90cc ${ }^{1} \mathrm{H}-\mathrm{NMR}$

$\left(300 \mathrm{MHz}, \mathrm{CDCl}_{3}\right)$
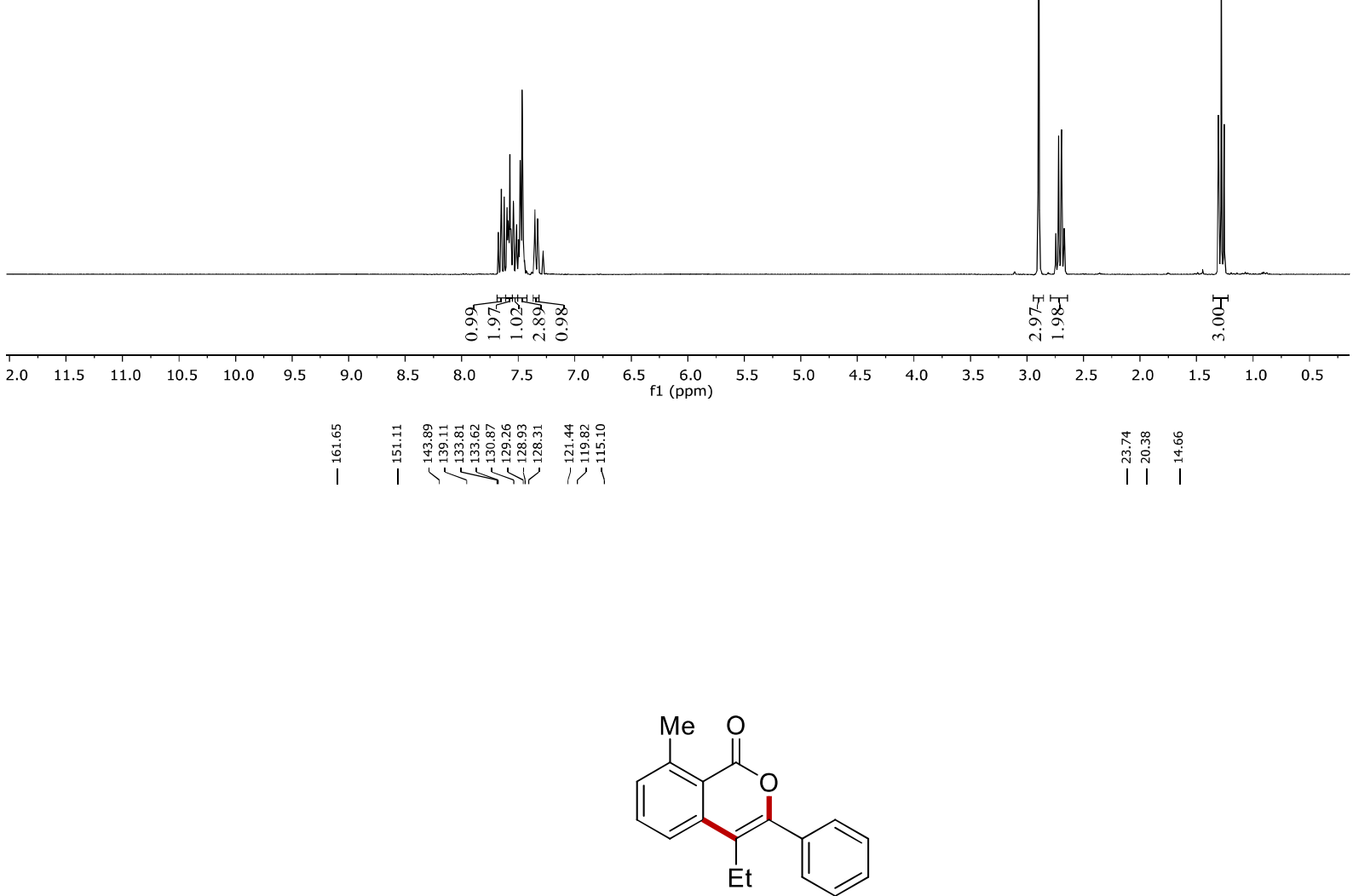

$90 \mathrm{cc}{ }^{13} \mathrm{C}-\mathrm{NMR}$

$\left(100 \mathrm{MHz} \mathrm{CDCl}_{3}\right)$

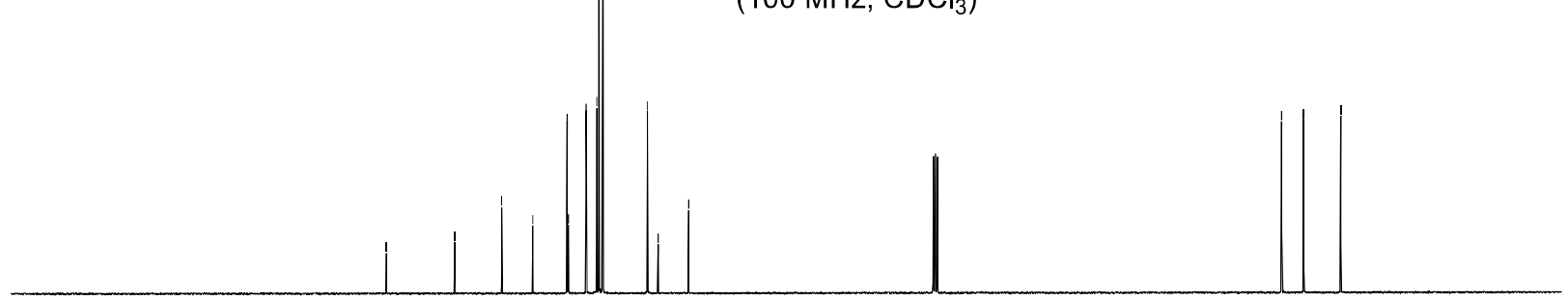

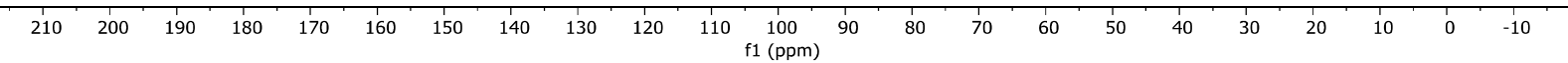




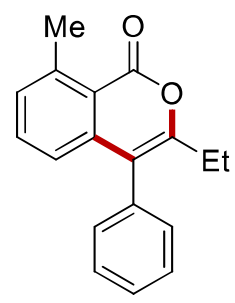

90cc ${ }^{1} \mathrm{H}-\mathrm{NMR}$

$\left(400 \mathrm{MHz}, \mathrm{CDCl}_{3}\right)$

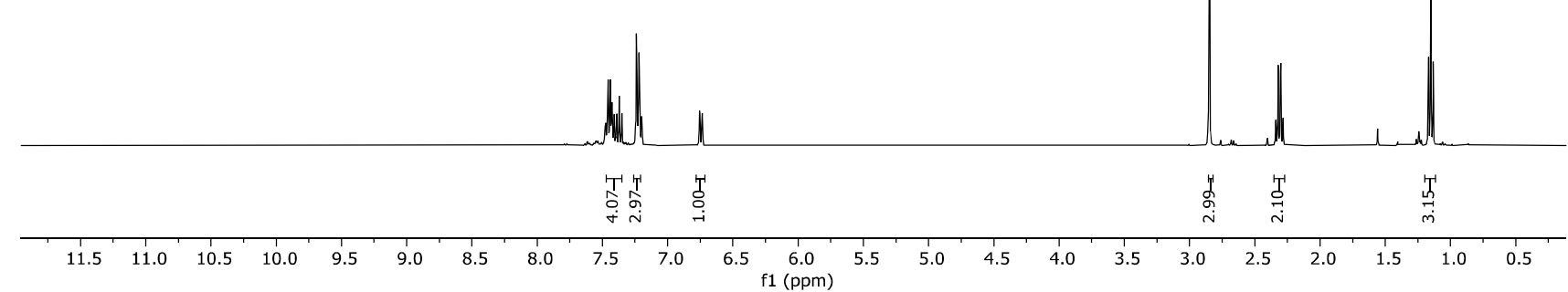

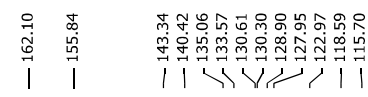

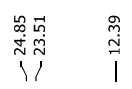<smiles>CCc1oc(=O)c2c(C)cccc2c1-c1ccccc1</smiles>

90cc ${ }^{13} \mathrm{C}-\mathrm{NMR}$

$\left(100 \mathrm{MHz}, \mathrm{CDCl}_{3}\right)$

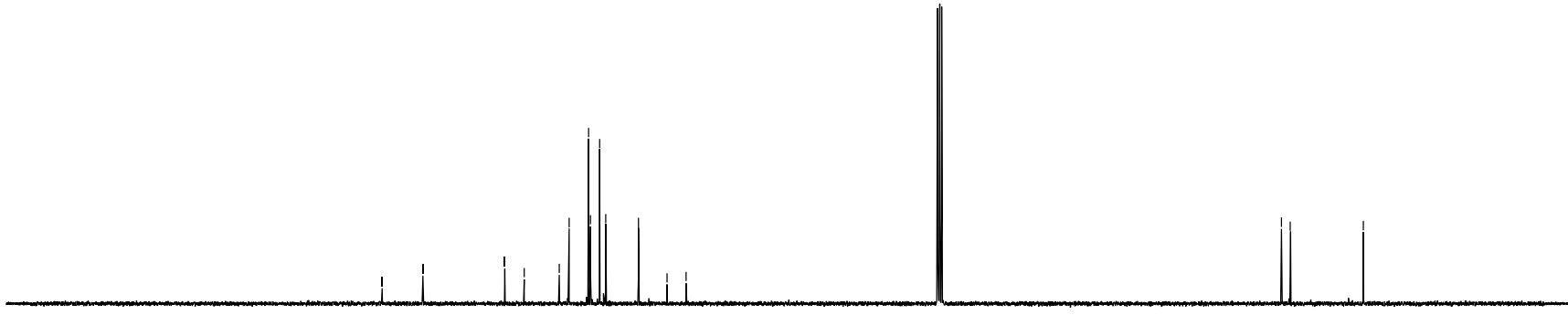

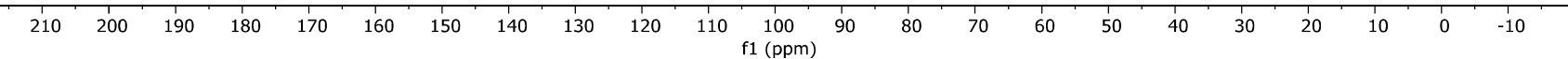




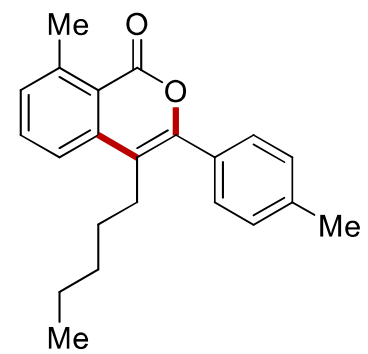

90cd ${ }^{1} \mathrm{H}-\mathrm{NMR}$

$\left(300 \mathrm{MHz}, \mathrm{CDCl}_{3}\right)$
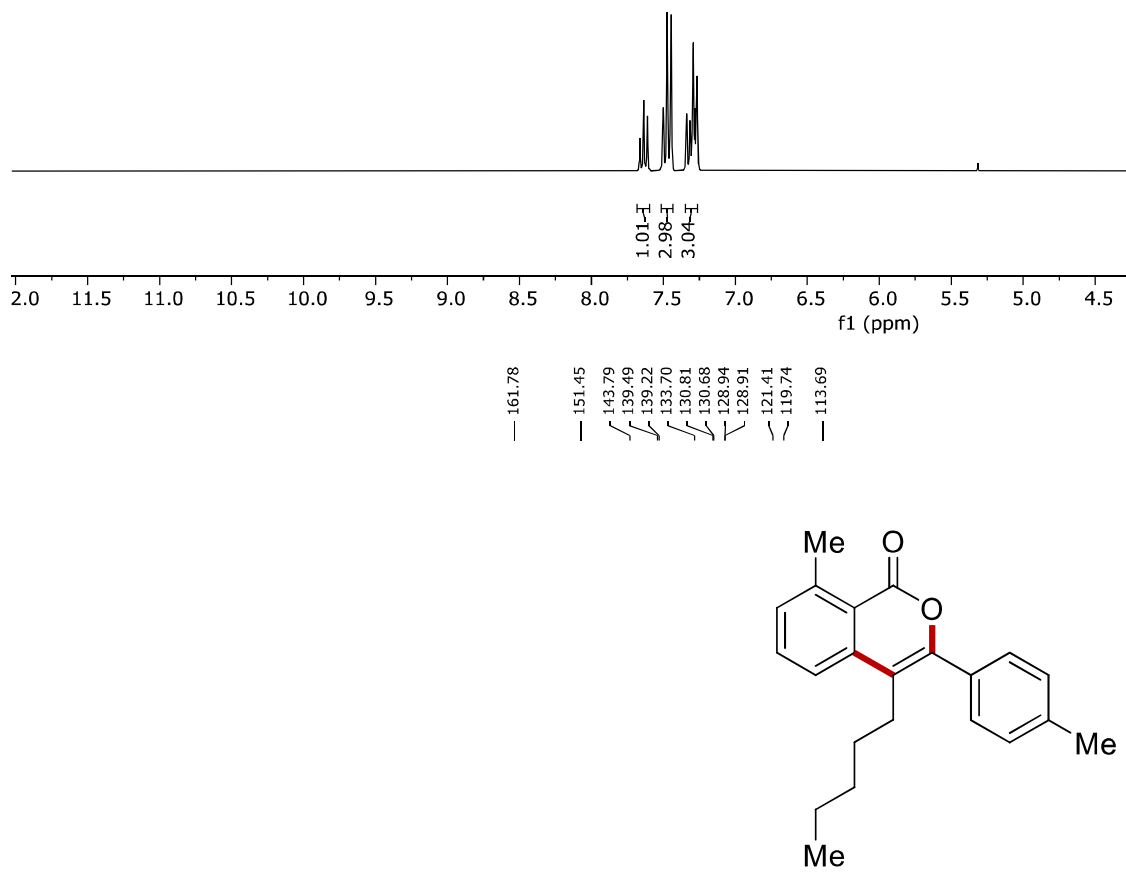

90cd ${ }^{13} \mathrm{C}-\mathrm{NMR}$

$\left(75 \mathrm{MHz} \mathrm{CDCl}_{3}\right)$

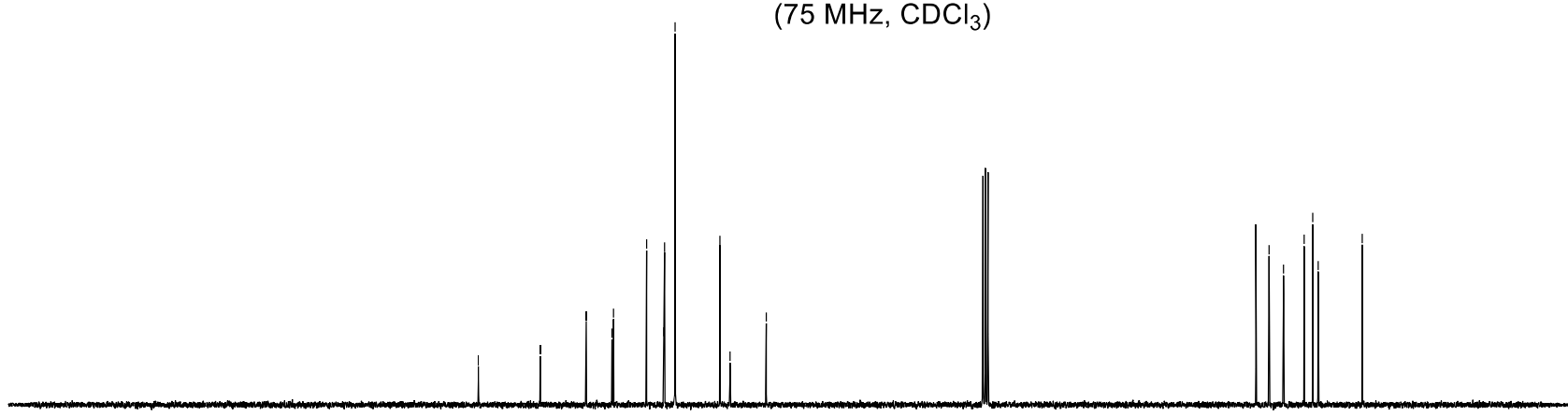

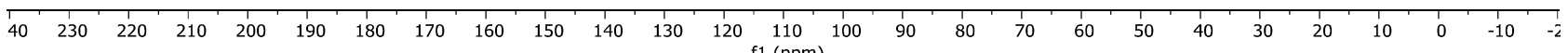



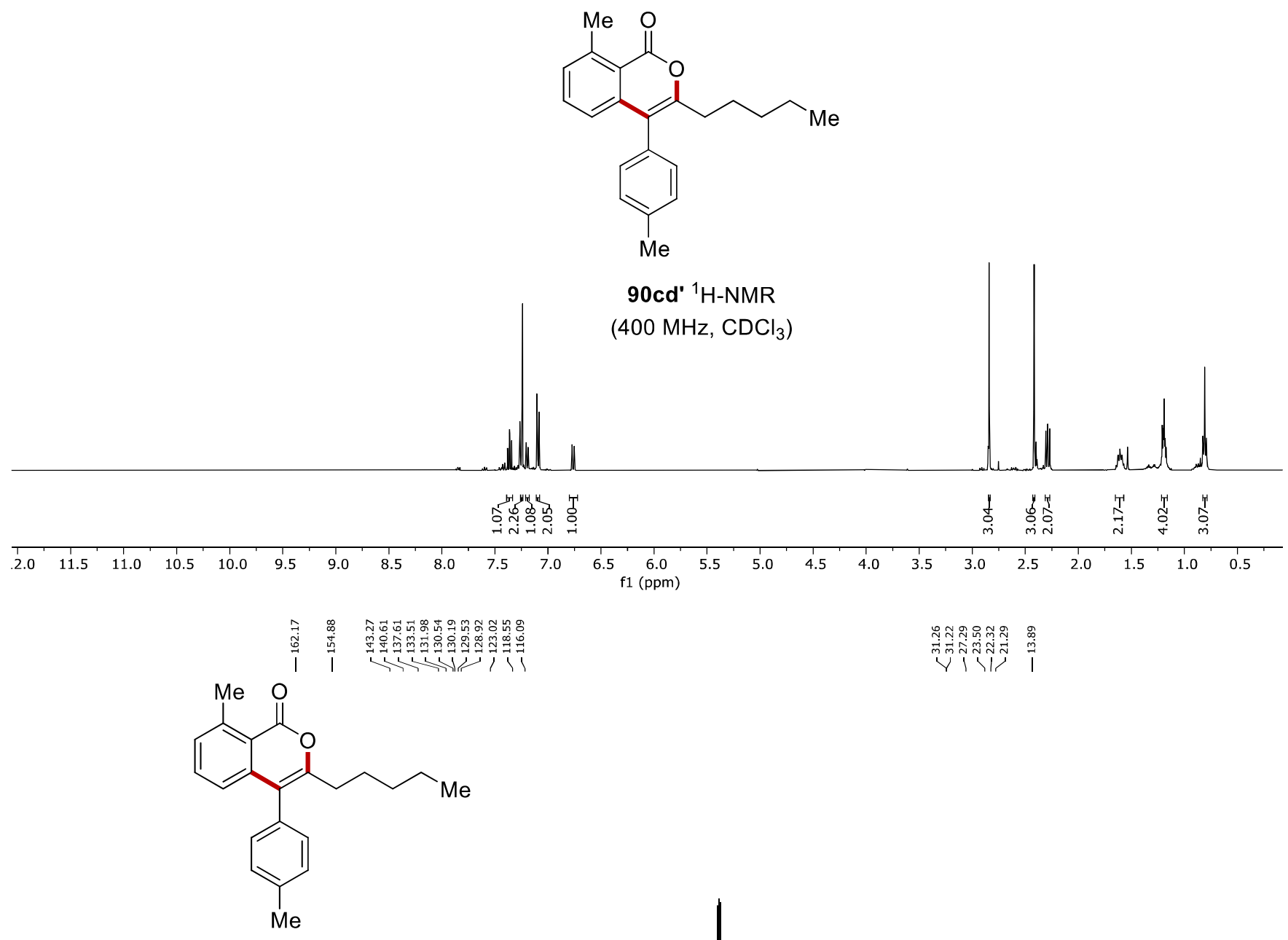

90cd' ${ }^{13} \mathrm{C}-\mathrm{NMR}$

$\left(100 \mathrm{MHz} \mathrm{CDCl}_{3}\right)$

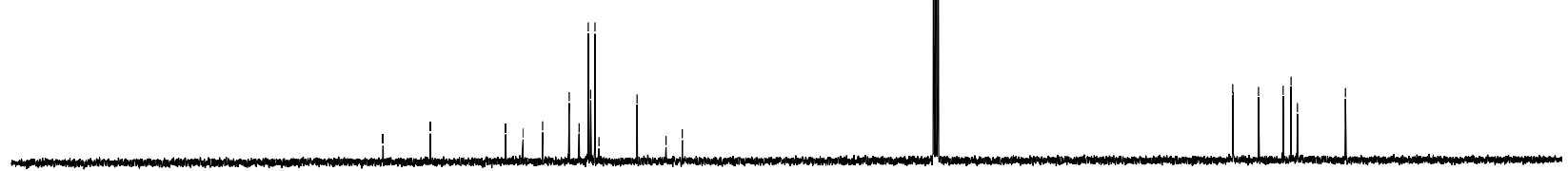

$\begin{array}{lllllllllllllllllllllllllllll}210 & 200 & 190 & 180 & 170 & 160 & 150 & 140 & 130 & 120 & 110 & 100 & 90 & 80 & 70 & 60 & 50 & 40 & 30 & 20 & 10 & 0 & -10\end{array}$ 

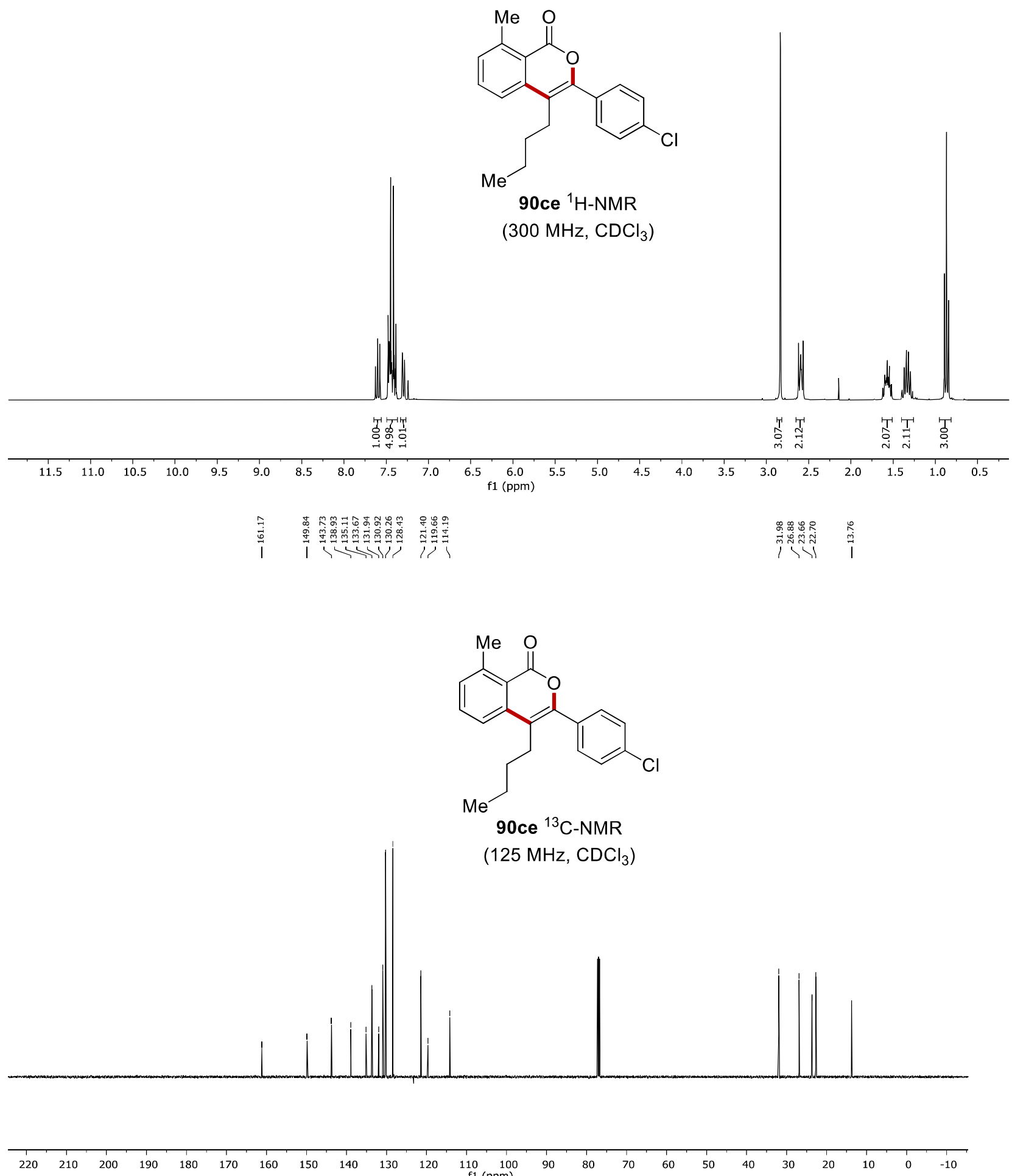


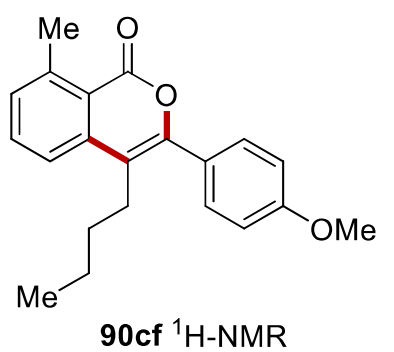

$\left(300 \mathrm{MHz}, \mathrm{CDCl}_{3}\right.$ )

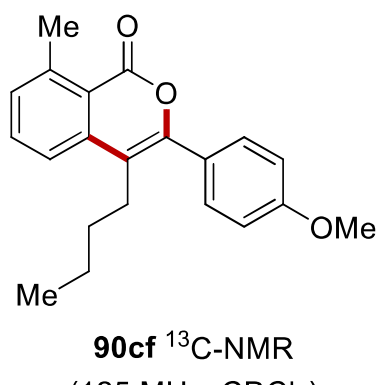

(125 MHz, $\mathrm{CDCl}_{3}$ )

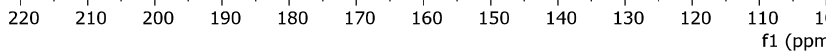




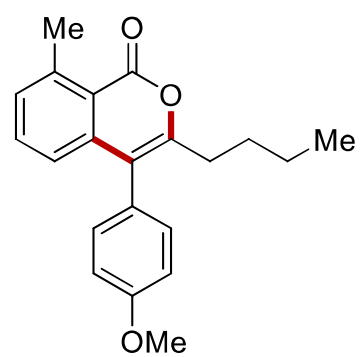

90cf' ${ }^{1} \mathrm{H}-\mathrm{NMR}$

(400 MHz, $\mathrm{CDCl}_{3}$ )

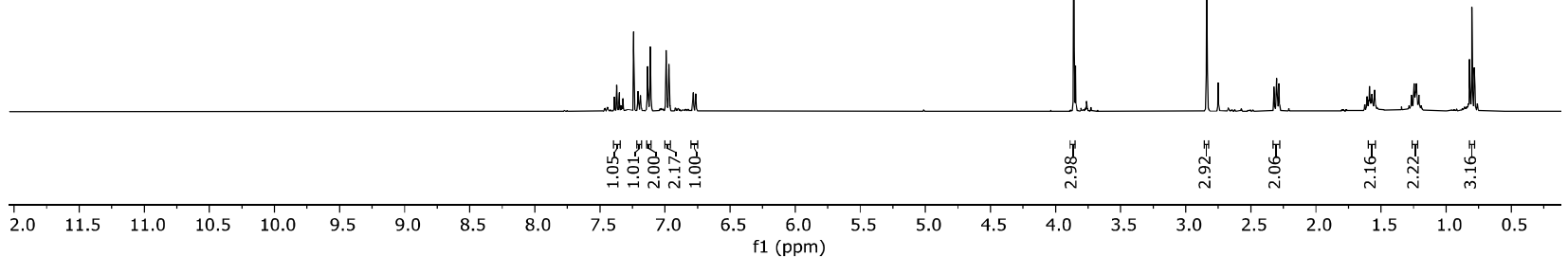

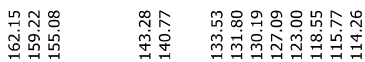

ओ। । मा।

总

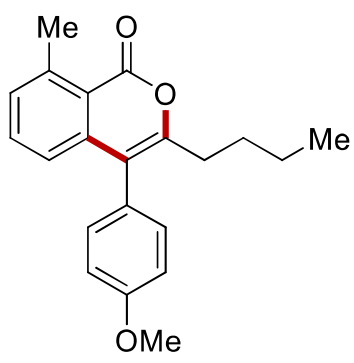

90cf' ${ }^{13} \mathrm{C}-\mathrm{NMR}$

$\left(100 \mathrm{MHz}, \mathrm{CDCl}_{3}\right.$ )

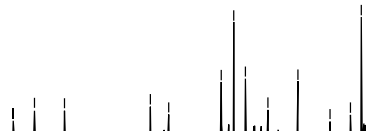




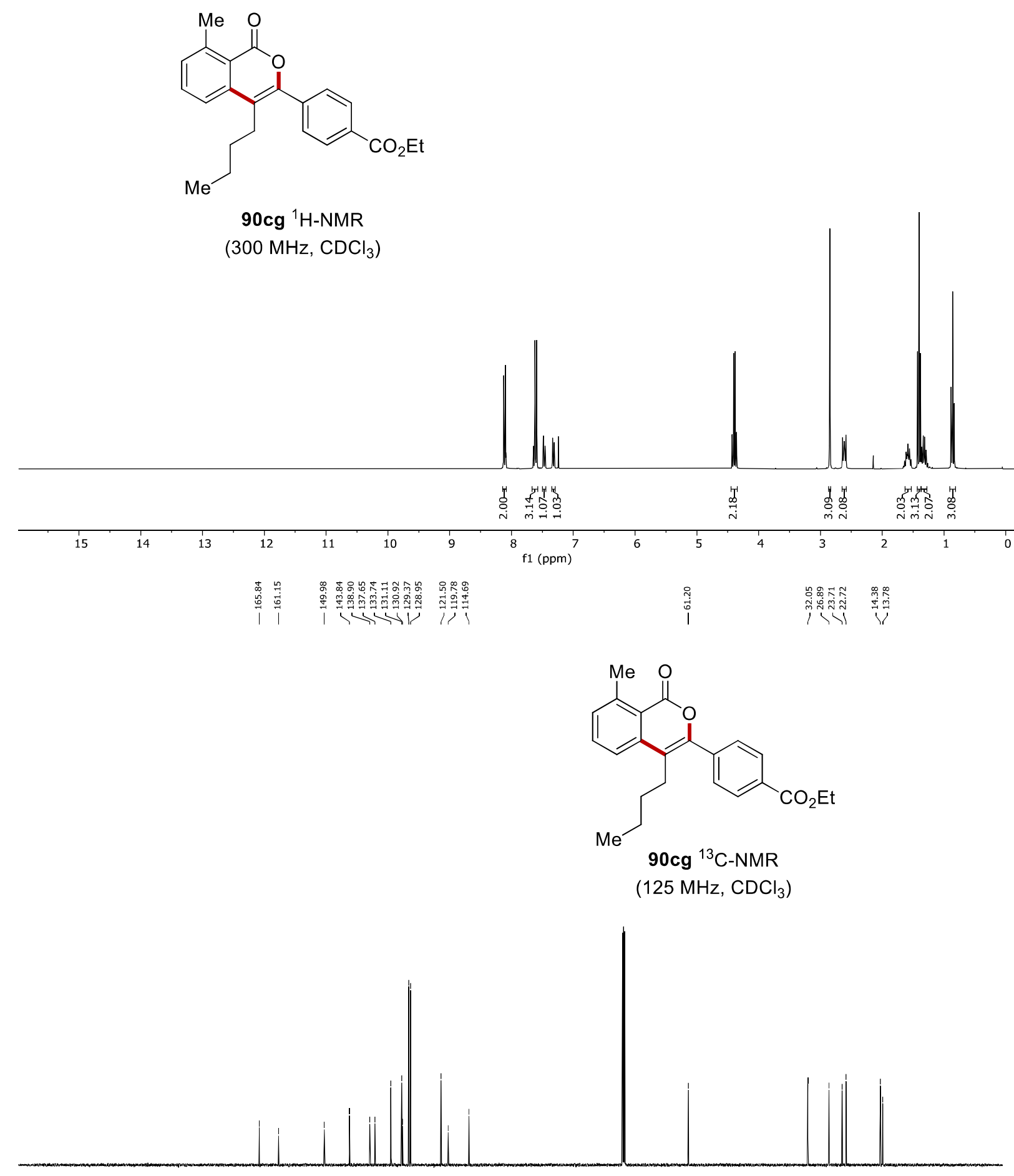

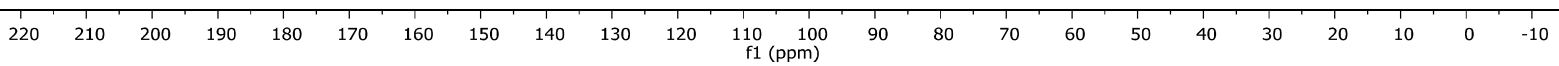




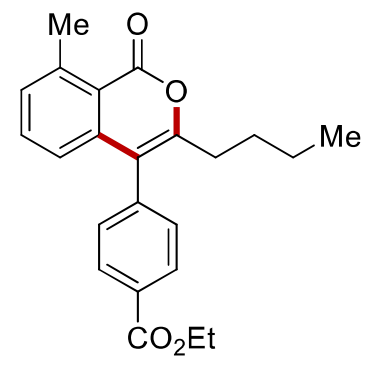

90 $\mathrm{cg}^{1}{ }^{1} \mathrm{H}-\mathrm{NMR}$

$\left(300 \mathrm{MHz}, \mathrm{CDCl}_{3}\right)$
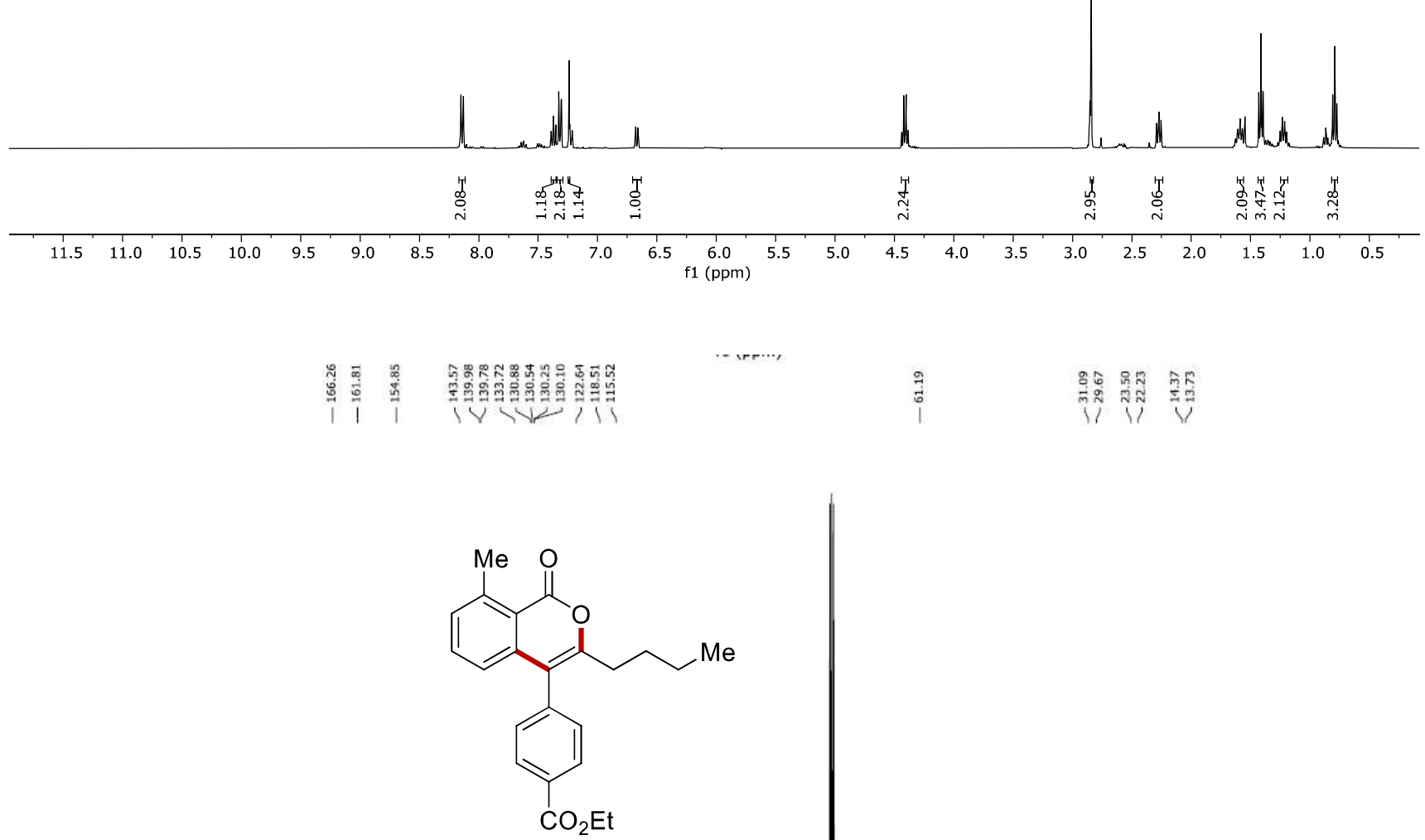

$90 \mathrm{cg}^{\prime 13} \mathrm{C}-\mathrm{NMR}$

$\left(100 \mathrm{MHz}, \mathrm{CDCl}_{3}\right)$

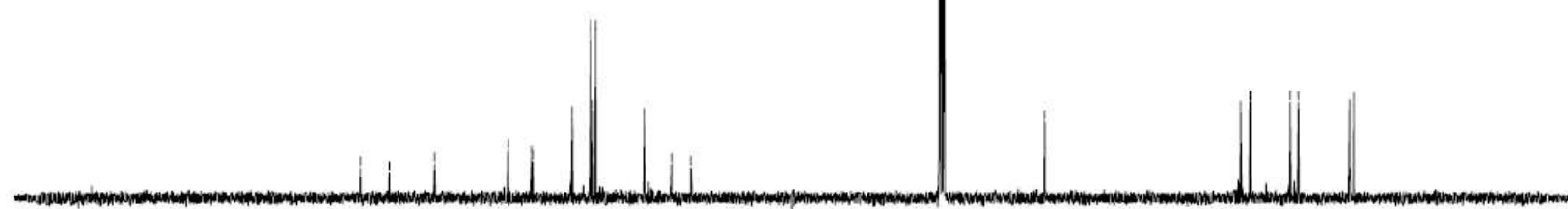

$\begin{array}{lllllllllllllllllllllllllllllllllll}210 & 200 & 190 & 180 & 170 & 160 & 150 & 140 & 130 & 120 & 110 & 100 & 90 & 80 & 70 & 60 & 50 & 40 & 30 & 20 & 10 & 0 & -10 & 10\end{array}$ 


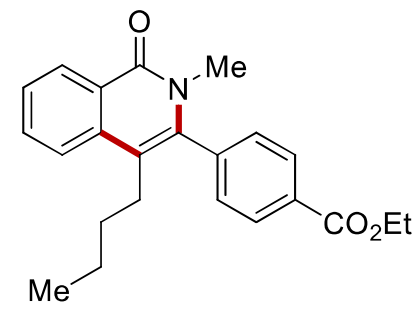

88ag ${ }^{1} \mathrm{H}-\mathrm{NMR}$

(400 MHz, $\mathrm{CDCl}_{3}$ )

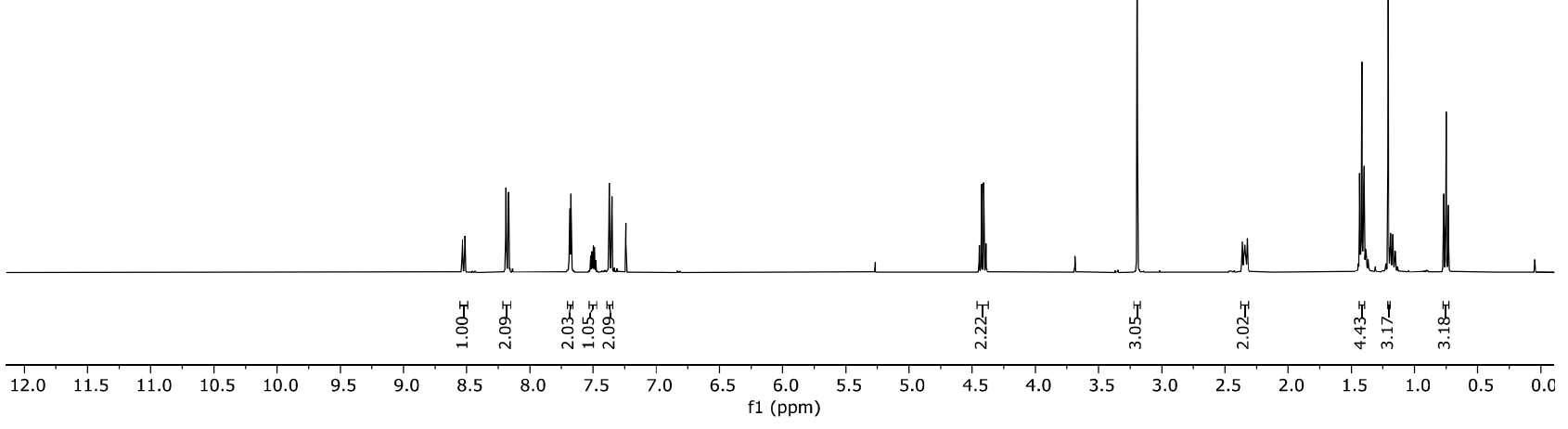

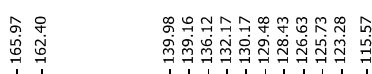

। 1 (1)

I

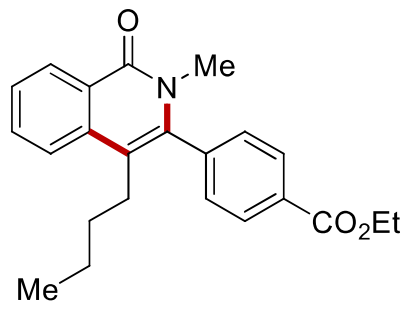

88ag ${ }^{13} \mathrm{C}-\mathrm{NMR}$

$\left(100 \mathrm{MHz}, \mathrm{CDCl}_{3}\right.$ )

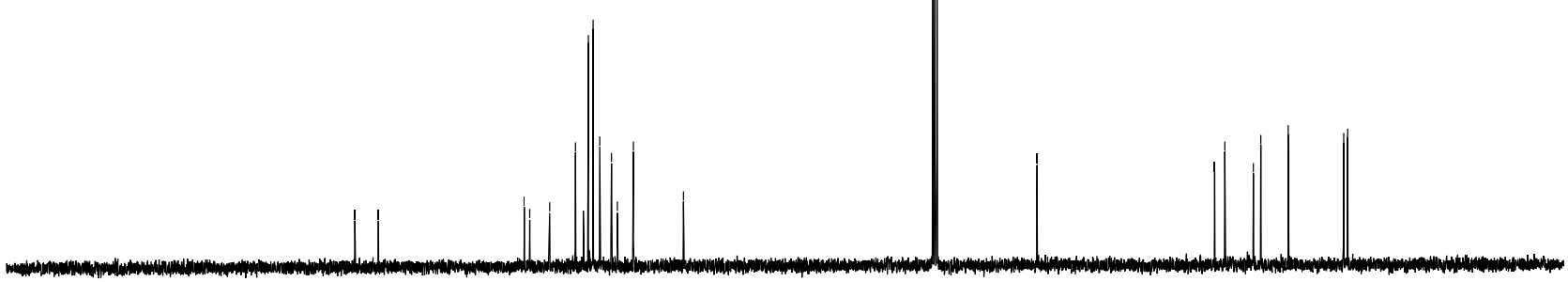

$\begin{array}{llllllllllllllllllllllll}210 & 200 & 190 & 180 & 170 & 160 & 150 & 140 & 130 & 120 & 110 & 100 & 90 & 80 & 70 & 60 & 50 & 40 & 30 & 20 & 10 & 0 & -10\end{array}$ 
7.3 C-H Oxygenation Reactions Enabled by Dual Catalysis with Electrogenerated Hypervalent Iodine Species and Ruthenium Complexes

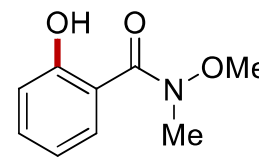

106a ${ }^{1} \mathrm{H}-\mathrm{NMR}$ (400 $\mathrm{MHz}, \mathrm{CDCl}_{3}$ )

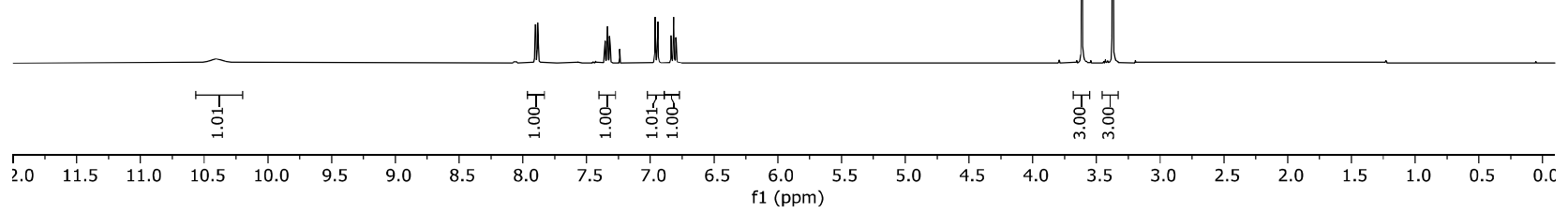




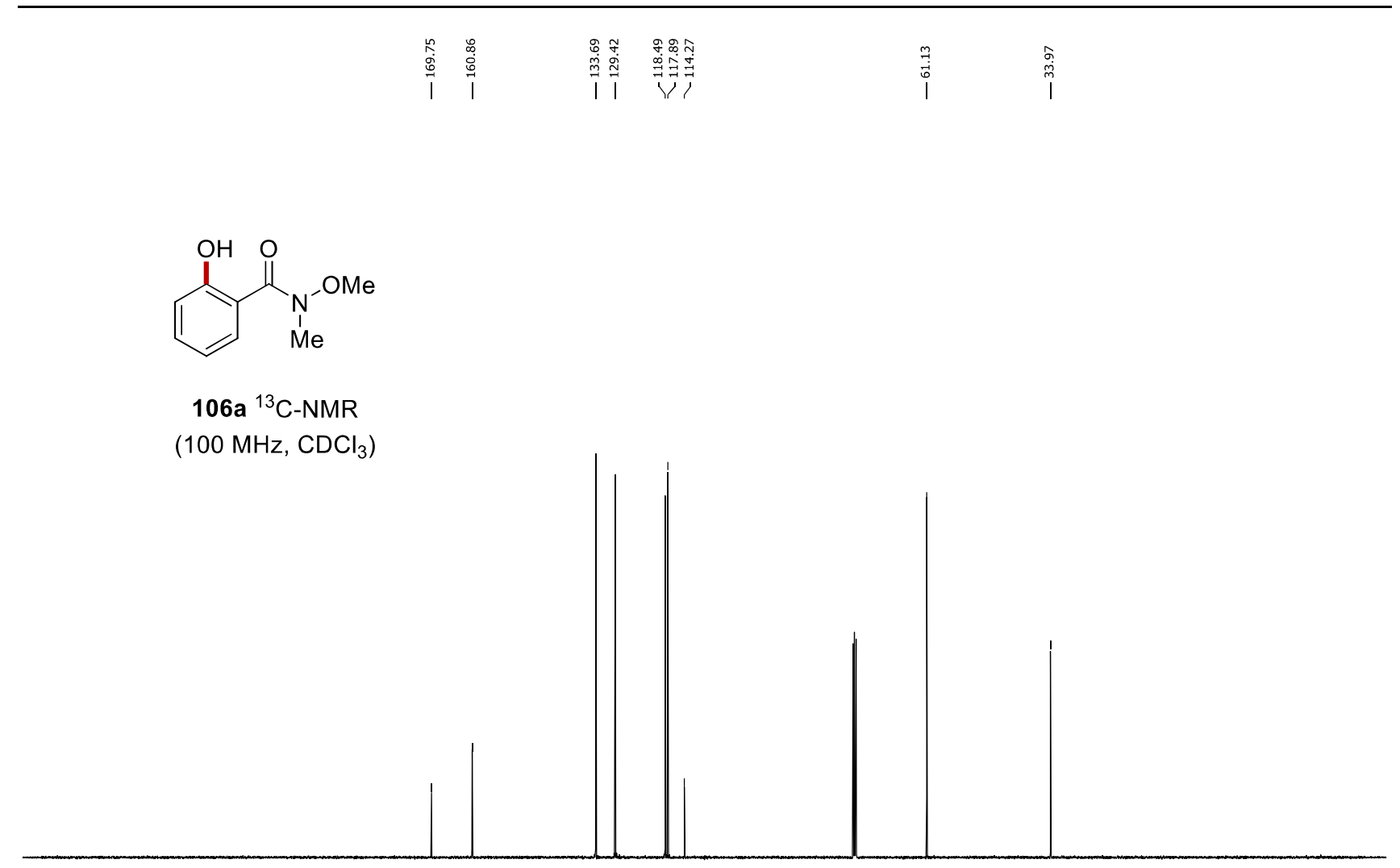

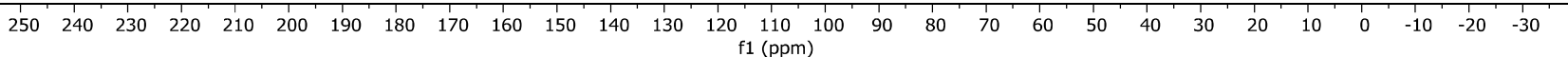<smiles>Cc1ccc(C(=O)N(C)C)c(O)c1</smiles>

106b ${ }^{1} \mathrm{H}-\mathrm{NMR}$

$\left(400 \mathrm{MHz}, \mathrm{CDCl}_{3}\right.$ )

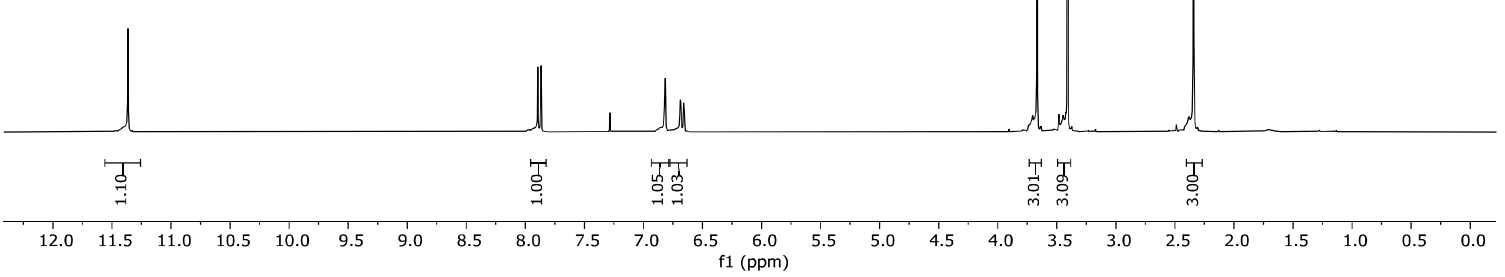



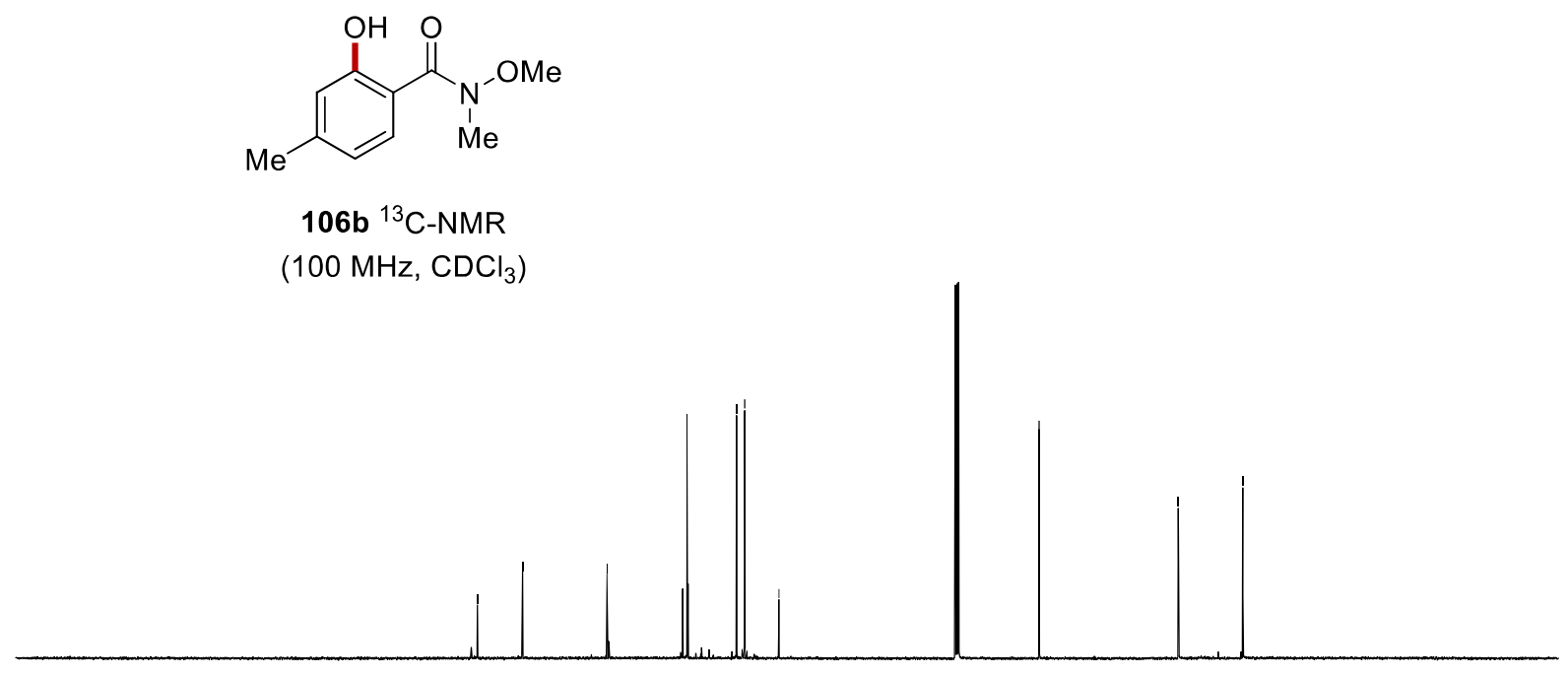

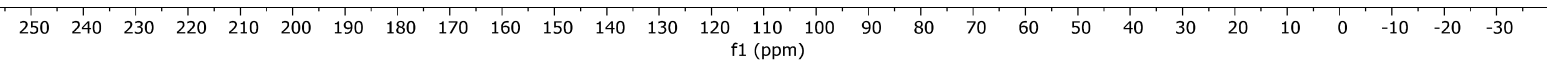

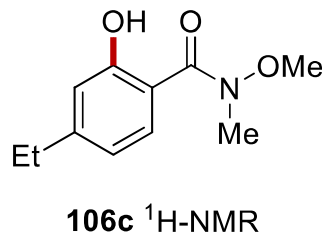

$\left(400 \mathrm{MHz}, \mathrm{CDCl}_{3}\right.$ ) 


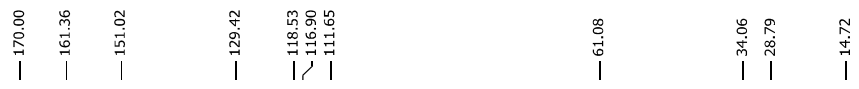

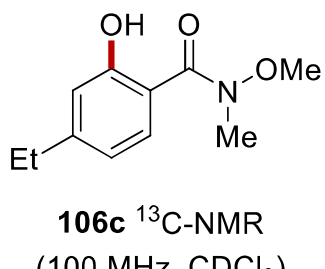

$\left(100 \mathrm{MHz}, \mathrm{CDCl}_{3}\right)$

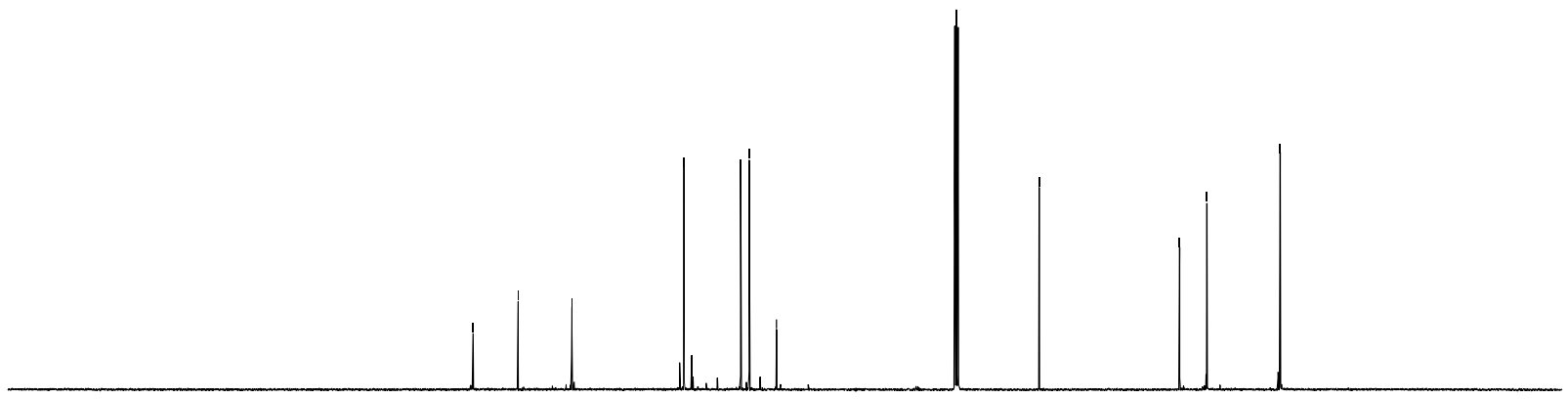

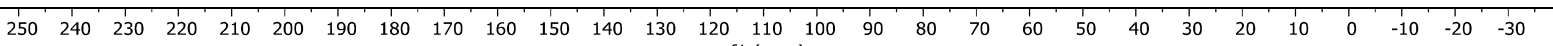
f1 (ppm)<smiles>CCN(C)C(=O)c1cc([N+](=O)[O-])c(C)cc1O</smiles>

106e ${ }^{1} \mathrm{H}-\mathrm{NMR}$

$\left(400 \mathrm{MHz}, \mathrm{CDCl}_{3}\right.$ )

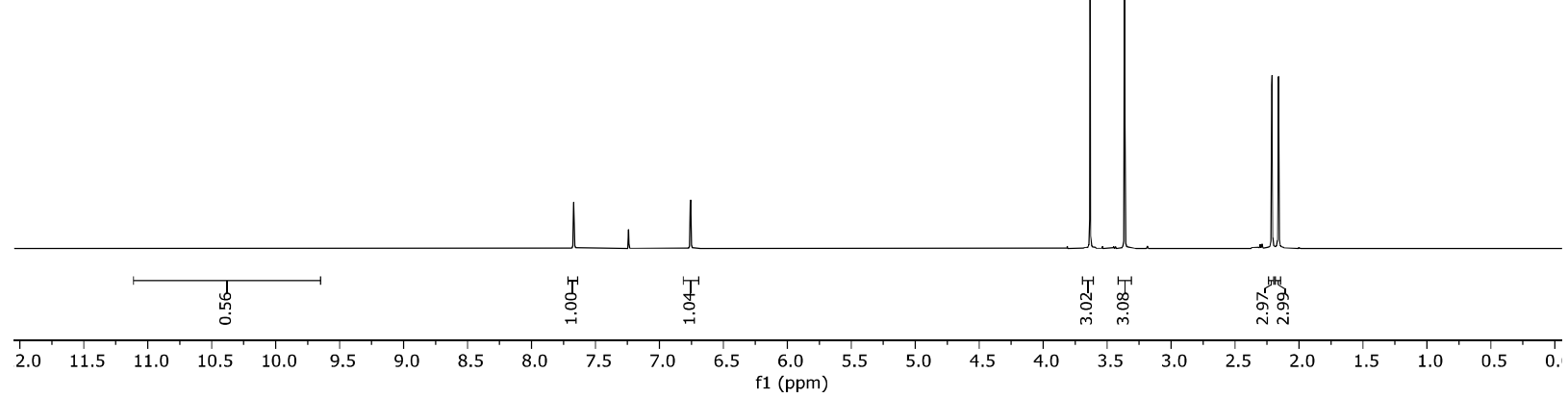




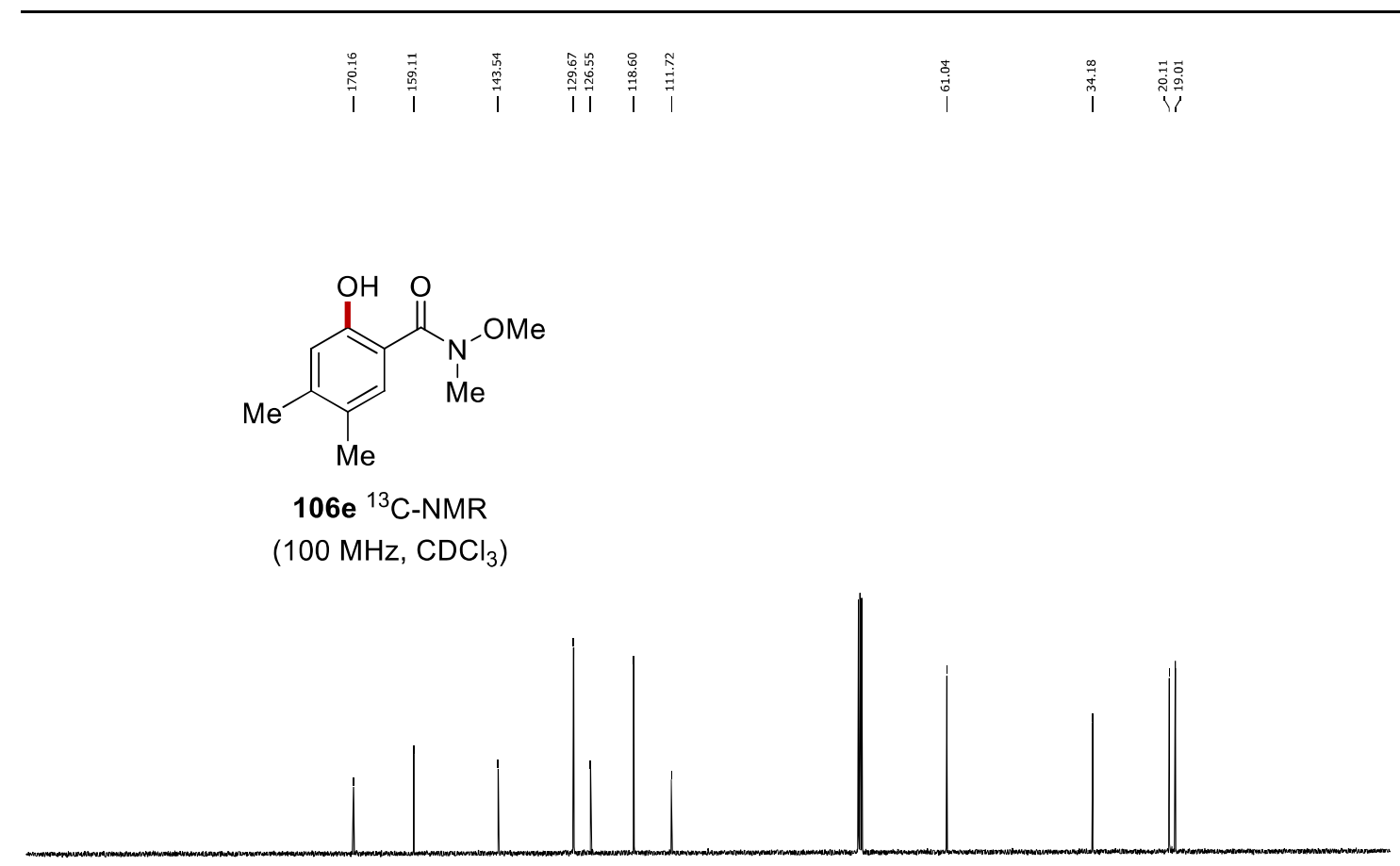

\begin{tabular}{llllllllllllllllllllllllllllllllllllllllll}
\hline 30 & 220 & 210 & 200 & 190 & 180 & 170 & 160 & 150 & 140 & 130 & 120 & 110 & 100 & 90 & 80 & 70 & 60 & 50 & 40 & 30 & 20 & 10 & 0 & -10 & -2
\end{tabular}<smiles>CON(C)C(=O)c1cc(Cl)c(Cl)cc1O</smiles>

$106 f^{1} \mathrm{H}-\mathrm{NMR}$ $\left(400 \mathrm{MHz}, \mathrm{CDCl}_{3}\right)$

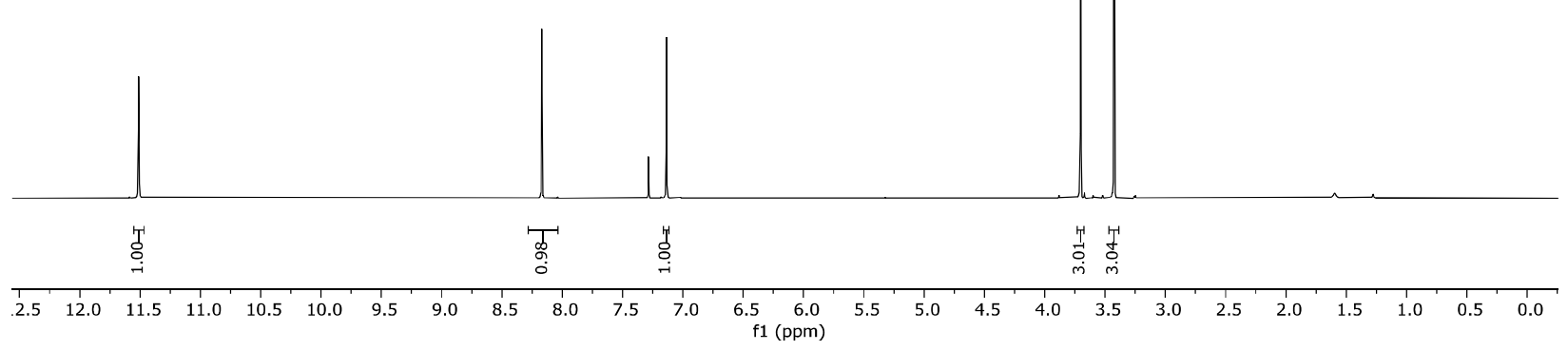




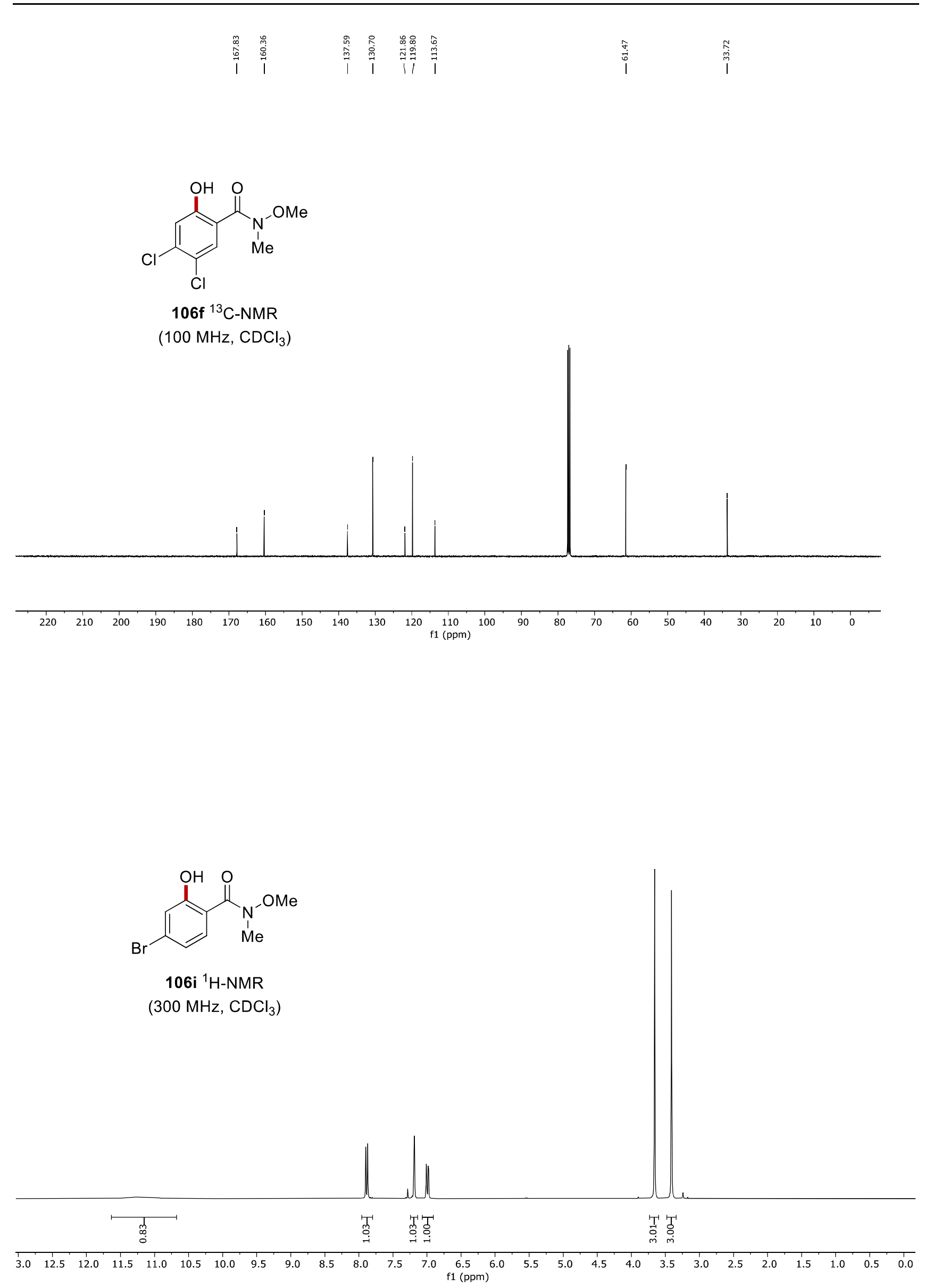


<smiles>CON(C)C(=O)c1ccc(Br)cc1O</smiles>

$106 i^{13} \mathrm{C}-\mathrm{NMR}$

$\left(100 \mathrm{MHz}, \mathrm{CDCl}_{3}\right.$ )
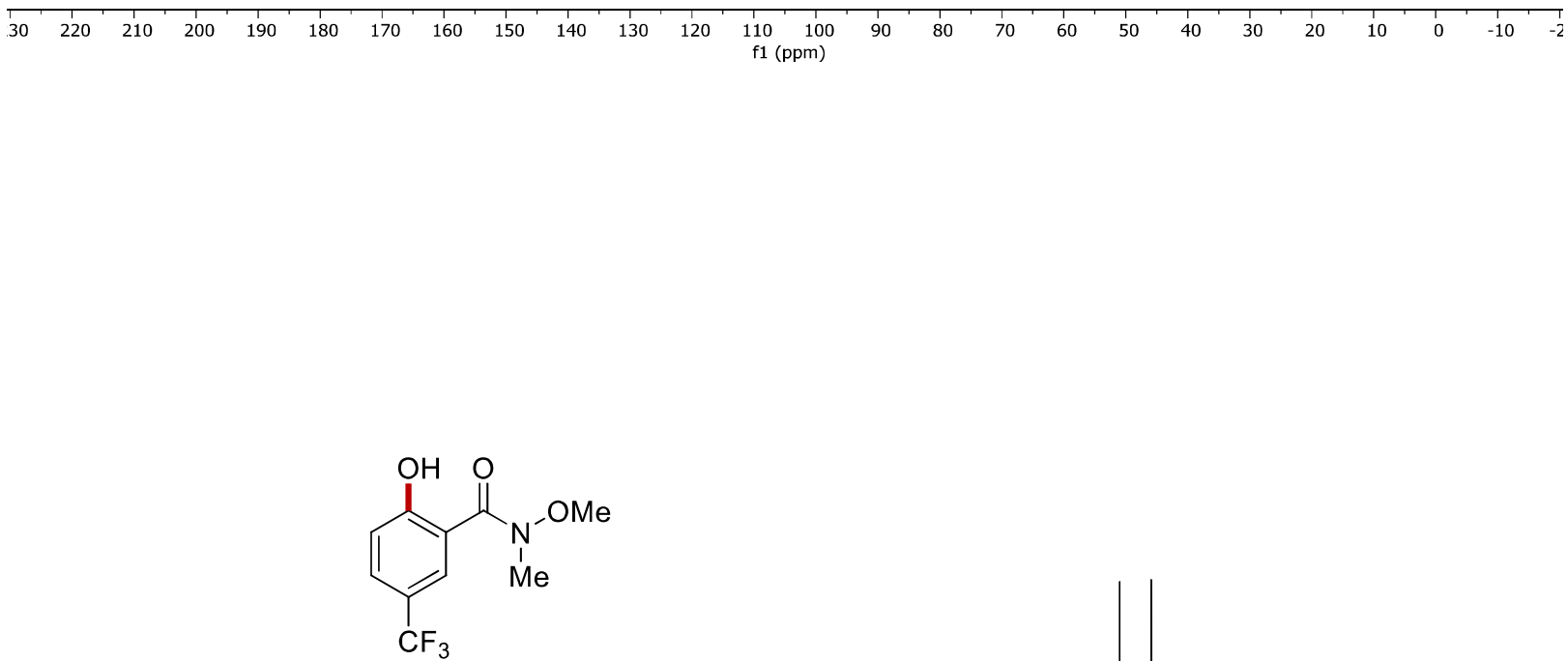

$106 \mathrm{I}^{1} \mathrm{H}-\mathrm{NMR}$

$\left(400 \mathrm{MHz}, \mathrm{CDCl}_{3}\right.$ )

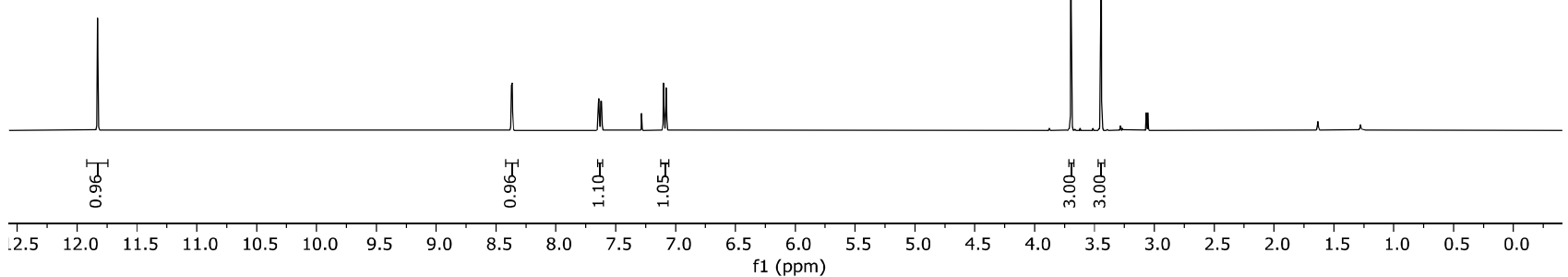



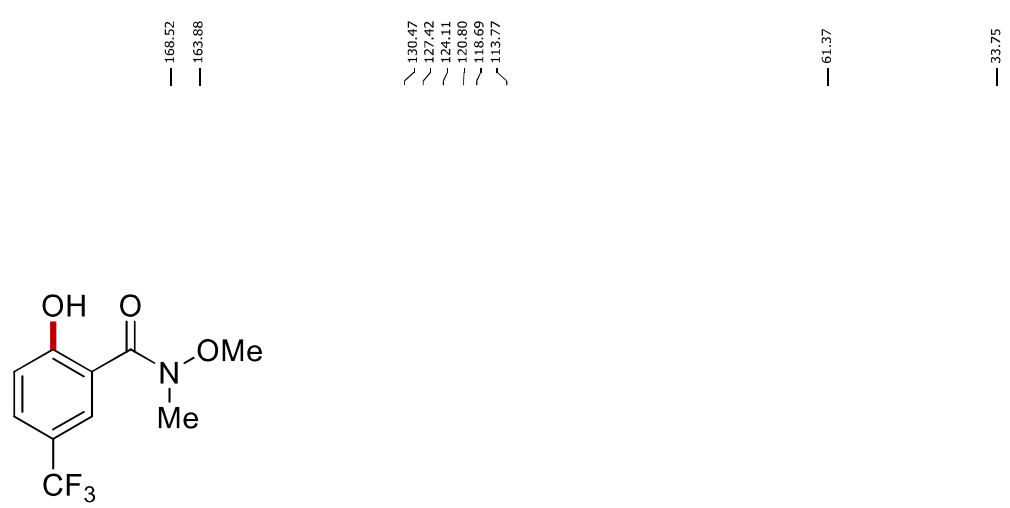

106I ${ }^{13} \mathrm{C}-\mathrm{NMR}$

$\left(100 \mathrm{MHz}, \mathrm{CDCl}_{3}\right.$ )
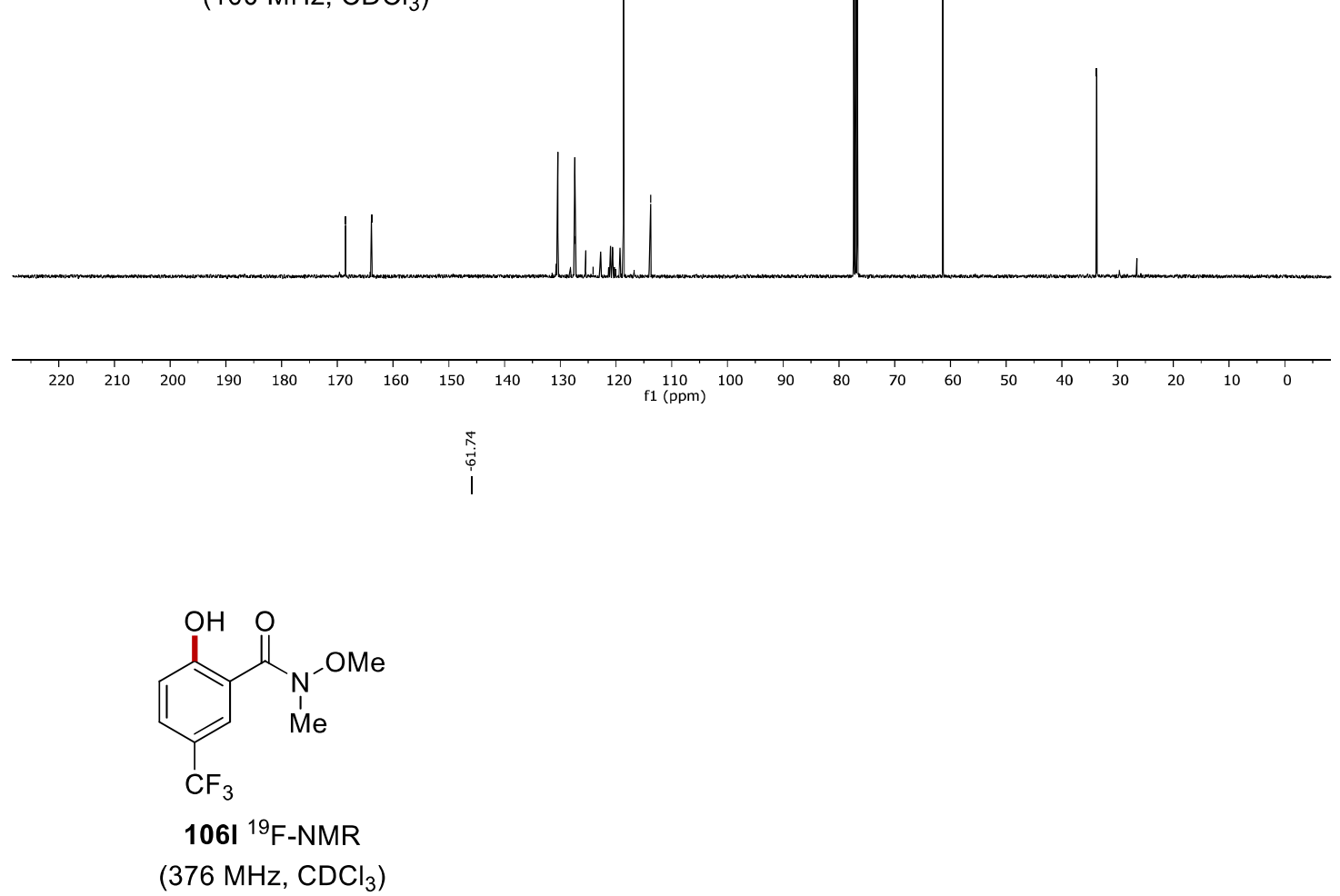

$\begin{array}{lllllllllllllllllllllllllll}10 & 0 & -10 & -20 & -30 & -40 & -50 & -60 & -70 & -80 & -90 & -100 & -110 & -120 & -130 & -140 & -150 & -160 & -170 & -180 & -190 & -200 & -210 & -220 & -230 & 1\end{array}$ 


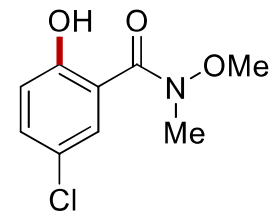

106m ${ }^{1} \mathrm{H}-\mathrm{NMR}$

(400 MHz, $\mathrm{CDCl}_{3}$ )

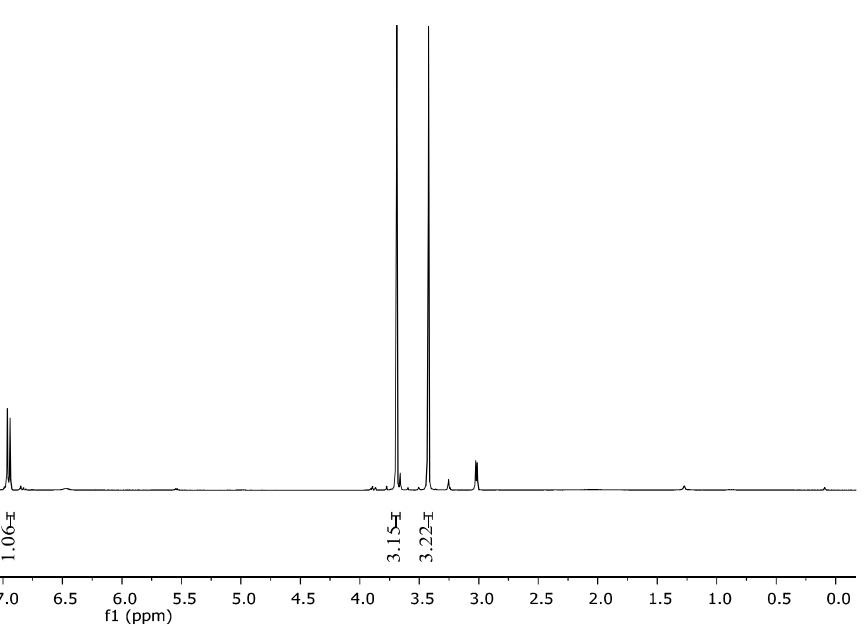

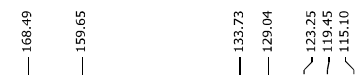

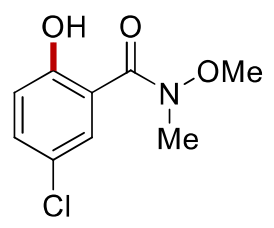

$106 \mathrm{~m}^{13} \mathrm{C}$-NMR

(100 MHz, $\mathrm{CDCl}_{3}$ )

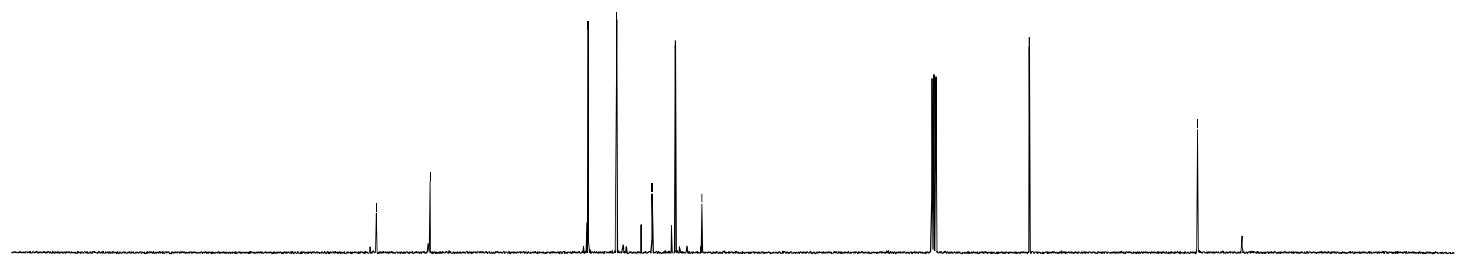

$\begin{array}{lllllllllllllllllllllll}220 & 210 & 200 & 190 & 180 & 170 & 160 & 150 & 140 & 130 & 120 & 110 & 100 & 90 & 80 & 70 & 60 & 50 & 40 & 30 & 20 & 10 & 0\end{array}$ 


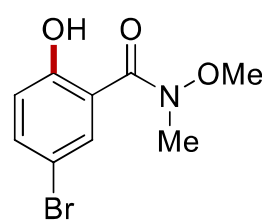

106n ${ }^{1} \mathrm{H}-\mathrm{NMR}$

$\left(400 \mathrm{MHz}, \mathrm{CDCl}_{3}\right)$
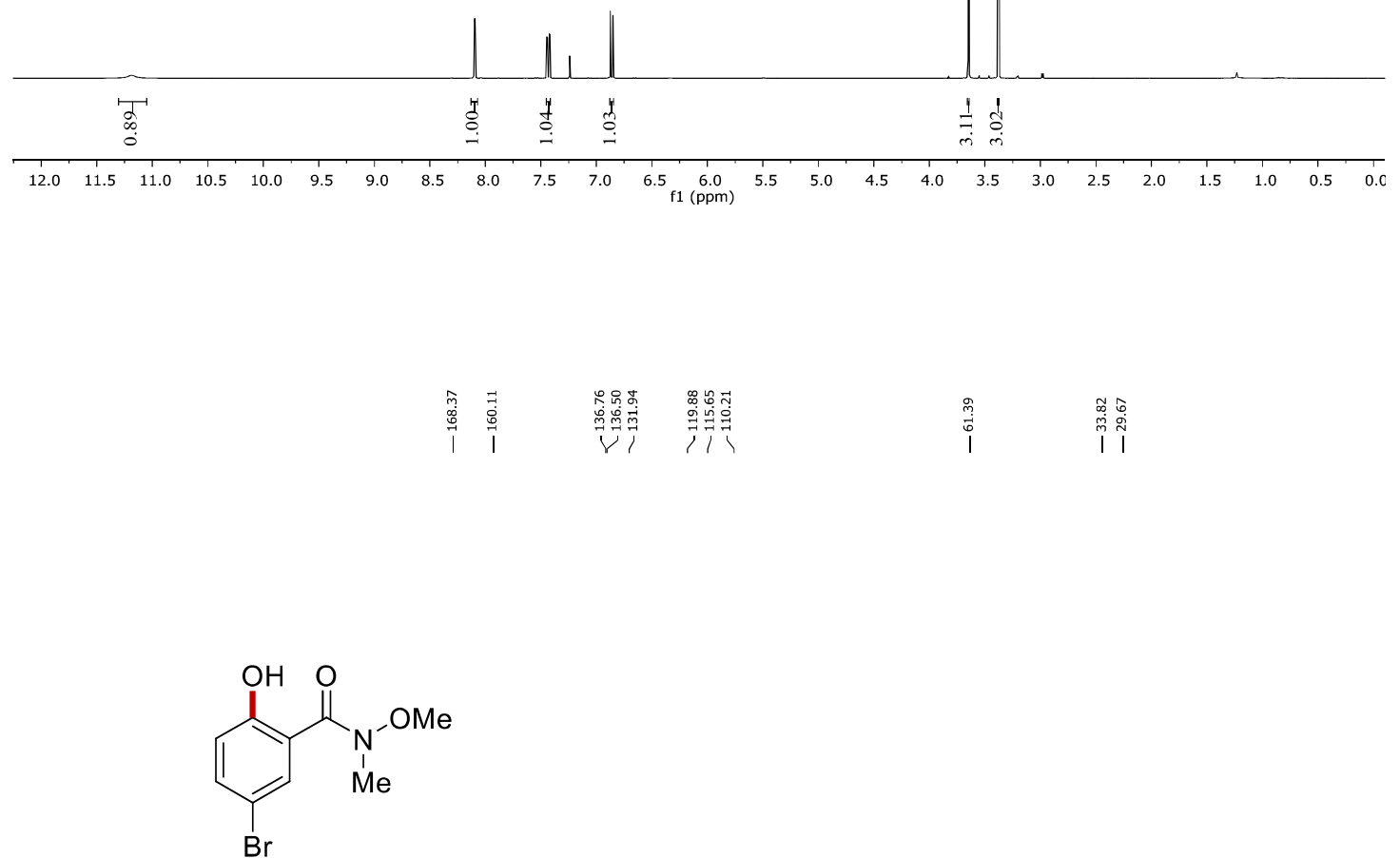

$106 n{ }^{13} \mathrm{C}-\mathrm{NMR}$ $\left(100 \mathrm{MHz}, \mathrm{CDCl}_{3}\right)$

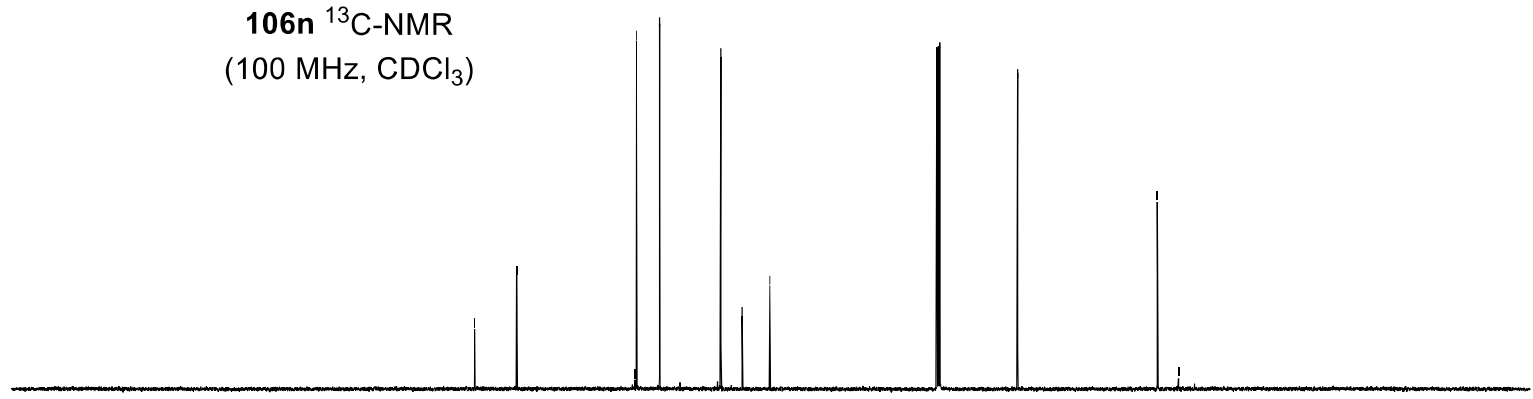

$\begin{array}{lllllllllllllllllllllllllllllllllllllll}250 & 240 & 230 & 220 & 210 & 200 & 190 & 180 & 170 & 160 & 150 & 140 & 130 & 120 & 110 & 100 & 90 & 80 & 70 & 60 & 50 & 40 & 30 & 20 & 10 & 0 & -10 & -20 & -30\end{array}$ 


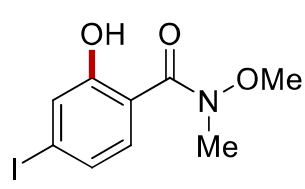

$1060{ }^{1} \mathrm{H}-\mathrm{NMR}$

$\left(400 \mathrm{MHz}, \mathrm{CDCl}_{3}\right)$

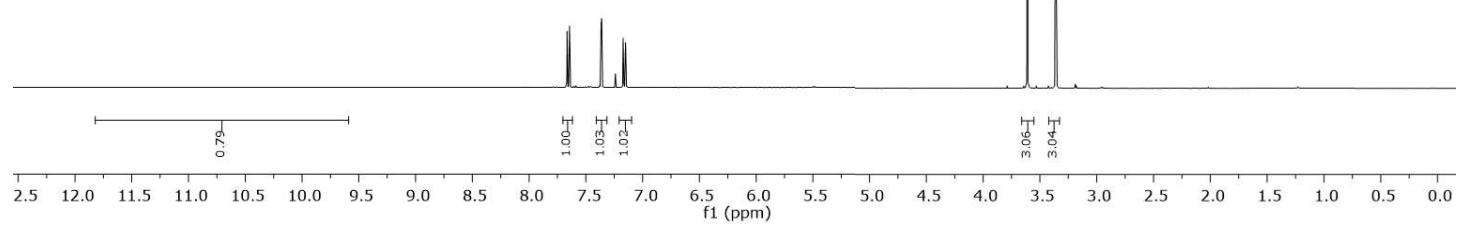

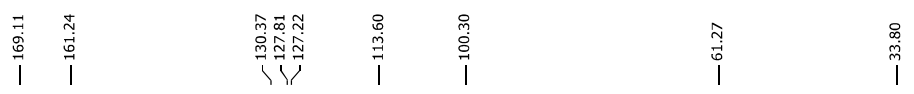

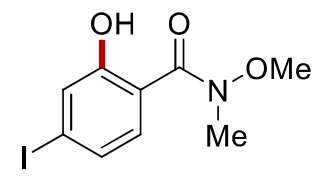

$1060^{13} \mathrm{C}-\mathrm{NMR}$

$\left(100 \mathrm{MHz}, \mathrm{CDCl}_{3}\right)$

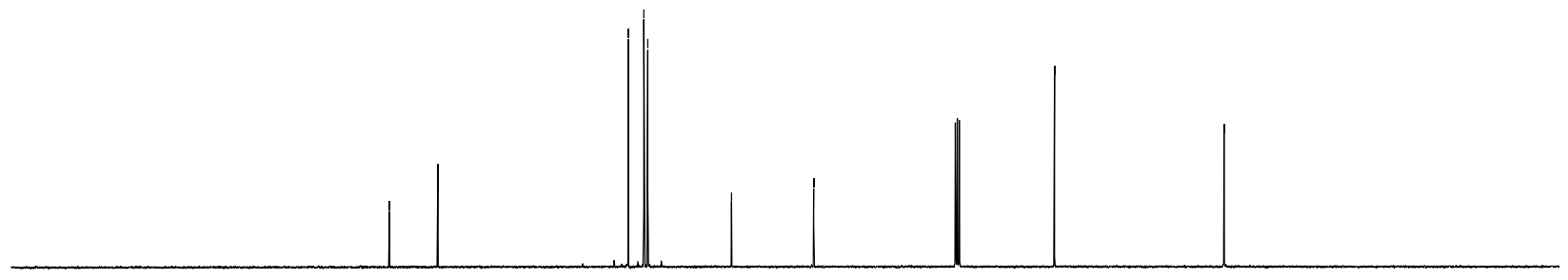

$\begin{array}{llllllllllllllllllllllllllllllllllllllllll}30 & 220 & 210 & 200 & 190 & 180 & 170 & 160 & 150 & 140 & 130 & 120 & 110 & 100 & 90 & 80 & 70 & 60 & 50 & 40 & 30 & 20 & 10 & 0 & -10 & -2\end{array}$ 

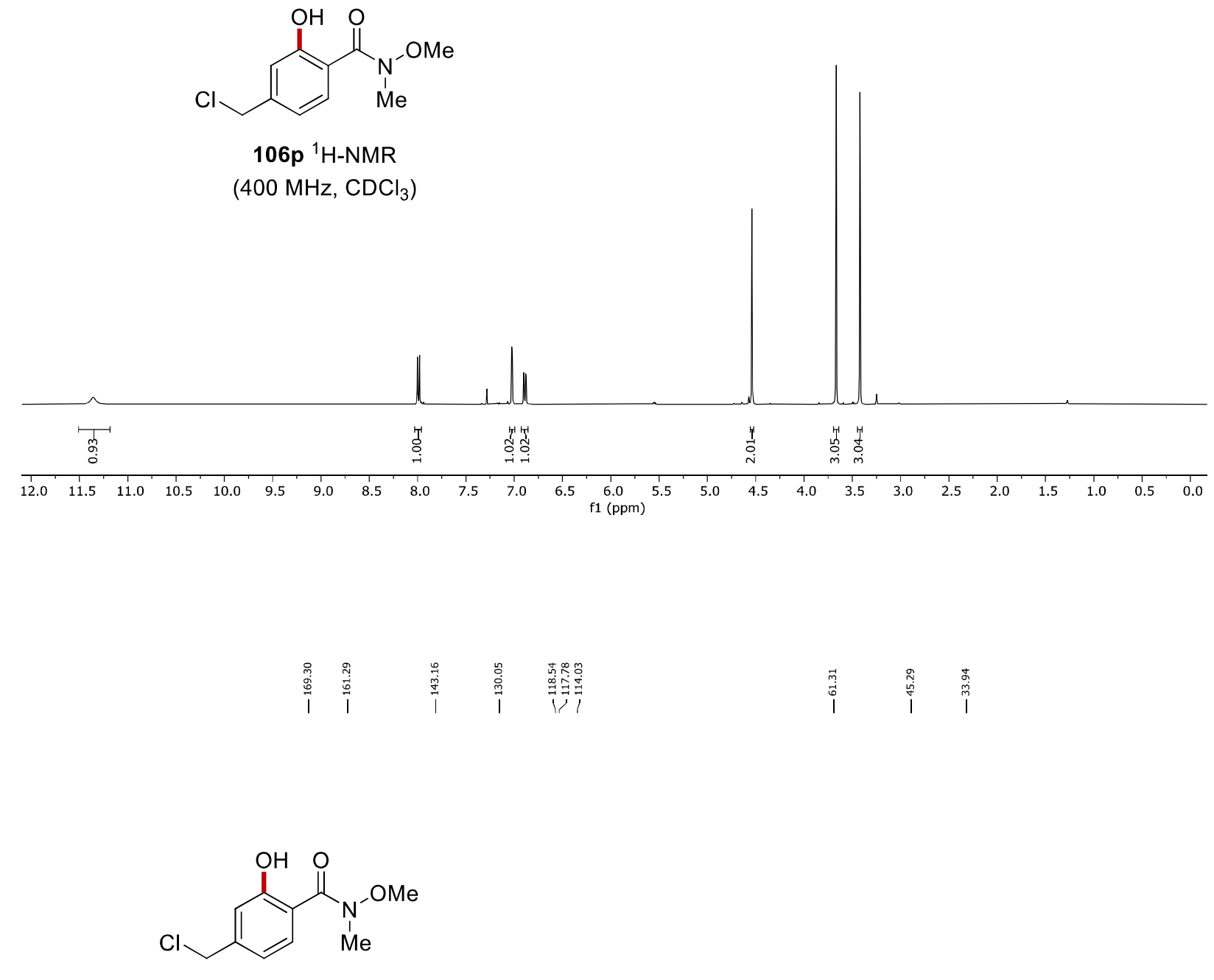

106p ${ }^{13} \mathrm{C}-\mathrm{NMR}$

$\left(100 \mathrm{MHz}, \mathrm{CDCl}_{3}\right.$ )

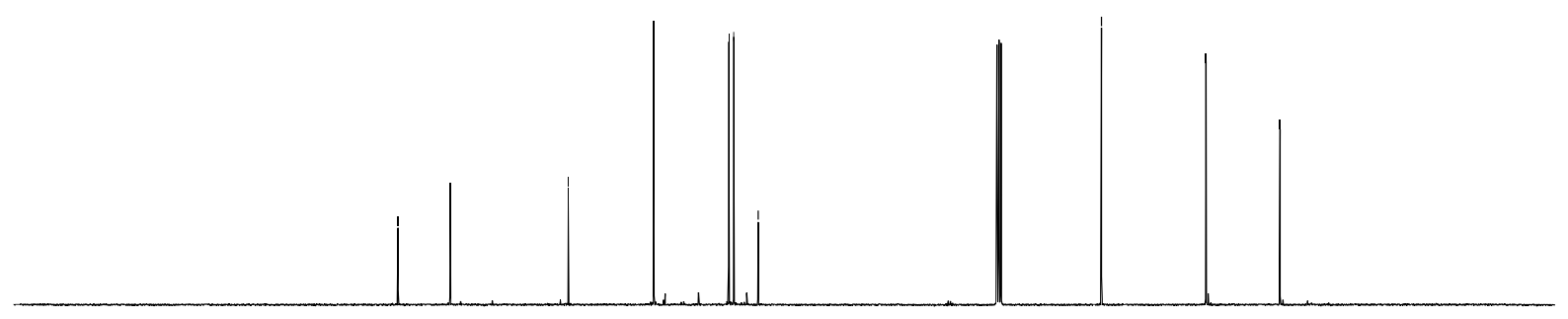

$\begin{array}{lllllllllllllllllllllll}1 & 1 \\ 220 & 210 & 200 & 190 & 180 & 170 & 160 & 150 & 140 & 130 & 120 & 110 & 100 & 90 & 80 & 70 & 60 & 50 & 40 & 30 & 20 & 10 & 0\end{array}$ 


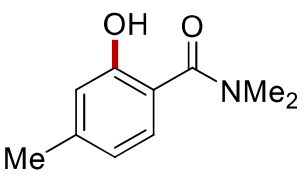

104b ${ }^{1} \mathrm{H}-\mathrm{NMR}$

$\left(300 \mathrm{MHz}, \mathrm{CDCl}_{3}\right)$
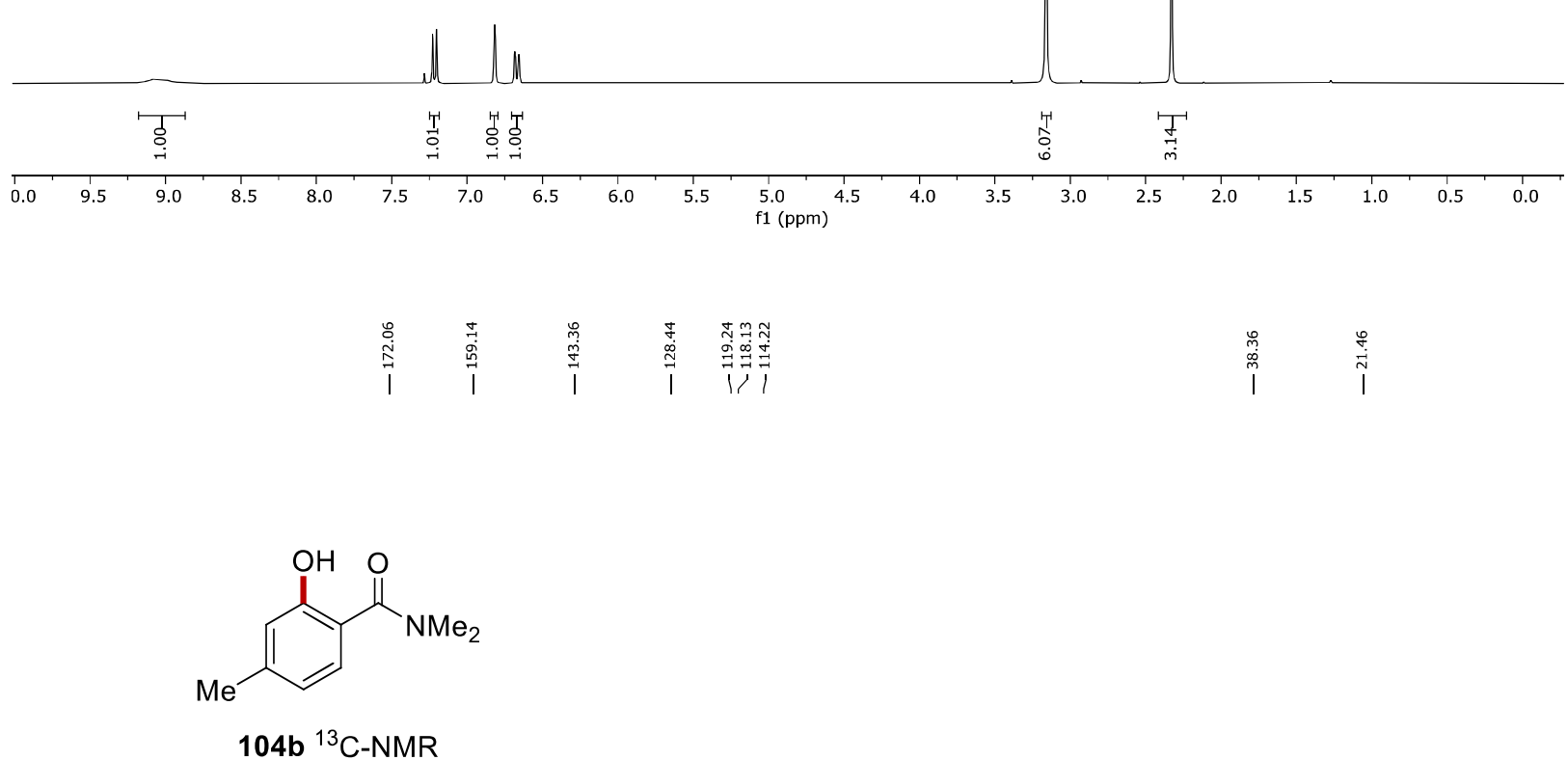

$\left(100 \mathrm{MHz}, \mathrm{CDCl}_{3}\right.$ )

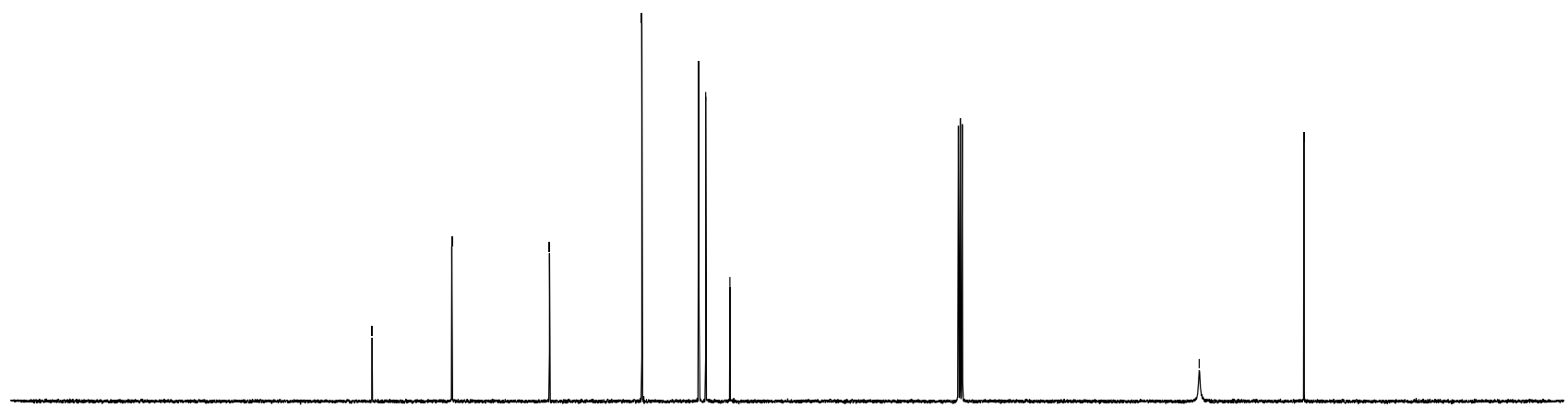

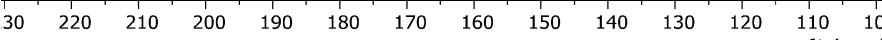

f1 (ppm) 


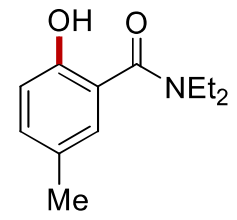

104d ${ }^{1} \mathrm{H}-\mathrm{NMR}$

(400 MHz, $\mathrm{CDCl}_{3}$ )

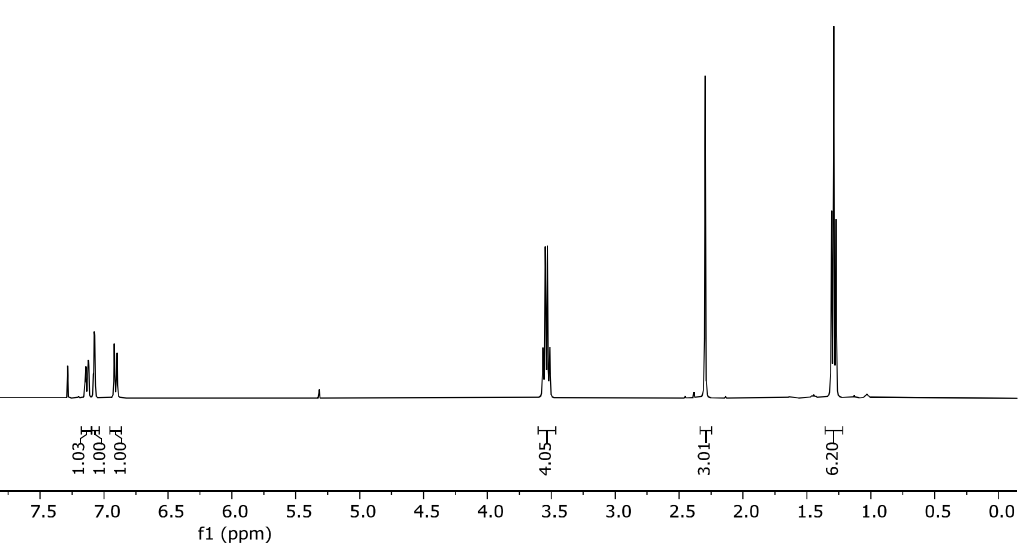

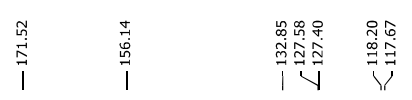

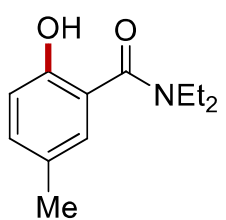

104d ${ }^{13} \mathrm{C}-\mathrm{NMR}$

$\left(100 \mathrm{MHz}, \mathrm{CDCl}_{3}\right.$ )

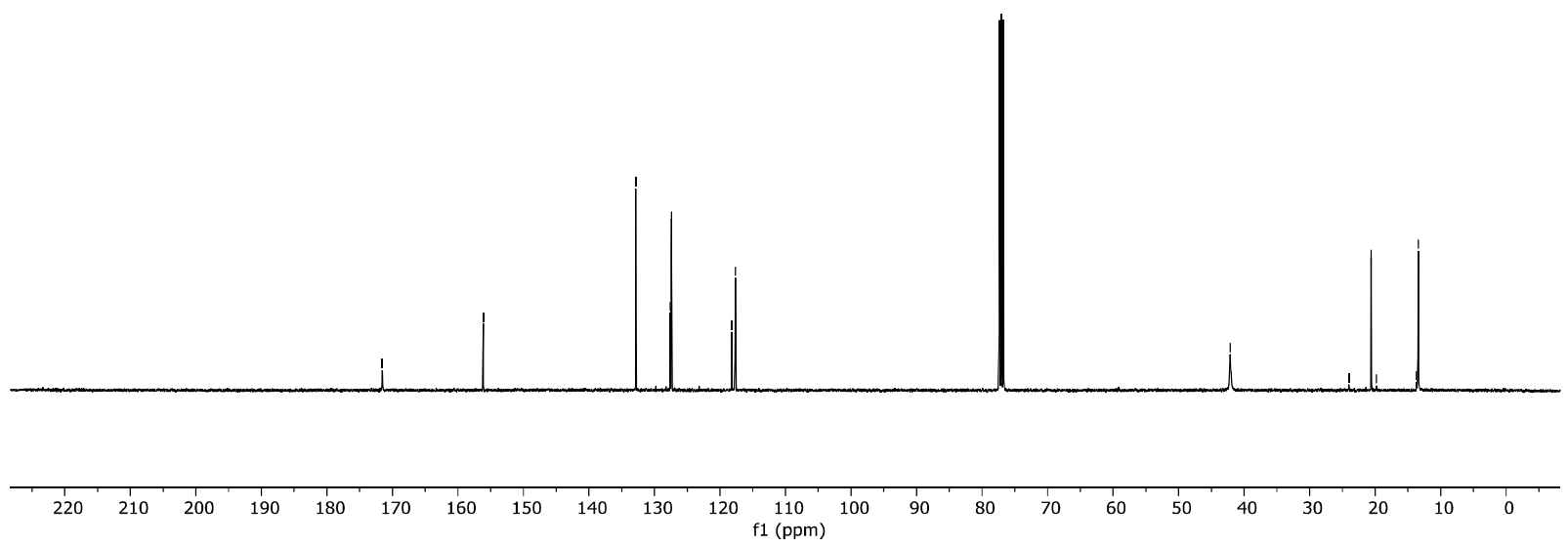




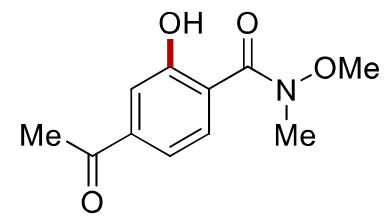

106q ${ }^{1} \mathrm{H}-\mathrm{NMR}$

(400 MHz, $\mathrm{CDCl}_{3}$ )<smiles>CON(C)C(=O)c1ccc(C(C)=O)cc1O</smiles>

$106 q{ }^{13} \mathrm{C}-\mathrm{NMR}$

$\left(100 \mathrm{MHz}, \mathrm{CDCl}_{3}\right.$ )

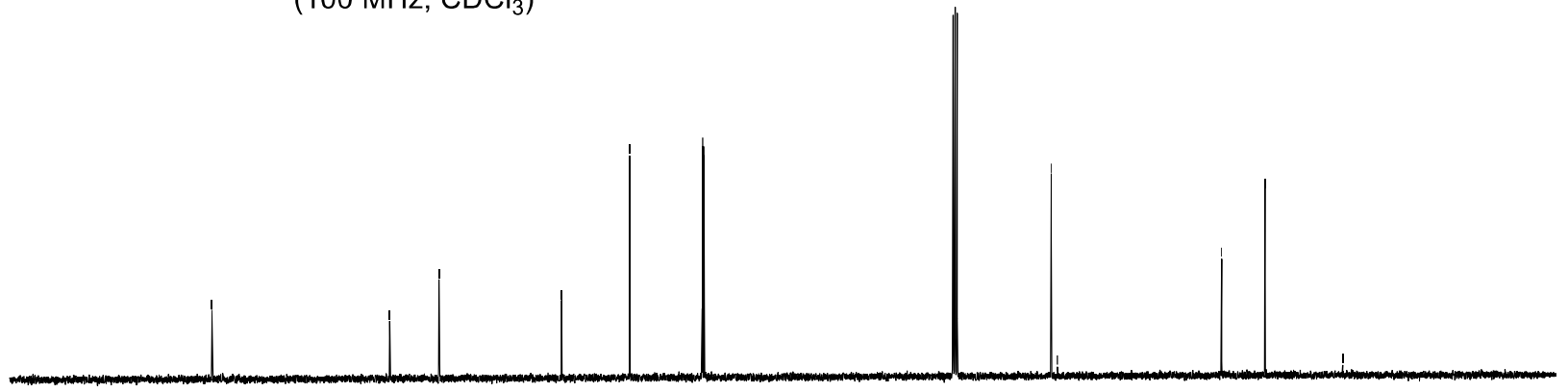

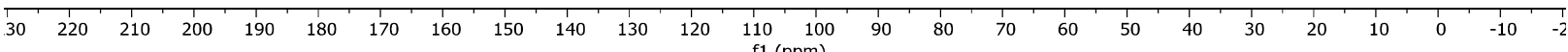




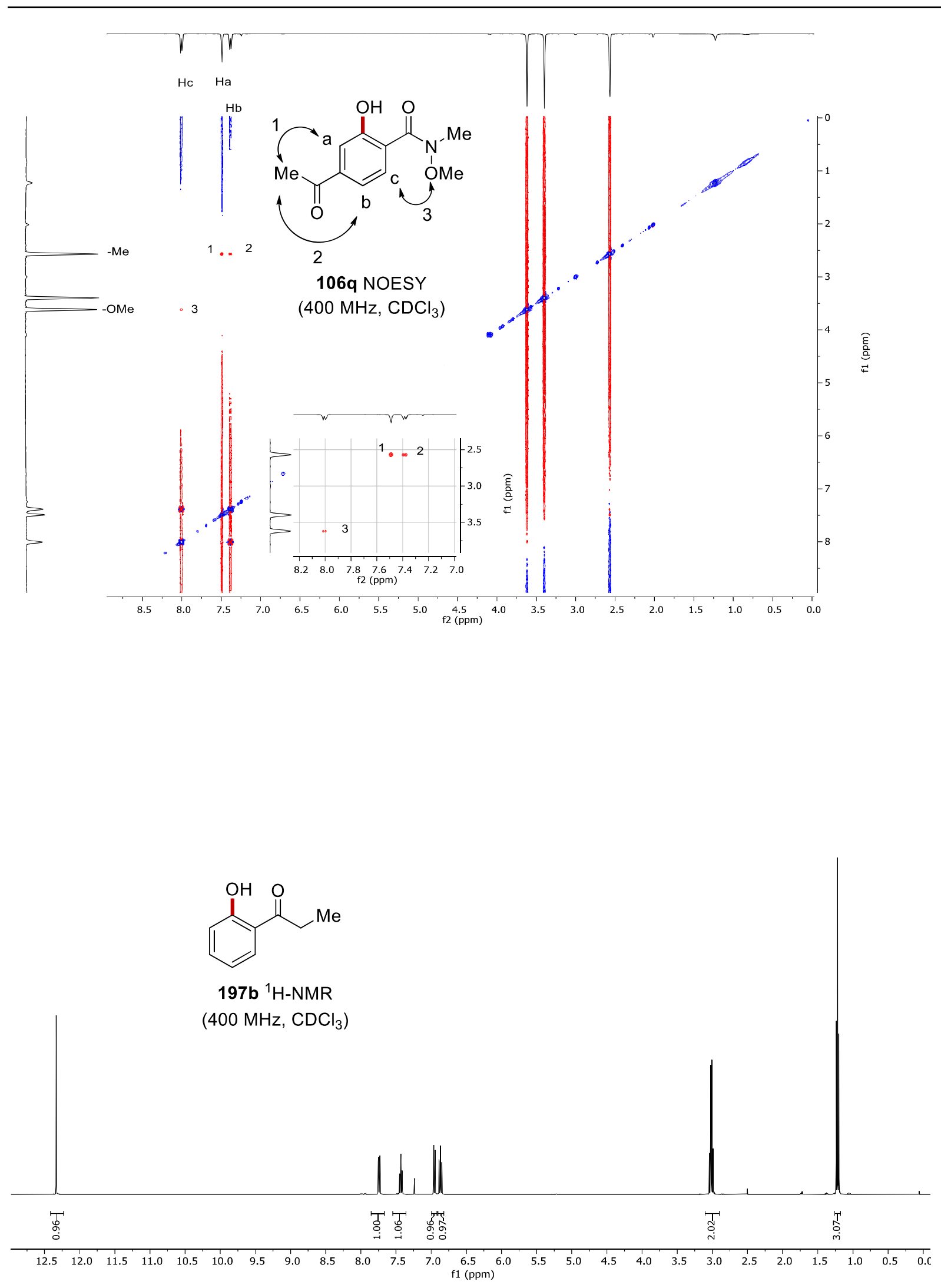



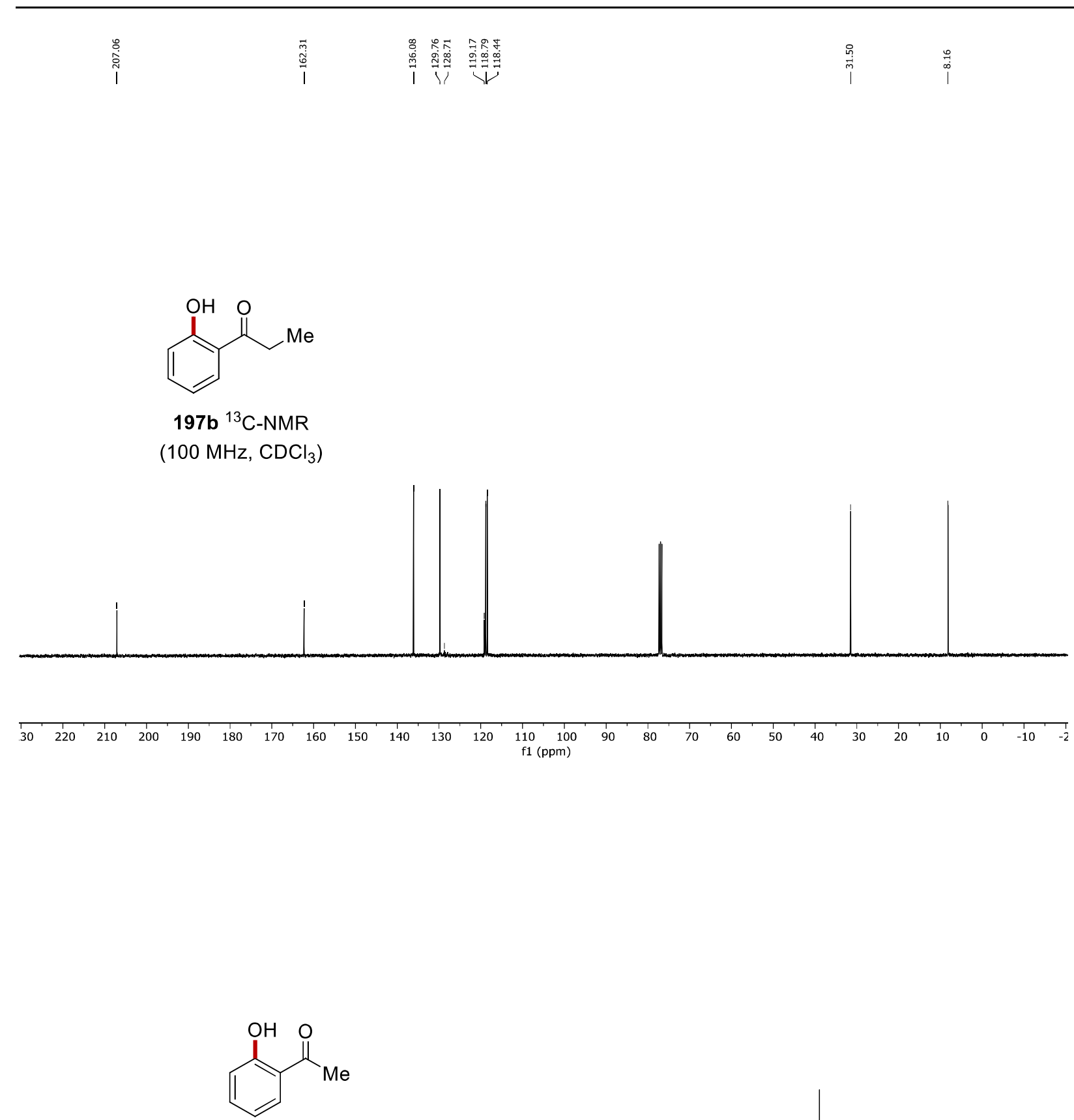

197c ${ }^{1} \mathrm{H}-\mathrm{NMR}$

$\left(400 \mathrm{MHz}, \mathrm{CDCl}_{3}\right.$ )

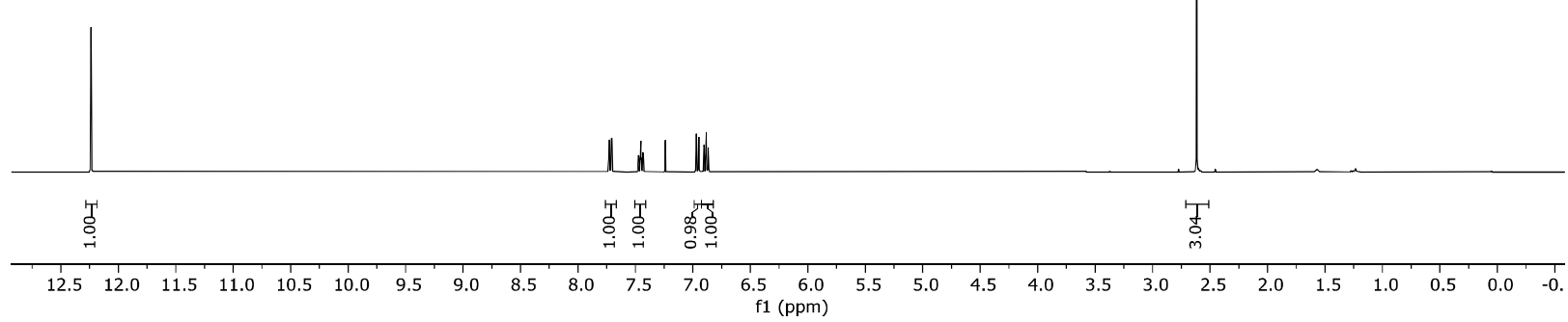




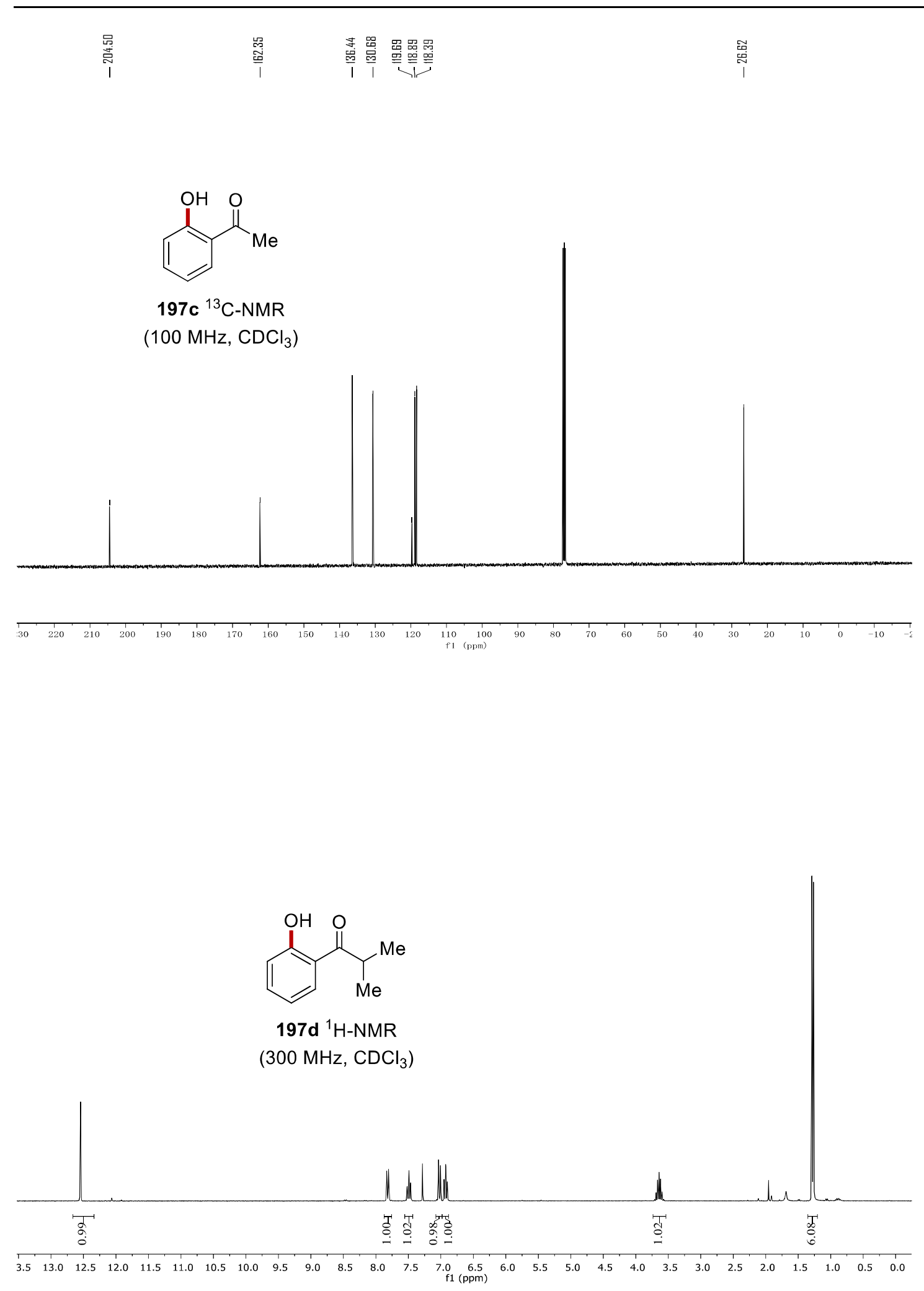




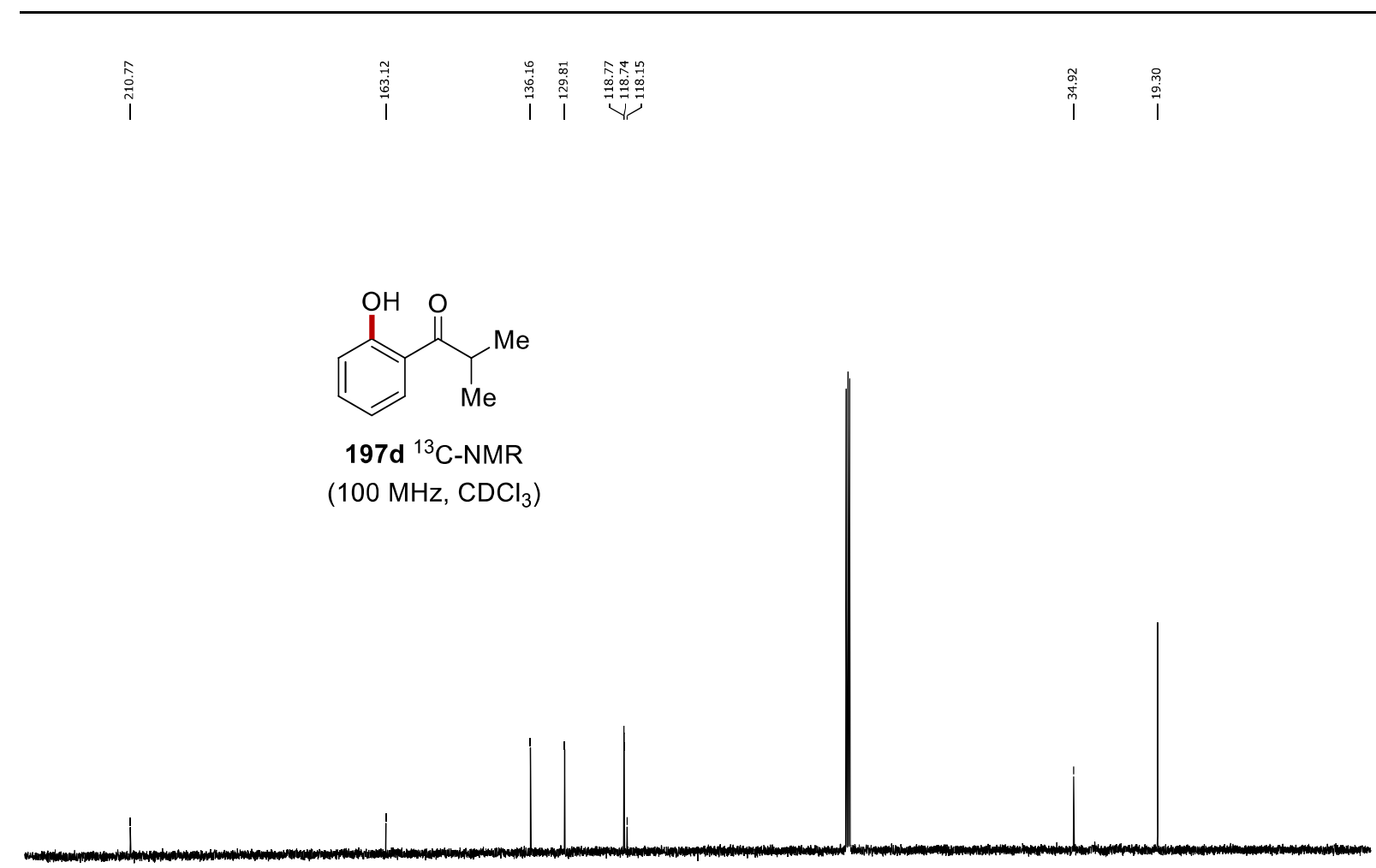

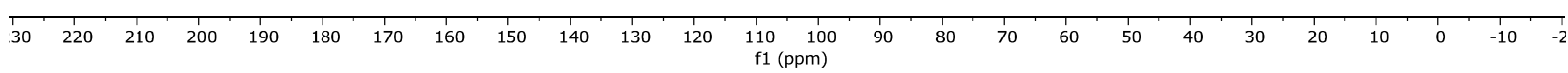<smiles>Cc1ccc(C(=O)C(C)(C)C)c(O)c1</smiles>

$197 \mathrm{e}^{1} \mathrm{H}-\mathrm{NMR}$

$\left(400 \mathrm{MHz}, \mathrm{CDCl}_{3}\right)$

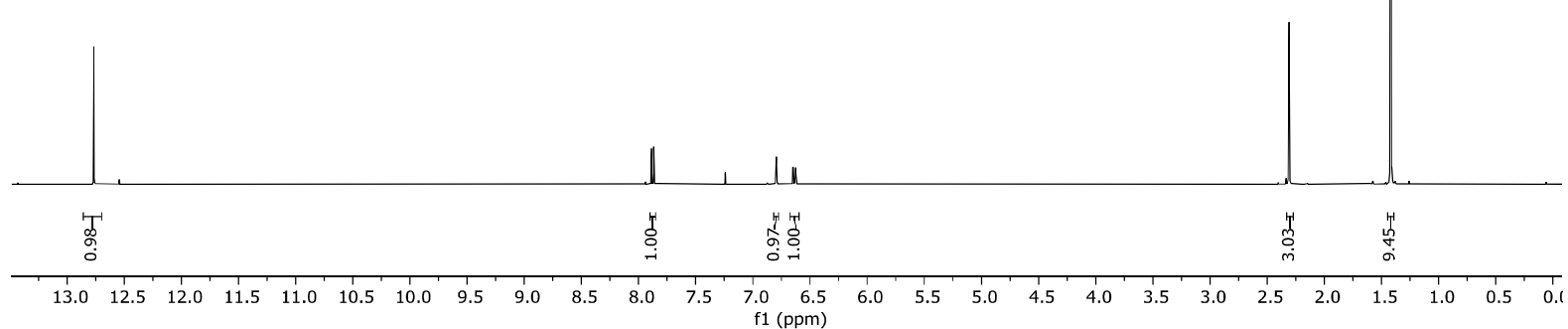




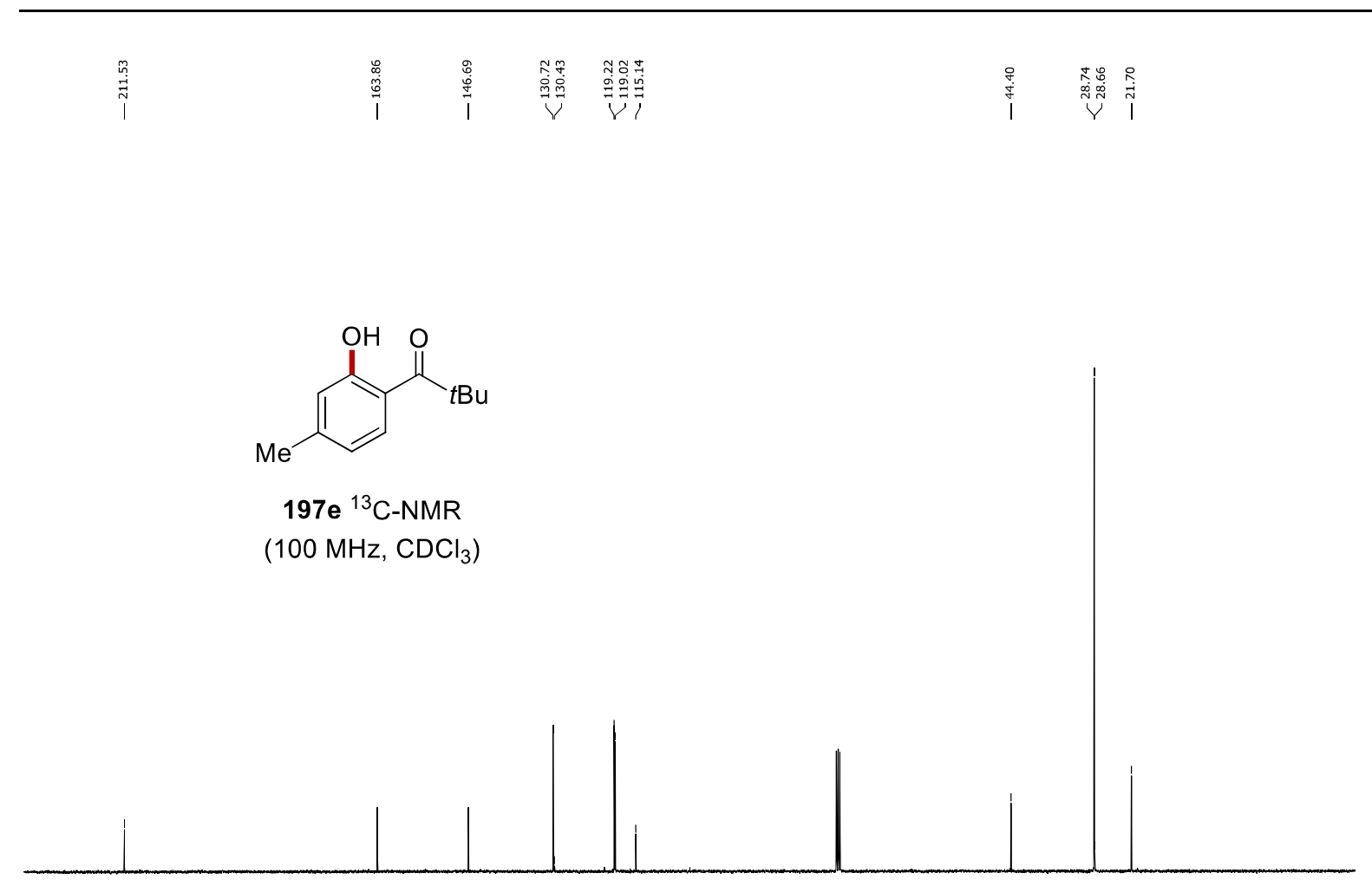

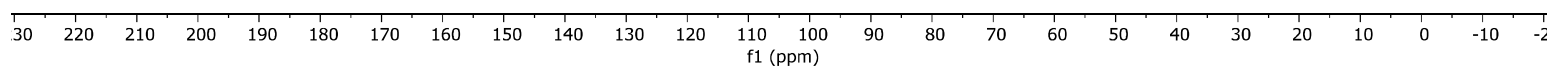<smiles>CC(C)(C)C(=O)c1ccc(Cl)cc1O</smiles>

$197 \mathrm{~h}{ }^{1} \mathrm{H}-\mathrm{NMR}$

(400 MHz, $\mathrm{CDCl}_{3}$ )

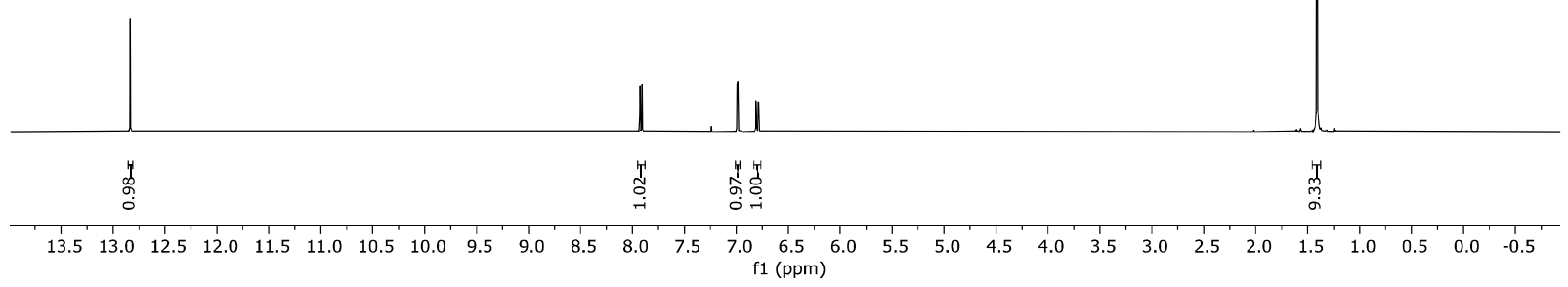




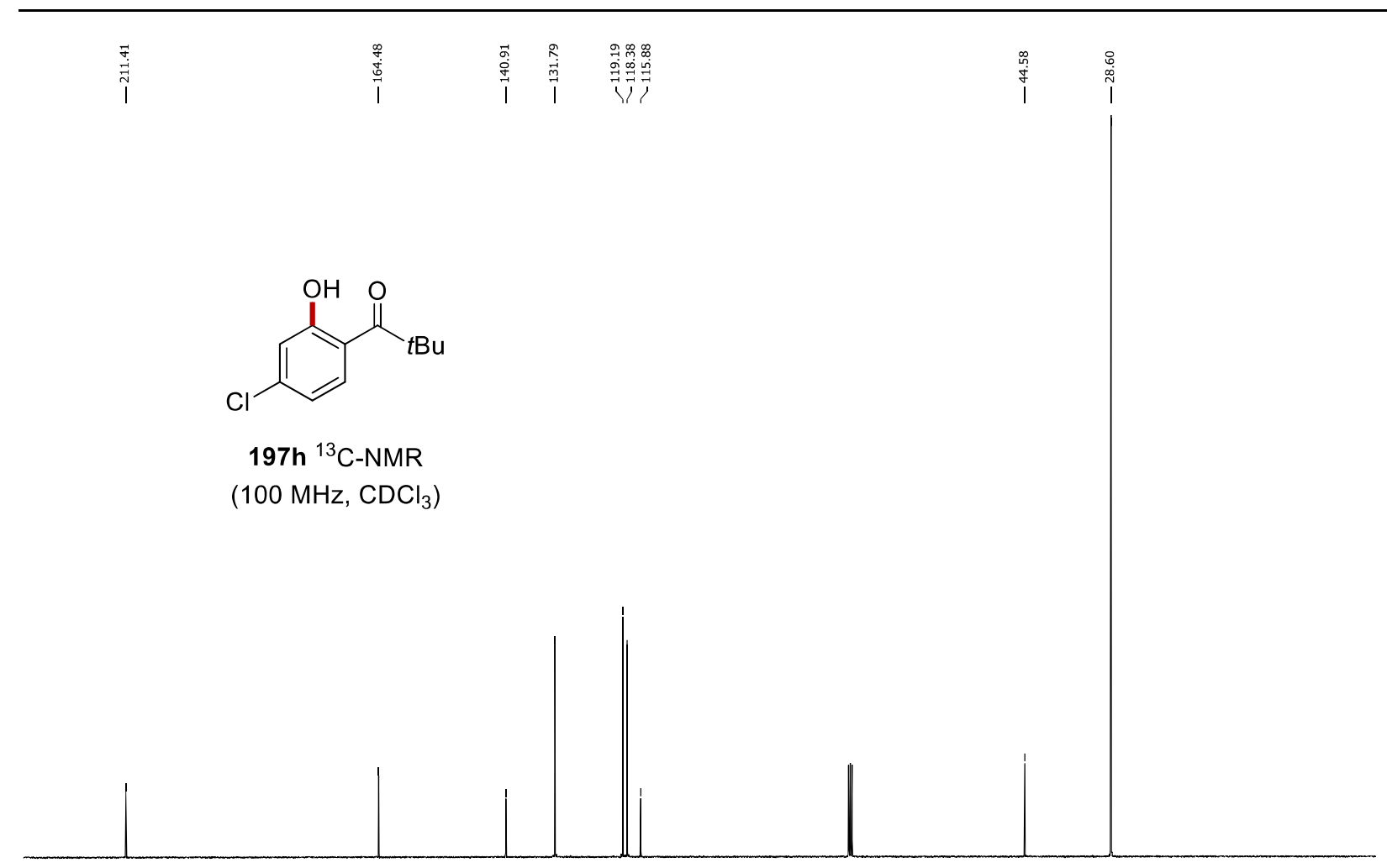

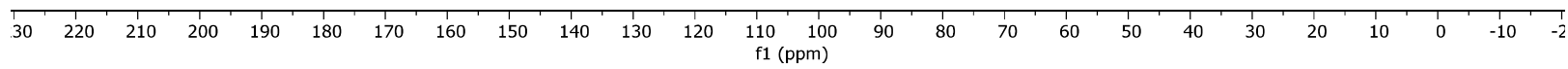<smiles>CC(C)(C)C(=O)c1ccc(F)cc1O</smiles>

197j ${ }^{1} \mathrm{H}-\mathrm{NMR}$

$\left(400 \mathrm{MHz}, \mathrm{CDCl}_{3}\right.$ )

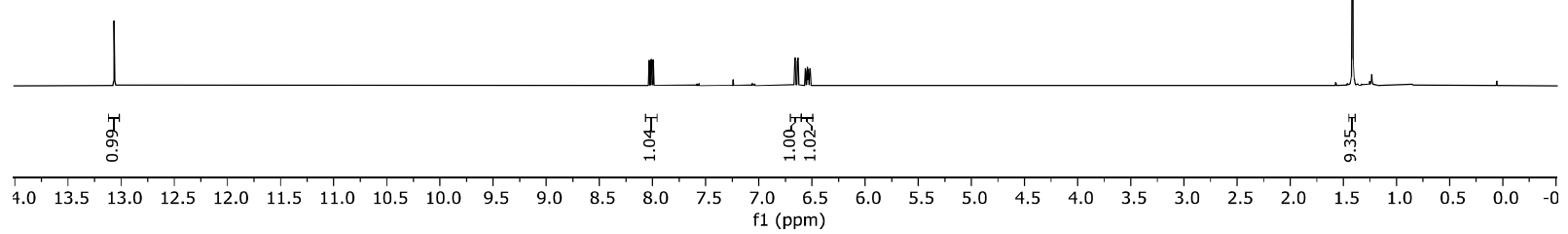



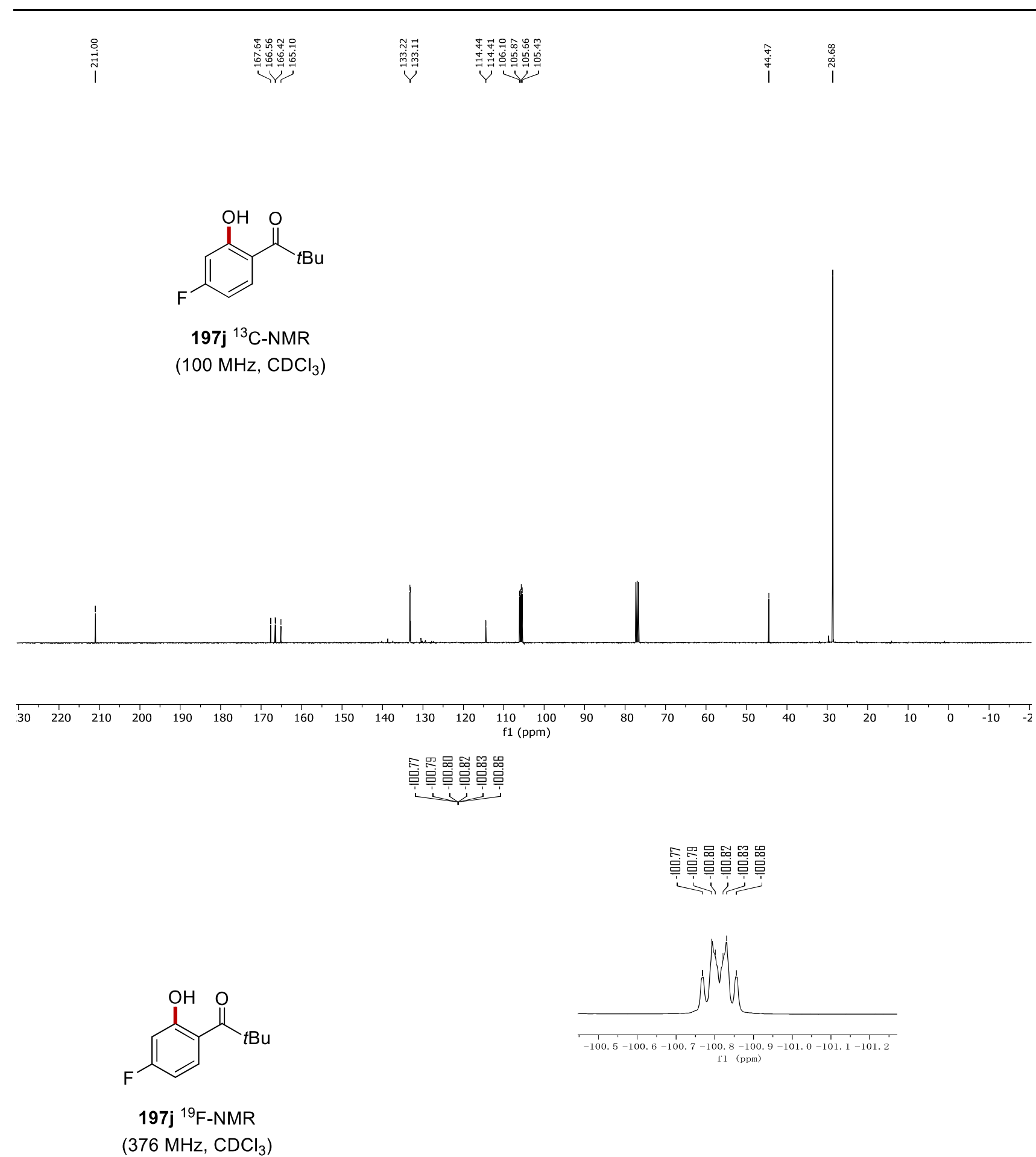

$\left(376 \mathrm{MHz}, \mathrm{CDCl}_{3}\right.$ ) 


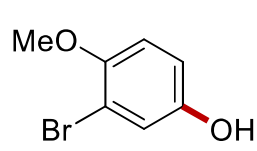

109a ${ }^{1} \mathrm{H}-\mathrm{NMR}$

$\left(600 \mathrm{MHz}, \mathrm{CDCl}_{3}\right.$ )
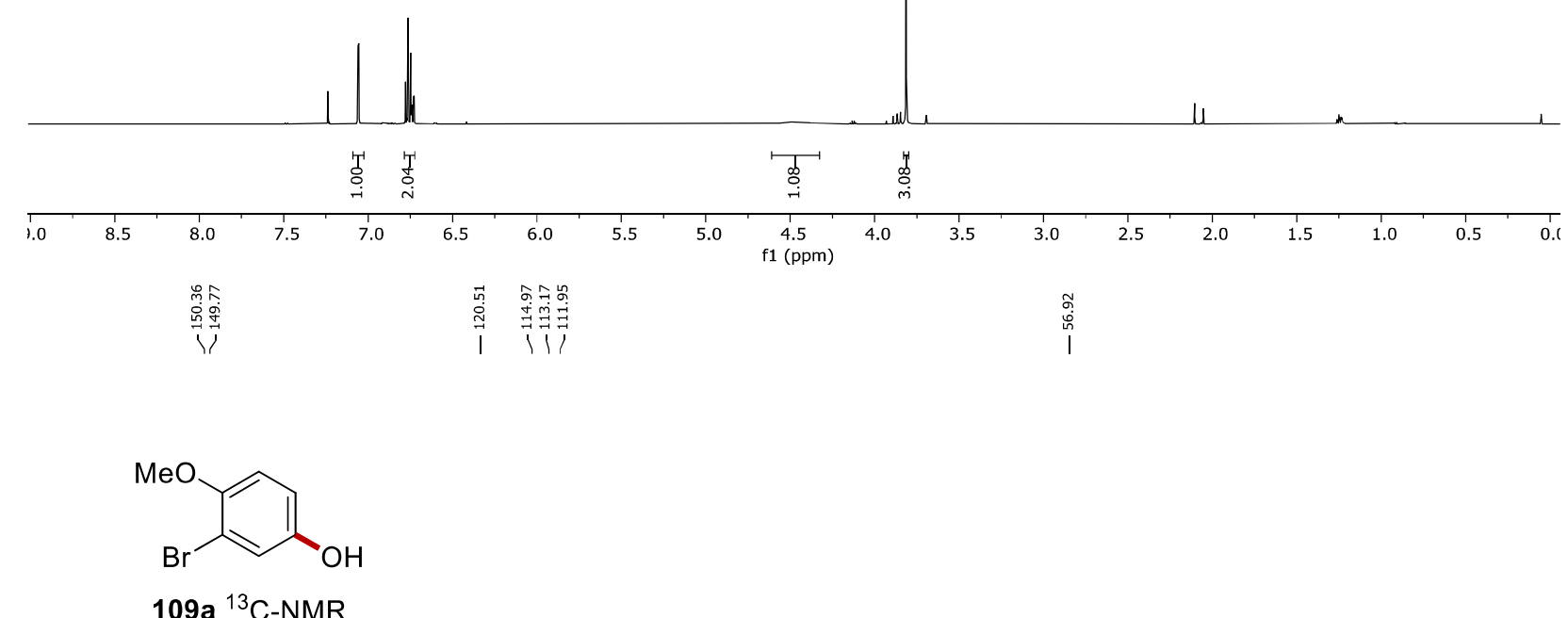

$\left(150 \mathrm{MHz}, \mathrm{CDCl}_{3}\right.$ )

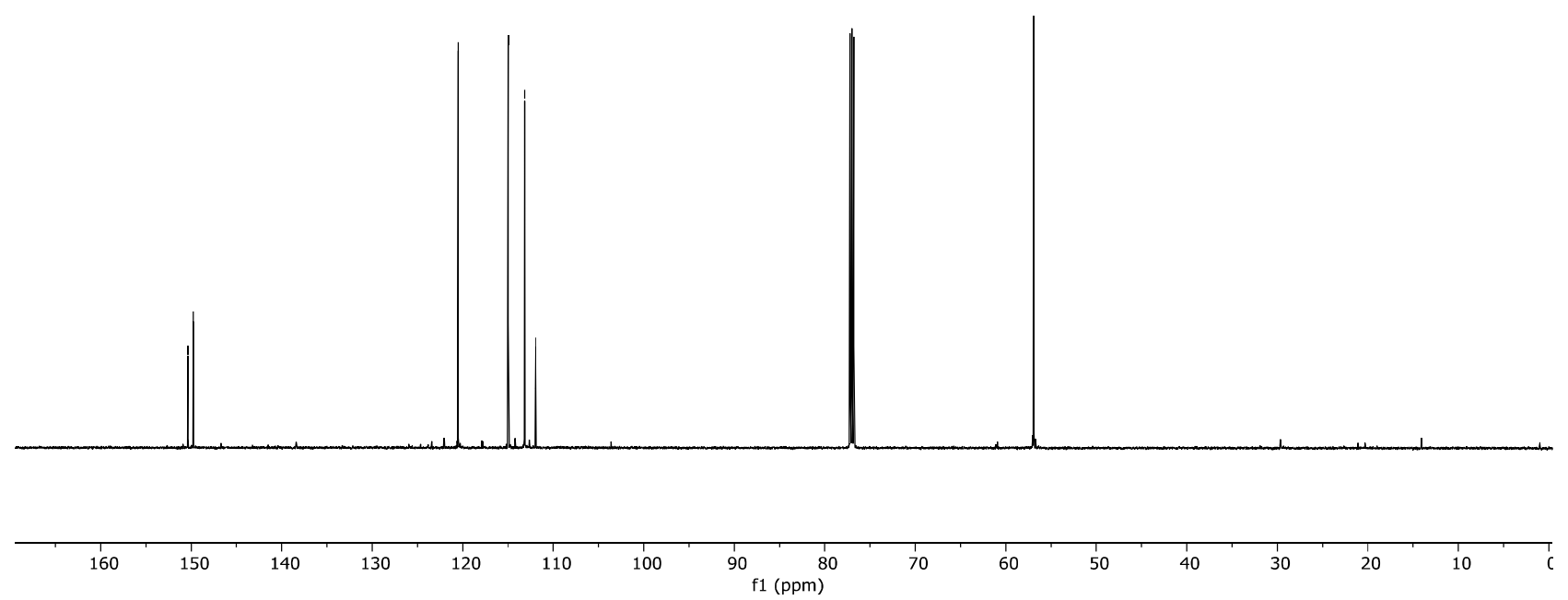




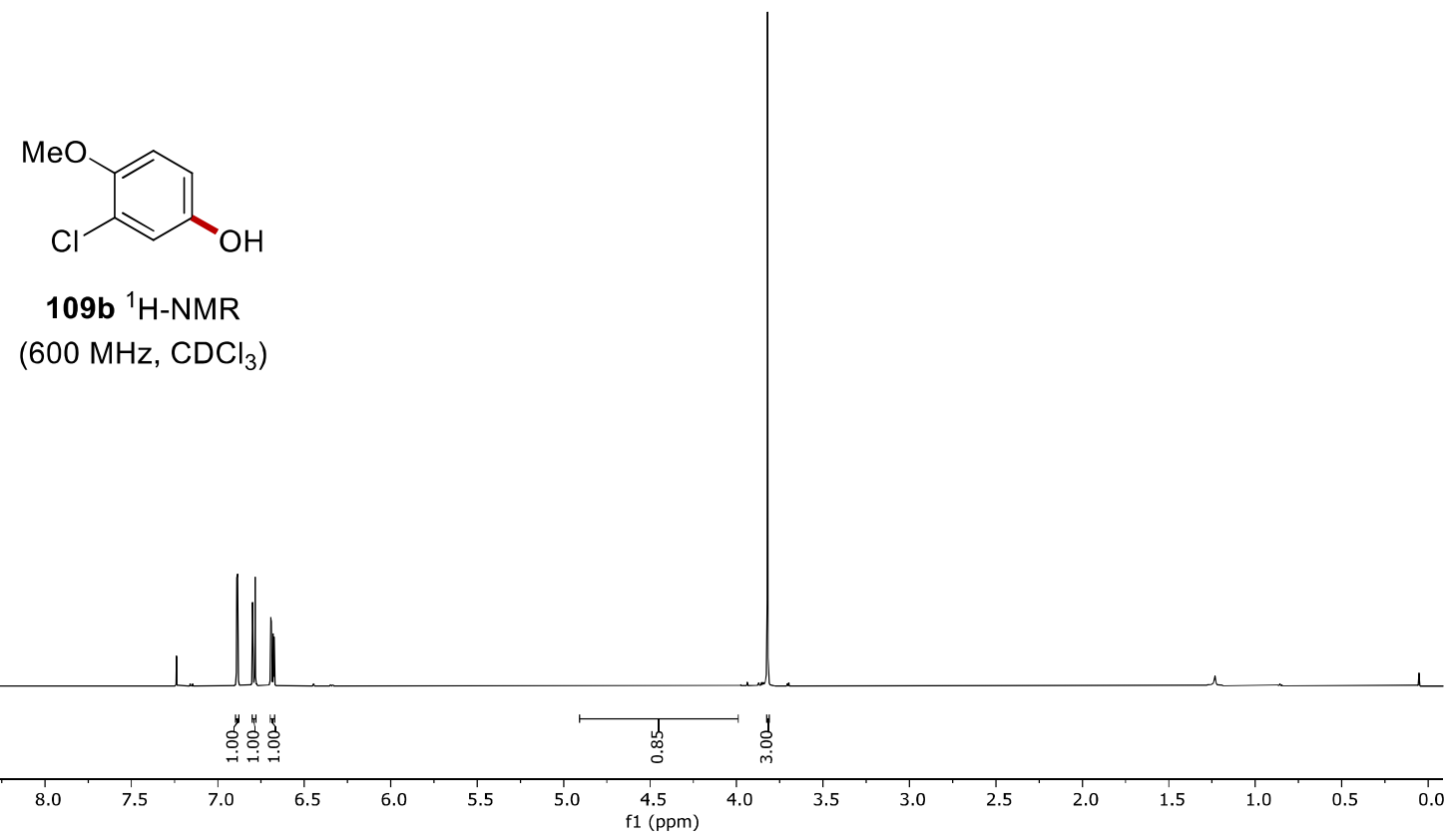

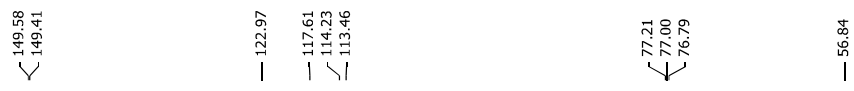

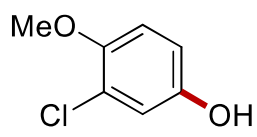

$109 \mathrm{~b}{ }^{13} \mathrm{C}-\mathrm{NMR}$

$\left(150 \mathrm{MHz}, \mathrm{CDCl}_{3}\right)$

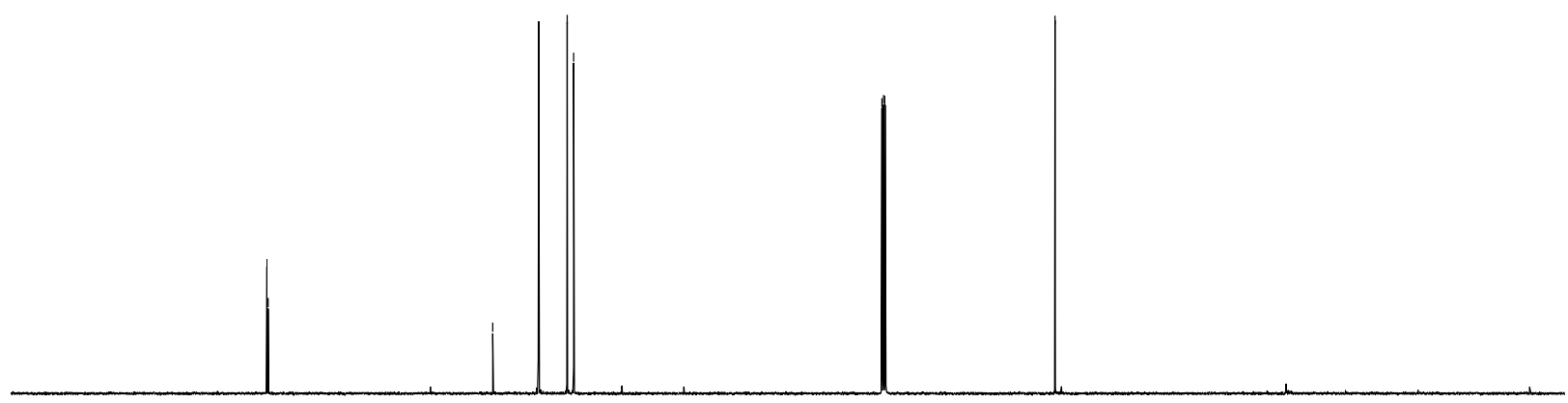

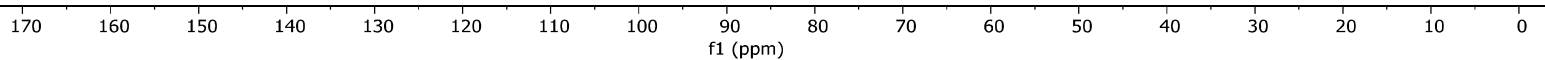


7.4 Rhoda-Electrocatalyzed Bimetallic C-H Oxygenation by Weak $O$-Coordination<smiles>Cc1ccc(C(=O)N(C)C)c(O)c1</smiles>

106b ${ }^{1} \mathrm{H}-\mathrm{NMR}$ (300 MHz, $\mathrm{CDCl}_{3}$ )

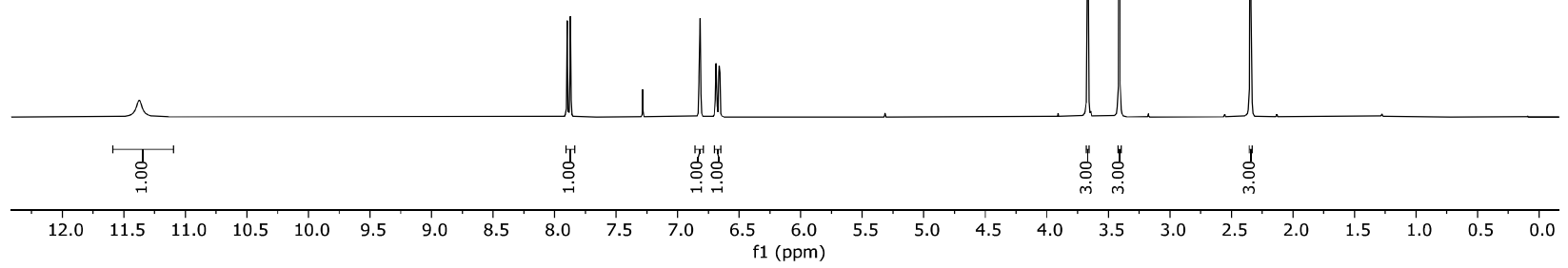<smiles>CON(C)C(=O)c1ccc(C)cc1O</smiles>

106b ${ }^{13} \mathrm{C}-\mathrm{NMR}$ $\left(100 \mathrm{MHz}, \mathrm{CDCl}_{3}\right.$ )

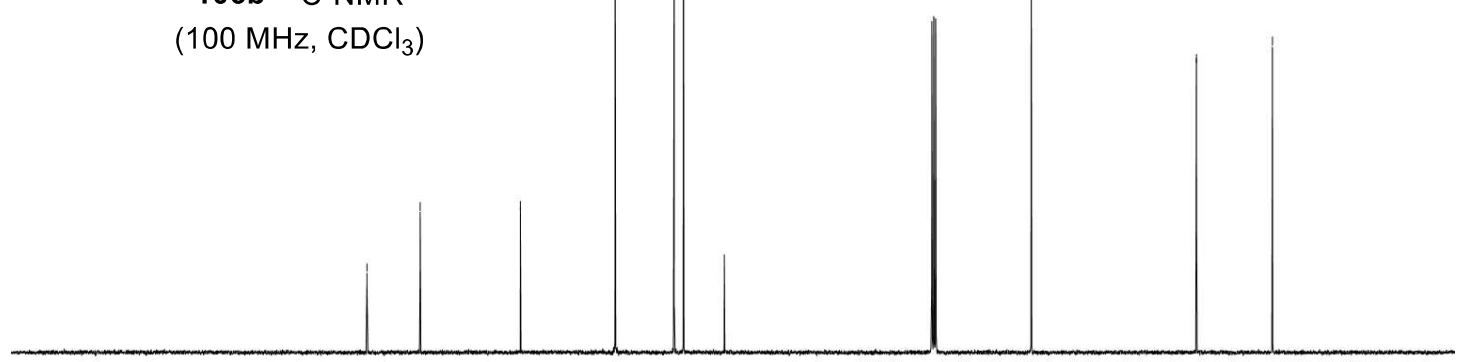



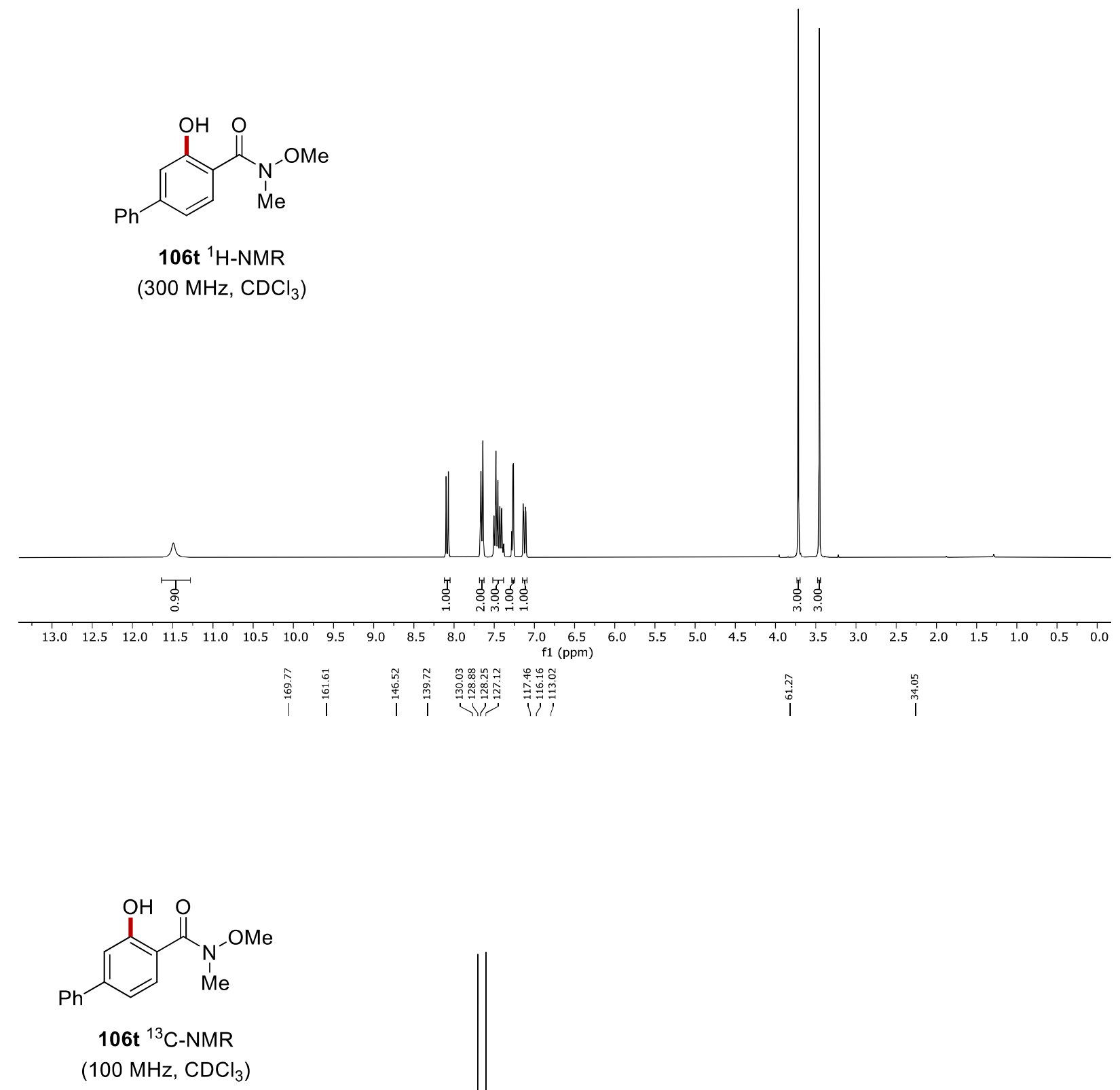

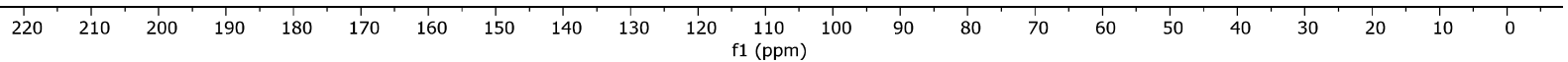




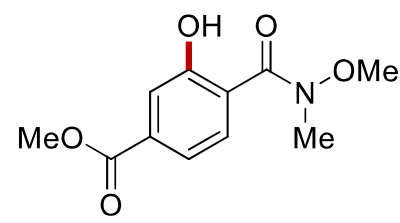

106u ${ }^{1} \mathrm{H}-\mathrm{NMR}$

(300 MHz, $\mathrm{CDCl}_{3}$ )

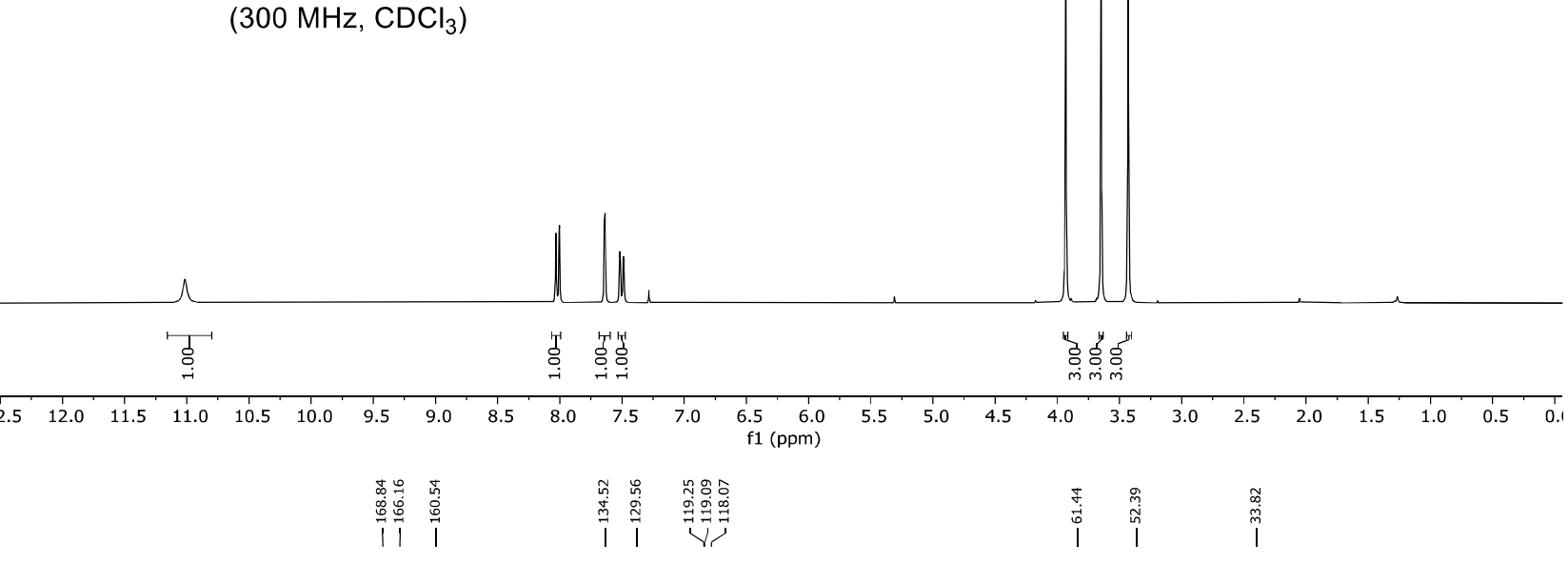<smiles>COC(=O)c1ccc(C(=O)N(C)C)c(O)c1</smiles>

${ }_{106 u}{ }^{13} \mathrm{C}-\mathrm{NMR}$

$\left(100 \mathrm{MHz}, \mathrm{CDCl}_{3}\right.$ )
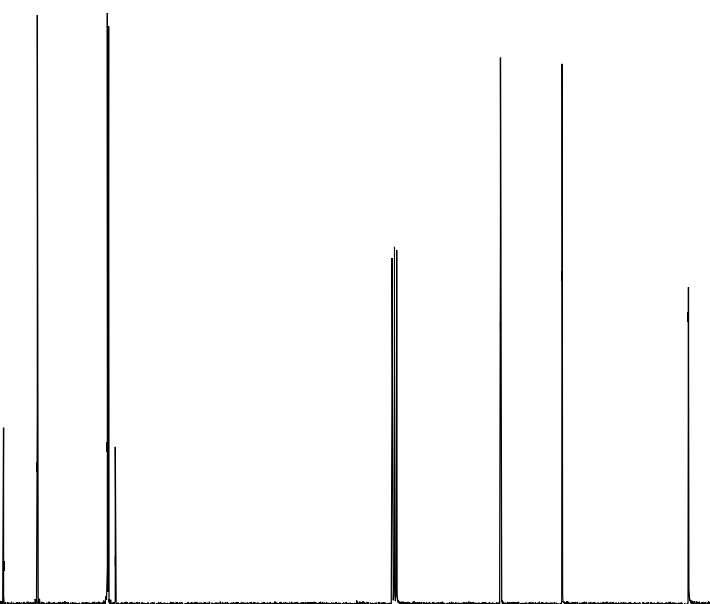


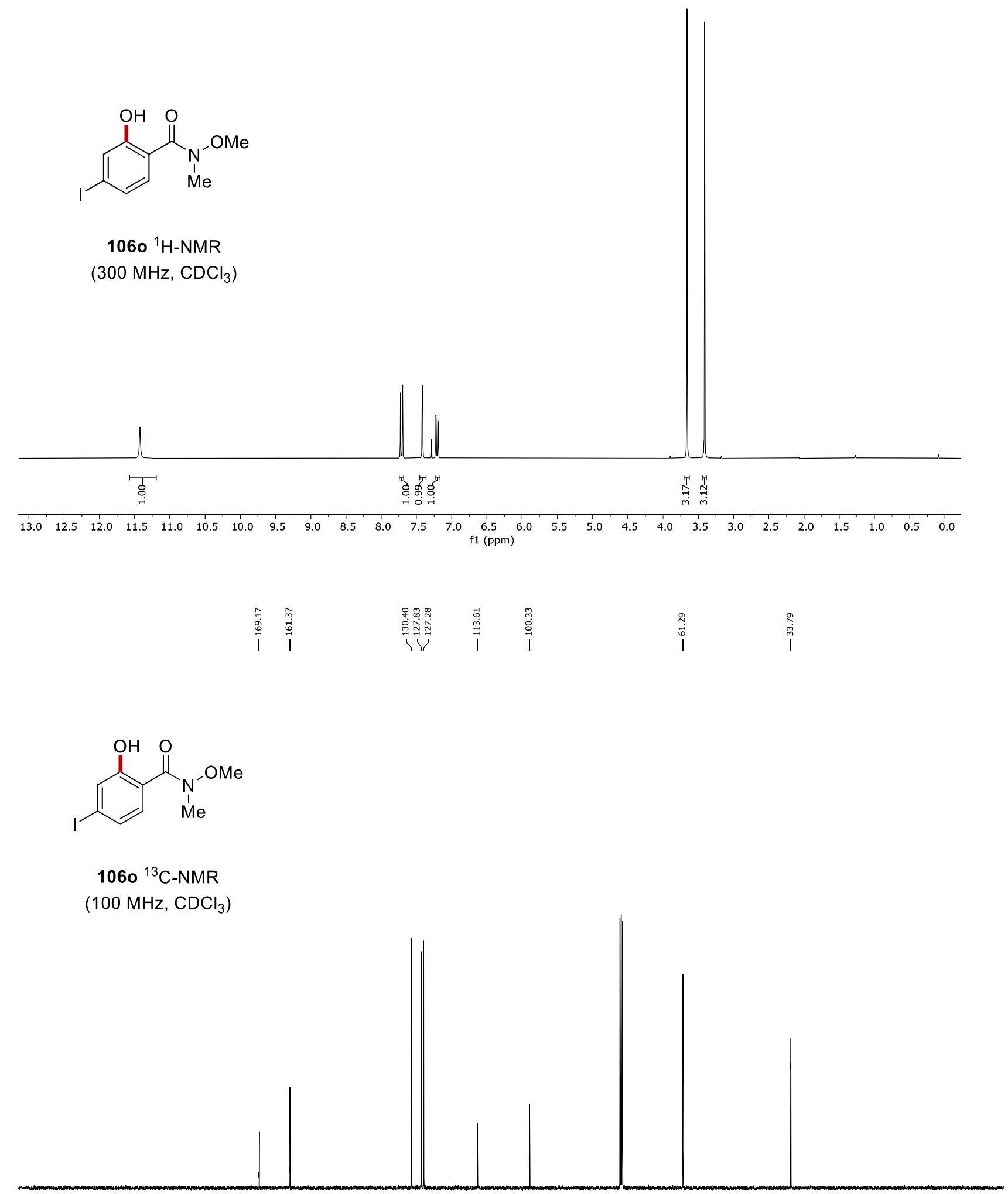

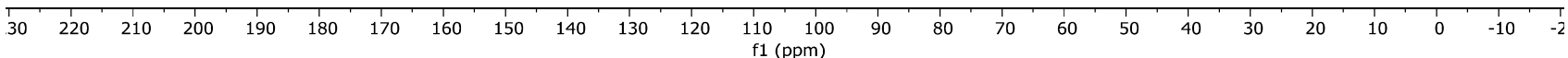




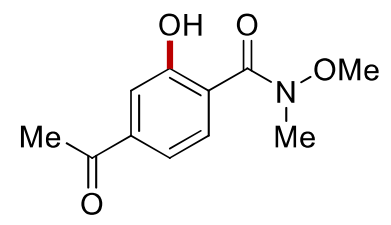

$106 q{ }^{1} \mathrm{H}-\mathrm{NMR}$

$\left(300 \mathrm{MHz}, \mathrm{CDCl}_{3}\right)$

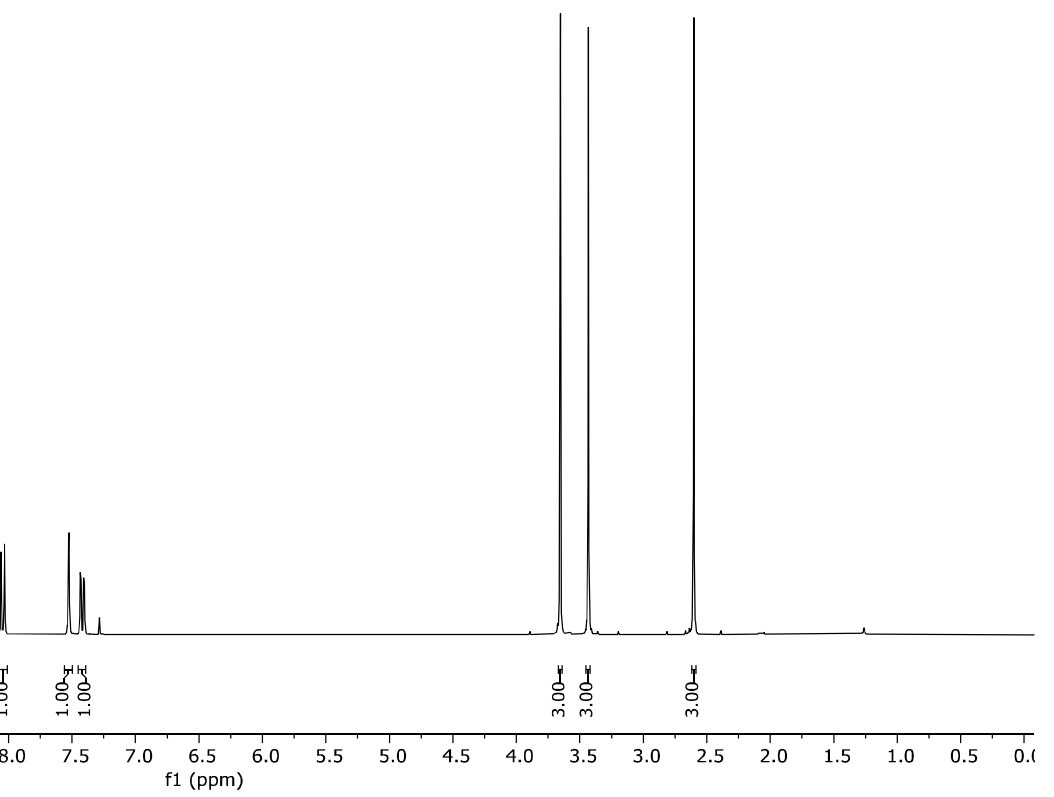

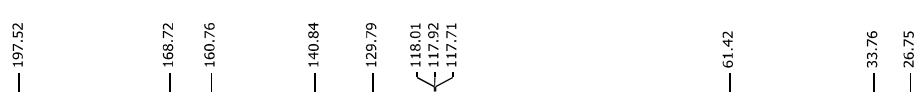<smiles>CON(C)C(=O)c1ccc(C(C)=O)cc1O</smiles>

106q ${ }^{13} \mathrm{C}-\mathrm{NMR}$

$\left(100 \mathrm{MHz}, \mathrm{CDCl}_{3}\right.$ )

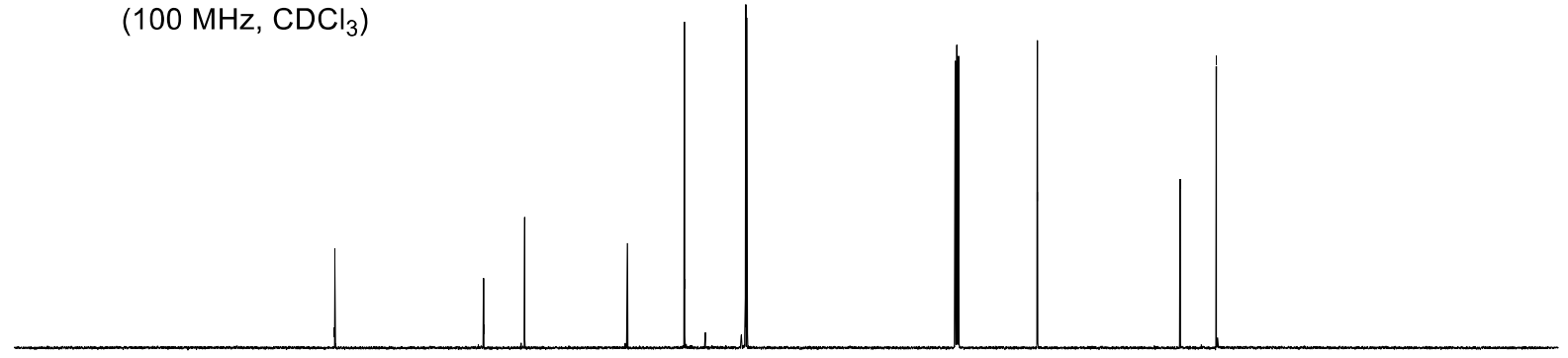

$\begin{array}{lllllllllllllllllllllllllllllll}250 & 240 & 230 & 220 & 210 & 200 & 190 & 180 & 170 & 160 & 150 & 140 & 130 & 120 & 110 & 100 & 90 & 80 & 70 & 60 & 50 & 40 & 30 & 20 & 10 & 0 & -10 & -20 & -30\end{array}$ f1 (ppm) 


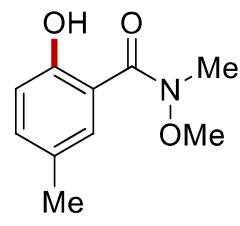

106j ${ }^{1} \mathrm{H}-\mathrm{NMR}$ (400 MHz, $\mathrm{CDCl}_{3}$ )

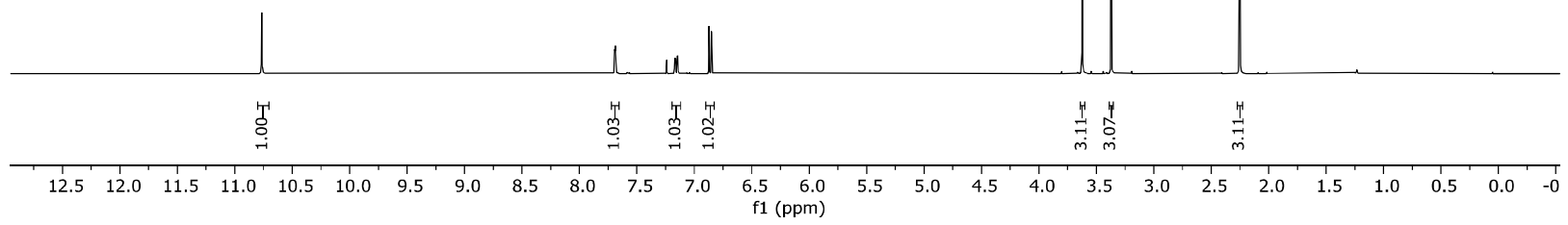

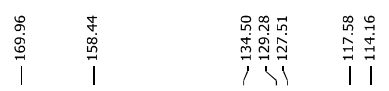

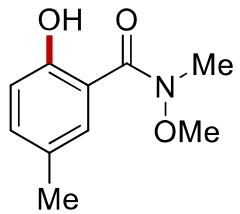

106j ${ }^{13} \mathrm{C}-\mathrm{NMR}$ $\left(100 \mathrm{MHz}, \mathrm{CDCl}_{3}\right)$

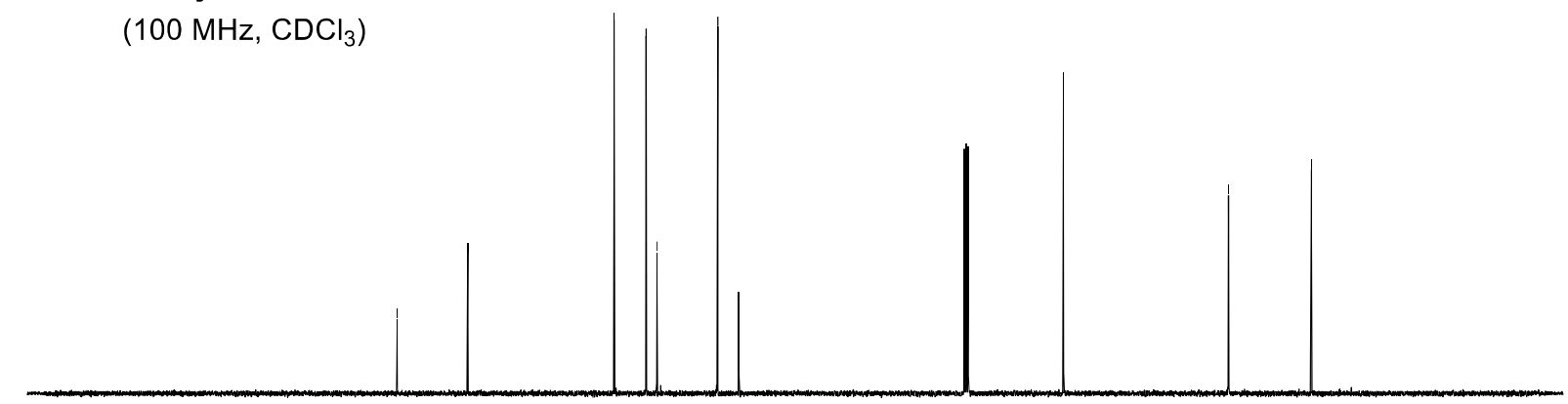

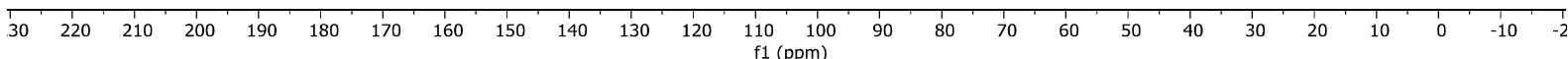




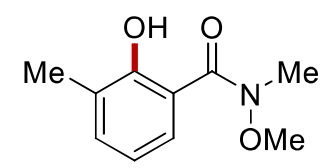

106j' ${ }^{1} \mathrm{H}-\mathrm{NMR}$

(400 MHz, $\mathrm{CDCl}_{3}$ )

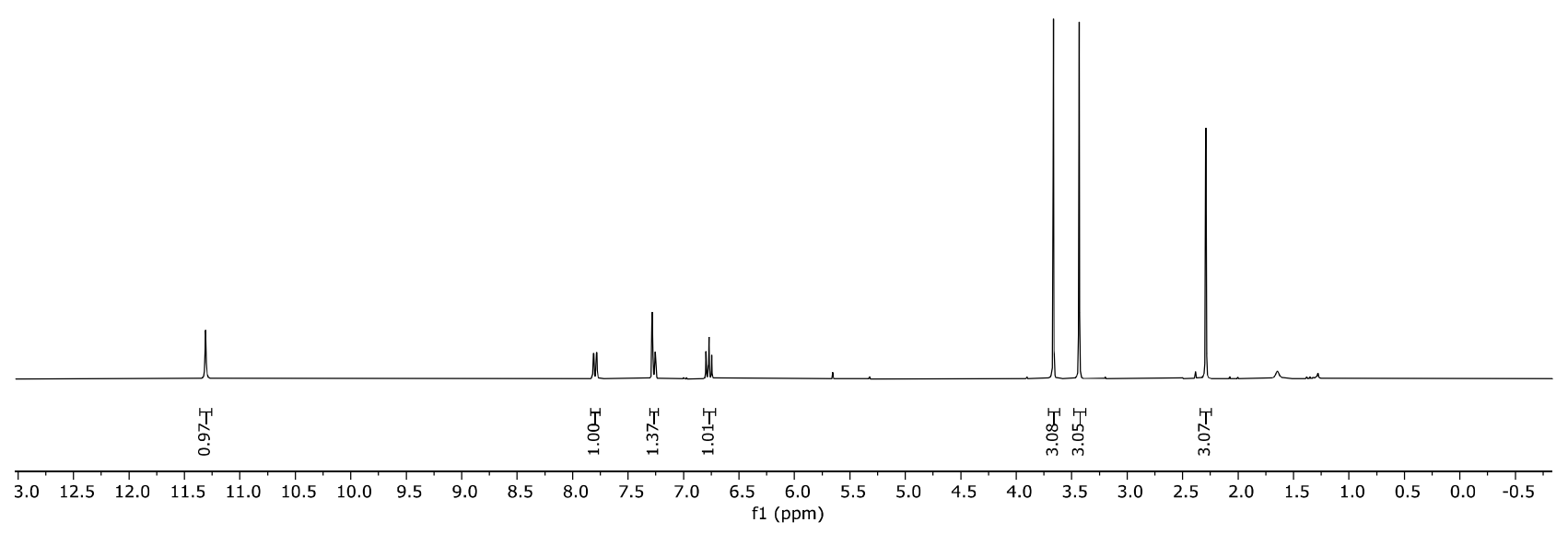

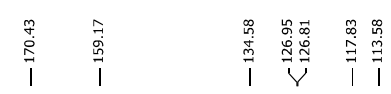

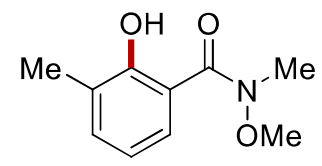

106j' ${ }^{13} \mathrm{C}-\mathrm{NMR}$

$\left(100 \mathrm{MHz}, \mathrm{CDCl}_{3}\right.$ )

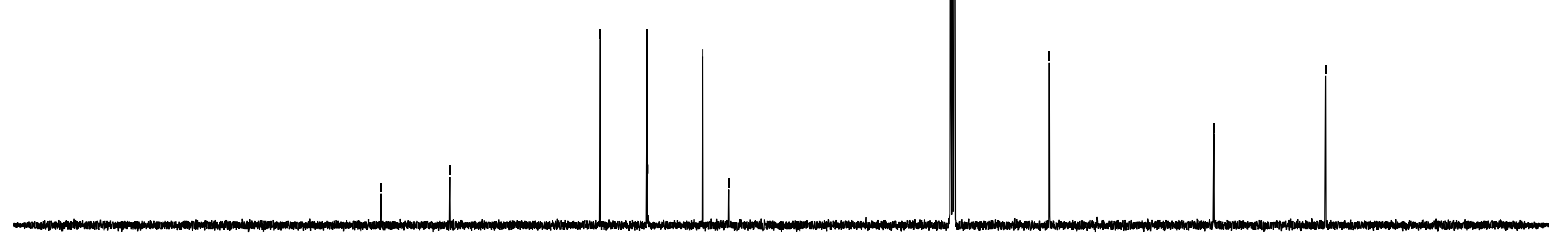

\begin{tabular}{llllllllllllllllllllllllllll}
\hline 30 & 220 & 210 & 200 & 190 & 180 & 170 & 160 & 150 & 140 & 130 & 120 & 110 & 100 & 90 & 80 & 70 & 60 & 50 & 40 & 30 & 20 & 10 & 0 & -10 & -2
\end{tabular} 
$\underbrace{\mathrm{O}}_{\mathrm{Cl}}$

$106 \mathrm{~m}^{1} \mathrm{H}-\mathrm{NMR}$

(400 MHz, $\mathrm{CDCl}_{3}$ )
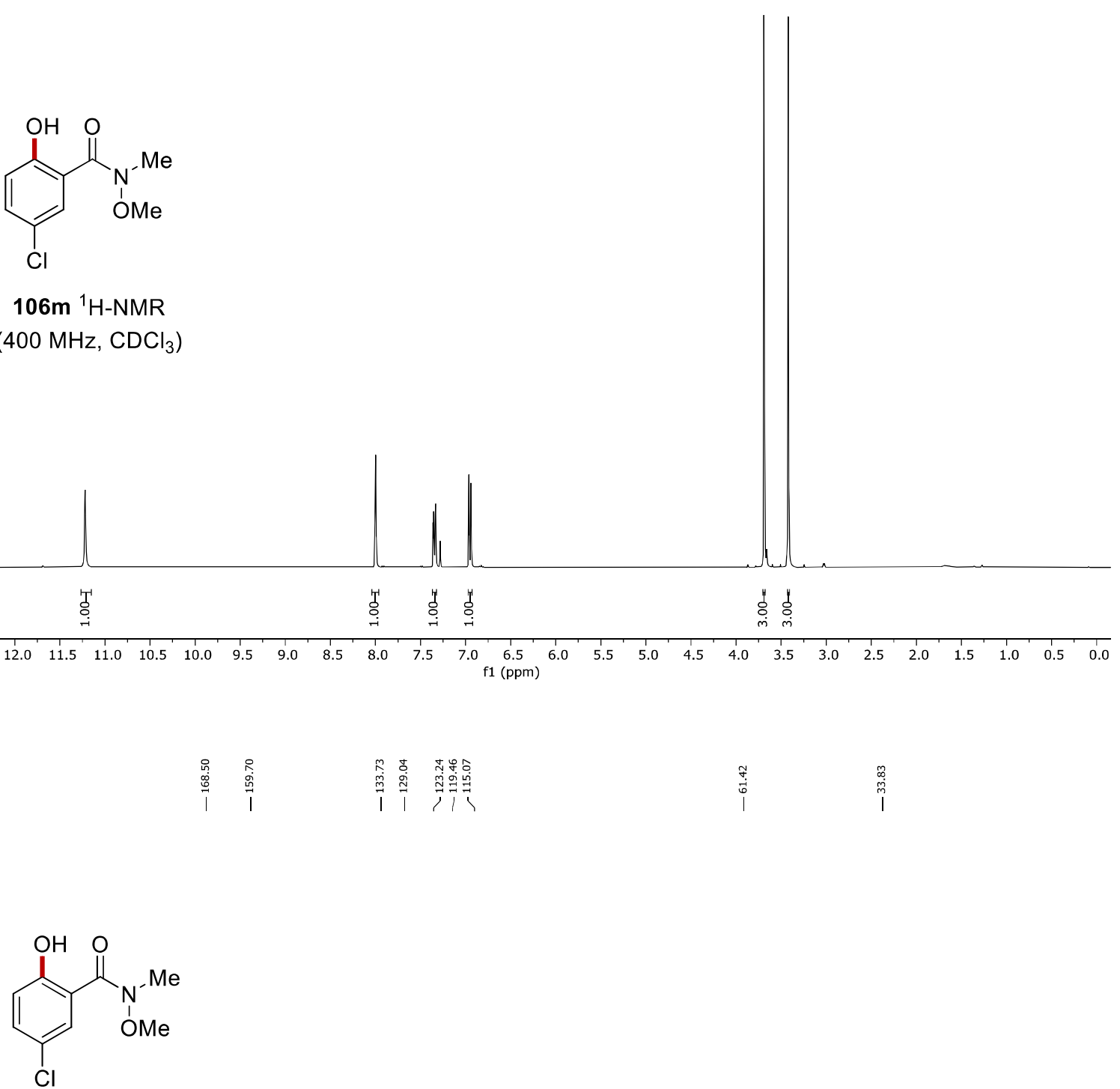

$106 \mathrm{~m}^{13} \mathrm{H}-\mathrm{NMR}$

$\left(100 \mathrm{MHz}, \mathrm{CDCl}_{3}\right.$ )

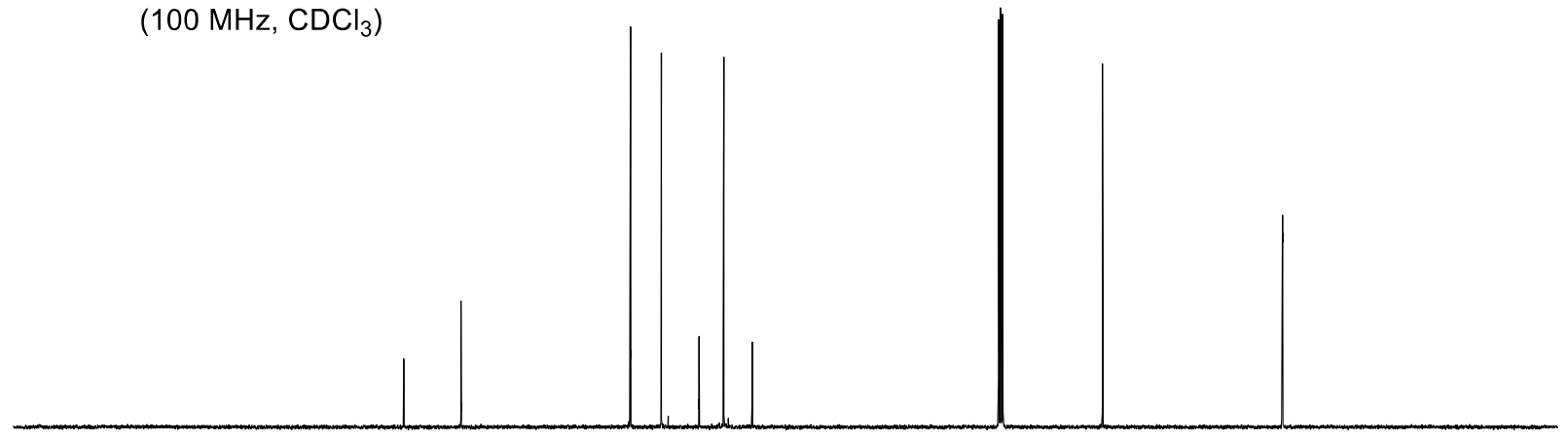

$\begin{array}{lllllllllllllllllllllllllllllll}220 & 210 & 200 & 190 & 180 & 170 & 160 & 150 & 140 & 130 & 120 & 110 & 100 & 90 & 80 & 70 & 60 & 50 & 40 & 30 & 20 & 10 & 0\end{array}$ 


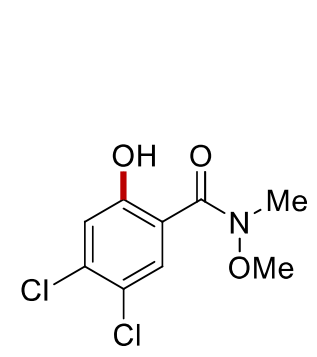

$106 f{ }^{1} \mathrm{H}-\mathrm{NMR}$

(300 MHz, $\mathrm{CDCl}_{3}$ )

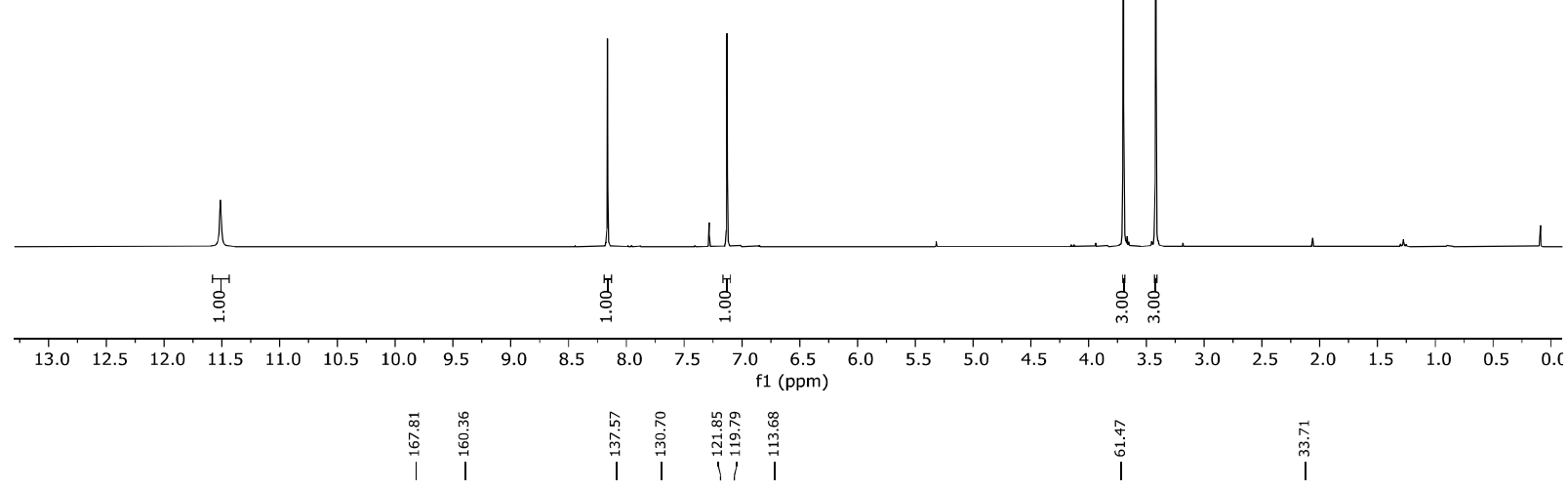<smiles>CON(C)C(=O)c1cc(Cl)c(Cl)cc1O</smiles>

$106 f{ }^{13} \mathrm{C}-\mathrm{NMR}$

$\left(100 \mathrm{MHz}, \mathrm{CDCl}_{3}\right.$ )

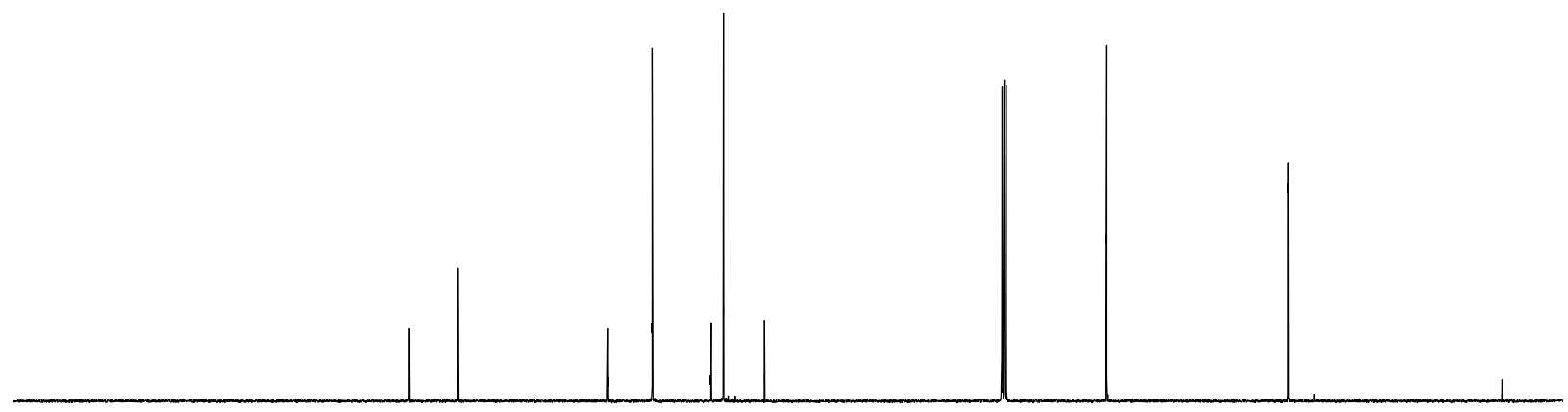

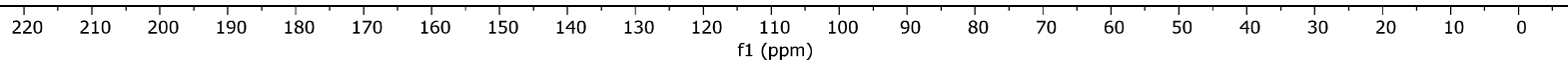




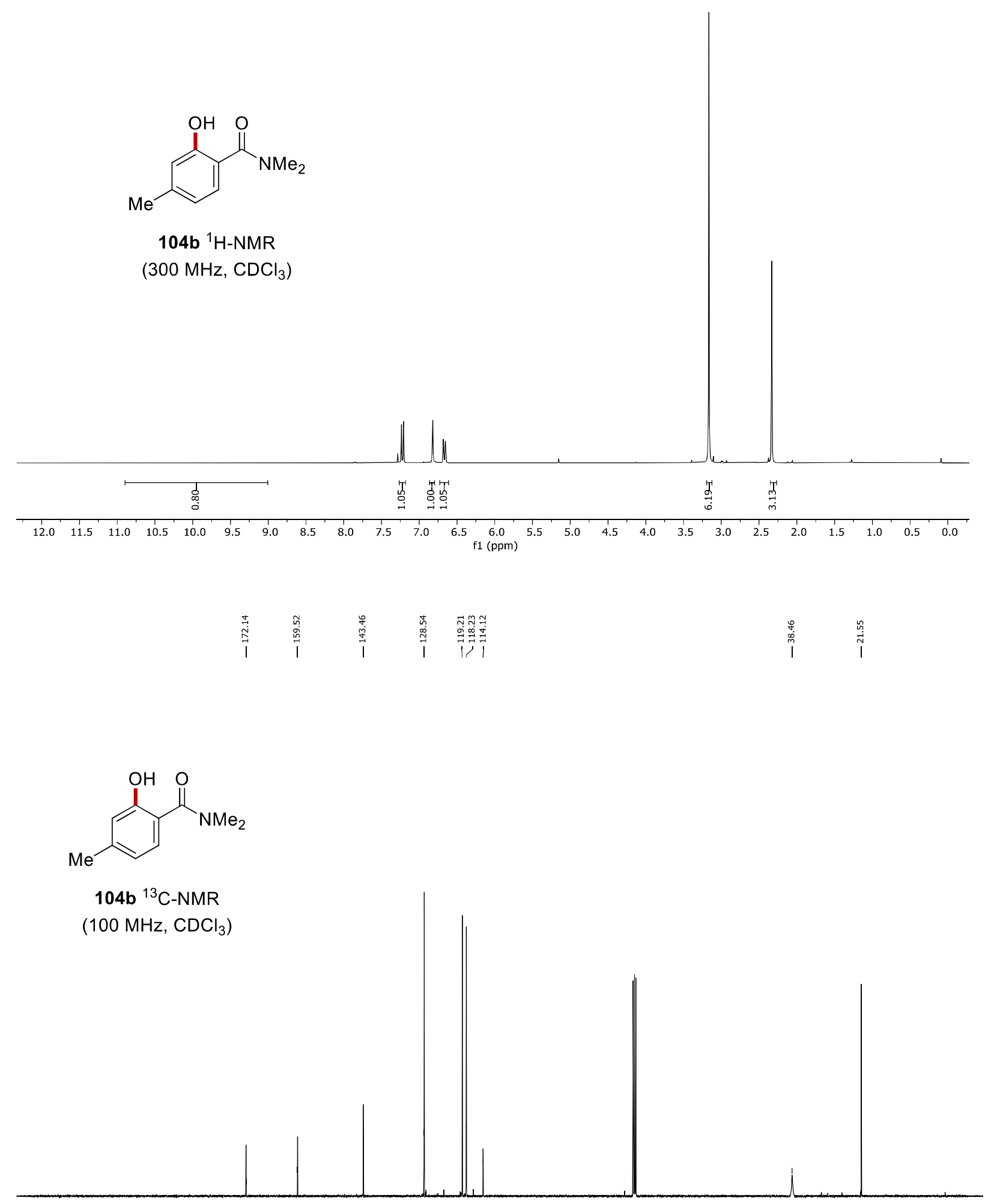

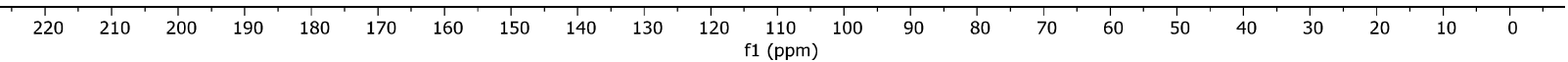



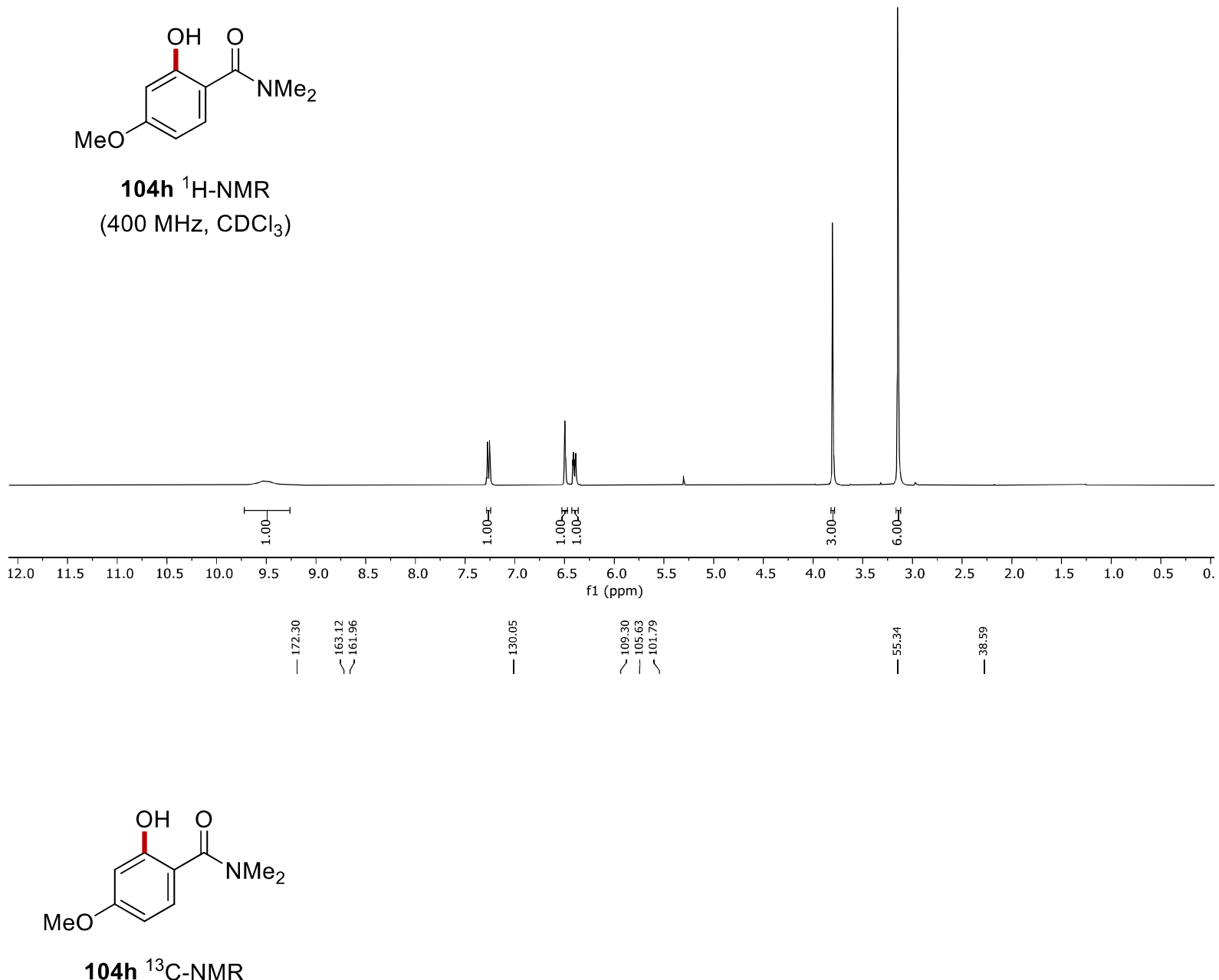

$\left(100 \mathrm{MHz}, \mathrm{CDCl}_{3}\right.$ )

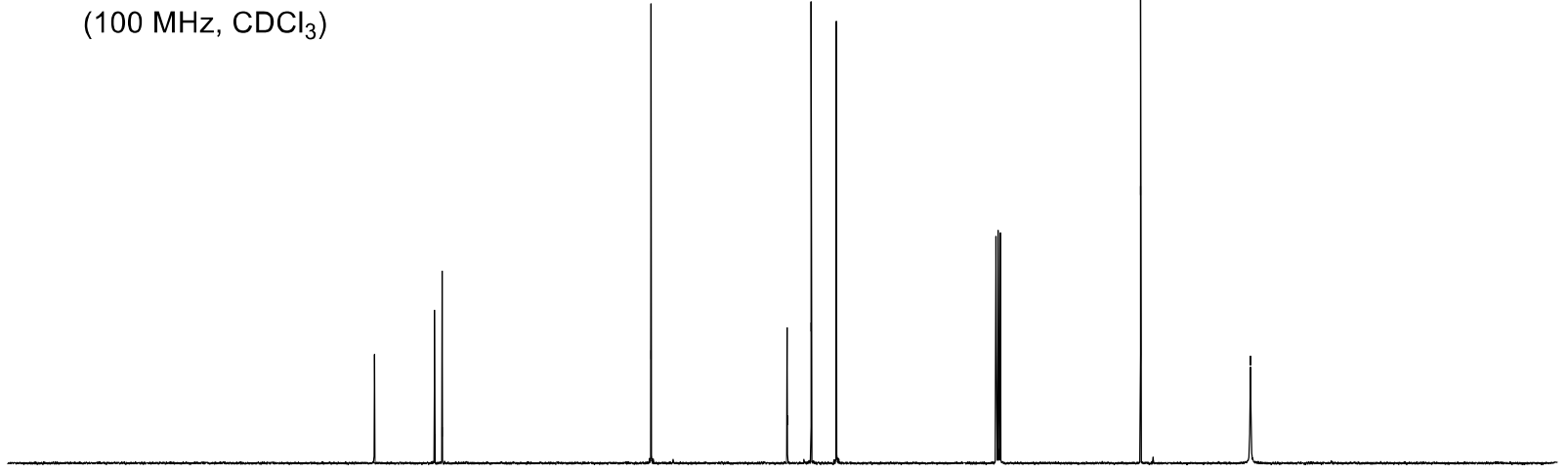

$\begin{array}{lllllllllllllllllllllll}220 & 210 & 200 & 190 & 180 & 170 & 160 & 150 & 140 & 130 & 120 & \begin{array}{c}110 \\ \mathrm{f} 1(\mathrm{ppm})\end{array} & 100 & 90 & 80 & 70 & 60 & 50 & 40 & 30 & 20 & 10 & 0\end{array}$ 


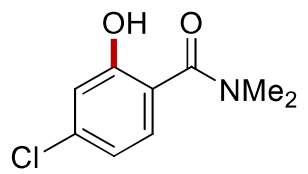

104i ${ }^{1} \mathrm{H}-\mathrm{NMR}$

$\left(400 \mathrm{MHz}, \mathrm{CDCl}_{3}\right)$

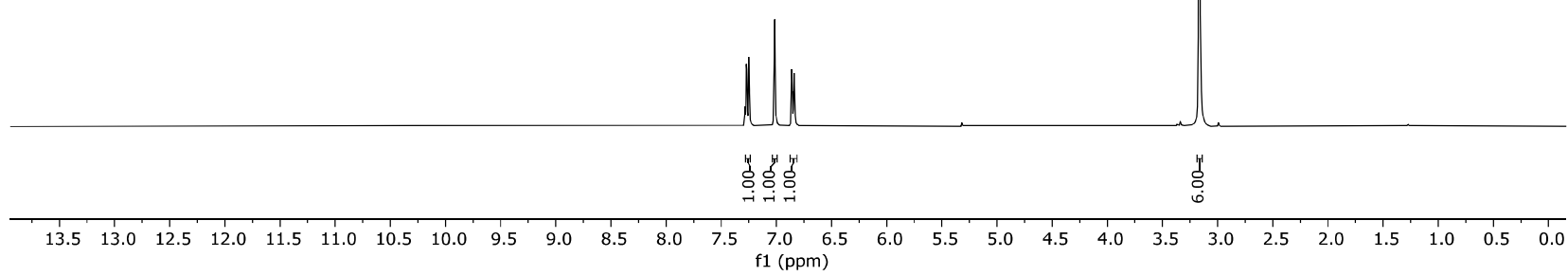

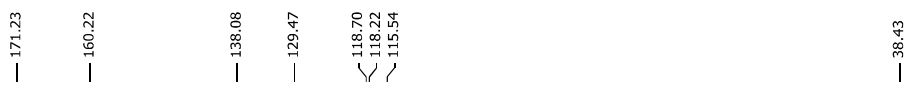

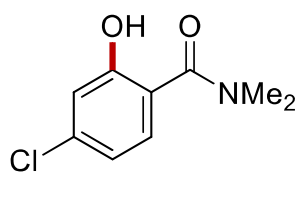

104i ${ }^{13} \mathrm{C}-\mathrm{NMR}$

$\left(100 \mathrm{MHz}, \mathrm{CDCl}_{3}\right.$ )

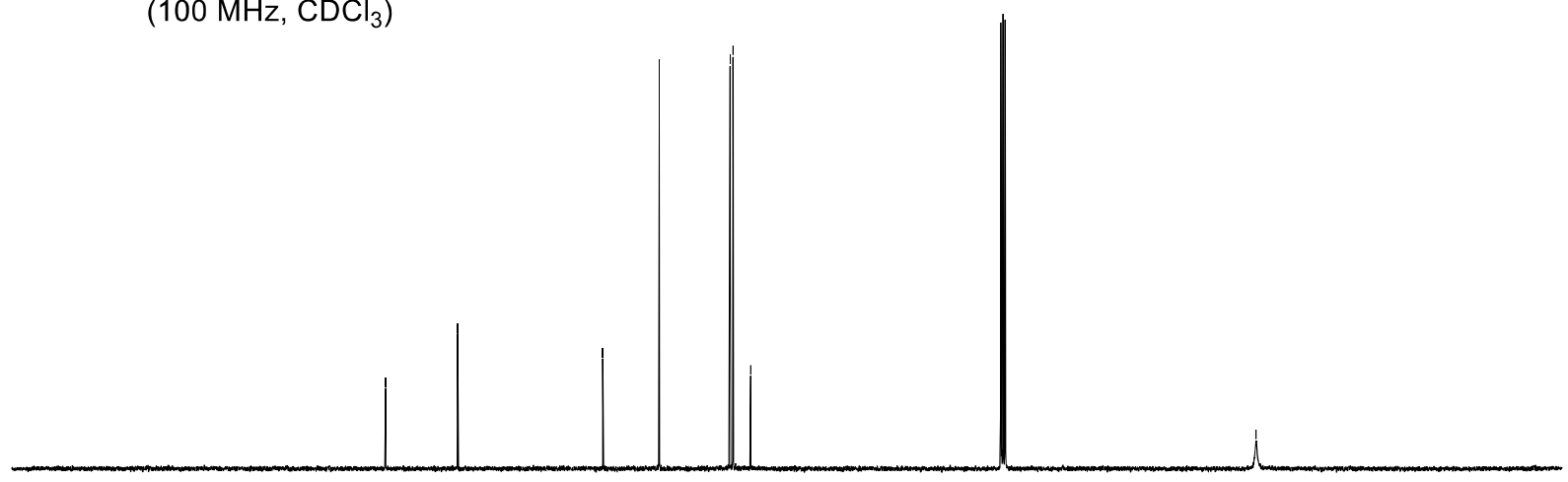

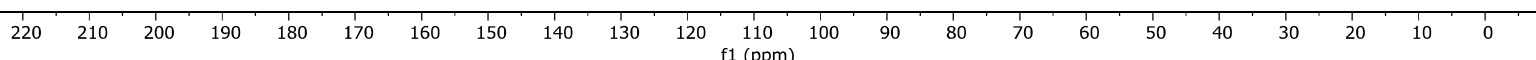




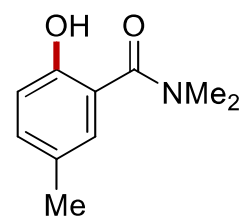

104k ${ }^{1} \mathrm{H}-\mathrm{NMR}$

(300 MHz, $\mathrm{CDCl}_{3}$ )

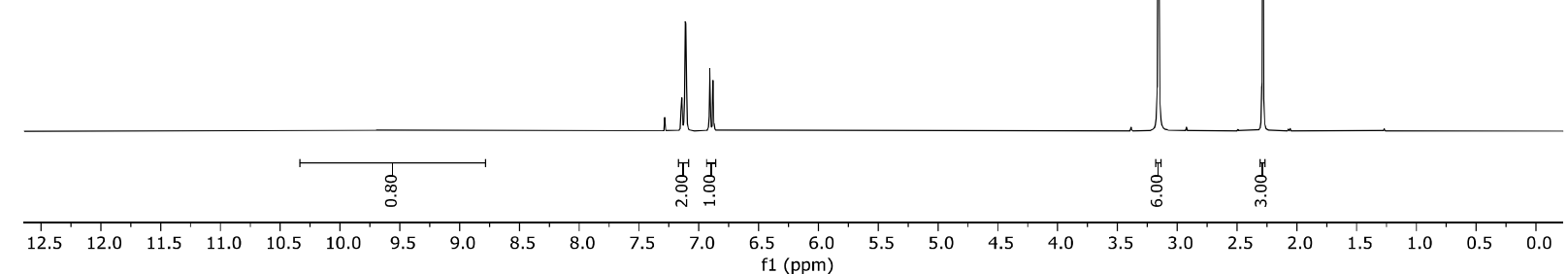

\begin{tabular}{|c|c|c|}
\hline 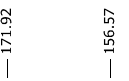 & 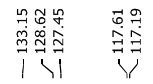 & $\underset{\substack{n \\
\infty}}{\stackrel{m}{0}}$ \\
\hline
\end{tabular}
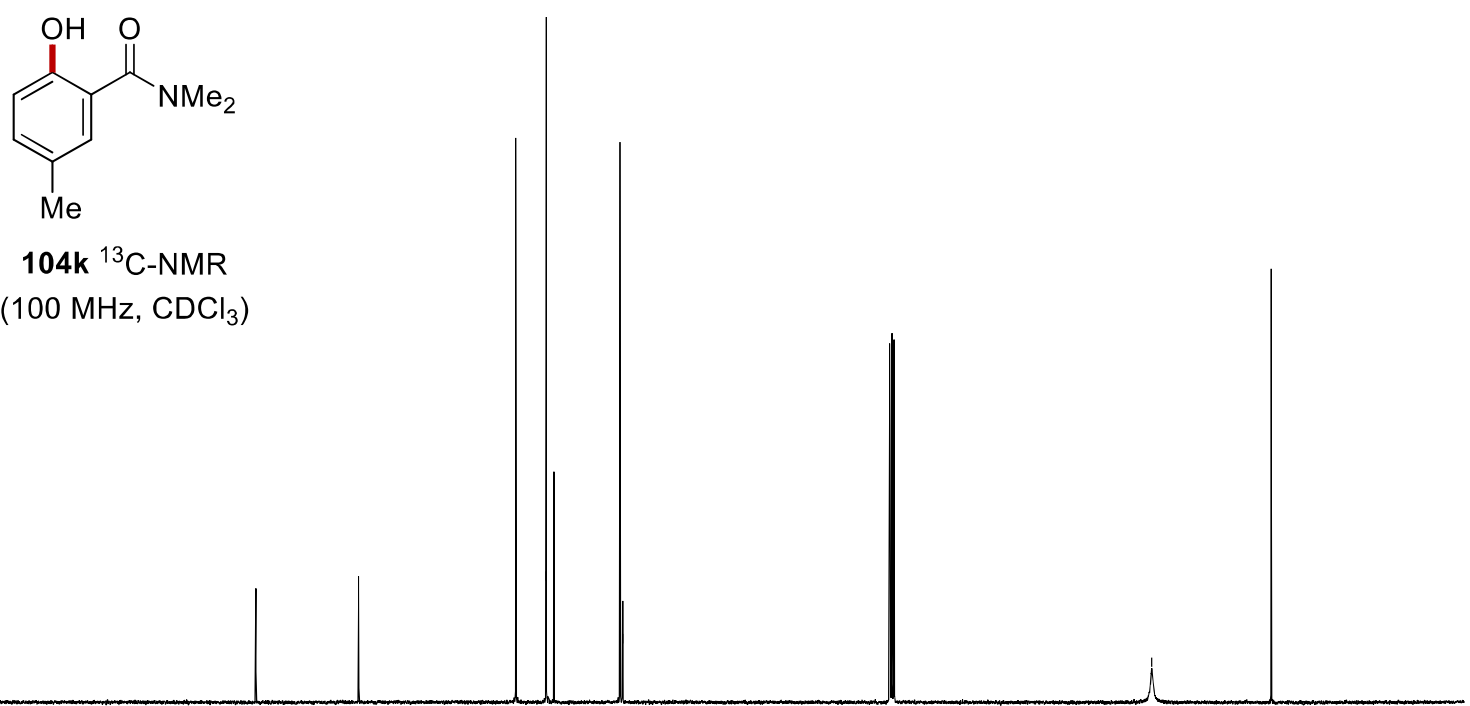

$\begin{array}{lllllllllllllllllllllllllllllll}220 & 210 & 200 & 190 & 180 & 170 & 160 & 150 & 140 & 130 & 120 & 110 & 100 & 90 & 80 & 70 & 60 & 50 & 40 & 30 & 20 & 10 & 0\end{array}$ 


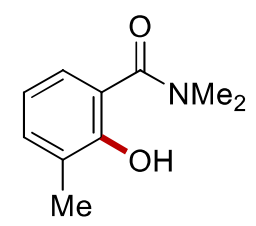

104k' ${ }^{1} \mathrm{H}-\mathrm{NMR}$

$\left(300 \mathrm{MHz}, \mathrm{CDCl}_{3}\right.$ )

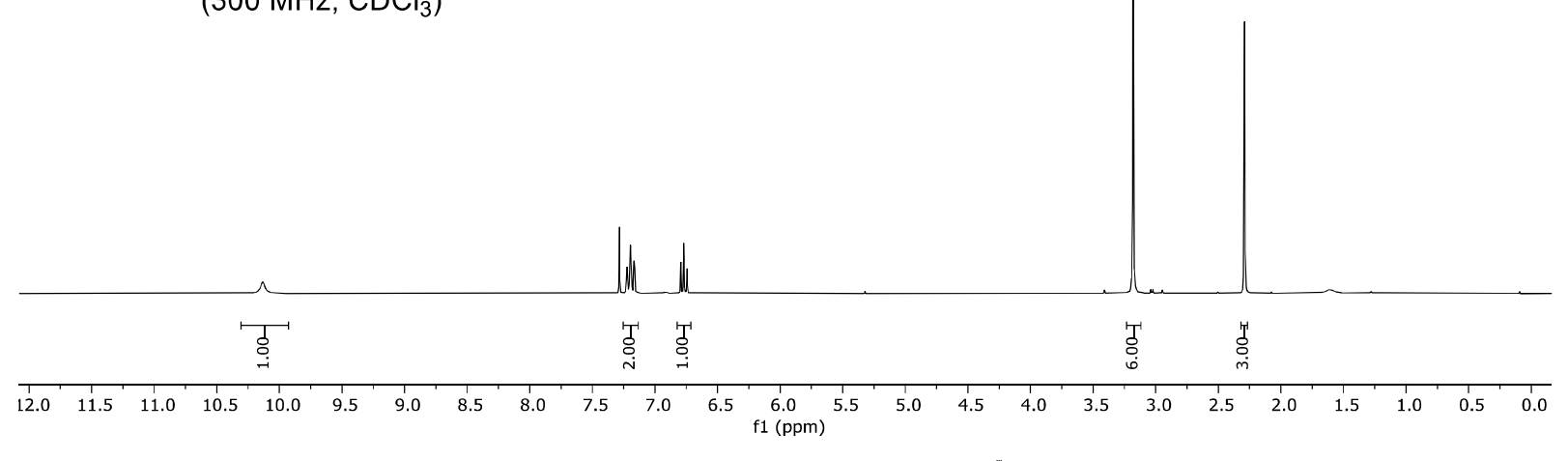<smiles>CNC(=O)c1cccc(C)c1O</smiles>

104k' ${ }^{13} \mathrm{C}-\mathrm{NMR}$

$\left(100 \mathrm{MHz}, \mathrm{CDCl}_{3}\right.$ )

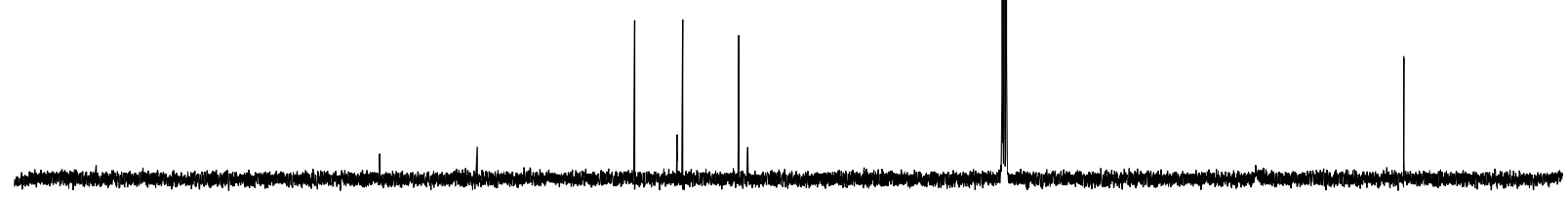

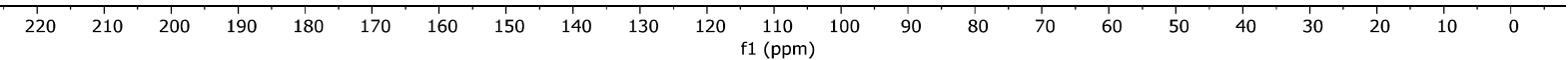




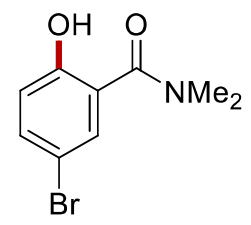

$104{ }^{1} \mathrm{H}-\mathrm{NMR}$

$\left(400 \mathrm{MHz}, \mathrm{CDCl}_{3}\right)$

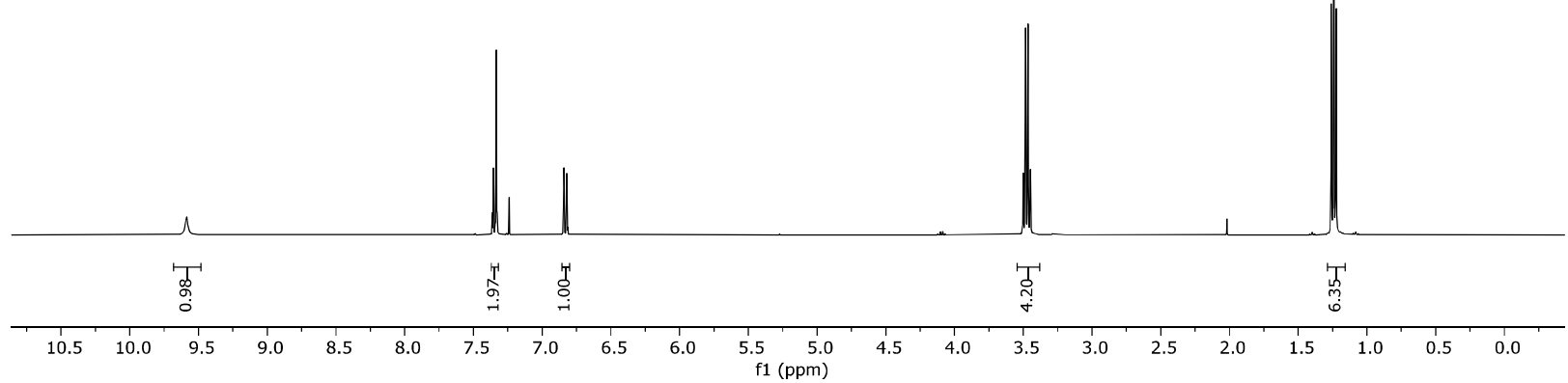

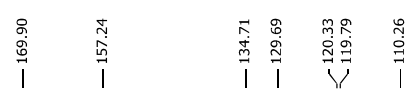<smiles>CC(=O)c1cc(Br)ccc1O</smiles>

104n ${ }^{13} \mathrm{C}-\mathrm{NMR}$ $\left(100 \mathrm{MHz}, \mathrm{CDCl}_{3}\right.$ )

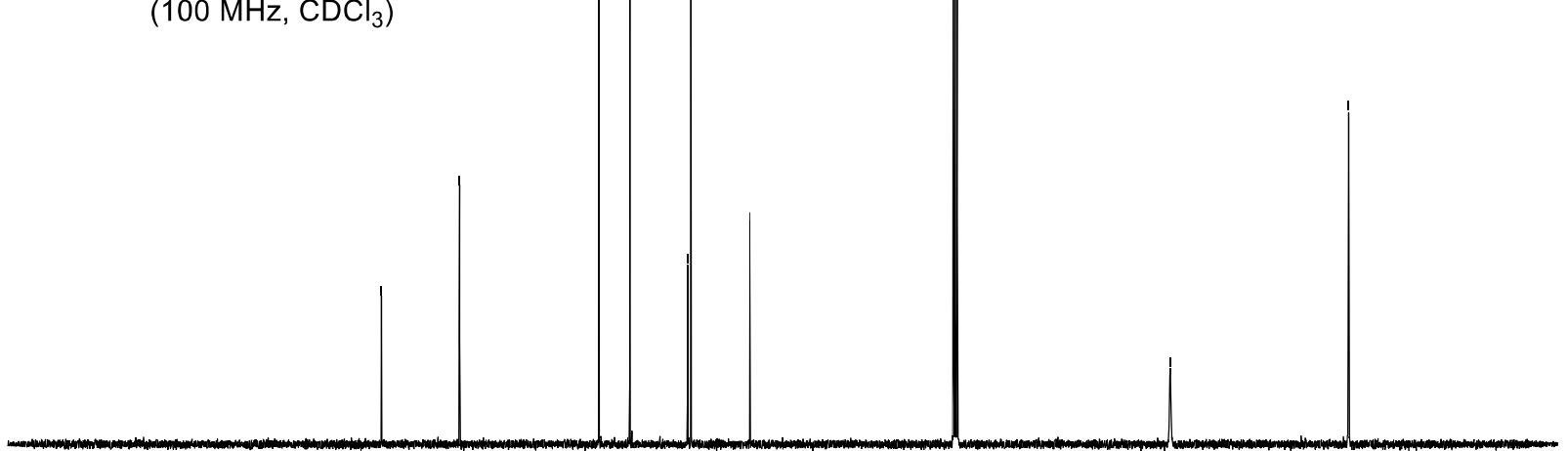

\begin{tabular}{llllllllllllllllllllllllll}
\hline & 220 & 210 & 200 & 190 & 180 & 170 & 160 & 150 & 140 & 130 & 120 & 110 & 100 & 90 & 80 & 70 & 60 & 50 & 40 & 30 & 20 & 10 & 0 & -10 & -2
\end{tabular} 


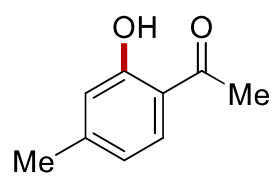

$197 n{ }^{1} \mathrm{H}-\mathrm{NMR}$

(300 $\mathrm{MHz}, \mathrm{CDCl}_{3}$ )

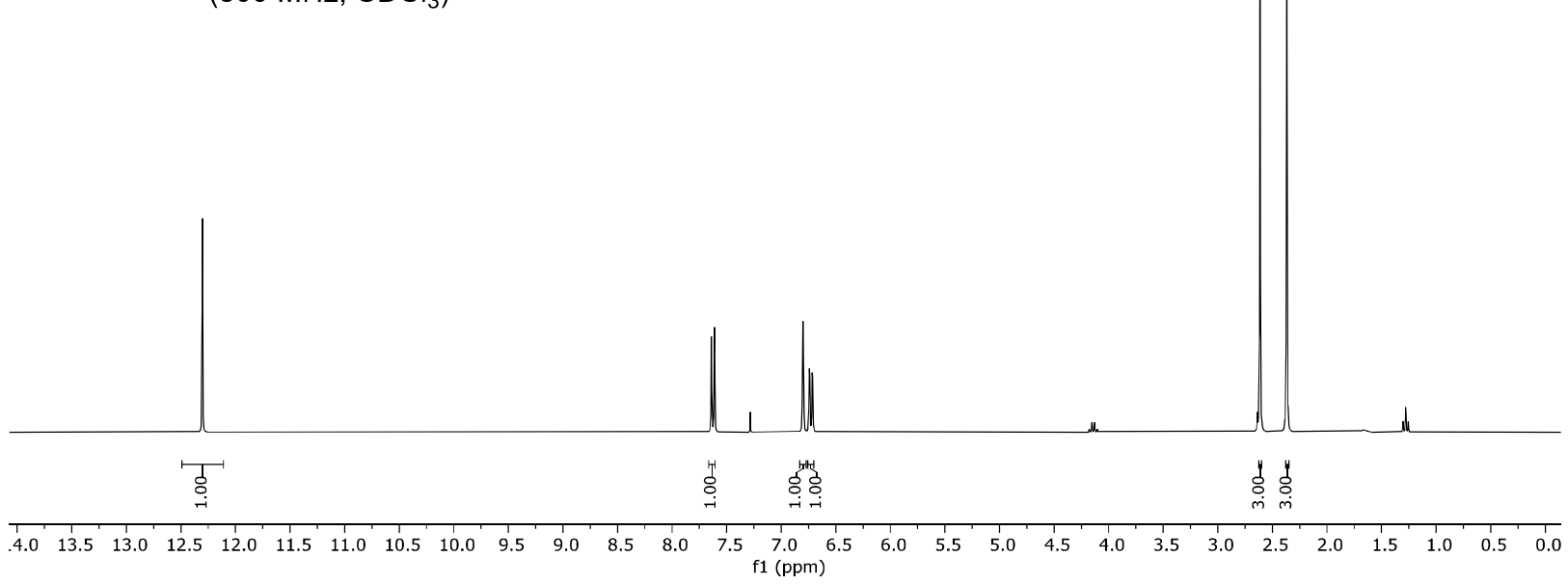

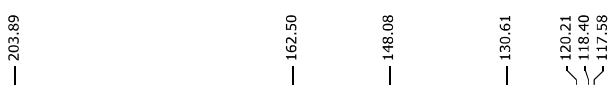<smiles>CC(=O)c1ccc(C)cc1O</smiles>

$197 n{ }^{13} \mathrm{C}-\mathrm{NMR}$

$\left(100 \mathrm{MHz}, \mathrm{CDCl}_{3}\right.$ )

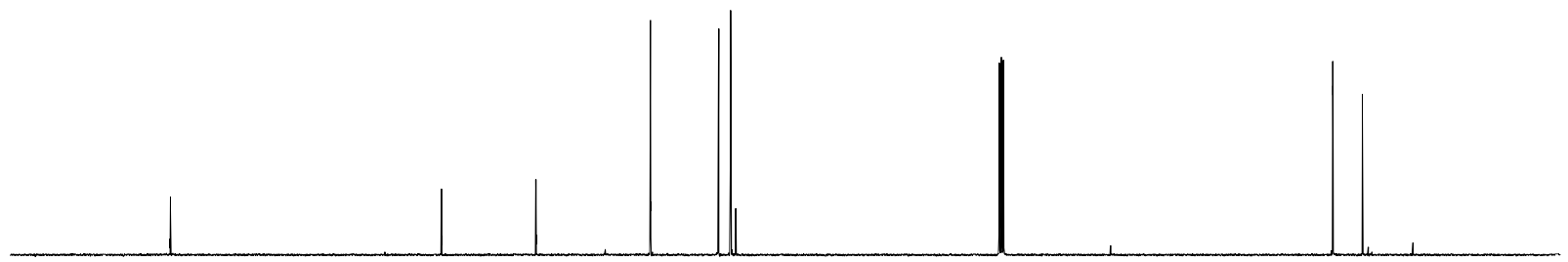

$\begin{array}{lllllllllllllllllllllllllll}1 & 220 & 210 & 200 & 190 & 180 & 170 & 160 & 150 & 140 & 130 & 120 & 110 & 100 & 90 & 80 & 70 & 60 & 50 & 40 & 30 & 20 & 10 & 0 & 10\end{array}$ 
7.5 Manganaelectro-Catalyzed Azine C-H Arylations and C-H Alkylations by Assistance of Weakly-Coordinating Amides<smiles>CCCCNC(=O)c1ncccc1-c1ccc(OC)cc1</smiles>

176aa ${ }^{1} \mathrm{H}-\mathrm{NMR}$ $\left(300 \mathrm{MHz}, \mathrm{CDCl}_{3}\right)$

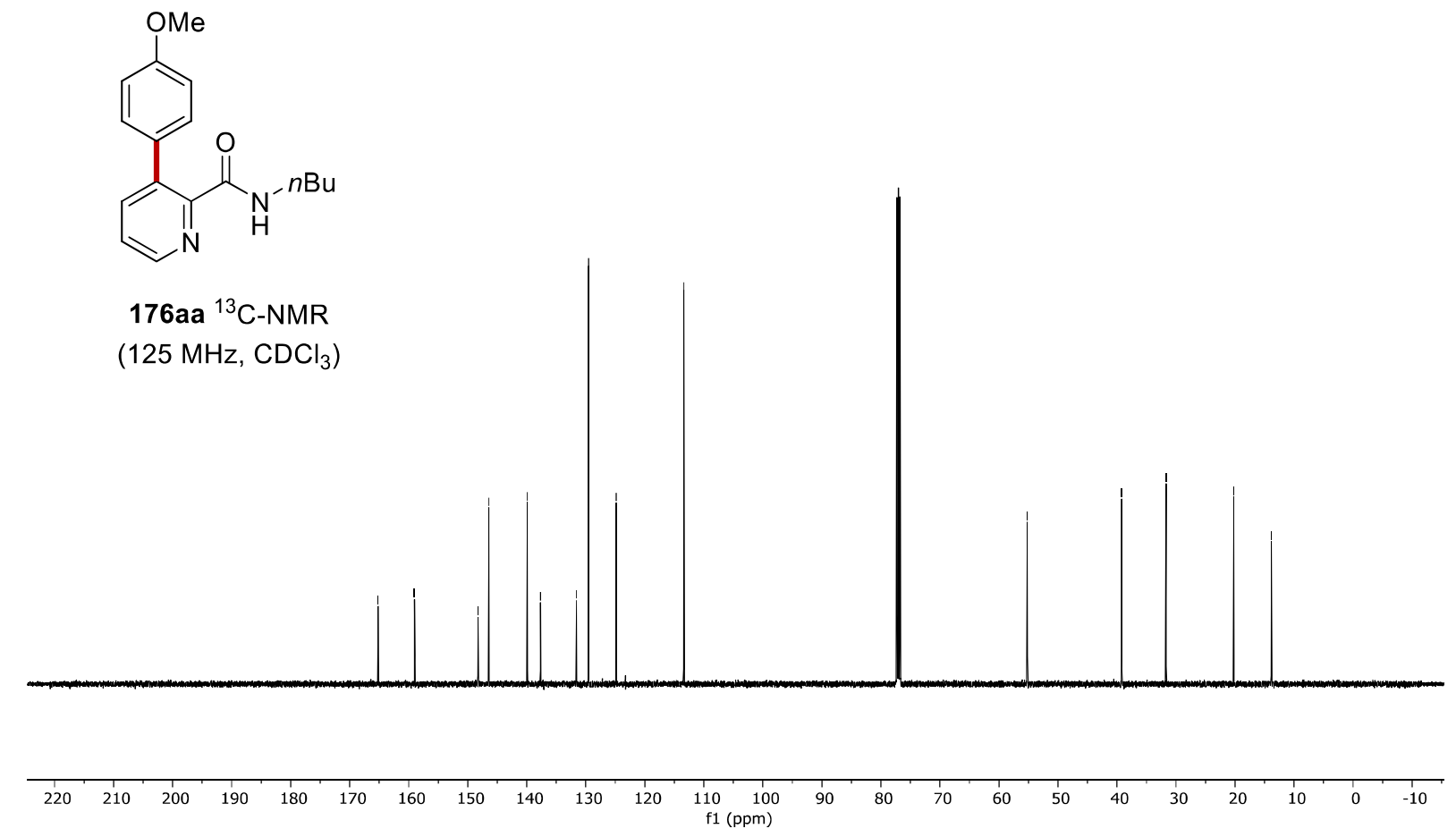

176aa ${ }^{13} \mathrm{C}-\mathrm{NMR}$ $\left(125 \mathrm{MHz}, \mathrm{CDCl}_{3}\right)$ 
$\underbrace{(-B n}_{N}$

176ba ${ }^{1} \mathrm{H}-\mathrm{NMR}$

$\left(300 \mathrm{MHz}, \mathrm{CDCl}_{3}\right.$ )

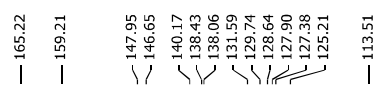<smiles>COc1ccc(-c2cccnc2C(=O)NCc2ccccc2)cc1</smiles>

176ba ${ }^{13} \mathrm{C}-\mathrm{NMR}$ $\left(100 \mathrm{MHz}, \mathrm{CDCl}_{3}\right.$ )

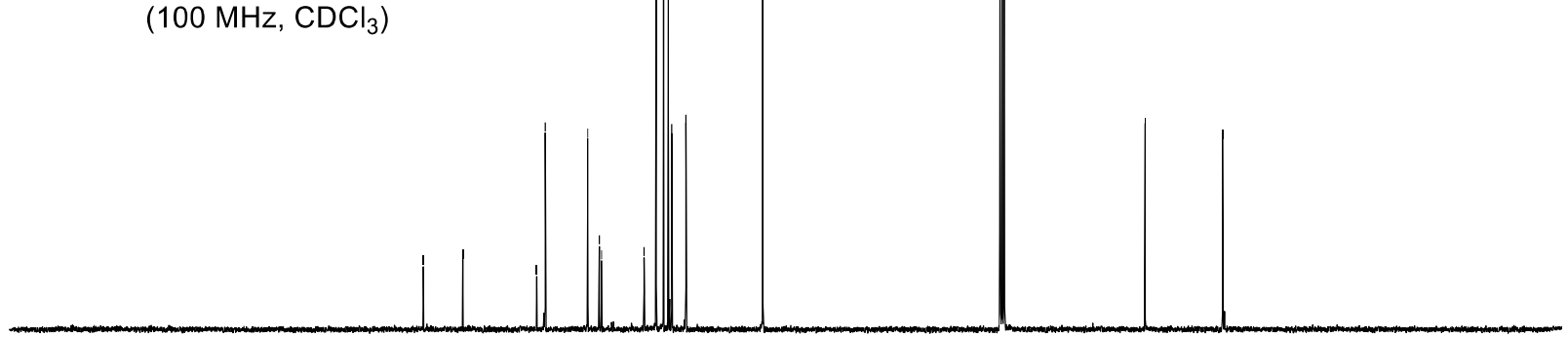

$\begin{array}{lllllllllllllllllllllllll}1 & 220 & 210 & 200 & 190 & 180 & 170 & 160 & 150 & 140 & 130 & 120 & 110 & 100 & 90 & 80 & 70 & 60 & 50 & 40 & 30 & 20 & 10 & 0\end{array}$ 


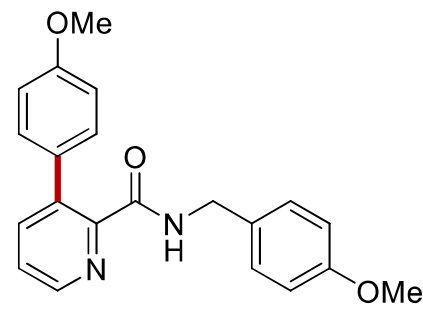

176da ${ }^{1} \mathrm{H}-\mathrm{NMR}$

(300 MHz, $\mathrm{CDCl}_{3}$ )

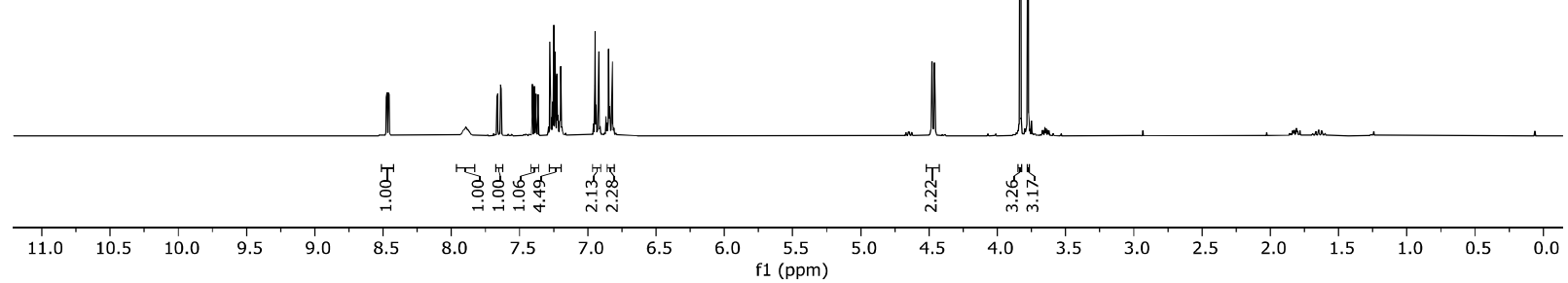

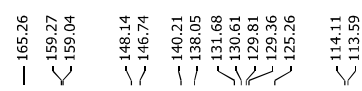

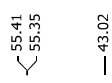<smiles>COc1ccc(CNC(=O)c2ncccc2-c2ccc(OC)cc2)cc1</smiles>

176 da ${ }^{13} \mathrm{C}-\mathrm{NMR}$

$\left(125 \mathrm{MHz}, \mathrm{CDCl}_{3}\right.$ )

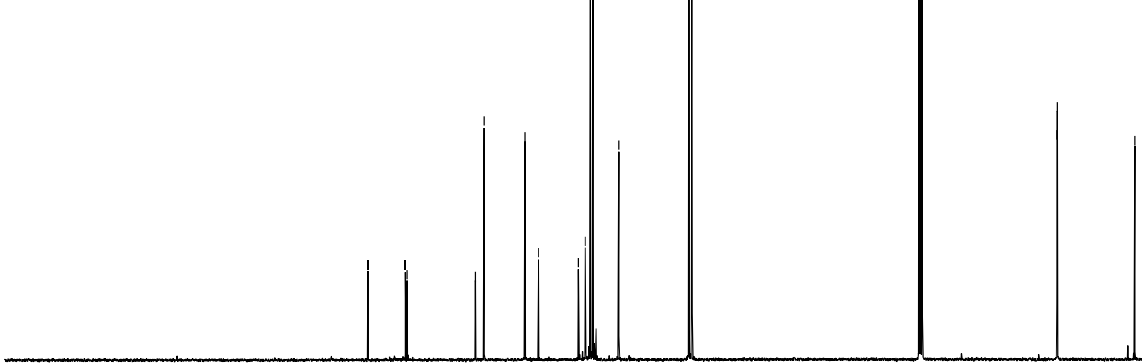

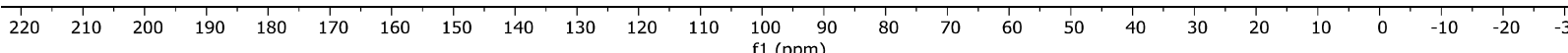




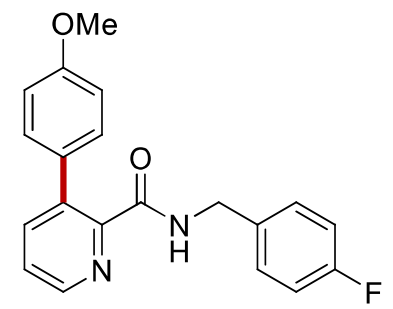

176ea ${ }^{1} \mathrm{H}-\mathrm{NMR}$

$\left(300 \mathrm{MHz}, \mathrm{CDCl}_{3}\right.$ )

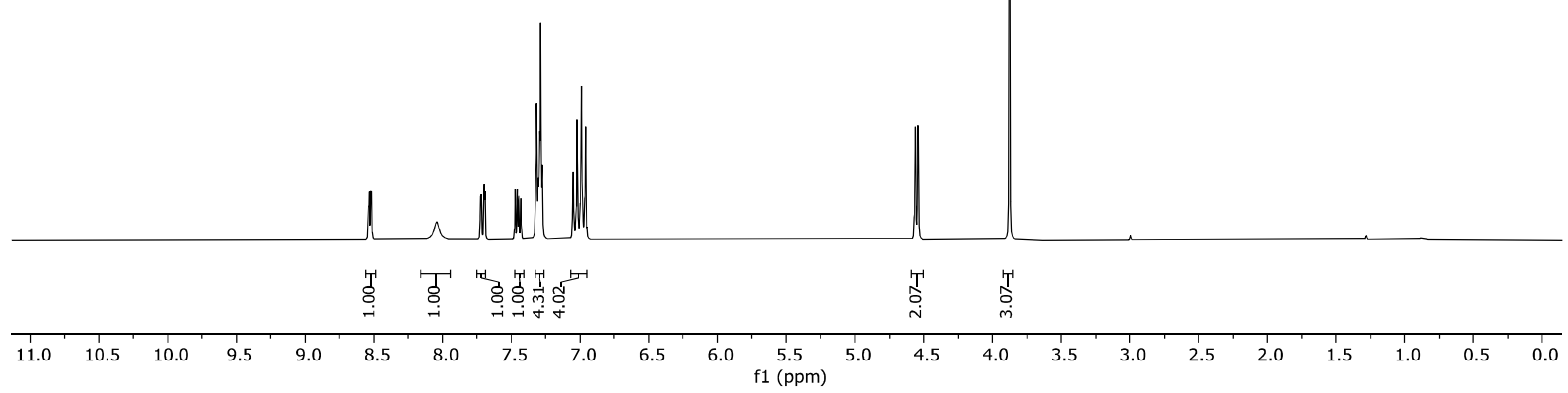

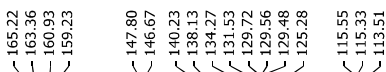<smiles>COc1ccc(-c2cccnc2C(=O)NCc2ccc(F)cc2)cc1</smiles>

176ea ${ }^{13} \mathrm{C}-\mathrm{NMR}$ $\left(100 \mathrm{MHz}, \mathrm{CDCl}_{3}\right.$ )

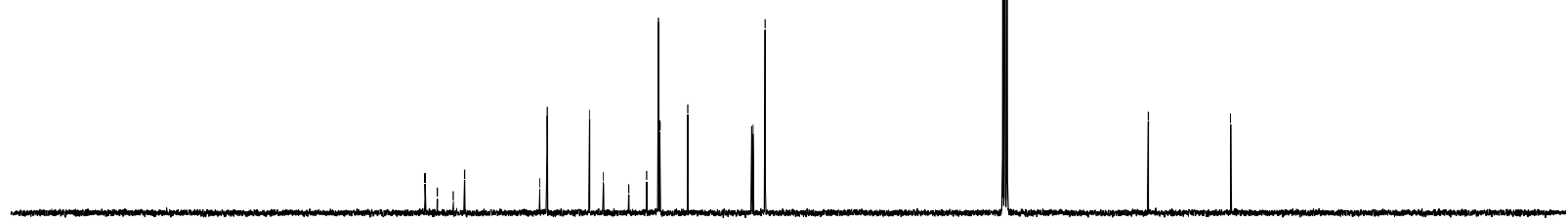

$\begin{array}{lllllllllllllllllllllllllllllll}220 & 210 & 200 & 190 & 180 & 170 & 160 & 150 & 140 & 130 & 120 & 110 & 100 & 90 & 80 & 70 & 60 & 50 & 40 & 30 & 20 & 10 & 0\end{array}$ 

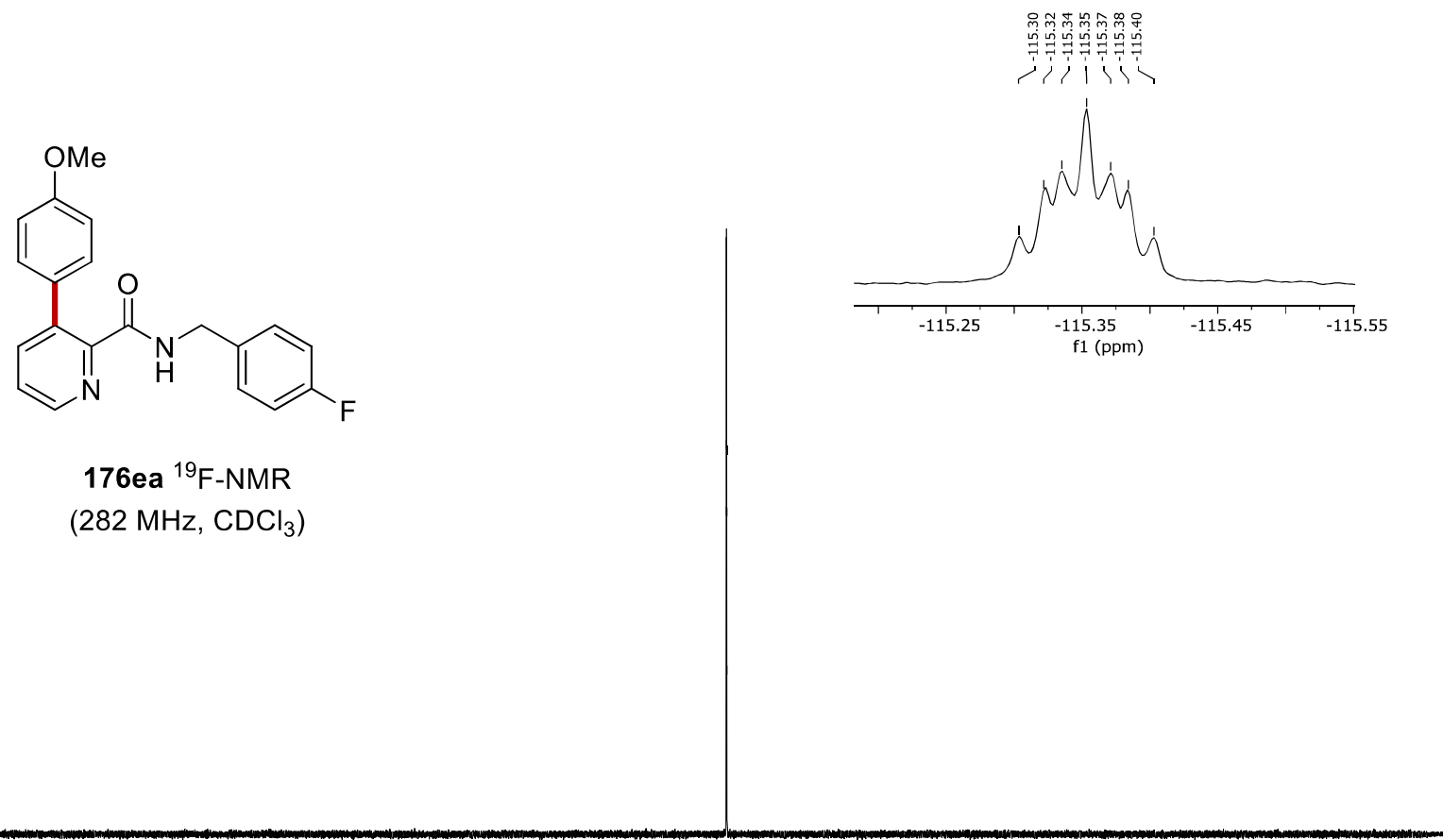

176ea ${ }^{19} \mathrm{~F}-\mathrm{NMR}$

(282 $\mathrm{MHz}, \mathrm{CDCl}_{3}$ )

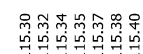

구국구국

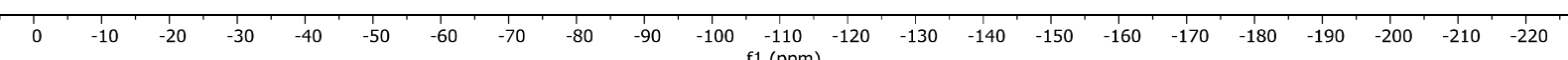<smiles>COc1ccc(-c2cccnc2C(=O)NCc2ccccc2F)cc1</smiles>

$176 f a{ }^{1} \mathrm{H}-\mathrm{NMR}$ (300 MHz, $\mathrm{CDCl}_{3}$ )

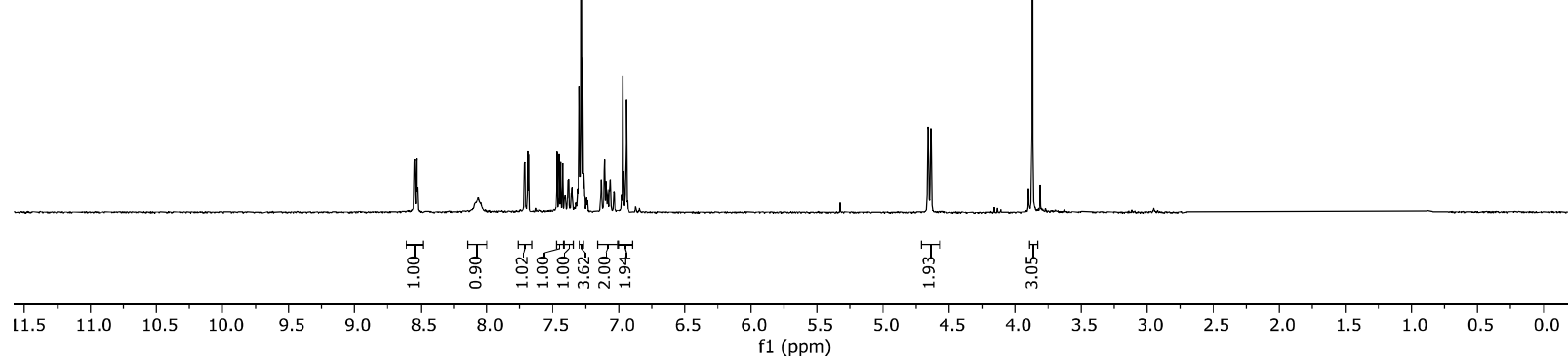




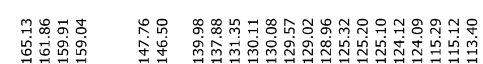

य) । । 1<smiles>COc1ccc(-c2cccnc2C(=O)NCc2ccccc2F)cc1</smiles>

$176 f a{ }^{13} \mathrm{C}-N M R$

$\left(125 \mathrm{MHz}, \mathrm{CDCl}_{3}\right.$ )
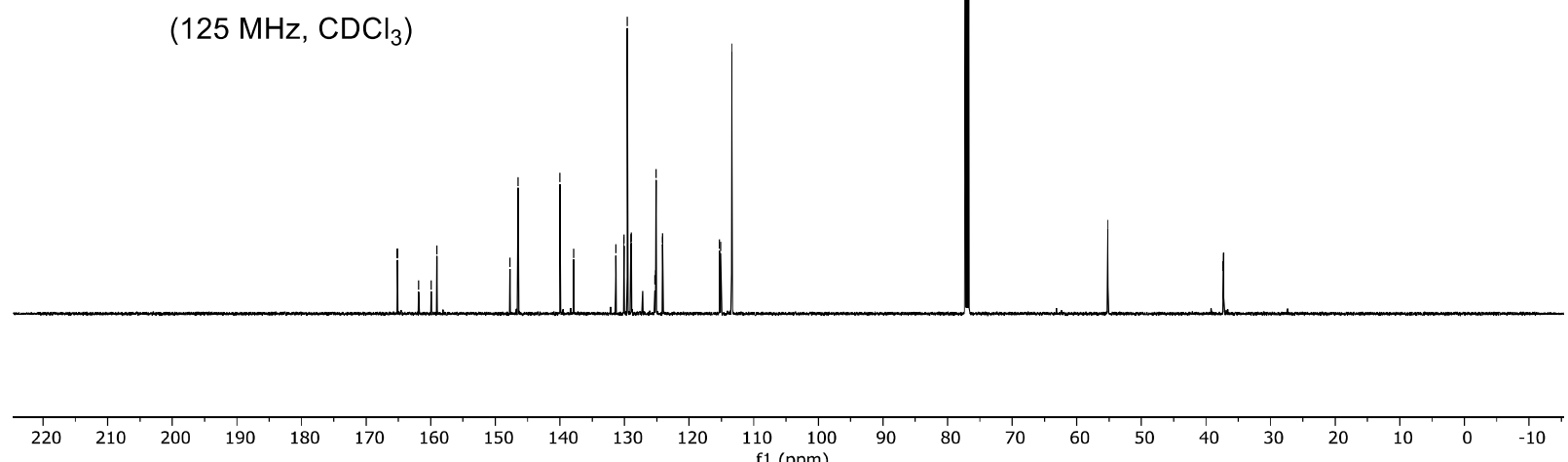

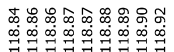<smiles>COc1ccc(-c2cccnc2C(=O)NCc2ccccc2F)cc1</smiles>

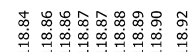

ivivij

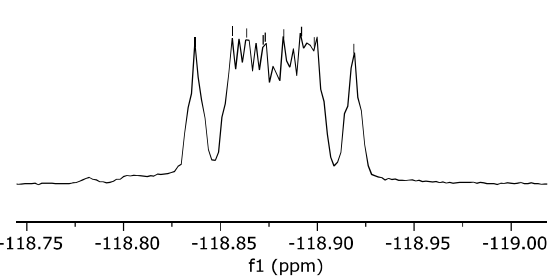

176 fa ${ }^{19}$ F-NMR

(282 $\mathrm{MHz}, \mathrm{CDCl}_{3}$ ) 
<smiles>COc1ccc(-c2cccnc2C(=O)NC2CCCc3ccccc32)cc1</smiles>

176ga ${ }^{1} \mathrm{H}-\mathrm{NMR}$

(400 MHz, $\mathrm{CDCl}_{3}$ )

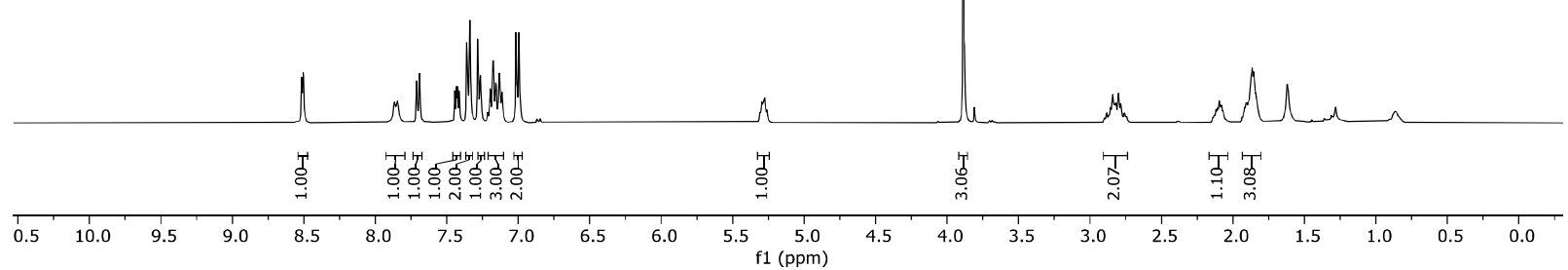

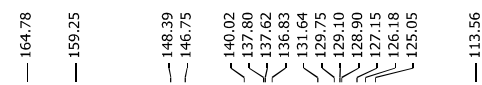

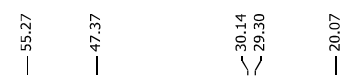<smiles>COc1ccc(-c2cccnc2C(=O)NC2CCCc3ccccc32)cc1</smiles>

176ga ${ }^{13} \mathrm{C}-\mathrm{NMR}$

(100 MHz, $\mathrm{CDCl}_{3}$ )

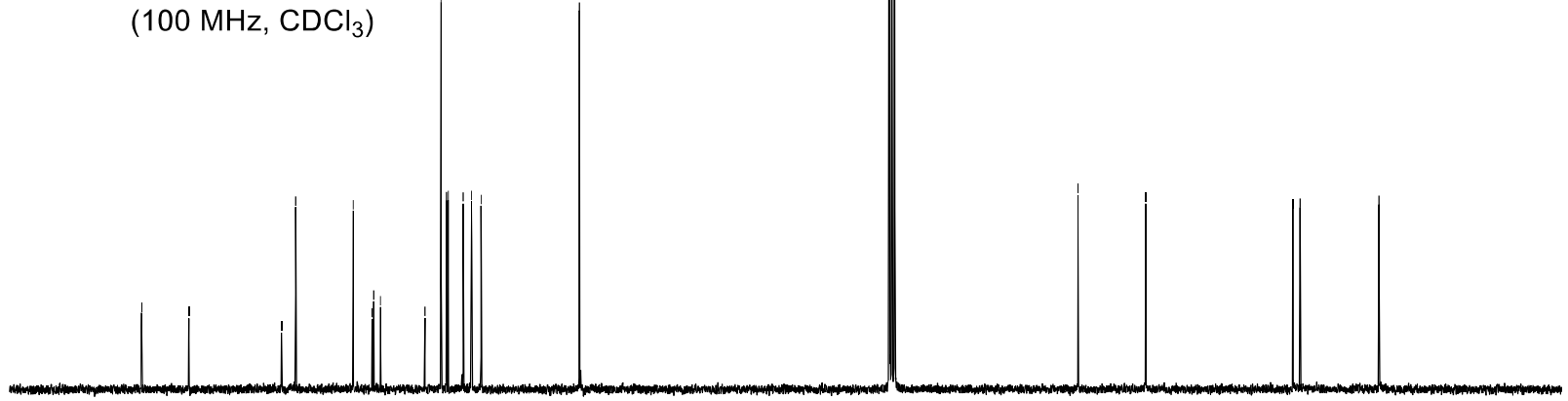

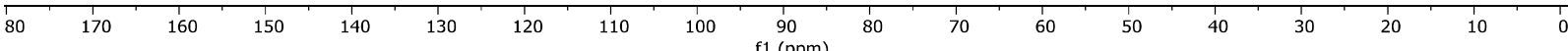




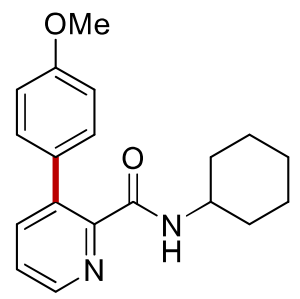

176ha ${ }^{1} \mathrm{H}-\mathrm{NMR}$

$\left(300 \mathrm{MHz}, \mathrm{CDCl}_{3}\right.$ )
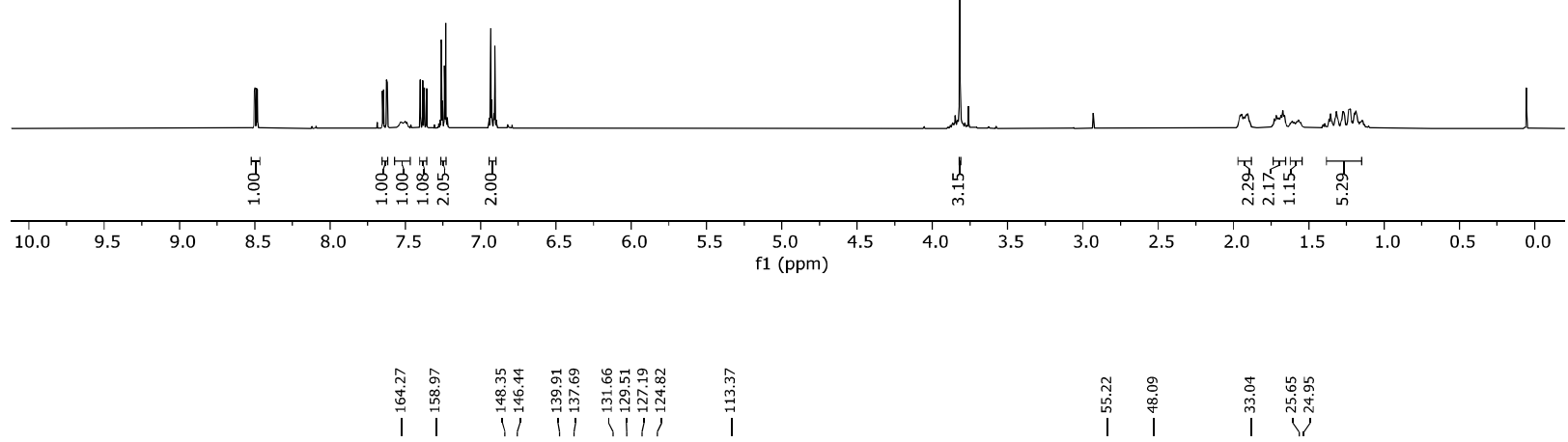<smiles>COc1ccc(-c2cccnc2C(=O)NC2CCCCC2)cc1</smiles>

176ha ${ }^{13} \mathrm{C}-\mathrm{NMR}$

(125 MHz, $\mathrm{CDCl}_{3}$ )

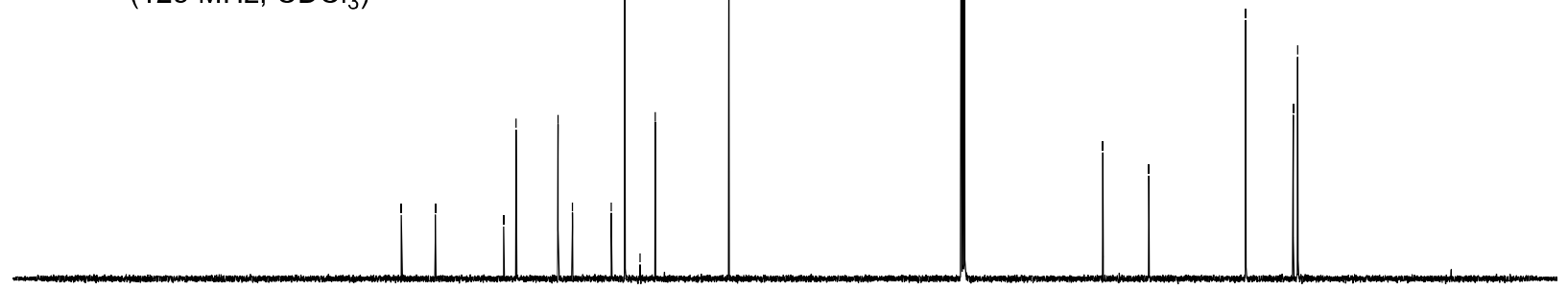

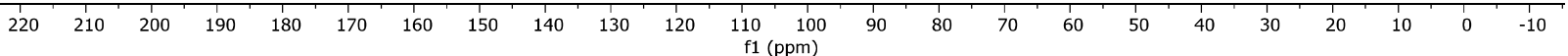




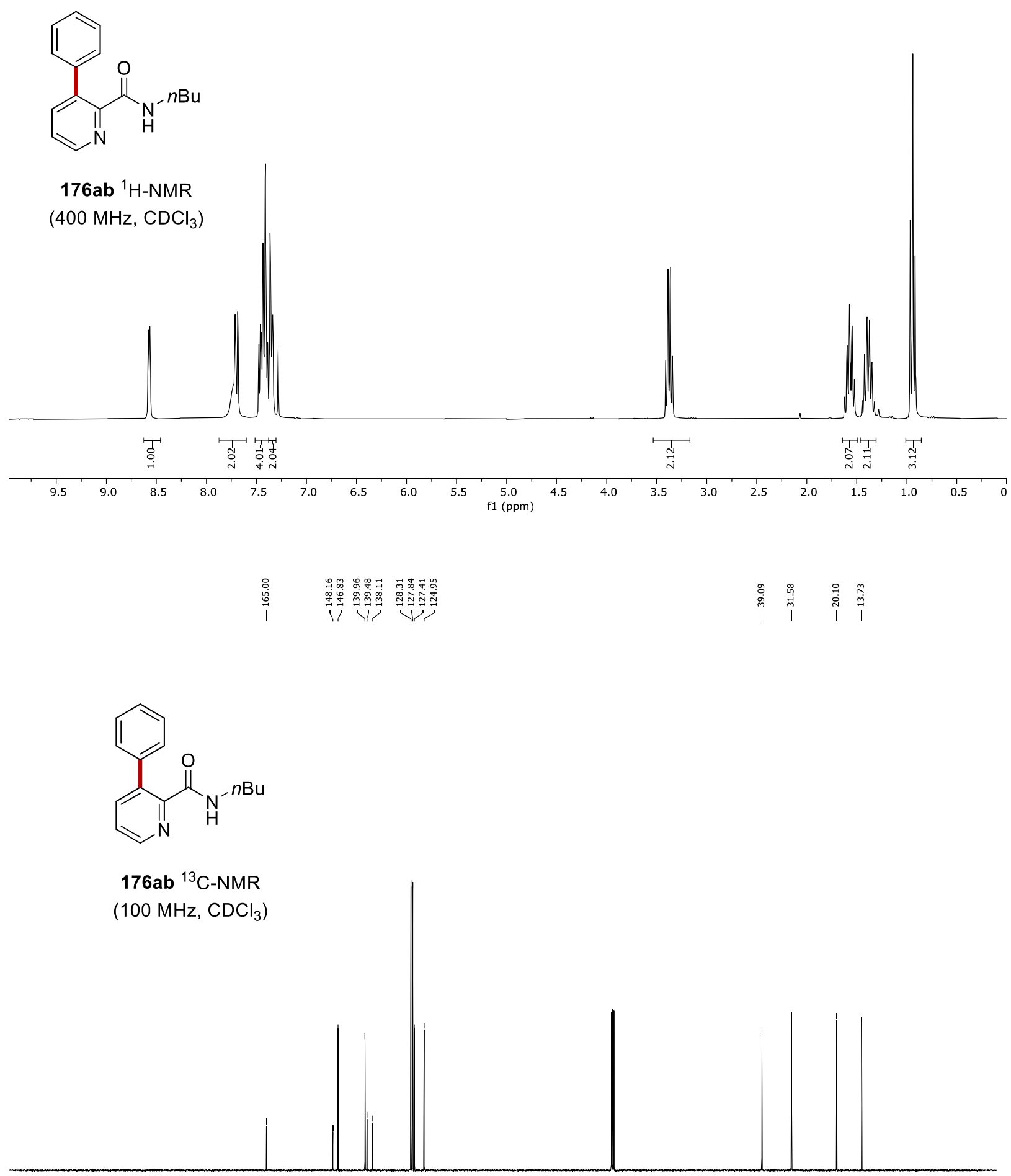

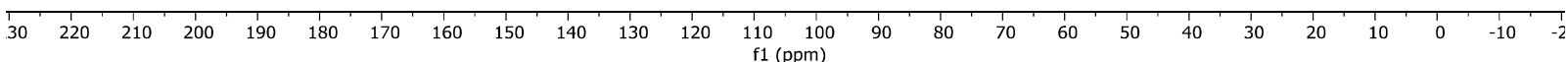




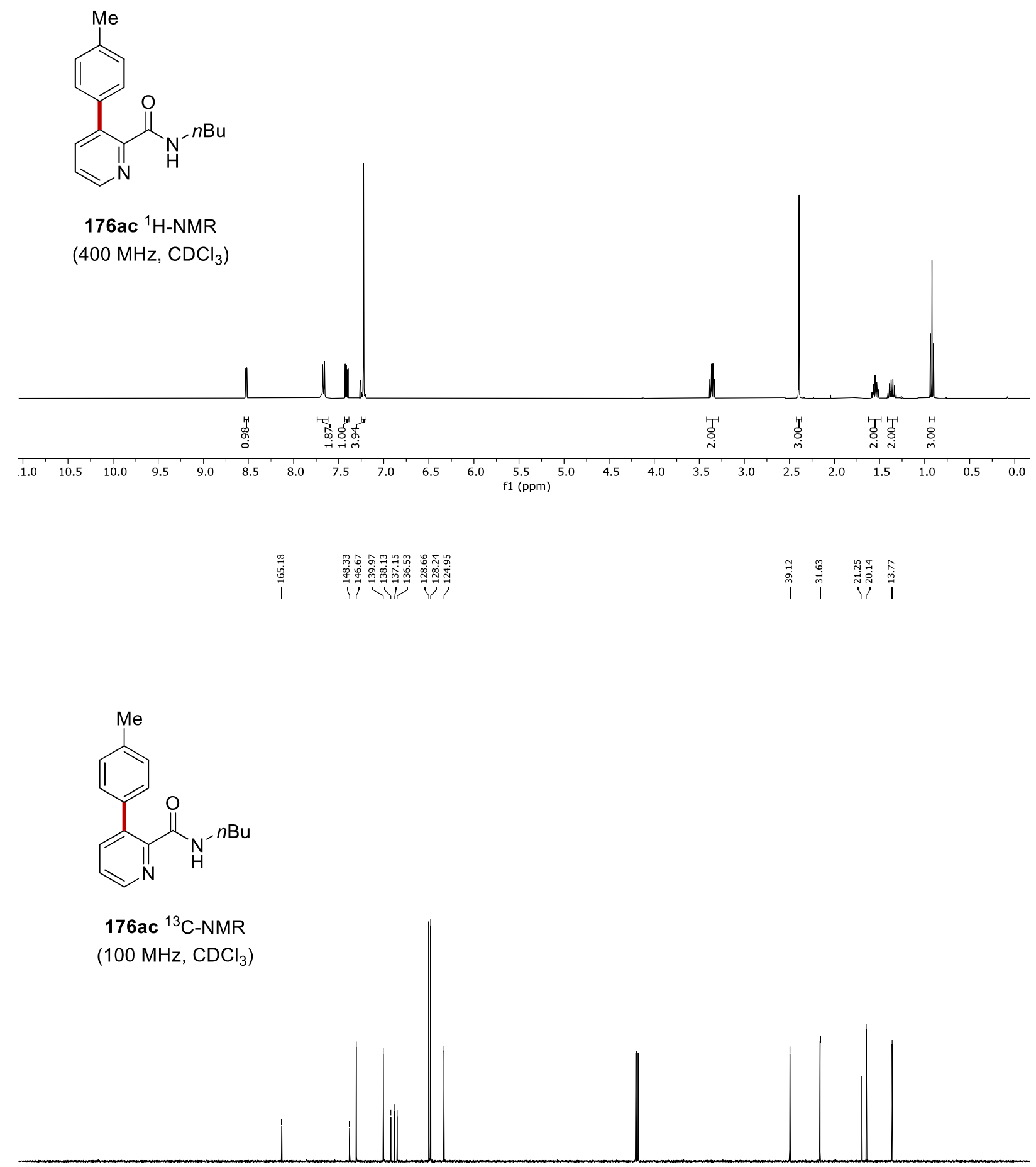

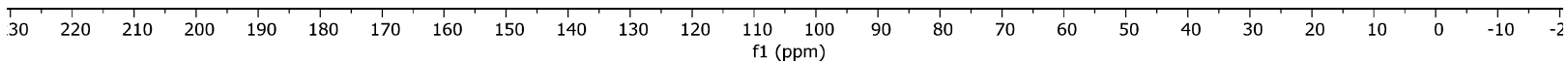


(N)

176ad ${ }^{1} \mathrm{H}-\mathrm{NMR}$

(400 MHz, $\mathrm{CDCl}_{3}$ )
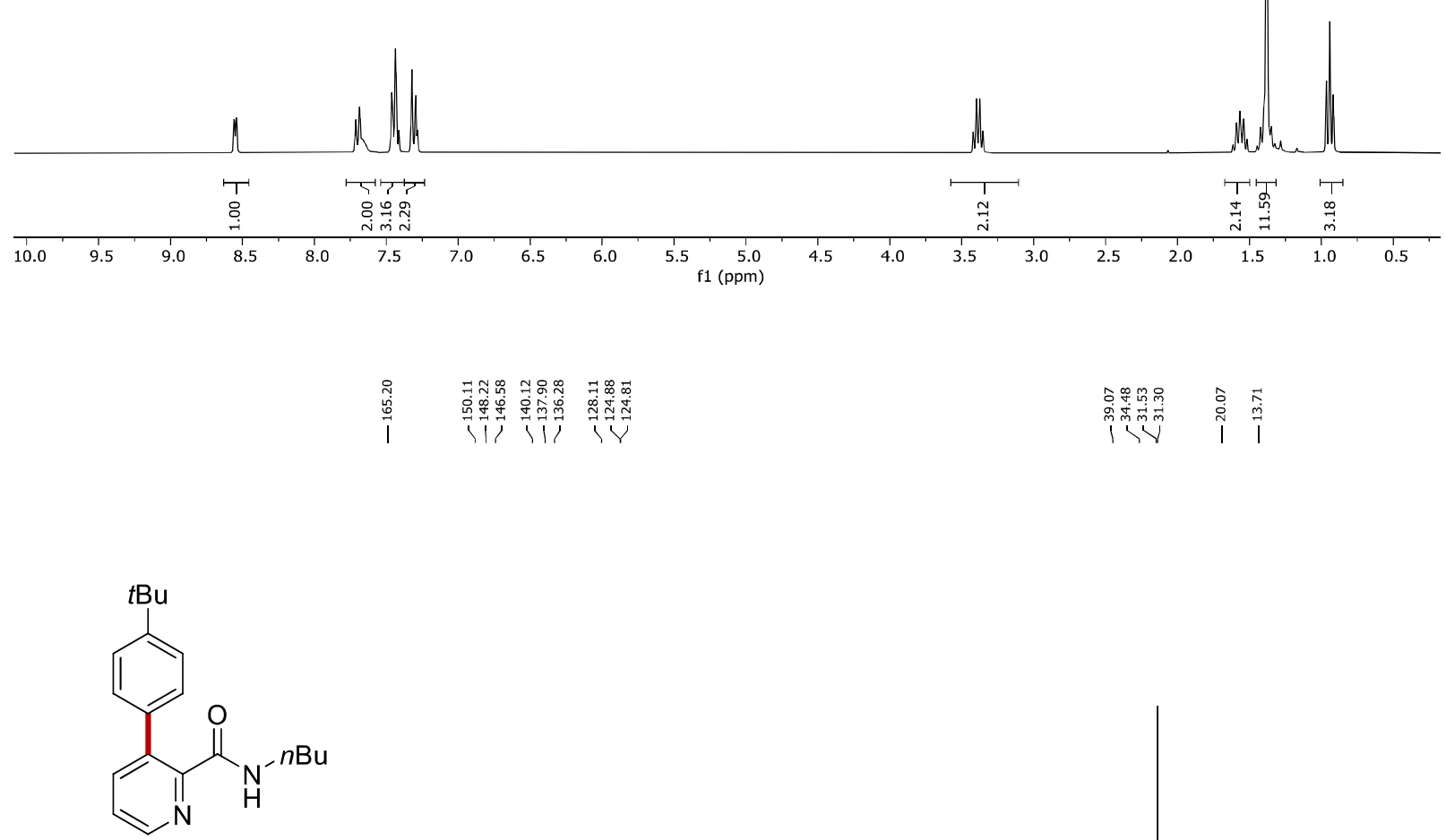

176ad ${ }^{13} \mathrm{C}-\mathrm{NMR}$

$\left(100 \mathrm{MHz}, \mathrm{CDCl}_{3}\right)$

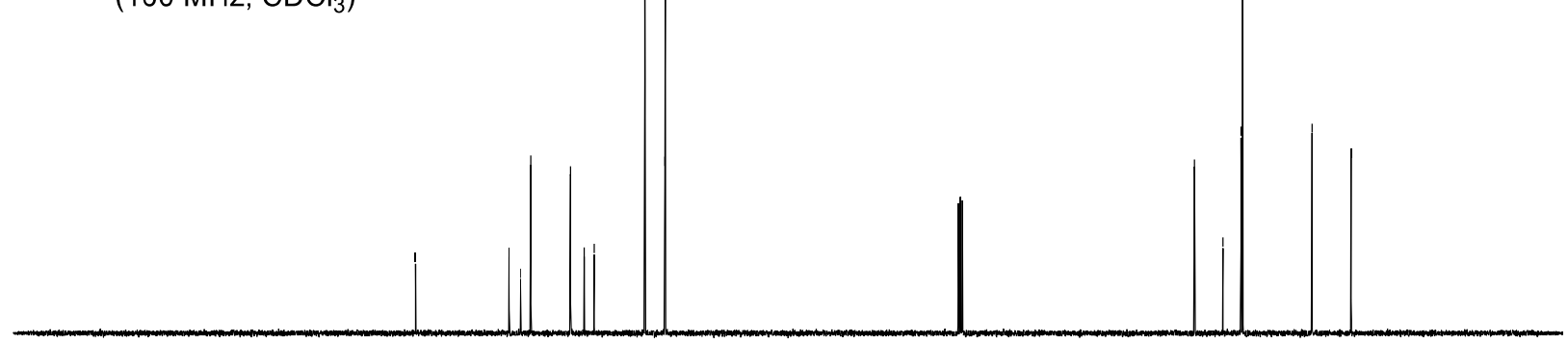

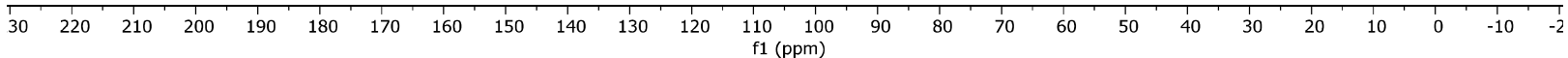



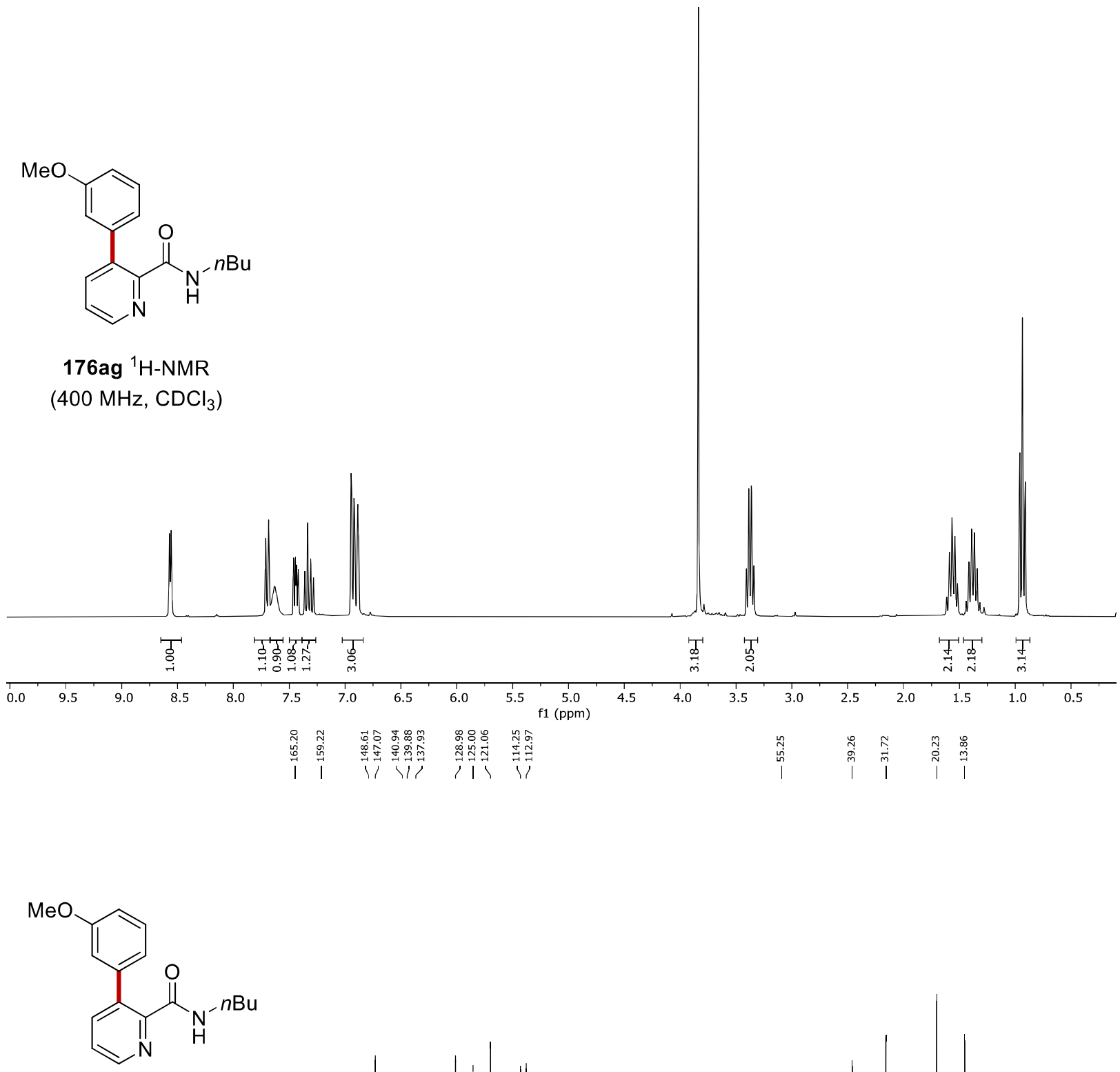

176ag ${ }^{13} \mathrm{C}-\mathrm{NMR}$ $\left(100 \mathrm{MHz}, \mathrm{CDCl}_{3}\right.$ ) 


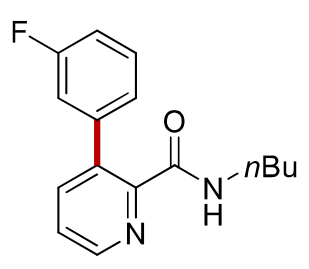

176ah ${ }^{1} \mathrm{H}-\mathrm{NMR}$ $\left(400 \mathrm{MHz}, \mathrm{CDCl}_{3}\right.$ )

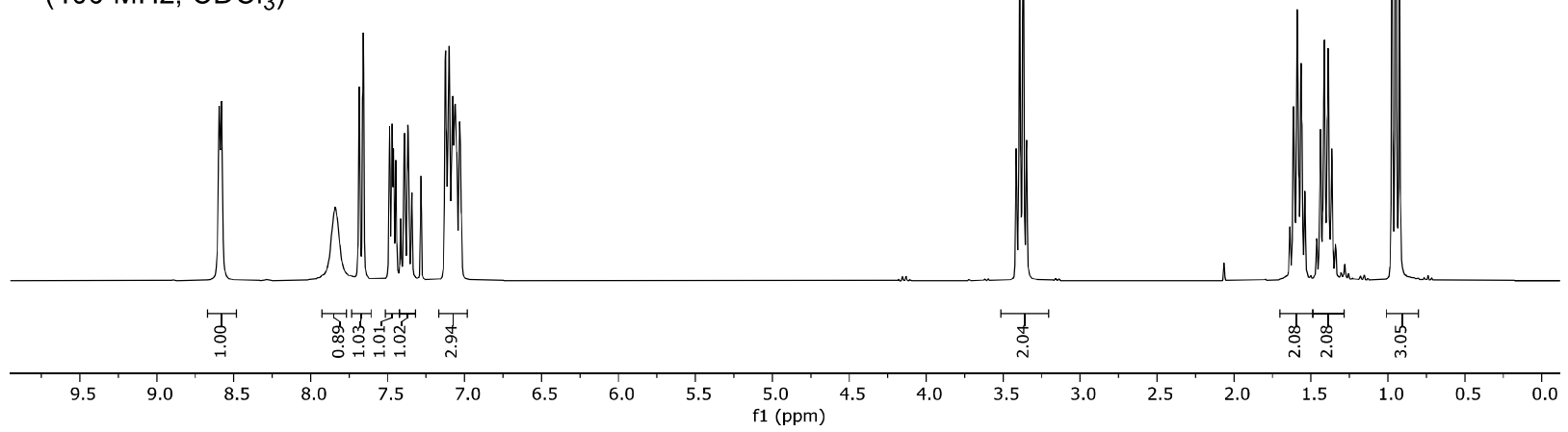<smiles>CCCCNC(=O)c1ncccc1-c1cccc(F)c1</smiles>

176ah ${ }^{13} \mathrm{C}-\mathrm{NMR}$

$\left(100 \mathrm{MHz}, \mathrm{CDCl}_{3}\right.$ )

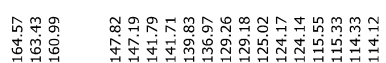
i)

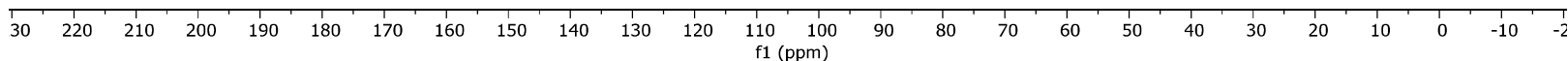




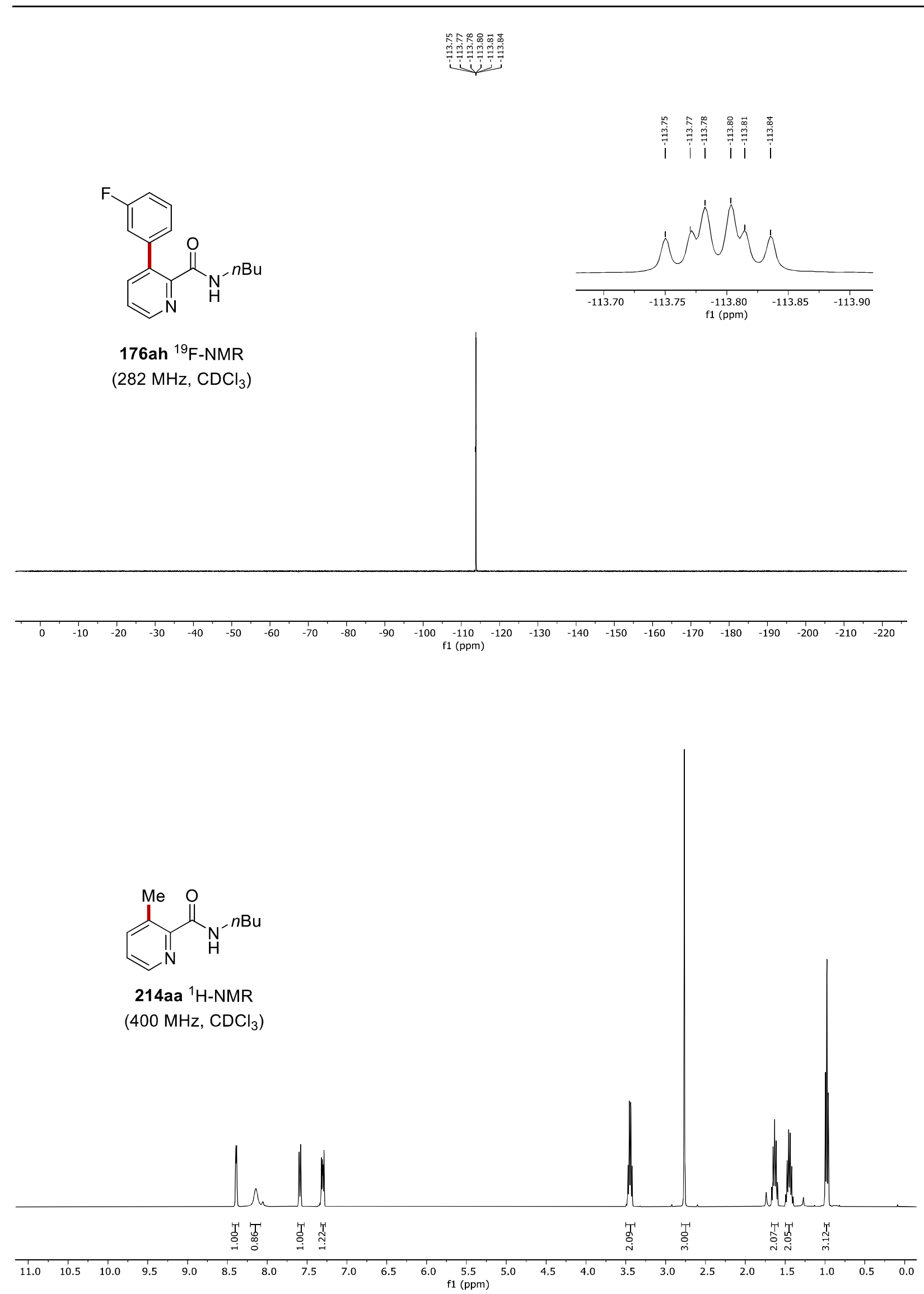



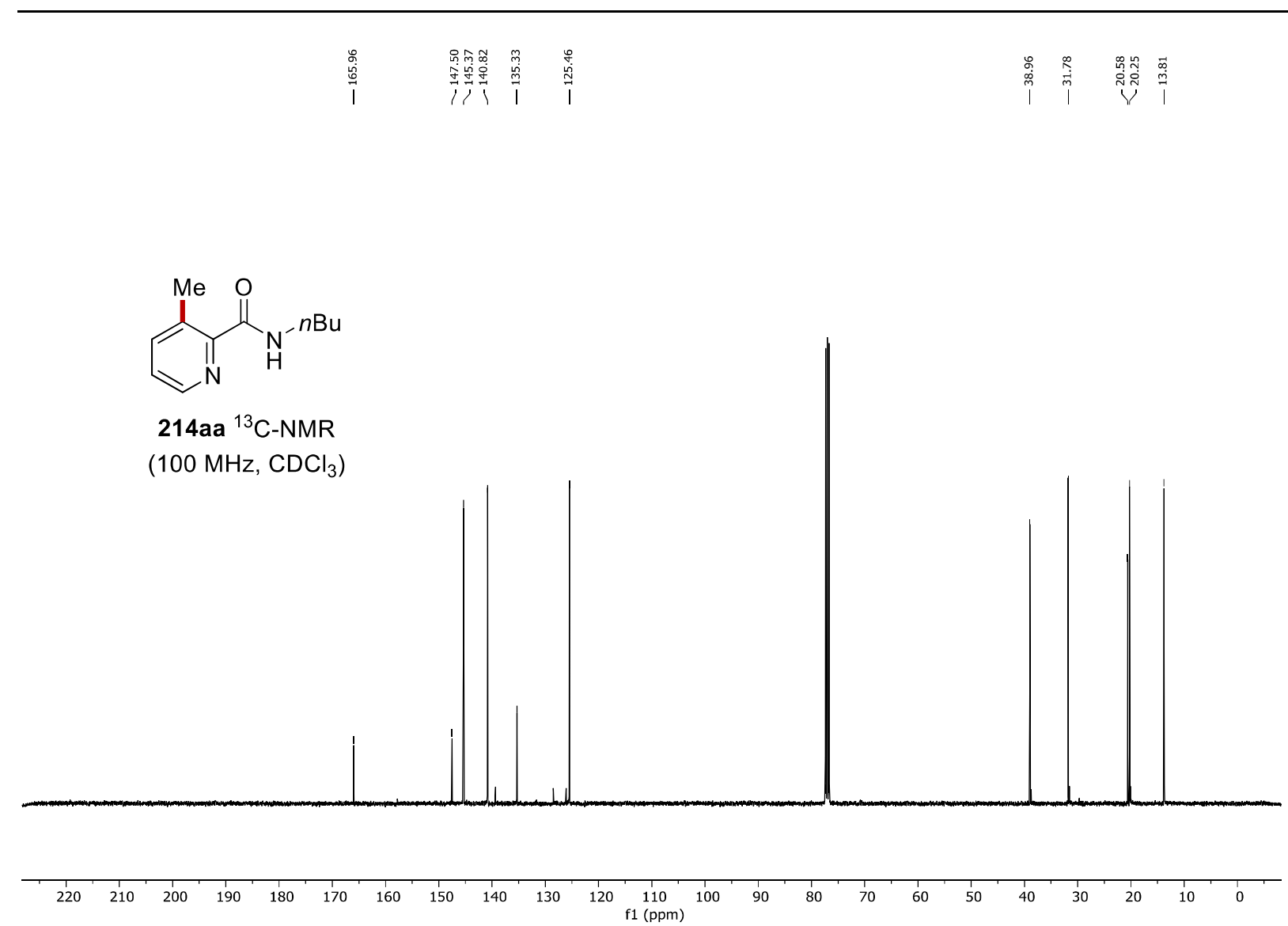

${ }_{N}^{M e}{ }_{H_{N}^{-n B u}}^{M e}$

214ab ${ }^{1} \mathrm{H}-\mathrm{NMR}$

$\left(400 \mathrm{MHz}, \mathrm{CDCl}_{3}\right.$ )

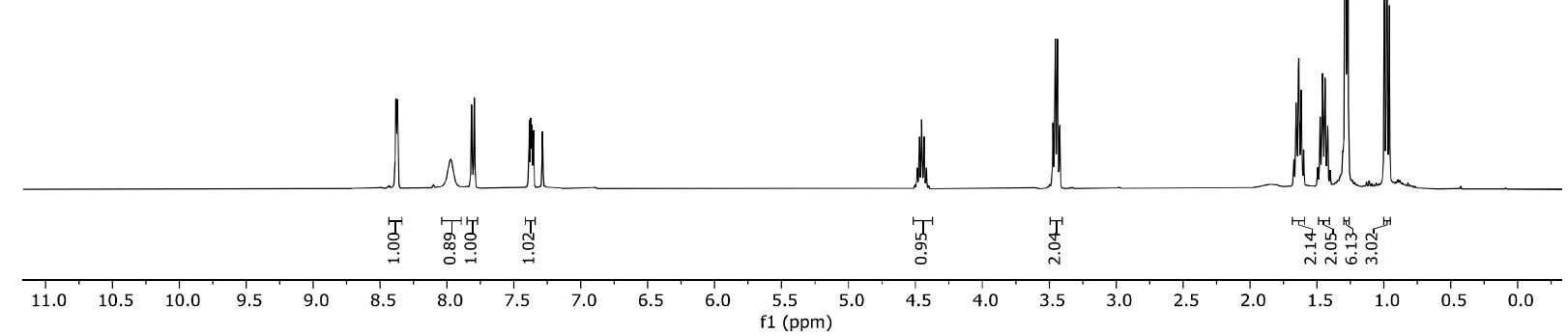


Appendix: NMR Sepctra

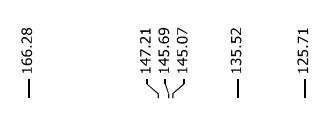

产路踶

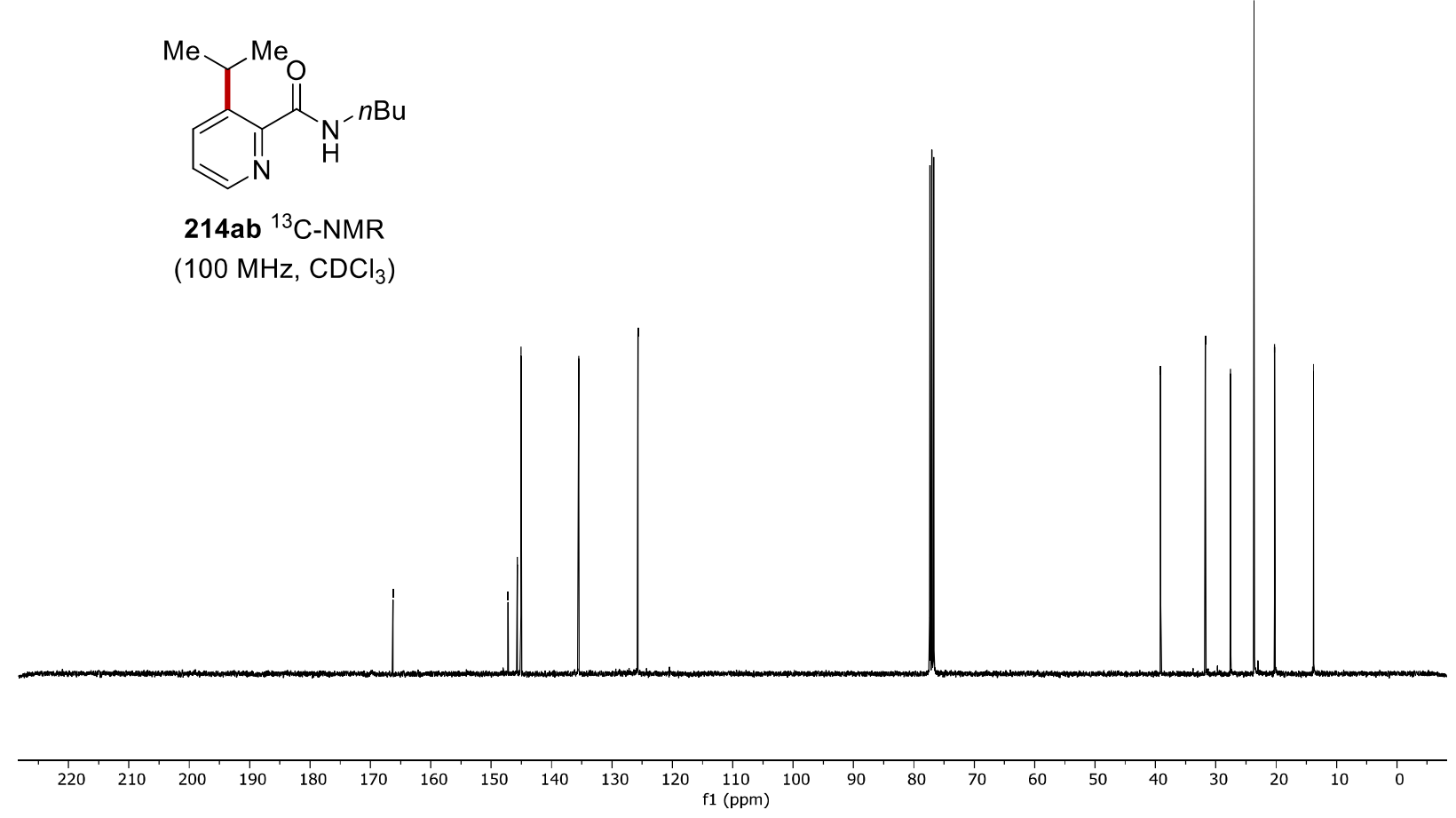<smiles>CCCCNC(=O)c1ncccc1Cc1ccccc1</smiles>

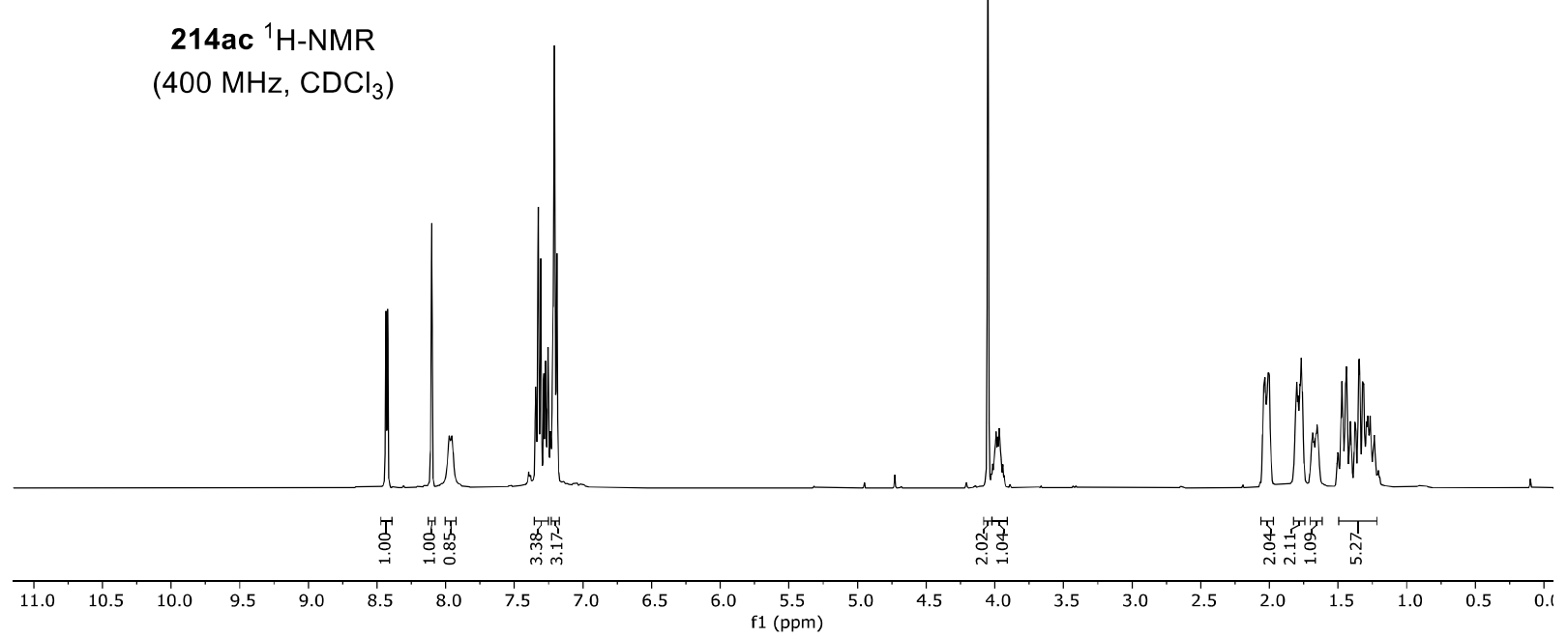

286 

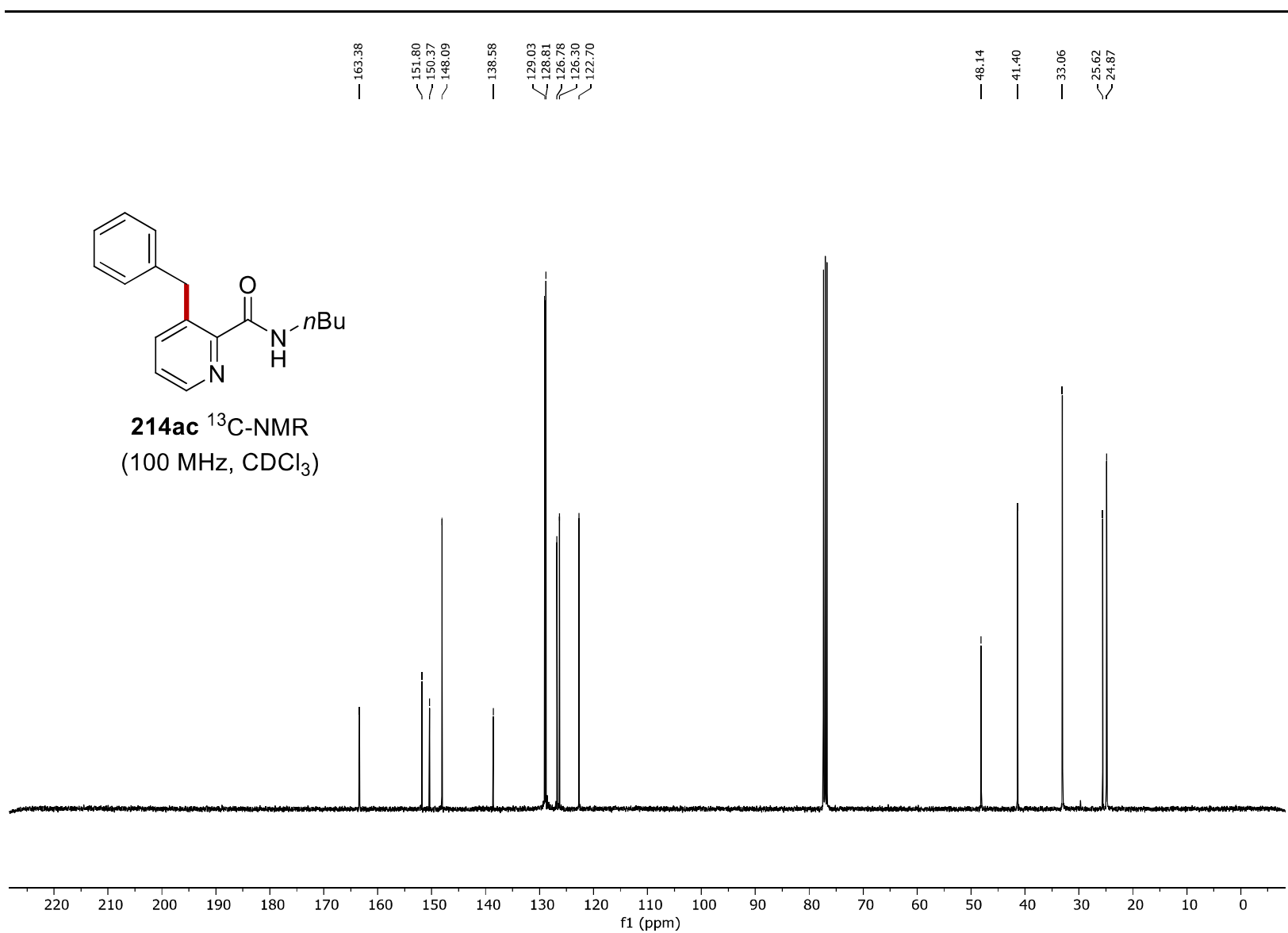